UNITED STATES DEPARTMENT OF THE INTERIOR

U.S. GEOLOGICAL SURVEY

JOINT NETWORKS IN THE TIVA CANYON AND TOPOPAH SPRING TUFFS OF
THE PAINTBRUSH GROUP, SOUTHWESTERN NEVADA

by

Constance K. Throckmorton ${ }^{1}$ and Earl R. Verbeek ${ }^{1}$

Open-File Report 95-2

This report is preliminary and has not been reviewed for conformity with U.S. Geological Survey editorial standards (or with the North American Stratigraphic Code).

${ }^{1}$ U.S. Geological Survey, Denver, Colorado 


\section{Copies of this Open-File Report}

may be purchased from

Books and Open-File Reports Section

Branch of Distribution

U.S. Geological Survey

Box 25425 Federal Center

Denver, Colorado 80225

\section{PREPAYMENT IS REQUIRED}

Price information will be published in the monthly listing

"New Publications of the Geological Survey"

FOR ADDITIONAL ORDERING INFORMATION

CALL: (303) 236-7476 


\section{CONTENTS}

Page

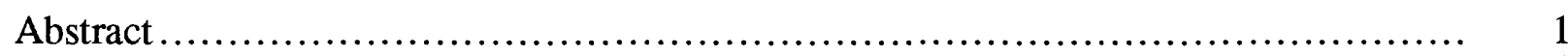

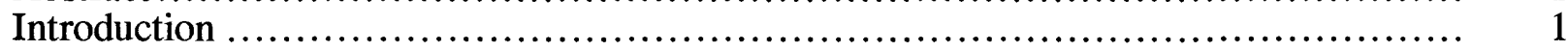

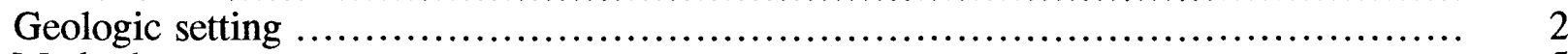

Methods....................................................................... 5

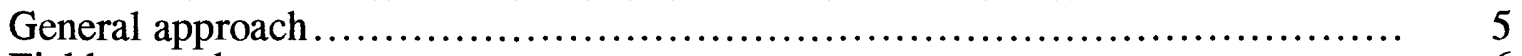

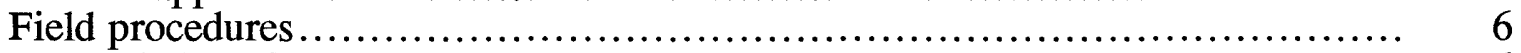

Choice of exposure................................................. 6

Preliminary evaluation of fracture network .................................... 7

Documentation of fracture-set properties ....................................... 7

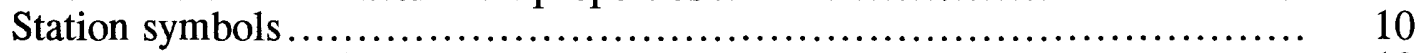

Results

Fracture-set symbols .......................................................... 10

Introduction

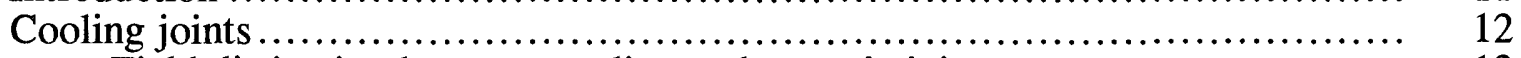

Field distinction between cooling and tectonic joints ..................... 12

Network patterns of steeply dipping cooling joints...................... 20

Subhorizontal cooling joints …..................................... 23

Preferred orientations of cooling joints .................................. 25

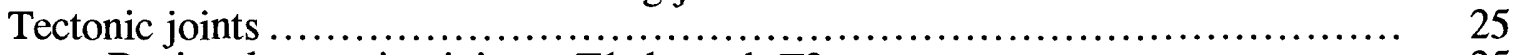

Regional extension joints: T1 through T3 sets ........................ 25

T1 set: North-striking joints ..................................... 27

T2 set: North-northwest-striking joints .................................. 27

T3 set: Northeast-striking joints............................... 30

Unloading joints: T4 and SH sets ................................. 33

T4 set: West-northwest-striking joints .............................. 33

SH set: Foliation-parallel joints ................................ 36

Discussion ....................................................................... 37

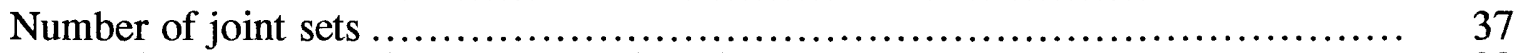

Network patterns of different volcanic units ................................ 38

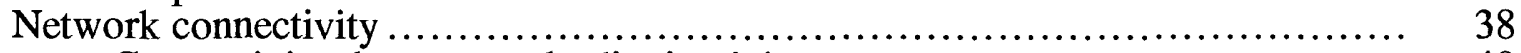

Connectivity due to steeply dipping joints............................. 40

Connectivity due to gently dipping joints.................................. 40

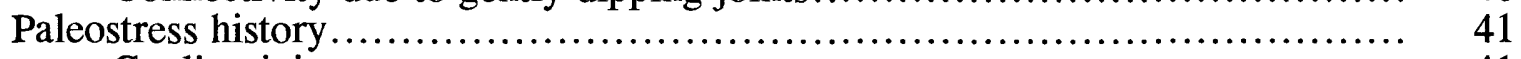

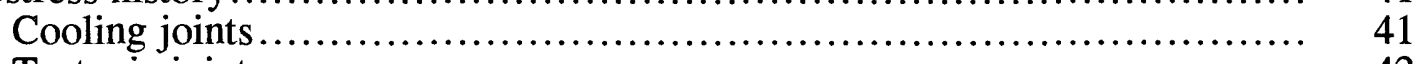

Tectonic joints ..................................................................... 42

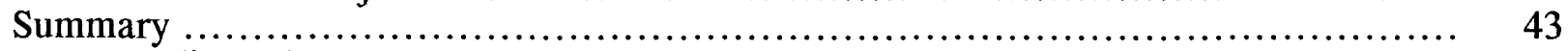

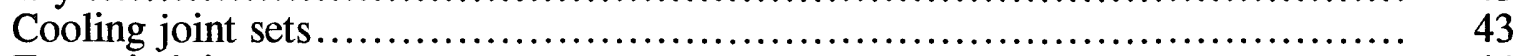

Tectonic joint sets ............................................................... 44

Paleostress history ................................................................... 45

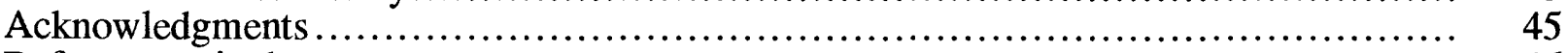

References cited ...................................................................... 46

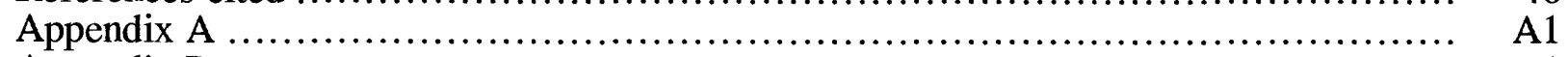

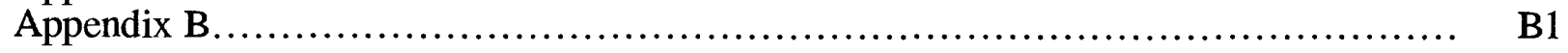




\section{ILLUSTRATIONS}

Page

Figure 1. Study area showing locations of field stations ............................ 3

2. Map units of the Tiva Canyon and Topopah Spring Tuffs in the study area................................................................. 4

3. Stereographic plot showing median orientations of T1-T4 joint sets for all stations .......................................................... 16

4. Stereographic plot of fracture orientations for T1-T4 joints for all stations .......................................................... 17

5. Photograph of reactivated, north-striking cooling joints on Fran Ridge ...... 18

6. Photograph of tubular structures on northeast-striking, steeply dipping cooling joint.

7. Photograph of reopened cooling joint in the clinkstone unit of the Tiva Canyon Tuff

8. Linear histogram showing strike difference between pairs of coolingjoint sets on and near Yucca Mountain

9. Strikes of cooling joints at station CUL4 showing apparent strong curvature of a cooling-joint set.

10. Photograph of tubular structures on a subhorizontal cooling joint

11. Map showing median orientations of cooling-joint sets in the Tiva Canyon and Topopah Spring Tuffs

12. Map showing median orientations of $\mathrm{T} 1$ tectonic joints in the Tiva Canyon and Topopah Spring Tuffs

13. Map showing median orientations of $\mathrm{T} 2$ tectonic joints in the Tiva Canyon and Topopah Spring Tuffs

14. Sketch showing common appearance of reactivated $\mathrm{T} 1$ joints at station TC4....

15. Map showing median orientations of $\mathrm{T} 3$ tectonic joints in the Tiva Canyon and Topopah Spring Tuffs

16. Map showing median orientations of T4 tectonic joints in the Tiva Canyon and Topopah Spring Tuffs

17. Linear histograms showing strike-frequency distributions of steeply dipping joints within two different volcanic units at Yucca Mountain

\section{TABLES}

Table 1. Median orientations of cooling joint sets in the study area...................

2. Median orientations and regional properties of tectonic joint sets $\mathrm{T} 1, \mathrm{~T} 2, \mathrm{~T} 3$, and $\mathrm{T} 4$ in the study area.

3. Median strikes of cooling joints for localities within enclosed area on figure 11 


\title{
JOINT NETWORKS IN THE TIVA CANYON AND TOPOPAH SPRING TUFFS OF THE PAINTBRUSH GROUP, SOUTHWESTERN NEVADA
}

\author{
Constance K. Throckmorton and Earl R. Verbeek
}

\begin{abstract}
Eight fracture sets were documented in the Tiva Canyon and Topopah Spring Tuffs at 41 localities in the northern half of Yucca Mountain and Fran Ridge. Two sets of steeply dipping cooling joints forming a rectangular array are present at many localities. Joints of the two sets are preferentially oriented within an area of at least $20 \mathrm{~km}^{2}$ on Yucca Mountain; median strike directions are $\mathrm{N} .45^{\circ} \mathrm{W}$. and N. $50^{\circ} \mathrm{E}$. In some places a third set of cooling joints is present. This set dips gently, parallel to compaction foliation in the tuff, and together with the other two sets forms a orthogonal, three-dimensional network. Common properties of cooling joints include exceptional surface smoothness; absence or sparsity of lithophysae intersecting the joint face; smooth, continuous traces; early age as demonstrated through abutting relations with other fractures sets; and large size. Tectonic fractures in the same exposures almost invariably are rougher and have more irregular traces.
\end{abstract}

Tectonic fractures at Yucca Mountain and Fran Ridge form five sets. Surface structures (inclusion and twist hackle, arrest lines) show that the fractures of all five sets are extension joints. Joints of three sets, all steeply dipping, have median strikes of N. $01^{\circ} \mathrm{W} ., \mathrm{N} .31^{\circ} \mathrm{W}$., and N. $38^{\circ} \mathrm{E}$. and record noncoaxial extension through time during Basin-and- Range faulting. Later joints include a set of steeply dipping cross joints (median strike N. $82^{\circ}$ W.) and a prominent set of gently dipping joints parallel or nearly so to compaction foliation in the tuff. Both sets are roughly contemporaneous and are interpreted as unloading joints that formed during erosion, as the tuffs adjusted to progressive reduction of confining pressure.

The nature of the fracture network, as defined by various combinations of the eight joint sets, differs from one volcanic unit to another in consistent ways. Cooling joints, for example, are the dominant components of the fracture network at nearly all localities examined in the upper lithophysal unit of the Tiva Canyon Tuff, but tectonic joints vastly outnumber cooling joints in the hackly unit lower in the formation. Strike-frequency distributions for the two units are dissimilar, and each must be modeled separately for fluid-flow simulations and mechanical stability. Other aspects of the fracture network (e.g., joint roughness) likewise differ from one unit to another. All networks examined to date, however, are well interconnected. The presence of alteration rinds and mineral coatings on joints of each set shows that all eight sets were conduits for subsurface fluid flow at Yucca Mountain and Fran Ridge.

\section{INTRODUCTION}

This study was undertaken as part of a larger effort by the U.S. Geological Survey to identify and characterize joint networks at Yucca Mountain, a candidate site for an underground high-level nuclear-waste repository in southwestern Nevada. The repository would be located about $150 \mathrm{~m}$ below the surface in the unsaturated zone below Yucca Mountain, and about $400 \mathrm{~m}$ above the water table. Joints provide potential paths by which water can reach the waste and transport it out of the repository, and paths by which gases can escape through the rock mass and into the atmosphere. An understanding of joint sets and how they interconnect to form a network is critical to understanding how fluids moving through the joint network may affect the suitability of the unsaturated zone under Yucca Mountain as a nuclear waste repository. Lateral and vertical variability, distribution, and other physical characteristics of joints provide information for development of hydrologic and tectonic models of the potential waste-storage site. 
The primary goal of this study was to develop a conceptual understanding of the regional joint network: what joint sets exist, the sequence in which they formed, their characteristics as a function of unit lithology, and their relation to the regional tectonic history. Site-specific data were collected to characterize joints in units of the Tiva Canyon and Topopah Spring Tuffs of the Paintbrush Group, of Miocene age.

The study area (fig. 1) encompasses Yucca Mountain and Fran Ridge, the narrow northtrending ridge flanking the east side of the mountain. Fran Ridge was included in the study because it provides abundant exposures of the Topopah Spring Tuff, which is poorly exposed on Yucca Mountain. Because fluid-flow paths through fractures depend on the physical characteristics of the fracture networks within lithostratigraphic units, stations were chosen to provide lateral and vertical coverage in the primary tuff units comprising Yucca Mountain and Fran Ridge.

This study provides site-specific data from 41 localities (field stations). Most of the stations are located in natural exposures; however, a few stations are located in excavated trenches or test pits. Eight stations are located in four lithologic units of the Topopah Spring Tuff and 33 stations are in eight lithologic units of the Tiva Canyon Tuff. The lithologic units referred to in this report are those described by Scott and Bonk (1984), shown in figure 2.

Data were collected to (1) develop and test criteria to distinguish cooling joints from tectonic fractures, (2) document the existence of distinct fracture sets in each unit, (3) determine the fracture network distribution and provide information on how many fractures are potentially hydrologically active, (4) assess the fracture connectivity of the fracture network, (5) assess the effect lithology has on fracture abundance and fracture distribution, and (6) document the mineralization history of fractures at Yucca Mountain.

A phased approach was planned; during the first phase the authors addressed the first three issues. Subsequent phases were to provide information to address the remaining issues, through detailed collection and analysis of quantitative fracture data using the methods developed and tested. The authors were about midway into the first phase of the study when our involvement with the effort ended.

Data and interpretations from the first phase of this study are presented in this report. Data are sparse or absent in some units; thus the authors caution that the interpretations presented in this report are preliminary. Sampling and analyses of mineral fill, coatings, and alteration zones, planned for the next phase, would have contributed significantly to understanding of the fluid-flow history and episodes of reactivation of joint sets at Yucca Mountain. In spite of these limitations, we believe the data collected during this study present will be useful for comparison with studies of fractures exposed in walls of the drift currently under construction for the Exploratory Studies Facility at Yucca Mountain.

\section{GEOLOGIC SETTING}

Yucca Mountain is composed of two voluminous, compositionally zoned ash-flow sheets, the Topopah Spring Tuff $\left(1200 \mathrm{~km}^{3}\right)$ and the Tiva Canyon Tuff $\left(1000 \mathrm{~km}^{3}\right), 300 \mathrm{~m}$ thick and $100 \mathrm{~m}$ thick, respectively. The Tiva Canyon Tuff comprises most of Yucca Mountain; the Topopah Spring Tuff is exposed on Fran Ridge. These formations, along with several thinner tuffs, form the Miocene Paintbrush Group, erupted from the Claim Canyon caldera about 2 $\mathrm{km}$ north of Yucca Mountain. The tuffs grade upward from high-silica rhyolite in their basal and central portions to quartz latite that forms a densely welded caprock near the top of the each sheet. Ash-fall deposits occur between the two ash-flow sheets. The mountain is 


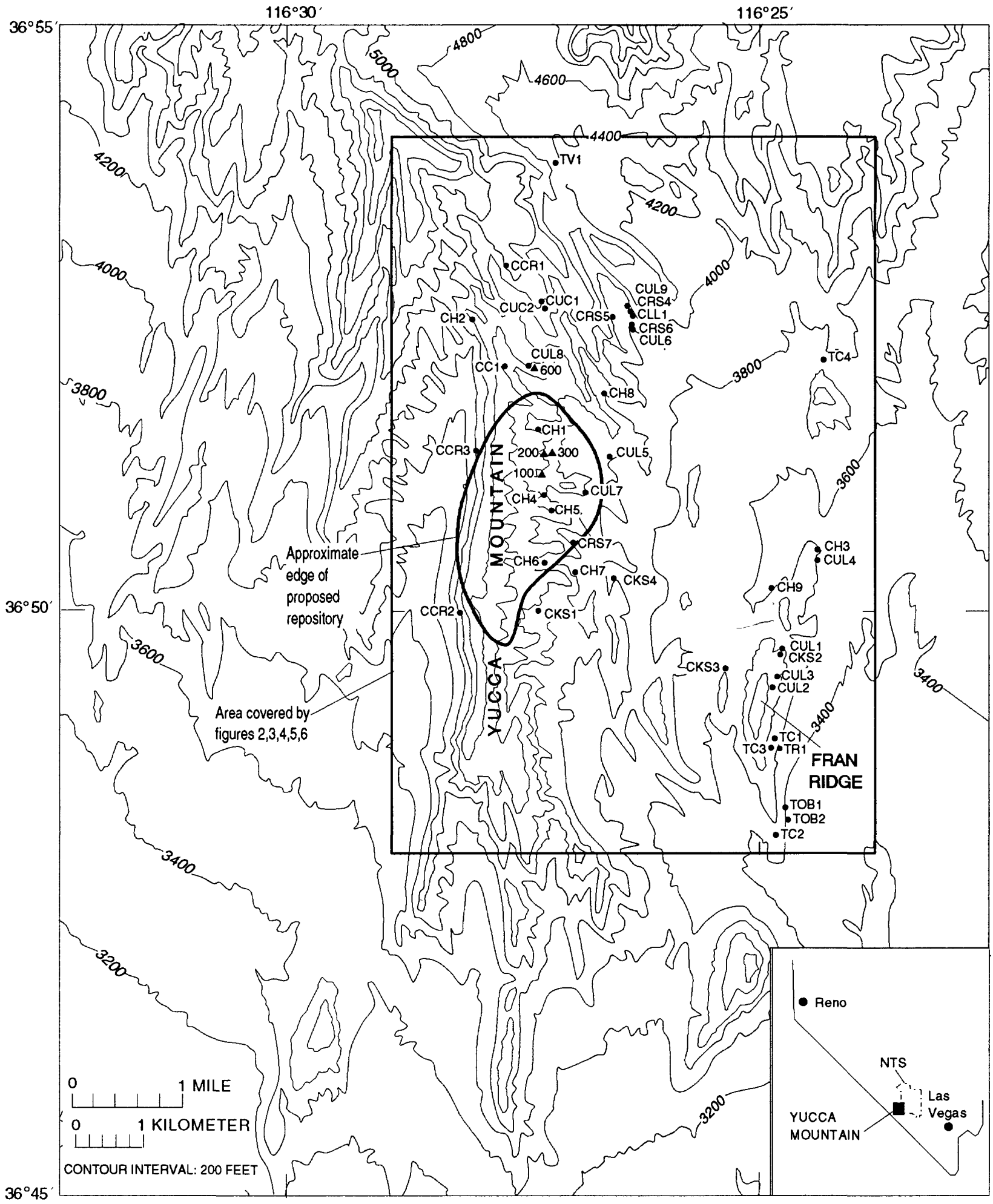

Figure 1.--Study area showing locations of 41 field stations in the Topopah Spring and Tiva Canyon Tuffs at Yucca Mountain and Fran Ridge. 


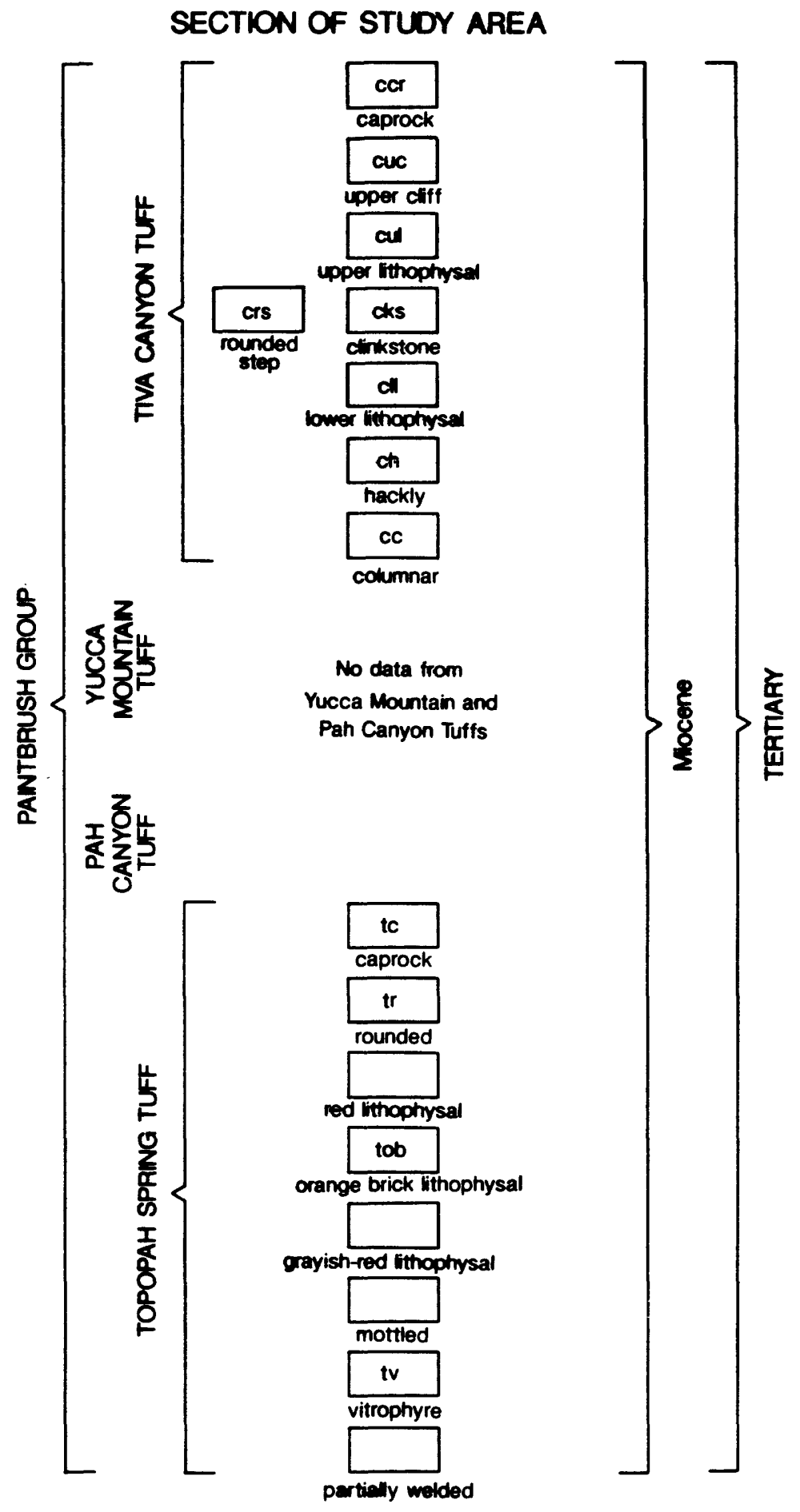

Figure 2.--Map units of the Tiva Canyon and Topopah Spring Tuffs in the study area. Boxes with no symbols are units for which no data were collected in this study. Refer to Scott and Bonk (1984) for detailed descriptions of units. 
underlain at a depth of 1-2 km by Paleozoic marine clastic rocks and Mesozoic granitic intrusions (Snyder and Carr, 1982). Summit surfaces are relatively flat, and prominent northtrending ridges and steep-sided ravines and washes characterize Yucca Mountain. Yucca Mountain comprises several structural blocks, bounded by north-trending, westward-dipping, high-angle faults that displace the volcanic strata as much as $400 \mathrm{~m}$ (Scott and Bonk, 1984). The strata dip gently $\left(5-10^{\circ}\right)$ northeast, east, or southeast. Carr (1984) discussed the regional tectonic and structural setting of Yucca Mountain; the stratigraphic and structural framework are summarized in Spengler and Fox (1989).

The Tiva Canyon and Topopah Spring Tuffs are lithologically similar and are characterized by densely welded to partially welded to nonwelded lithophysal and nonlithophysal zones and vitrophyres characteristic of ash flow sheets. Scott and Bonk (1984) divided the Tiva Canyon and Topopah Spring Tuffs into several informal units at Yucca Mountain, based primarily on mineralogic features (presence of lithic fragments and phenocryst abundance), textural features (degree of welding, lithophysal cavity abundance), and weathering characteristics observed in the field. The two tuffs record different geomagnetic polarities; the Tiva Canyon Tuff is reversed and the Topopah Spring Tuff is normal (Rosenbaum, 1986). Paleomagnetic data from Miocene ash-flow sheets have been interpreted to show that Yucca Mountain has undergone a southward-increasing clockwise vertical-axis rotation as large as $30^{\circ}$ since about $13 \mathrm{Ma}$ (Rosenbaum and others, 1991; Hudson and Sawyer, 1994).

\section{METHODS}

The manner in which natural fracture networks should be studied and documented in the field has long been debated in the geologic literature. Though the methods used vary considerably with the problem to be addressed, opinion often is divided even where common purpose exists. Because fracture studies at Yucca Mountain are no exception, we here discuss both our general approach to such studies and our specific field procedures in some detail.

\section{General Approach}

Most fracture studies involve some variant of either a "global inventory" or a "selective inventory." A global inventory, as the name implies, involves measuring all fractures present within a prescribed area or along a prescribed scanline. A common variant is to measure fractures "at random" until some arbitrary number of measurements has been attained. Properties to be documented for each fracture vary with purpose and observer but commonly include, at a minimum, orientation and some indication of fracture size. Recognition of fracture sets and interpretation of the fracture network typically are accomplished after the fact, through statistical manipulation of the resultant data. Rose diagrams of fracture strike, for example, commonly are employed to define fracture sets. Advantages of this approach include objectivity, speed, high degree of data reproducibility, and minimal need for prior training in fracture analysis. The main disadvantage, discussed below, is that the data are of limited utility for some aspects of repository evaluation at Yucca Mountain.

Selective inventories generally are more demanding in that they require conceptual understanding of the local fracture network before measurements can begin. A necessary first step is to determine how many sets of fractures are present and the order in which they formed--in effect, to perceive the overall network in terms of its component parts. Once the evolution of the local network is understood, the properties of each fracture set can be documented in turn. An obvious advantage over global inventories is that data from individual fracture sets are kept separate from the beginning, and thus the relation between any given fracture-set property and other factors--rock composition, degree of welding, and stratigraphic position among them--can be more effectively defined and quantified. The main disadvantage is that quality of the results depends in part on the skill of the observer. Where fracture sets are well defined and readily recognized on sight, the fracture data are highly reproducible and 
require less time to gather than the equivalent data from a global inventory. In areas of exceptional complexity, however, reproducibility of data requires time, patience, and experienced personnel.

Most previous studies of fractures at Yucca Mountain, published and unpublished, employed some variant of a global inventory approach: the fracture network was studied in toto, and various of its properties were portrayed in synoptic plots. That network, however, evolved over time and is the end product of several disparate processes, including (1) contraction upon cooling of the rock, (2) tectonic extension, (3) unloading during erosion of overburden load, and (4) weathering. To study some or all of these fracture types together limits the usefulness of the data obtained and invalidates some of the results. What significance, for example, should one attach to frequency distributions of fracture lengths when the fracture network at locality $\mathrm{X}$ is an amalgam of sets $\mathrm{A}, \mathrm{C}$, and D and that at locality $\mathrm{Y}$ is some combination of sets B and C? Such plots cannot readily be compared from one locality to another in any meaningful way, and the combined data provide only limited understanding of geologic controls on spatial variability in network geometry. More importantly, the manner in which any given fracture property (length, height, spacing . . .) varies with other properties (lithology, unit thickness, depth) is not always constant but differs from one fracture set to another. One might predict, for example, that joints due to tectonic crustal extension are present throughout the volcanic sequence at Yucca Mountain, whereas late "cross joints" formed during erosional unloading decline rapidly in abundance with depth-thus, fracture networks exposed in surface rocks must differ in some important respects from those at depth, even in identical rock types. Lorenz and Finley (1991) discussed a prominent example for an area of sedimentary rocks in western Colorado. Measured properties of the total fracture network as seen in surface exposures, then, can prove misleading unless the geologist understands which components of that network have significance at repository depths and which do not.

We conclude that both approaches to joint studies have merit, but for different purposes. The voluminous data from global inventory studies doubtless will prove useful for modeling the near-surface fracture network at those specific localities where data were gathered, and for gaining some preliminary impression of network heterogeneity in different volcanic units. However, true understanding of geologic controls on fracture-network geometry within large, heterogeneous masses of rock such as the Yucca Mountain block cannot be achieved through such an approach. Our study thus concentrated on selective inventories from the outset.

\section{Field Procedures}

Most stations are in areas of discontinuous natural outcrop. Five stations are located in excavated trenches or test pits. Each station was restricted to one lithologic unit so comparison of fracture networks from other units could be made. The size of field stations was determined by (1) degree of exposure, (2) complexity of fracture network, (3) "coarseness" of the fracture network, and (4) orientation of fractures with respect to exposure surface. Initial efforts were concentrated in the northern half of Yucca Mountain to avoid possible structural complications due to the rocks being rotated (Rosenbaum and others, 1991) at the southern half of Yucca Mountain.

\section{Choice of exposure}

Acceptance or rejection of an exposure as a study site was guided by several factors, including the need for a reasonable geographic distribution of data points, the need to study all volcanic units present, and quality of the exposure. The most important factor, however, was the nature of the fracture network itself. During the initial phases of any regional fracture study it is imperative to gather data only from exposures where fracture sets are visually obvious and the relations among them clear, for only then does one have any chance of 
deciphering basic elements of the regional network quickly and reliably using the selective inventory approach. Study of exposures where fracture sets are ill-defined is inadvisable during early stages of the study because the observer is not yet sufficiently knowledgeable to deal with them. Later, however, when the general nature of the regional fracture network is well understood, one should return to such sites. Exposures once deemed so complex as to be uninterpretable may then yield a wealth of new information.

Most of our field stations were chosen in accordance with these guidelines, but exceptions were made for several localities of particular scientific interest. Chief among these are the two test pits near the south end of the east flank of Fran Ridge and a trench exposure west of the same ridge, near the Paintbrush fault. In all three of these places the local fracture network is incompletely understood and only partially documented.

\section{Preliminary evaluation of fracture network}

A preliminary evaluation of the fracture network was made at each study site to accomplish several objectives: (1) to determine how many sets are present and the order in which they formed, (2) to develop some familiarity with the general physical characteristics of the fractures in each set, and (3) to locate and mark sites of particular importance for later study (for example, where fractures showed well-exposed mineral coatings, prominent surface structures, or clear age relations with other fractures). Also important during this phase was to differentiate between cooling joints, tectonic joints, and fractures due to weathering or blasting. Fractures in the latter two categories were immaterial to our study and hence were excluded from measurement; in any case they generally comprised a negligible proportion of the total fracture network. Characteristics collectively indicative of weathering-induced fractures include lack of mineral coatings or fillings other than caliche, young age (they abut all other fractures present), small size (lengths $<50 \mathrm{~cm}$; heights $<20 \mathrm{~cm}$ ), nonsystematic orientation, irregular surfaces, and fresh, relatively unaltered walls. Blast-induced fractures, potentially present in only two (TOB1, TOB2) of the 41 exposures studied, commonly were recognizable by their radiating pattern away from the borehole. Their surfaces tend to be much rougher than those of other fractures, a consequence of high-energy fracture propagation; prominent twist hackle over appreciable portions of the fracture surface is typical (Kulander and others, 1979). Blast-induced fractures, like those due to weathering, have fresh, unmineralized surfaces and abut all other fractures present.

\section{Documentation of fracture-set properties}

The method utilized in this study is one in which fracture sets were defined in the field and the properties of each set were described separately. Recognition of genetic sets of fractures in the field was based on multiple properties which in combination are unique to each set; these properties include orientation, length, height, shape, surface roughness, surface structures, alteration and mineralization, and abutting and crosscutting relations with other fractures. The first and last of these properties are most critical in defining fracture sets and in establishing the sequence of fracture in each exposure. Knowledge of which sets exist and the order in which they formed then enabled us to (1) correlate sets from one locality to another and thereby define the overall fracture pattern, and (2) document geologic controls (rock type, previous fracture history, unit thickness) on fracture-set geometry and differences in network characteristics from one volcanic unit to another.

Some of the data recorded at each station pertain to individual fractures, while some of the information characterizes the set as a whole. Fracture orientations (strike and dip) were measured for individual fractures comprising the set. Semiquantitative and descriptive data recorded for each set include joint expression, size (height and length), shape, spacing, and surface roughness. Much of these data are commonly expressed as a range. Surface structures were noted from individual joint surfaces, as were mineral coatings and fillings, and alteration 
rinds along fracture surfaces. Terminating relationships were recorded for individual fractures.

In addition to the joint-set attributes mentioned above, descriptive data recorded at each station include stratigraphic unit, approximate size of exposure, percent of area exposed, slope inclination, and (if appropriate) comments on compaction foliation in the tuff. Fracture apertures were not measured because joint-bounded blocks at the surface almost everywhere have moved somewhat with respect to neighboring blocks as a result of several processes, among them root and frost wedging, and downhill creep. The magnitude of these effects is such that we place little value in aperture measurements from surface exposures. More useful measurements of fracture aperture are obtainable from drill cores and from the repository shaft and associated drifts.

The fracture properties recorded for each set are defined below and summarized in Appendix A for each locality.

\section{Fracture orientation}

The orientation (strike and dip) of fractures identified as belonging to a set is listed in Appendix B. The number of fractures measured for each set was determined by orientational variability or, at some stations, by the number of joints available for measurement. Fewer measurements are required to derive a median orientation characteristic of the set where joints of a given set show little variation in both strike and dip. However, where orientations are more variable (greater than $20^{\circ}$ ), more measurements are needed to ensure that the calculated median is truly representative. Median orientations, rather than mean orientations, are preferred, because means calculated from small samples are highly sensitive to outlier measurements. In addition, the mean is a statistic properly applied only to normal distributions, whereas the actual shapes of frequency distributions of fracture strike and dip for the various sets at Yucca Mountain remain undefined.

Median strikes for fractures of gentle dip, whose strikes commonly box the compass and thus define circular distributions, cannot be defined. For these sets a visual measure of central tendency was defined from the distribution of points as shown on a stereographic plot.

\section{Expression}

Expression is a descriptive term indicating the degree of visual prominence of a joint set. Descriptors used in this study range from very well (signifying an obvious set, usually the most prominent of those present), well (fairly obvious or quickly seen), moderate (not obvious, but discernible with little effort), to poor (difficult to recognize). These descriptors are useful to the current investigators as they serve as reminders of the relative importance of the specific set to the local fracture network and alert subsequent investigators visiting the same exposures to the degree of effort required to recognize the joint sets.

The expression of a fracture set at any given locality is influenced by several factors, including the orientation of the exposure, fracture spacing, fracture size, and fracture abundance. Set expression varies considerably from one locality to the next, reflecting not only variation in orientation of the exposed surface, but also lithologic changes and natural variation in fracture abundances. For example, a station may not contain a well-expressed set, or four fracture sets may be present at a station but all may be poorly expressed.

The orientation of the exposure with respect to the orientation of the fracture set greatly influences set expression. For example, only a few fractures with orientations parallel to a vertical cliff face may be visible if the face does not extend far into the cliff, while numerous fractures with strikes perpendicular to the cliff face are easily seen. Similarly, gently sloping exposures readily expose steeply dipping fractures rather than horizontal fractures or fractures 
with low dip. Fractures may also be more readily seen in lithologic units where weathering has exposed intersections of horizontal and vertical fractures, to form ledges comprising steps and risers. Exposures of the rounded step unit of the Tiva Canyon Tuff commonly form conspicuous ledges where both fracture sets are obvious.

\section{Shape}

Shape refers to the overall configuration of a joint surface. The joint surfaces may be nonplanar, subplanar, or planar. Additional descriptors (gently, sharply, curviplanar, sinuous, etc.,) were used where appropriate.

\section{Surface roughness}

Roughness, in addition to shape, is an important surface morphology characteristic because it affects fluid flow through fractures of small aperture and also is a prime factor in determining fracture shear strength. In our study, fractures were described as very smooth, smooth, fairly smooth, fairly rough, rough, or very rough as judged by running one's hand over the fracture surface. This descriptive measure of roughness thus refers to small (a few millimeters or less) irregularities within areas of $10-50 \mathrm{~cm}^{2}$ on the fracture surface. Our tactile impression has the advantage of speed and revealed consistent differences among fracture sets of different genesis. Barton and Choubey (1977) used a semiquantitative measure of roughness, the Roughness Coefficient, to refer to surface irregularities over a linear distance of $20 \mathrm{~cm}$ rather than within a discrete area of the fracture surface.

\section{Length, height}

Fracture lengths and heights are measured parallel to the strike and dip lines, respectively, of the fracture surface. Fracture visibility is greatly influenced by the orientation of the exposure. Lengths of fractures are best measured on gently sloping exposures and their heights on cliff faces; only rarely are both dimensions obtainable from the same exposure. In many places, only small portions of fractures are visible. Thus, our field notes commonly make a distinction between exposed lengths and heights versus true lengths and heights. Total ranges and common ranges for the set were recorded, if appropriate. True lengths and heights typically represent a conservative measure of the actual fracture size because the dimensions measured represent only the actual fracture dimensions within the plane of the outcrop.

For horizontal or gently dipping fractures of insignificant height, the maximum dimension of the exposed part of the fracture was recorded as an estimator of the fracture diameter. As for fractures of steeper dip, a distinction was made between exposed maximum dimension and true maximum dimension.

\section{Surface structures}

Fracture-surface structures, such as arrest lines, inclusion hackle, and twist hackle, all of which indicate extensile failure of the rock, were noted. At several localities, fractures were observed to hook (curve toward and terminate against another nearby fracture at high angles). Slickenside striations were noted at one locality.

\section{Spacing}

Spacing is the perpendicular distance between adjacent fractures of the same set within the outcrop. At most localities, a common range and the total range of spacings were recorded. 


\section{Mineralization/alteration}

Field tests to characterize minerals were limited to inspection with a hand lens, simple hardness tests, and checking for the presence of carbonate minerals with dilute hydrochloric acid. Mineral coatings and fillings were noted and described along with alteration rinds and discolored surfaces along the fracture surfaces. Commonly, minerals on the joint surfaces were observed to be layered. Evidence of recracking and healing of the fracture was noted.

\section{Terminations}

Under this heading we recorded the principal evidence by which the sequence of fractureset formation was interpreted. Abutting and crosscutting relations among coexisting sets of fractures were noted whenever observed. At any given locality, fractures of the first set to form show mostly blind endings within the rock--the fractures gradually taper to hairline cracks and then to zero width because no other fractures were yet present to impede their growth. Fractures of later sets, however, have less rock volume within which to grow before encountering another fracture. The mechanical properties of existing fractures generally are much different from those of the adjacent rock and represent physical barriers to fracture propagation. Thus, younger fractures commonly terminate against older ones. Also common are crosscutting fractures, which represent places where the walls of older fractures were bonded together in stress-transmitting contact, generally through cementation by minerals precipitated in the intervening void space ("healed" fractures). If both fractures are filled, the fracture with the continuous, unbroken fill is the younger. All of these relative-age criteria are for extension fractures, or common joints such as those discussed in this report. Relative-age criteria for crosscutting shear fractures are well known and not repeated here.

Although abutting and crosscutting relations generally offer the most powerful means of determining sequence of fracture, ambiguous relations were commonly observed. These arise from several causes: tectonic reactivation, so that newly propagated segments of old fractures grow to abut younger ones; offset of crosscutting fractures to produce false terminations; and surficial movement of joint-bounded blocks due to gravitative relaxation, downhill creep, frost-wedging, root wedging, etc., which alter the original geometry of fracture terminations and intersections. Careful observation can minimize the complications. Younger growth segments of older fractures, for example, commonly are of different orientation and may be unmineralized, although the original segment is filled.

\section{Station symbols}

Field descriptions and stereoplots for the various stations are arranged in the appendices in stratigraphic order. The prefix letters used for each station (CH, CKS, TR, etc.) correspond to the lithologic unit within which the data were taken and are identical to the symbols used by Scott and Bonk (1984) on their geologic map (fig. 2). A number placed after the letter designation ( $\mathrm{CH} 1, \mathrm{CH} 4, \mathrm{CKS} 4, \mathrm{CKS5}$, TR1) distinguishes different localities within the same lithologic unit. Specific fracture sets at each station are identified by the suffixes described below.

\section{Fracture-set symbols}

As knowledge grew as to how many sets exist, the order in which they formed, and how the sets of one locality correlate to those at another, we developed a formal symbology wherein each label has a consistent, specific meaning from one locality to another. 
Extension joints that formed during cooling of the ash-flow tuffs at Yucca Mountain are common elements of the regional fracture network and were recorded at numerous localities. Cooling joints in many places show sufficiently strong evidence of preferential orientation that they can be divided into sets, designated $\mathrm{C} 1, \mathrm{C} 2$, etc. in relative order of decreasing prominence. Commonly two sets of steeply dipping joints at approximate right angles are present. In some localities a third set of cooling joints nearly parallel to the rock foliation is present. Because the cooling sets formed during a comparatively short interval of geologic time and are roughly contemporaneous, no implication of relative age is given by the symbols. As noted above, the numbers given to the sets imply relative prominence rather than relative age. Even so, among sets of steep to vertical cooling joints, the most prominent set often can be shown to be the oldest.

Cooling joints at a few localities show such weak evidence of preferred orientation that sets cannot be defined with confidence; these joints we label CM (for cooling joints, miscellaneous).

Tectonic joints are labeled $\mathrm{T}$, and for these the numerical suffix $i$ s an indicator of relative age. T1, for example, refers to all joints that formed during the earliest known period of tectonic jointing at Yucca Mountain, T2 to the joints formed during the next-younger period, and so on. In one case, a tectonic set was identified but the authors were uncertain of its correlation to other tectonic sets. This set is labeled $\mathrm{T}$ without a numerical suffix.

SH is used as a general term to refer to sets of subhorizontal or gently dipping joints where proof or strong evidence of an origin by cooling is lacking. Nearly all of these are unloading joints that formed during erosion and consequent decrease of lithostatic load, but whether there was more than one such episode currently is uncertain. Foliation-parallel unloading joints in the Topopah Spring Tuff, for example, could have formed early, during erosion of the upper parts of that unit, or later, after eruption and subsequent removal of the overlying Tiva Canyon Tuff. For this reason we do not fit the SH joints into the T1-T4 fracture chronology but at each locality have attempted to deduce their origin.

Finally, $M$ refers to sparse miscellaneous joints or joints that cannot be assigned to sets with confidence.

\section{RESULTS}

\section{Introduction}

The fracture network in the study area includes cooling joints of various types, at least four sets of tectonic fractures, weathering joints, and local blasting fractures. Only those fractures in the first two categories are discussed here. Sets of cooling and tectonic joints are present in different combinations and to various degrees of expression at different localities. The character of the local fracture network thus differs, sometimes markedly, from one locality to another, but a strongly defined regional pattern nonetheless exists.

Median orientations of all cooling joint sets are listed in Table 1 and those for tectonic sets are listed in Table 2 and plotted on figure 3. In addition, regional properties of each tectonic set (grand median orientation, strike range, strike dispersion) are given in Table 2. Median orientations were also calculated for cooling joint sets with preferred NE and NW strikes (table 3). Fracture orientations for sets from each station, plotted onto lower hemisphere equal-area projections (Schmidt net) are provided in Appendix B. For sets of horizontal joints, an informal measure of central tendencies was plotted on the stereonets, since medians cannot be calculated. Orientations of individual fractures belonging to T1-T4 joint sets are plotted in figure 4 . 


\section{Cooling Joints}

\section{Field distinction between cooling and tectonic joints}

Cooling joints in the volcanic units at Yucca Mountain and Fran Ridge comprise an important and locally dominant component of the fracture network (fig. 5). In some places they are instantly recognizable by the presence of "tubular structures" on their surfaces (fig. 6). Tubular structures were first studied in the upper lithophysal unit of the Tiva Canyon Tuff by Morgan (1984), who described them (p. iii-iv) as "distinctive channels or tubes, usually one centimeter or less in diameter, that characteristically form a braided pattern within the plane of the fracture". Their origin was later attributed to tensional tearing of joint surfaces upon vertical expansion of the ash-flow sheet as gases exsolved from the cooling tuff (Barton, 1984; Barton and Larsen, 1985; Barton and others, 1993). Formation of joints with tubular structures must thus be envisioned as a two-stage process: thermal contraction of the tuff during early cooling to form the initial fractures with quenched, smooth surfaces, followed by gas-driven expansion of the tuff upon further cooling to stretch the fracture surfaces and form the tubes. These gases caused the volume of the rockmass to expand during this latter stage so that cohesion between the two fracture surfaces was regained. Photomicrographs of thin sections across such healed fractures are shown in Morgan (1984).

A further characteristic of cooling joints in the upper lithophysal unit is their exceptional smoothness. Small-scale topographic relief on a fracture face can be expressed by a Joint Roughness Coefficient (RC) (Barton and Choubey, 1977) on a scale from 0 (very smooth) to 20 (exceedingly rough). Morgan's data for 5,000 fractures in the upper lithophysal unit showed that most of the smoothest fractures in that unit, those with roughness coefficients of only $0-1$, also have tubular structures and thus are cooling joints. Morgan further noted that these smooth joints tend to be both long and nearly planar, and that none of them intersect the abundant lithophysal cavities in the rock. The latter observation implies that the tubular structures themselves served as avenues of gas escape at the cooling joint surfaces so that lithophysal cavities formed only at a certain distance away from them. Fractures with rougher surfaces almost uniformly lack tubular structures, intersect numerous lithophysal cavities (and hence postdate them), and were interpreted by Morgan as tectonic fractures if fairly long and as weathering joints if short. Later studies on cleared pavement surfaces (Barton and others, 1993) confirmed these results. Measured roughness coefficients for cooling joints range only from 1 to 4 with a peak at $\mathrm{RC}=2$, whereas those for later tectonic fractures range from 3 to 18 with a peak at RC $=10$ (Barton and Hsieh, 1989; Barton and others, 1993).

Tubular structures, where present, provide undisputed evidence for cooling joints and are prominently developed in many exposures of the upper lithophysal unit. Even there, however, fractures lacking tubular structure but possessing all other characteristics of an origin by cooling--appreciable length, planarity, exceptionally smooth surfaces, and orientations in common with known cooling joints nearby--were noted both by Morgan (1984) and Barton and Larsen (1985). The absence of tubular structure, then, appears not to disprove an origin by cooling. Moreover, the combination of characteristics developed by Morgan (1984) and later workers for recognizing cooling joints was based almost exclusively on studies within the upper lithophysal unit and might not be valid for other units of different lithology, where tubular structures commonly are absent. Because cooling joints are not everywhere obvious as such, much of our early work concentrated on developing field criteria to distinguish them from tectonic joints in the other volcanic units exposed at Yucca Mountain. 
Table 1. Median orientations of cooling joint sets in the study area.

\begin{tabular}{|c|c|c|c|c|}
\hline \multirow[b]{2}{*}{ Station } & \multirow[b]{2}{*}{ C1 } & \multicolumn{2}{|c|}{ Cooling Sets } & \multirow[b]{2}{*}{$\mathrm{C} 4$} \\
\hline & & $\mathrm{C} 2$ & $\mathbf{C 3}$ & \\
\hline TV1 & N14E/84NW & N74W/85SW & -- & -- \\
\hline TOB1 & N28W/85SW & N80E/89SE & $N 62 E / 10 S E^{2}$ & -- \\
\hline TOB2 & N19W/83SW & $\mathrm{N} 60 \mathrm{E} / 67 \mathrm{NW}$ & N34W/84SW & -- \\
\hline TR1 & $\mathrm{N} 10 \mathrm{E} / 90$ & N70W/90 & $N 11 W / 15 N E^{1}$ & -- \\
\hline TC1 & N77E/79NW & N49W/83SW & $\mathrm{N} 26 \mathrm{E} / 83 \mathrm{NW}$ & -- \\
\hline TC2 & N03E/78NW & N83W/85SW & $N 02 E / 17 S E^{1}$ & -- \\
\hline TC3 & N11E/88NW & N50W/89SW & N42E/81NW & $\mathrm{N} 88 \mathrm{~W} / 86 \mathrm{NW}$ \\
\hline TC4 & N89W/80NE & N13E/87SE & 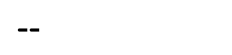 & -- \\
\hline $\mathrm{CC} 1$ & -- & -- & -- & -- \\
\hline $\mathrm{CH} 1$ & $\mathrm{~N} 70 \mathrm{E} / 87 \mathrm{NW}$ & -- & -- & -- \\
\hline $\mathrm{CH} 2$ & -- & -- & -- & -- \\
\hline $\mathrm{CH} 3$ & -- & -- & -- & -- \\
\hline $\mathrm{CH} 4$ & -- & -- & -- & -- \\
\hline $\mathrm{CH} 5$ & -- & -- & -- & -- \\
\hline $\mathrm{CH} 6$ & $N 34 E / 19 S E^{1}$ & -- & -- & -- \\
\hline $\mathrm{CH} 7$ & -- & -- & -- & -- \\
\hline $\mathrm{CH} 8$ & -- & -- & -- & -- \\
\hline $\mathrm{CH} 9$ & N69W/83SW & $\mathrm{N} 46 \mathrm{E} / 87 \mathrm{NW}$ & $N 67 W / 20 N E^{1}$ & -- \\
\hline CLL1 & N70W/73NE & -- & -- - - - n & -- \\
\hline CKS1 & -- & -- & -- & -- \\
\hline CKS2 & $\mathrm{N} 76 \mathrm{E} / 88 \mathrm{SE}$ & $\mathrm{N} 22 \mathrm{~W} / 84 \mathrm{SW}$ & -- & -- \\
\hline CKS3 & N35W/79SW & N55E/87NW & -- & -- \\
\hline CKS4 & $\mathrm{N} 75 \mathrm{E} / 85 \mathrm{NW}$ & -- & -- & -- \\
\hline CRS4 & -- & -- & -- & -- \\
\hline CRS5 & N70W/83NE & -- & -- & -- \\
\hline CRS6 & N39W/86NE & N53E/81NW & -- & -- \\
\hline CRS7 & $\mathrm{N} 55 \mathrm{~W} / 85 \mathrm{SW}$ & -- & -- & -- \\
\hline CUL1 & $\mathrm{N} 76 \mathrm{E} / 87 \mathrm{NW}$ & $\mathrm{N} 21 \mathrm{~W} / 86 \mathrm{SW}$ & -- & -- \\
\hline CUL2 & N10W/83SW & $\mathrm{N} 76 \mathrm{E} / 89 \mathrm{NW}$ & $N 79 W / 21 N E^{1}$ & -- \\
\hline CUL3 & N11W/78SW & N80E/88SE & $N 48 W / 10 N E^{1}$ & -- \\
\hline CULA & N01W/84SW & N90E/90 & -- & -- \\
\hline CUL5 & N45W/83NE & $\mathrm{N} 38 \mathrm{E} / 85 \mathrm{NW}$ & -- & -- \\
\hline CUL6 & -- & - & -- & -- \\
\hline CUL7 & N55E/80NW & $\mathrm{N} 45 \mathrm{~W} / 83 \mathrm{NE}$ & -- & -- \\
\hline CUL8 & $\mathrm{N} 34 \mathrm{~W} / 89 \mathrm{NE}$ & $\mathrm{N} 42 \mathrm{E} / 78 \mathrm{NW}$ & -- & -- \\
\hline CUL9 & $\mathrm{N} 50 \mathrm{E} / 75 \mathrm{NW}$ & $\mathrm{N} 51 \mathrm{~W} / 79 \mathrm{NE}$ & -- & -- \\
\hline CUC1 & -- & -- & -- & -- \\
\hline CUC2 & N38W/86NE & N36E/77NW & N02E/83NW & -- \\
\hline CCR1 & N71E/89NW & $\mathrm{N} 20 \mathrm{~W} / 87 \mathrm{SW}$ & - & -- \\
\hline CCR2 & N52E/87SE & $\mathrm{N} 43 \mathrm{~W} / 84 \mathrm{SW}$ & $N 24 E / 11 S E^{1}$ & -- \\
\hline CCR3 & $\mathrm{N} 40 \mathrm{E} / 84 \mathrm{NW}$ & N69W/87SW & -- & -- \\
\hline
\end{tabular}

${ }^{1}$ Median orientations of gently dipping cooling joint sets.

${ }^{2}$ Two gently dipping sets (C3a, C3b) occur in different parts of the outcrop. Median orientation is given for most prominent set. Refer to field data in Appendix A for more information. 
Table 2. Median orientations and regional properties of tectonic joint sets in the study area

\begin{tabular}{|c|c|c|c|c|}
\hline \multirow[b]{2}{*}{ Station } & \multirow[b]{2}{*}{ T1 } & \multicolumn{2}{|c|}{ Tectonic Sets } & \multirow[b]{2}{*}{ T4 } \\
\hline & & T2 & T3 & \\
\hline TV1 & -- & N30W/88NE & -- & -- \\
\hline TOB1 & N01E/89NW & -- & N50E/86SE & - \\
\hline TOB2 & N05E/79SE & -- & -- & -- \\
\hline TR1 & $\mathrm{N} 10 \mathrm{E} / 86 \mathrm{NW}$ & N41W/84SW & -- & -- \\
\hline TC1 & N05E/77NW & -- & -- & -- \\
\hline TC2 & N02W/81SW & -- & N39E/77NW & N87W/89SW \\
\hline TC3 & $\mathrm{N} 11 \mathrm{E} / 80 \mathrm{NW}$ & -- & -- & -- \\
\hline $\mathrm{TC} 4$ & N04E/86SW & $\mathrm{N} 18 \mathrm{~W} / 81 \mathrm{NE}$ & -- & $\mathrm{N} 88 \mathrm{~W} / 87 \mathrm{NE}$ \\
\hline $\mathrm{CC} 1$ & N04E/85NW & N45W/87SW & $\mathrm{N} 46 \mathrm{E} / 83 \mathrm{NW}$ & N86W/89NE \\
\hline $\mathrm{CH} 1$ & N12W/84SW & $\mathrm{N} 52 \mathrm{~W} / 90^{1}$ & -- & $\mathrm{N} 80 \mathrm{~W} / 86 \mathrm{NE}$ \\
\hline $\mathrm{CH} 2$ & N06E/84NW & -- & N28E/87NW & $\mathrm{N} 76 \mathrm{~W} / 90$ \\
\hline $\mathrm{CH} 3$ & N04W/78SW & $\mathrm{N} 33 \mathrm{~W} / 77 \mathrm{SW}$ & $\mathrm{N} 36 \mathrm{E} / 87 \mathrm{NW}$ & N85W/88NE \\
\hline $\mathrm{CH} 4$ & N08E/86NW & $\mathrm{N} 22 \mathrm{~W} / 88 \mathrm{NE}$ & -- & N79W/83SW \\
\hline $\mathrm{CH} 5$ & -- & -- & $\mathrm{N} 35 \mathrm{E} / 90$ & -- \\
\hline $\mathrm{CH} 6$ & N04W/88SW & N30W/85SW & $\mathrm{N} 47 \mathrm{E} / 89 \mathrm{NW}$ & N82W/86SW \\
\hline $\mathrm{CH} 7$ & N09E/85NW & -- & $\mathrm{N} 46 \mathrm{E} / 89 \mathrm{NW}$ & N86W/88SW \\
\hline $\mathrm{CH} 8$ & N03E/89SE & N43W/86SW & -- & N87E/88SE \\
\hline $\mathrm{CH} 9$ & N04W/82SW & -- & -- & -- \\
\hline CLL1 & $\mathrm{N} 11 \mathrm{~W} / 86 \mathrm{NE}$ & -- & N28E/85SE & -- \\
\hline CKS1 & N02W/80SW & -- & N44E/85NW & $\mathrm{N} 90 \mathrm{E} / 81 \mathrm{~S}$ \\
\hline CKS2 & -- & -- & N26E/84SE & $\mathrm{N} 72 \mathrm{~W} / 85 \mathrm{SW}$ \\
\hline CKS3 & -- & -- & -- & -- \\
\hline CKS4 & N06W/86SW & $\mathrm{N} 31 \mathrm{~W} / 77 \mathrm{SW}$ & -- & -- \\
\hline CRS4 & N07W/88SW & -- & -- & -- \\
\hline CRS5 & -- & -- & -- & -- \\
\hline CRS6 & N05W/90 & -- & -- & N78W/81NE \\
\hline CRS7 & -- & $\mathrm{N} 24 \mathrm{~W} / 87 \mathrm{SW}$ & -- & -- \\
\hline CUL1 & -- & $\mathrm{N} 32 \mathrm{~W} / 84 \mathrm{SW}$ & N35E/87NW & $\mathrm{N} 72 \mathrm{~W} / 76 \mathrm{SW}$ \\
\hline CUL2 & -- & -- & -- & -- \\
\hline CUL3 & -- & -- & -- & -- \\
\hline CUL4 & -- & -- & -- & -- \\
\hline CUL5 & N07W/88NE & -- & N18E/86SE & -- \\
\hline CUL6 & N09W/83NE & -- & N50E/81NW & -- \\
\hline CUL7 & -- & -- & -- & -- \\
\hline CUL8 & -- & -- & -- & -- \\
\hline CUL9 & N10E/86NW & N31W/82SW & -- & $\mathrm{N} 75 \mathrm{~W} / 81 \mathrm{SW}$ \\
\hline CUC1 & -- & N21W/85SW & -- & -- \\
\hline CUC2 & -- & -- & -- & -- \\
\hline CCR1 & -- & N27W/86SW & -- & -- \\
\hline CCR2 & -- & -- & -- & -- \\
\hline CCR3 & -- & -- & -- & -- \\
\hline \multicolumn{5}{|l|}{ Grand median } \\
\hline Strike range & N11E-N12W & N18W-N52W & N18E-N50E & N72W-N87E \\
\hline \multicolumn{5}{|l|}{ Strike } \\
\hline dispersion & $23^{\circ}$ & $34^{\circ}$ & $32^{\circ}$ & $21^{\circ}$ \\
\hline
\end{tabular}

${ }^{1}$ Two subsets of T2 (T2a, T2b) occur in different parts of the outcrop. Median orientation is given for most prominent set. Refer to field data in Apendix A for more information. 
Table 3. Median strikes of cooling joints for localities within enclosed area on Figure 11.

\begin{tabular}{|c|c|c|}
\hline \multirow[b]{2}{*}{ Station } & \multicolumn{2}{|c|}{ Cooling Sets } \\
\hline & NE-striking & NW-striking \\
\hline $\mathrm{CH} 1$ & $N 70 E_{2}^{3}$ & -- \\
\hline CH6 & $\mathrm{N} 34 \mathrm{E}^{3}$ & - \\
\hline CLL1 & - & $\mathrm{N}^{2} 0 \mathrm{~W}^{3}$ \\
\hline CKS4 & $N 75 E^{3}$ & - \\
\hline CRS5 & - & $\mathrm{N} 70 \mathrm{~W}^{3}$ \\
\hline CRS6 & $\mathrm{N} 53 \mathrm{E}$ & N39 $W^{3}$ \\
\hline CRS7 & -- & $\mathrm{N} 55 \mathrm{~W}^{3}$ \\
\hline CUL5 & N38E & $\mathrm{N}_{45 \mathrm{~W}^{3}}$ \\
\hline CUL7 & $N 55 E^{3}$ & $\mathrm{~N} 45 \mathrm{~W}$ \\
\hline CUL8 & $\mathrm{N} 42 \mathrm{E}$ & $\mathrm{N} 34 \mathrm{~W}^{3}$ \\
\hline CUL9 & $\mathrm{N}^{2} \mathrm{E}^{3}$ & $\mathrm{~N} 51 \mathrm{~W}$ \\
\hline CUC2 & $\mathrm{N} 36 \mathrm{E}$ & $\mathrm{N} 38 \mathrm{~W}^{3}$ \\
\hline CCR1 & $\mathrm{N}^{2} 1 \mathrm{E}^{3}$ & N20W \\
\hline CCR2 & $\mathrm{N} 52 \mathrm{E}^{3}$ & $\mathrm{~N} 43 \mathrm{~W}$ \\
\hline CCR3 & $N 40 E^{3}$ & N69W \\
\hline Pvmt $100^{1}$ & $\mathrm{~N} 48 \mathrm{E}^{3}$ & N45W \\
\hline Pvmt $200^{1}$ & $\mathrm{~N} 37 \mathrm{E}^{3}$ & -- \\
\hline Pvmt $300^{1}$ & $\mathrm{~N} 36 \mathrm{E}$ & $\mathrm{N} 40 \mathrm{~W}^{3}$ \\
\hline Pvmt $600^{2}$ & $N 35 E^{3}$ & - \\
\hline
\end{tabular}

$1=$ Refer to Barton and others (1993)

2 = Pavement 600 was mapped in 1985 by C.K. Throckmorton; C.C. Barton, unpub. data, 1985

$3=$ Dominant set 
$\mathbf{n}=$

68

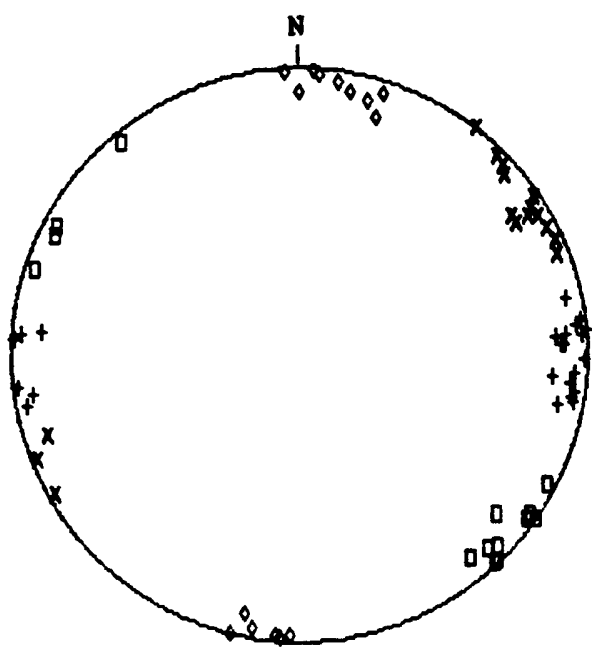

$\begin{array}{lll}+\operatorname{MEDT1} & \mathbf{n}= & 24 \\ \times \operatorname{MEDT2} & \mathbf{n}= & 16 \\ -\operatorname{MEDT3} & \mathrm{n}= & 14 \\ -\operatorname{MEDT4} & \mathrm{n}= & 15\end{array}$

Schmidt net, lower hemisphere projection

MEDT1

N04E85NW

N12W84SW

N06E84NN

NO 4 W78SW

NOBE86NN

NO4W88SW

NO9E85N

NO3E89SE

N04W82SW

NO2W80SW

No6W86SW

N11W86NE

N07W88SW

No5W9OSW

N07W88NE

N09W83NE

N10E86N

NO5E7 7NW

No 2 W81SW

N11E8ONW

NO4E86SE

NO1E69NW

NO5E7 9SE

N10E86NW
MEDT2 MEDT3 MEDT4

\begin{tabular}{|c|c|c|}
\hline $\begin{array}{l}\text { N45W87SW } \\
\text { N27W86SW } \\
\text { N52W80SW1 } \\
\text { N34W88SWl } \\
\text { N33W77SW } \\
\text { N22W88NE } \\
\text { N30W85SW } \\
\text { N43W86SW } \\
\text { N31W77SW } \\
\text { N24W87SW } \\
\text { N21W85SW } \\
\text { N32W84SW } \\
\text { N31W82SW } \\
\text { N18W81NE } \\
\text { N41WB4SW }\end{array}$ & $\begin{array}{l}\text { N46E83NW } \\
\text { N28E87NW } \\
\text { N36E87NW } \\
\text { N35E9ONW } \\
\text { N47E88NW } \\
\text { N46E89NW } \\
\text { N44E85NW } \\
\text { N26E84SE } \\
\text { N28E85SE } \\
\text { N35E87NW } \\
\text { N18E86SE } \\
\text { N50E81NW } \\
\text { N39E77NN } \\
\text { N50E86SE }\end{array}$ & $\begin{array}{l}\text { N86WB9ND } \\
\text { NBOWB6ND } \\
\text { N76W9OND } \\
\text { N85WB8ND } \\
\text { N79WB3SW } \\
\text { NB2WB6SW } \\
\text { N86WB8SW } \\
\text { NB7EB8SE } \\
\text { N9OEB1SE } \\
\text { N72WB5SW } \\
\text { N78WB1ND } \\
\text { N72W76SW } \\
\text { N75WB1SW } \\
\text { NB7WB9SW } \\
\text { NB8W87ND }\end{array}$ \\
\hline
\end{tabular}

N76W9ONE

N85W88NE

N82WB6SW

N86W88SW

N87E88SE

N78W81NL

${ }^{1}$ Median orientations are given for two subsets of T2 (T2a, T2b), that occur in different parts of the outcrop at station CH1. Refer to field data in Appendix A for more information.

Figure 3.--Stereographic plot showing median orientations of T1-T4 joint sets for all stations. 
T1 JOINTS, ALL STATIONS

$\mathrm{n}=354$

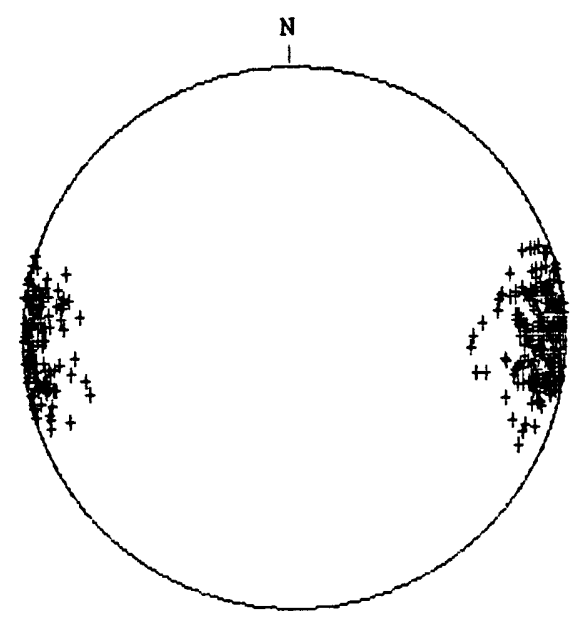

Schmidt net, lower hemisphere projection

T3 JOINTS, ALL STATIONS

$\mathrm{n}=181$

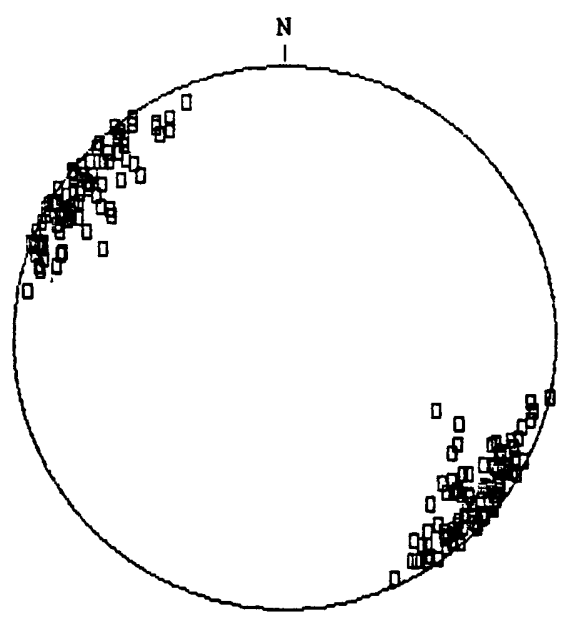

Schmidt net, lower hemisphere projection
T2 JOINTS, ALL STATIONS

$\mathbf{n}=198$

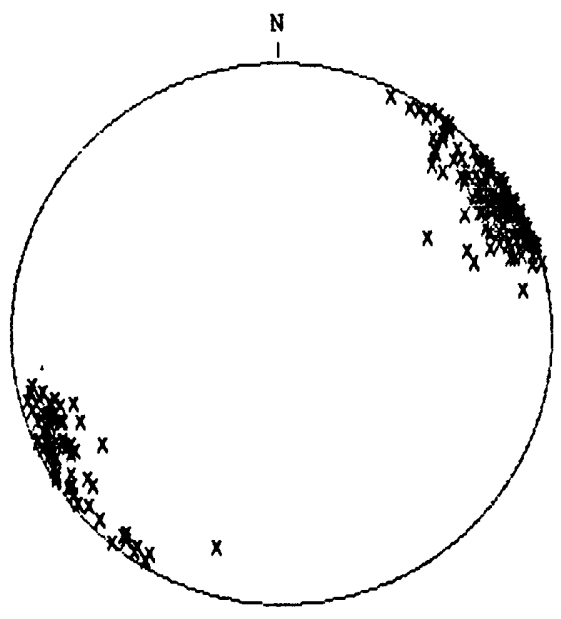

Schmidt net, lower hemisphere projection

T4 JOINTS, ALL STATIONS

$n=207$

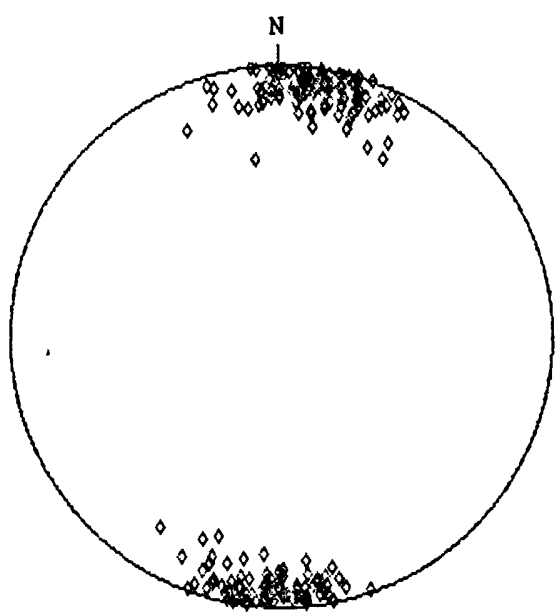

Schmidt net, lower hemisphere projection

Figure 4.--Stereographic plot showing fracture orientations of T1-T4 joints for all stations. Explanation of symbols shown on figure 3 . 


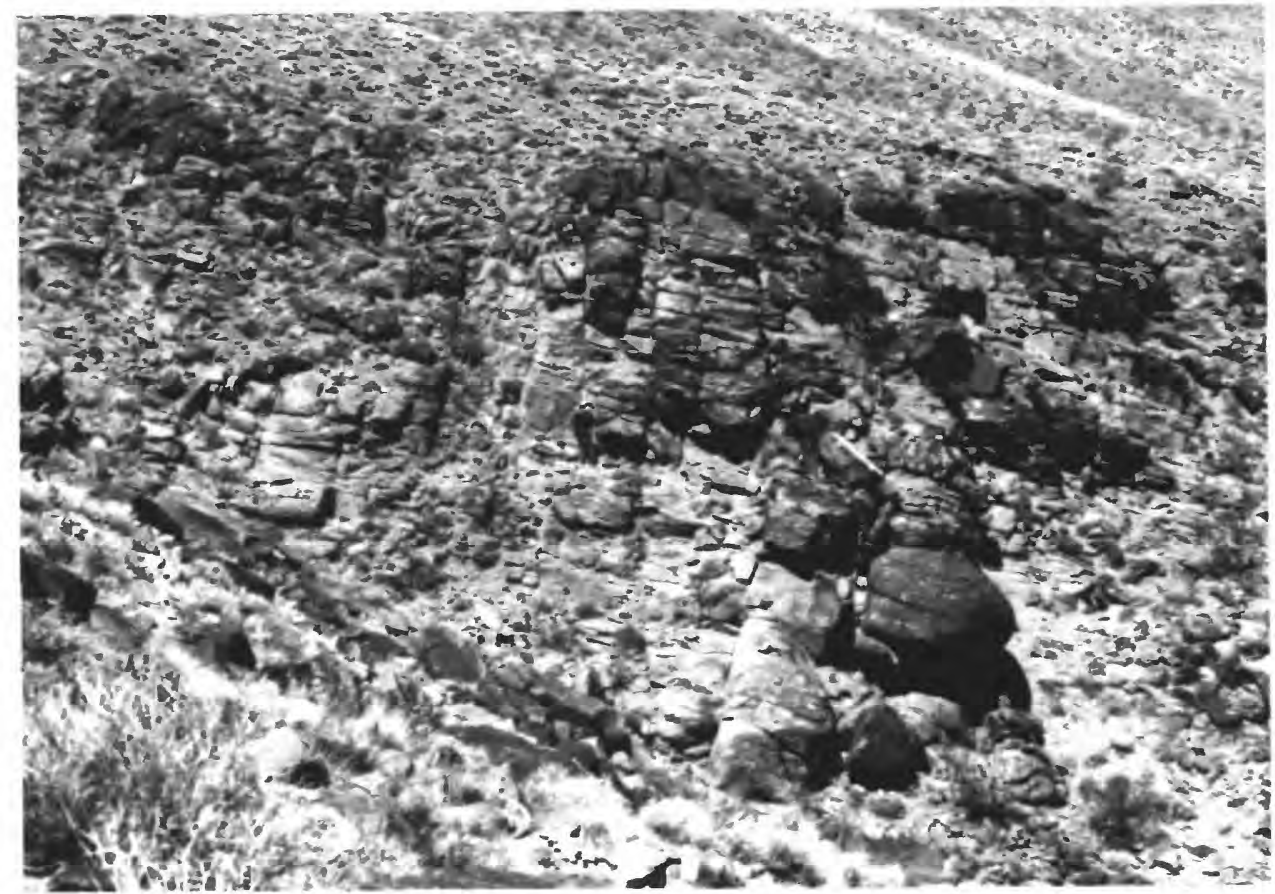

Figure 5.--Photograph of reactivated, prominent north-striking cooling joints on east side of Fran Ridge in the Topopah Spring Tuff, just south of station TC3. Joints extend from the caprock unit downward through the thin lithophysal unit into the rounded step unit. One joint (N02W/82SW) is $20 \mathrm{~m}$ long and $16 \mathrm{~m}$ high. Many joints with similar orientations are of comparable size. View is to north.

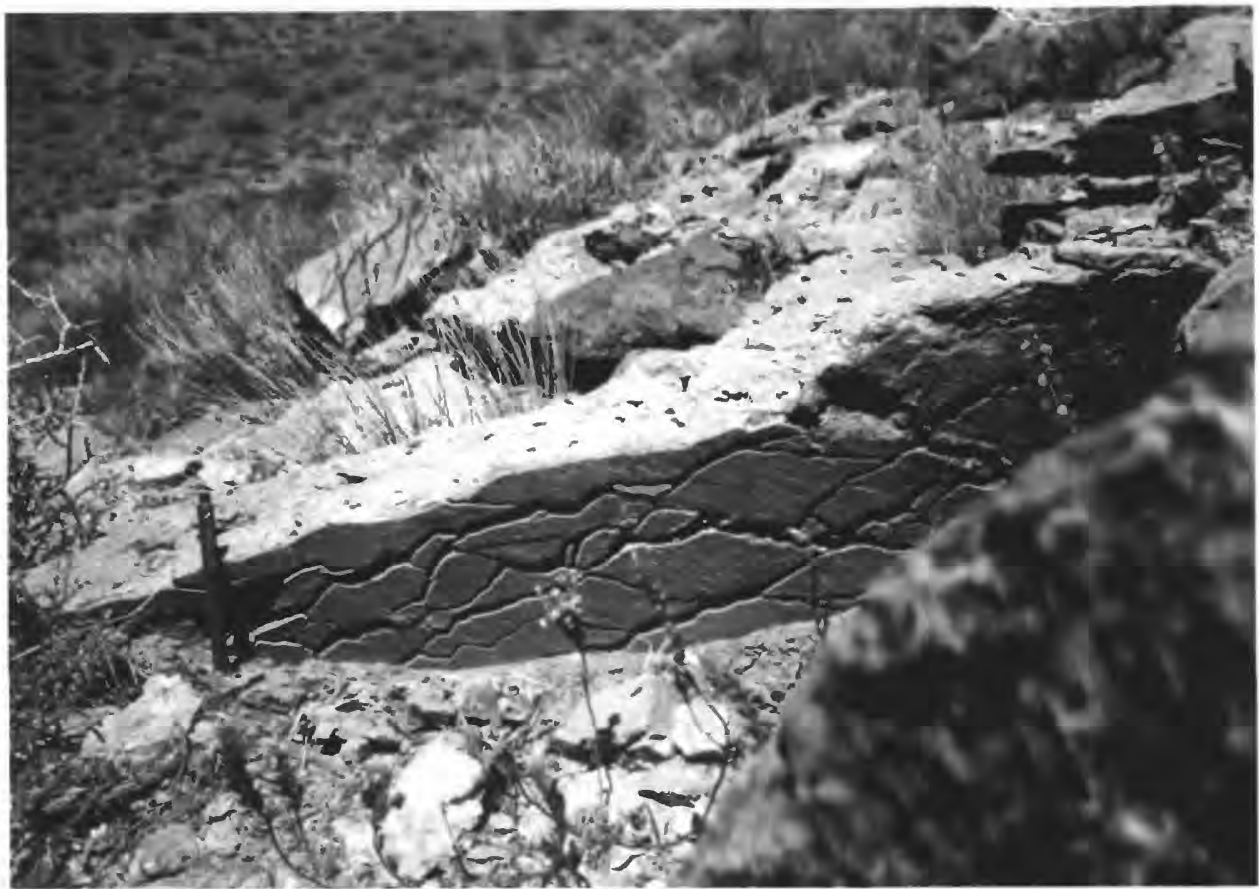

Figure 6.--Tubular structures on N27E/89NW cooling joint $6 \mathrm{~m}$ north of station CUL5. Exposed joint surface is approximately $2 \mathrm{~m}$ in length and $0.7 \mathrm{~m}$ in height. Tube diameters range from 0.4 to $1 \mathrm{~cm}$. View is northwest. 
Tubular structures proved to be sparse or absent in most volcanic units but were found on some cooling joints within the orange brick unit of the Topopah Spring Tuff and the hackly, lower lithophysal, upper lithophysal, upper cliff, and caprock units of the Tiva Canyon Tuff. These joints provided a starting point to document other properties by which cooling joints might be recognized in the same and possibly other units. A constant property of known cooling joints in all units studied was very low surface roughness. By itself, however, smoothness to the touch is not diagnostic of cooling joints, for the surfaces of undisputed tectonic joints in several units (vitrophyre, orange brick, rounded, hackly, and rounded step) are nearly as smooth as those of cooling joints in the same exposures. Very smooth tectonic joints are nonetheless uncommon, and smoothness remains a prime criterion for recognizing cooling joints in all units studied.

The evident planarity of cooling joints, a property remarked upon by Morgan (1984) for cooling joints within the upper lithophysal unit of the Tiva Canyon Tuff, is characteristic only of areas where they form two well-defined, nearly vertical sets at approximate right angle to each other. Elsewhere, where the pattern of cooling joints is of fundamentally different geometry (see following section), shapes of cooling joints range from gently sinuous to markedly curved. Tectonic joints, as later discussed, generally range in shape from subplanar (gently to moderately sinuous) to nearly planar--thus, gross fracture shape is not often a reliable discriminator between cooling and tectonic fractures. On a finer, decimeter scale, however, the shapes of cooling joints and tectonic fractures exhibit consistent differences in nearly all units studied. The differences are most apparent in their traces on pavement surfaces: traces of cooling joints are smoothly continuous, as if they had been drawn with a French curve, whereas those of tectonic joints in the same exposures are distinctly more irregular. Though some of the surface irregularities on tectonic joints are sufficiently small that they are expressed in the Joint Roughness Coefficient mentioned above, others are of broader wavelength and are best detected visually.

Early in this study, fracture size (primarily length) was recognized as a useful criterion for identifying cooling joints in units where tubular structures are sparse or absent. Our results support and extend the correlation noted earlier by Morgan (1984) for the upper lithophysal unit: the smoothest fractures in most of the exposures studied are among the longest fractures present. At stations TC2, TC4, CRS6, CUL4, and CCR1, for example, most of the cooling joints belonging to the most prominent set $(\mathrm{C} 1)$ have lengths of $5 \mathrm{~m}$ or more, but the later tectonic fractures generally are only $0.5-3 \mathrm{~m}$ long. The length difference between cooling and tectonic joints in some exposures is so marked that the cooling joints are recognizable on sight. The commonly shorter length of tectonic fractures resulted in part from their formation in a rock already cut by abundant cooling joints, whose presence impeded lateral growth of later fractures.

All of the above criteria for recognition of cooling joints refer to properties of individual fractures. Their collective network geometry, however, can also aid in their recognition. For example, a large number of triple junctions--three fractures radiating from a common point at approximate $120^{\circ}$ interplanar angles--can only signify a crude hexagonal network of cooling joints. Network geometries of cooling joints are discussed in more detail below.

The final criterion for recognition of cooling joints, and in some respects the most powerful one, is relative age: only the oldest fractures in any given exposure can be considered as potential cooling joints. Close attention to abutting and crosscutting relations was paid in our studies to establish relative age of fracture sets wherever possible. The results confirmed that fractures showing the properties mentioned above--very low surface roughness, smooth, continuous traces, appreciable length, and locally marked sinuosity or curvature--consistently are the oldest (fig. 7). We thus interpret them as cooling joints and conclude that a 
combination of these characteristics, together with demonstration of early relative age, is sufficient to distinguish cooling from tectonic joints in most areas where tubular structures are absent.

\section{Network patterns of steeply dipping cooling joints}

Quantitative analysis of the network geometries of steeply dipping cooling joints was to have been one element of our later work at Yucca Mountain, and we have made no special study of them. Reconnaissance field work, however, soon showed that the prominent rectangular pattern documented by Morgan (1984) and Barton and Larsen (1985) for parts of the upper lithophysal unit, though common in other units as well, does not everywhere apply; cooling joints in some places conform instead to crude hexagonal networks or to networks of mudcrack geometry. We here provide a few preliminary observations.

Cooling joints in moderately to densely welded parts of the columnar unit, near the base of the Tiva Canyon Tuff, divide the rock into the abundant, crude, vertical columns for which the unit was named by Scott and Bonk (1984). Brief examination of low, cliff outcrops of the columnar unit in Drill Hole Wash revealed numerous places where three fractures radiate from a common vertical axis, thereby confirming that many of the fractures present are cooling joints and that their pattern is based on an hexagonal motif. Column diameters of $20-100 \mathrm{~cm}$ are common. Tectonic joints in the columnar unit are uncommon at Drill Hole Wash, in large part because the sheer abundance of cooling joints inhibited their formation. Hexagonal networks of cooling joints, though possibly common in the columnar unit, were not noted by us in any of the other units studied.

Two sets of steeply dipping cooling joints at approximate right angle to each other were documented at 23 of 41 joint stations in the Topopah Spring and Tiva Canyon Tuffs and comprise the dominant pattern of cooling joints at Yucca Mountain. Map units in which such rectangular networks were found include the vitrophyre, orange brick, rounded, and caprock units of the Topopah Spring Tuff and the hackly, clinkstone, rounded step, upper lithophysal, upper cliff, and caprock units of the Tiva Canyon Tuff. Further work almost certainly will disclose them in other units also. Angles between the two sets, as measured clockwise from the dominant $(\mathrm{C} 1)$ to the subordinate (C2) cooling set, range from $71^{\circ}$ to $115^{\circ}$ and have a median value of $89.5^{\circ}$ (fig. 8). Departures of more than $10^{\circ}$ from true perpendicularity may reflect sparsity of data as much as reality: at five of seven stations showing such departure, only 4-8 cooling joints of the subordinate set were found for measurement. Weak expression of one cooling set relative to the other is common. An extreme example is pavement 100 (fig. 1) of Barton and Larsen (1985), wherein one cooling set is represented by abundant, long, closely spaced joints and the second only by several short joints. At several of our stations, too (CH1, CH6, CLL1, CKS4, CRS5, CRS7), we measured one well-expressed set of cooling joints but were unable to verify the certain presence of a second set. At pavement 600, located in the northern part of the study area, only one, poorly expressed cooling set is present, although two sets at right angles are documented at a nearby station (CUL8). Nearly equal development of the two sets, though uncommon, was noted at stations TOB1, CUL7, and CCR3.

Gentle curvature of rectangular cooling-joint networks over distances of tens to hundreds of meters seemingly is common, but only rarely is the curvature pronounced at that scale. Data from one example are shown in fig. 9 for a set of probable cooling joints at station CUL4, just above the base of the upper lithophysal unit at a locality near the north end of Fran Ridge. 


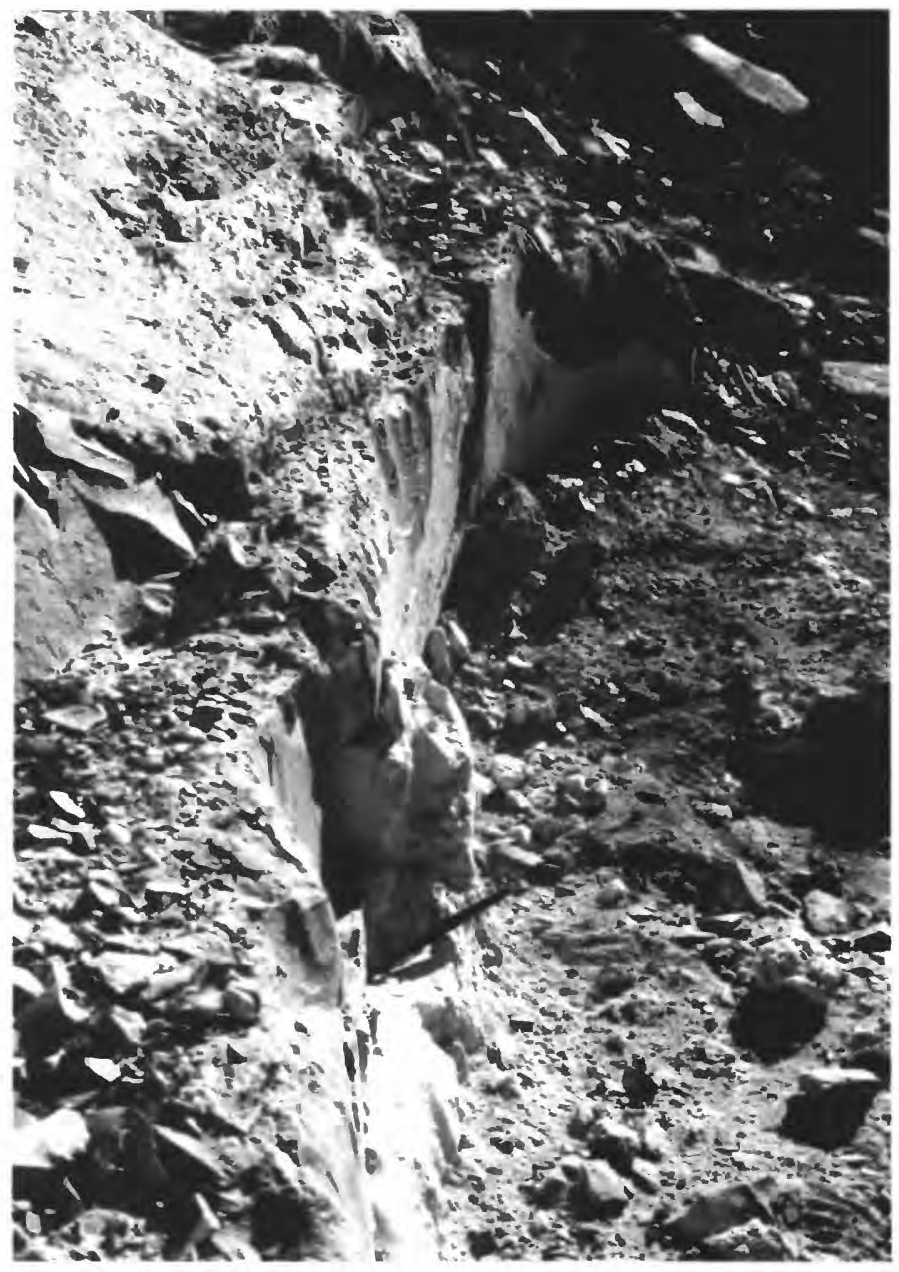

Figure 7.--Cooling joint belonging to $\mathrm{C} 2$ set, exposed in trench (locality CKS3), $0.3 \mathrm{~km}$ west of Fran Ridge. Joint curves $34^{\circ}$ over a length of $2.6 \mathrm{~m}$. Dip change is very gradual. Joint has been reopened, probably during movement on the Paintbrush fault, and is filled with a 13$\mathrm{cm}$-thick, white, noncalcareous mineral fill (resembling chalcedony or opaline silica). Small, angular pieces of clinkstone are present within the fill. 


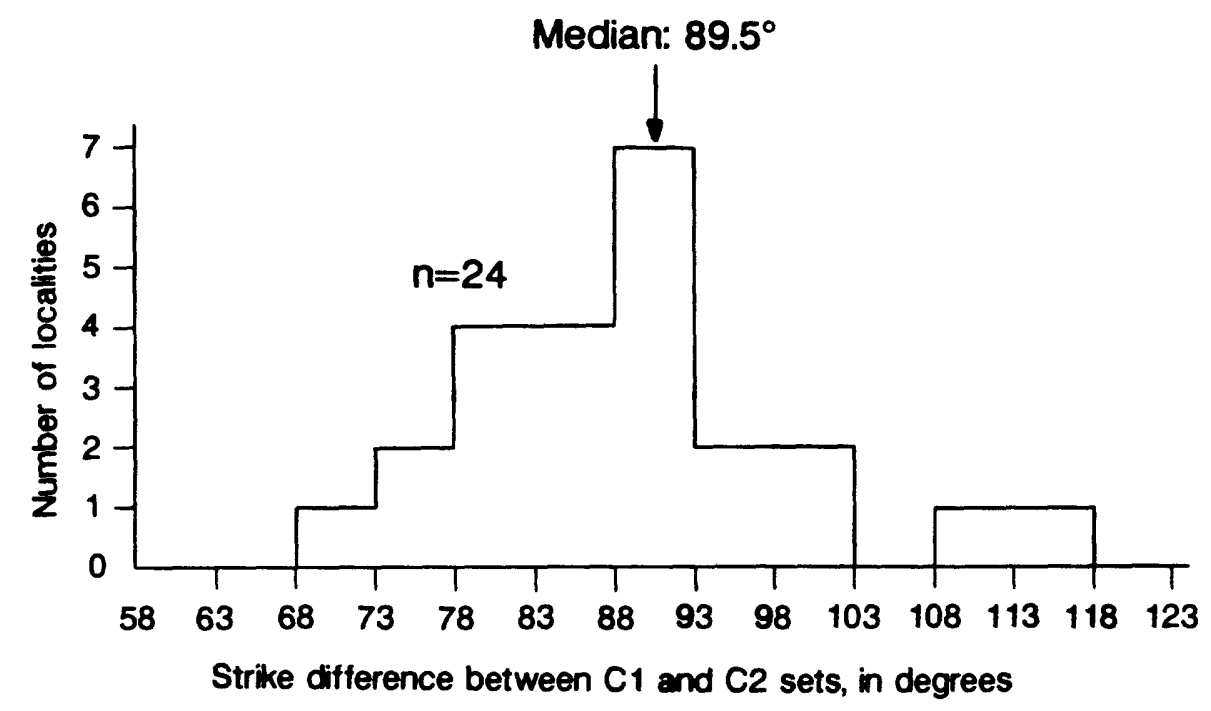

Figure 8.--Linear histogram showing strike difference between pairs of cooling-joint sets on and near Yucca Mountain. The plot reflects the common tendency for cooling-joint sets to form crude rectangular networks. The median angle between sets is $89.5^{\circ}$. At one locality (TC3) near the top of the Topopah Spring Tuff, two cooling episodes resulted in four cooling sets which locally coexist; thus 24 joint-set pairs are represented from 23 localities. $\mathrm{n}=$ total number of joint-set pairs.

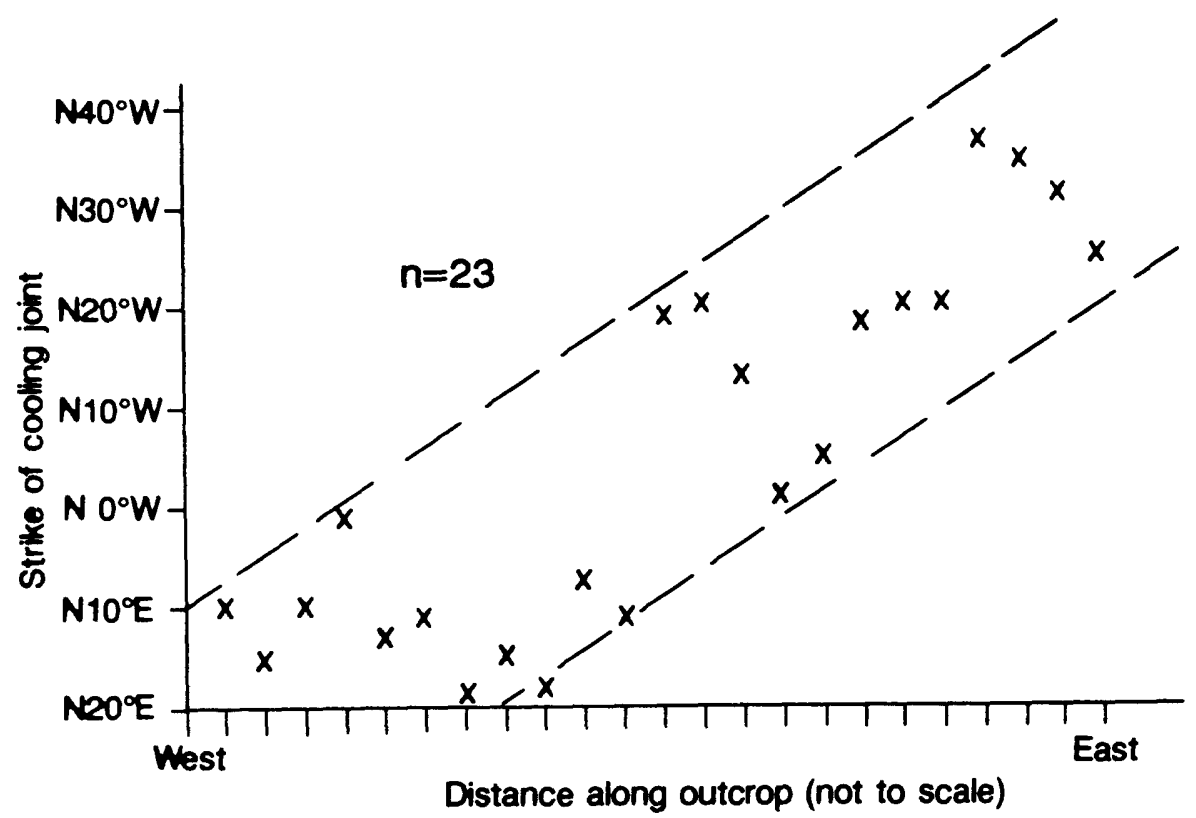

Figure 9.--Strikes of cooling joints at station CUL4, plotted from the west end of the outcrop (left) to the east end (right), showing apparent strong curvature of a cooling-joint set within a horizontal distance of several tens of meters. Distances along horizontal axis not to scale. $\mathrm{n}=$ total number of measurements. 
The large $\left(56^{\circ}\right)$ strike dispersion of this set, from N. $19^{\circ} \mathrm{E}$. to N. $36^{\circ} \mathrm{W}$., at first proved puzzling until the data were plotted in the order in which they were measured from one end of the outcrop to the other. The resultant plot (fig. 9) suggests that the cooling-joint set curves $50^{\circ}$ over a lateral distance of only $30 \mathrm{~m}$, from N. $20^{\circ}$ E. strikes at the west end of the outcrop to $\mathrm{N} .30^{\circ} \mathrm{W}$. strikes near the east end.

Cooling joints with a distinctive mudcrack geometry seemingly are rare at Yucca Mountain and are not present at any of our $\mathbf{4 1}$ formal joint stations. Nevertheless we noted them in several places, and they may be more common than is generally realized. Characteristics of this pattern include pronounced curvature of some of the fractures, lack of triple junctions (as opposed to their common presence in hexagonal networks), and consistent right-angle terminations of one fracture against another.

\section{Subhorizontal cooling joints}

Cooling joints of low dip, parallel to foliation in the tuff or transecting it at low angles, were documented at eight localities on Yucca Mountain and Fran Ridge (table 1). At seven of them the presence of tubular structures on the joint surfaces served as proof of origin (fig. 10). Median dips of these joints range from $8^{\circ}$ to $21^{\circ}$ to the northeast or southeast, reflecting the generally eastward tilt of the rocks. To date we have found low-dipping cooling joints in the orange brick, rounded, and caprock units of the Topopah Spring Tuff and in the hackly, upper lithophysal, and caprock units of the Tiva Canyon Tuff. Though seemingly widespread there is no mention of them in the previous literature, probably because they often passed unrecognized among the generally much greater numbers of unloading joints of similar orientation. In addition to tubular structures, distinction between the two types of joints is based on the following criteria:

- The cooling joints have smooth, undulatory, subplanar to nonplanar surfaces. Unloading joints commonly are of similar shape but have decidedly rougher surfaces.

- The cooling joints only rarely cut lithophysae, even in units where lithophysal cavities are abundant. The later unloading joints cut through lithophysae indiscriminately and, as later discussed, commonly originated at them.

- Abutting relations at several localities show that the gently dipping cooling joints are either the oldest joints present or formed during the same time period as those of steep dip. At station TR1, for example, numerous, nearly vertical joints of the earliest known tectonic set terminate against smooth joints parallel to foliation; the low-dipping joints are thus interpreted as due to cooling. Similarly, at station CUL3, the continuity of tubular structures on one gently dipping cooling joint intersected by a second, vertical cooling joint demonstrates the early age of the low-dipping joint. Numerous abutting relations at station TC2 show that the gently dipping cooling joints formed later than some of those of steep dip and earlier than others. Foliation-parallel fractures due to unloading, in contrast, are much younger and characteristically terminate against or intersect the steeply dipping tectonic joints.

- At two localities (TC2, CCR2) the cooling joints increase in abundance downward, the opposite of the expected trend for unloading joints. 


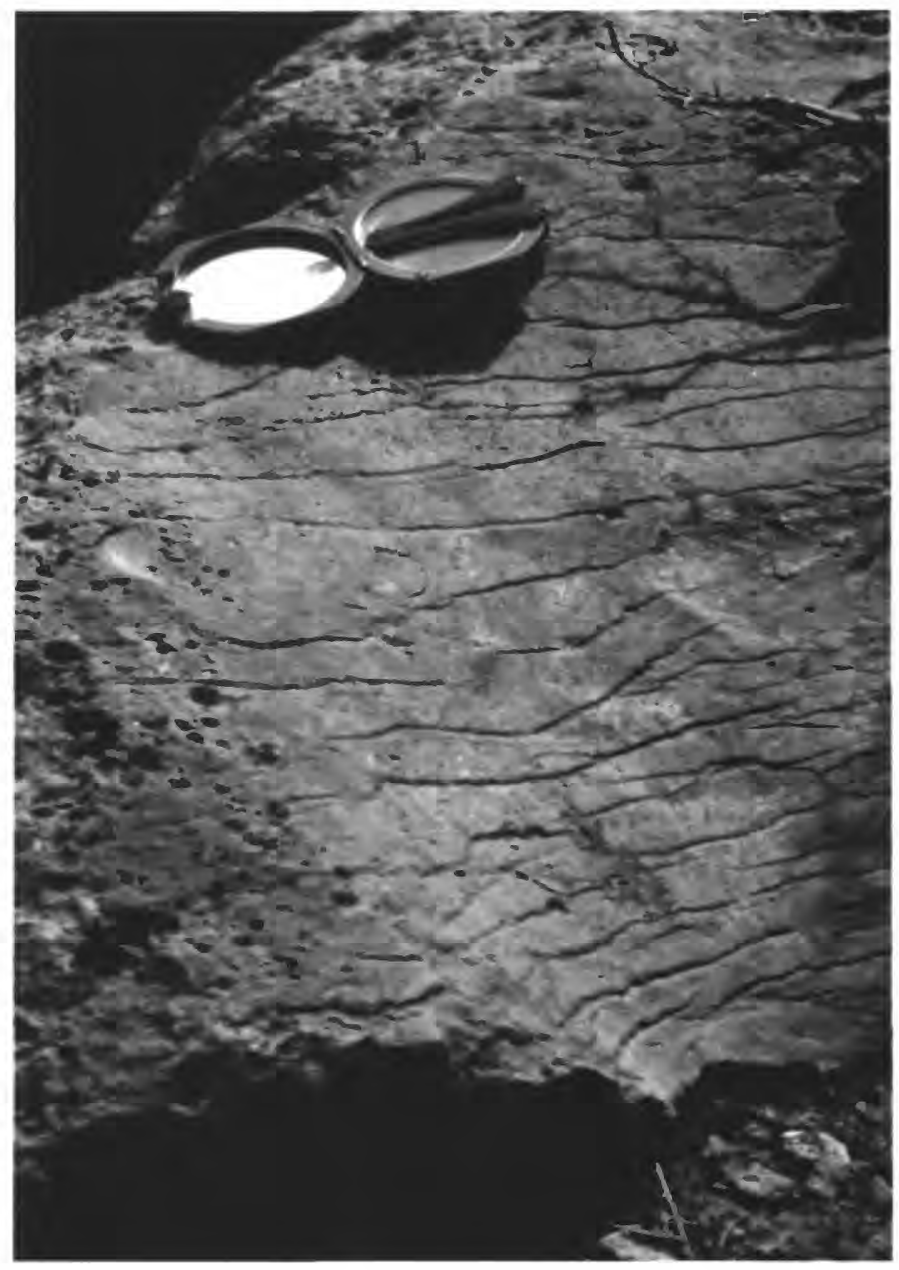

Figure 10.--Tubular structures on subhorizontal cooling joint at station CUL3 on Fran Ridge. The joint surface is smooth and slightly irregular in shape. Tube diameters range from 1-3 $\mathrm{mm}$ and are spaced $4-7 \mathrm{~cm}$ apart. 
The low-dipping cooling joints thus have several properties in common with those of steep dip: smooth surfaces, early age relative to tectonic joints, tubular structures, common undulatory shape, and, in some localities, large size. Collectively these properties are useful in distinguishing cooling from unloading joints in the much same manner as steeply dipping cooling joints are distinguishable from tectonic fractures.

At all localities but one (CH6) where foliation-parallel cooling joints were found, two sets of steeply dipping cooling joints are present also. In three dimensions these joints form mutually orthogonal fracture arrays, but in most places the joints of all three sets differ markedly in average size, abundance, and spacing. The low-dipping cooling joints invariably are less abundant than those of the other two sets but at some localities are fairly prominent nonetheless.

\section{Preferred orientations of cooling joints}

Median orientations of cooling joint sets are shown in figure 11 and listed in Table 1 . The data, though too sparse to be definitive, suggest that cooling joints in Tiva Canyon Tuff within the northern part of the Yucca Mountain block--the area enclosed by the dashed line on the figure--are preferentially oriented and thus potentially amenable to realistic characterization. The proposed repository site lies within this area.

Strike data for cooling joints at 15 localities and four pavements within the proposed repository site are listed in Table 3 to show their consistency. Relative prominence of each set is shown. The data are readily interpretable in terms of two sets, one striking N. $20^{\circ}-70^{\circ} \mathrm{W}$. and the other N. $34^{\circ}-71^{\circ} \mathrm{E}$. (grand medians are N. $45^{\circ} \mathrm{W}$. and N. $50^{\circ} \mathrm{E}$., respectively). The total strike range represented by the two sets is less than half the possible range of $180^{\circ}$ and underscores the nonrandom nature of the rectangular cooling-joint pattern at this scale. Preferred orientations of cooling joints over an area of about $0.2 \mathrm{~km}^{2}$ was demonstrated from the earlier work of Morgan (1984) and Barton and others $(1989,1993)$. Our results suggest the same is true for most of the northern half of Yucca Mountain within an area of more than $20 \mathrm{~km}^{2}$ underlain by various units of the Tiva Canyon Tuff.

\section{Tectonic Joints}

The term tectonic joint is used here in its broadest sense to indicate all natural joints not related to contractional cooling or to surficial processes such as weathering and mass wasting. Tectonic joints thus potentially include joints due to regional crustal extension or compression, volcanism and caldera formation, and unloading due to erosion of overlying rock. Our results suggest that five sets of tectonic joints are present in the field area and that they formed in the order discussed below.

\section{Regional extension joints: T1 through T3 sets}

Tectonic joints striking within $40^{\circ}$ of due north are present in great numbers on Yucca Mountain. Where well-formed they are divisible into three sets on the basis of orientation and abutting relations. Probably most or all of them are elements of a regionally consistent joint network, but this inference cannot be tested until the nature of that network has been documented over a far larger area than has been studied to date. The tectonic significance of each set remains uncertain for the same reason, though their generally northerly strikes suggest an origin by Basin-and-Range crustal extension, the differing strikes of each set possibly reflecting noncoaxial extension over time. 


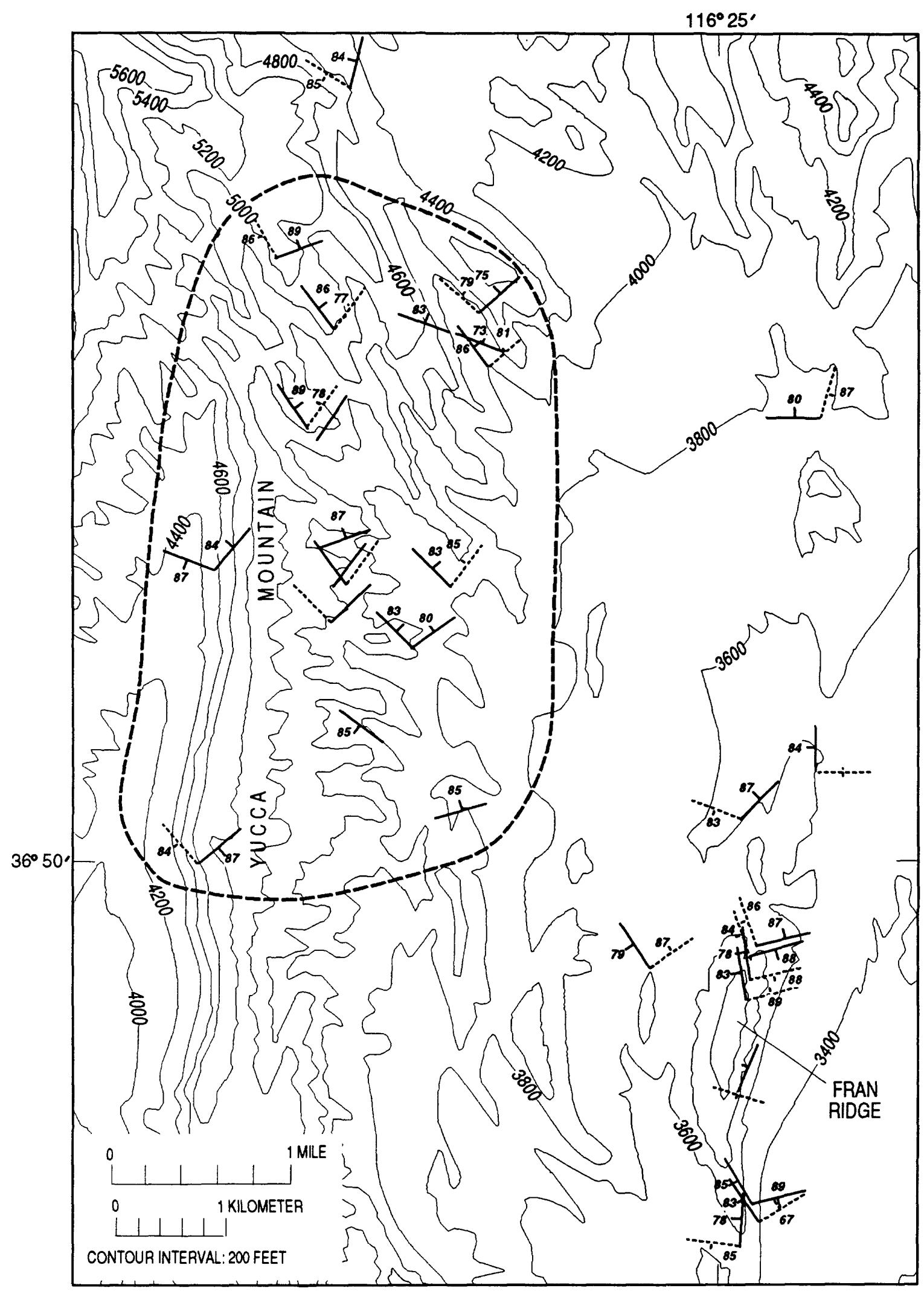

Figure 11.--Map showing median orientations of cooling-joint sets in the Tiva Canyon and Topopah Spring Tuffs. Dashed line encloses area within which cooling-joint sets show preferred NW and NE strikes. Solid and dashed strike symbols indicate dominant and subordinate sets, respectively. Not all stations on Fran Ridge are plotted due to the close proximity of stations. 


\section{T1 set: North-striking joints}

A set of joints (fig. 12, table 2) with a grand median orientation (median of median orientations calculated for each joint set) of N. $01^{\circ} \mathrm{W} .86^{\circ} \mathrm{SW}$. was documented at nearly 60 percent of all localities studied. These earliest formed tectonic joints show the lowest strike dispersion $\left(23^{\circ}\right)$ from place to place of any regional extension set: their strikes range only from N. $11^{\circ} \mathrm{E}$. to N. $12^{\circ} \mathrm{W}$. Surface structures on $\mathrm{T} 1$ joints typically are inconspicuous, but local arrest lines and twist hackle show that they are extension fractures.

The prominence of the T1 set varies greatly but in general is inversely related to that of the cooling joints. Where cooling joints are few, as in much of the hackly unit, the T1 set reaches its greatest development. The T1 set is present at eight of the nine stations studied within this unit, and at five it is the dominant set. Conversely, where cooling joints are both large and abundant, as in much of the upper lithophysal unit of the Tiva Canyon Tuff, the T1 joints form only a weak set or are absent; we found them, in low numbers, in only three of nine localities. The effect of prominent existing sets of joints in suppressing the development of later sets is well illustrated by the T1 set at Yucca Mountain.

At many localities joints of the $\mathrm{T} 1$ set are the largest of all tectonic joints present; only some of the earlier cooling joints are larger. Exposed lengths of 2-5 m are common among T1 joints, and some may be traced for more than $7 \mathrm{~m}$ in exposures large enough to permit it. These values likely are close to true lengths in several places (TR1, CH7, CRS4), but in others, where few ends of $\mathrm{T} 1$ joints are exposed, their true lengths remain unknown. Exposed heights of 1-3 m are the norm, but some have exposed heights of 4-6 m (CH1) and rarely as much as $12 \mathrm{~m}$ (TOB1). In places, however, the presence of abundant lithophysal cavities appears to have inhibited the development of large tectonic joints: T1 joints at station CLL1 in the lower lithophysal unit and at station CUL5 in the upper lithophysal unit are uniformly small, less than a meter in maximum dimension.

Surface properties (gross shape, roughness) of T1 joints differ from unit to unit, but subplanar to locally planar joints with moderately rough to very rough surfaces are characteristic of more than 60 percent of the localities at which the T1 set is present. T1 joints are commonly planar, and those with surfaces as smooth as those of typical cooling joints are rare. Smooth to fairly smooth T1 joints are most common in the hackly unit (eight localities), but even there they are noticeably rougher than cooling joints in the same exposures.

Regardless of overall shape or surface roughness, however, the irregular traces of $\mathrm{T} 1$ joints on a centimeter to decimeter scale set them apart from cooling joints, with their smoothly continuous traces, at most localities.

\section{T2 set: North-northwest-striking joints}

Tectonic joints of the T2 set (fig. 13, table 2) were documented at 15 of 41 (37 percent) of the localities studied and have a grand median orientation of N. $31^{\circ} \mathrm{W} .86^{\circ} \mathrm{SW}$. Local twist hackle and arrest lines show that the T2 joints are extension fractures, as do common hooks of individual $\mathrm{T} 2$ joints into joints of the same and older sets. 


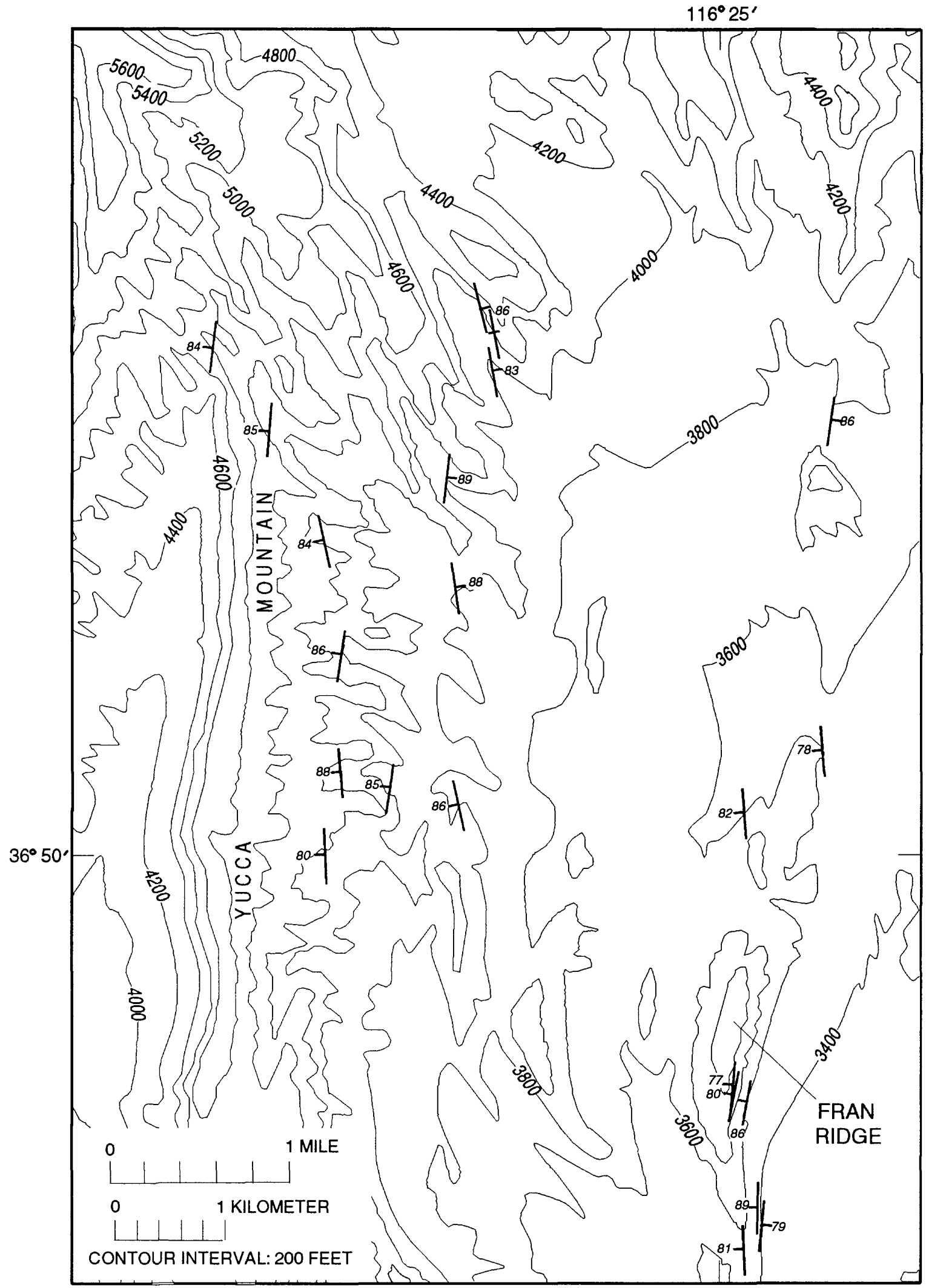

Figure 12.--Map showing median orientations of $\mathrm{T} 1$ tectonic joints in the Tiva Canyon and Topopah Spring Tuffs. All stations are not plotted due to the close proximity of stations. 


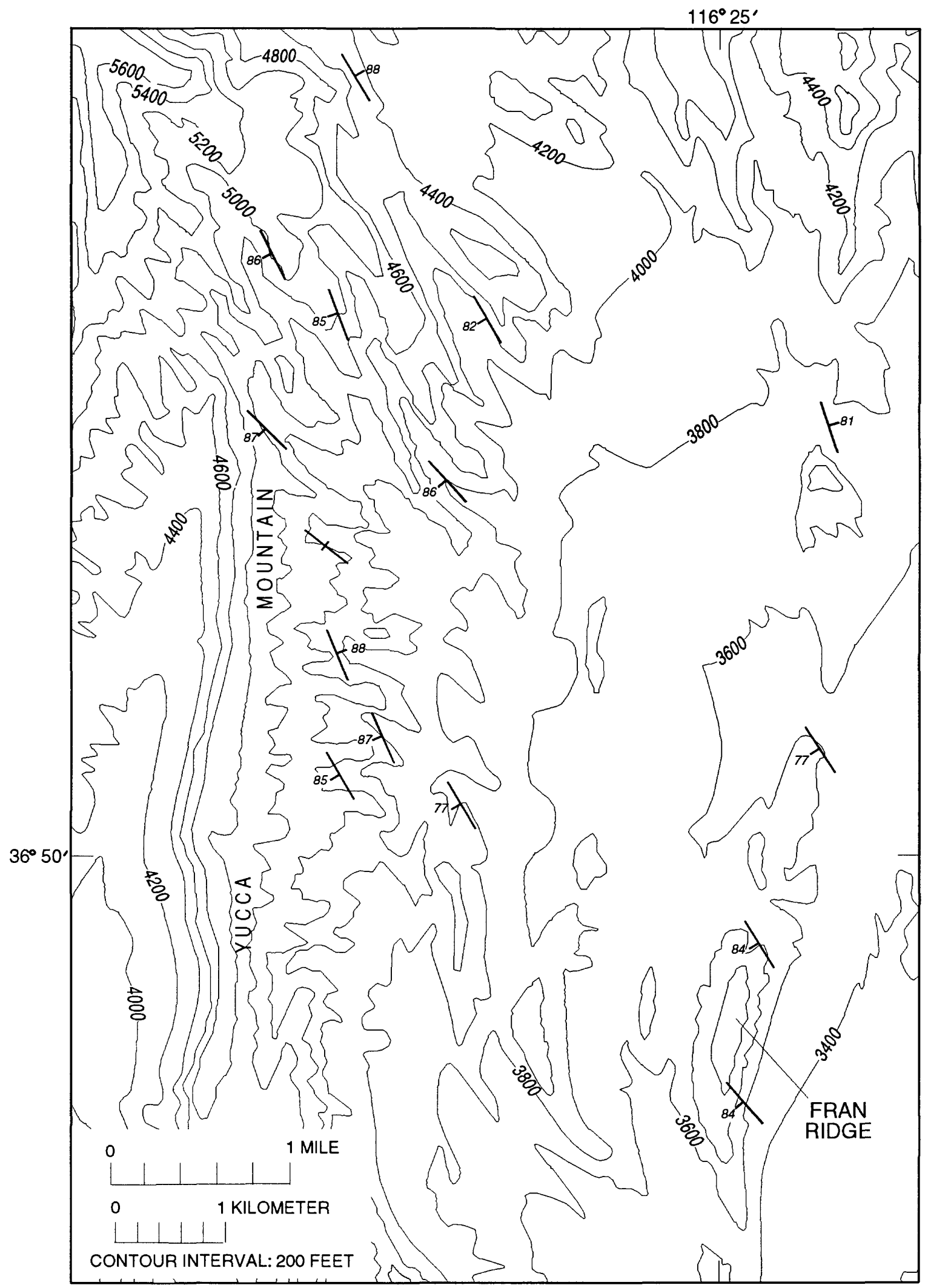

Figure 13.--Map showing median orientations of $\mathrm{T} 2$ tectonic joints in the Tiva Canyon and Topopah Spring Tuffs. 
Several properties of the $\mathrm{T} 2$ set of joints are a direct consequence of their younger age relative to the $\mathrm{T} 1$ set:

- At 11 of the 15 stations where the T2 set was documented, its prominence is inversely related to the abundance of older joints in much the same manner as discussed previously for the T1 set. At stations CH6, CRS7, and CCR1, for example, where joints of earlier sets are sparse, abundant $\mathrm{T} 2$ joints constitute the dominant component of the local fracture network. Conversely, at stations TR1, CC1, $\mathrm{CH} 3, \mathrm{CH} 4$, and $\mathrm{CH} 8$, the $\mathrm{T} 2$ set is only weakly developed, but at all five stations the T1 set is prominent. At 26 other localities--more than 60 percent of those studied--the T2 joints are absent, in large part because their development was inhibited by abundant joints already present.

- Median orientations of T2 joints are more variable from place to place than those of the $\mathrm{T} 1$ set because the $\mathrm{T} 2$ joints formed in more-fractured, less isotropic rock. Most T2 joints strike within the range of N. $20^{\circ} \mathrm{W}$. to N. $40^{\circ} \mathrm{W}$., but the total strike deviation of $34^{\circ}\left(\mathrm{N} .18^{\circ} \mathrm{W}\right.$. to N. $52^{\circ} \mathrm{W}$.) is $12^{\circ}$ greater than that of the T1 set.

- T2 joints are shorter on average than those of older sets because, during growth, they commonly terminated against fractures already present. Exposed lengths of 2.5 $\mathrm{m}$ or less are typical of most localities, as at station TV1, where closely spaced cooling joints of north-northeast strike constrained lateral growth of the later T2 joints. The only stations where lengthy T2 joints were recorded are CUC1 and CCR1, where the large thickness of the upper cliff unit and the absence of the T1 set allowed joints of exceptional dimension to form.

Traces of $\mathrm{T} 2$ joints commonly are gently curved or sinuous along strike, but at a few localities they are very nearly planar. Their surfaces, though everywhere rougher and more irregular than those of cooling joints in the same exposures, seem smoother than those of coexisting T1 joints. Reasons for the different surface morphologies remain obscure, and we have made no special study of them, but it should be noted that tectonic joint sets of different roughness in the same rock are known from many localities worldwide.

Abutting relations between $\mathrm{T} 2$ and $\mathrm{T} 1$ joints were observed at a sufficient number of localities that the relative age of the two sets seems fairly well established. The tips of T1 joints locally served as origin points for the later propagation of $\mathrm{T} 2$ joints, as shown in fig. 14, confirming this age relationship. The resultant structure has the appearance of a single kinked joint but is due to two stages of growth, during the second of which minor left-lateral shear occurred on the T1 joints. Similar structures have recently been described by Cruikshank and others (1991).

\section{T3 set: Northeast-striking joints}

The T3 set of joints (fig. 15, table 2), with a grand median orientation (strike and dip) of N. $38^{\circ}$ E. $88^{\circ} \mathrm{NW}$., was documented at 14 of 41 localities. Surface structures on these joints are sparse, but their origin as extension fractures is indicated by local arrest lines, abundant hooks of T3 joints into older joints, and, at one locality (CC1), by the lack of shear offset along $\mathrm{T} 3$ joints where they cut conspicuous pumice fragments within the tuff. 


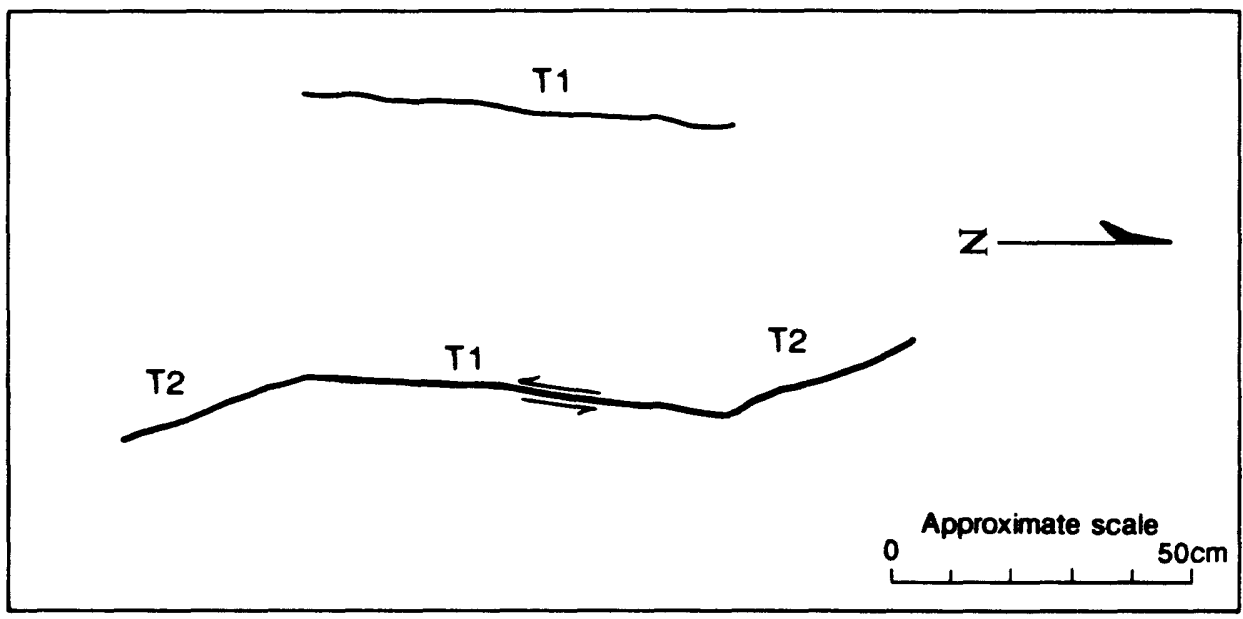

Figure 14.--Sketch showing common appearance of reactivated T1 joints at station TC4. Top, original joint. Bottom, resultant structure after reactivation during formation of the $\mathrm{T} 2$ joint set. New growth segments coincide in strike with those of $\mathrm{T} 2$ joints in adjacent rock.

Opening of $\mathrm{T} 2$ joint segments is accompanied by a minute amount of left-lateral shear on the original T1 joint. See Cruikshank and others (1991) for discussion of similar structures. 


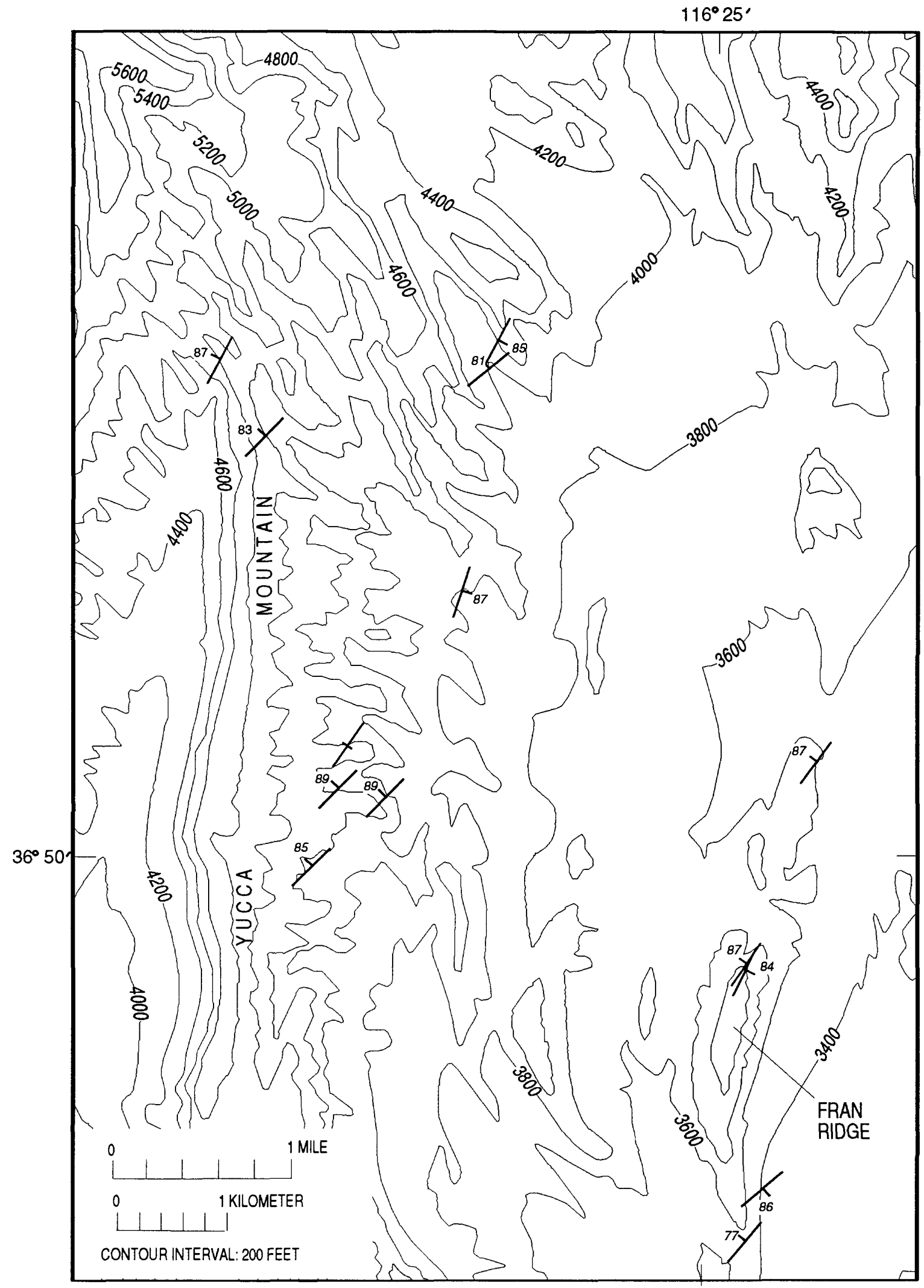

Figure 15.--Map showing median orientations of T3 tectonic joints in the Tiva Canyon and Topopah Spring Tuffs. 
To an even greater degree than joints of the $T 2$ set, most properties of the T3 joints reflect their development in rock already abundantly fractured:

- The T3 set, though present at approximately the same number of localities as the T2 set, is subordinate to one or another of the older tectonic sets. The set is absent from station $\mathrm{CH} 4$, where abundant $\mathrm{T} 1$ joints form the dominant component of the local fracture network.

- $\quad$ T3 joints commonly are shorter than those of earlier sets because their lateral growth was constrained by fractures already present. Joints older than the T3 set in some localities (CC1) are so numerous that the heights of $\mathrm{T} 3$ joints exceed their lengths. The marked effect of previous fracture history on $\mathrm{T} 3$ joint size is perhaps best illustrated by station $\mathrm{CH} 2$. T1 joints in most of this large exposure are so numerous and closely spaced that the later T3 joints are small, only $0.5-$ $1.5 \mathrm{~m}$ long and $0.2-0.6 \mathrm{~m}$ high, except toward the west end of the outcrop. There, where $\mathrm{T} 1$ joints are more widely spaced and locally absent, the T3 joints grew to much larger size: 4-6 $\mathrm{m}$ long and 2-3 $\mathrm{m}$ high.

- The effect of joint propagation within fractured, anisotropic rock, where local stress directions commonly deviate from the regional (far-field) stresses, is reflected in the subplanar to locally nonplanar shapes of many T3 joints. T3 joints commonly are undulatory along strike, and some are markedly curved, much more so than those of earlier tectonic sets. The only place where planar T3 joints were recorded is the western end of station $\mathrm{CH} 2$, where, as noted above, earlier joints are anomalously sparse.

- Hooklike terminations of T3 joints against other joints are more common than among $\mathrm{T} 1$ or $\mathrm{T} 2$ joints because the $\mathrm{T} 3$ joints in most places propagated in rock already well fractured.

Surfaces of T3 joints range from fairly smooth (rare) to rough (common). Even among the most smooth T3 joints, however, their traces are irregular on a centimeter to decimeter scale, much like those of other tectonic joints and distinctly dissimilar to those of cooling joints.

T3 joints hooking toward and terminating against $\mathrm{T} 1$ joints were documented at so many localities that the later age of the T3 set seems assured. The T3 and T2 sets, however, are present together at only four of the localities studied, and abutting relations were visible at only two of them ( $\mathrm{CH} 3$ and $\mathrm{CH} 6)$. Though the presence of several T3 joints abutting T2 joints at both localities supports the sequence of formation given here, inference that the T3 set is the younger should be regarded as tentative, not proven.

\section{Unloading joints: T4 and SH sets}

The two youngest joint sets at Yucca Mountain formed upon reduction of lithostatic load during erosion as the rock adjusted to new, near-surface stress conditions. Both sets, as explained below, have genetic parallels among common types of unloading joints in sedimentary and plutonic rocks.

\section{T4 set: West-northwest-striking joints}

Steeply dipping T4 joints (grand median orientation: N. $82^{\circ}$ W. $88^{\circ}$ SW.; table 2 , fig. 16) form a widespread but generally minor component of the fracture network at Yucca Mountain. Among the 15 localities where we documented their properties, the set is weakly to only moderately developed at 12 of them, and nowhere do they constitute the dominant joint set. 


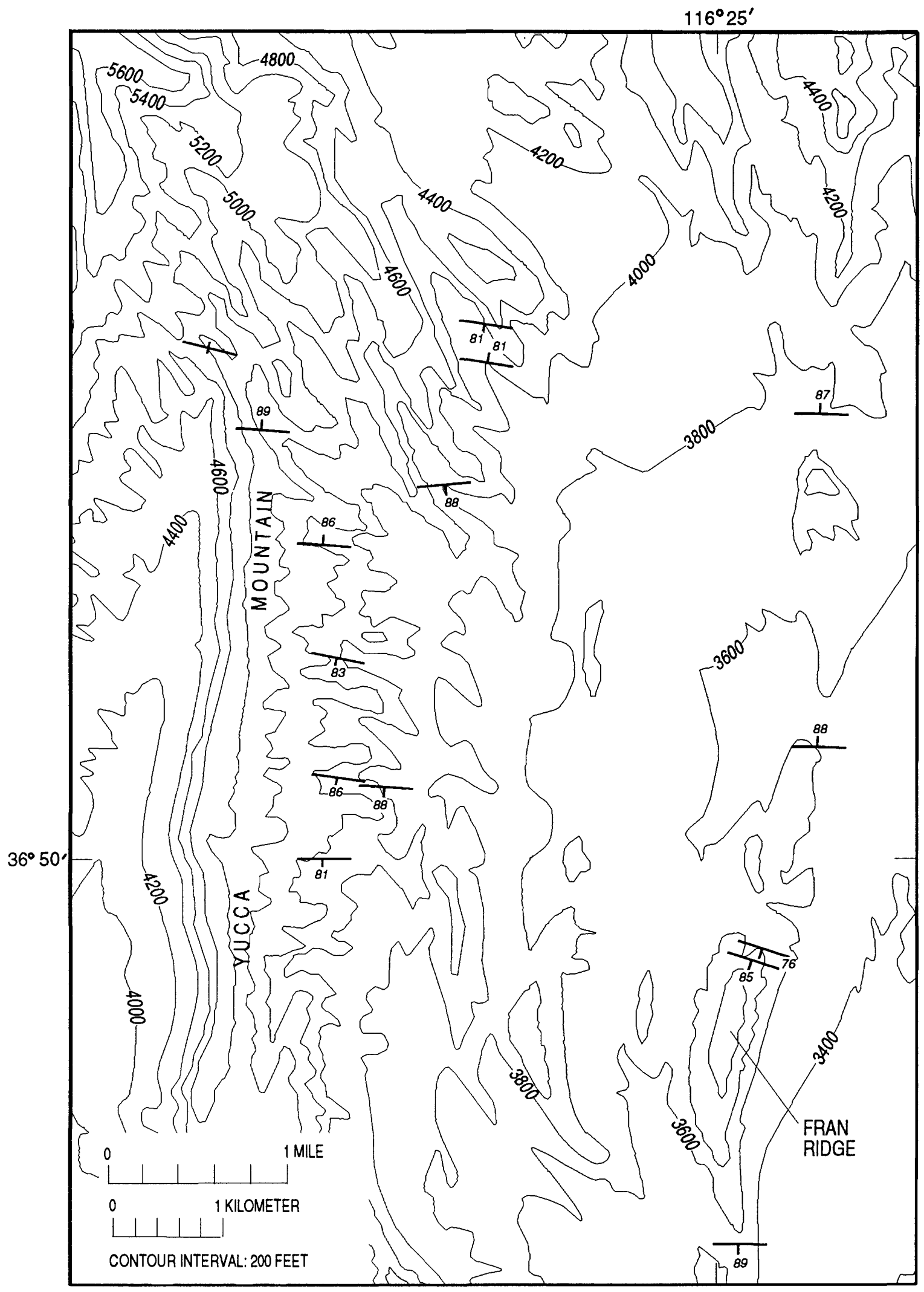

Figure 16.--Map showing median orientations of T4 tectonic joints in the Tiva Canyon and Topopah Spring Tuffs. 
In many places, however, the T4 set is visually obvious because its joints strike at high angles to those of all other tectonic sets.

At nearly all localities the $\mathrm{T} 4$ joints are short--commonly far shorter, on average, than those of all older sets. Lengths of only $0.2-1.5 \mathrm{~m}$ are typical. Sizes of T4 joints in many places were controlled by the spacings between adjacent $\mathrm{T} 1$ joints, against which they commonly abut at both ends. Similar terminations against joints of the T2 and T3 sets, as well as against cooling joints, further limited the lengths to which most T4 joints could grow. T4 joints that cross multiple older joints and thereby achieve significant length (3-5 m) were noted at several localities but are common at none of them. The heights, too, of T4 joints tend to be smaller than those of preceding sets, in part because short joints rarely grow to great height, but in larger part because the $\mathrm{T} 4$ joints in many places terminate against the foliation-parallel unloading joints described in the next section.

The T4 joints in most places formed in rock already highly fractured and thus mechanically anisotropic. Deviations of local stress directions from the regional (far field) stresses during growth of the T4 joints are reflected in several of their properties, most obviously shape: commonly they are of irregular form, notably more so than those of other sets, and among all tectonic joints they show the greatest tendency to curve along strike. Where T4 joints deviate out-of-plane their surfaces commonly display twist hackle. Multiple arrest lines were also noted in a few localities and, together with twist hackle, show that the T4 joints propagated as extension fractures. Further evidence of extension (mode I) propagation is the presence of inclusion hackle (Kulander and others, 1979), one component of the structure that in aggregate geologists call plumose structure. The inclusions in this case are sanidine crystals--mineral grains resistant to fracture, and around which the advancing fracture front commonly split on a microscopic scale. At low light angles these microscopic irregularities of the fracture surface lend a distinctive streaked appearance to the joint face.

Joints of the T4 set commonly strike about perpendicular to those of the T1 or T3 sets and thus form a crude set of cross joints with respect to those earlier sets. T4 joints of nearly eastwest strike are most common (table 2), reflecting the widespread abundance of the northstriking T1 joints: the two sets are present together at 13 of the 15 localities where T4 joints were measured. At the remaining two localities (CKS2, CUL1), where the north-northeaststriking joints of the T3 set are dominant instead, the T4 joints strike $\mathrm{N}$. $72^{\circ} \mathrm{W}$. rather than east-west. A tendency for late unloading joints to form at high angles to whichever earlier set dominates the local fracture network is common to many areas worldwide (Gay, 1973) and reduces the value of such joints as paleostress indicators, as later discussed. The seeming absence of east-northeast-striking $\mathrm{T} 4$ joints perpendicular to $\mathrm{T} 2$ joints, though puzzling, probably reflects the fact that the $\mathrm{T} 2$ set is nowhere dominant over the $\mathrm{T} 1$ set at those localities where the late $\mathrm{T} 4$ set was measured.

Spacings of T4 joints at the outcrop scale are related to those of earlier sets. The clearest example is station $\mathrm{CC} 1$, where a prominent rectangular network of $\mathrm{T} 1$ and $\mathrm{T} 4$ joints dominates the local fracture network, and joints of other sets are sparse. In most of this exposure the T4 joints are spaced $15-40 \mathrm{~cm}$ apart, but their spacings decrease to as little as $10 \mathrm{~cm}$ in places where the earlier T1 joints are unusually abundant. The tendency for cross joints to be most abundant where earlier joints perpendicular to them are most closely spaced is related to a similar but more well known effect, the tendency for joints of any particular set to increase in abundance with decreasing bed thickness. Note that this effect is opposite to that of all earlier joints, which tend to be least abundant wherever joints of any older set are best developed. The difference lies in the angular relations from one set to another, as later discussed in the section on Number of Joint Sets. The mechanics of cross-joint formation and controls on their spacing were discussed recently by Gross (1993). 
The T1 and T4 sets are present together at so many localities that their relative age is clear, as revealed by numerous terminations of T4 joints against those of the T1 set. Abutting relations between $\mathrm{T} 4$ joints and those of the $\mathrm{T} 2$ and $\mathrm{T} 3$ sets were visible at fewer localities and are far less numerous, though suggestive of T4 being the youngest set. Relatively short lengths, commonly curved traces, and terminations against older joints are general properties of the T4 set.

\section{SH set: Foliation-parallel joints}

A set of joints parallel or nearly so to compaction foliation in the Tiva Canyon and Topopah Spring Tuffs was found at almost half the localities studied (20 of 41 stations). In most of these the set is a prominent one; spacings of 0.3-1.0 m are typical. The SH joints are most abundant in exceptionally brittle rock, such as the orange brick unit of the Topopah Spring Member and the black vitrophyre subunit of the caprock unit of the same member. At the two localities studied in this latter rock type (stations TC1 and TC4) the SH joints are spaced only $5-24 \mathrm{~cm}$ and $2-20 \mathrm{~cm}$ apart, respectively. The presence of abundant SH joints is responsible for the stepped, ledgelike appearance of many outcrops on and near Yucca Mountain.

The SH joints commonly have a dual nature, depending on whether they parallel foliation or transect it. Most SH joints, though statistically parallel to foliation as a set, do not follow the foliation planes exactly but cut across them at low angles. Such joints generally have subplanar to nonplanar, markedly undulatory shapes and irregular, rough to very rough surfaces. However, where parts of the same joints split along foliation planes, or where entire SH joints opened along those planes in rock where compaction foliation is well developed, the joint surfaces are more nearly planar and conspicuously smoother.

Sizes of SH joints vary widely, depending on whether they cut across or terminate against the steeply dipping joints of older sets. At station $\mathrm{CC1}$, for example, the dimensions of SH joints in an east-west direction were determined by the $2-35 \mathrm{~cm}$ spacings between adjacent $\mathrm{T} 1$ joints, against which many $\mathrm{SH}$ joints terminate. The SH joints likewise terminate against $\mathrm{T} 3$ and $\mathrm{T} 4$ joints and as a result are small in all directions; maximum dimensions of $0.2-1.3 \mathrm{~m}$ are typical of this locality. In other places, however, where joints of preceding sets are more widely spaced or where SH joints more commonly intersect rather than abut older joints, the $\mathrm{SH}$ joints grew to much larger size. Maximum exposed dimensions of 2-5 $\mathrm{m}$ are common at some localities, but rare individual SH joints 7-8.5 $\mathrm{m}$ across were seen at two of them.

Flattened lithophysal cavities commonly served as origin flaws for SH joints, which began growth at cavity edges and propagated radially into the rock. The SH joint geometry is both distinctive and expected: in vertical section the joints bisect the cavities along their greatest diameter rather than intersect them randomly, a result of high induced tensile stress where the radius of curvature of the cavity was least. The theoretical basis for elliptical flaws in rock serving as stress concentrators for fracture initiation is treated in most introductory texts on rock mechanics; many field examples illustrating the process are known.

The late age of the SH set relative to cooling joints and tectonic joints of the T1 through T3 sets is well established through abutting relations at numerous localities. Abutting relations with the T4 set are ambiguous, a probable indication that both sets formed during the same time period to accommodate the minor three-dimensional strains induced during erosion of superincumbent load. We thus view both the T4 and SH joints as unloading joints, the SH joints representing the volcanic equivalents of the more familiar exfoliation (sheeting) joints in massive plutonic rocks.

The late age, rough surfaces, and tendency to intersect numerous lithophysal cavities generally serve to distinguish SH unloading joints from gently dipping cooling joints of much earlier age. In some units, however--notably parts of the hackly unit, where joints of all sets 
have fairly smooth surfaces and lithophysae are sparse to absent--apparent terminations of preT4 tectonic joints against $\mathrm{SH}$ joints suggest that some cooling joints are included in the SH set. Distinction between the two was most difficult at station $\mathrm{CH} 1$, where several terminations of T2 joints against smooth, gently dipping joints parallel to foliation suggest an early age and thus a cooling origin for the latter, but the rough surfaces of portions of the same joints where they cut across compaction foliation instead suggest an origin due to unloading. A likely but unproven possibility is that early, foliation-parallel cooling joints were reactivated and grew larger during later erosional unloading, thereby creating ambiguous abutting relations and variable joint-surface properties.

Evidence of similar reactivation is more clear at station $\mathrm{CH} 2$, also in the hackly unit, where smooth, gently dipping joints with discolored surfaces (alteration rinds) are coated with a white to cream-colored, noncalcareous mineral (presumably quartz), but the outermost portions of the same joints are exceedingly rough, not discolored, and unmineralized. The extreme difference in character between inner and outer portions of the same joints is most compatible with an interpretation of reactivated cooling joints. The process of reactivating a gently dipping cooling joint--essentially an extremely flat, elliptical crack--is mechanically analogous to that of propagating a new unloading joint from the margins of a flattened lithophysal cavity, as discussed above.

\section{DISCUSSION}

\section{Number of Joint Sets}

The joint network at Yucca Mountain, so far as known, consists of three cooling sets followed by five tectonic sets. No exposure examined by us, however, contains all eight sets. Three to five sets are common at most localities and a few contain as few as two or as many as six.

That only about half the total number of known sets are present at most localities is an obvious measure of the tendency for early joint sets to inhibit the development of later ones. The process of joint-set suppression is conceptually simple: the more a given volume of rock is fractured, the more likely any further strain will be accommodated through slight movements on joints already present rather than through development of new fractures.

The degree to which that process is effective is related to several factors, among them the angular relations between existing joints and potential new joints, and the degree of cohesion between opposing faces of the old joints. Where the acute angle between old and potential new joints is $30^{\circ}$ or less the suppression of new joints by old commonly is marked, as already noted for the T2 and T3 sets, both of which tend to be weakly developed or absent where great numbers of $\mathrm{T} 1$ joints are present. Where the acute angle between sets is instead $70^{\circ}$ or more, so that older joints are unfavorably oriented for reactivation, little or no suppression will occur. Such is the case for the T4 set, which formed at high angles to all other tectonic sets and is present at more localities than any other set save T1. Suppression also will not occur where joints of older sets have been effectively "healed" through mineralization so that movement of one joint wall relative to the other no longer is possible.

Early cementation of cooling joints by vapor-phase crystallization is a likely reason that the later T1 set is so common at Yucca Mountain and Fran Ridge and why tectonic sets in general are only slightly underrepresented there. Were all sets developed equally one should find, on average, five tectonic sets for every three cooling sets--a ratio of $3: 5$. The actual ratio, 3:3.9, indicates a modest overabundance of cooling sets. 


\section{Network Patterns of Different Volcanic Units}

Joint data currently available suggest that the overall style of the fracture network within each volcanic unit present at Yucca Mountain is characteristic of that unit, but network styles change vertically, and in some cases dramatically, from one unit to another. In a gross sense, then, vertical heterogeneity in the joint network greatly exceeds that in any lateral direction, and each volcanic unit should be modeled for fluid-flow behavior and mechanical stability separately. Data are available from too few localities to specify details of network properties in each of the several dozen volcanic units present, but a few examples are noted here to point out a promising avenue for further work.

The two most studied units at Yucca Mountain and nearby areas are the hackly and the upper lithophysal units. Nine joint stations were established in each--enough to verify the degree of consistency within each unit and reveal some of the major differences between them:

- As suggested by earlier pavement studies (Morgan, 1984; Barton and Larsen, 1985; Barton and others, 1993), joint networks in the upper lithophysal unit are dominated by cooling joints. Among all sets identified by us in that unit, roughly 60 percent are cooling sets and 40 percent are tectonic. In the hackly unit the opposite is true: only 20 percent of the sets measured are due to cooling, and 80 percent are tectonic.

- The numerous cooling joints in the upper lithophysal unit cluster about the $\mathrm{N} .45^{\circ} \mathrm{W}$. and N. $50^{\circ}$ E. strikes noted previously for the northern half of Yucca Mountain (fig. 17A). Joints of similar strike are less common in the hackly unit (fig. 17B), where instead most joints strike within $30^{\circ}$ of due north (T1 through T3 sets) or nearly east-west (T4). Frequency distributions of joint strike within the two units are markedly dissimilar.

- Differences in surface roughness between cooling and tectonic joints reach an extreme in the upper lithophysal unit, where roughness coefficients (RC) for each fracture type are normally distributed with peaks of $\mathrm{RC}=2$ for cooling joints and $\mathrm{RC}=$ 10 for tectonic joints (Barton and others, 1993). Our qualitative data confirm these relations for a much larger area; surfaces of cooling joints are smooth to very smooth and those of tectonic joints consistently and obviously rougher. Within the hackly unit, however, the roughness distinction is less conspicuous: though surfaces of cooling joints invariably are described in our notes as "smooth" or "very smooth" (much like those of the upper lithophysal unit), surfaces of more than two-thirds of the tectonic sets were described not as "rough" but as either "fairly smooth" or "smooth". Frequency distributions of surface roughness for cooling and tectonic joints, if measured, likely would show strong overlap in the hackly unit. Fracture-surface roughness thus is related to lithology in a definable and consistent way. As a criterion for distinguishing cooling from tectonic joints, surface roughness is most valuable in the upper lithophysal unit, where earlier fracture studies were concentrated. Elsewhere the distinction is not as straightforward.

\section{Network Connectivity}

Connectivity--the extent to which fractures in a given volume of rock are interconnected--is a key property in determining the fluid-flow behavior of fracture networks. Barton and Hsieh (1989) and Barton and others (1993) provided initial data on network connectivity at Yucca Mountain through fracture maps of four pavement exposures (three in the upper lithophysal unit of the Tiva Canyon Tuff and one in the orange brick unit of the Topopah Spring Tuff). 


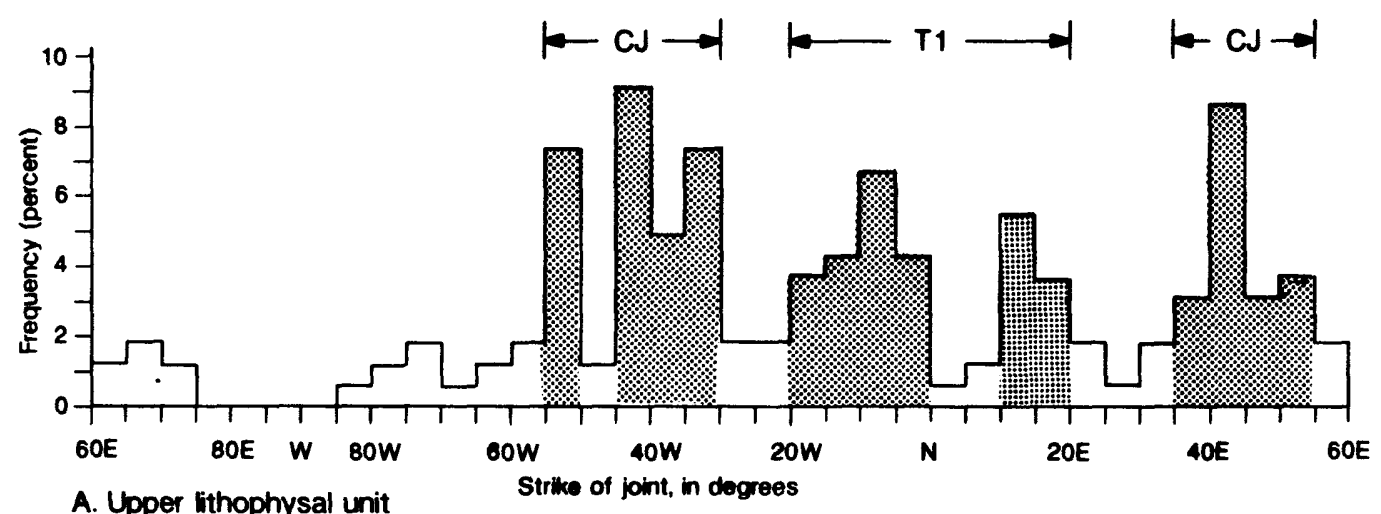

A. Upper lithophysal unit

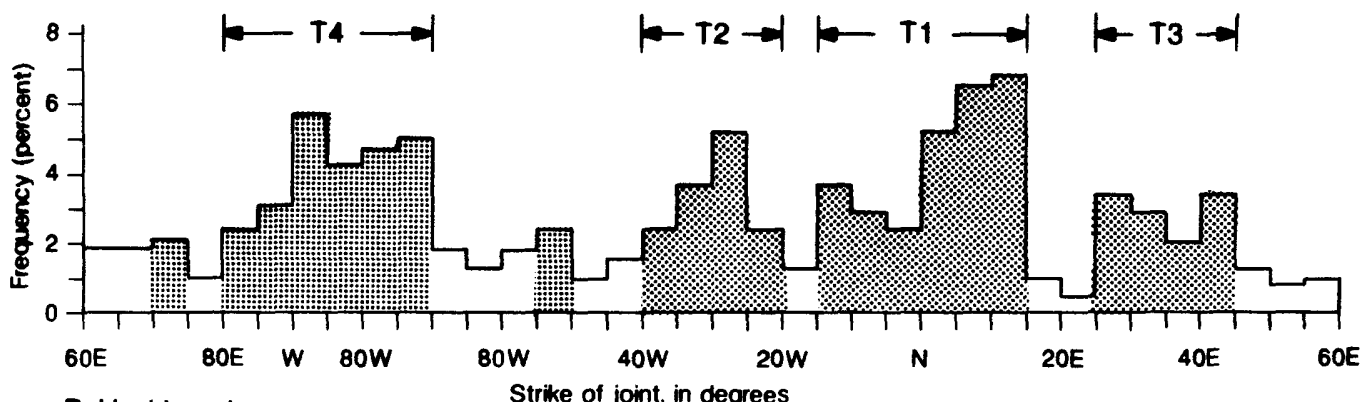

B. Hackly unit

Figure 17.--Linear histograms showing strike-frequency distributions of steeply dipping joints within two volcanic units at Yucca Mountain. A, upper lithophysal unit. B, hackly unit. Note origin point at $\mathrm{N} .60^{\circ} \mathrm{E}$.; this direction corresponds to minima in both distributions so that positions of the maxima can more clearly be compared. Strike data are plotted with $5^{\circ}$ class interval; classes containing 2 percent or more of the data are shaded. $\mathrm{CJ}=$ cooling-joint set; $\mathrm{T}=$ tectonic set. 
Nearly all fractures measured on these four pavements dip steeply, $65^{\circ}$ or more. The discussion below briefly addresses connectivity in these and other volcanic units at Yucca Mountain and stresses the importance of gently dipping fractures to fluid flow.

\section{Connectivity due to steeply dipping joints}

Barton and others (1993) published a ternary diagram for four pavement exposures in which they reported the relative proportions of blind fracture endings (fractures dying out as hairline cracks in the rock), intersections (crossing fractures), and terminations (one fracture ending against another). The proportions for all three pavements in the upper lithophysal unit are closely similar and plot within a narrow area on the diagram, indicating 40-51 percent terminations, 26-33 percent blind endings, and 21-27 percent intersections. The pattern of connectivity within this unit thus appears relatively constant, at least within the small portion of Yucca Mountain from which the data were obtained. Data for a fourth pavement in the nonlithophysal unit, however, reveal a much different pattern--a dearth of blind endings and a ratio of terminations to intersections of about 60:40. Full statistical treatment of the results for all four pavements is difficult because no provision was made to separate data for fractures with two, one, or no ends exposed; the necessary information must be recaptured from the fracture maps. Nonetheless it has been firmly established that the measured fracture networks in the two units studied are well interconnected at the outcrop, and that pavement studies provide an effective means of assessing map-view patterns of fracture connectivity for models of fluid flow.

Outcrop studies in incompletely exposed bedrock are more poorly suited to study of fracture connectivity because details of fracture terminations and intersections frequently are obscured by surface debris and vegetation. Our observations are thus necessarily qualitative in nature. Nevertheless, joint networks at almost all of our stations, and in numerous other exposures inspected casually, are well interconnected. The high degree of connectivity is due in part to the complexity of the joint history; the development through time of three or more joint sets at nearly all places within the Tiva Canyon and Topopah Spring Tuffs provided ample opportunity for fracture interaction to occur. The sheer abundance of early formed cooling and $\mathrm{T} 1$ joints in many places further increased the odds of fracture interaction because subsequent joints could not grow to any appreciable length before encountering other fractures. And finally, mineral precipitation effectively bonded the opposing walls of numerous fractures into stress-transmitting contact, thereby commonly allowing new fractures to cut across many of those already present. Together these three factors resulted in abundant fracture intersections and terminations in most of the volcanic units at Yucca Mountain and Fran Ridge, with the possible exception of some weakly welded tuffs that have not yet been studied extensively, but within which the joints are more widely spaced. The degree of fracture connectivity demonstrated through the pavement studies of Barton and Hsieh (1989) and Barton and others (1993) probably is not unusual for the region.

\section{Connectivity due to gently dipping joints}

Patterns of fracture connectivity as documented through pavement studies reveal twodimensional views through networks that are interconnected in three dimensions. The connectivity of fractures dipping at high angles to compaction foliation in the tuff is accurately represented, but network linkages due to fractures dipping at low angles or parallel to foliation are obscured. For this reason, probably, the occurrence and significance to fluid flow of foliation-parallel joints at Yucca Mountain seems scarcely to have been recognized.

Foliation-parallel joints at Yucca Mountain, as previously discussed, are of two types, cooling (early) and unloading (late). The cooling joints are only sporadically abundant but the unloading joints widespread and common. Terminations and intersections of both types of joint with steeply dipping joints of other sets are common. Also common on joints of both sets are 
alteration rinds, discolored surfaces, and remnant coatings of a white to cream-colored, finegrained, noncalcareous, presumably siliceous mineral. The field relations thus show that gently dipping cooling and unloading joints were conductive elements of an interconnected fracture network and long served as conduits for subsurface fluid flow. Some remain conductive, as at stations TC-1, TC-3, and TC4, where mineral coatings 1-3 mm thick with botryoidal outer surfaces attest to large original apertures and incomplete closure of the gently dipping fractures by mineralization. The significance of such fractures at repository depths remains uncertain; the unloading joints, in particular, should wane in abundance with depth. They should not, however, be regarded as purely surficial, for analogous joints in some areas persist to depths of $300 \mathrm{~m}$ or more (Verbeek and Grout, 1983), and the common presence of continuous mineral coatings on them at Yucca Mountain shows that they also were conduits for subsurface fluid flow. Inspection of drill cores and data from the recently excavated decline ramp into the proposed repository should provide the needed information. Regardless, the contribution of foliation-parallel joints to past and present fluid flow at Yucca Mountain should not be underestimated.

\section{Paleostress History}

Extension joints are excellent and sensitive recorders of paleostress history because they commonly form at lower levels of differential stress than do faults. Moreover, their abundance in most exposures affords essentially unlimited opportunity to document regional stress histories from integration of data from many closely spaced localities, each of which provides a partial record of a more complex whole.

The fractures of all eight sets discussed in this report are extension joints, as shown both by surface structures on the joint faces and, in areas undisturbed by later faulting, by common lack of visible shear offset where the fractures transect lumps of pumice embedded in the tuff. The orientations of three components of the stress field can be read from extension joints. Sigma $3\left(\sigma_{3}\right)$, the minimum principal compressive stress, is the perpendicular to the fracture plane. Within the horizontal plane, the maximum horizontal compressive stress $\left(\sigma_{\mathrm{hmax}}\right)$ and the minimum horizontal compressive stress $\left(\sigma_{\mathrm{hmin}}\right)$ are parallel and perpendicular, respectively, to joint strike, regardless of the dip of the joint. Note that only one of the principal stress axes of the stress tensor can readily be determined from extension joints and that none of the principal stresses need be horizontal. The phrase "maximum (or minimum) principal horizontal stress", found in some of the literature on Yucca Mountain and surroundings, is meaningless. The stress components $\sigma_{\mathrm{hmax}}$ and $\sigma_{\mathrm{hmin}}$, when discussed for areas of appreciable size, can be viewed as roughly equivalent to the directions of tectonic crustal compression and extension, respectively.

\section{Cooling joints}

The stress significance of consistently oriented rectangular sets of cooling joints in the Tiva Canyon Tuff on Yucca Mountain is problematic in that the cause of the consistent orientations is unknown. Barton and others (1993) suggested that the rectangular pattern reflects eruption of the tuff onto a tilted surface in much the same way that mudcracks (which, like cooling joints, are contraction fractures) on a sloping surface commonly form one set of long cracks oriented parallel to the slope and a second set of shorter cracks downdip. A downdip component of layer-parallel extension due to gravity is responsible for the preferred orientation of the dominant set. Observation of mudcracks along the sloping shorelines of lakes (Allen, 1982) and experiments in drying tilted pans of mud (Kindle, 1917) lend credence to this view. If true, the cooling-joint orientations reflect underlying topography and have no regional paleostress significance. Left unexplained, however, is why the northeast-striking set of cooling joints on Yucca Mountain is dominant in some places and the northwest-striking set in 
others (fig. 11; table 3). Careful measurement of the orientations of the dominant cooling set and of compaction foliation of the tuff in the same outcrops should help resolve the problem.

Older cooling joints within the Topopah Spring Tuff generally show much different orientations. With only eight joint stations in this unit it is too early to define areal patterns, but we draw attention here to the east flank of Fran Ridge, where geologic relations at two stations (TC2, TR1) and at additional outcrops between them are consistent with tectonic extension during cooling of the ash-flow sheet. Median strikes of the dominant (C1) cooling set in this area range from N. $03^{\circ}$ E. to N. $11^{\circ}$ E. along a $6-\mathrm{km}$ length of the ridge. A second, more weakly expressed set (C2) is present at right angles to the first, as is a third set of gently westward-dipping, foliation-parallel cooling joints. Also present in the same exposures are common joints of the T1 set, which strike N. $02^{\circ} \mathrm{W}$. to N. $11^{\circ} \mathrm{E}$., nearly parallel to the $\mathrm{C} 1$ joints. The $\mathrm{T} 1$ joints, however, are much smaller and rougher, and they consistently abut the $\mathrm{C} 2$ and foliation-parallel cooling joints. Strong differences in joint style and consistent abutting relations establish that two parallel sets are present. The parallelism between the two sets could be mere coincidence, but inasmuch as normal faulting in the region began prior to volcanism and continued as the ash flows were emplaced (Scott and others, 1983), it could equally well reflect tectonic extension of the ash-flow sheet while it was cooling. North-striking cooling joints in the overlying Tiva Canyon Tuff in the same area (stations CUL2 through CUL4) support the latter interpretation. If true, (a) crustal extension with $\sigma_{3}$ oriented nearly east-west was already active during emplacement of the Topopah Spring and Tiva Canyon Tuffs, (b) tectonic extension of the cooling ash-flow sheets controlled the orientation of the dominant set of cooling joints in both units, and (c) continuing extension in the same direction later led to formation of the $\mathrm{T} 1$ tectonic joints in the same rocks. This interpretation raises anew the question of the significance of cooling joints in the Tiva Canyon Tuff on Yucca Mountain: if their orientations reflect crustal stress rather than paleotopography, directions of crustal extension during Tiva Canyon time were different in different structural blocks, implying decoupling along major interblock faults. Much more data than are available at present will be required for confident interpretation.

\section{Tectonic joints}

The paleostress significance of tectonic joints at Yucca Mountain is more straightforward than that of cooling joints; regionally consistent tectonic joints can only imply a regionally consistent stress field. Evidence that normal faulting began prior to volcanism and continued during and after it (Scott and others, 1983) necessitates that the T1 through T3 sets be viewed within the context of Basin-and-Range extensional tectonism. So viewed, the orientations of the T1 through T3 joint sets (figs. 12, 13, 15) imply noncoaxial crustal extension through time, with extension directions shifting from nearly due east (T1) to east-northeast (T2) and thence to southeast (T3). As noted above, stresses compatible with the T1 extension direction may have existed well before $\mathrm{T} 1 \mathrm{time}$, during and perhaps before emplacement of the Paintbrush Group. How long that stress state persisted is unknown because the age of the T1 joint set is not well constrained by stratigraphic evidence; nor is the age of the T2 set that succeeded it. The T3 set may be of Quaternary age because its strike (median N. $38^{\circ}$ E.) is almost exactly perpendicular to the N. $50^{\circ} \mathrm{W}$. direction of $\sigma_{\mathrm{hmin}}$ inferred by Carr (1974) from his regional studies of Quaternary faulting. Similar directions of contemporary $\sigma_{\text {hmin }}$ have been inferred for the region from hydrofracture tests and orientations of borehole breakouts (Haimson and others, 1974; Rogers and others, 1983; Springer and others, 1984; Stock and others, 1985; Stock and Healy, 1988).

Directions of $\sigma_{\mathrm{hmin}}$ as read from the joint history at Yucca Mountain are very nearly equivalent to orientations of $\sigma_{3}$ because the joints of all three sets have near-vertical dips (table 2). The orientations of the other two principal stresses for each fracture episode must lie within the plane representing the median orientation of each set, but without further evidence 
their plunges cannot be given--that is, one cannot tell from the mere presence of a set of joints whether those joints formed in a normal-slip stress field ( $\sigma_{1}$ vertical), a strike-slip stress field ( $\sigma_{1}$ horizontal), or an oblique-slip stress field. Thus, the relation of the jointing history to the complex record of normal and strike-slip faulting events at Yucca Mountain and nearby areas (Scott and others, 1984; Minor, 1989, in press; O'Neill and others, 1991; Spengler and others, 1994) is incompletely known. Further evidence might take the form of propagation directions of joints as read from surface structures (plumose structure, arrest lines), senses of slip on faulted joints (not uncommon on Yucca Mountain) as determined from slickenside striations and the geometry of subsequent growth segments (Cruikshank and others, 1991), and integration of the results obtained with data from fault-slip studies. The latter are underway (S.J. Minor, oral commun., 1994).

No special paleostress significance should be attached to the T4 and SH joints because they formed as the tuff was being decoupled from the regional crustal stress field as the rocks were brought to increasingly shallow crustal levels through erosion. Both sets of joints record decreasing confining pressure and stress release in directions not readily accommodated by fractures already present.

\section{SUMMARY}

The fracture network at Yucca Mountain includes three sets of cooling joints that formed during cooling of the Tiva Canyon and Topopah Spring Tuffs, followed by five sets of tectonic joints. Three sets of tectonic joints formed during regional crustal extension, and two younger tectonic sets, strikingly different in style, are due to unloading and erosion of overlying rock. These joint sets are present in different combinations and to varying degrees of expression at 41 localities studied. The character of the local fracture network thus differs, sometimes markedly, from one locality to another, but a strongly defined regional pattern nonetheless exists.

\section{Cooling Joint Sets}

Two sets of steeply dipping cooling joints at approximate right angles were documented throughout much of the study area, in a total of ten units. Weak expression of one cooling set relative to the other is common. In the northern half of Yucca Mountain, joints of one set strike N. $34^{\circ}-75^{\circ}$ E., while the other set ranges in strike from N. $20^{\circ}-70^{\circ} \mathrm{W}$. (grand medians are $\mathrm{N} .45^{\circ} \mathrm{W}$. and $\mathrm{N} .50^{\circ} \mathrm{E}$., respectively).

At several localities these two sets comprise the dominant component of the fracture network. Distinguishing characteristics of these sets in the upper lithophysal unit of the Tiva Canyon Tuff include tubular structures, appreciable length, exceptionally smooth surfaces, and abutting relation indicating early age. In other units, where tubular structures commonly are lacking, a combination of the remaining characteristics, together with demonstration of early relative age, is sufficient to distinguish cooling from tectonic joints.

A third, subhorizontal-cooling joint set is present in six units of the Topopah Spring and Tiva Canyon Tuffs. These gently dipping joints parallel the foliation in the tuff or transect it at low angles. Smooth, undulatory, subplanar to nonplanar surfaces, and absence of lithophysae on the joint surfaces, and demonstrated early age, separate these joints from unloading joints of similar orientation. Abutting relations at several localities show that the gently dipping cooling joints are either the oldest joints present or formed during the same time period as those of steep dip. Both the low-dipping cooling joints and the steeply dipping cooling joints have properties in common, including smooth surfaces, early age relative to tectonic joints, tubular structures, common undulatory shape, and in some localities, large size. 


\section{Tectonic Joint Sets}

Three regional extension joint sets (T1 through T3) were identified and their order of formation determined. Grand median orientations (strike and dip) of T1, T2, and T3 joint sets are N. $01^{\circ}$ W. $86^{\circ} \mathrm{SW}$.; N. $31^{\circ}$ W. $86^{\circ} \mathrm{SW}$.; and N. $38^{\circ}$ E. $88^{\circ} \mathrm{NW}$. (table 2), respectively. The order of formation of each set (T1 earliest, T2 next, T3 later) has been determined on the basis of abutting relations.

The earliest formed set (T1) is present at 24 of the field stations and, as expected, has the lowest strike dispersion $\left(23^{\circ}\right)$ of the three sets. Development of $\mathrm{T} 1$ joints is inversely related to that of the cooling joints. Where cooling joints are both large and abundant, as in much of the upper lithophysal unit of the Tiva Canyon Tuff, the T1 joints are present in low numbers or are absent. Conversely, where cooling joints are few, as in much of the hackly unit, the T1 set reaches it greatest development. Joint size of the T1 set varies from unit to unit; lengths as great as $7 \mathrm{~m}$ may be traced where $\mathrm{T} 1$ growth was not confined by earlier cooling joints. Subplanar to locally planar joints and moderately rough to very rough surfaces characterize T1 joints in most of the units at which the set is present. Where T1 joints occur in the hackly unit, however, the joint surfaces are smooth to fairly smooth.

The north-northwest-striking $\mathrm{T} 2$ set was documented at 15 field stations. Their later age relative to the $\mathrm{T} 1$ set is evident from several properties. (1) The prominence of the T2 set is inversely related to that of older joints in much the same manner as discussed previously for the T1 set. (2) Median orientations of T2 joints are more variable than those of the T1 set because the T2 joints formed in more-fractured, less isotropic rock. (3) T2 joints are shorter on average than those of older sets because, during growth, they commonly terminated against fractures already present.

The T3 set of joints was documented at about the same number (14) of field stations as the $\mathrm{T} 2$ set. Abutting relationships show that the T3 set is younger than T1, but its age relative to the T2 set remains tentative. The T3 set has many properties characteristic of sets developed in rock already abundantly fractured: (1) T3 joints are subordinate (lower numbers) to one or another of the older tectonic sets. (2) In general, T3 joints are shorter because their growth was constrained by fractures already present. (3) The subplanar to locally nonplanar T3 joint shapes are indicative of joint propagation within fractured, anisotropic rock, where local stress directions commonly deviate from the regional (far-field) stresses. (4) Hooklike terminations of T3 joints against other joints are common. (5) Strike dispersion (32 ${ }^{\circ}$ ) is high, as would be expected of jointing in anisotropic rock.

Unloading joints of the T4 set (grand median orientation: N. $82^{\circ} \mathrm{W} .88^{\circ} \mathrm{SW}$ ), constitute a minor component of the fracture network; they are widespread but their size and spacings are restricted by earlier sets. Joints of the $\mathrm{T} 4$ set commonly strike at high angles to other tectonic sets, most commonly joints of the T1 or T3 sets. Numerous T4 joints terminate against those of the T1 set; thus they are unquestionably younger than the T1 set. Abutting relations with joints of the T2 and T3 set are scarce, but the relations observed suggest a younger age for T4.

Foliation-parallel joints (SH) occur at 20 stations, where the joints are conspicuous. Abutting relations at numerous localities establish the late age of the SH set relative to cooling joints and the tectonic joints of the T1, T2, and T3 sets. Abutting relations with the T4 set are ambiguous, a probable indication that both sets formed during the same time period to accommodate the minor three-dimensional strains induced during erosion of superincumbent load. The late age, rough surfaces, and tendency to intersect numerous lithophysal cavities serve to distinguish SH unloading joints from gently dipping cooling joints of much earlier age. 
Joint data currently available suggest that the overall style of the fracture network within each volcanic unit present at Yucca Mountain is characteristic of that unit, but that network style changes vertically, and in some cases dramatically, from one unit to another. Each volcanic unit should be modeled for hydrologic flow and mechanical stability separately.

\section{Paleostress History}

The T1 through T3 sets of tectonic joints on and near Yucca Mountain record changing directions of $\sigma_{\text {hmin }}$ through time, from nearly east-west (T1) to east-northeast (T2) and then to southeast (T3). The latter direction is compatible both with paleostresses inferred from the regional record of Quaternary faulting and with the contemporary stress state as measured from borehole data. The changing stress directions are interpreted to reflect noncoaxial extension directions during Basin-and Range crustal extension in the region.

The possible paleostress significance of the earlier cooling joints remains uncertain because the cause of their preferred orientations has not yet been established. The most likely cause, that the preferred orientations reflect cooling of a tilted ash-flow sheet deposited on a nonhorizontal surface, suggests that the cooling-joint sets reflect underlying paleotopography more than regional stress.

\section{ACKNOWLEDGMENTS}

This study was partly supported by the Nevada Nuclear Waste Storage Investigations Project of the Civilian Radioactive Waste Management Program. The authors wish to thank the following personnel at the Mercury, Nevada facility: Jerry Magner and Dan Blout assisted the authors in the field and Ron Martin provided vehicles and equipment. We wish also to thank Michael Chornack for suggesting several exceptional exposures for study. The authors gratefully acknowledge Ramon E. Sabala and Mike Duncan for their computer graphics and drafting assistance and Sharon Rosema for formatting and proofing the text. This report benefited from a careful review by John C. Lorenz of Sandia National Laboratories, New Mexico. 


\section{REFERENCES CITED}

Allen, J.R.L, 1982, Sedimentary structures--their character and physical basis, v. II: Amsterdam, Netherlands, Elsevier Scientific Publishing Company, 679 p.

Barton, C.C., 1984, Tectonic significance of fractures in welded tuff, Yucca Mountain, southwest Nevada \{abs\}: Geological Society of America Abstracts with Programs, v. 16, no. 6, p. 438-439.

Barton, C.C., and Hsieh, P.A., 1989, Physical and hydrologic flow properties of fractures: 28th International Geological Congress Field Trip Guidebook T385, American Geophysical Union, Washington, D.C., 36 p.

Barton, C.C., and Larsen, Eric, 1985, Fractal geometry of two-dimensional fracture networks at Yucca Mountain, southwestern Nevada: International Symposium on Fundamentals of Rock Joints, Bjorkliden, Lapland, Sweden, September 15-20, 1985, Proceedings, p. 77-84.

Barton, C.C., Larsen, Eric, Page, W.R., and Howard, T.M., 1993, Characterizing fractured rock for fluid-flow, geomechanical, and paleostress modeling: Methods and preliminary results from Yucca Mountain, Nevada: U.S. Geological Survey Open-File Report 93-269, 62 p., 1 plate.

Barton, C.C., Page, W.R., and Morgan, T.L., 1989, Fractures in outcrops in the vicinity of drill hole USW G-4, Yucca Mountain, Nevada--Data analysis and compilation: U.S. Geological Survey Open-File Report 89-92, 133 p.

Barton, Nick, and Choubey, Vishnu, 1977, The shear strength of rock joints in theory and practice: Rock Mechanics, v. 10, p. 1-54.

Carr, W.J., 1984, Summary of tectonic and structural evidence for stress orientation at the Nevada Test Site: U.S. Geological Survey Open-File Report 74-176, 53 p.

Cruikshank, K.M, Zhao, Guozhu, and Johnson, A.M., 1991, Analysis of minor fractures associated with joints and faulted joints: Journal of Structural Geology, v. 13, no. 8, p. 865-886.

Gay, S.P., Jr., 1973, Pervasive orthogonal fracturing in Earth's continental crust: Salt Lake City, Utah, American Stereo Map Company Technical Publication 2, 121 p.

Gross, M.R., 1993, The origin and spacing of cross joints--Examples from the Monterey Formation, Santa Barbara coastline, California: Journal of Structural Geology, v. 15, no. 6, p. $737-751$.

Haimson, B.C., Lacomb, J., Jones, A.H., and Green, S.J., 1974, Deep stress measurement in tuff at the Nevada Test Site: Advances in Rock Mechanics, v. IIa; Washington D.C., National Academy of Sciences, p. 557-561.

Hudson, M.R., and Sawyer, D.A., 1994, Paleomagnetism and rotation constraints for the middle Miocene southwestern Nevada volcanic field: Tectonics, v. 13, no. 2, p. 258-277.

Kindle, E.M., 1917, Some factors affecting the development of mudcracks: Journal of Geology, v. 25, no. 2, p. 135-144.

Kulander, B.R., Barton, C.C., and Dean, S.L., 1979, Applications of fractography to core and outcrop fracture investigations: U.S. Department of Energy Report METC/SP-79/3, $179 \mathrm{p}$.

Lorenz, J.C., and Finley, S.J., 1991, Regional fractures II--Fracturing of Mesaverde reservoirs in the Piceance basin, Colorado: American Association of Petroleum Geologists Bulletin, v. 75 , no. 11, p. 1738-1757.

Minor, S.A., 1989, Paleostress investigation near Rainier Mesa, Nevada Test Site, in Olsen, C.W., and Carter, J.A. eds., Fifth Symposium on Containment of Underground Nuclear Explosions, Proceedings: Lawrence Livermore National Laboratory Report CONF-8909163, v. 2, p. 457-482. in press, Superimposed local and regional paleostresses--fault-slip analysis of Neogene Basin-and Range faulting near a middle Miocene caldera complex, Yucca Flat, southern Nevada: Journal of Geophysical Research. 
Morgan, T.L., 1984, Fracture characterization in the Tiva Canyon Member, Paintbrush Tuff, Yucca Mountain, Nevada: Ft. Collins, Colorado State University, M.S. thesis, 126 p.

O'Neill, J.M., Whitney, J.W., and Hudson, M.R., 1991, Photogeologic and kinematic analysis of lineaments at Yucca Mountain, Nevada: Implications for strike-slip faulting and oroclinal bending: U.S. Geological Survey Open-File Report 91-623, 24 p., 1 plate.

Rogers, A.M., Harmsen, S.C., Carr, W.J., and Spence, William, 1983, Southern Great Basin seismological data report for 1981 and preliminary data analysis: U.S. Geological Survey Open-File Report 83-669, 243 p.

Rosenbaum, J.G., 1986, Paleomagnetic directional dispersion produced by plastic deformation in a thick Miocene welded tuff, southern Nevada: Implications for welding temperatures: Journal of Geophysical Research, v. 91, no. B12, p. 12,817-12,834.

Rosenbaum, J.G., Hudson, M.R., and Scott, R.B., 1991, Paleomagnetic constraints on the geometry and timing of deformation at Yucca Mountain, Nevada: Journal of Geophysical Research, v. 96, no. B2, p. 1963-1979.

Scott, R.B., Bath, G.D., Flanigan, V.J., Hoover, D.B., Rosenbaum, J.G., and Spengler, R.W., 1984, Geological and geophysical evidence of structures in northwest-trending washes, Yucca Mountain, southern Nevada, and their possible significance to a nuclear waste repository in the unsaturated zone: U.S. Geological Survey Open-File Report 84-567, 23 p.

Scott, R.B., and Bonk, Jerry, 1984, Preliminary geologic map of Yucca Mountain, Nye County, Nevada, with geologic sections: U.S. Geological Survey Open-File Report 84-494, scale 1:12,000.

Scott, R.B., Spengler, R.W., Diehl, Sharon, Lappin, A.R., and Chornack, M.P., 1983, Geologic character of tuffs in the unsaturated zone at Yucca Mountain, southern Nevada, in Mercer, J.W., Rao, P.S.C., and Marine, I.W., eds., Role of the unsaturated zone in radioactive and hazardous waste disposal: Ann Arbor Science, Ann Arbor, Michigan, p. 289-335.

Snyder, D.B., and Carr, W.J., 1982, Preliminary results of gravity investigations at Yucca Mountain and vicinity, southern Nye County, Nevada: U.S. Geological Survey Open-File Report 82-701, 36 p.

Spengler, R.W., Braun, C.A., Martin, L.G., and Weisenberg, C.W., 1994: The Sundance fault: A newly recognized shear zone at Yucca Mountain, Nevada: U.S. Geological Survey Open-File Report 94-49, $11 \mathrm{p}$.

Spengler, R.W., and Fox, K.F., Jr., 1989, Stratigraphic and structural framework of Yucca Mountain, Nevada, in Nuclear Waste management 1988; Perspectives on national and international programs and technology, Part II: Radioactive Waste Management and the Nuclear Fuel Cycle Journal, v. 13 (1-4), p. 21-36.

Springer, J.E., Thorpe, R.K., and McKague, H.L., 1984, Borehole elongation and its relation to tectonic stress at the Nevada Test Site: Lawrence Livermore National Laboratory Report UCRL-53528, 43 p.

Stock, J.M., and Healy, J.H., 1988, Stress field at Yucca Mountain, Nevada, in Carr, M.D., and Yount, J.C. eds., Geologic and hydrologic investigations of a potential nuclear waste disposal site at Yucca Mountain, southern Nevada: U.S. Geological Survey Bulletin 1790, p. 87-94.

Stock, J.M., Healy, J.H., Hickman, S.H., and Zoback, M.D., 1985, Hydraulic fracturing stress measurements at Yucca Mountain, Nevada, and relationship to the regional stress field: Journal of Geophysical Research, v. 90, no. B10, p. 8691-8706.

Verbeek, E.R., and Grout, M.A., 1983, Fracture studies at C-a mine, Piceance Creek basin, Colorado: Geological Society of America Abstracts with Programs, v. 15, no. 5, p. 375. 

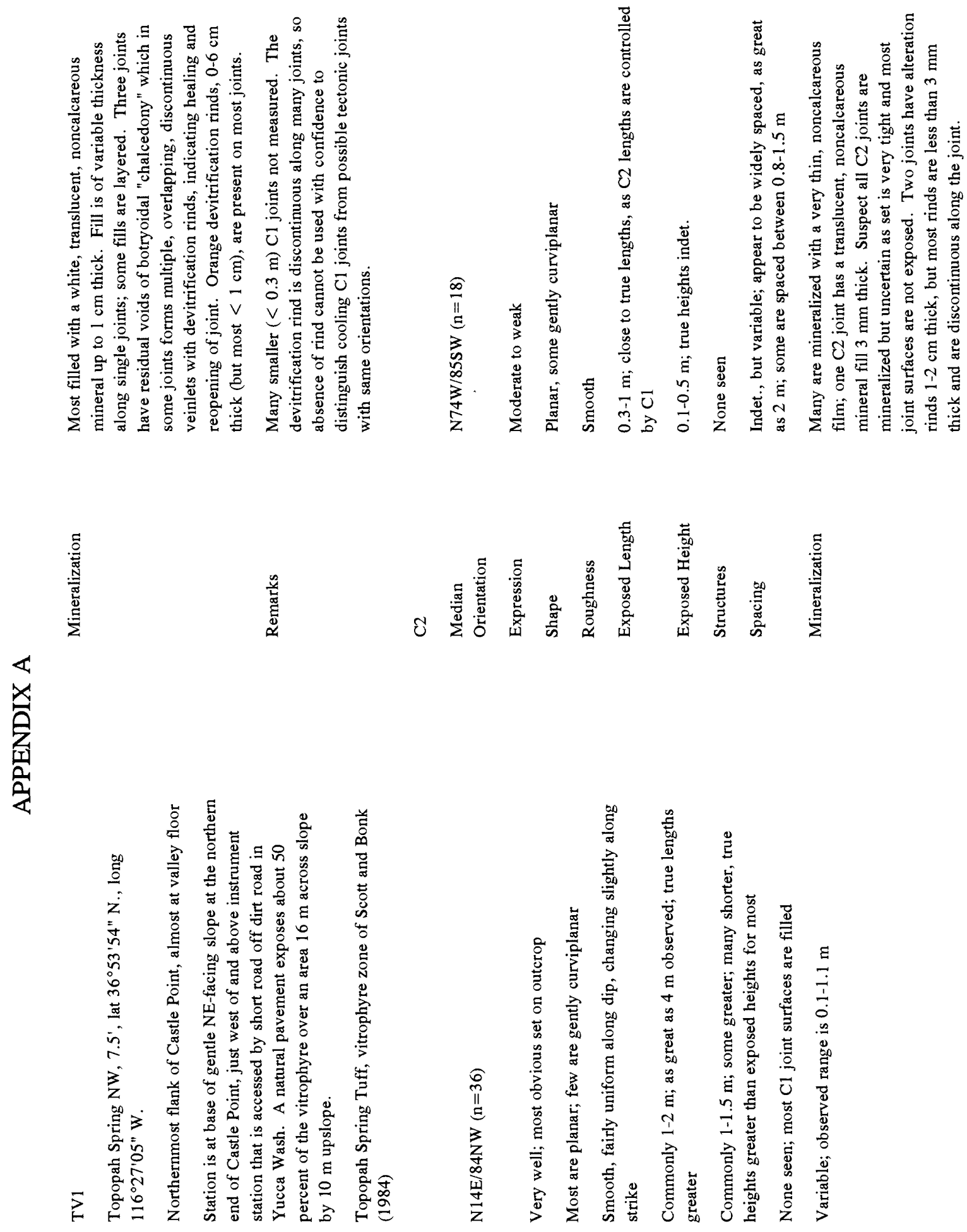

III 


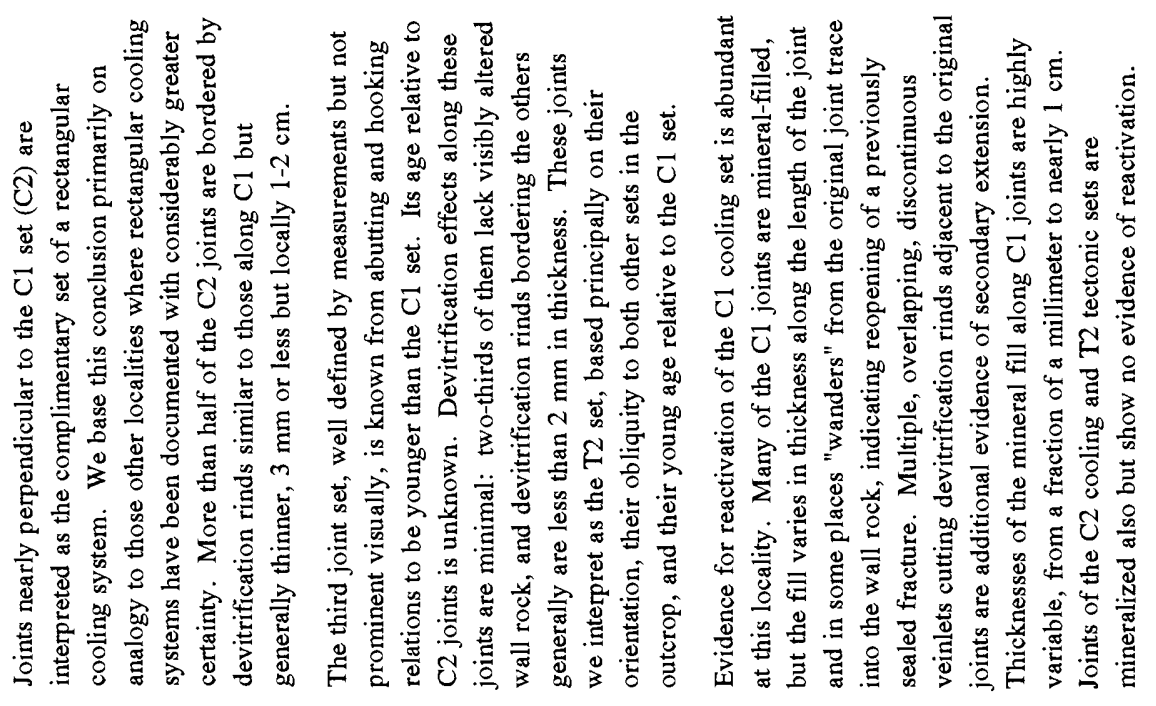

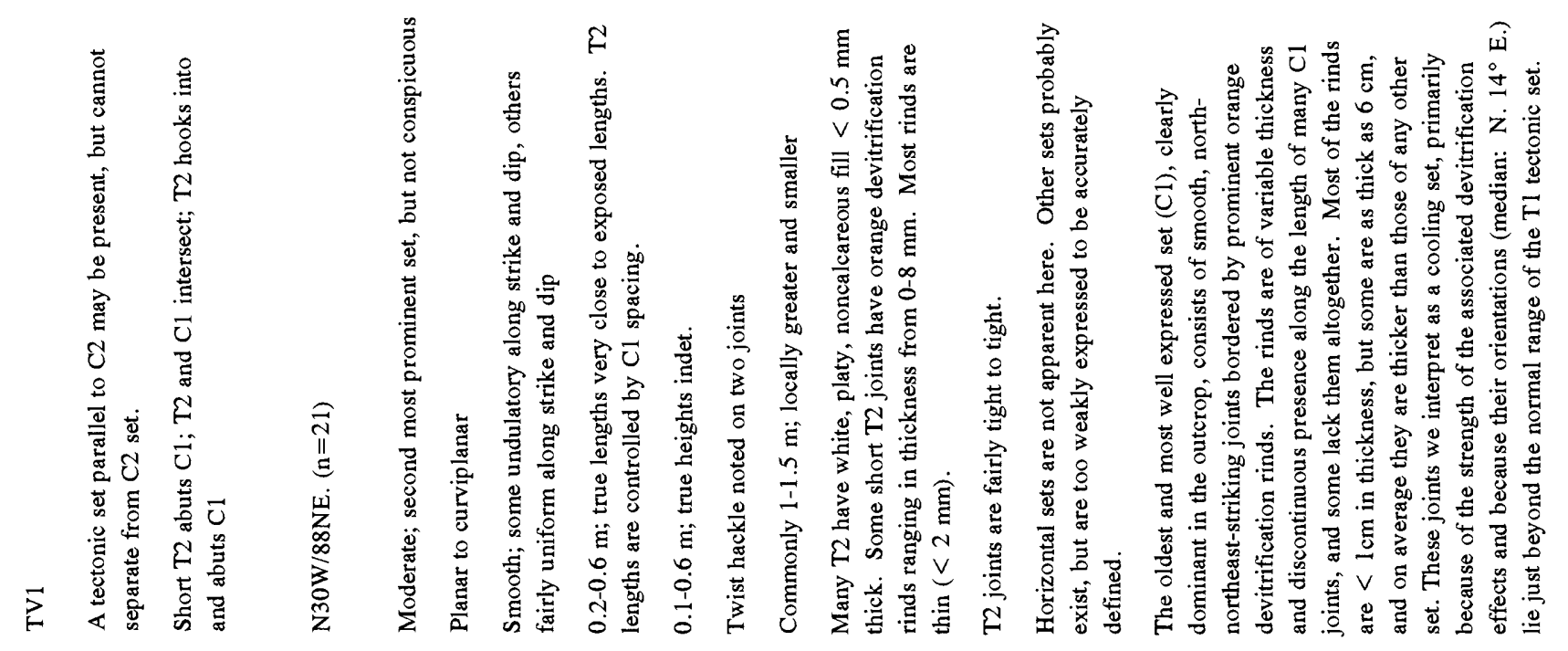

III 


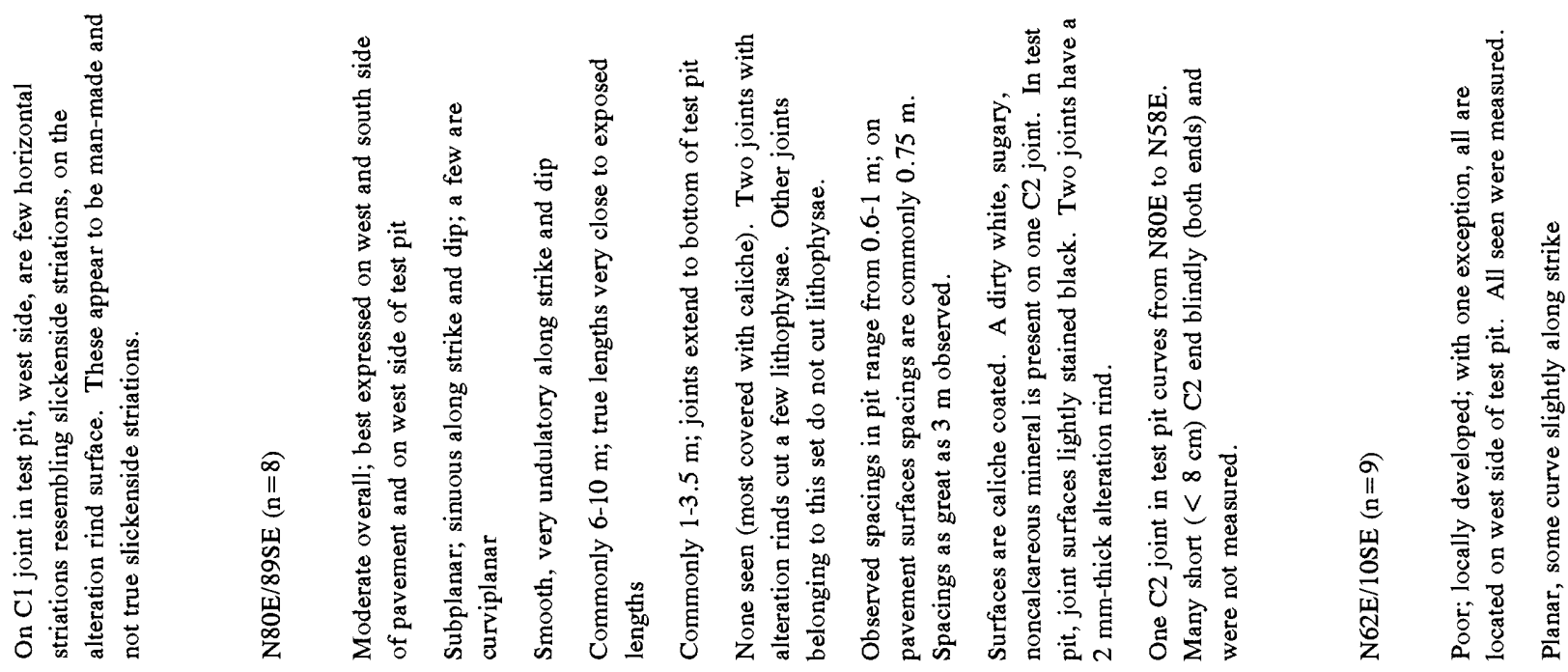

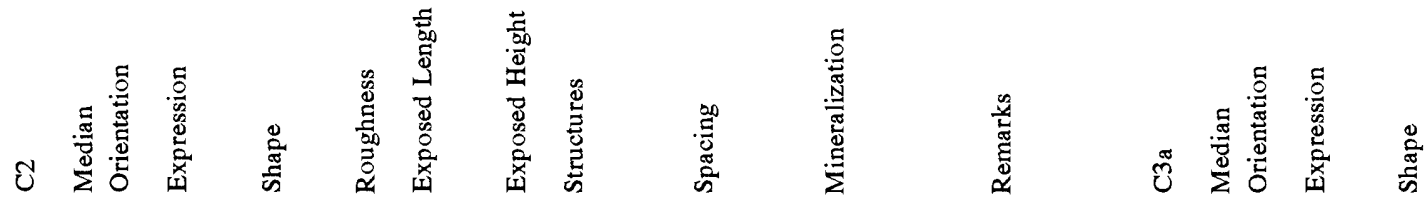

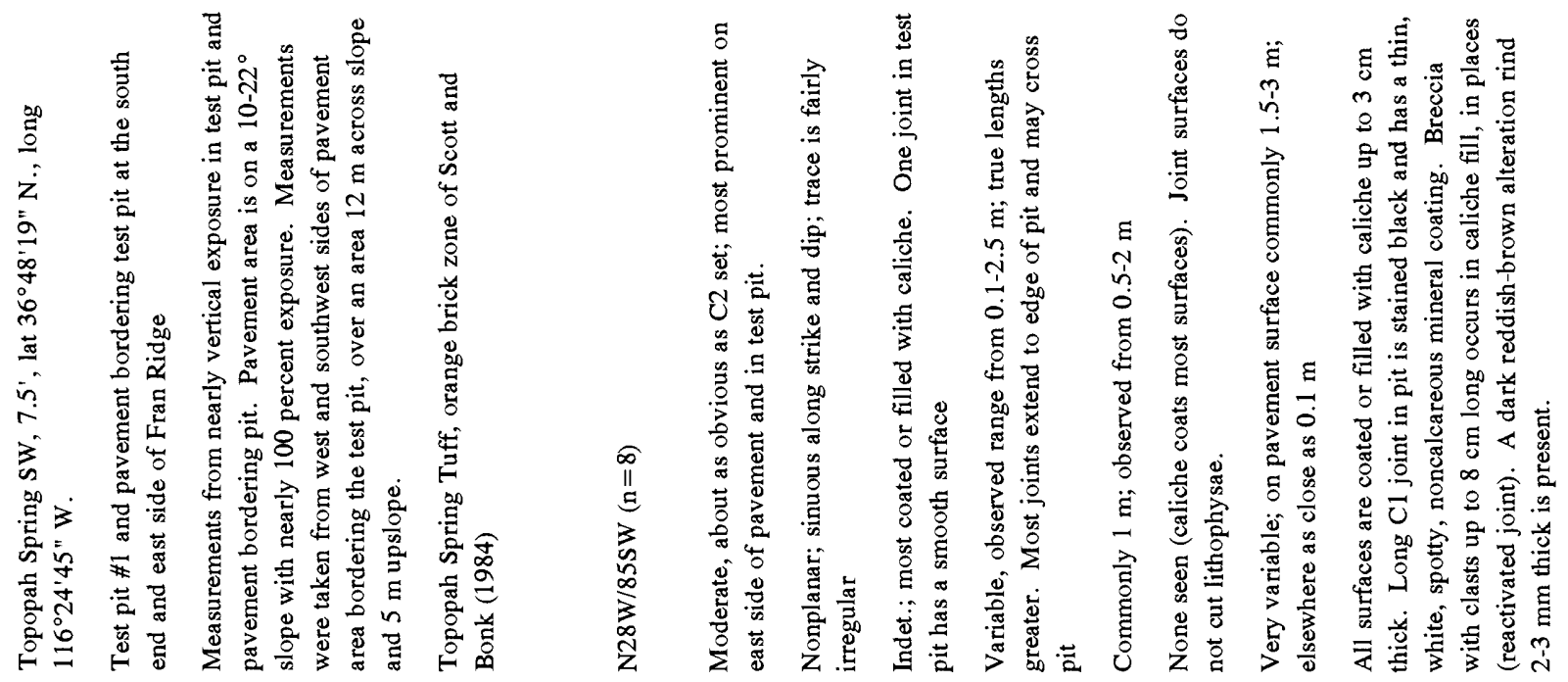

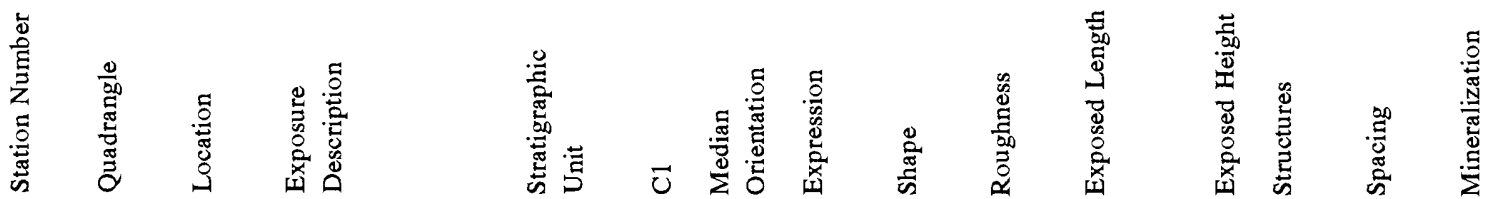




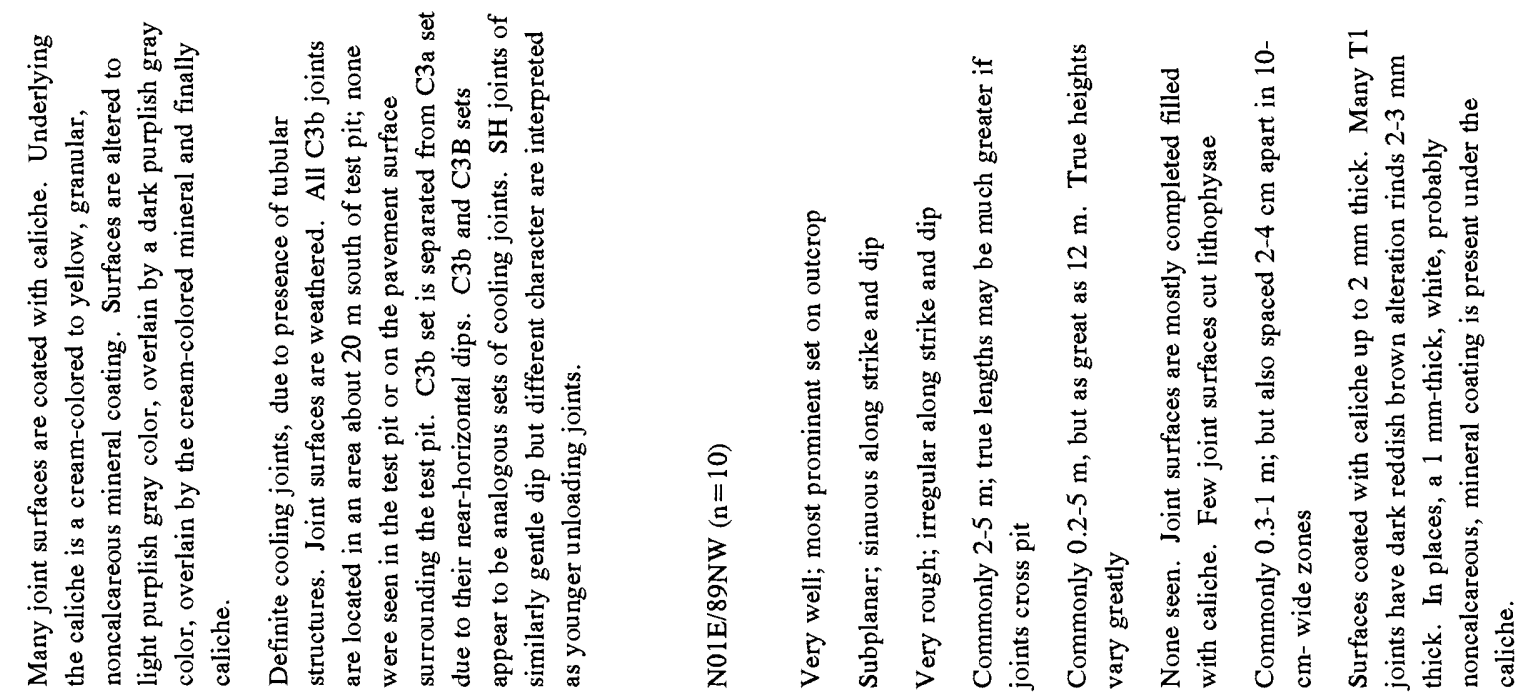

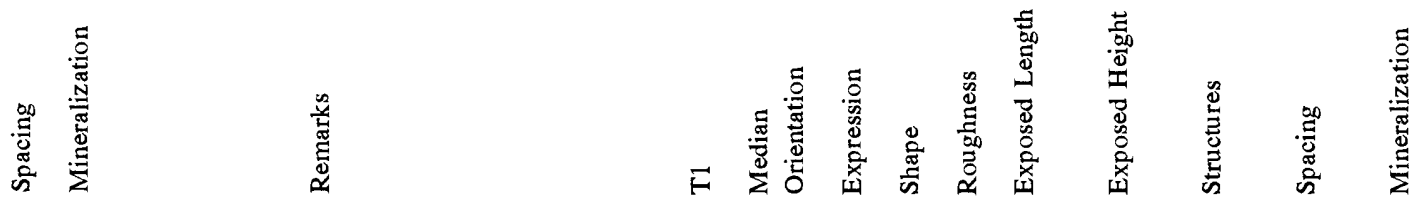

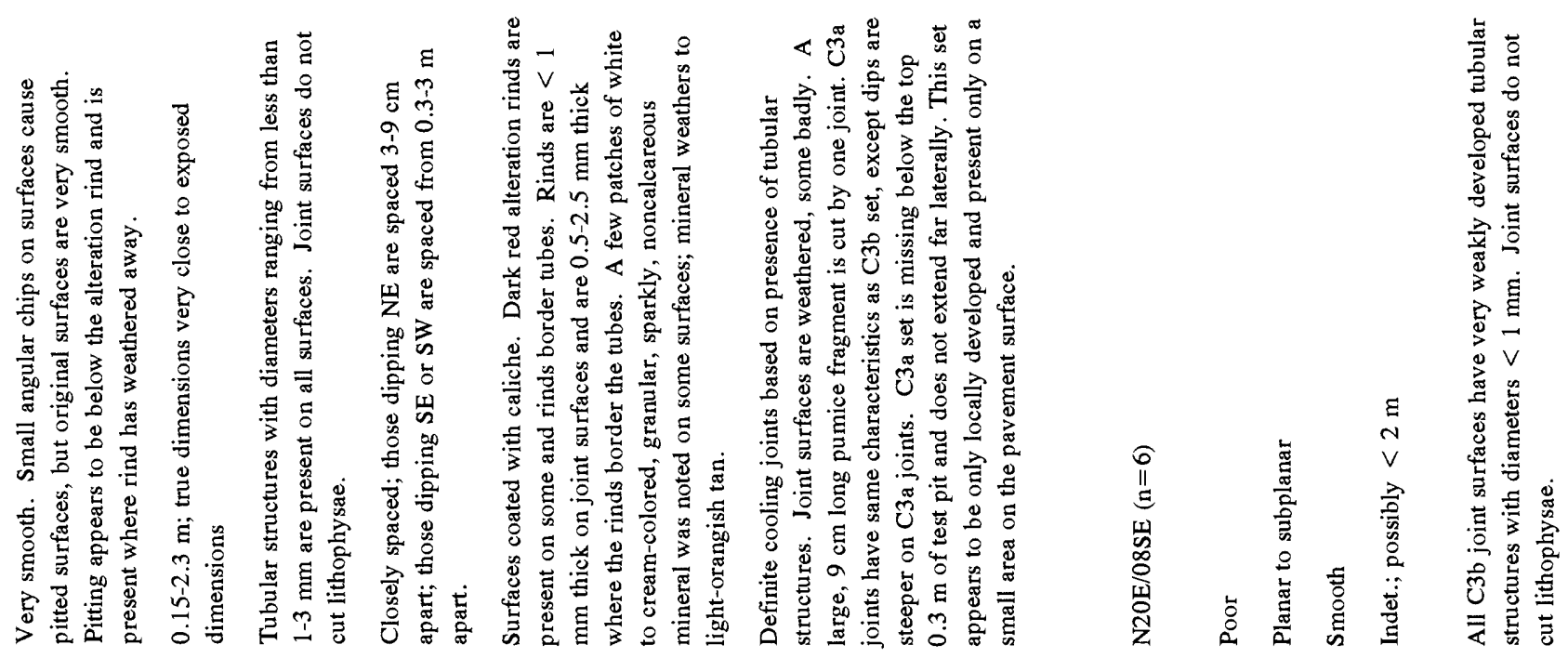

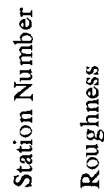

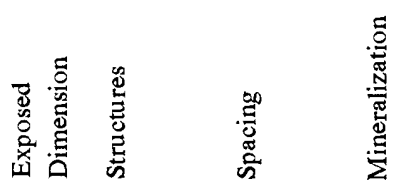

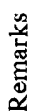

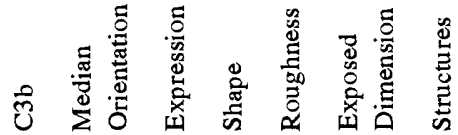



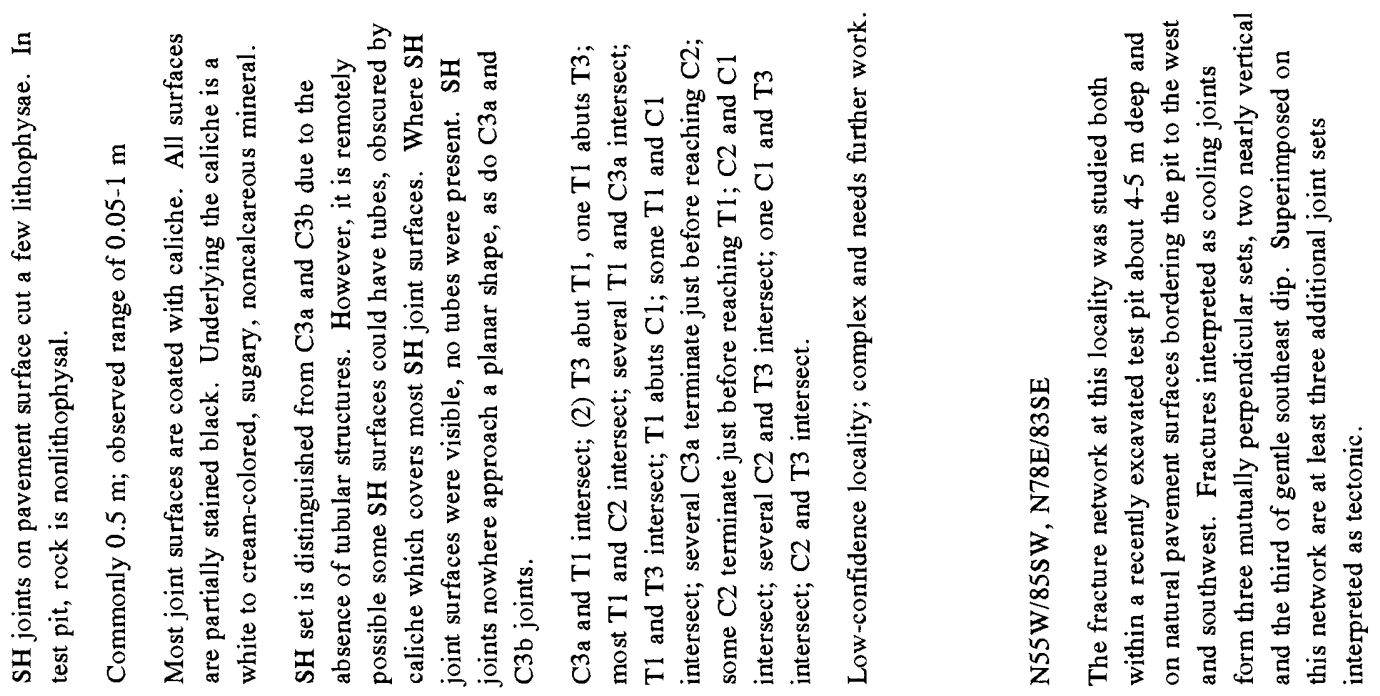

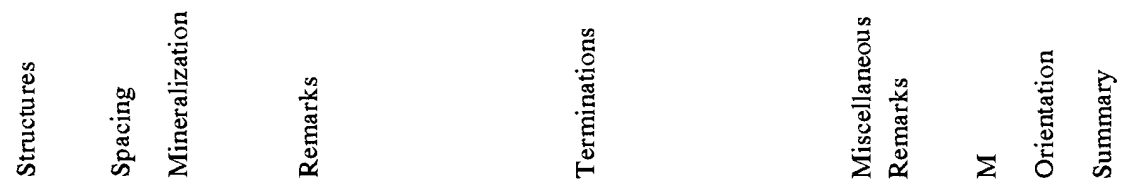

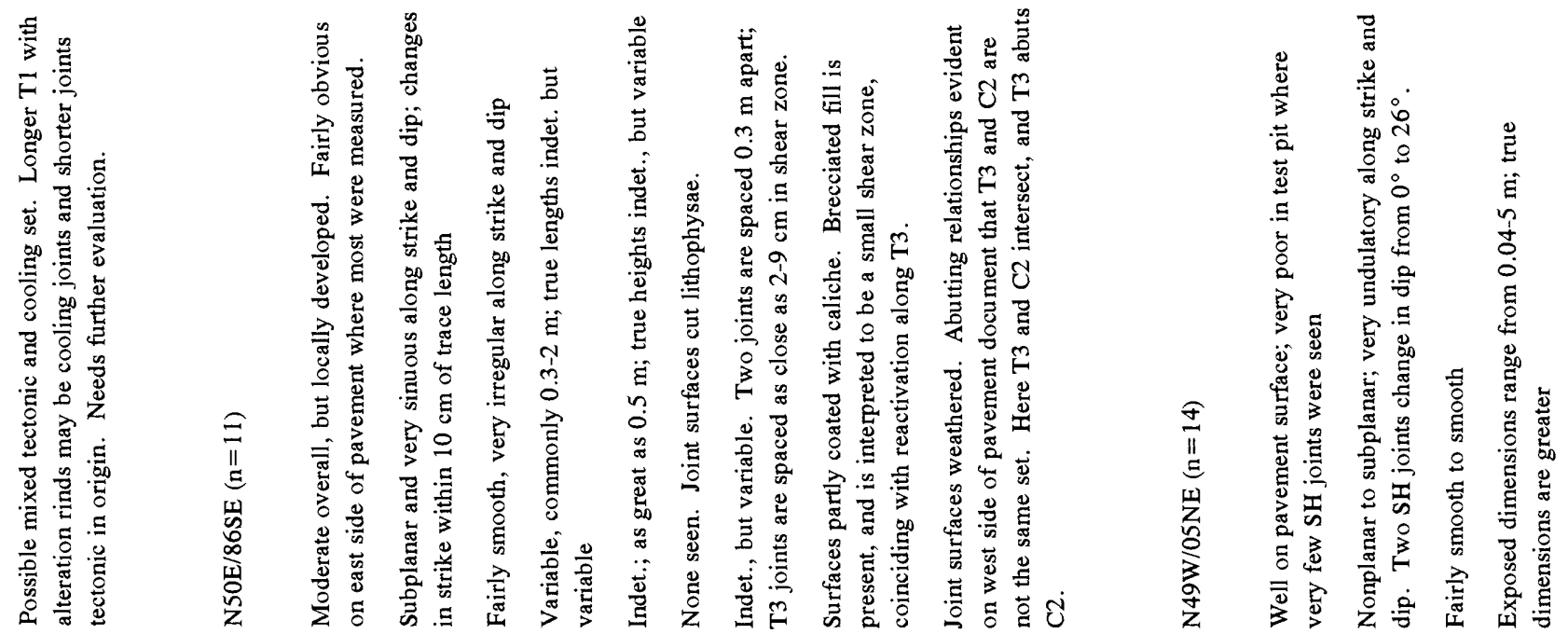

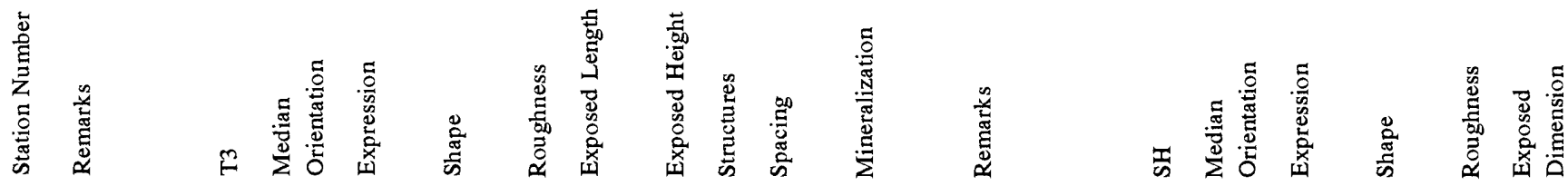




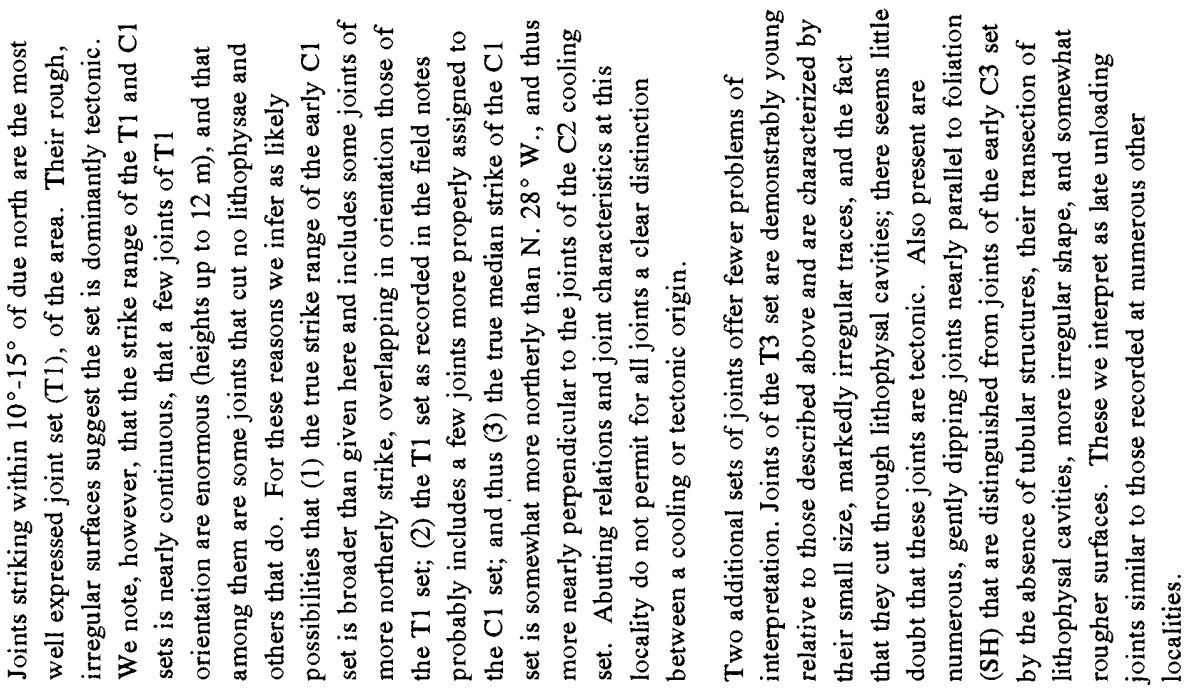

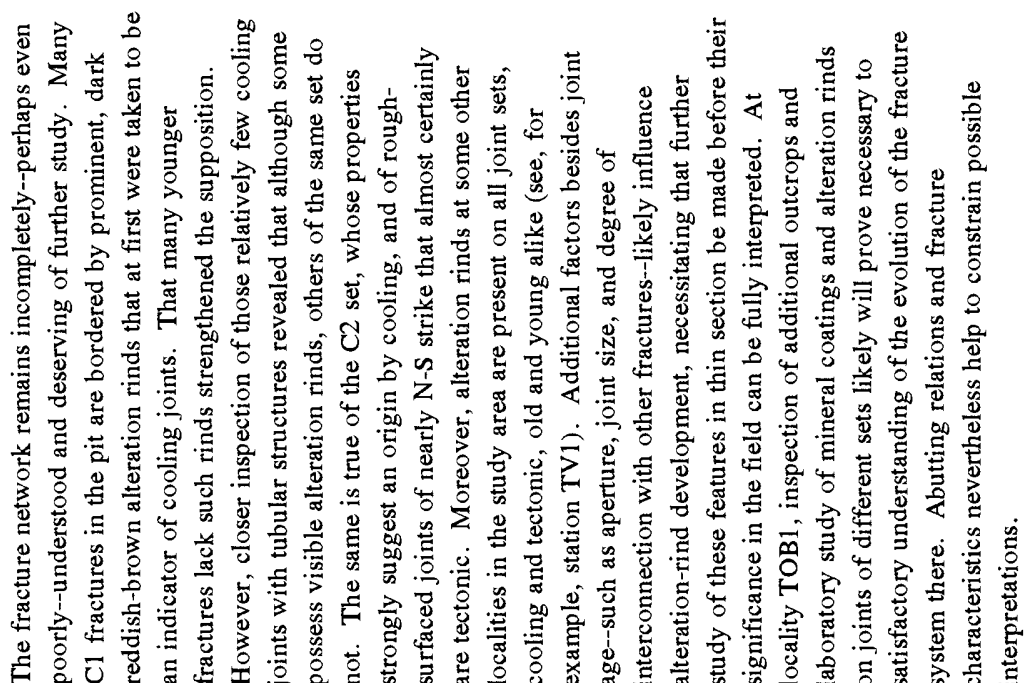

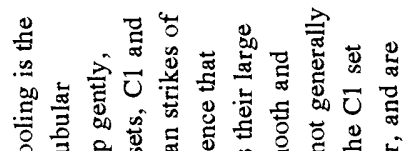

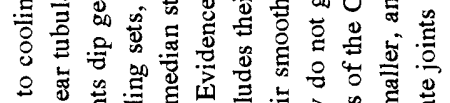

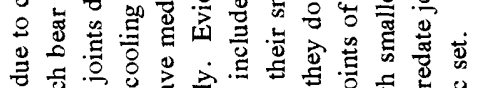

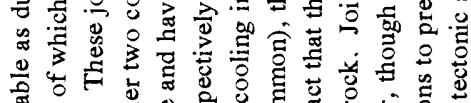

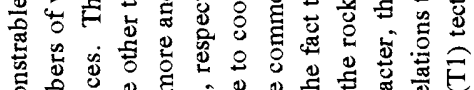

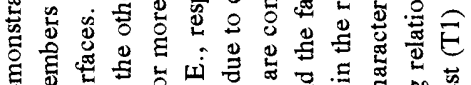

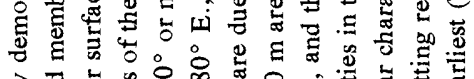

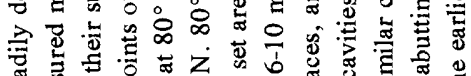

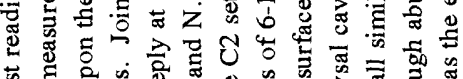

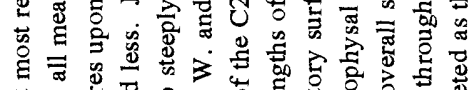




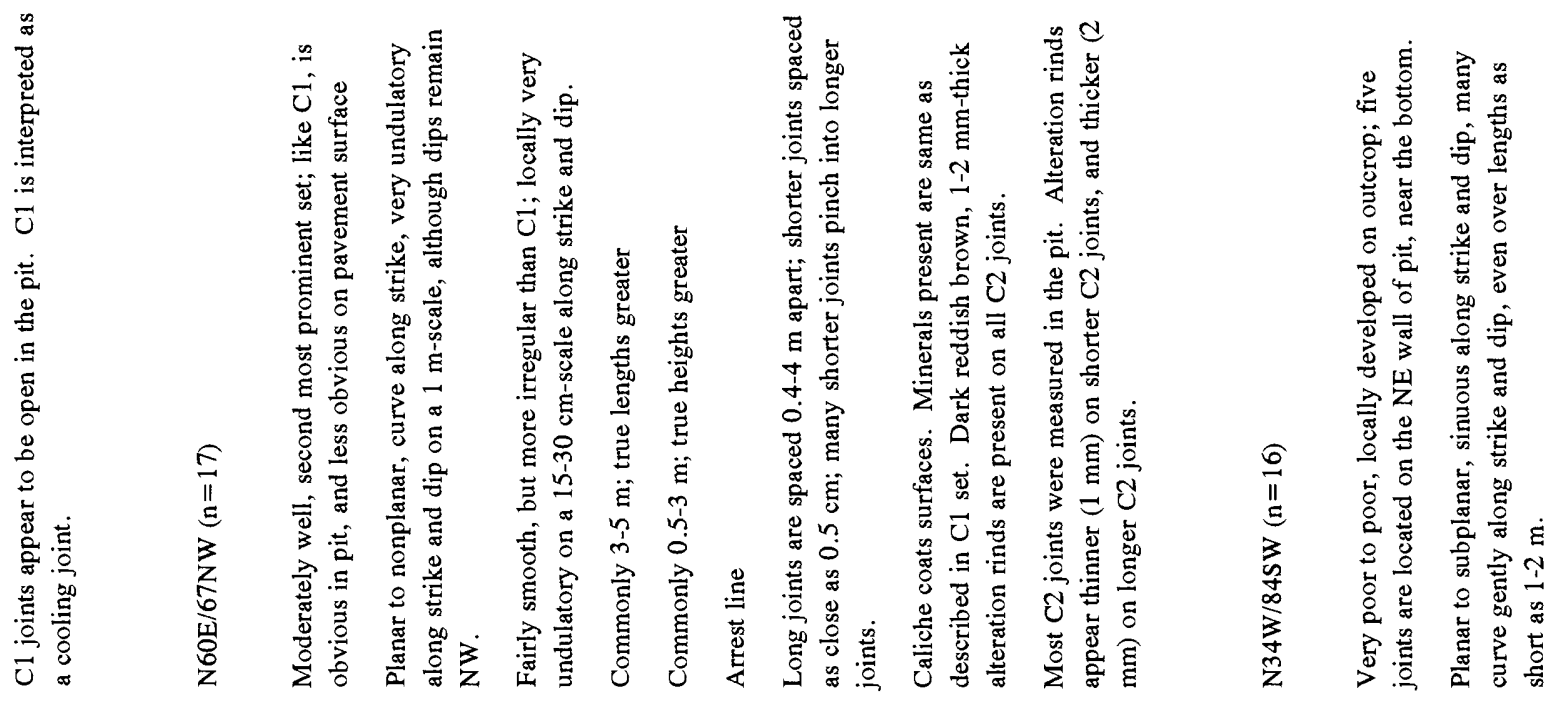

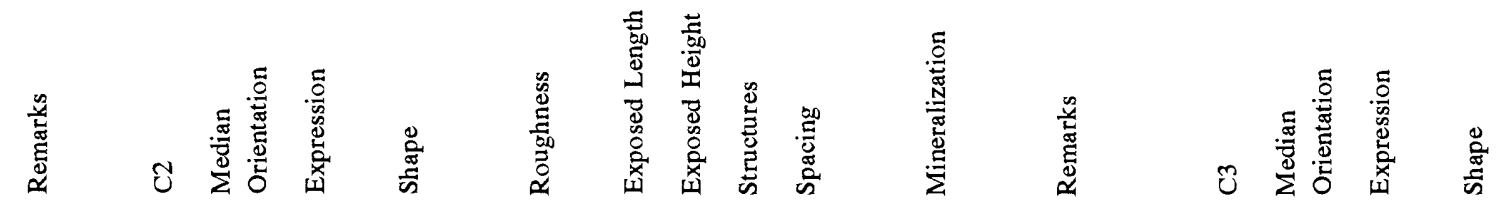

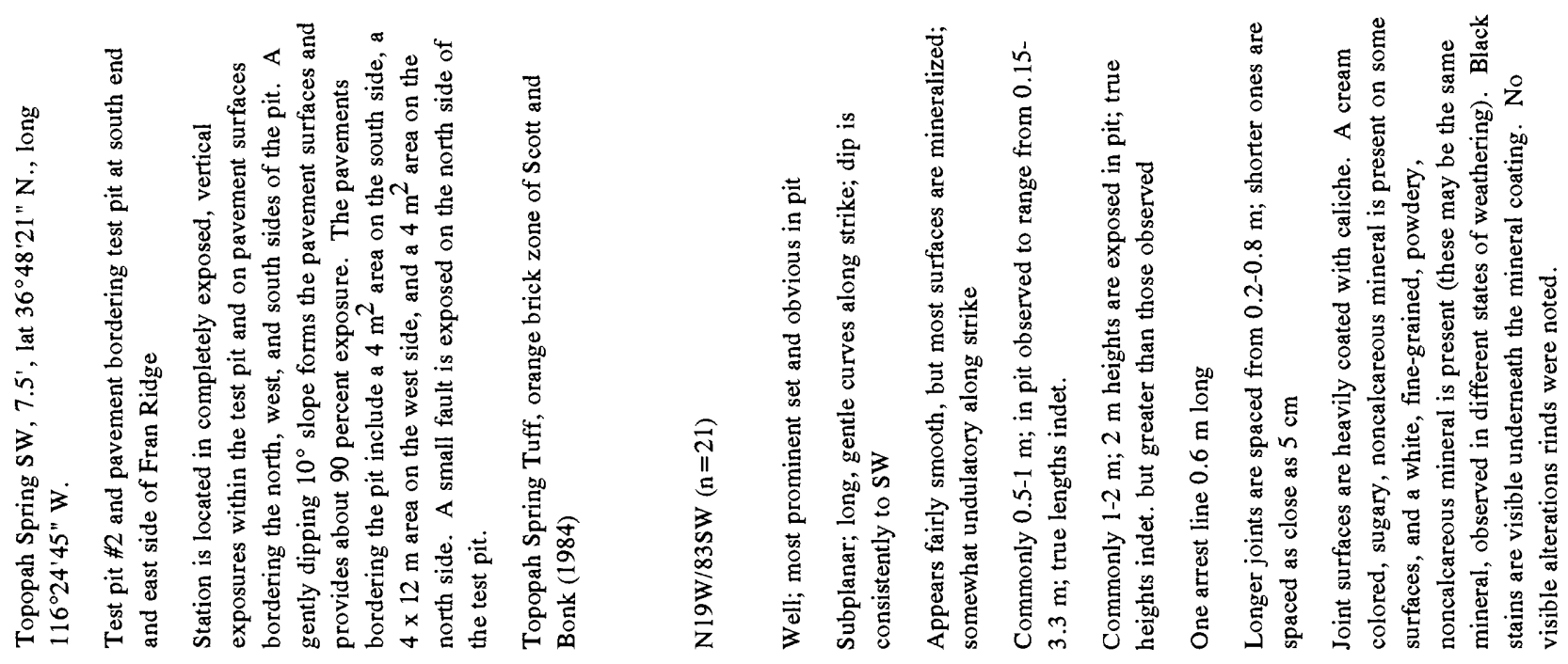

IIII 

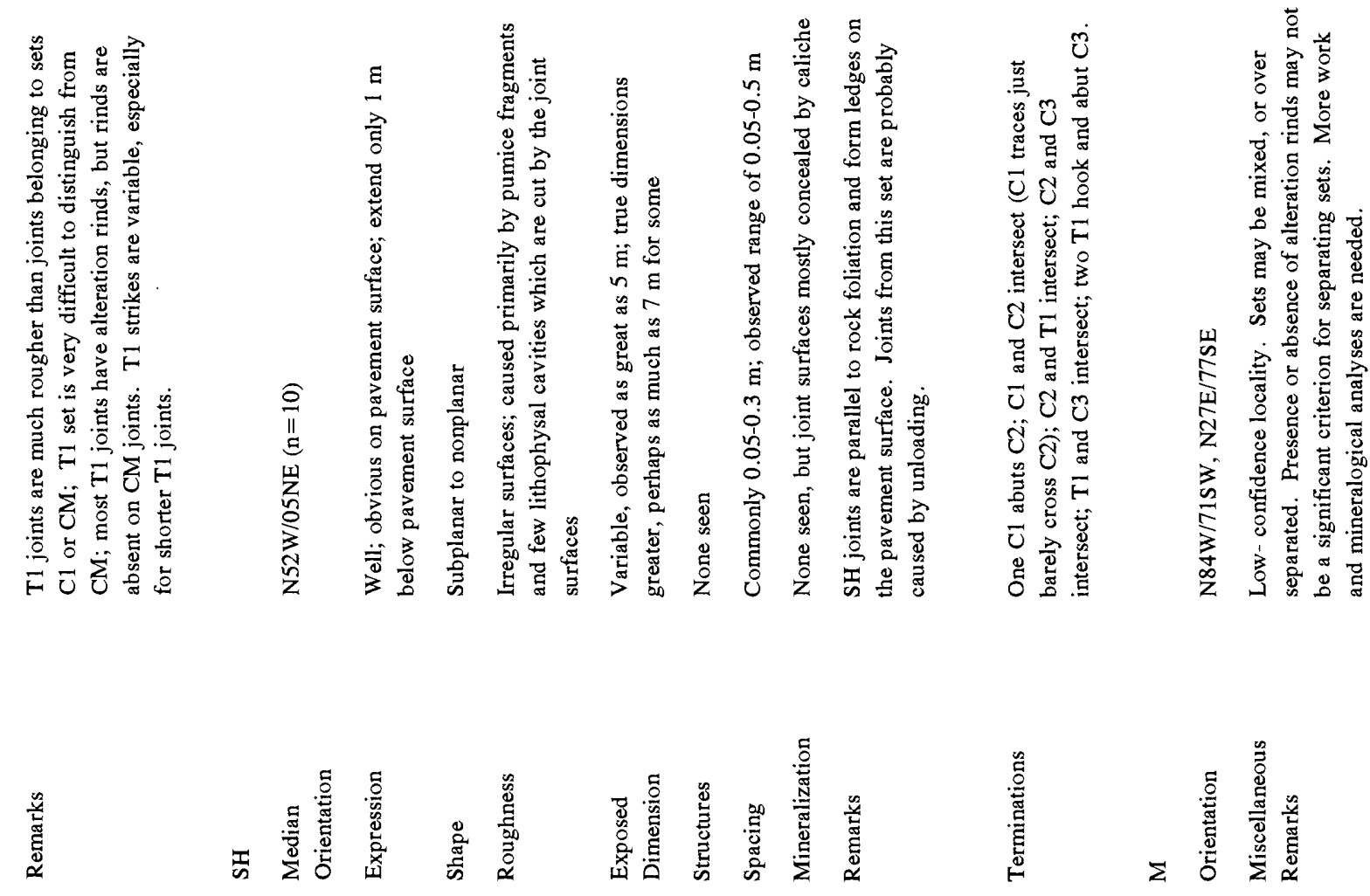

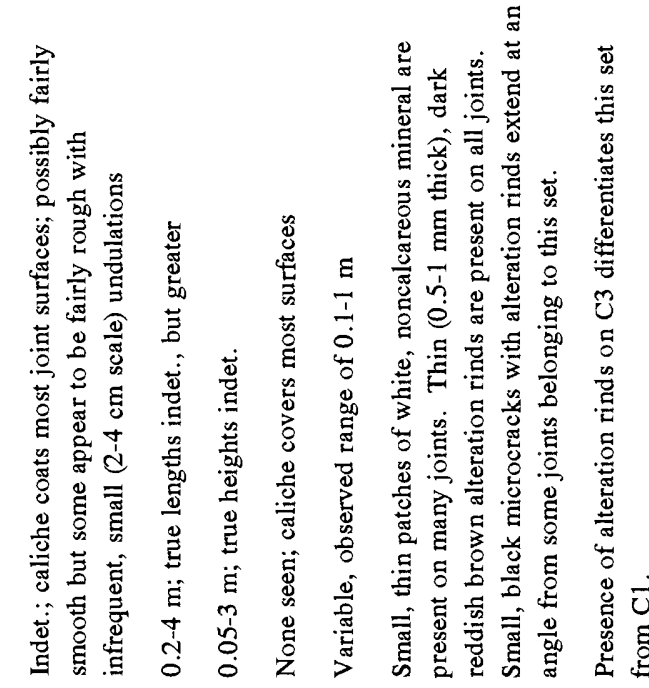

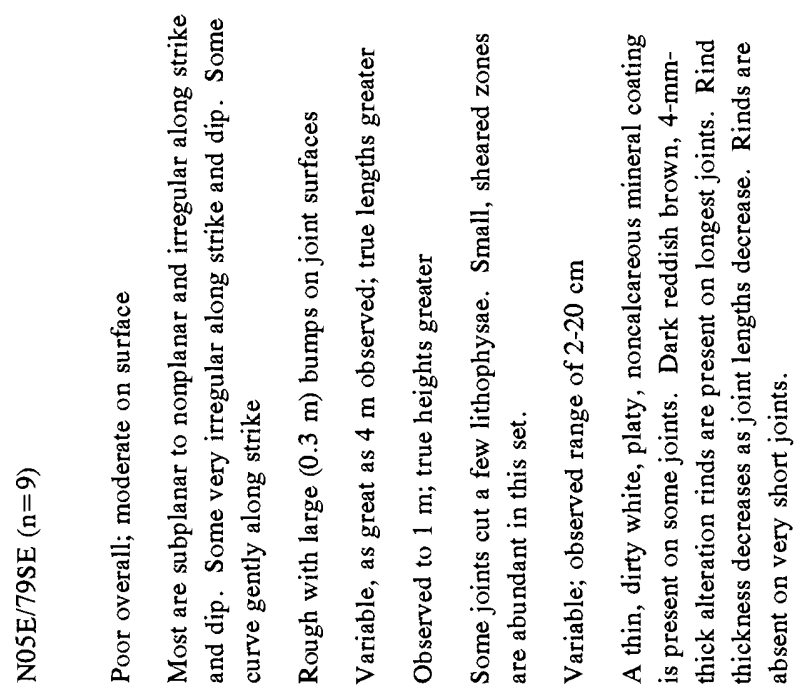

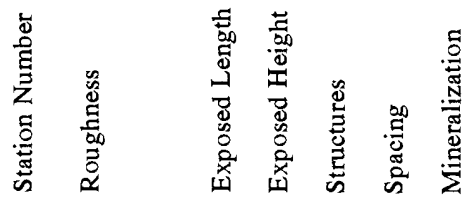

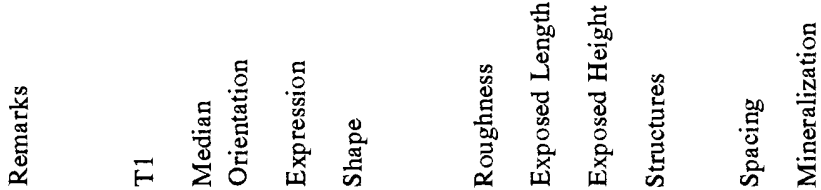



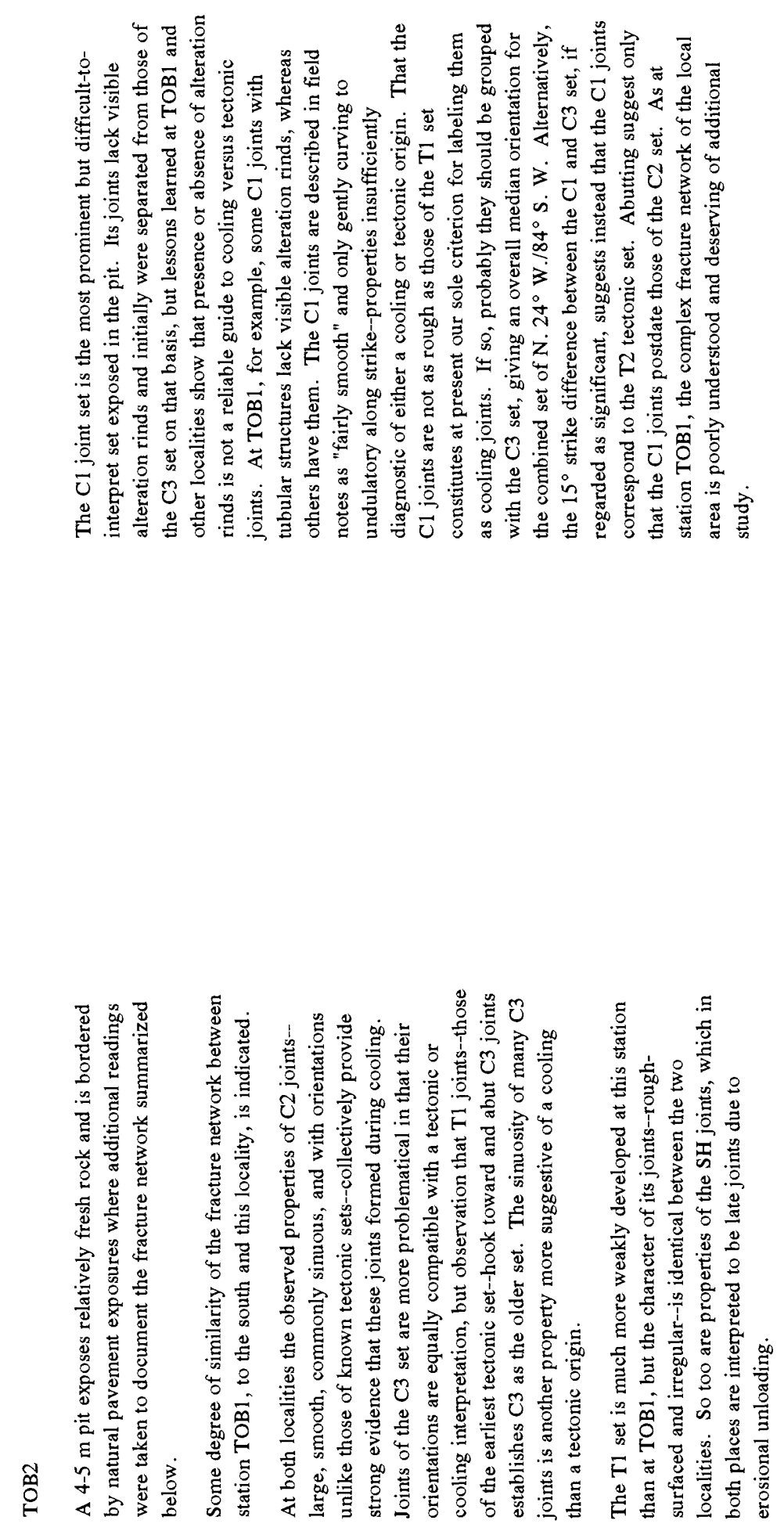

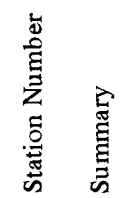




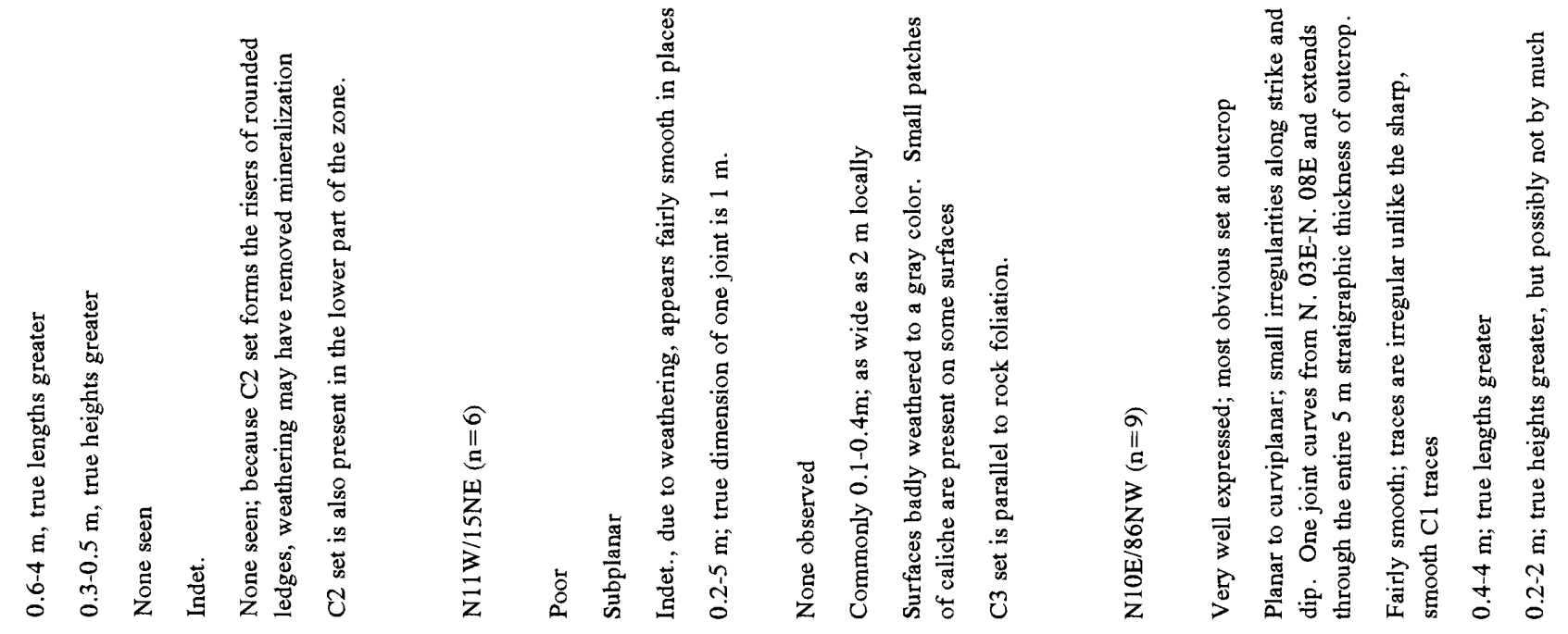

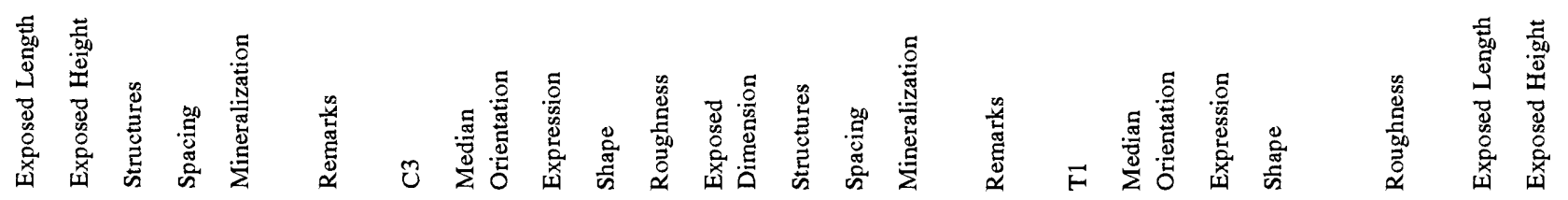
웆

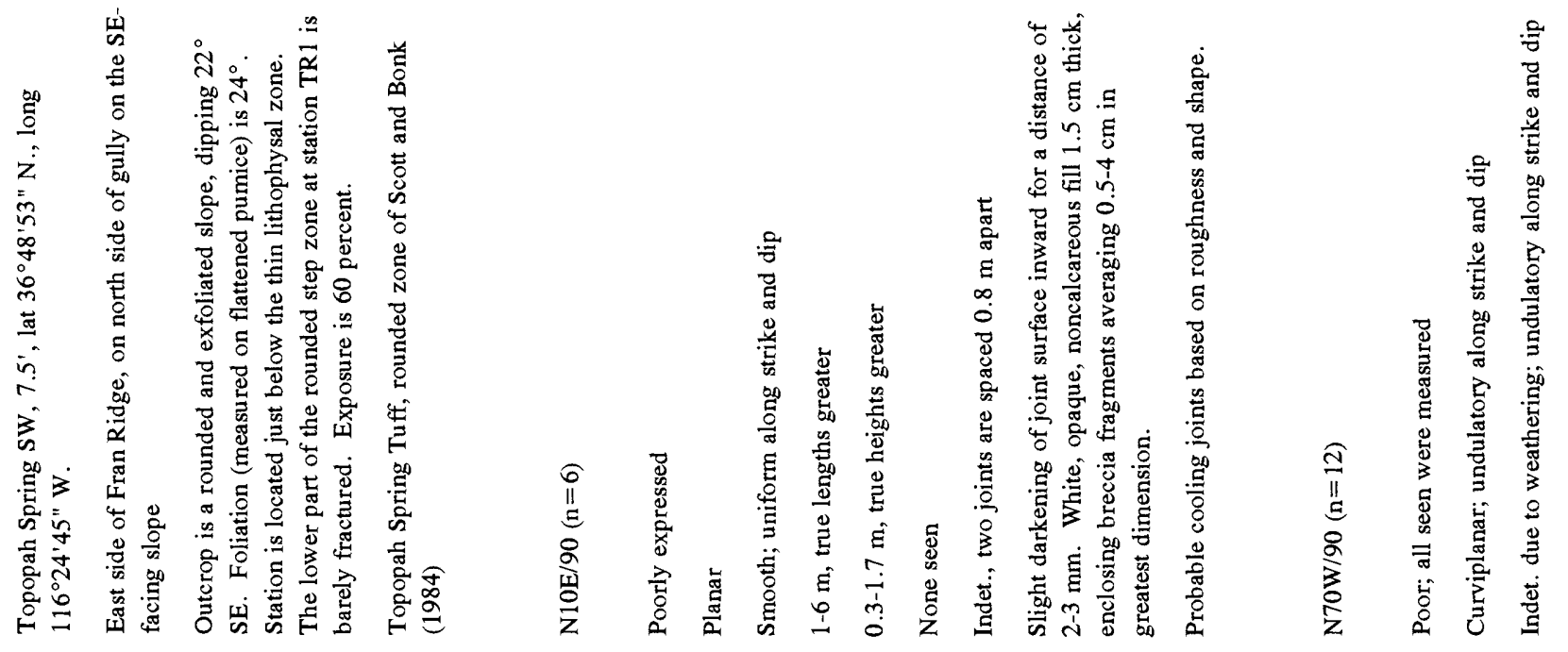

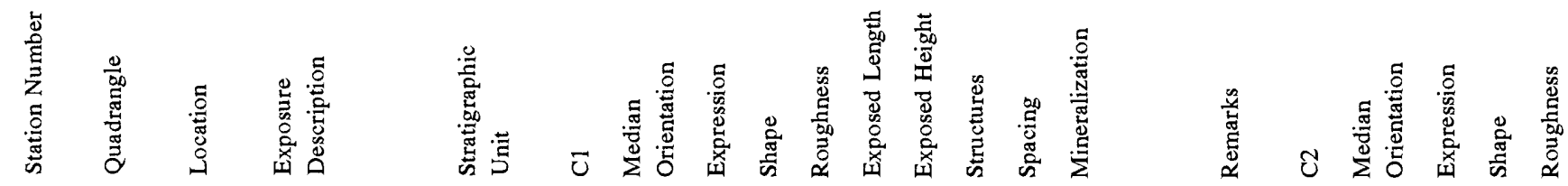




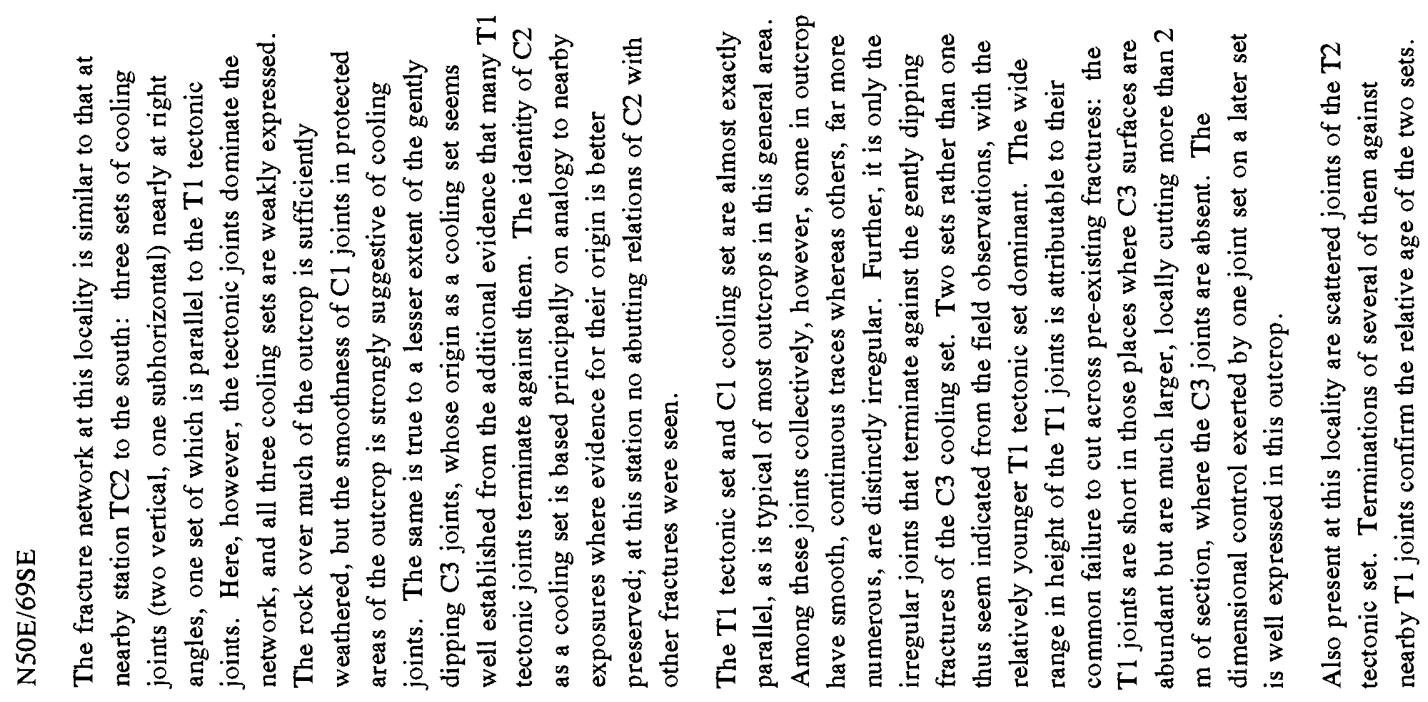

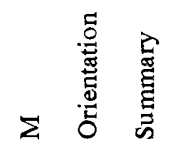
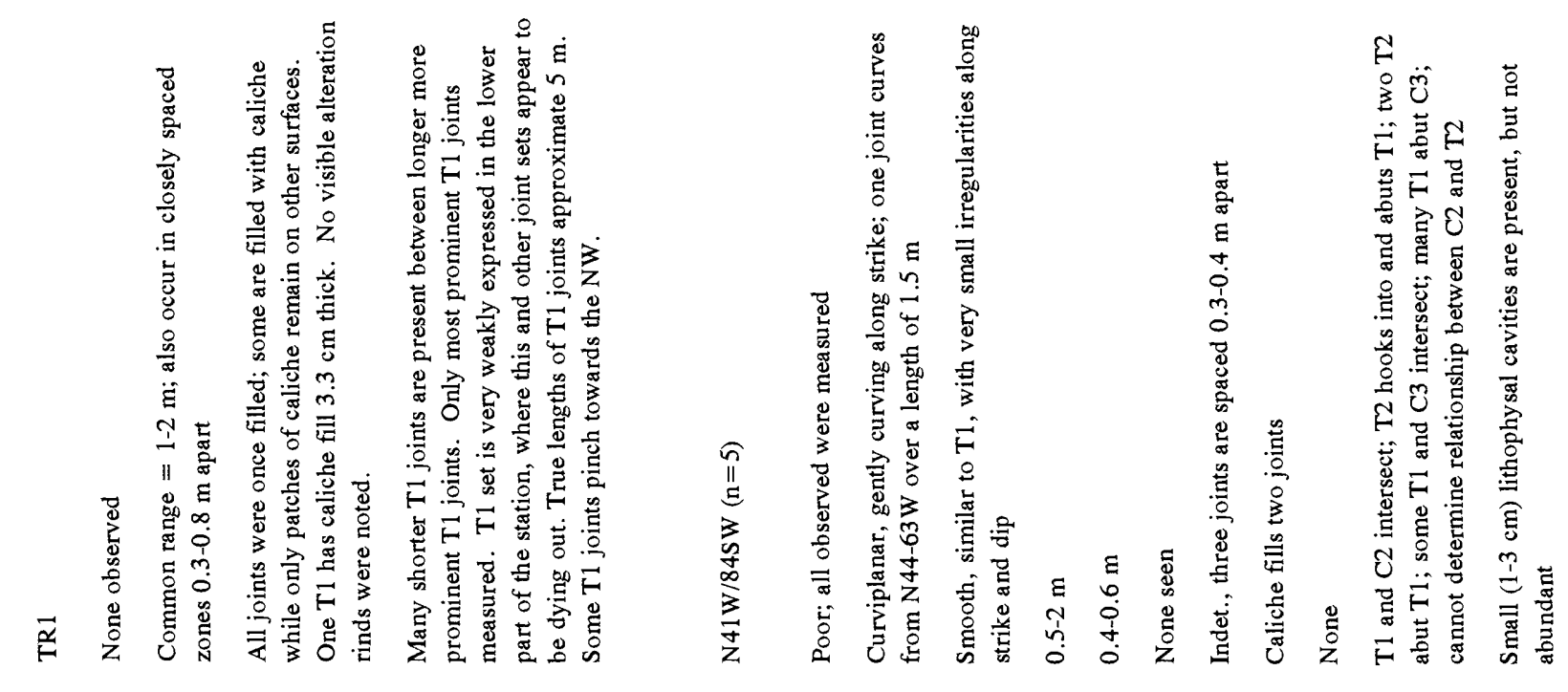

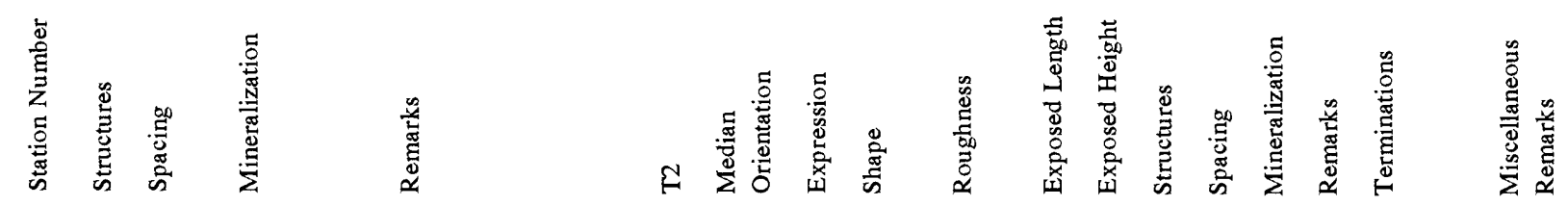




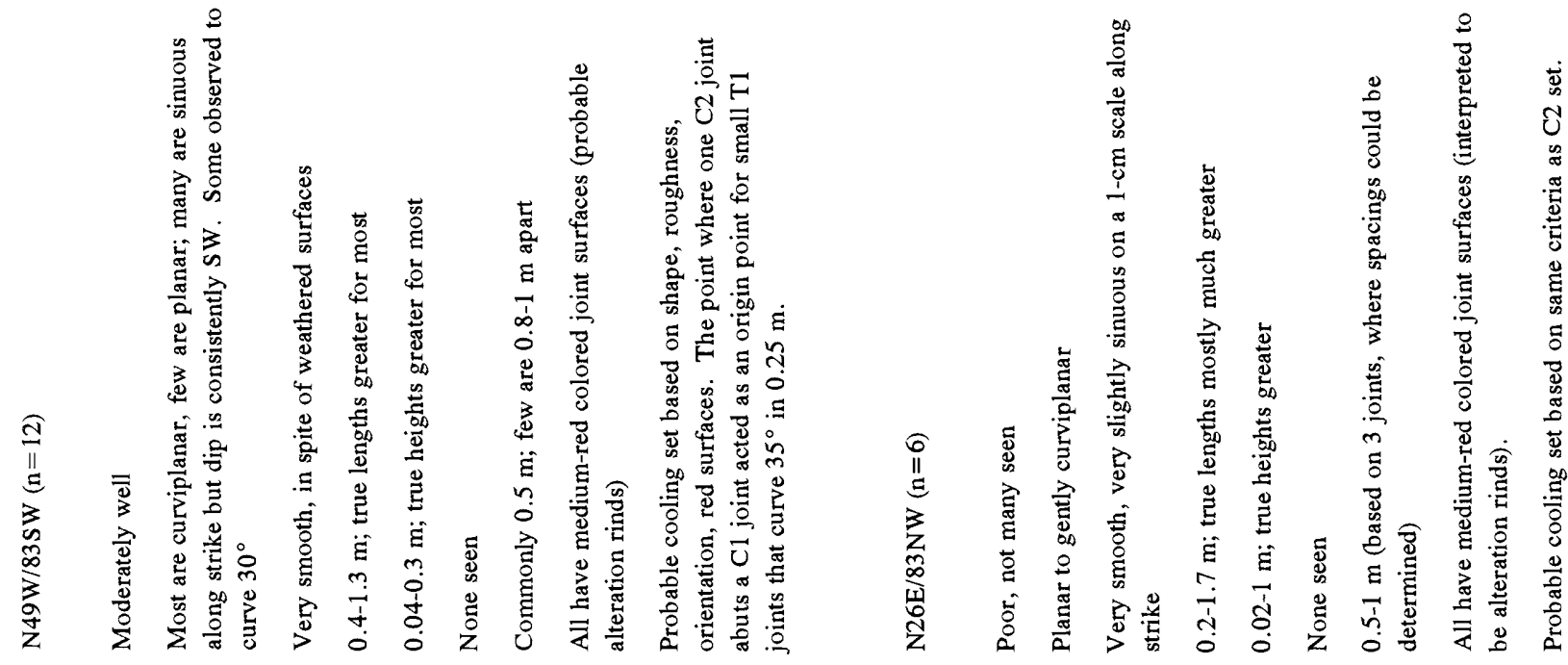

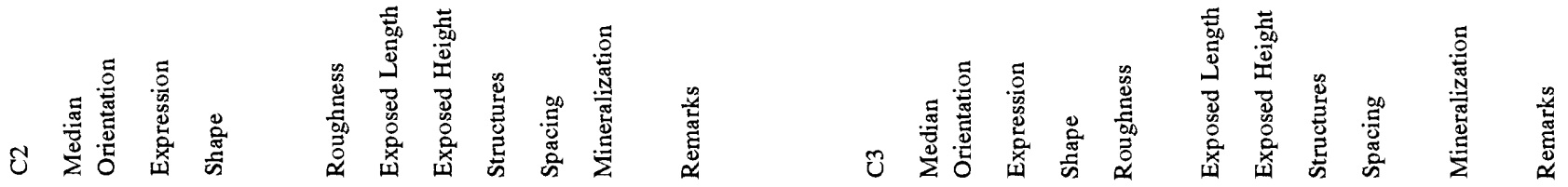

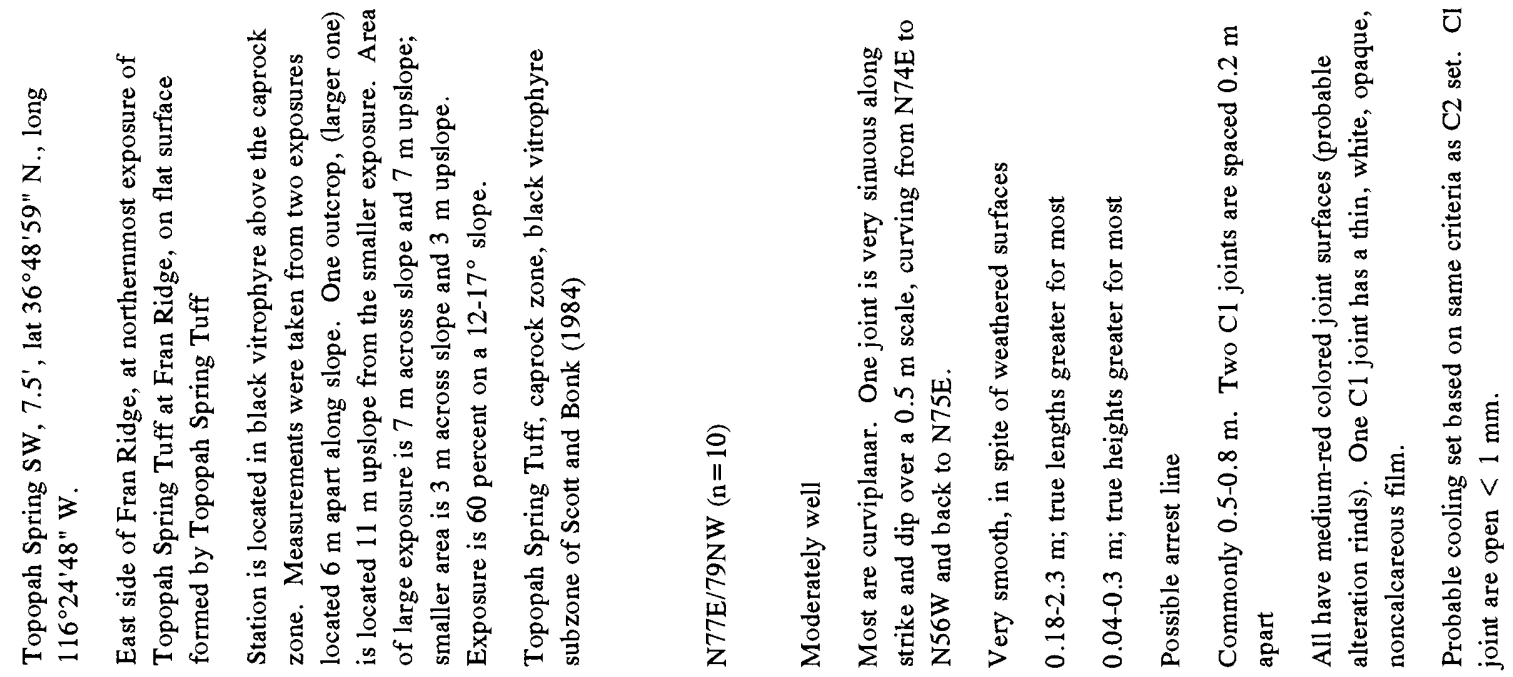

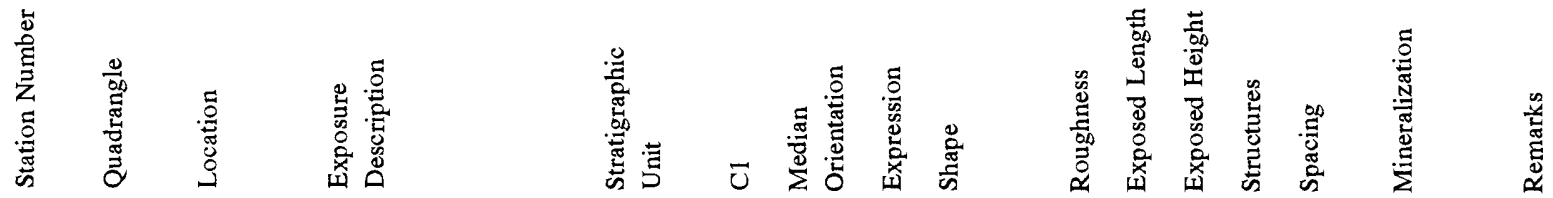



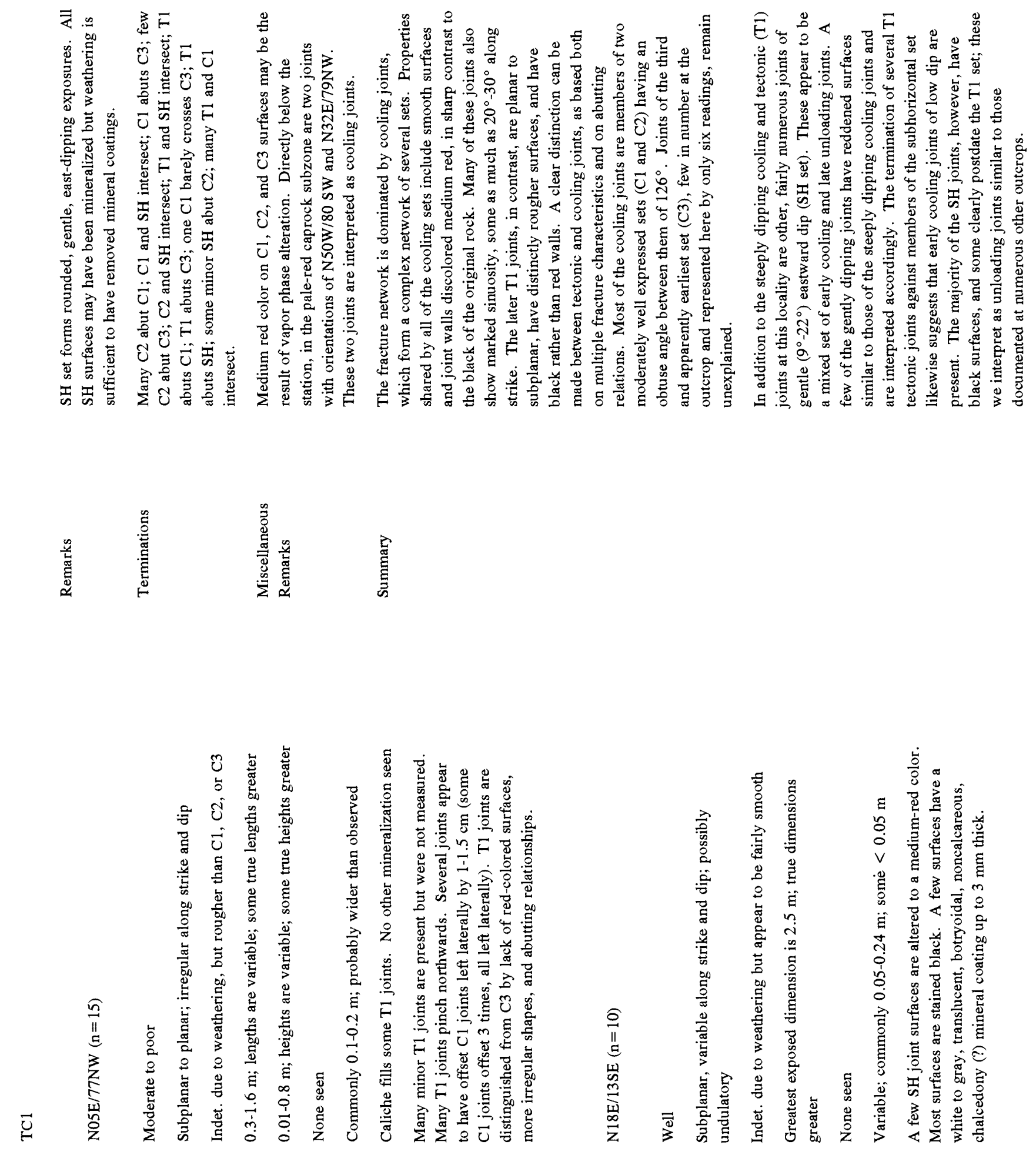

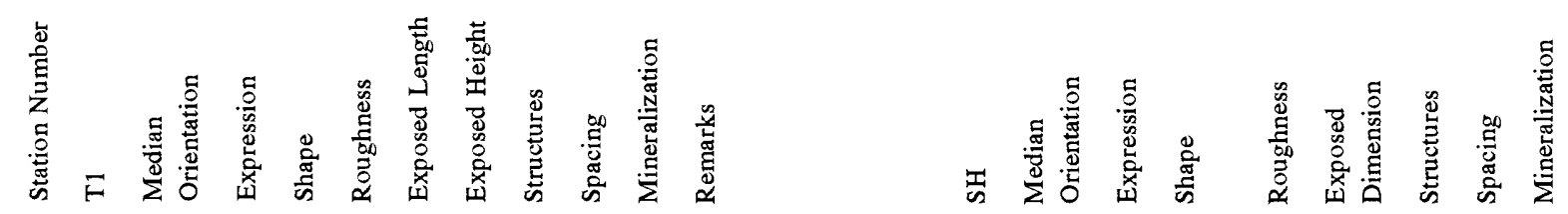




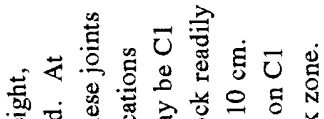

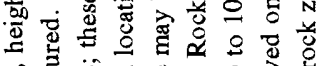

站要

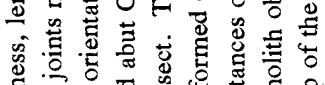

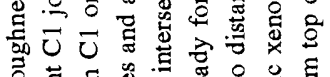

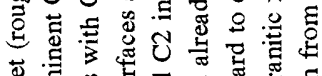

क

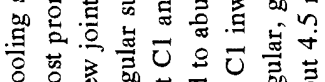

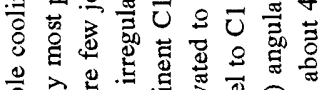

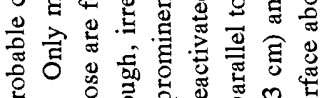

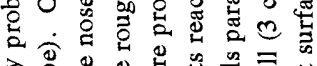

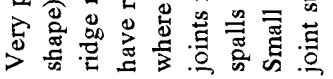

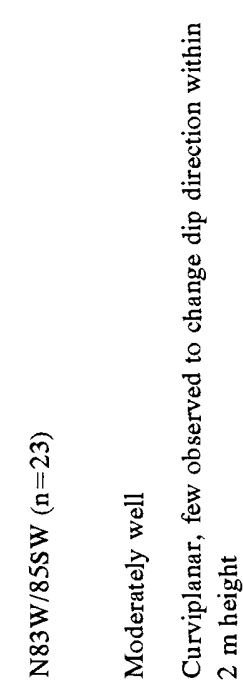

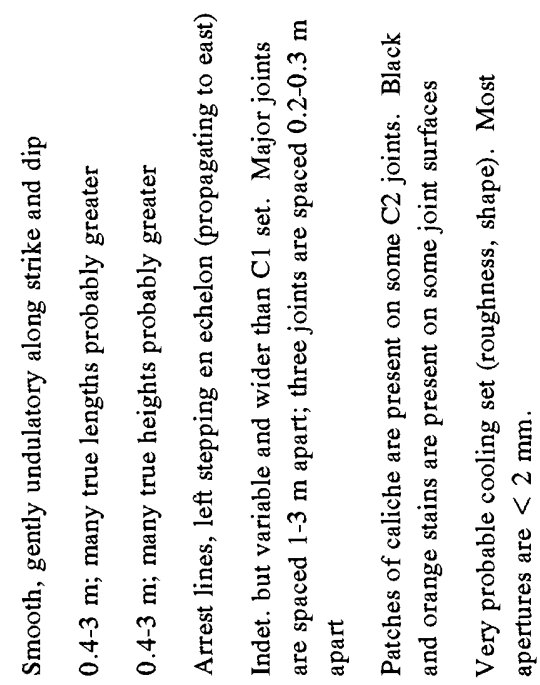

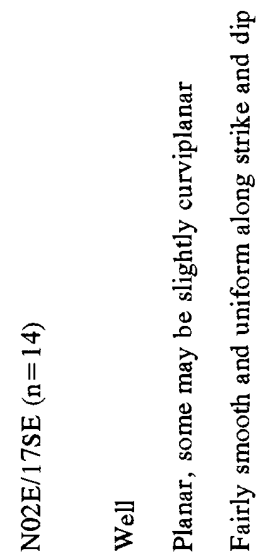

密

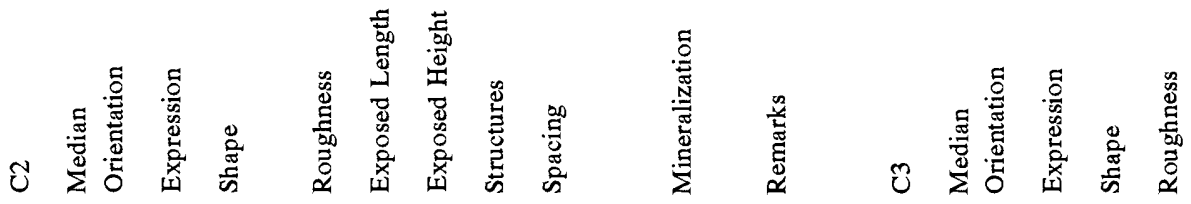
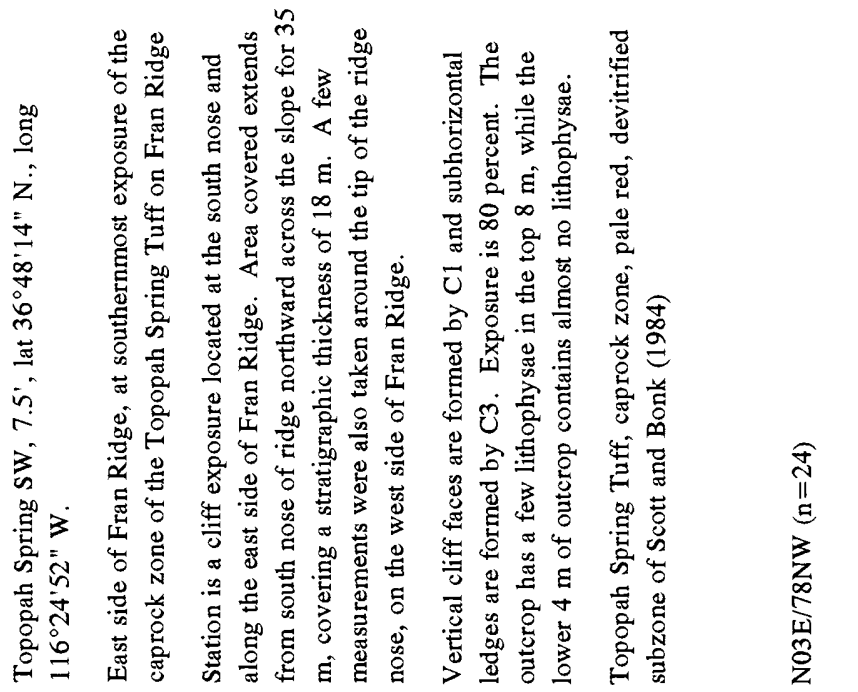

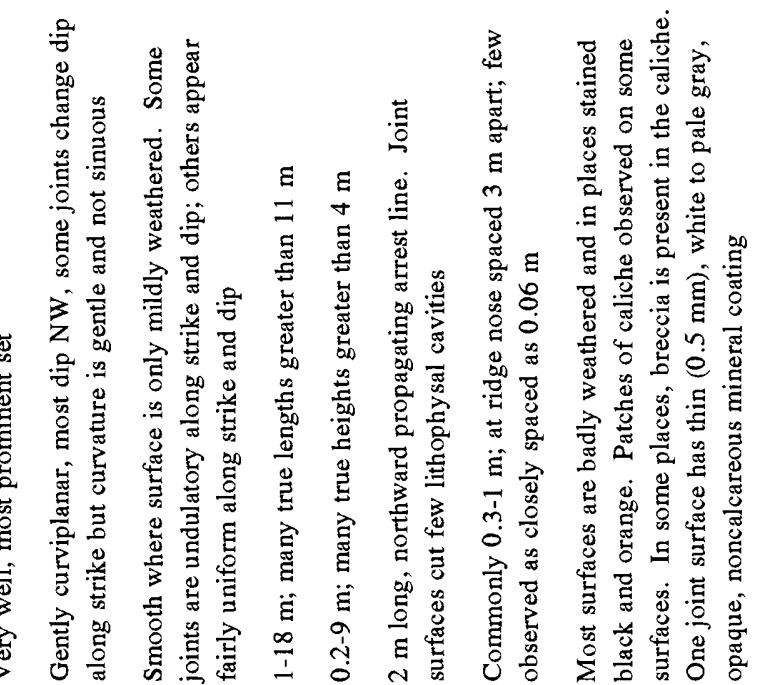

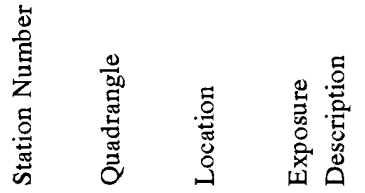

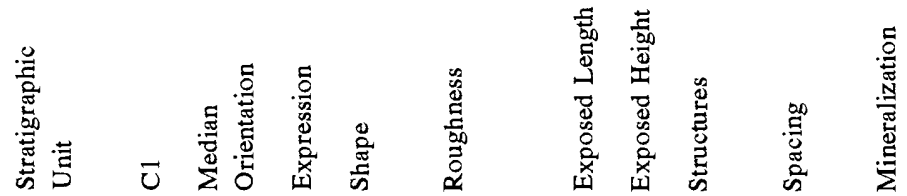




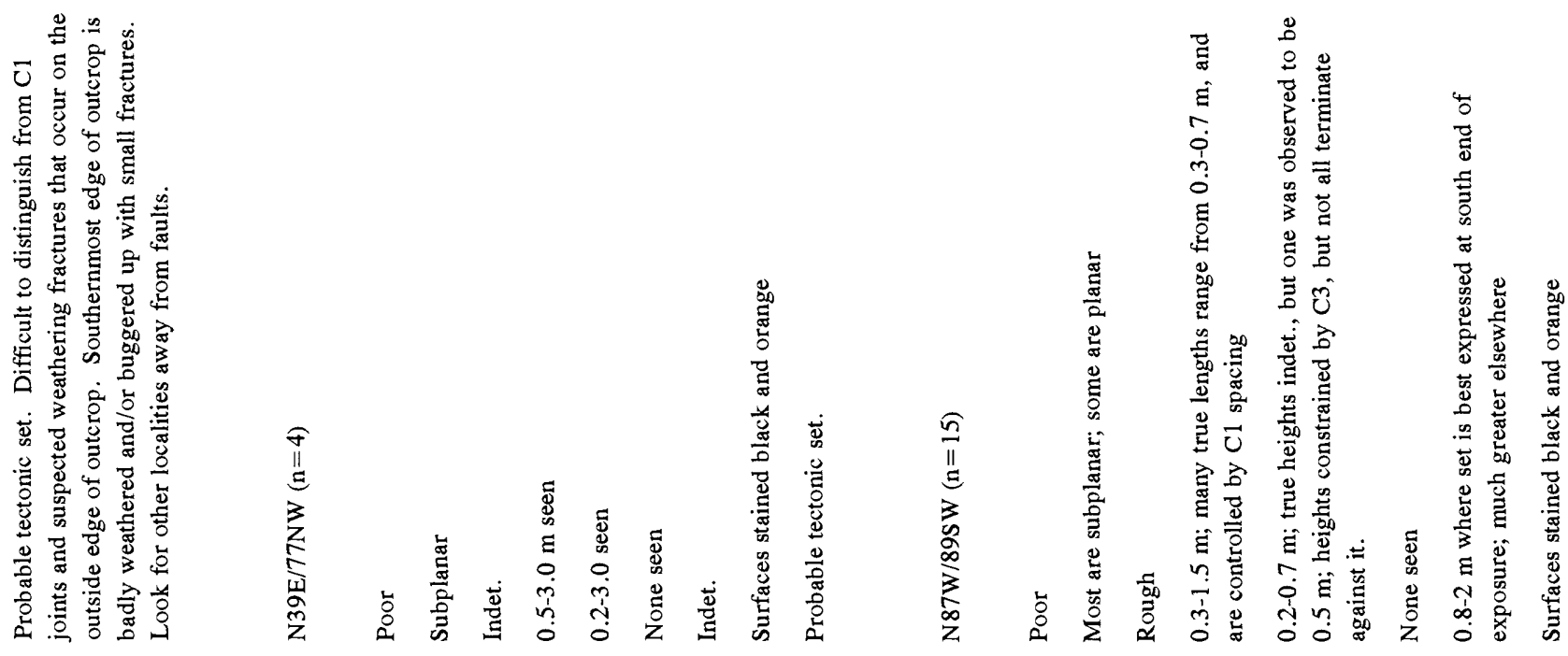

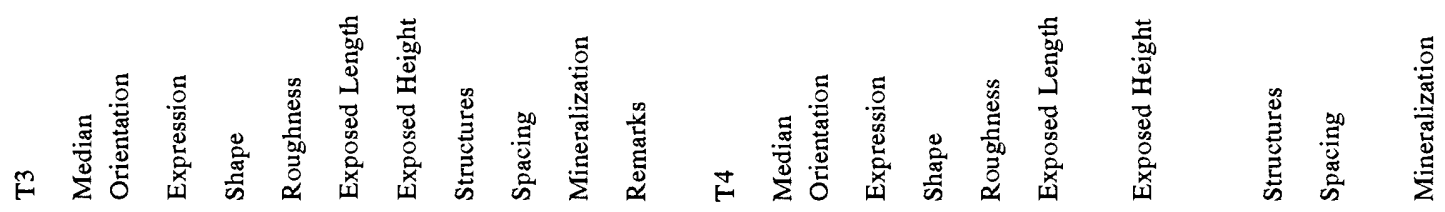

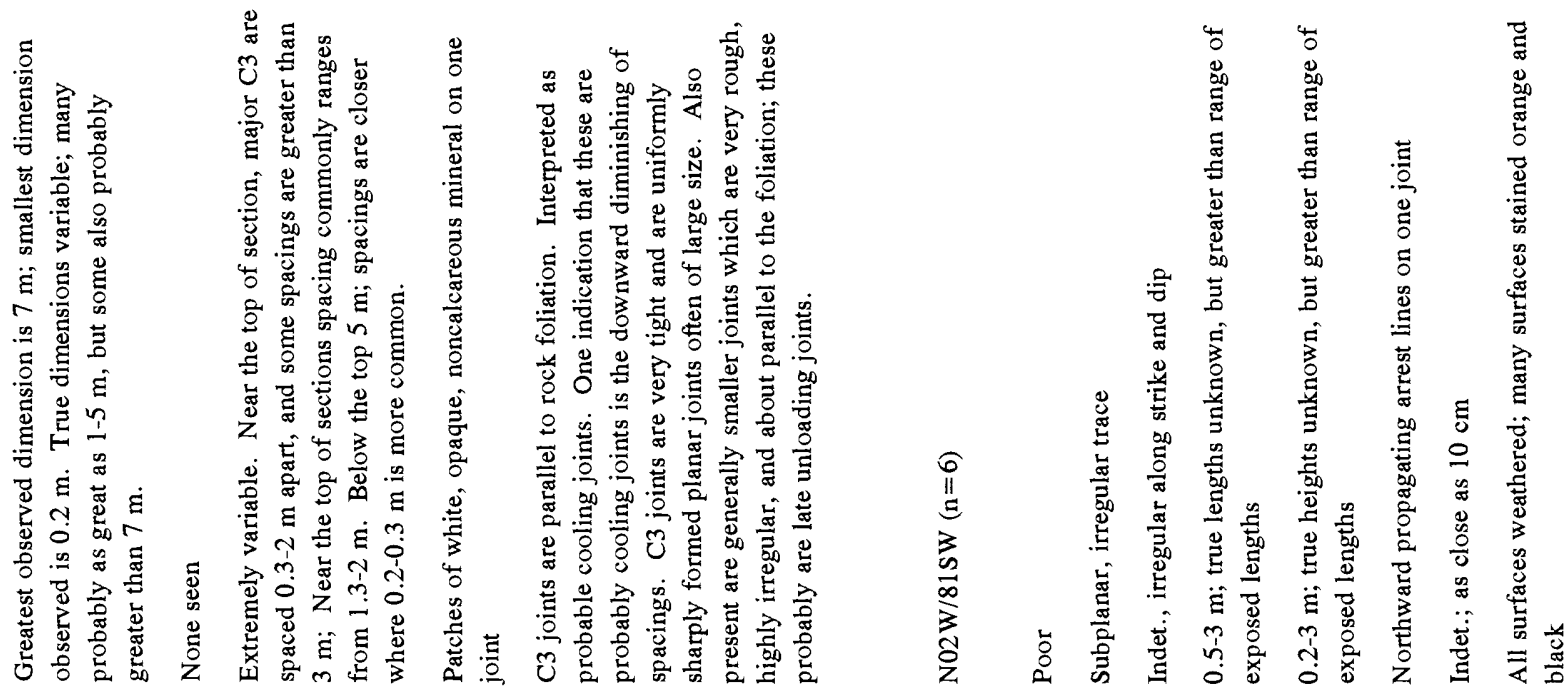

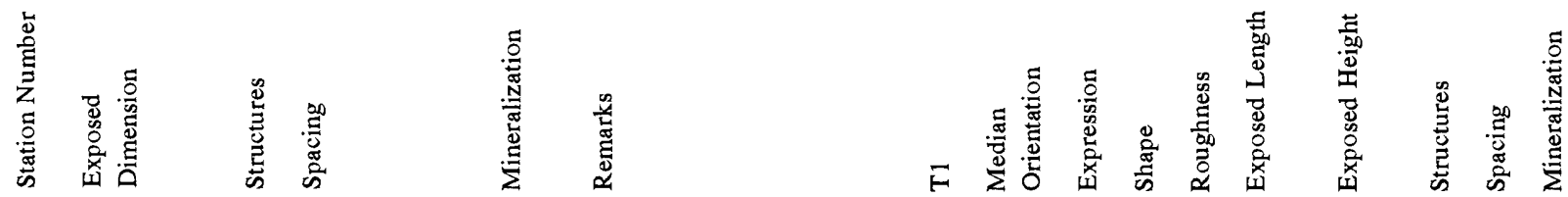



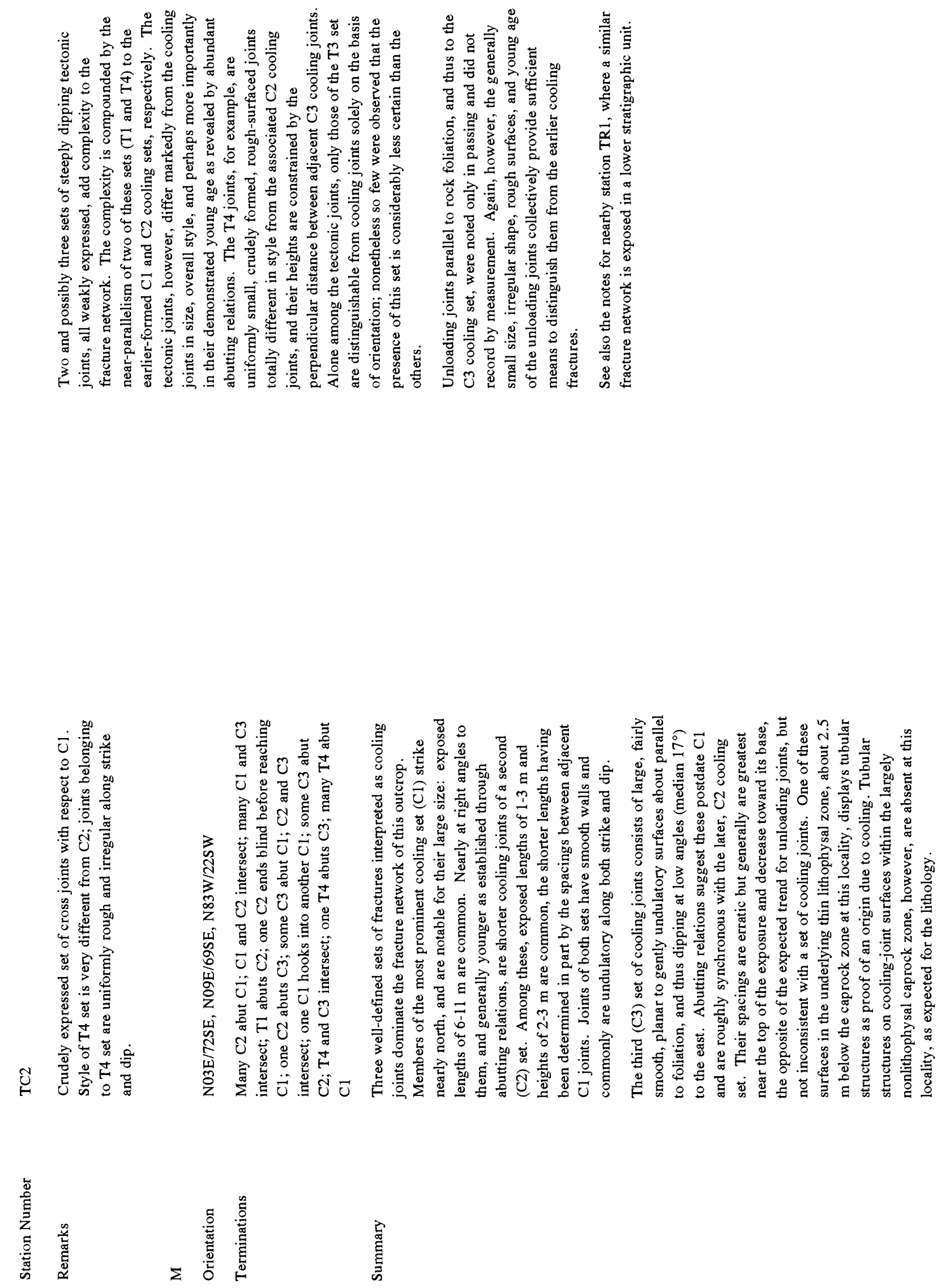

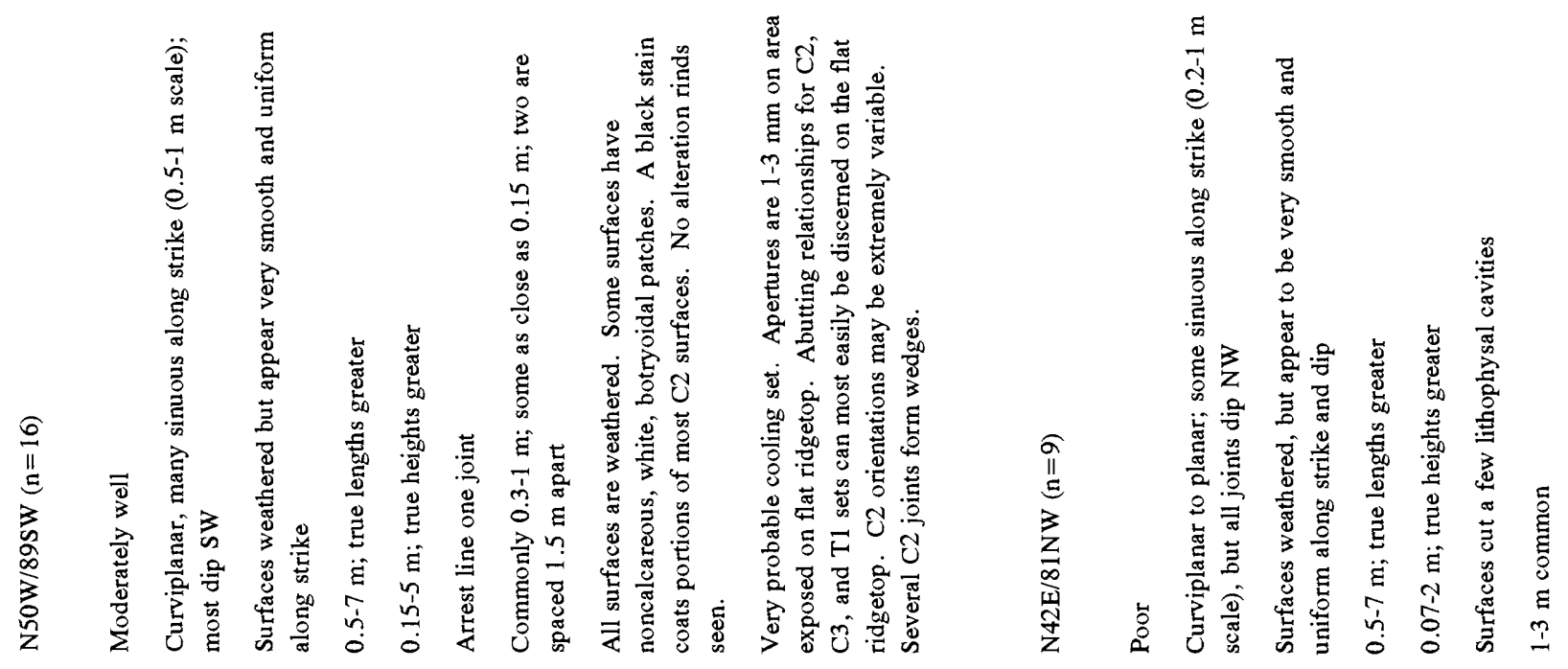

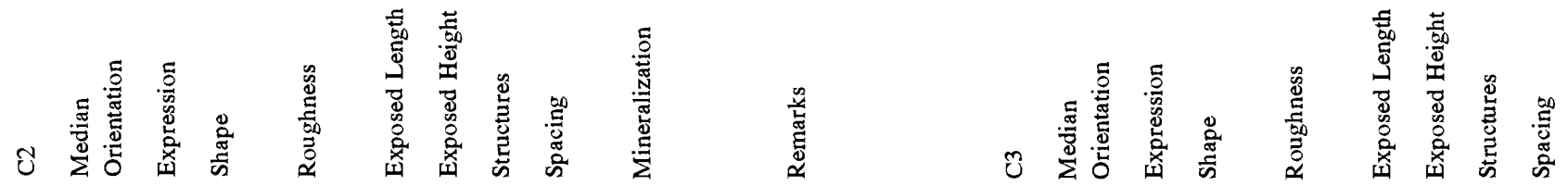

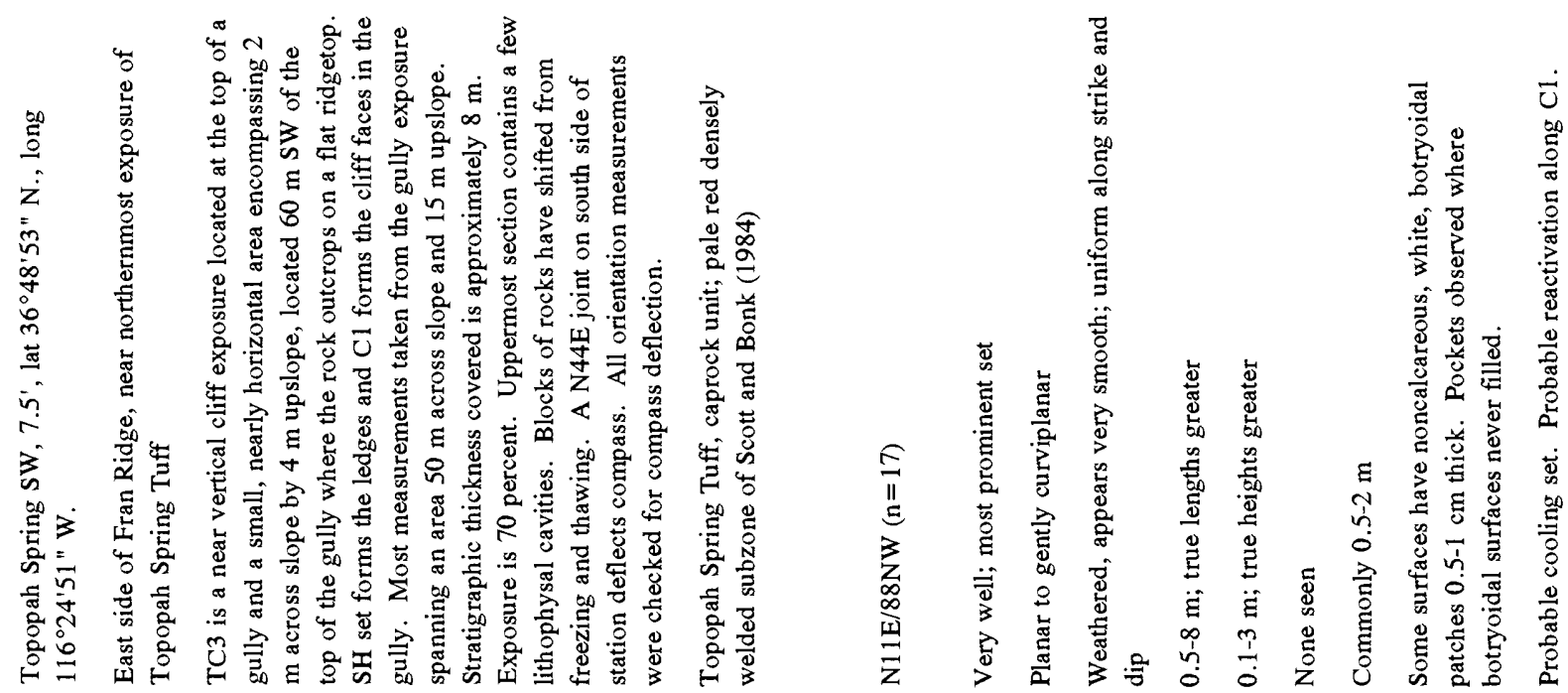

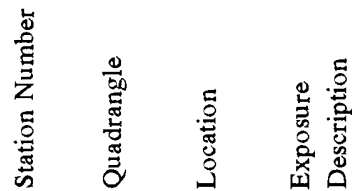

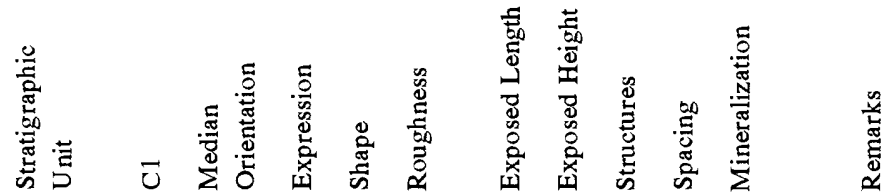




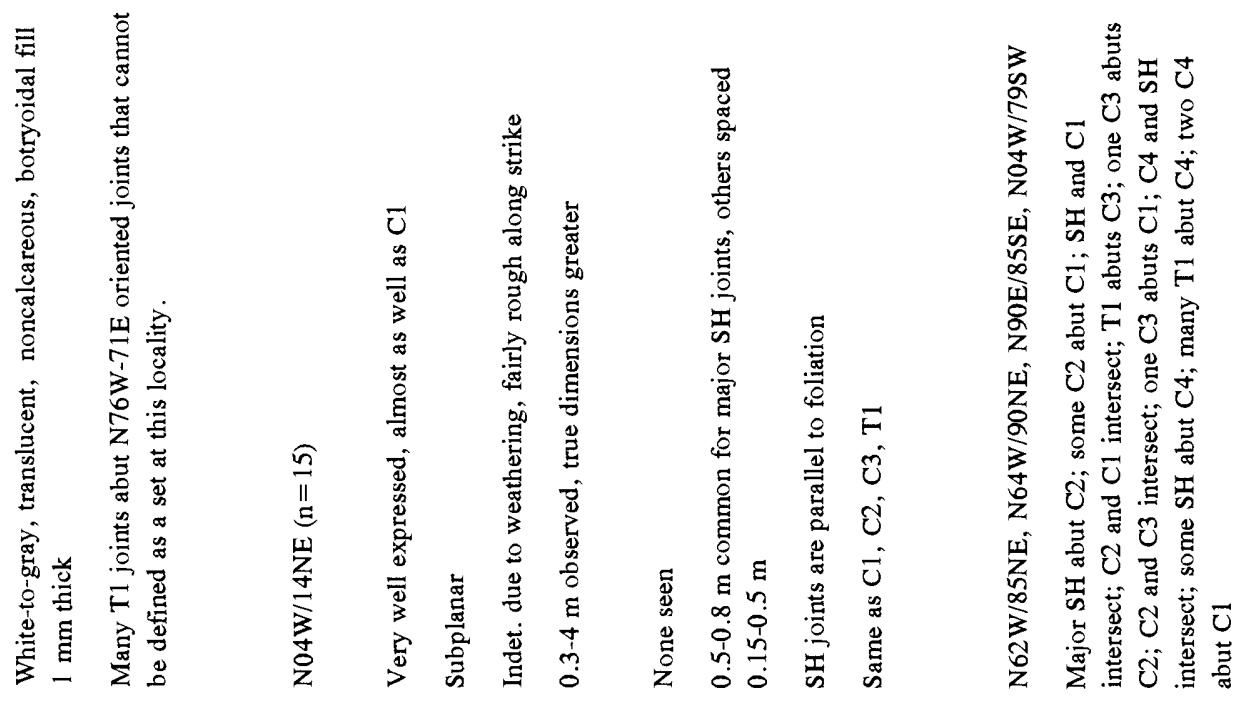

II:IHUH,II

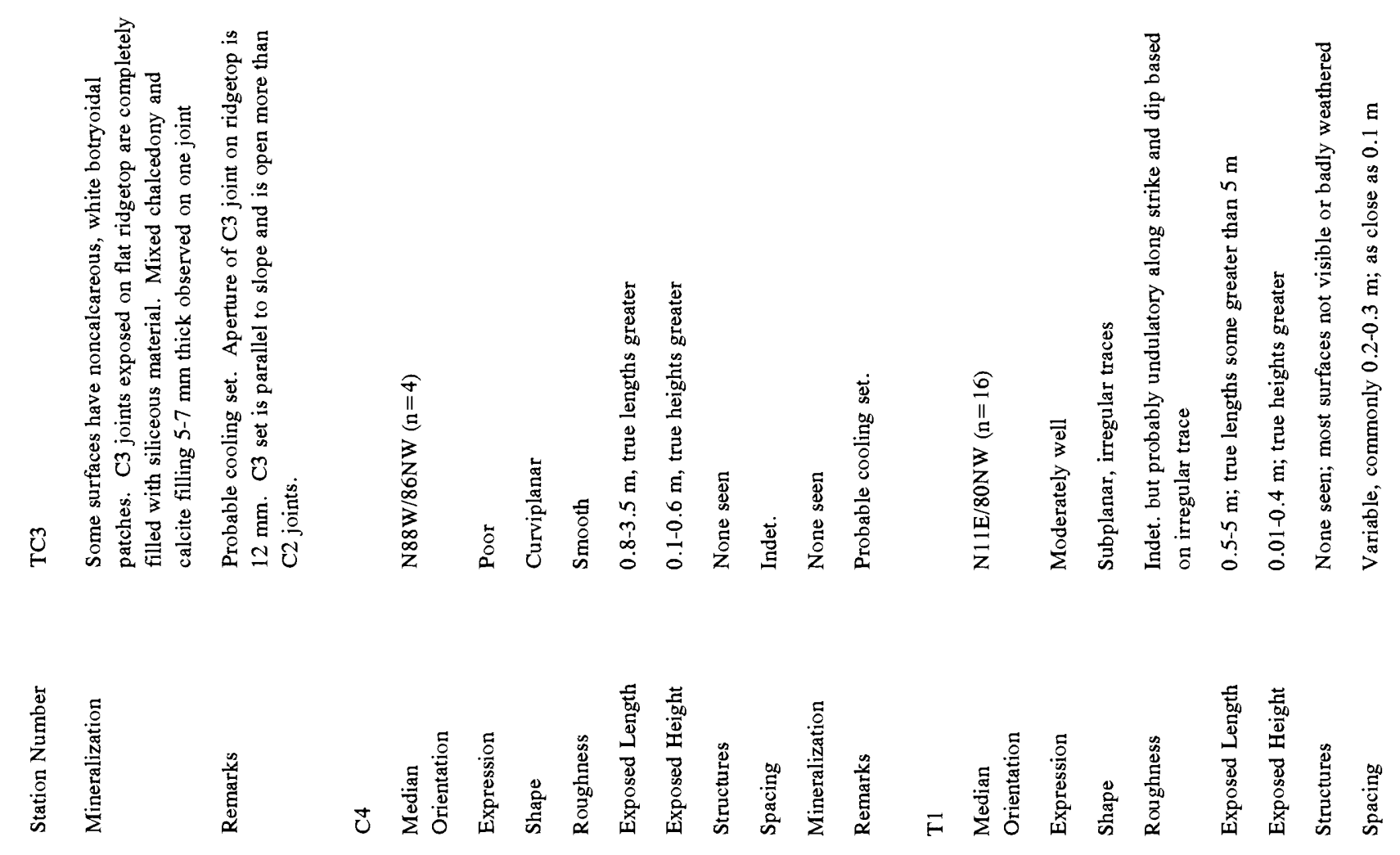



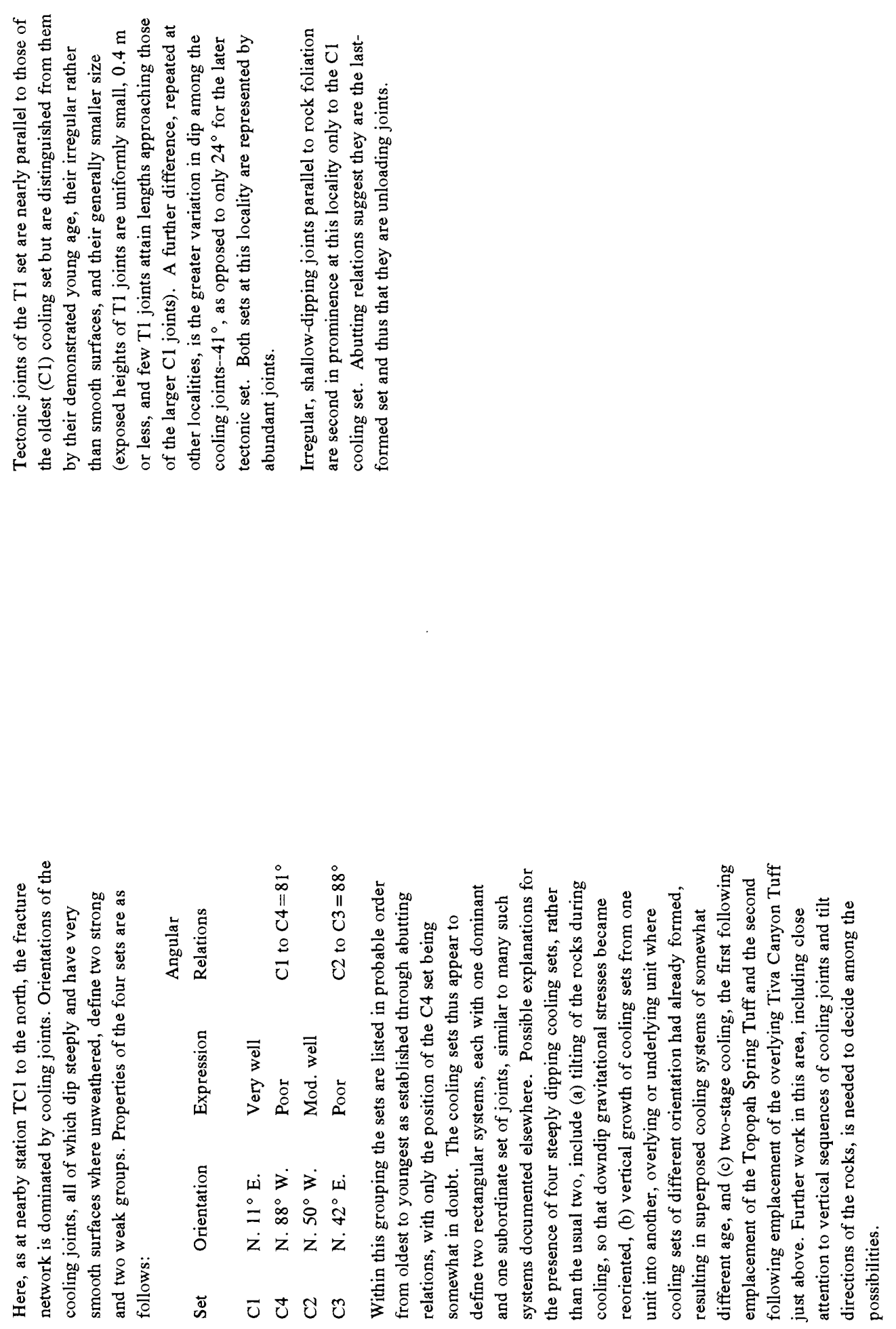


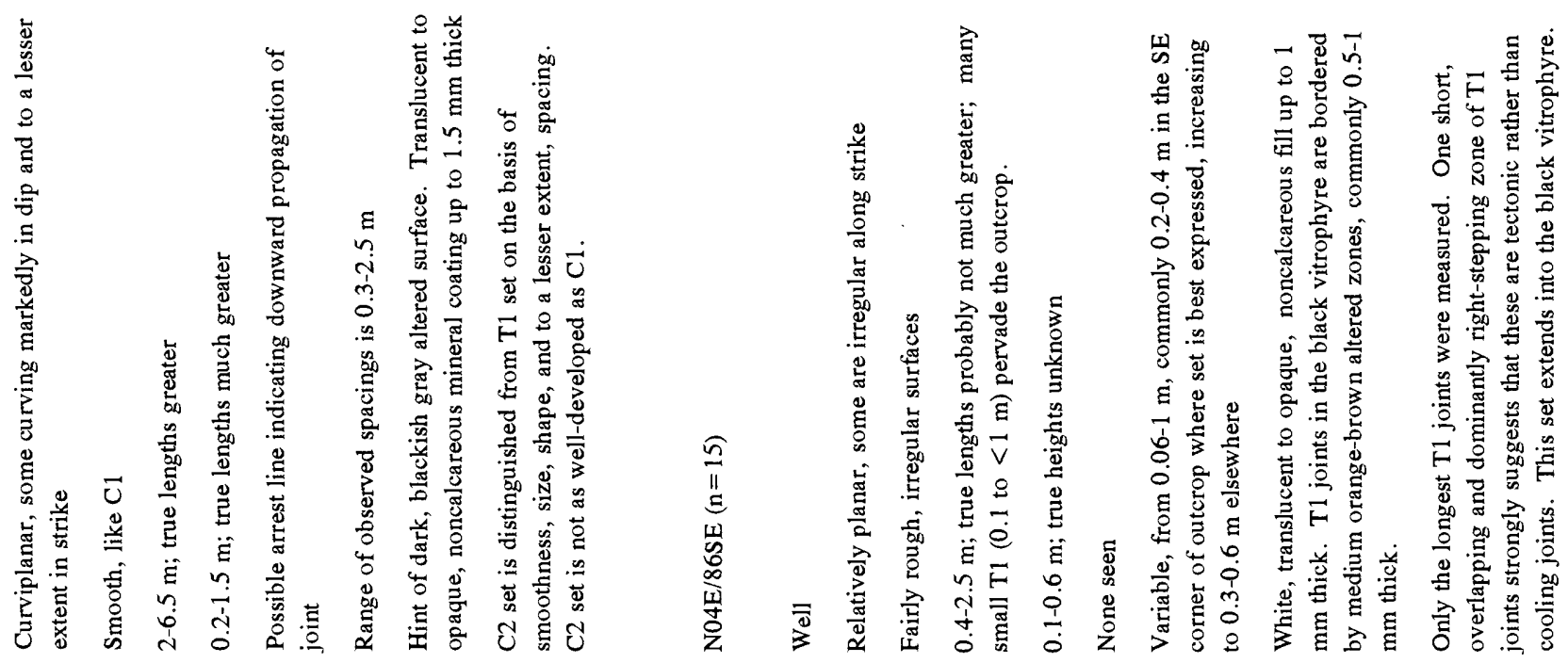

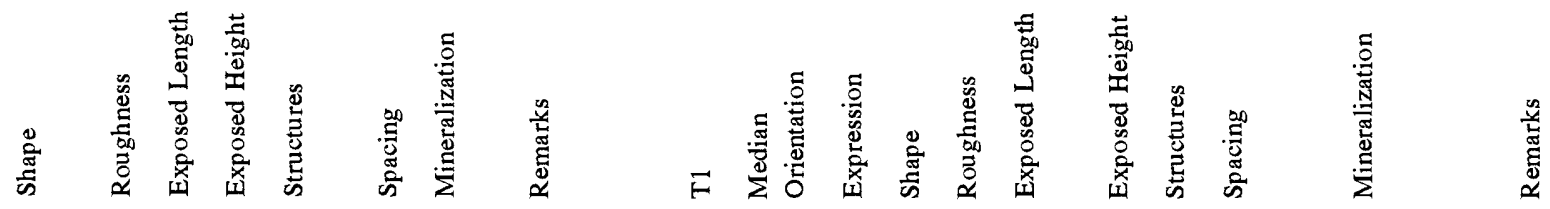

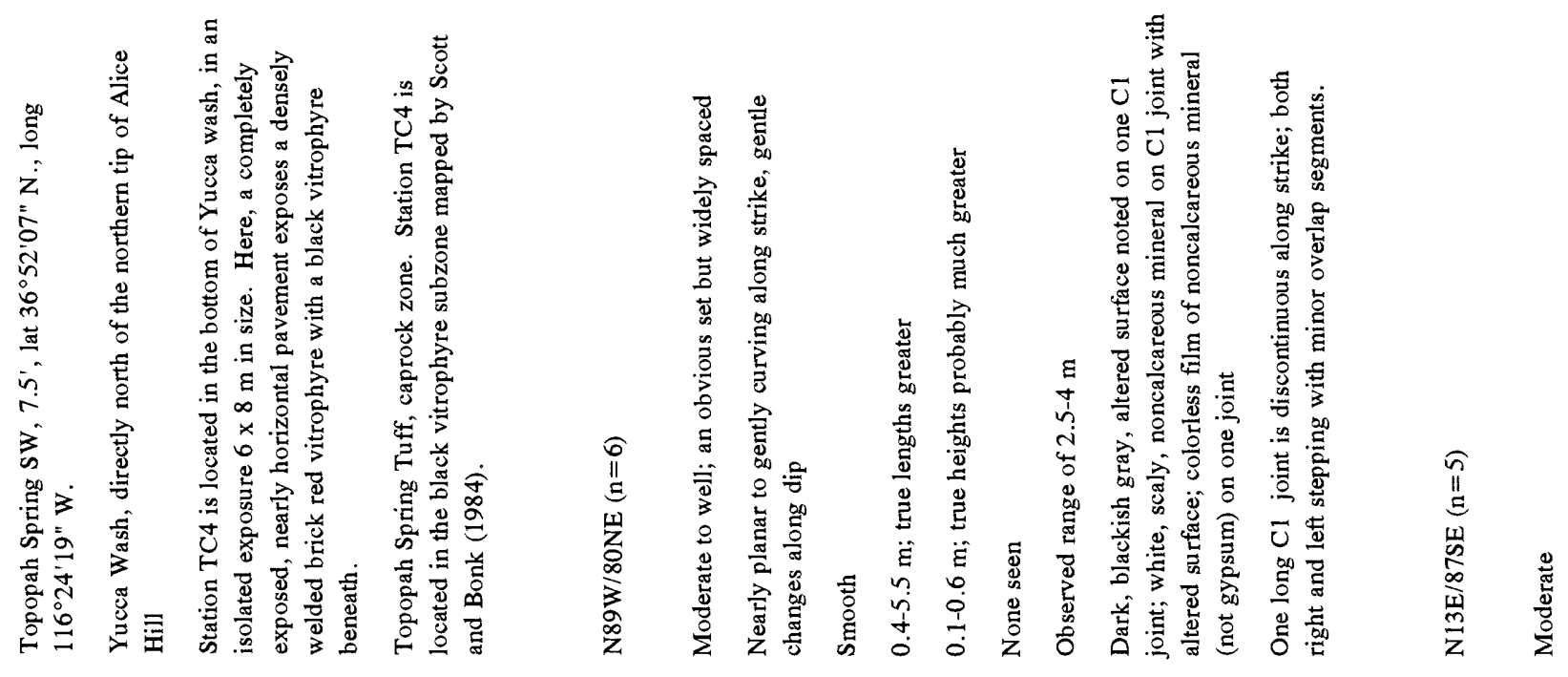

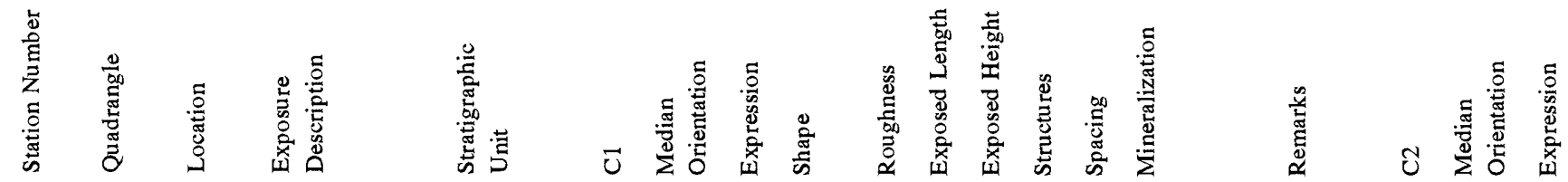




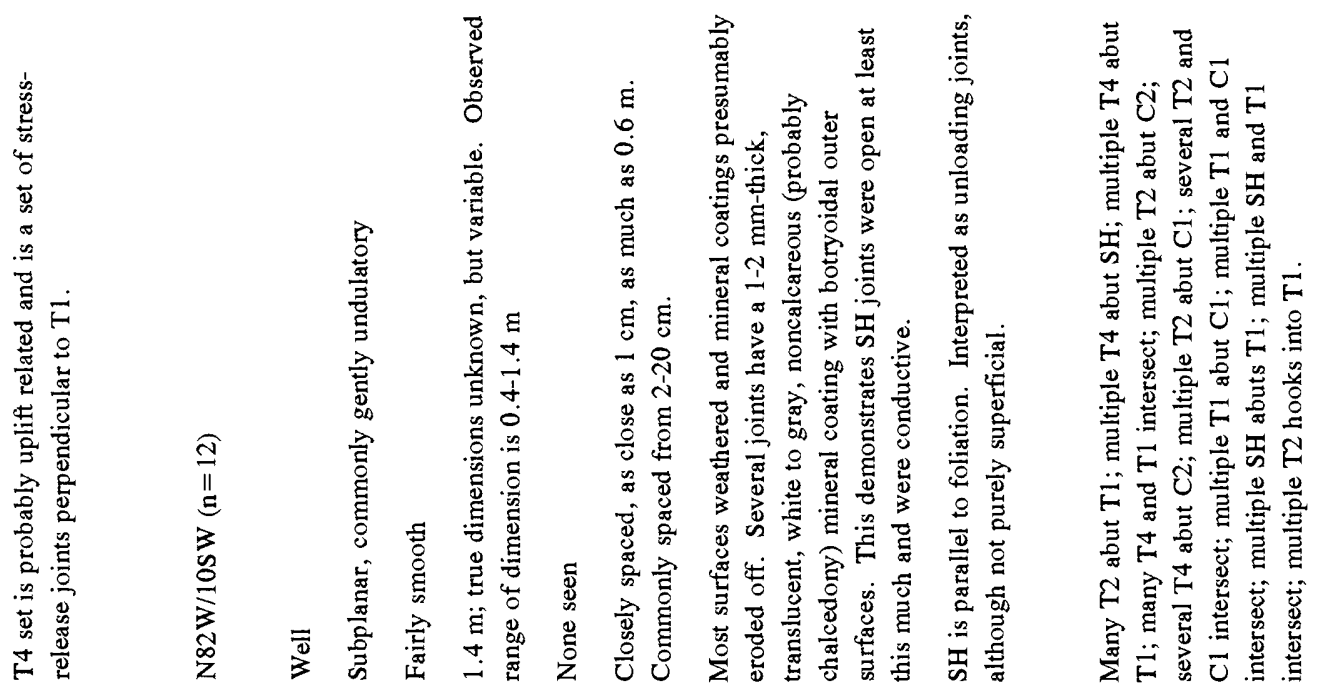

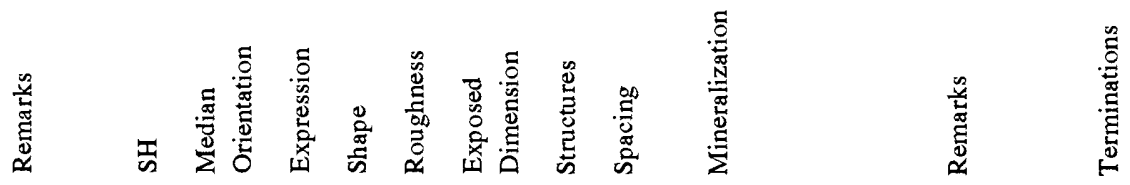

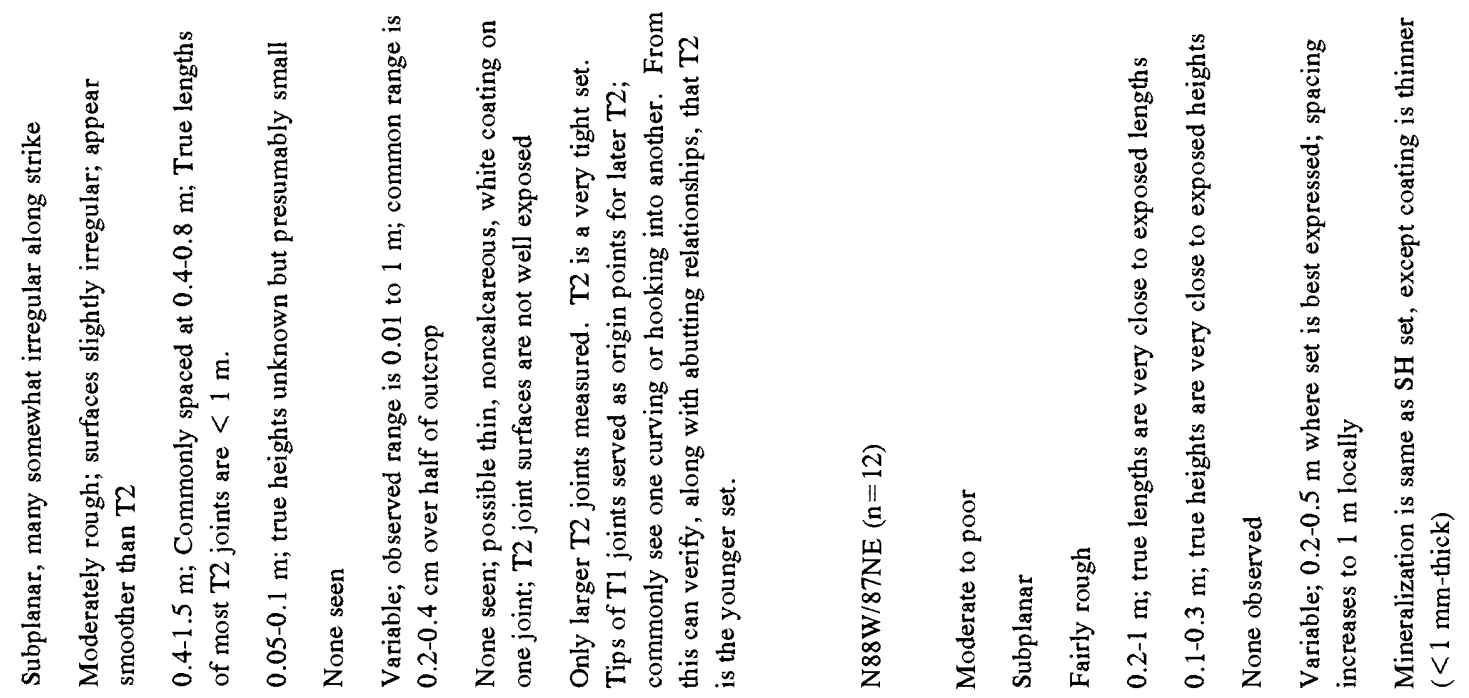

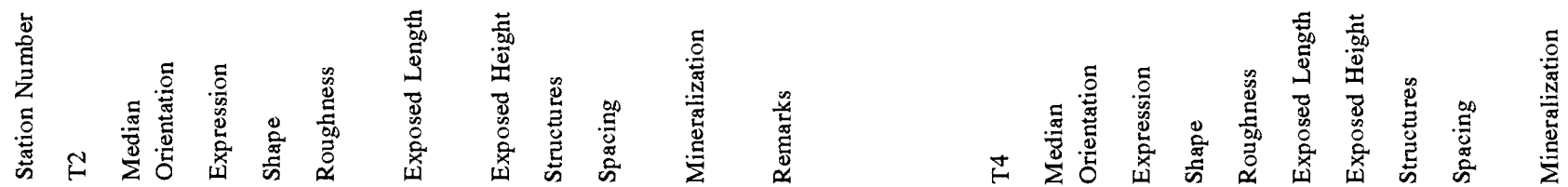



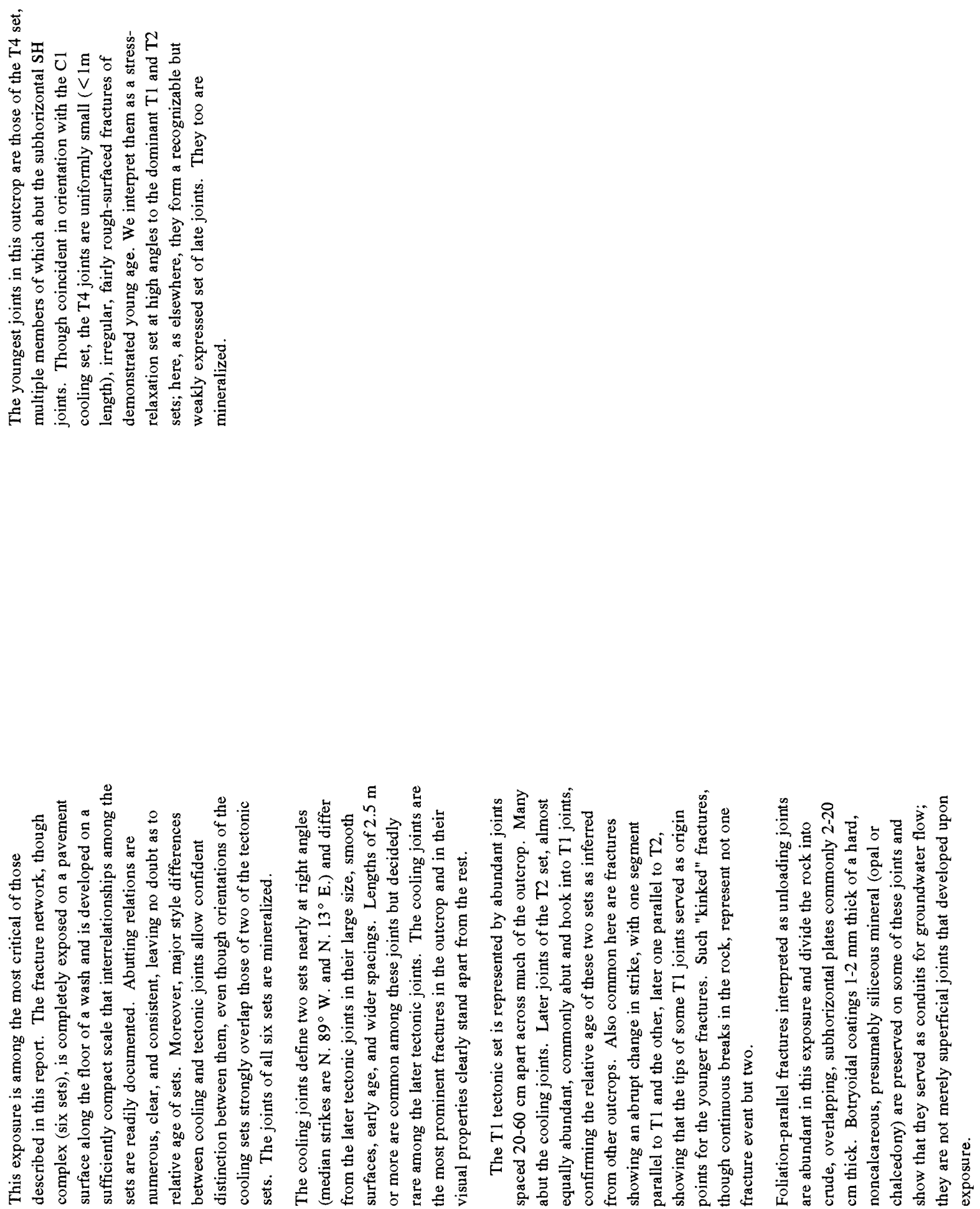


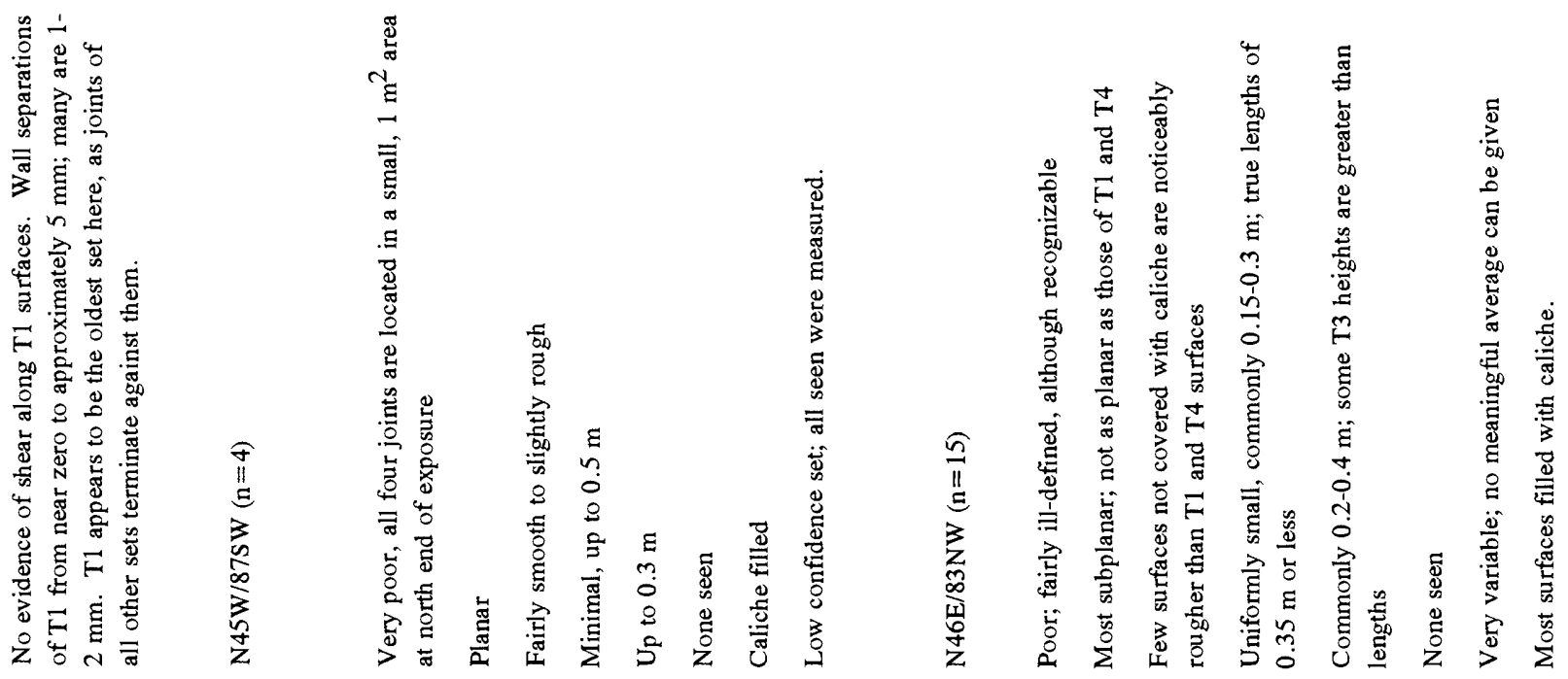

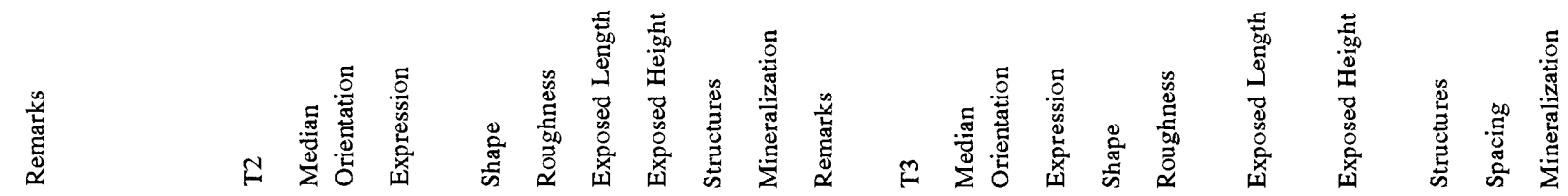

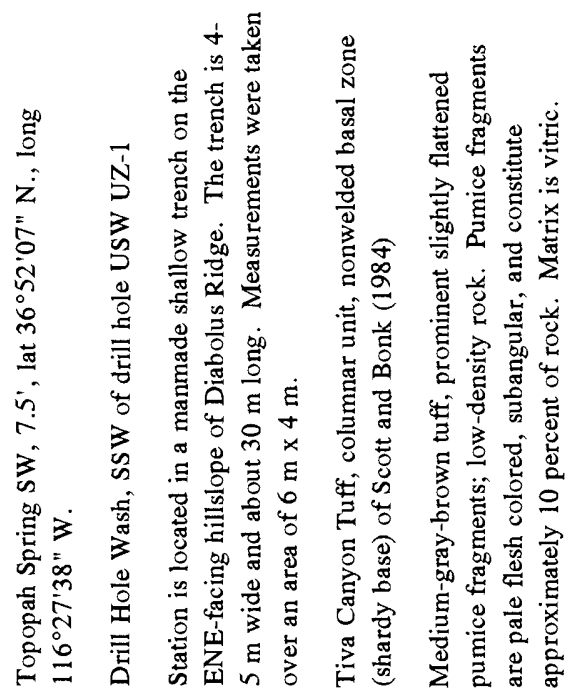

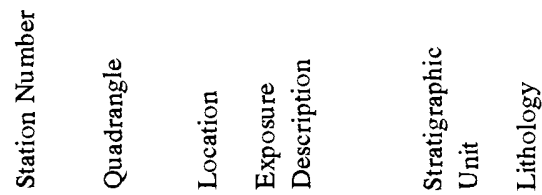

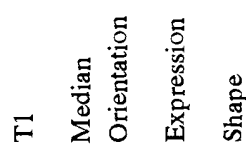

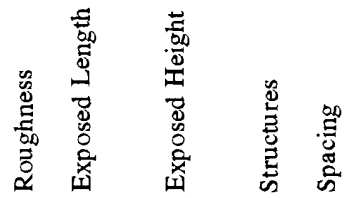

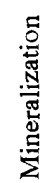




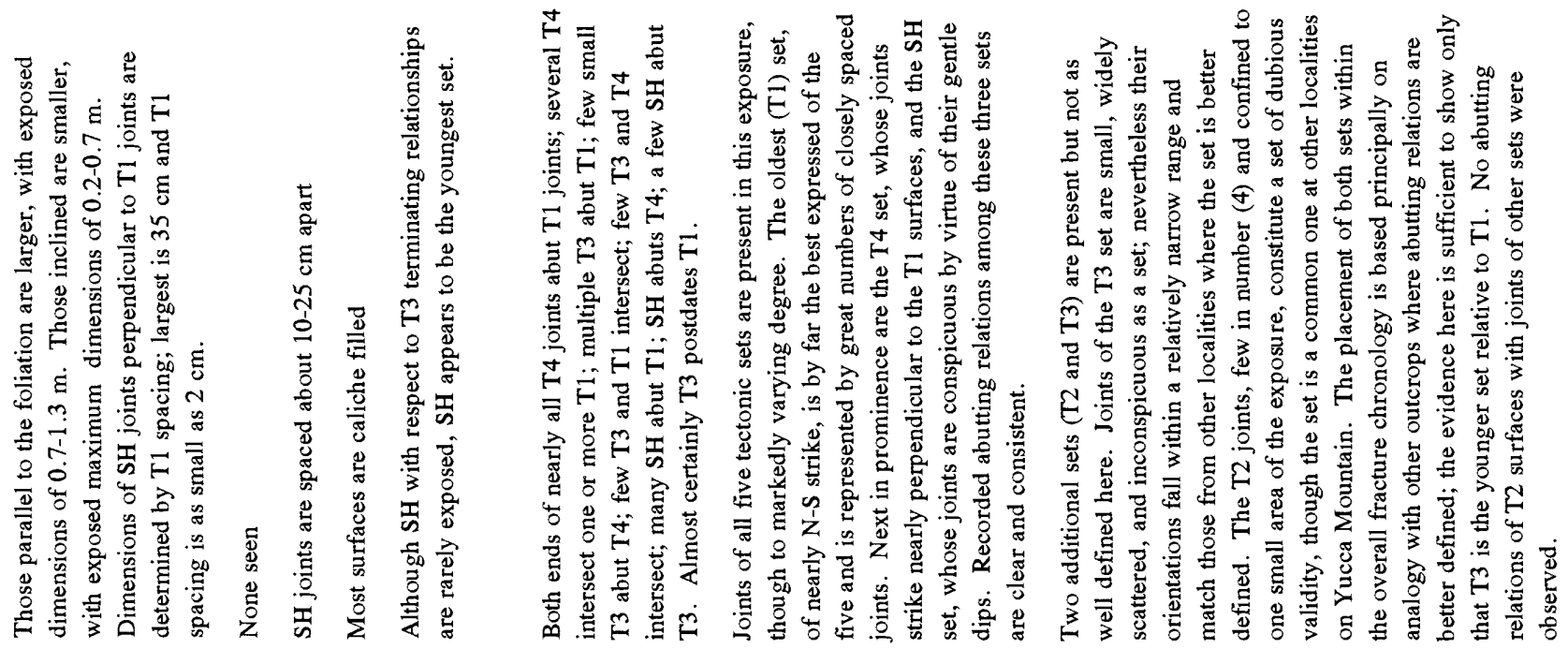

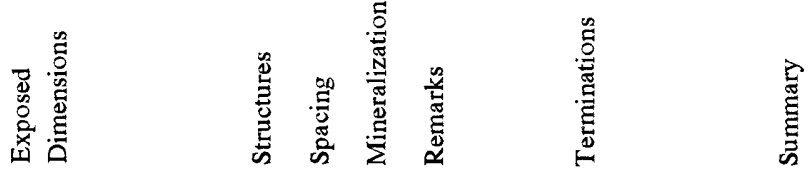

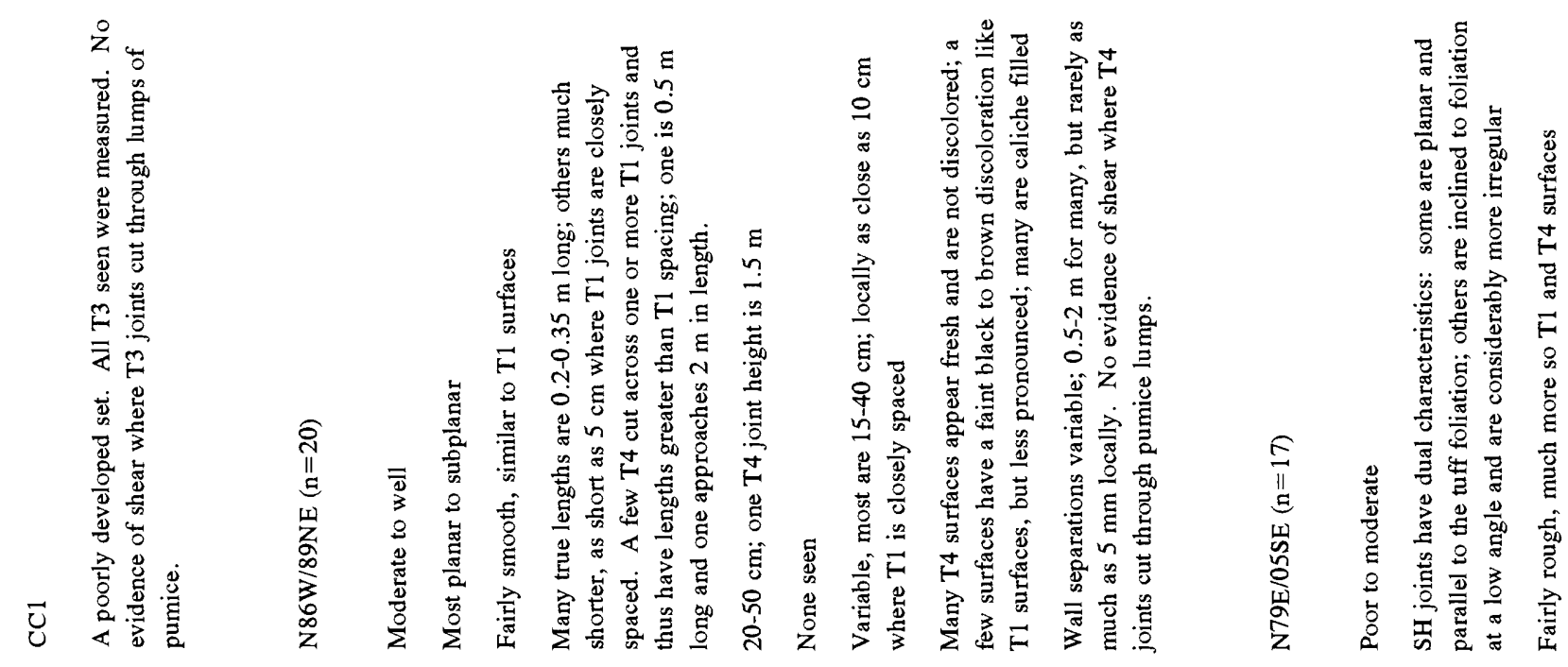

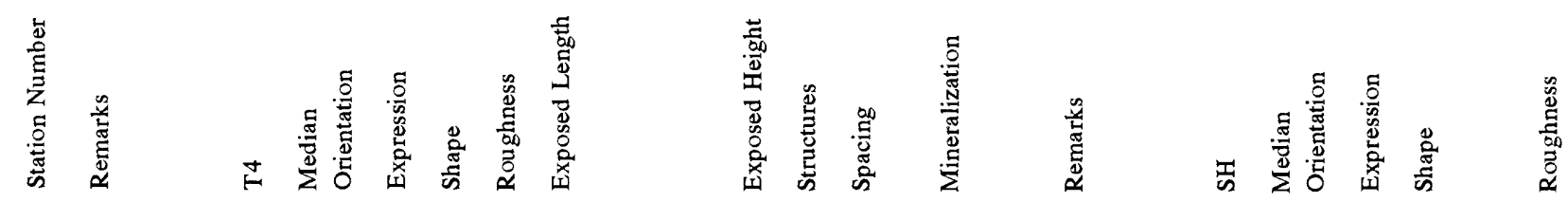



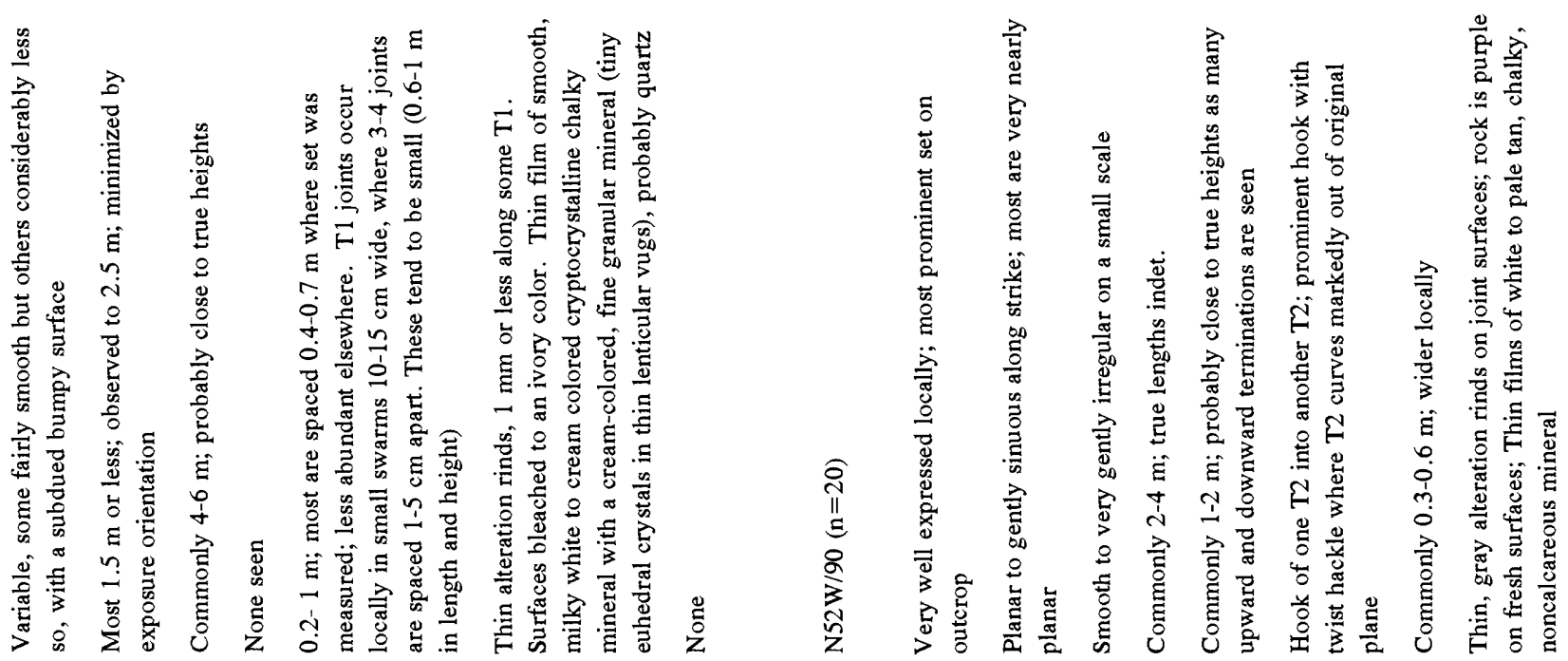

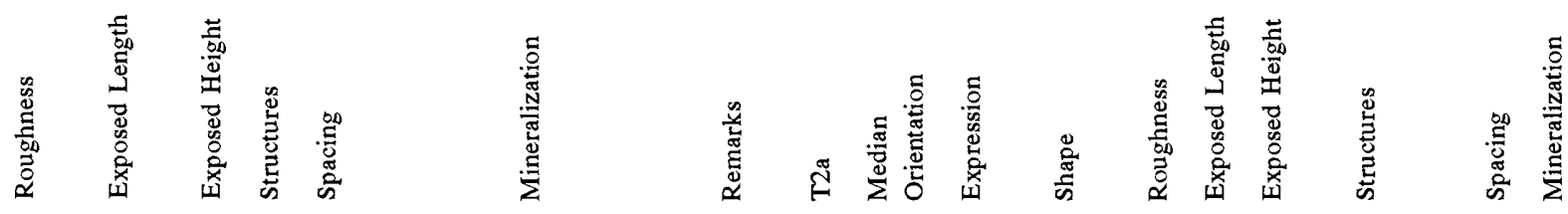

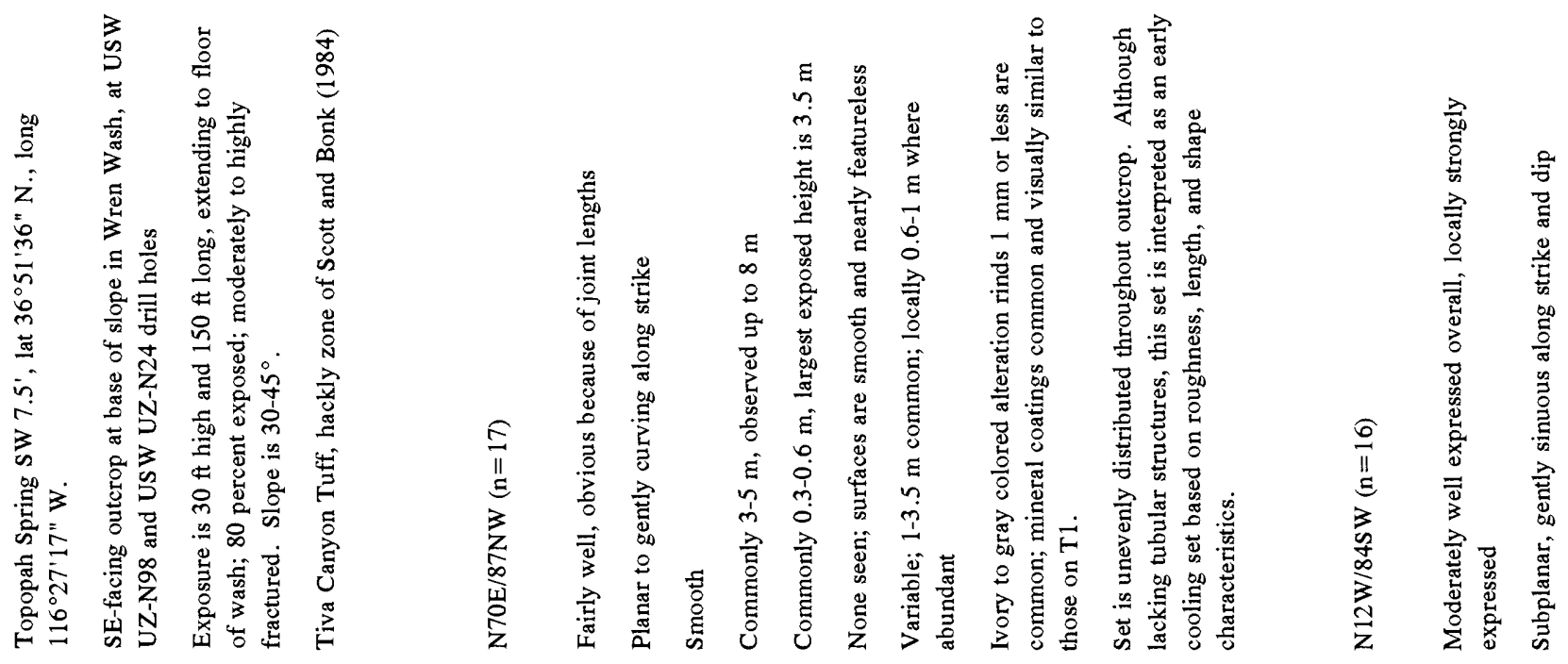

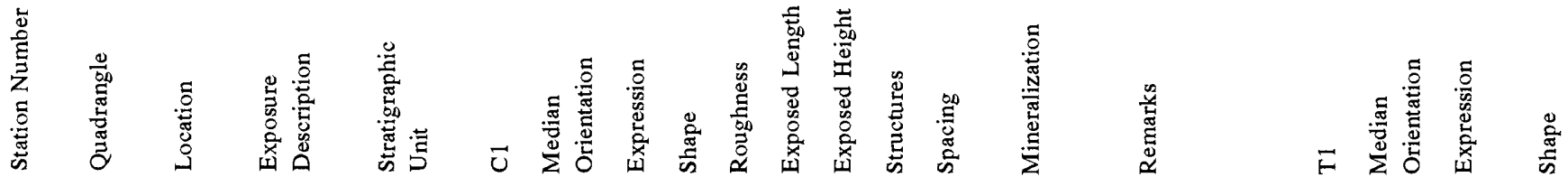




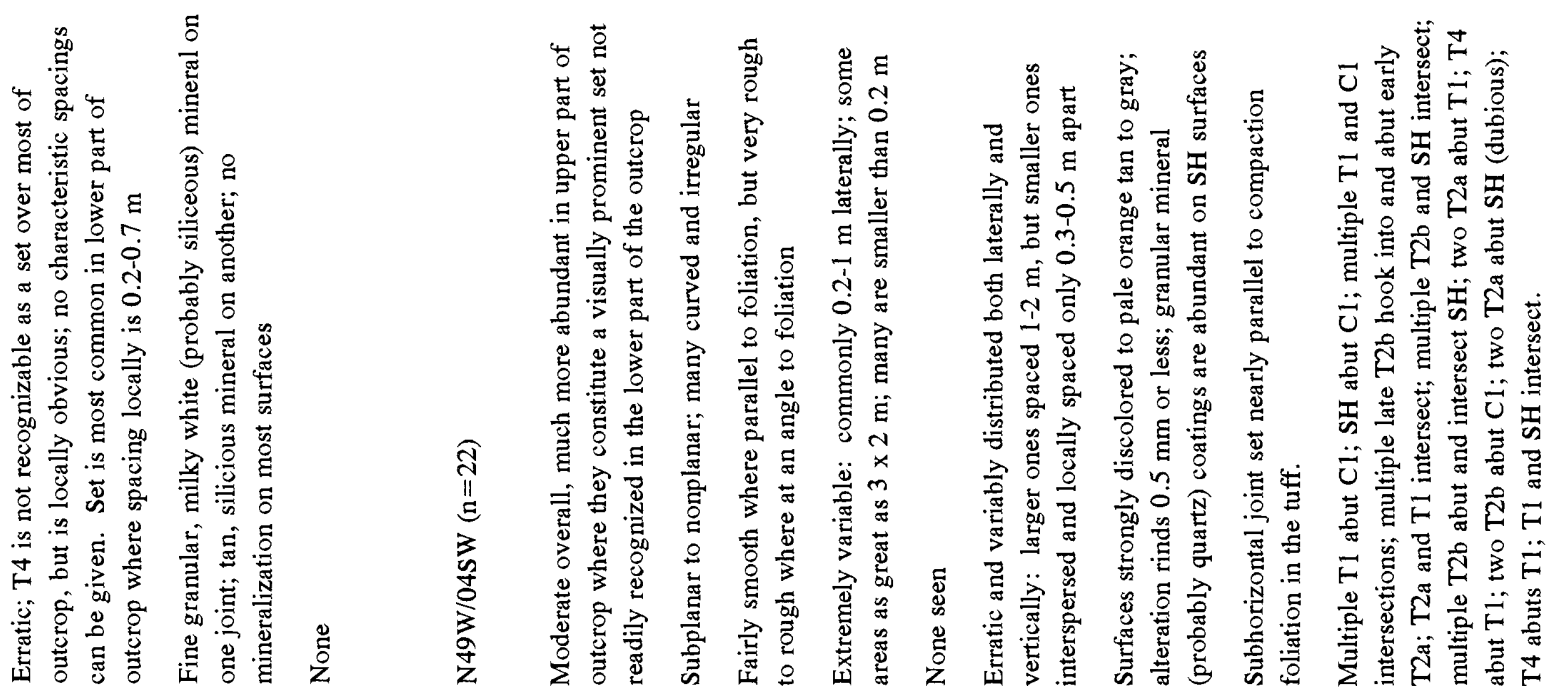

$1|\Pi\|n\| n| 1 \mid$

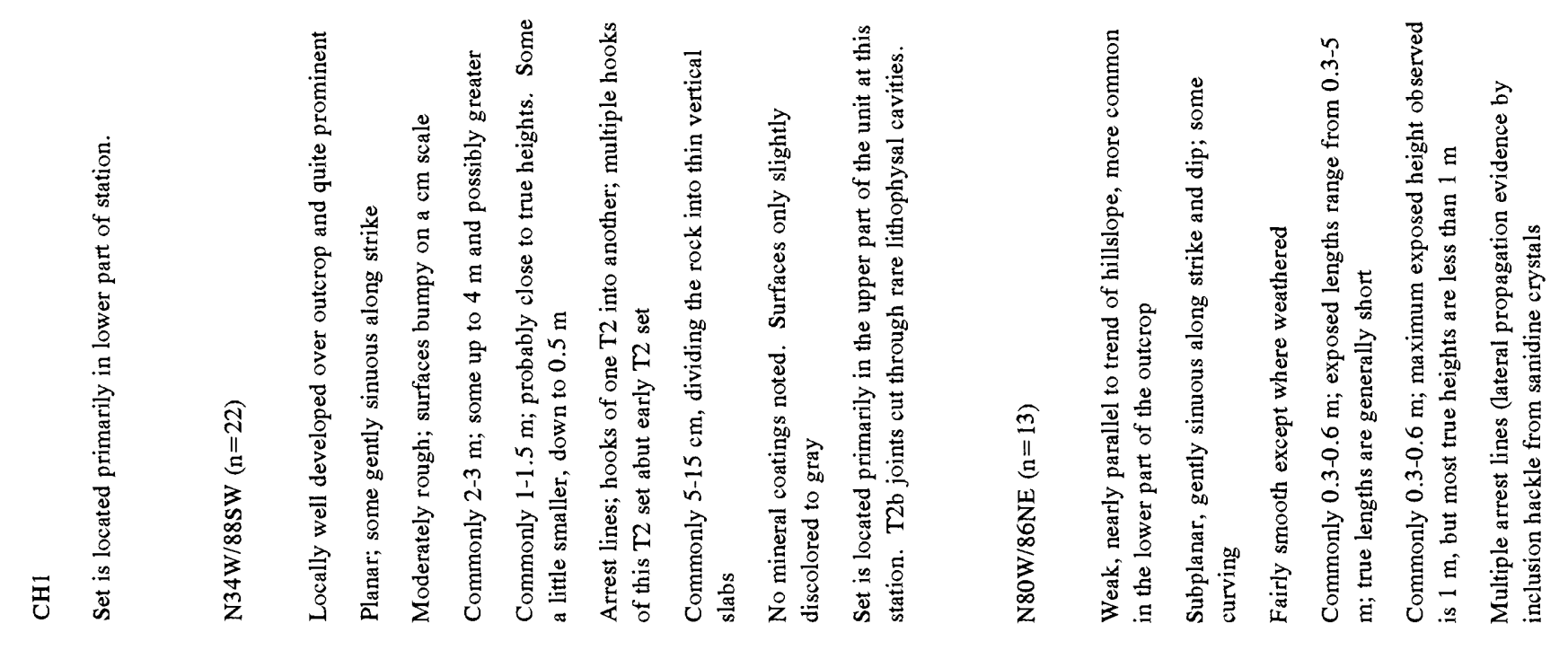

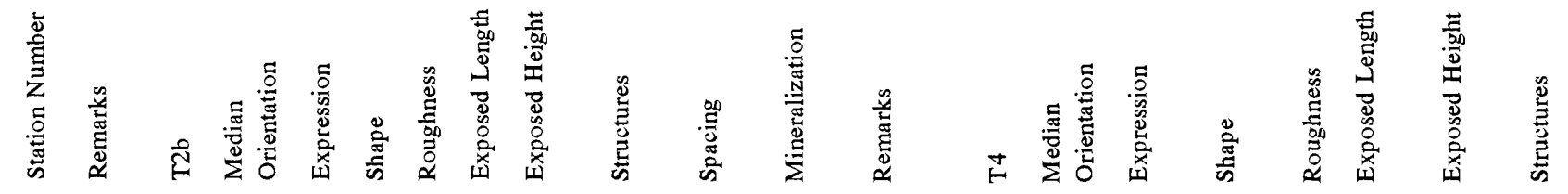



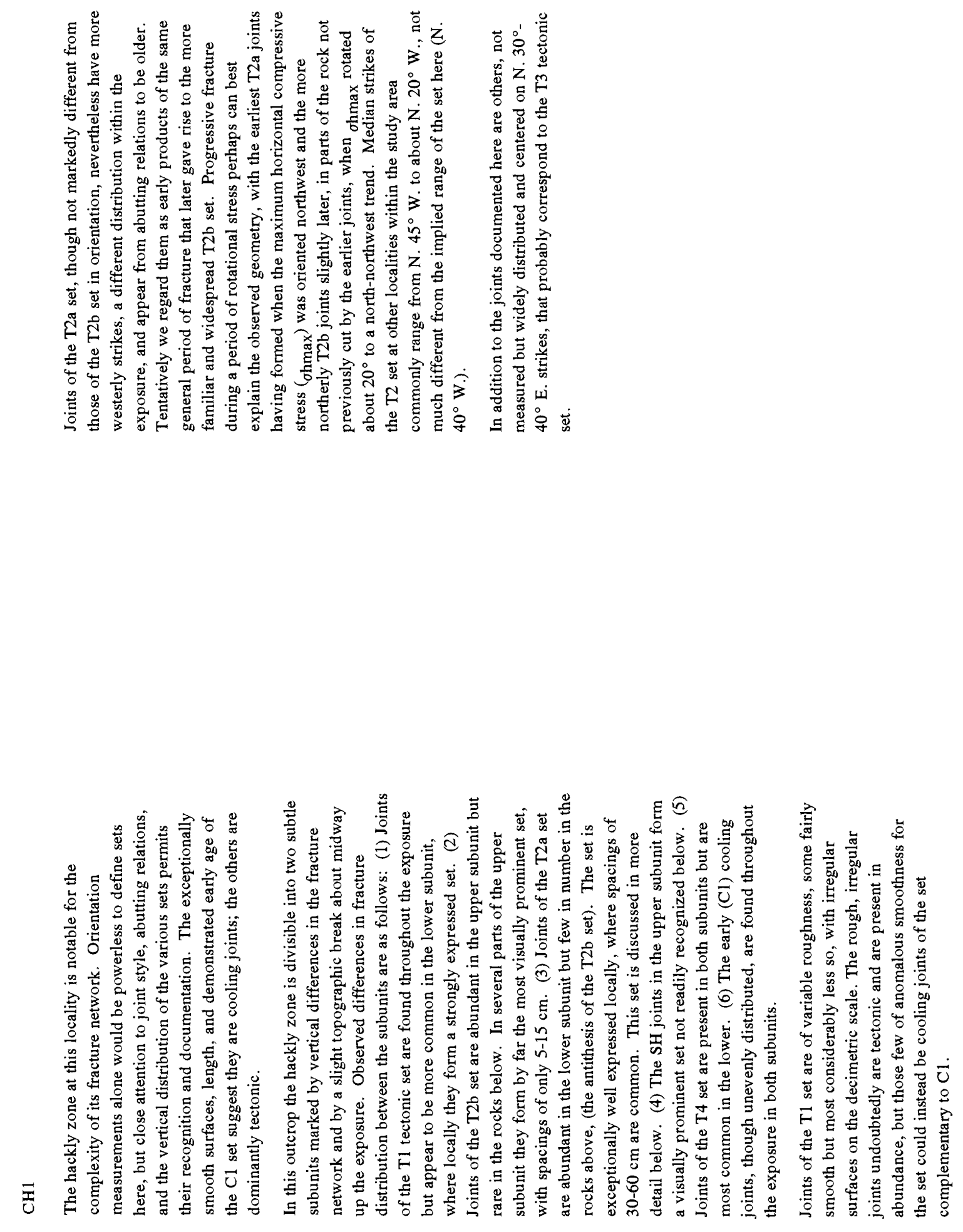

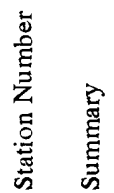




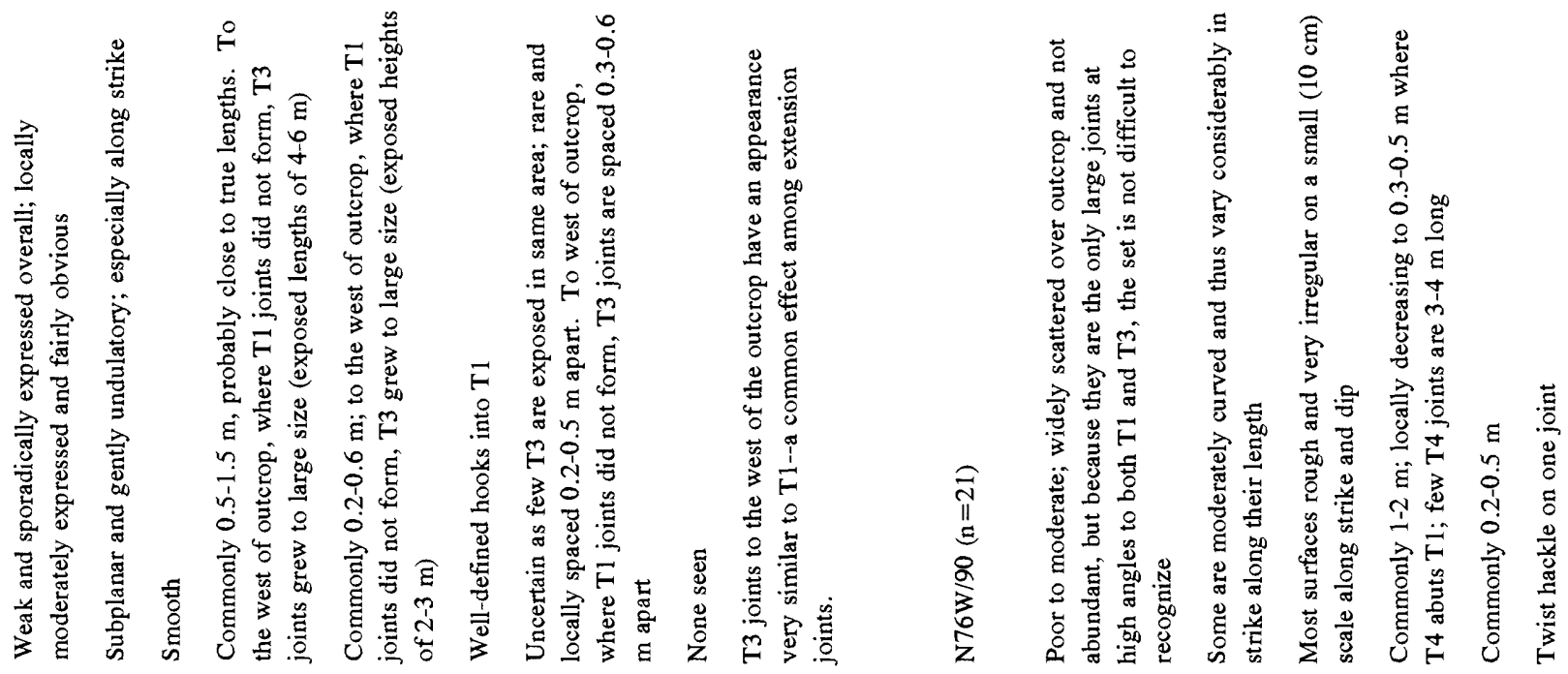

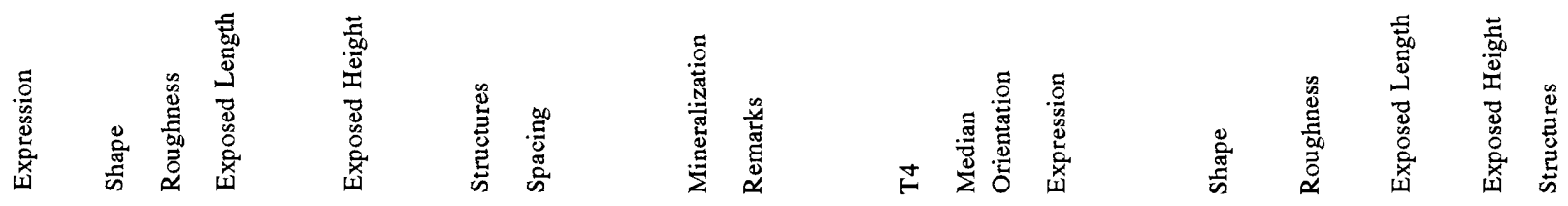

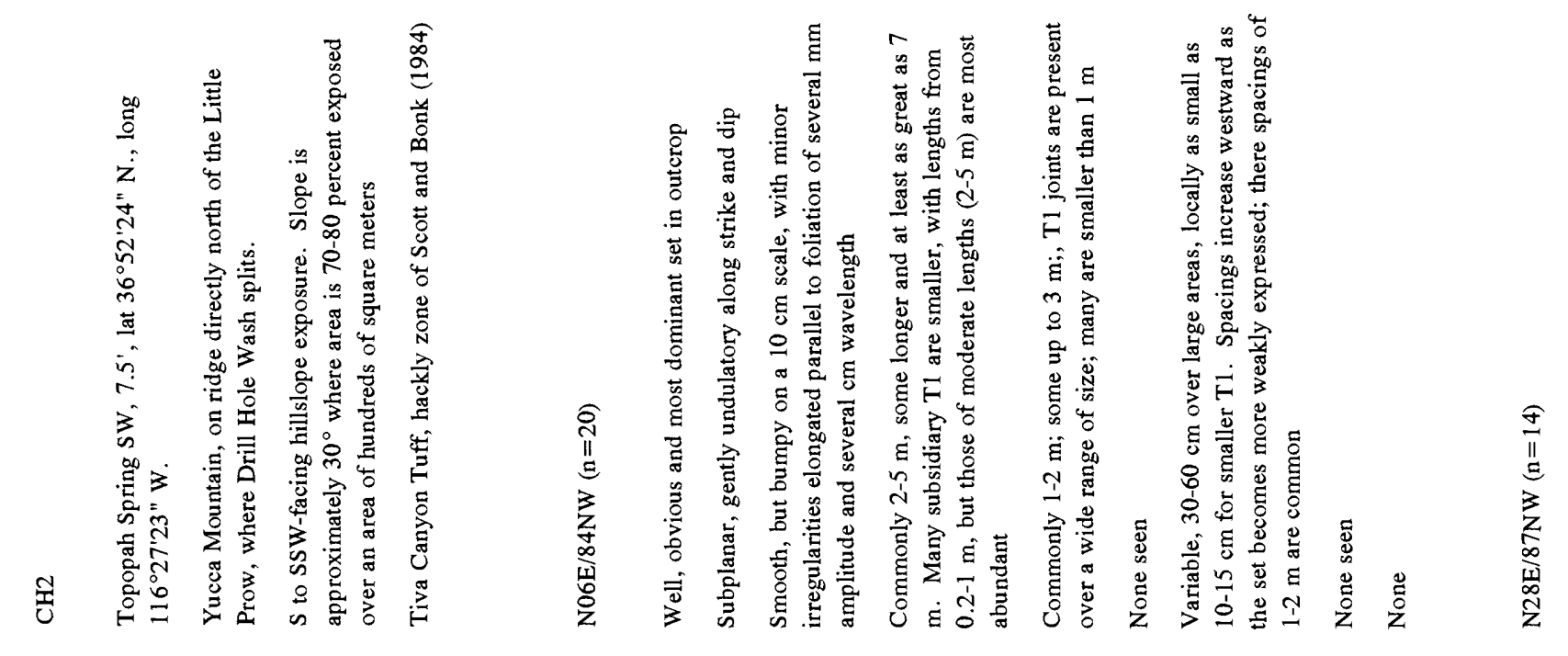

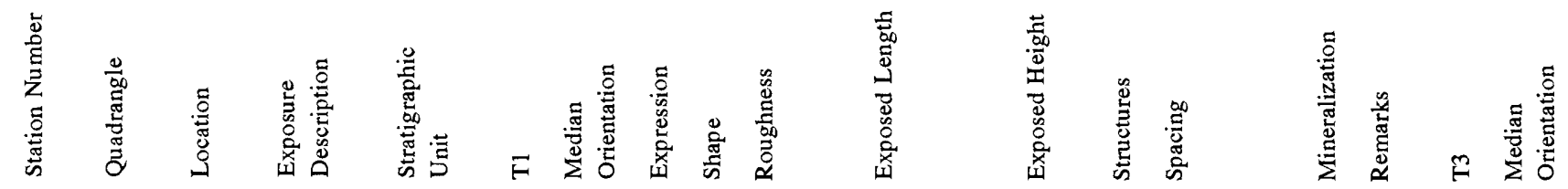




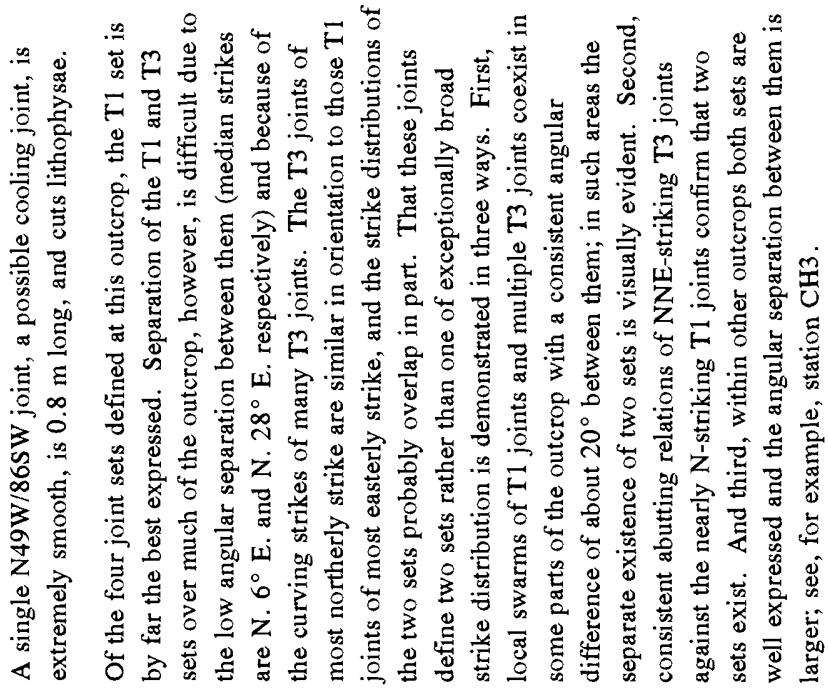

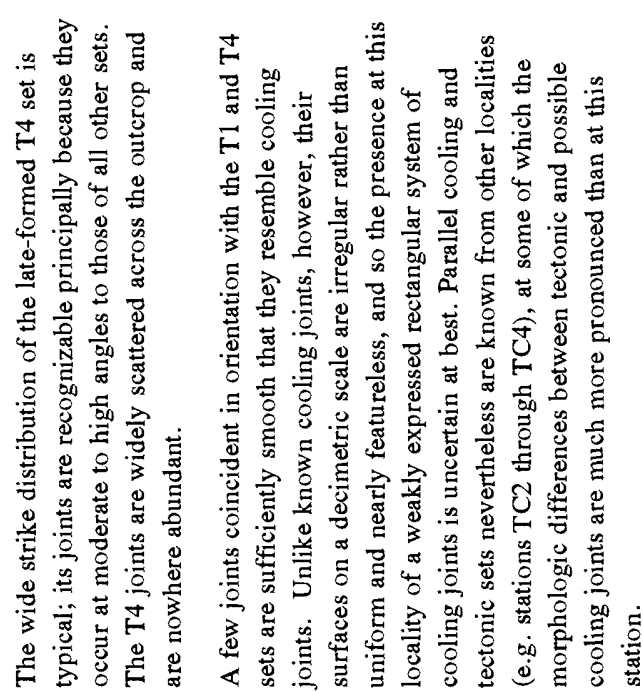

हี

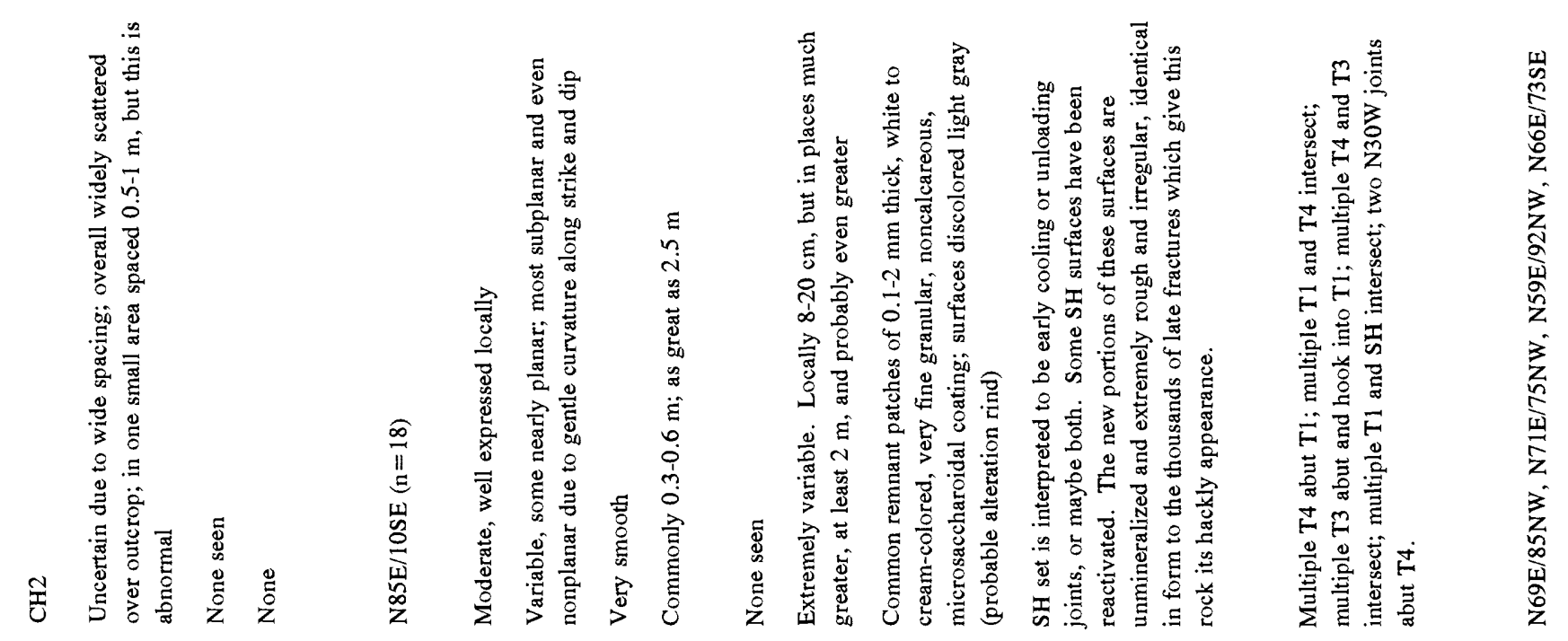

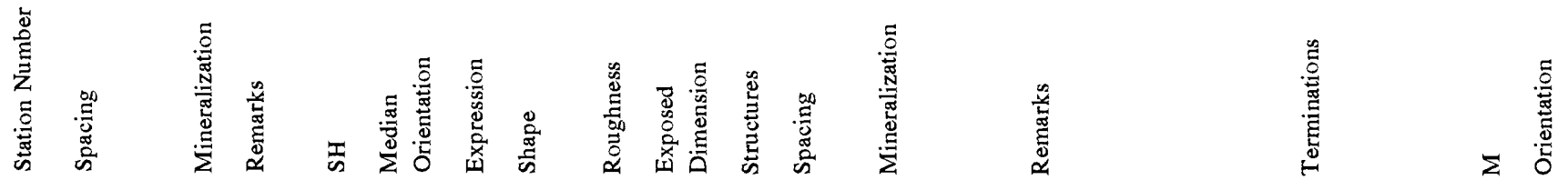




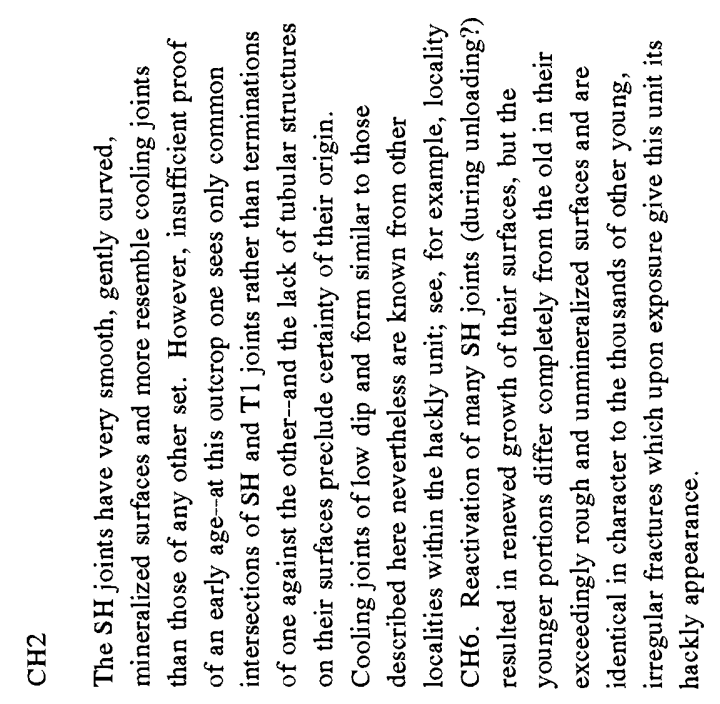




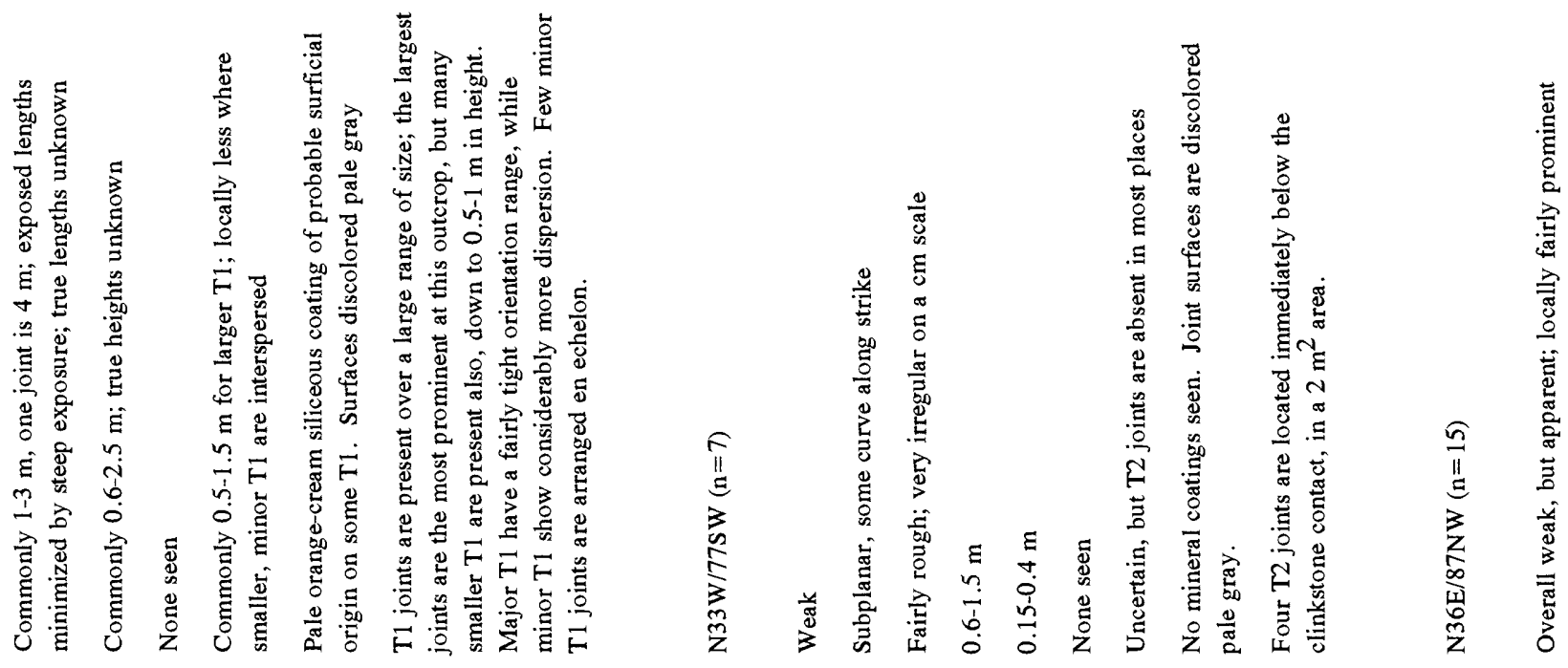

IIII

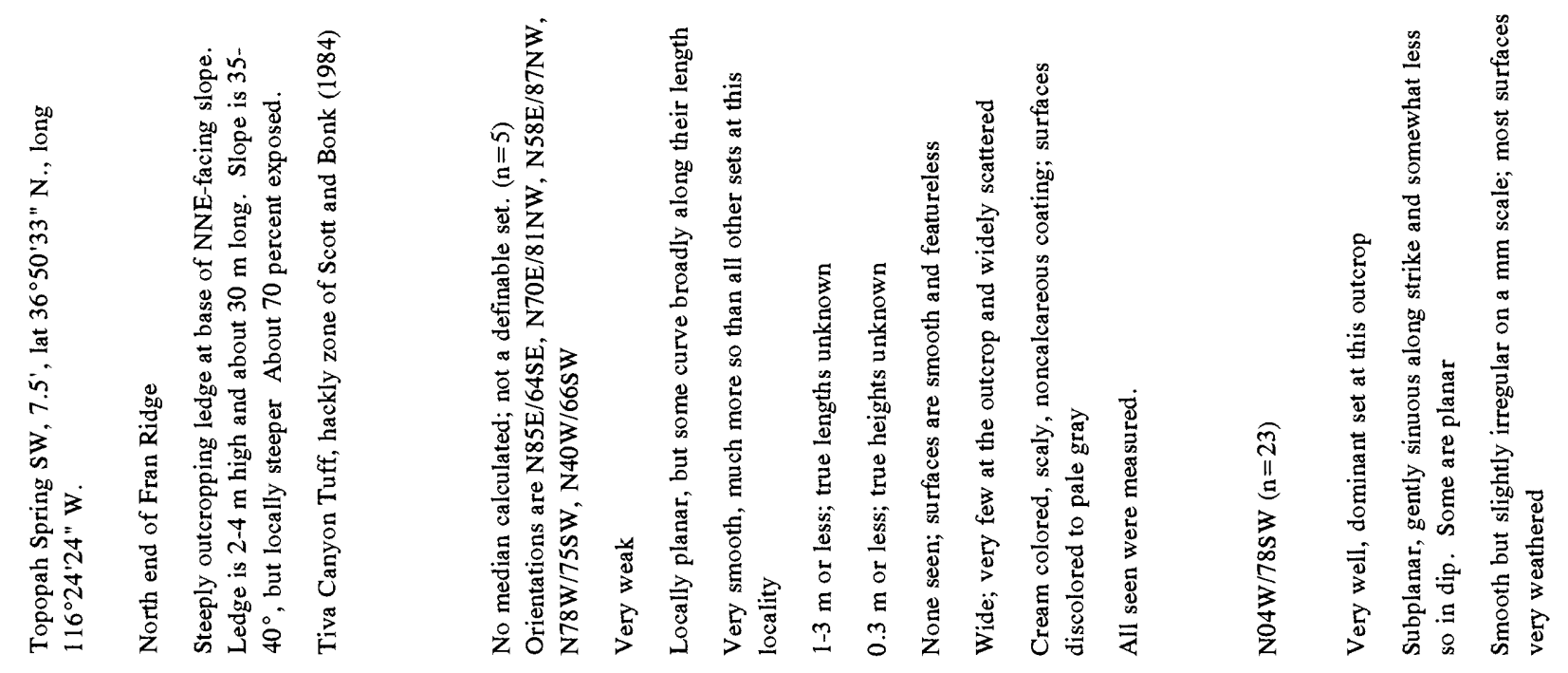

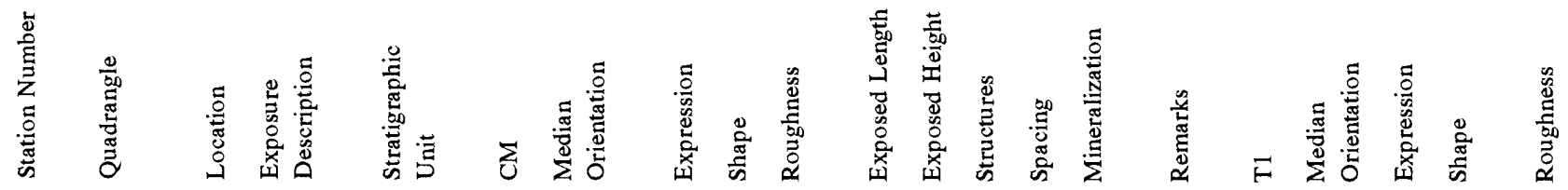




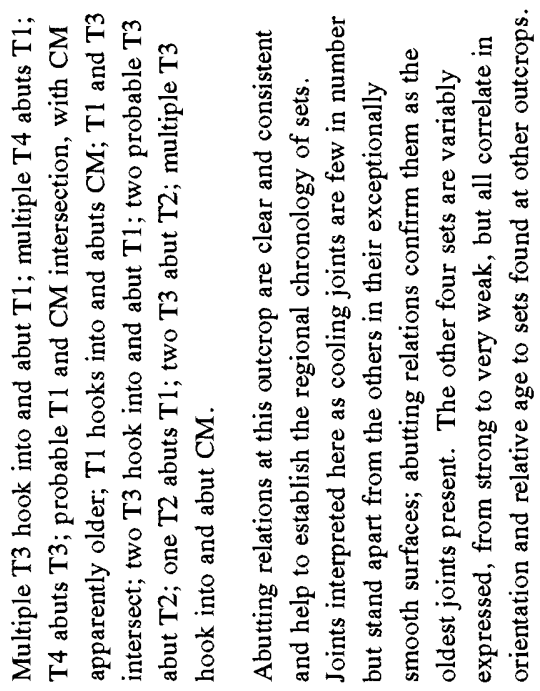

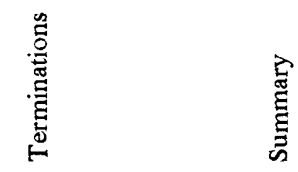

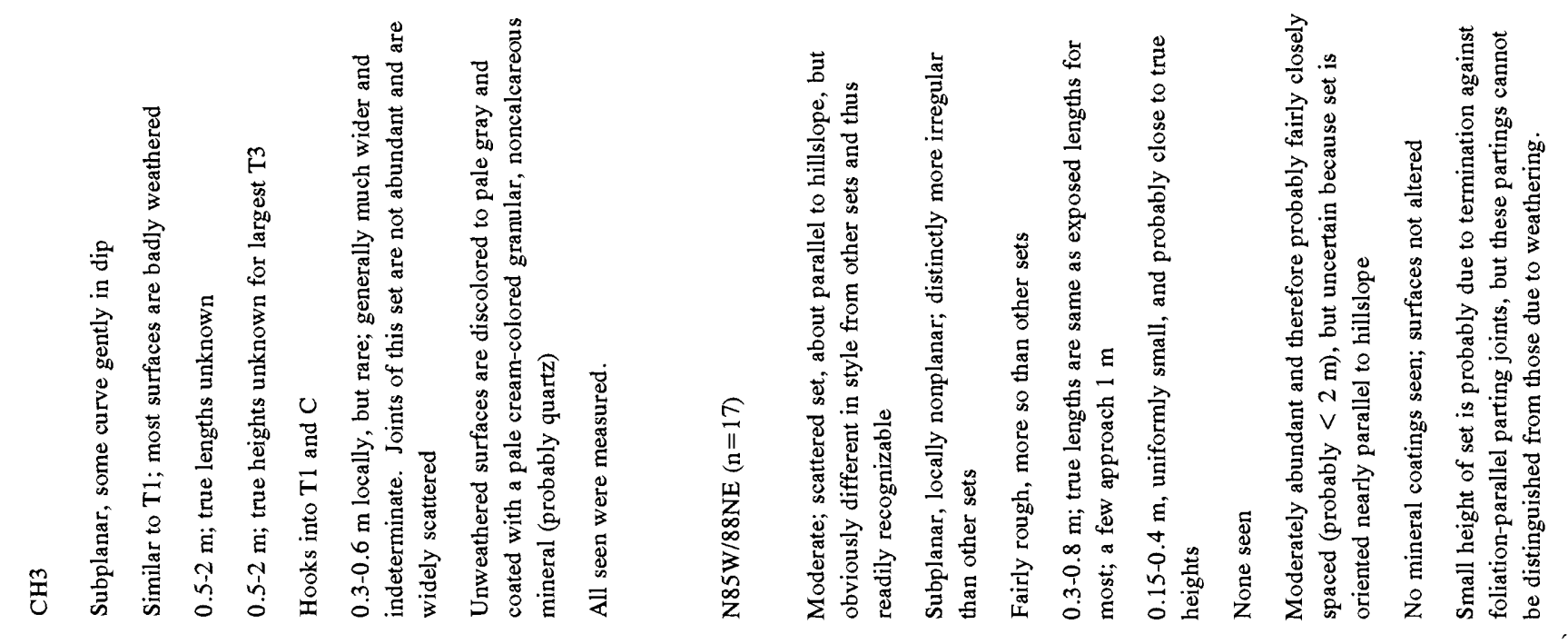

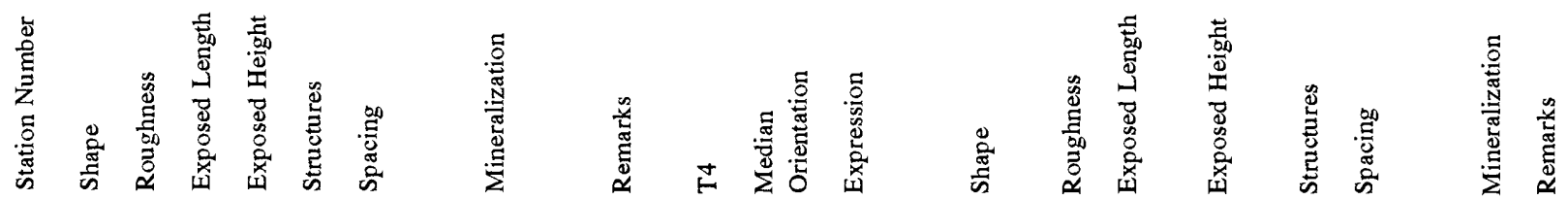




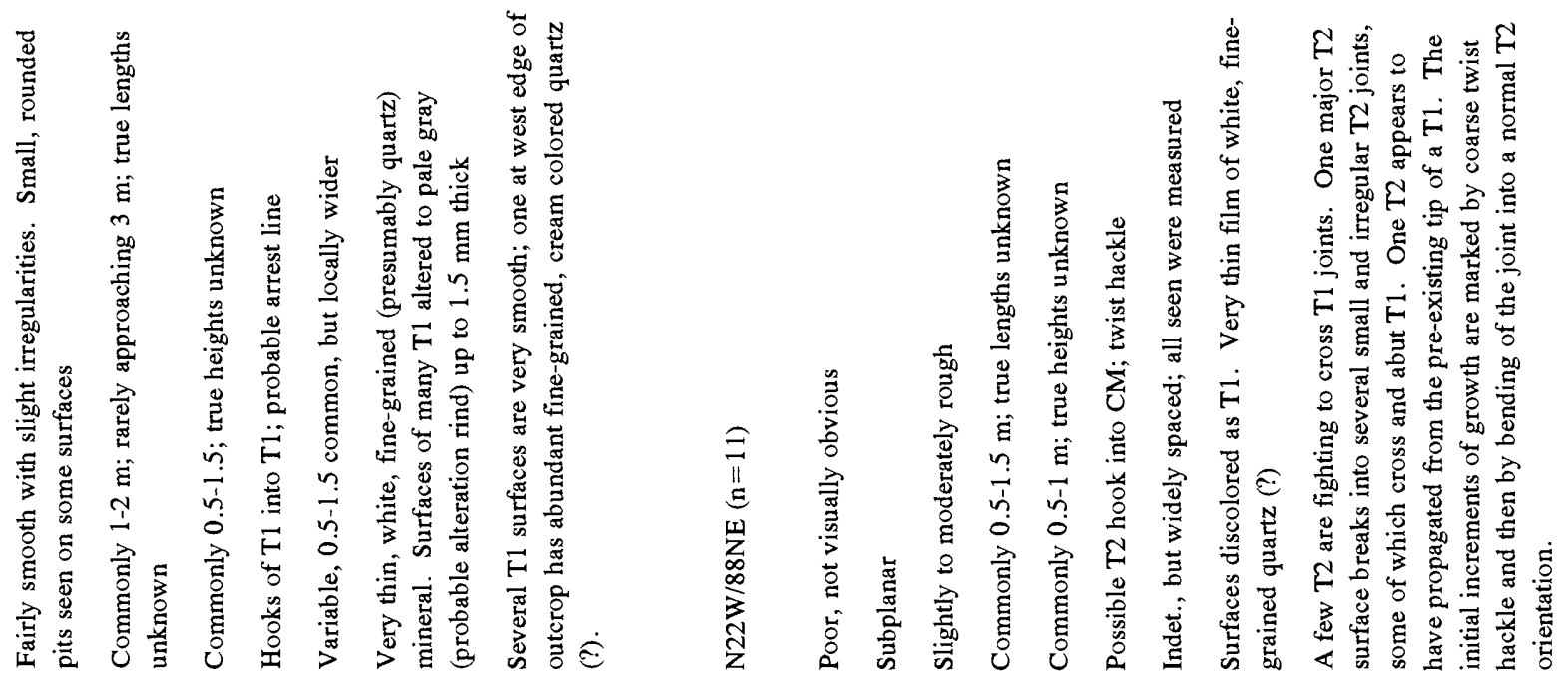

IIIII

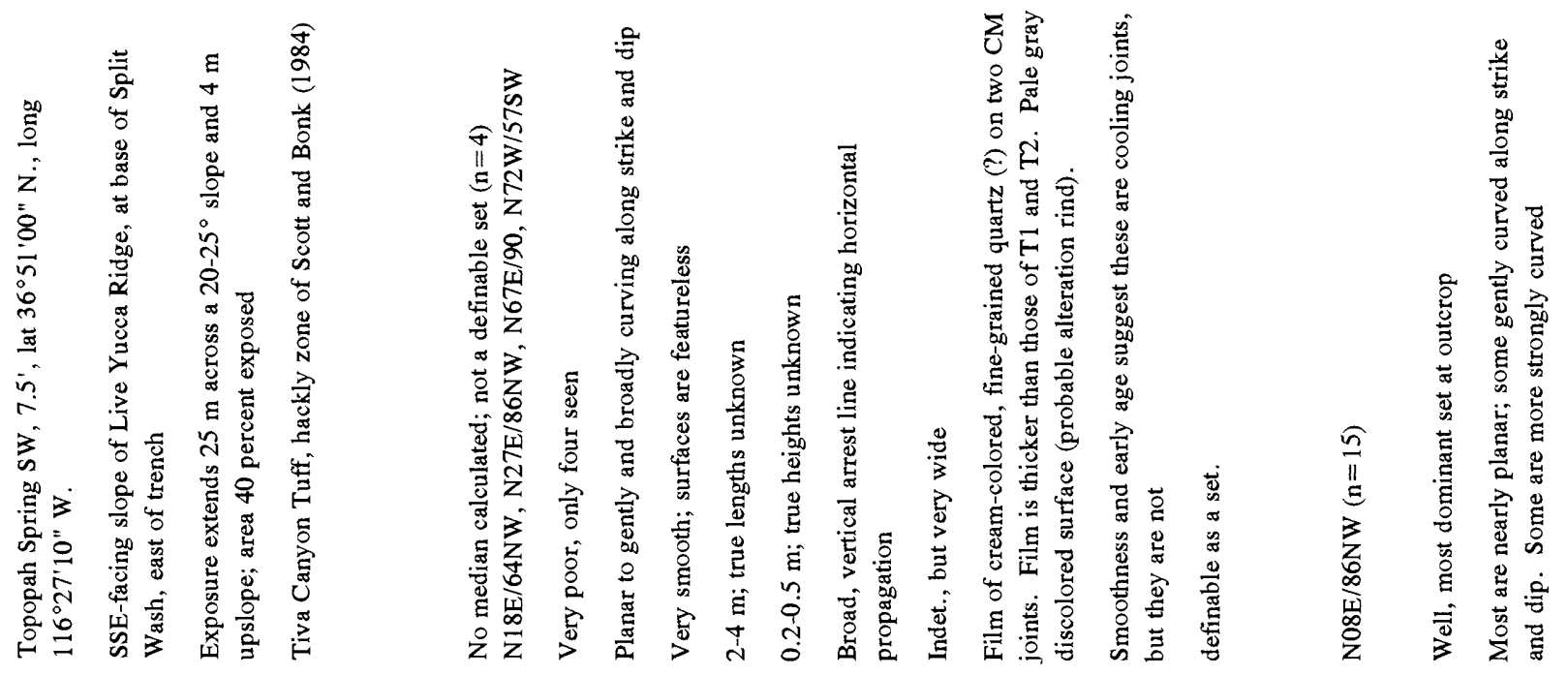

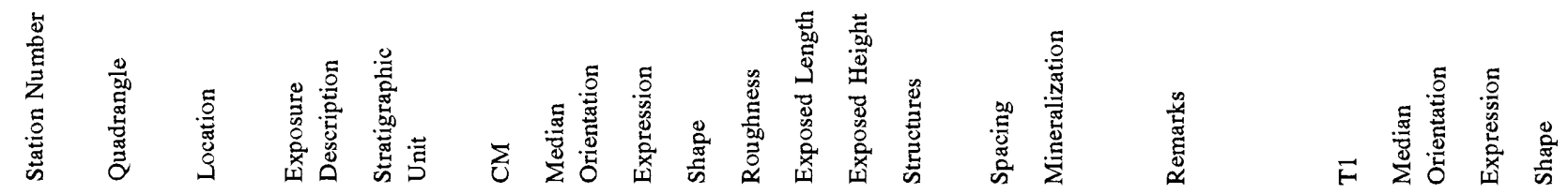




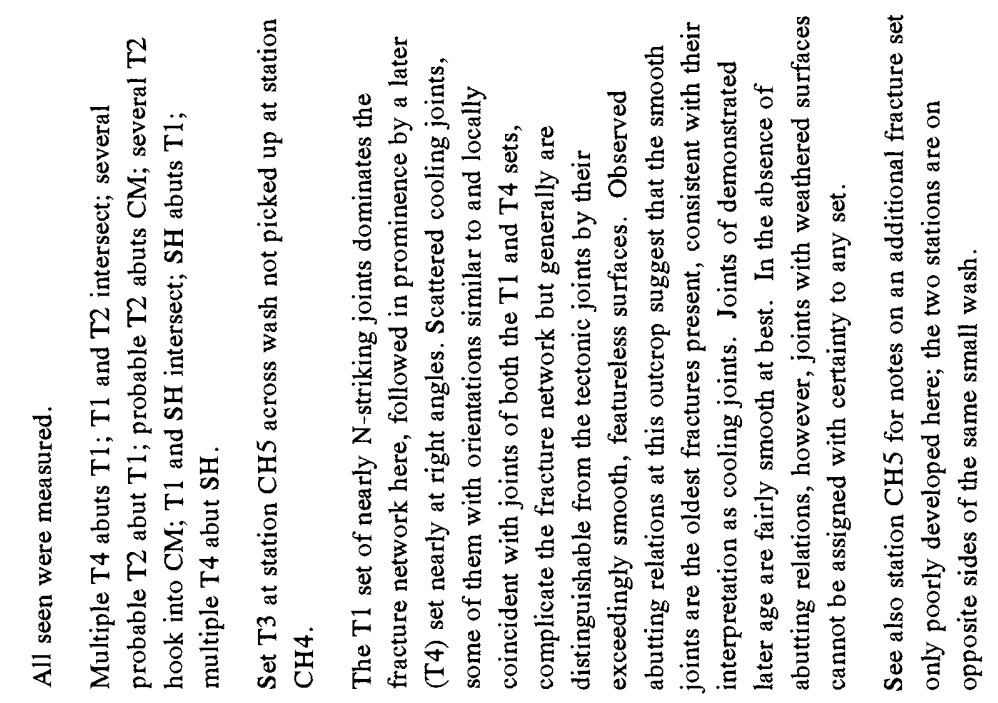

1) II

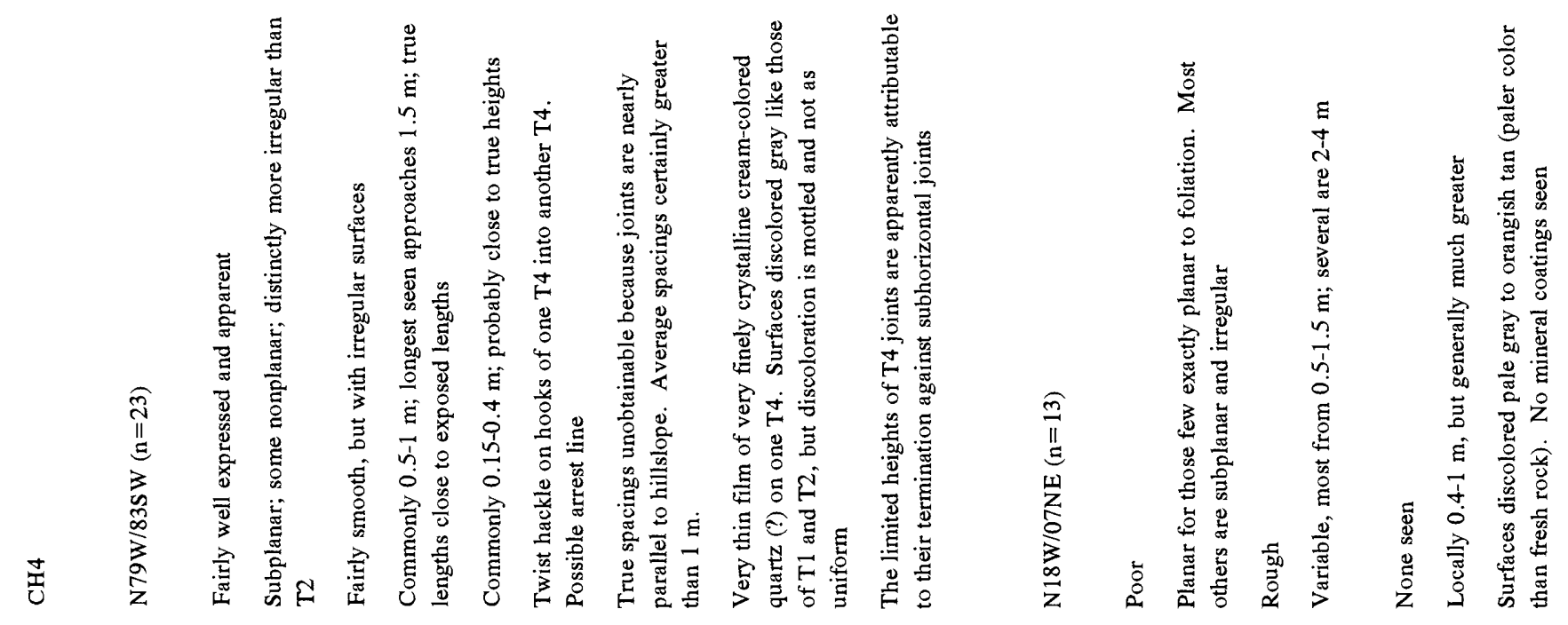

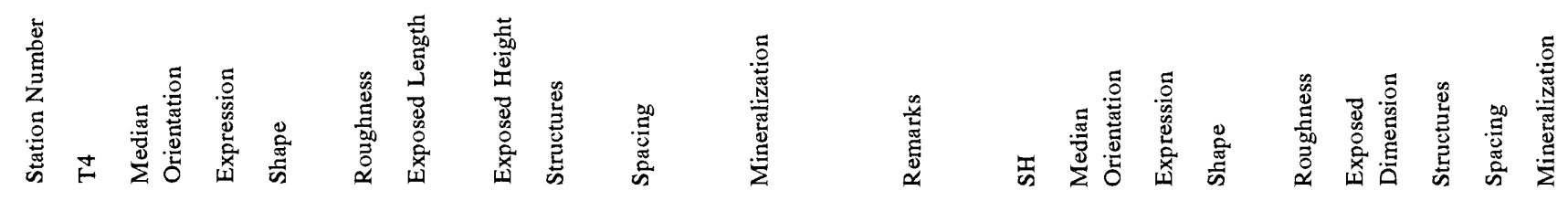




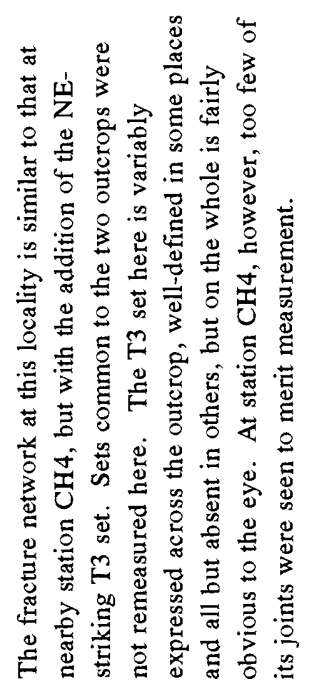

हूँ

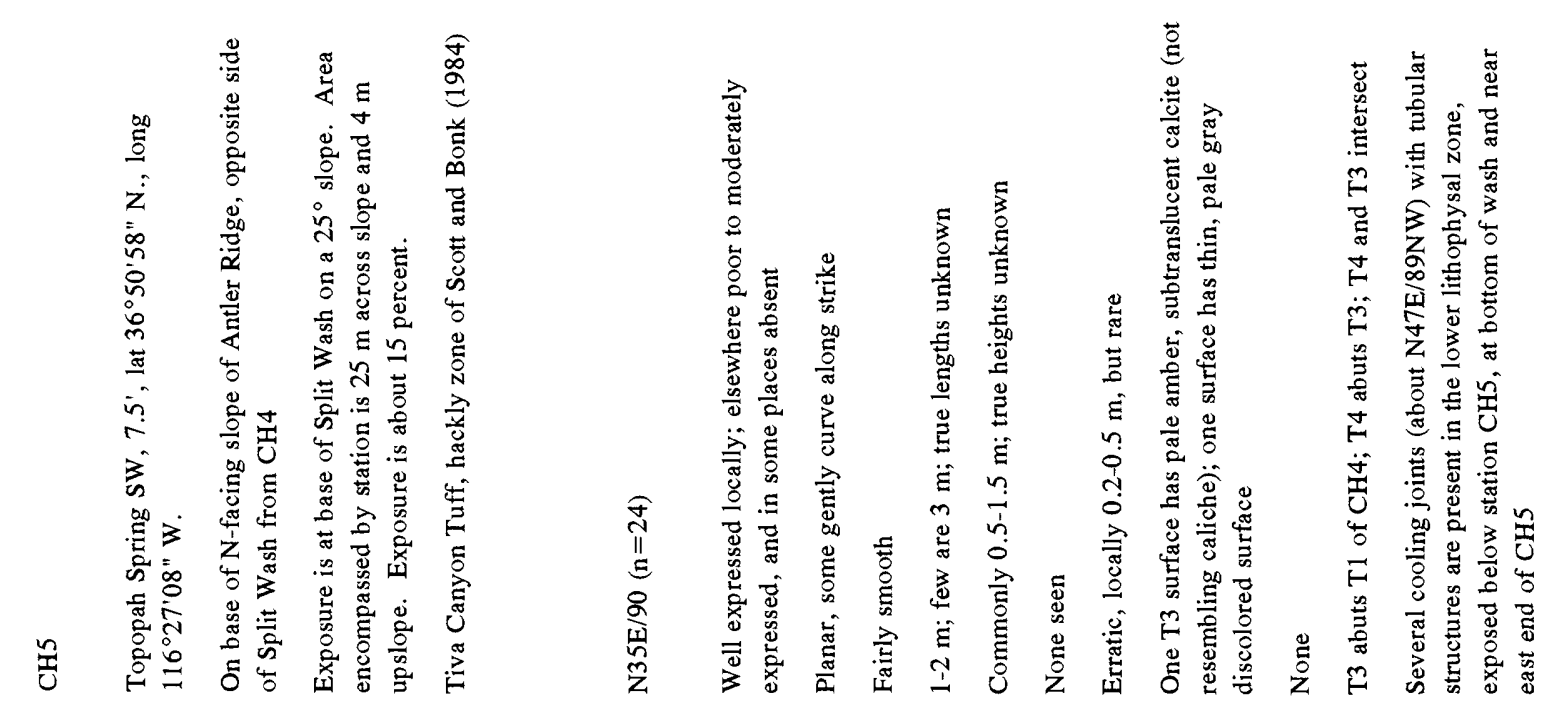

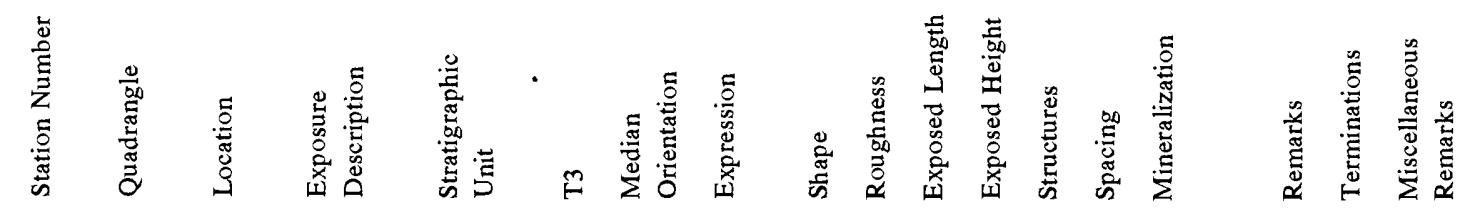




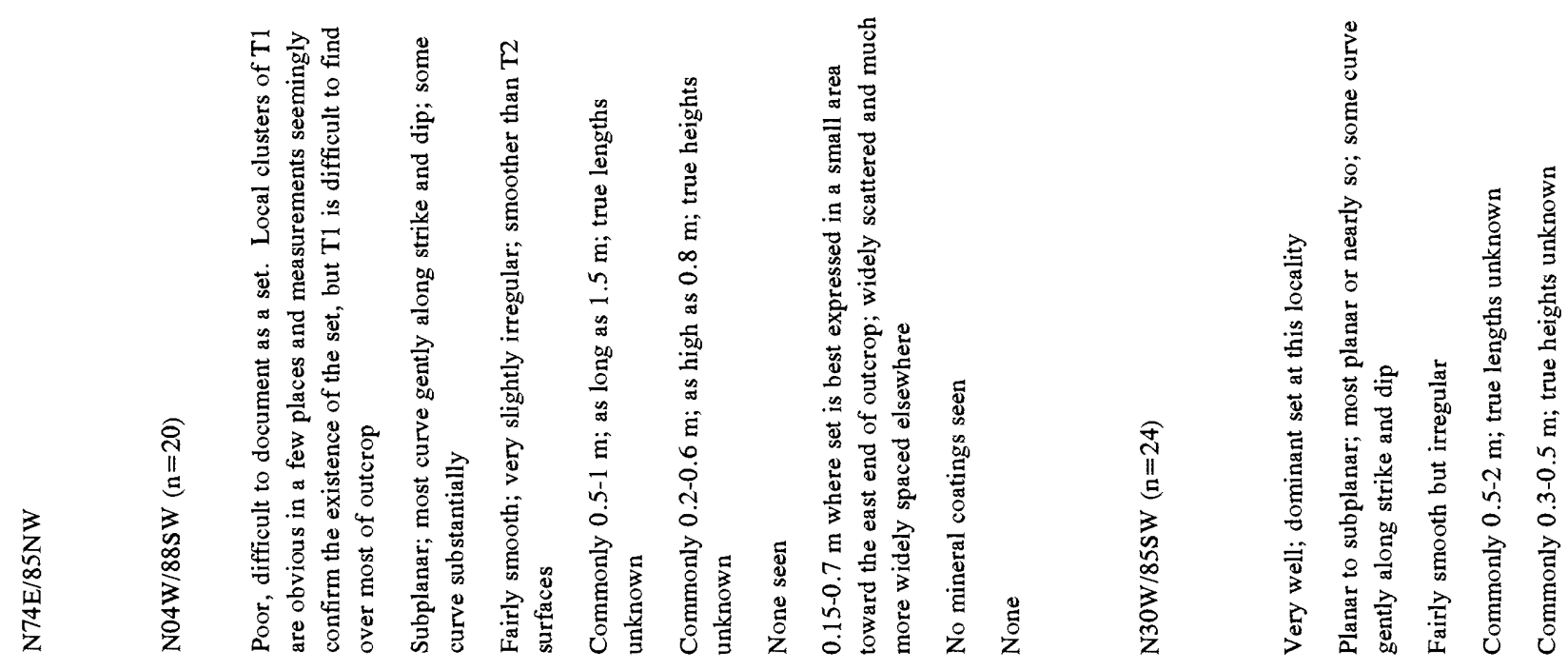

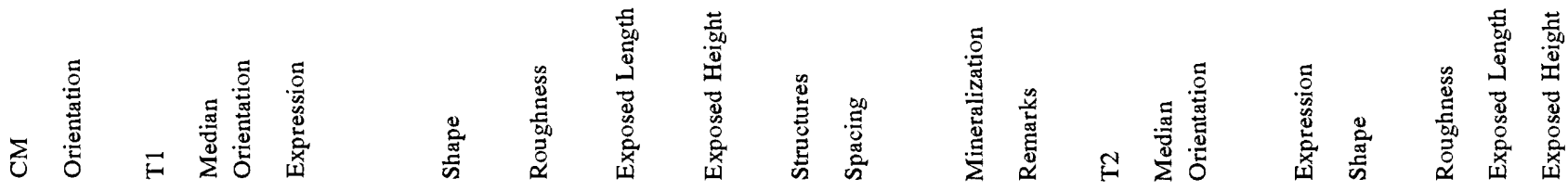

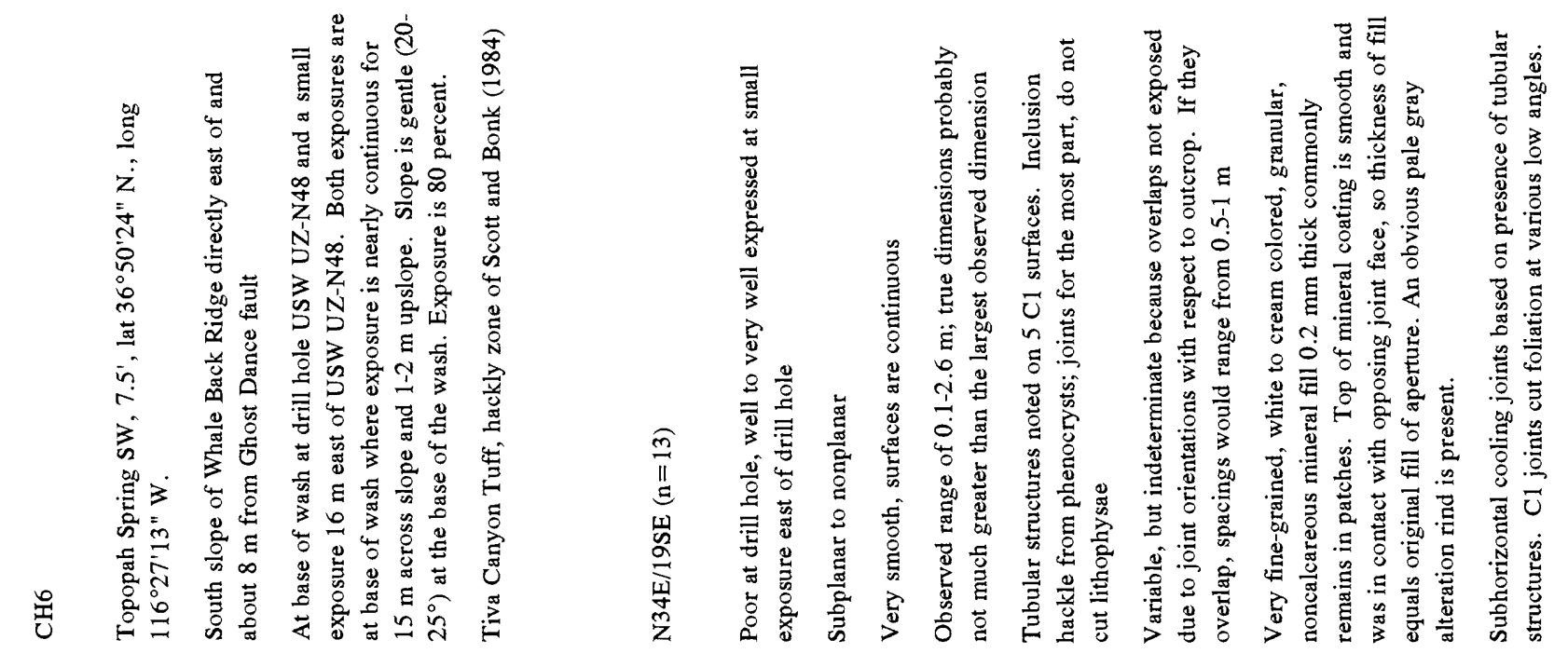

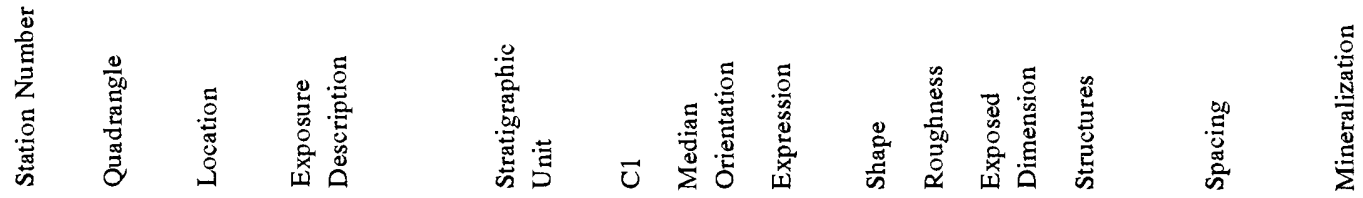




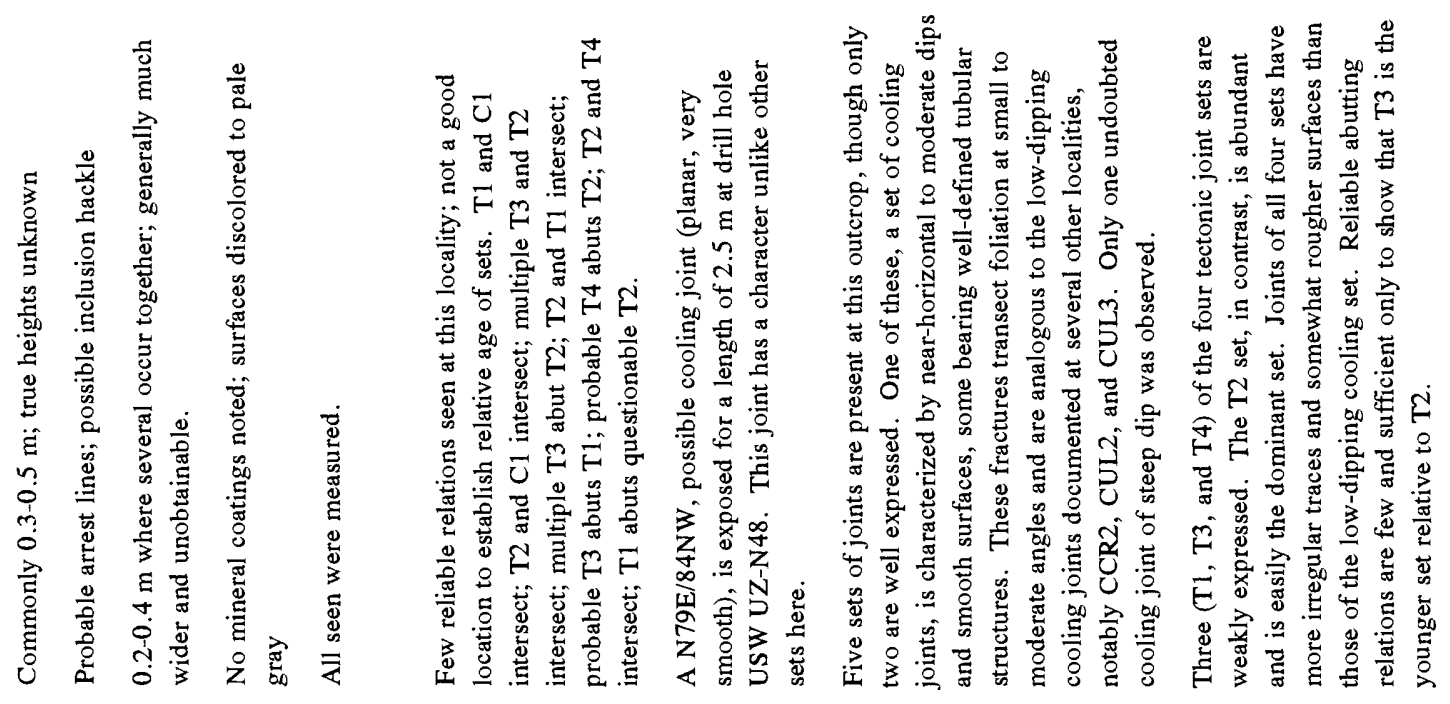

IIIIII

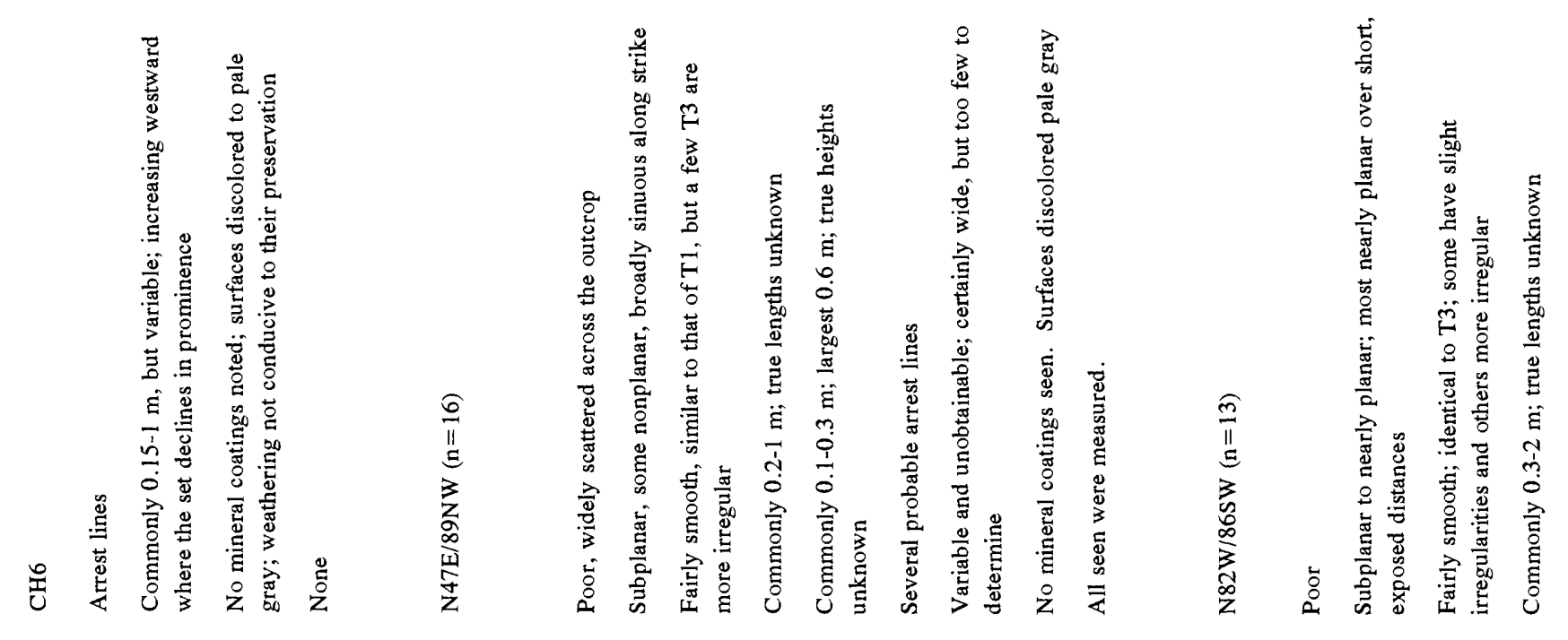

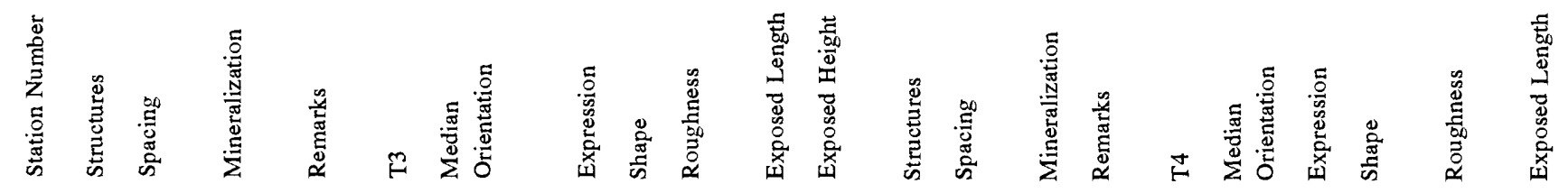




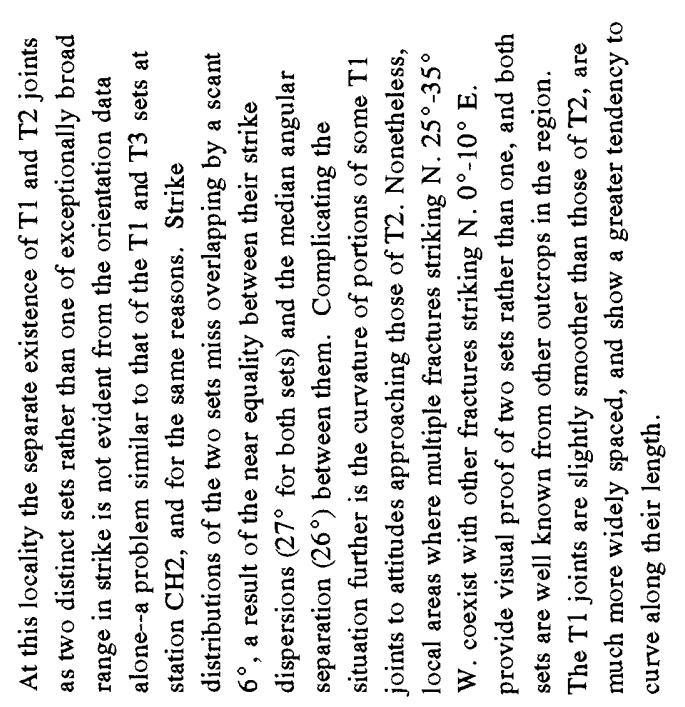



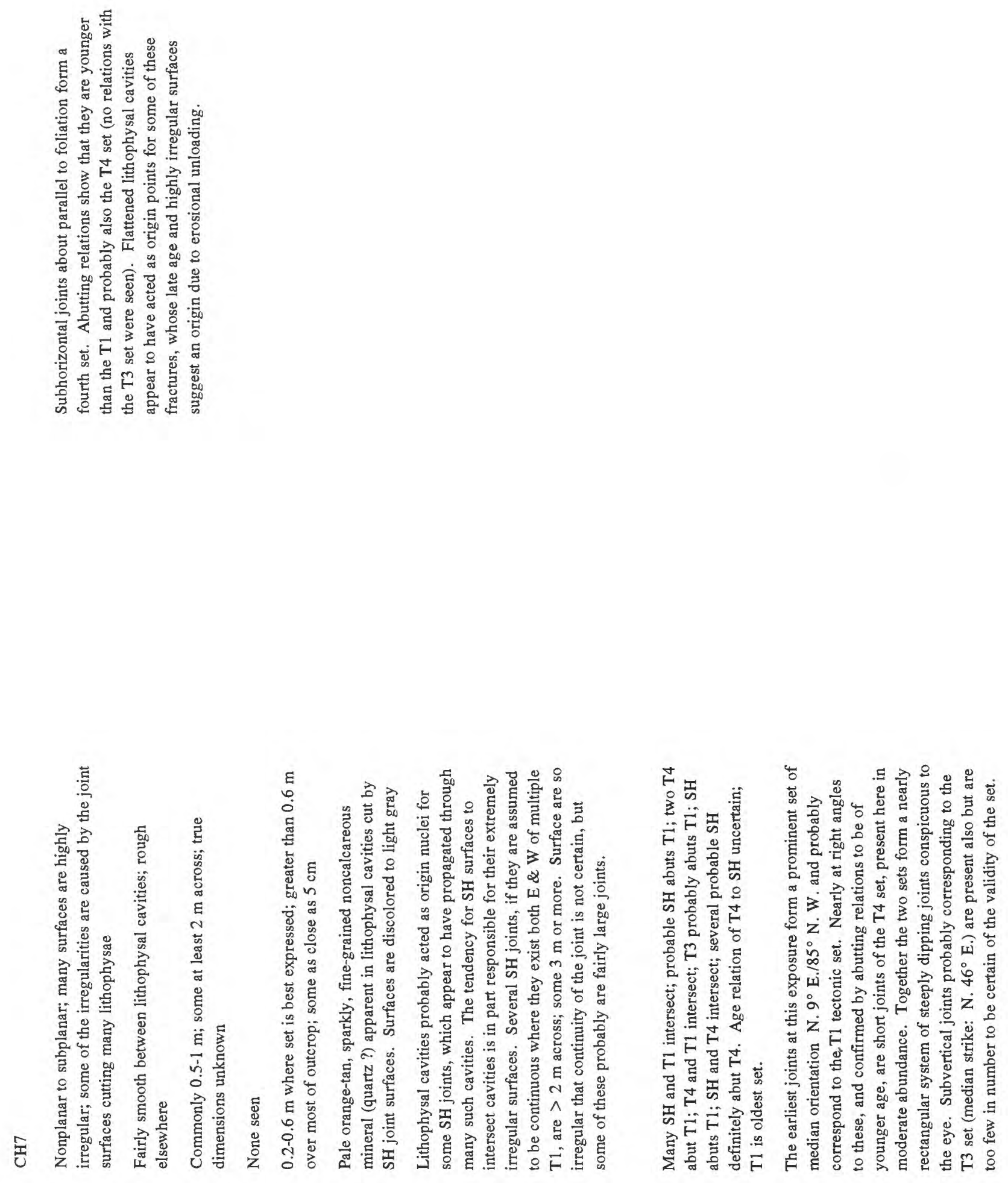

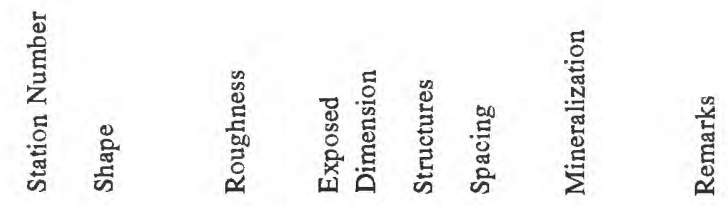

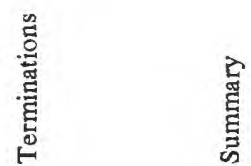




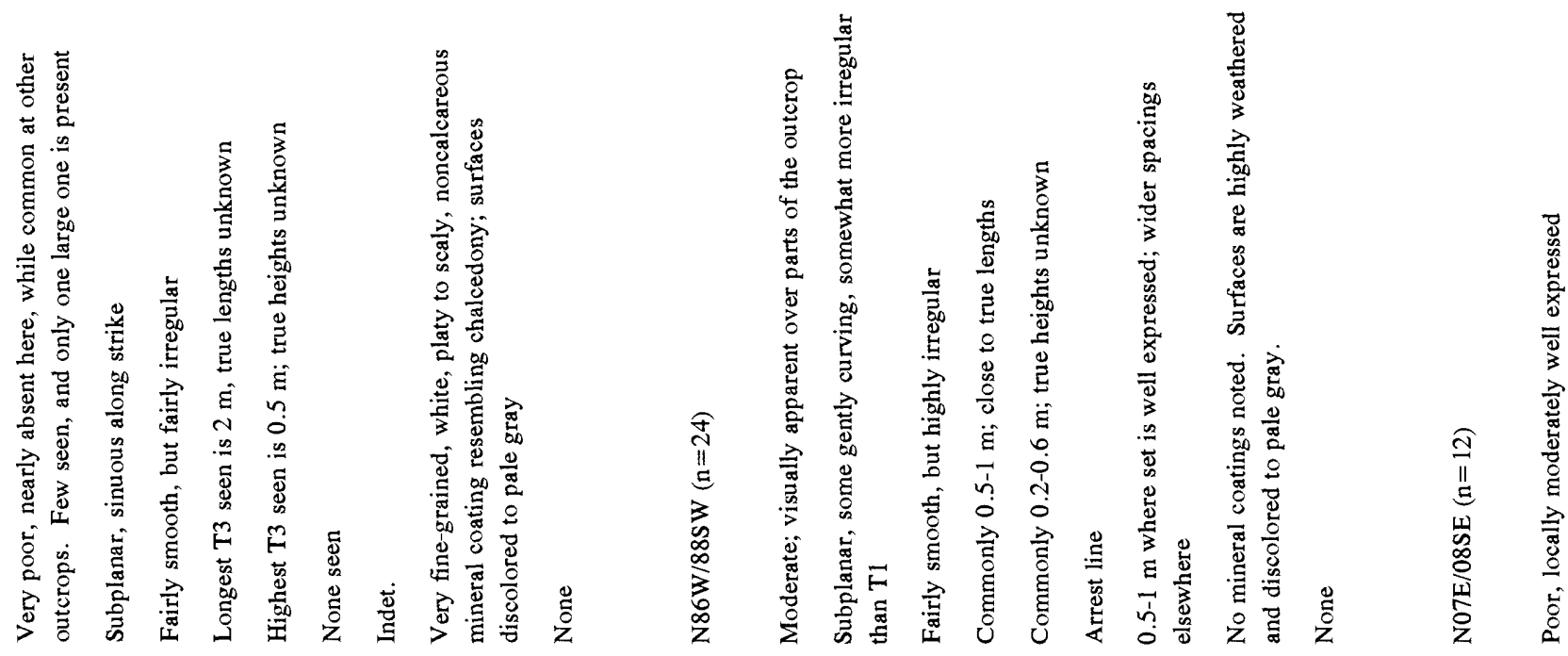

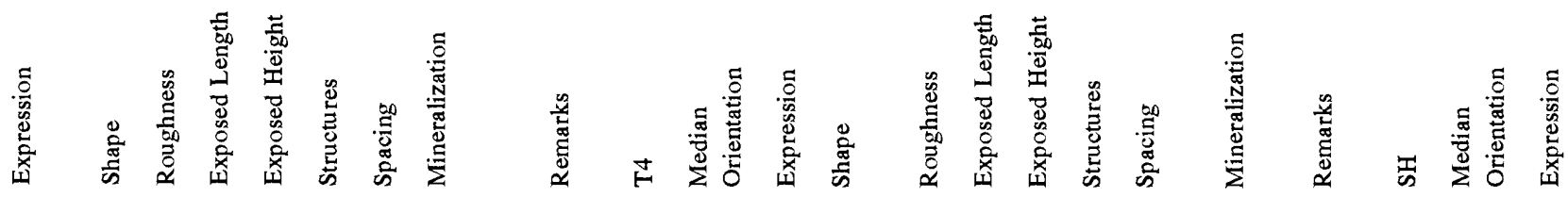

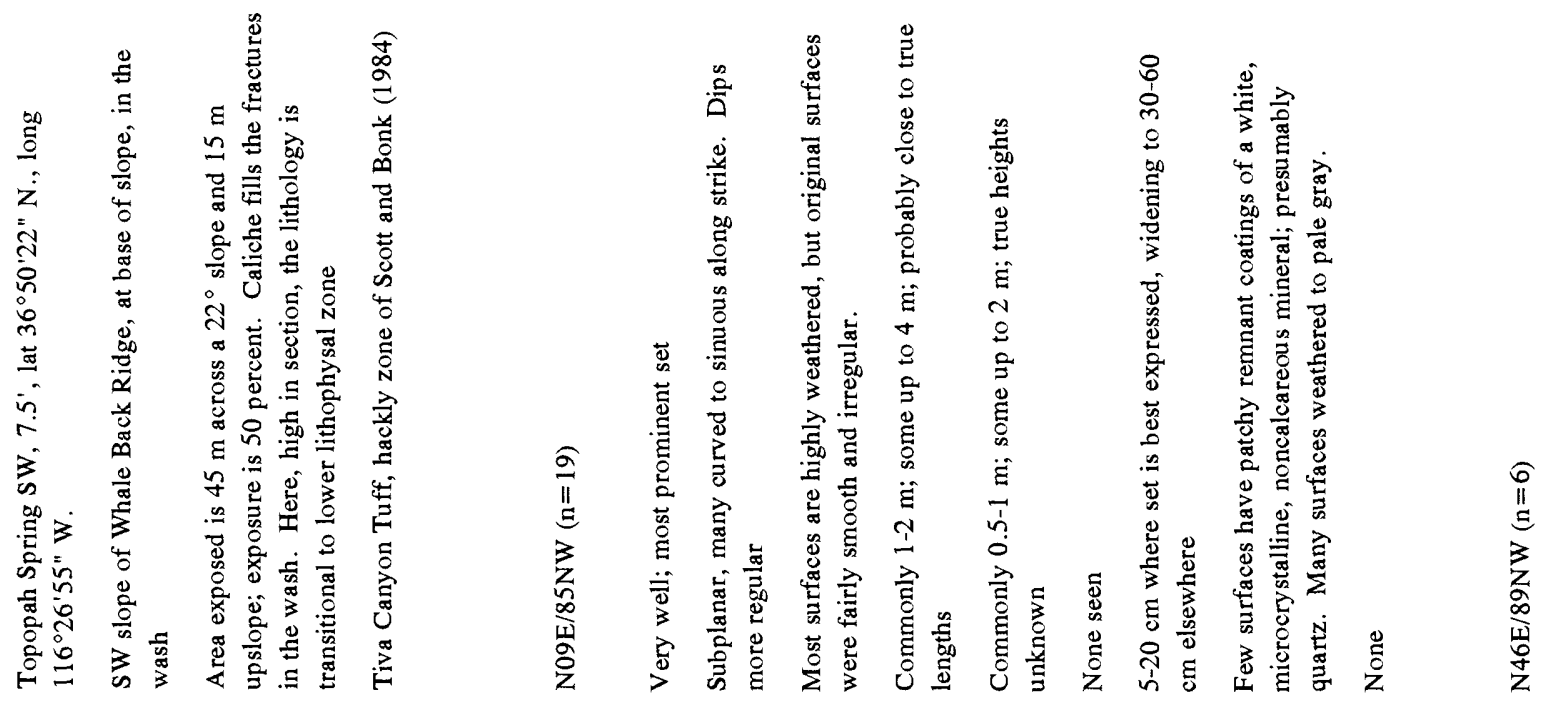

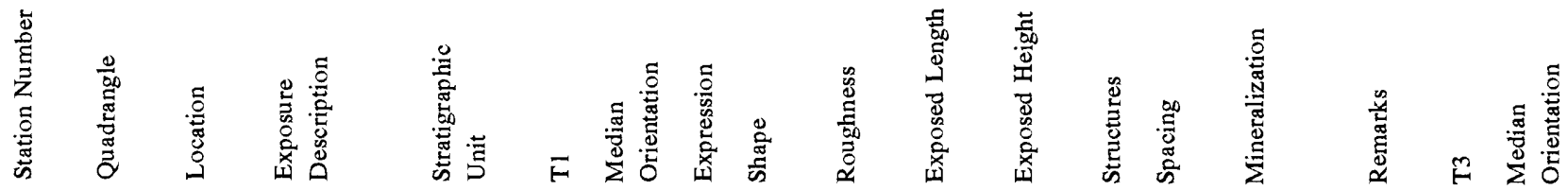


!

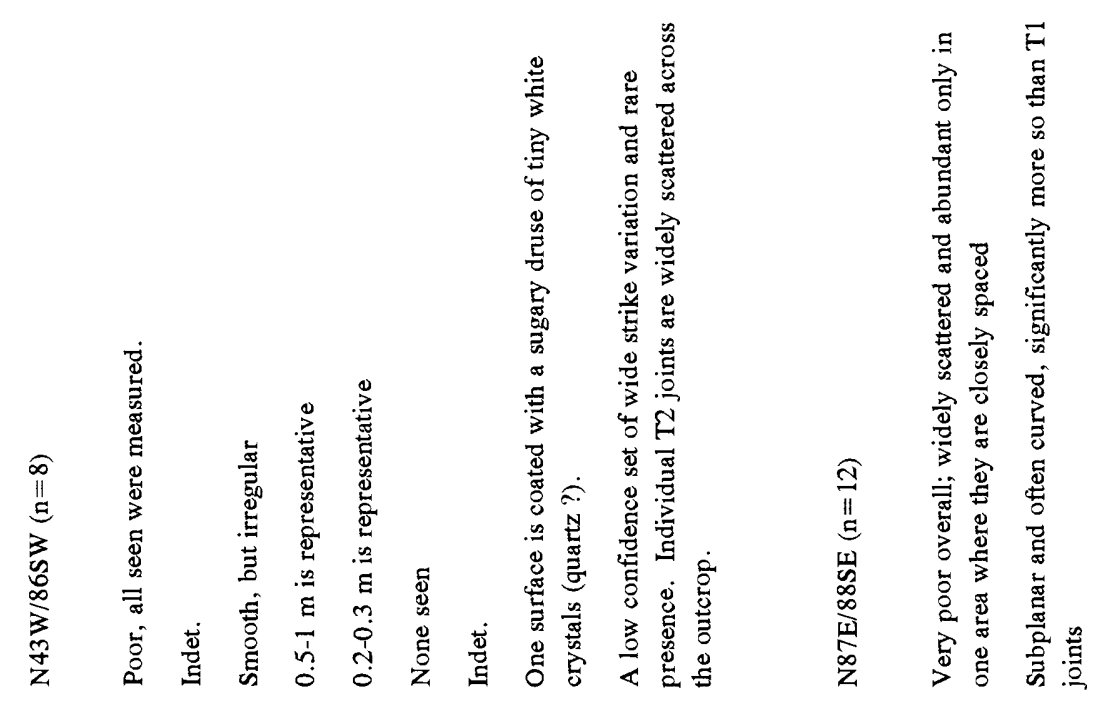

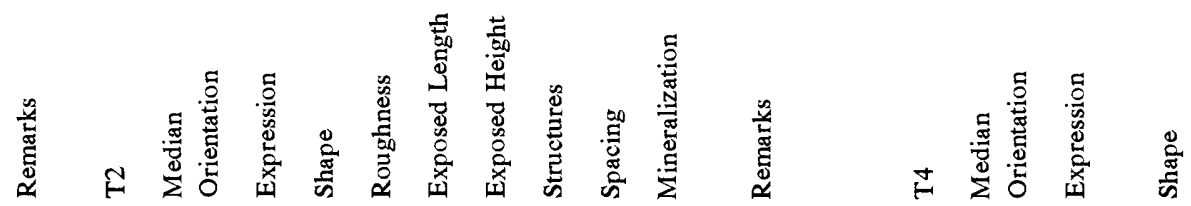
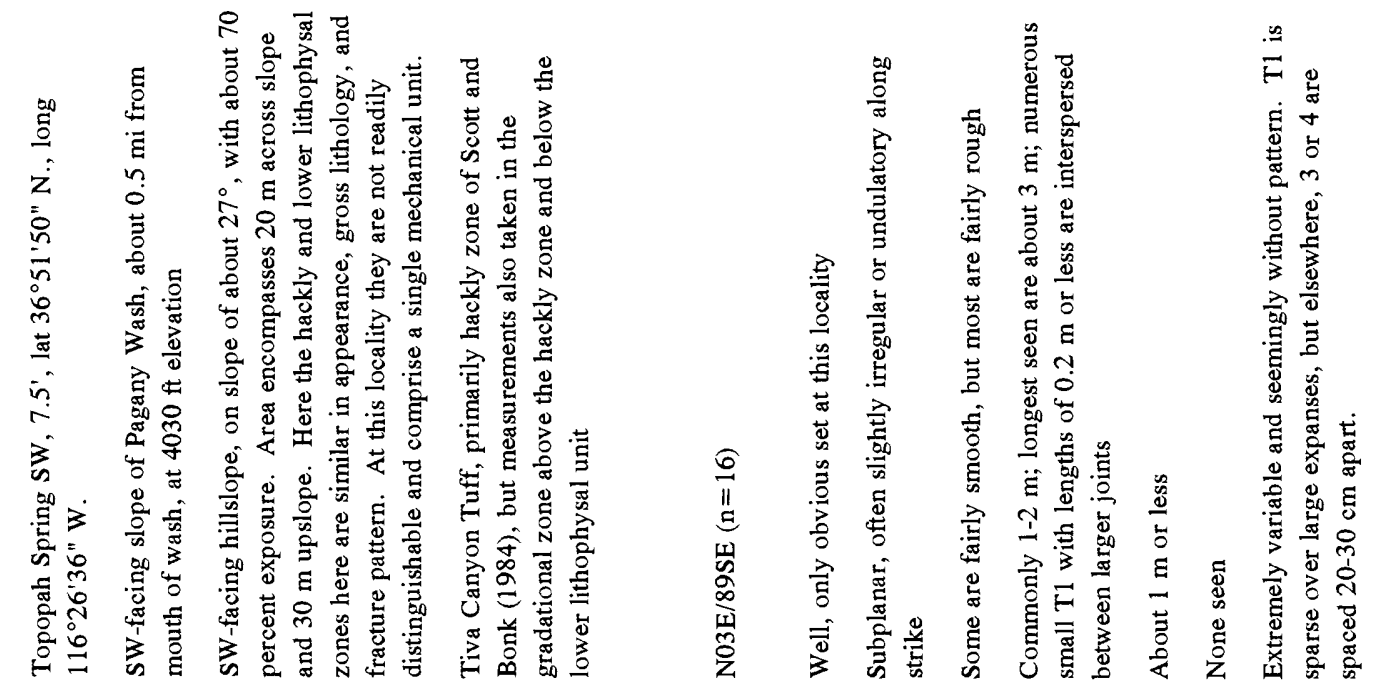

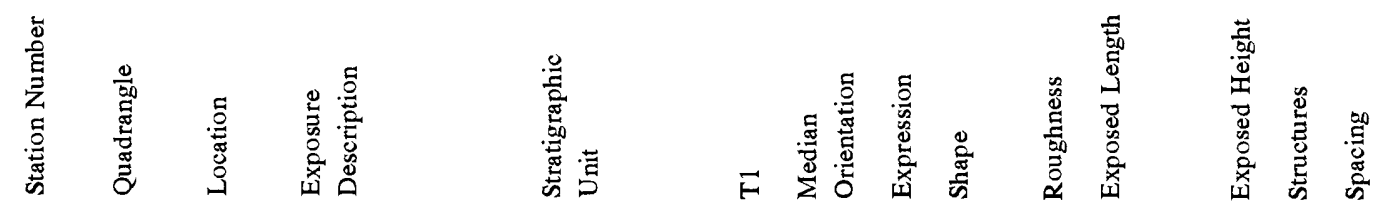




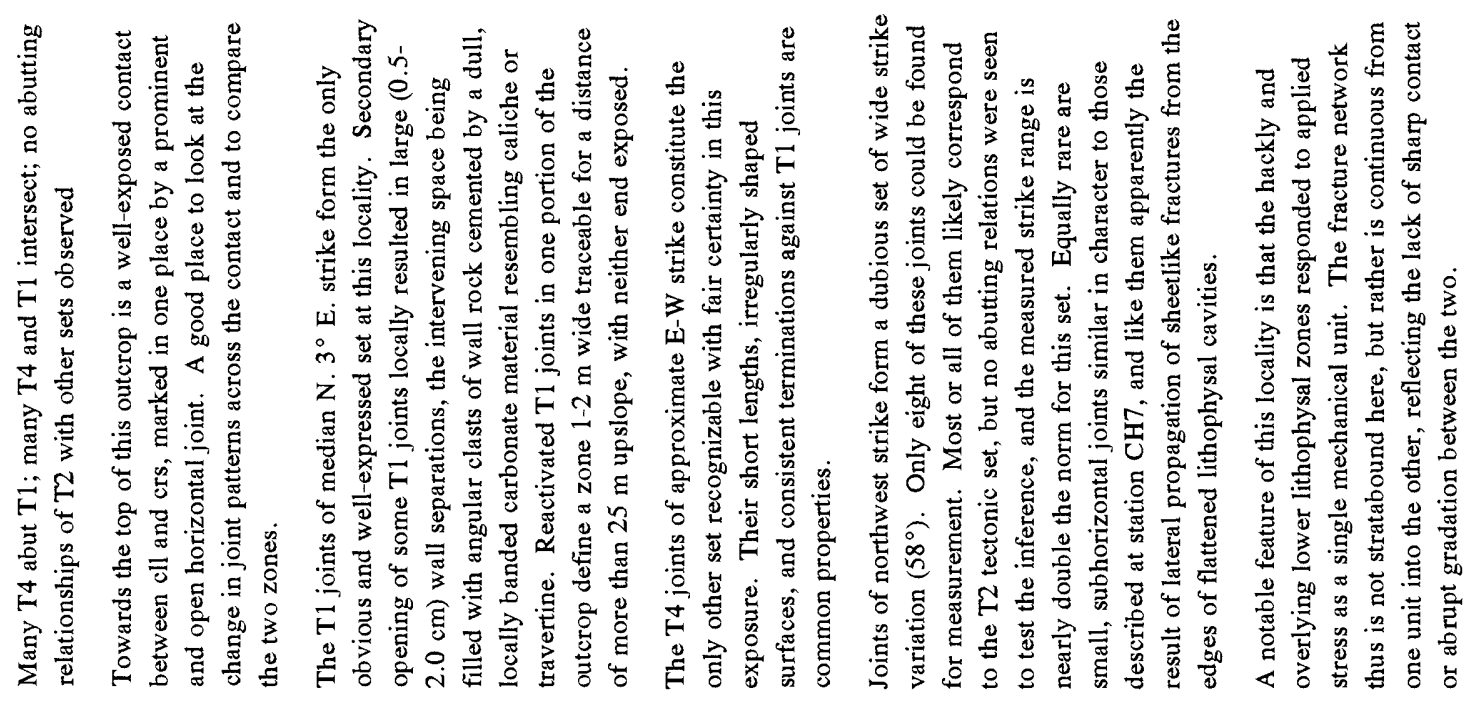

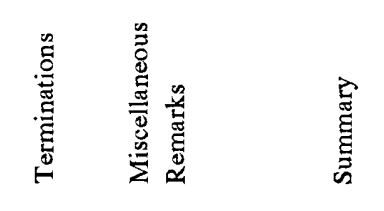

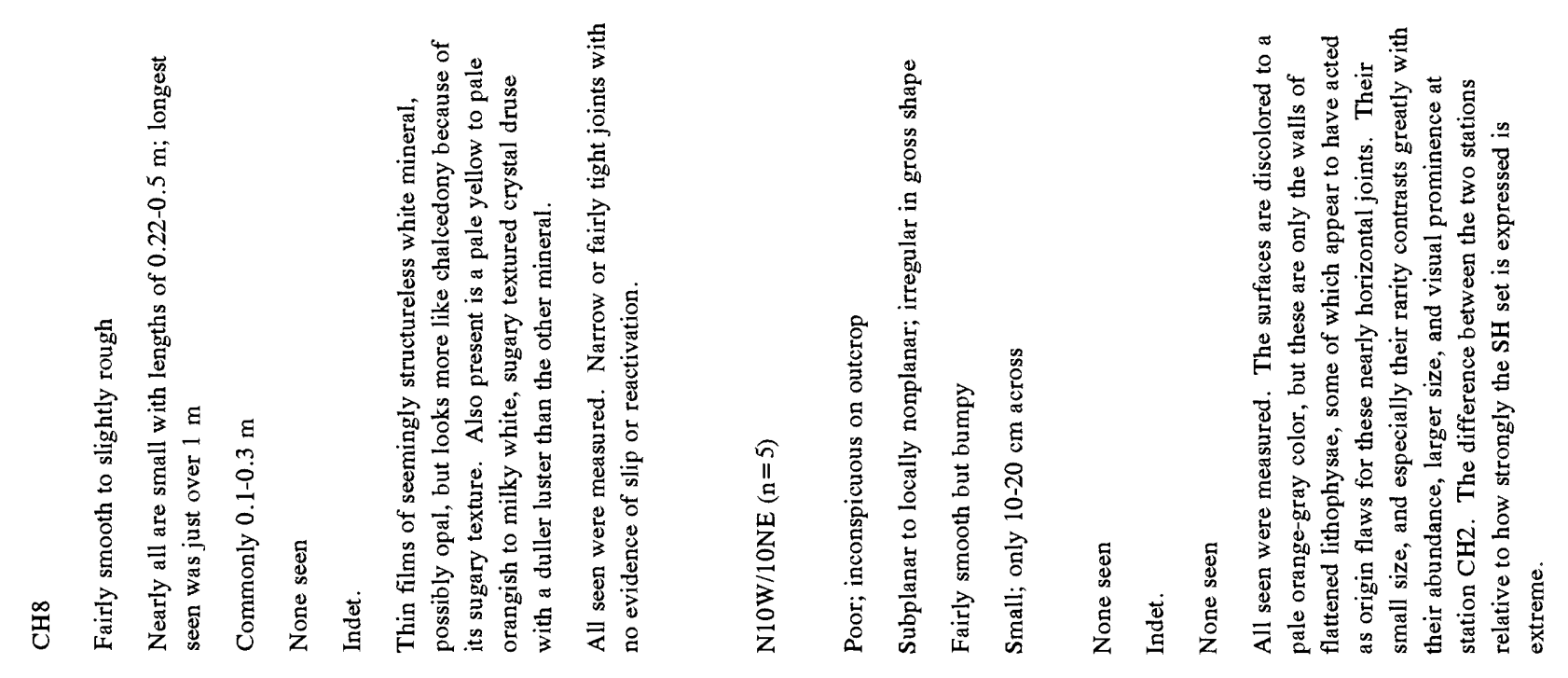

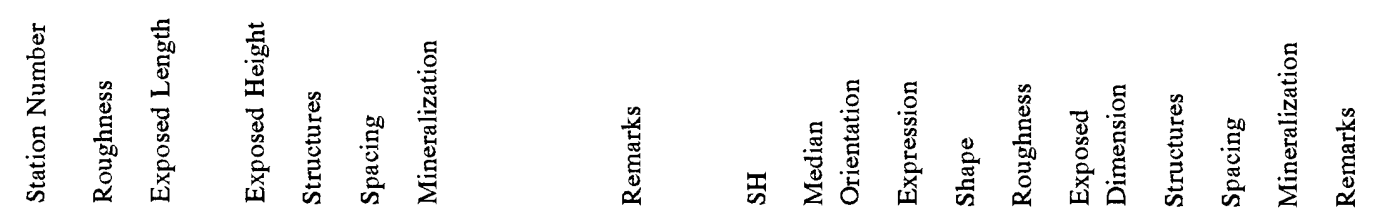




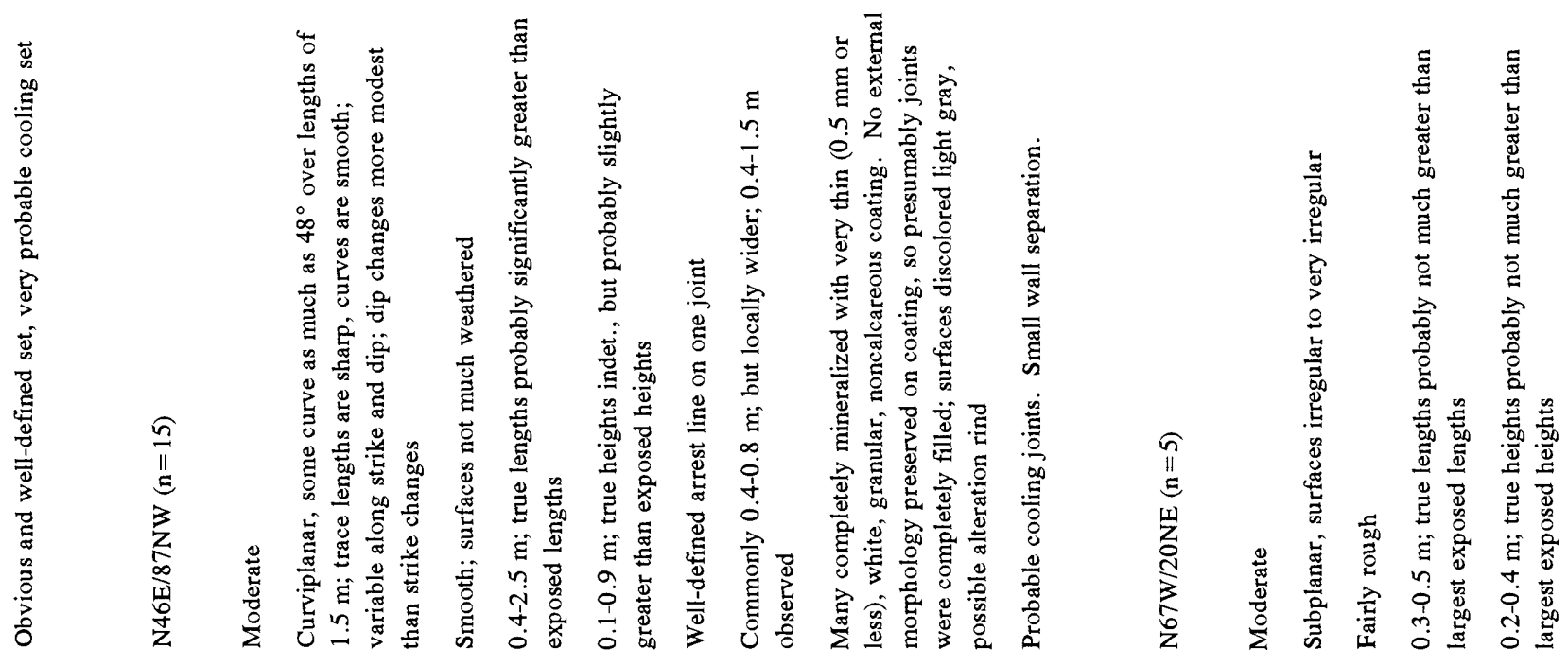

1.
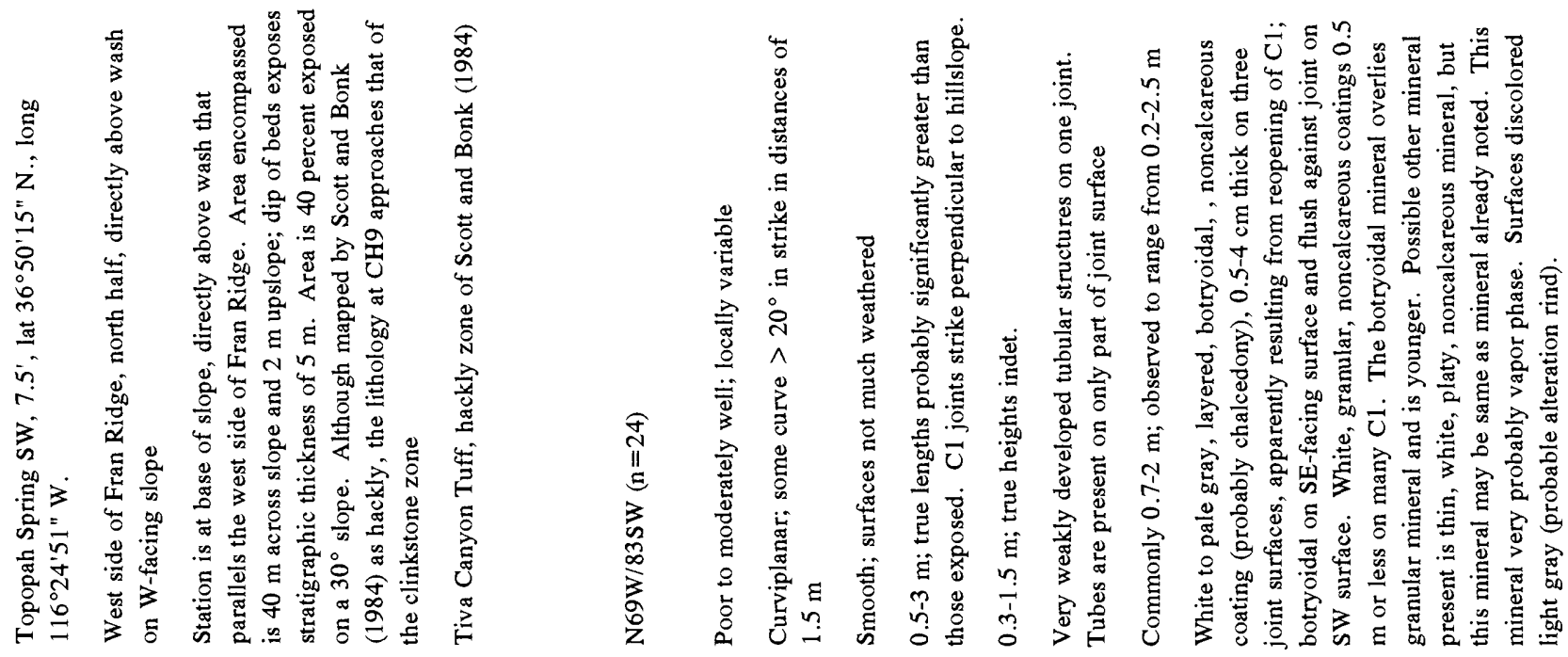

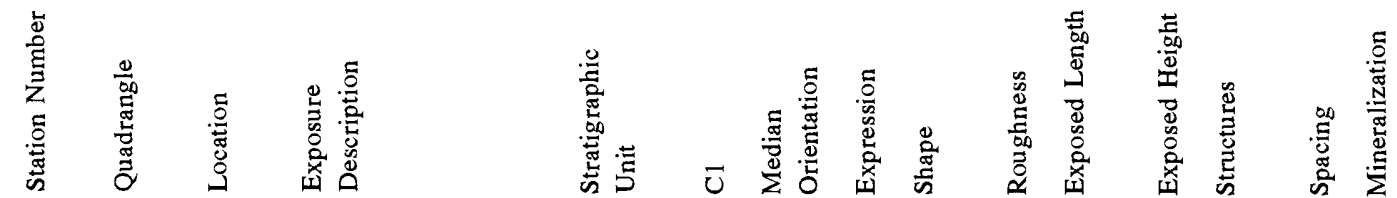




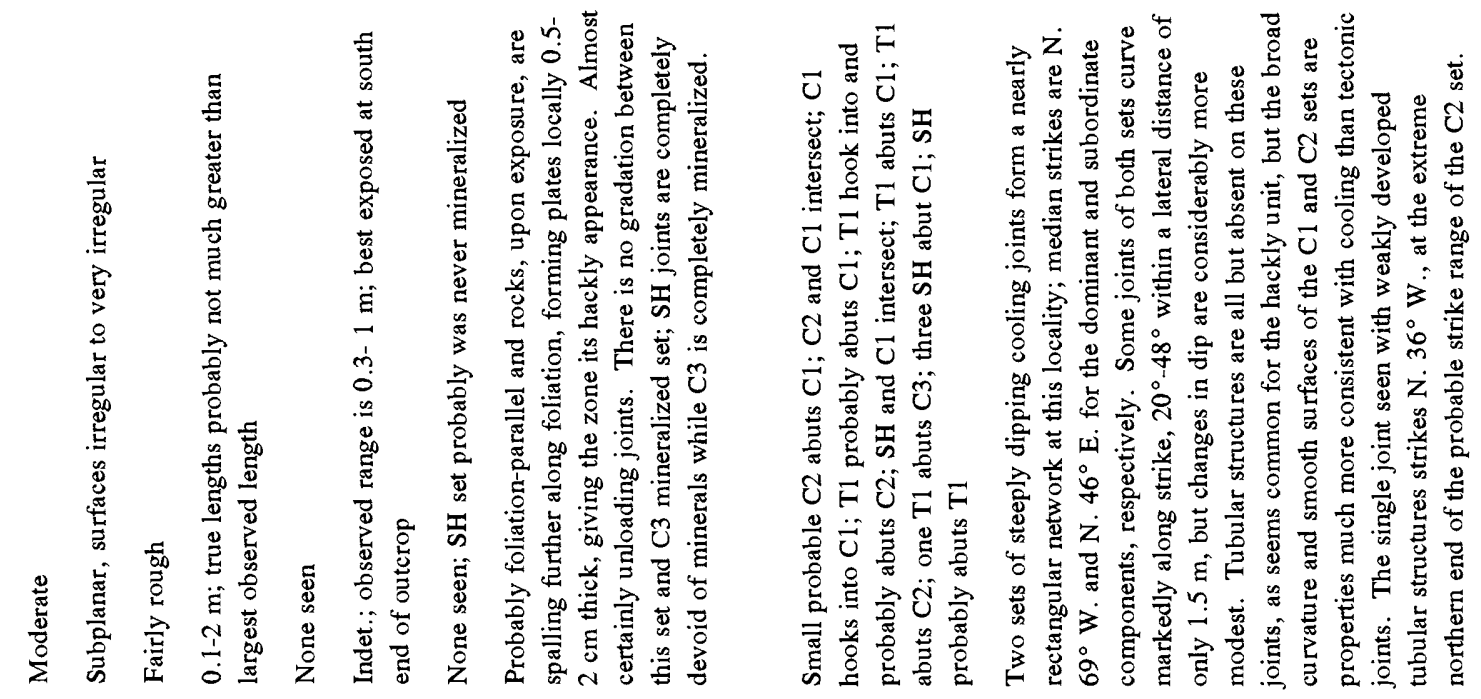

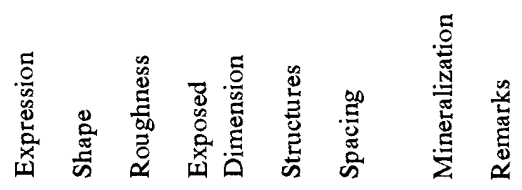
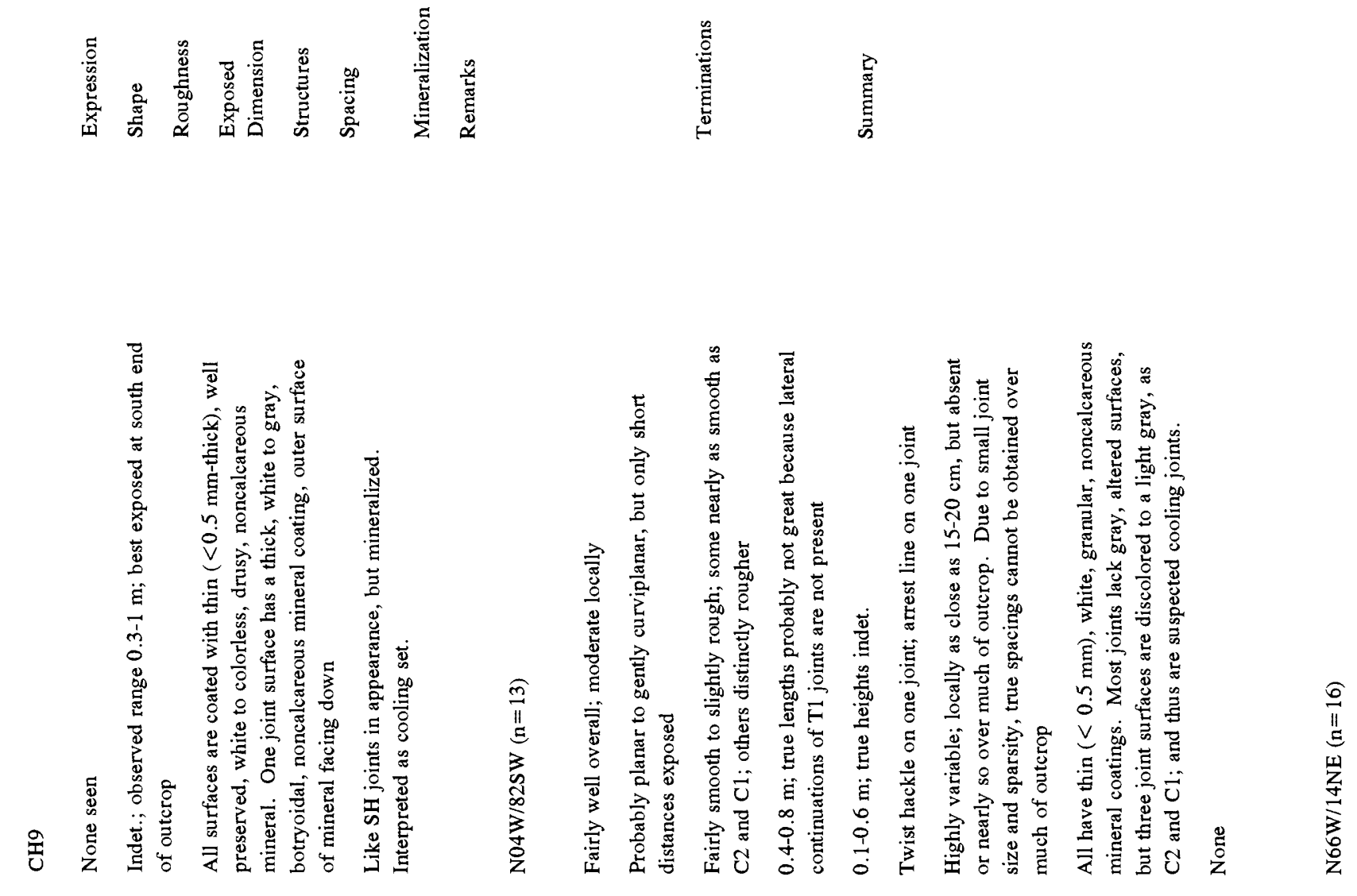

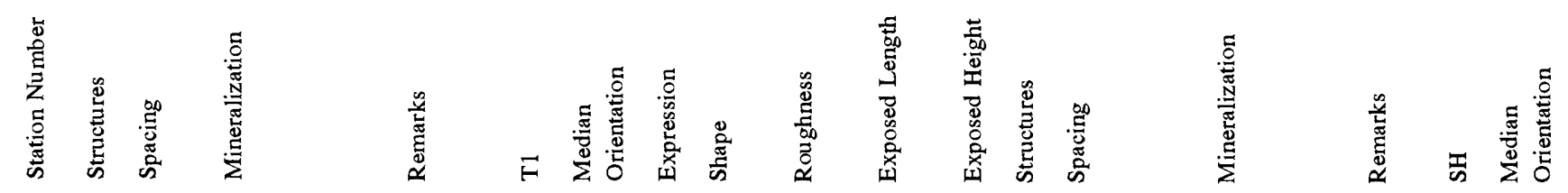



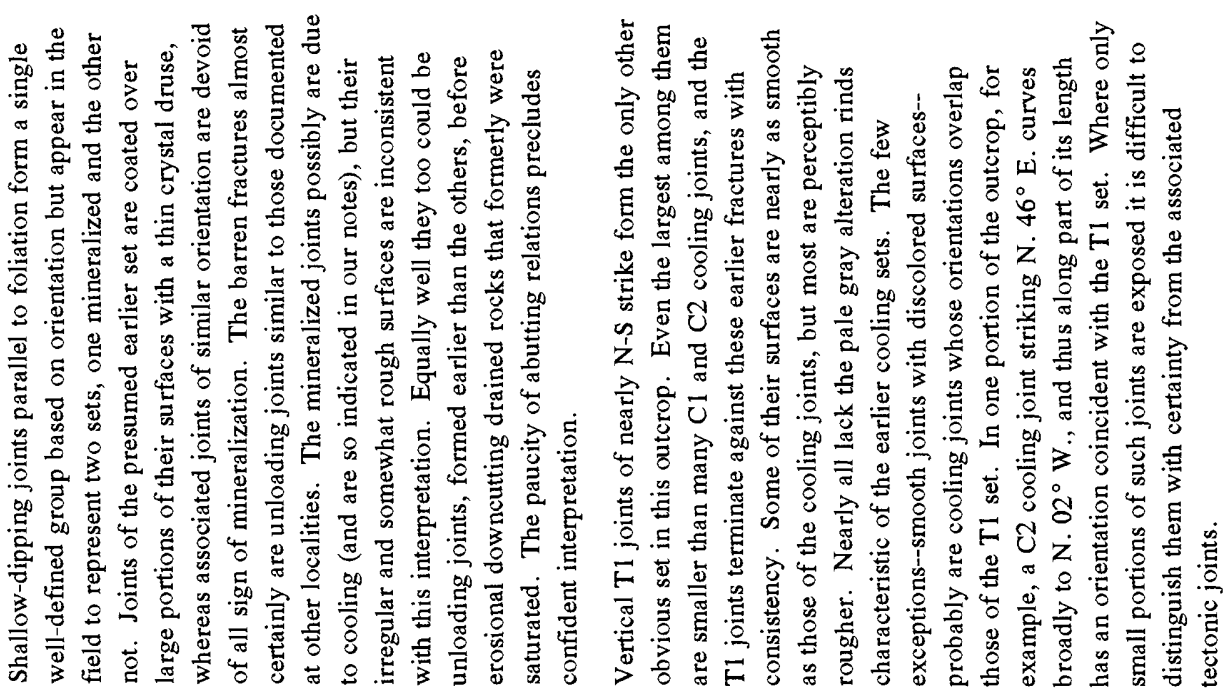


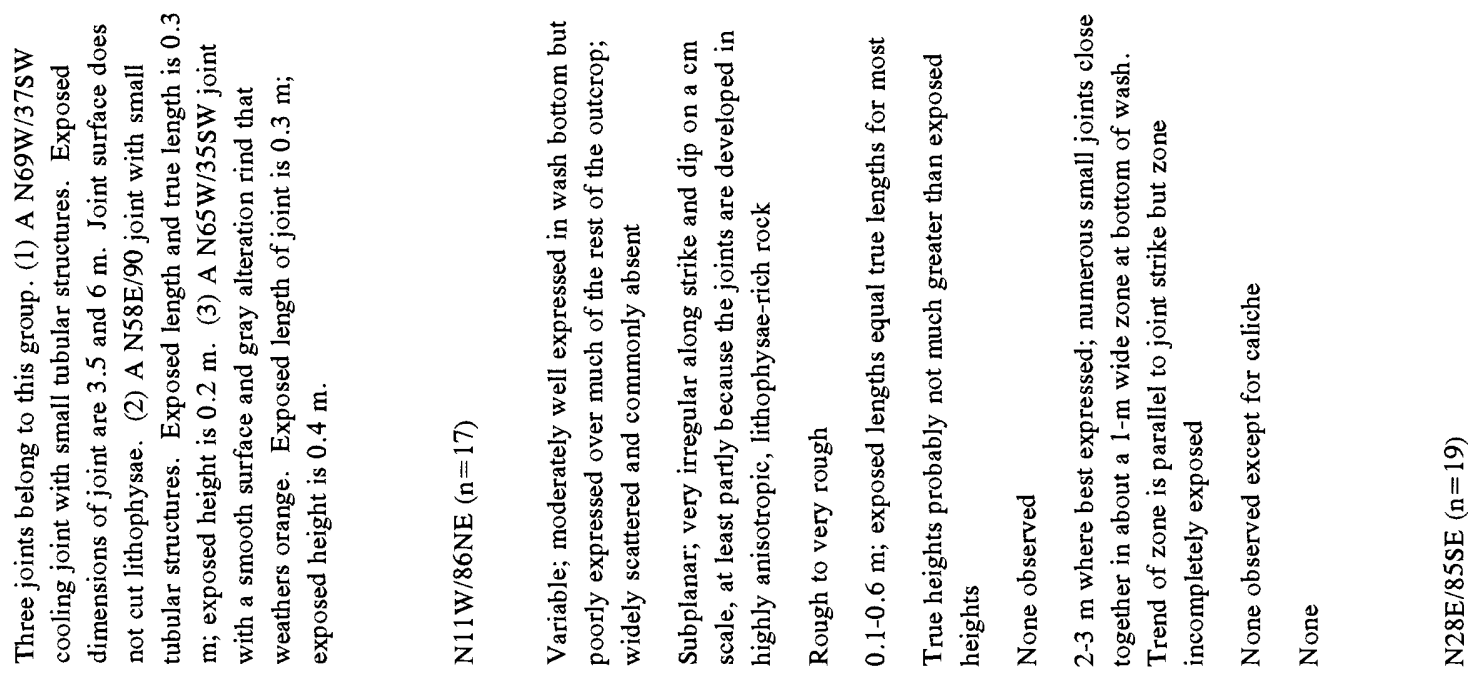

方

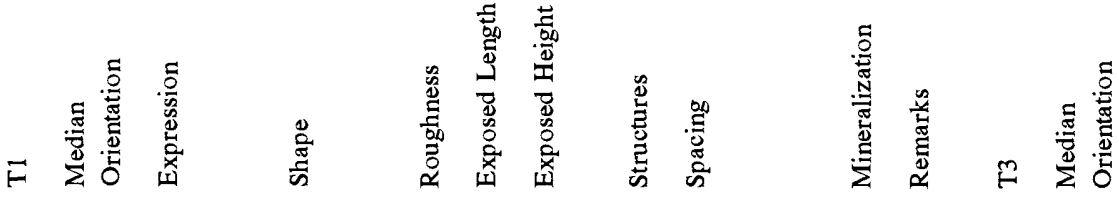

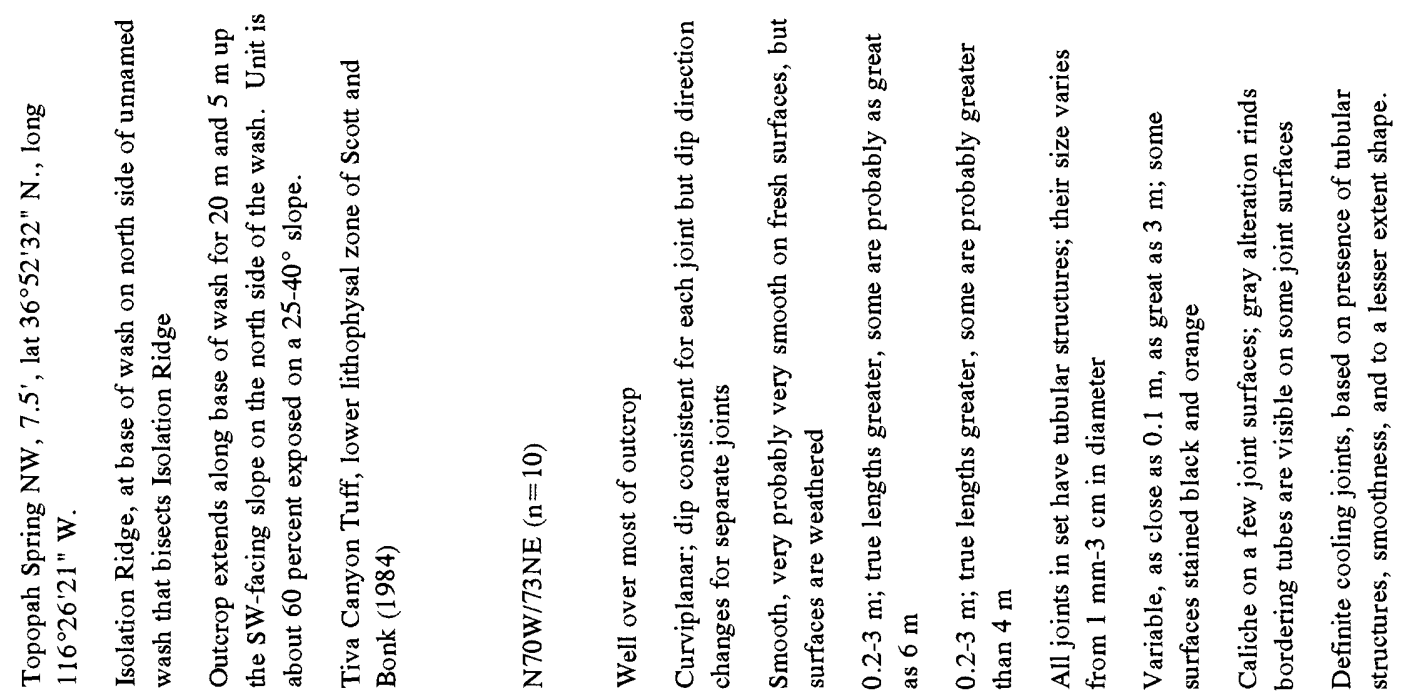

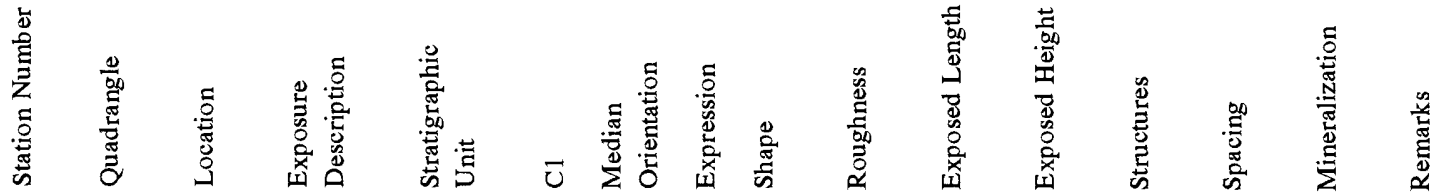




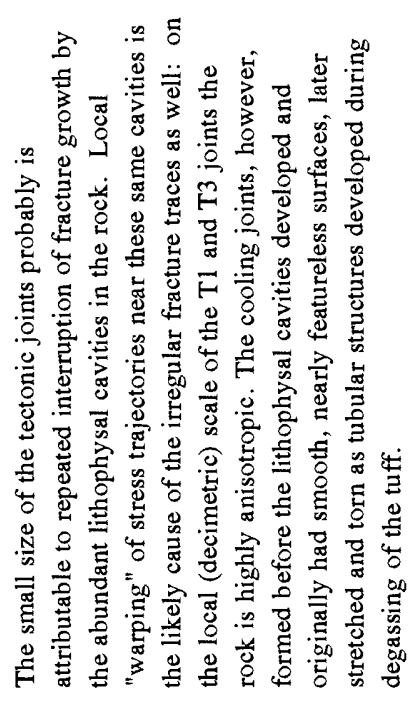

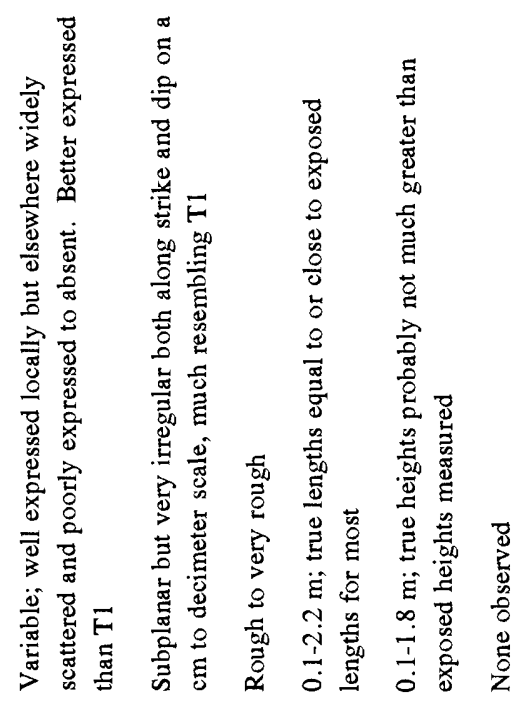
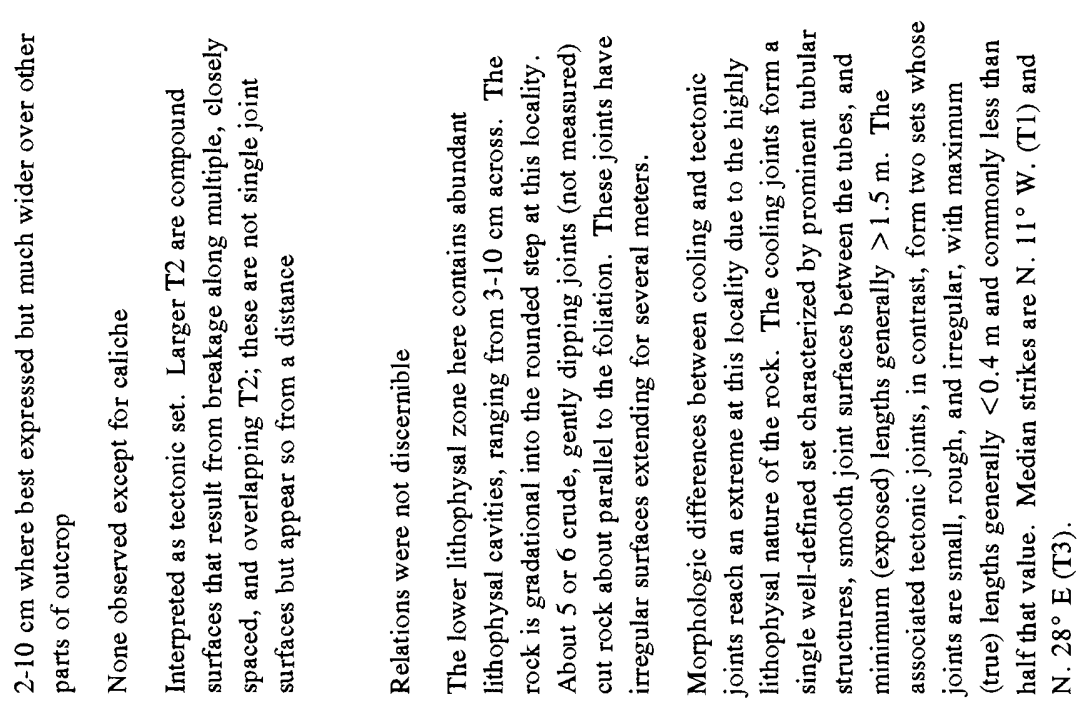

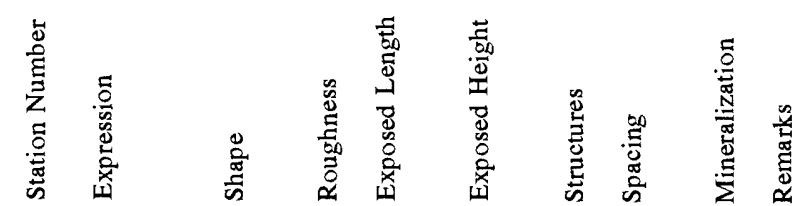

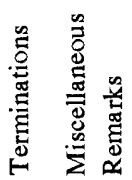



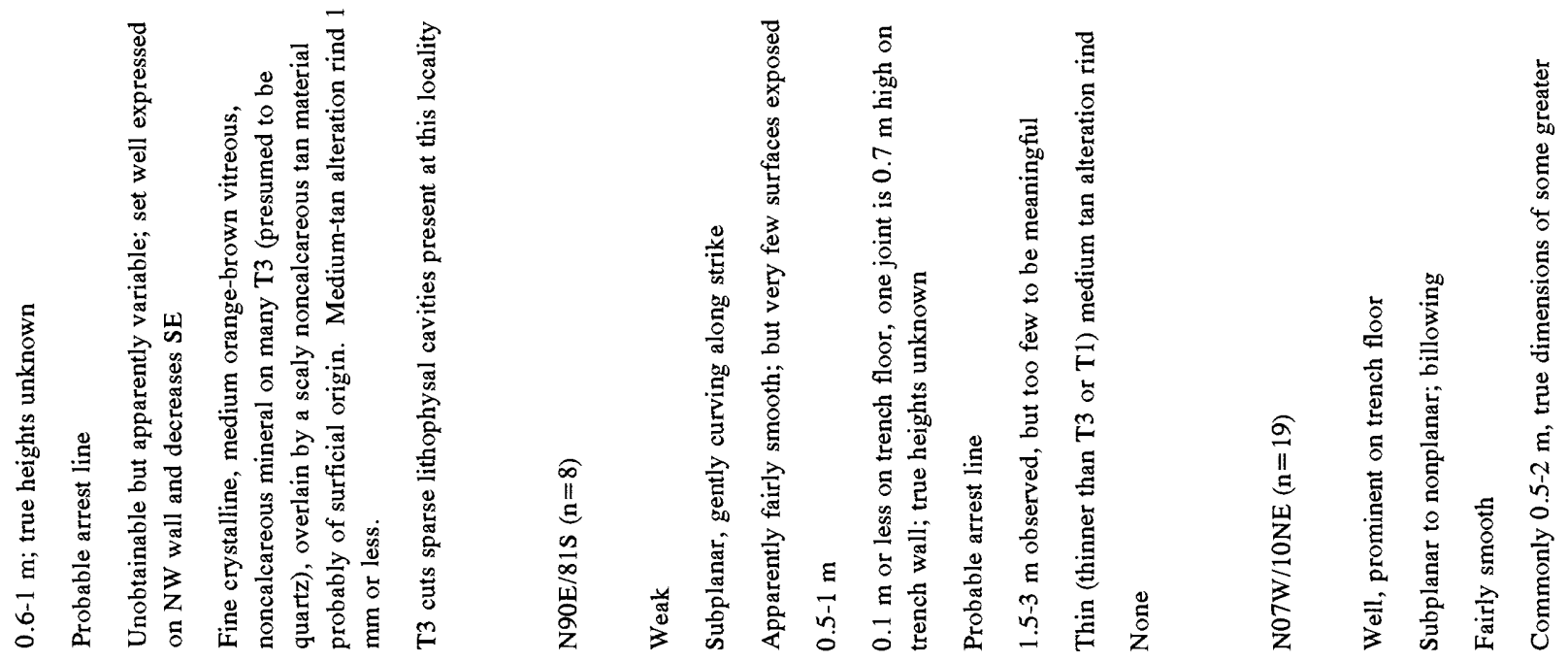

111
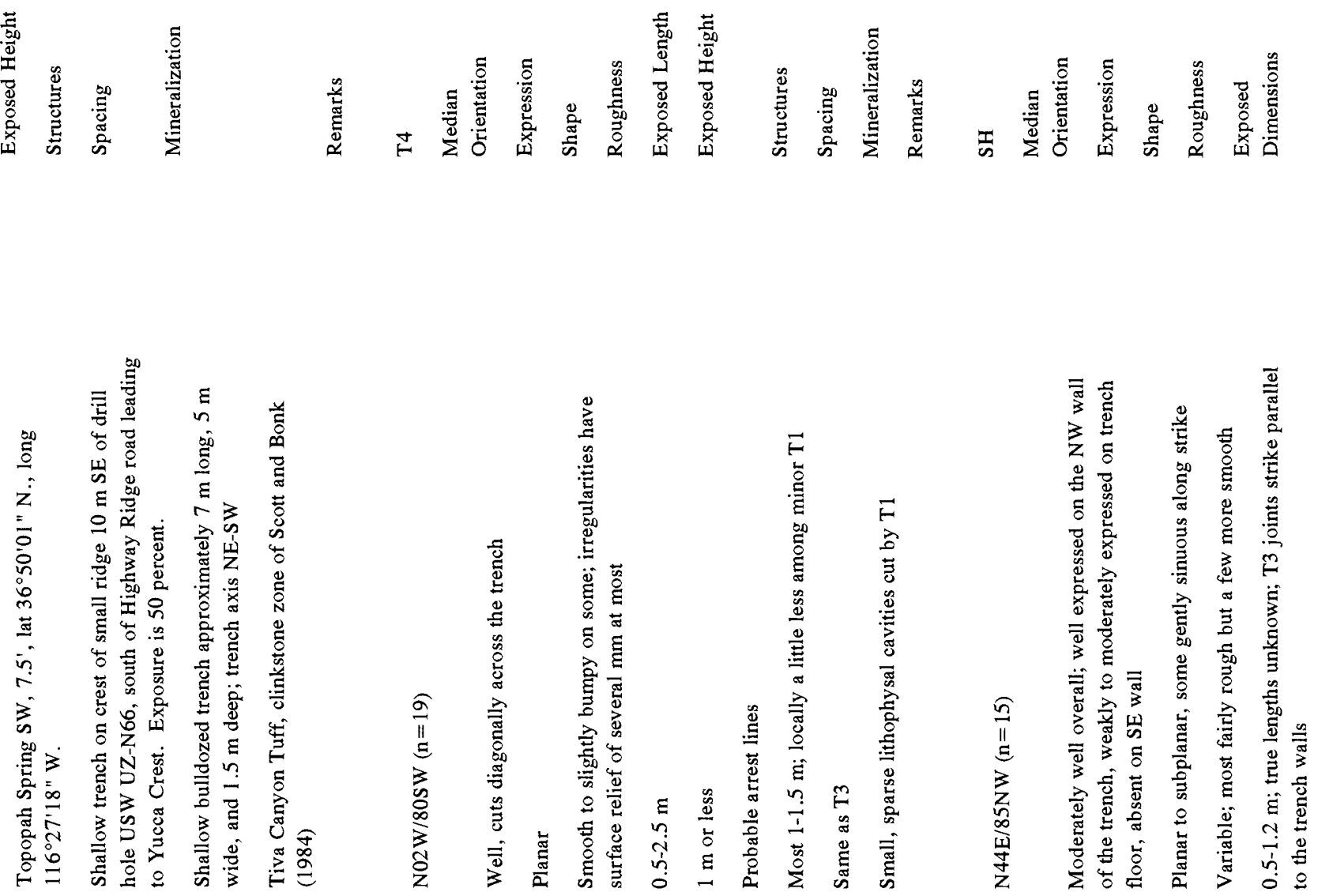

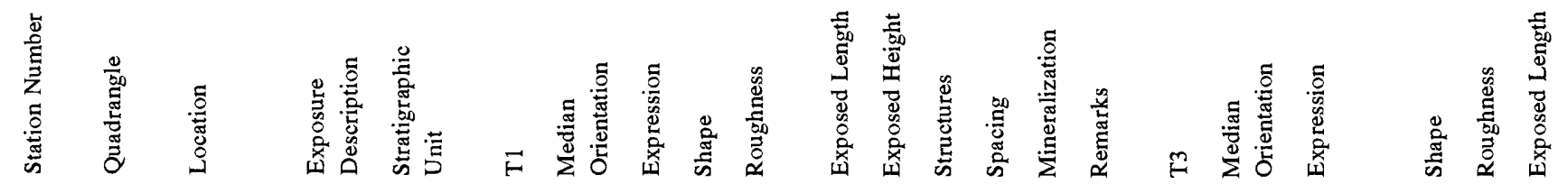




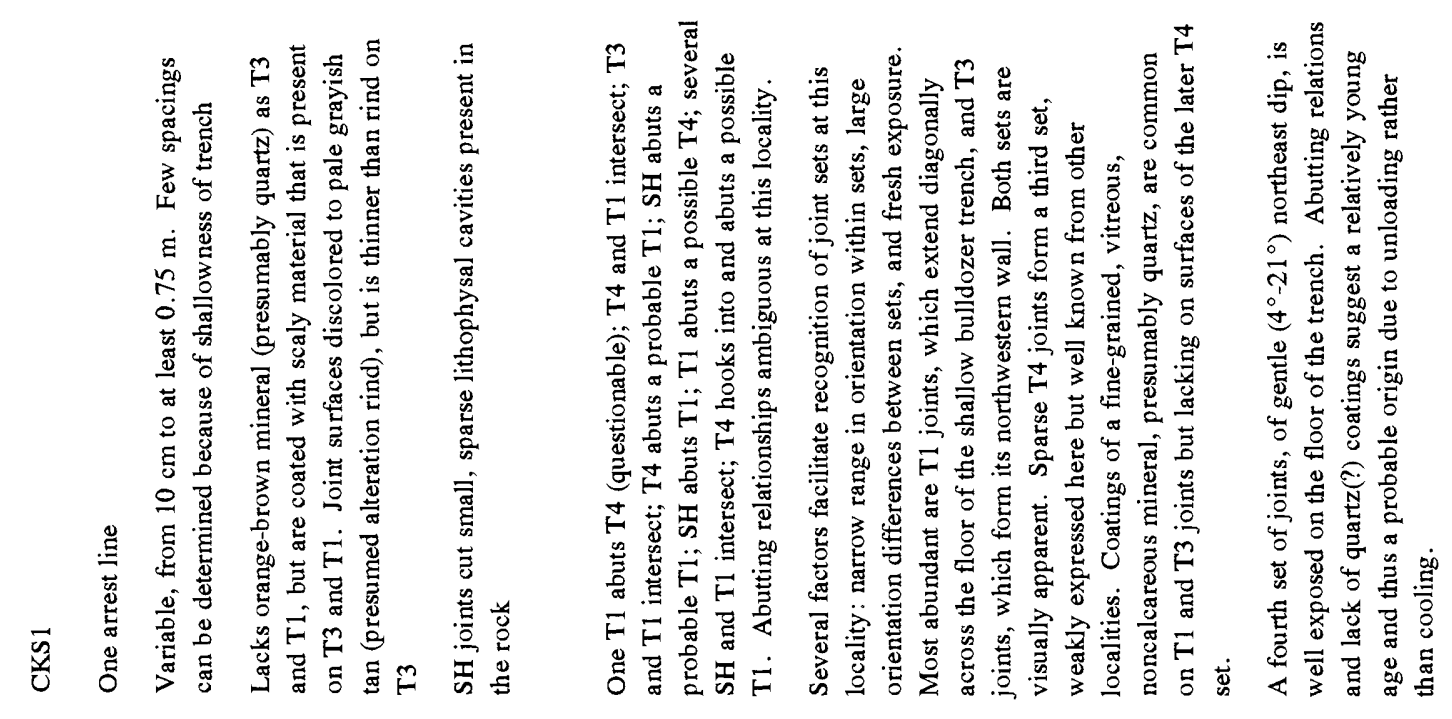

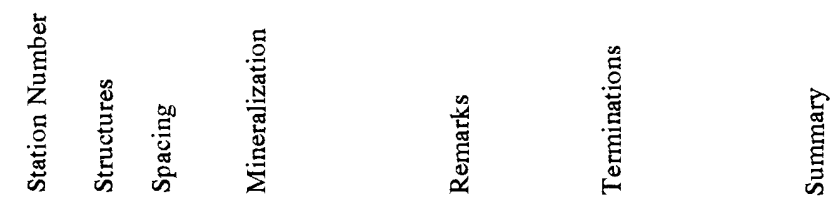



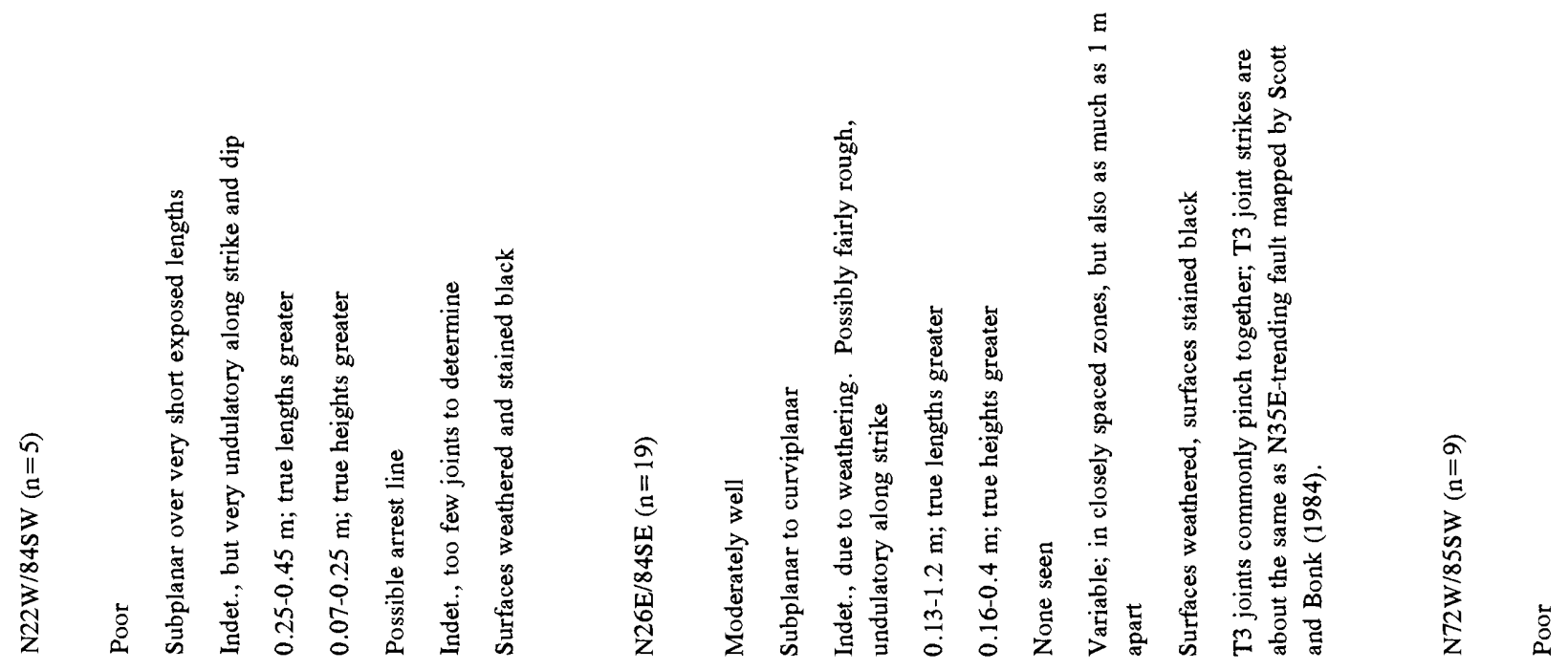

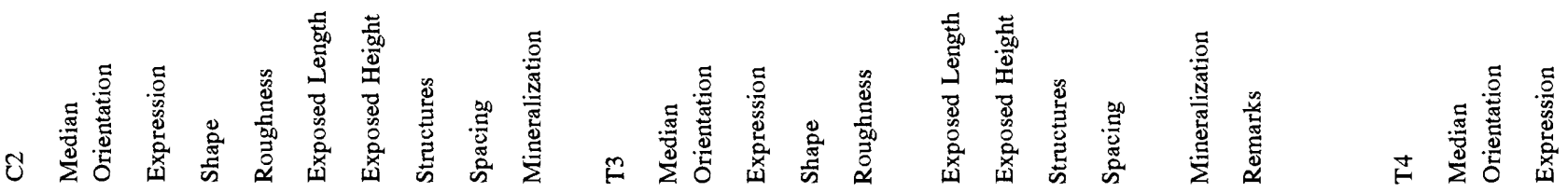

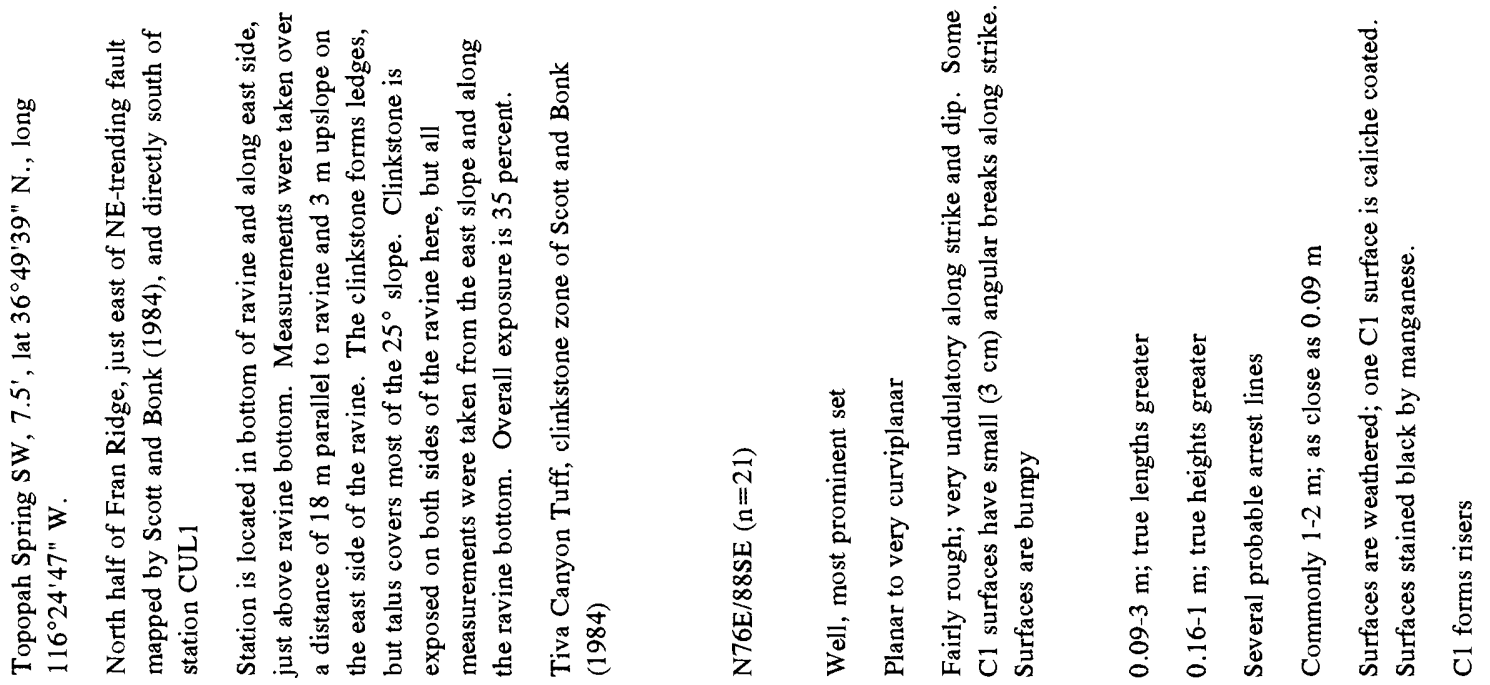

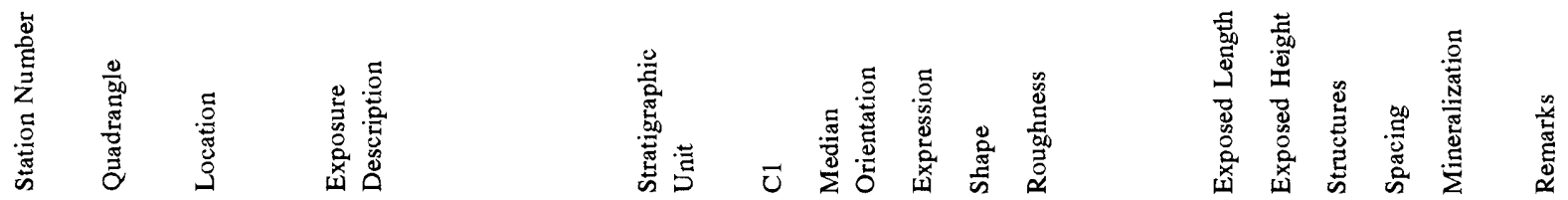



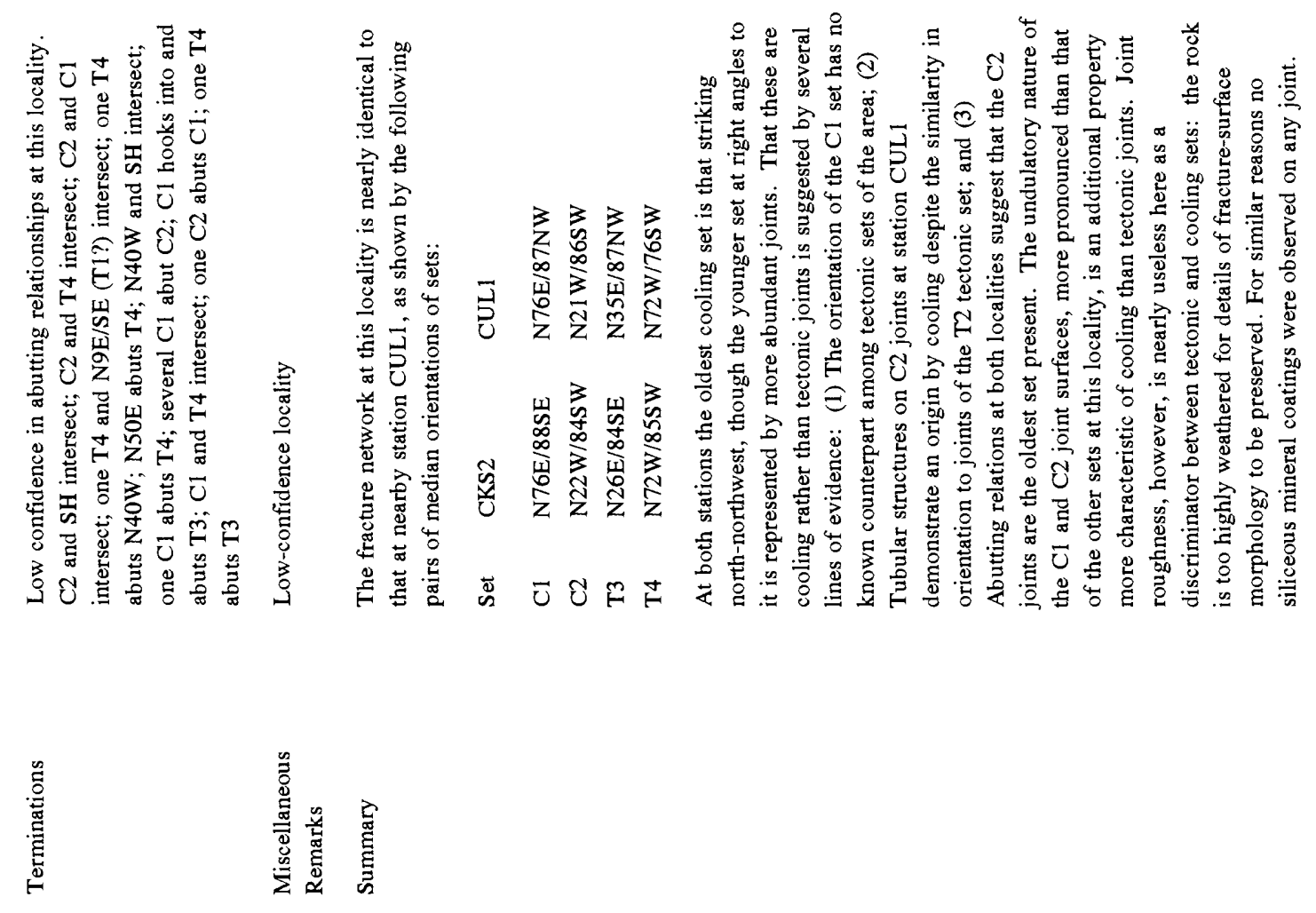

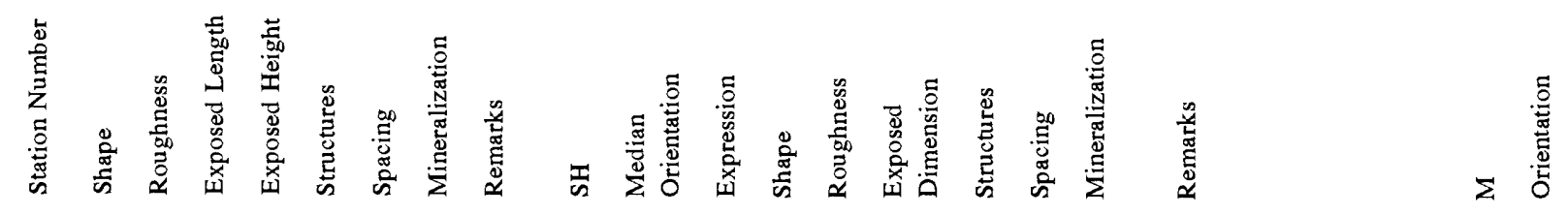




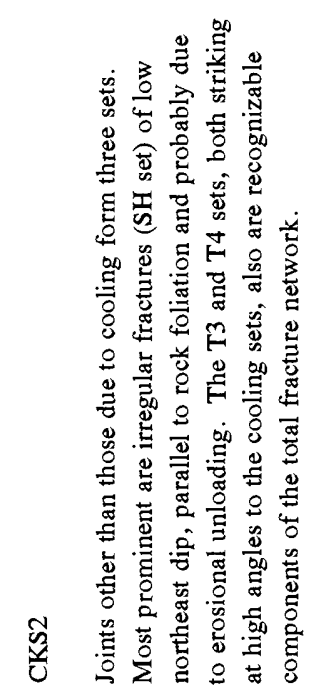

है 

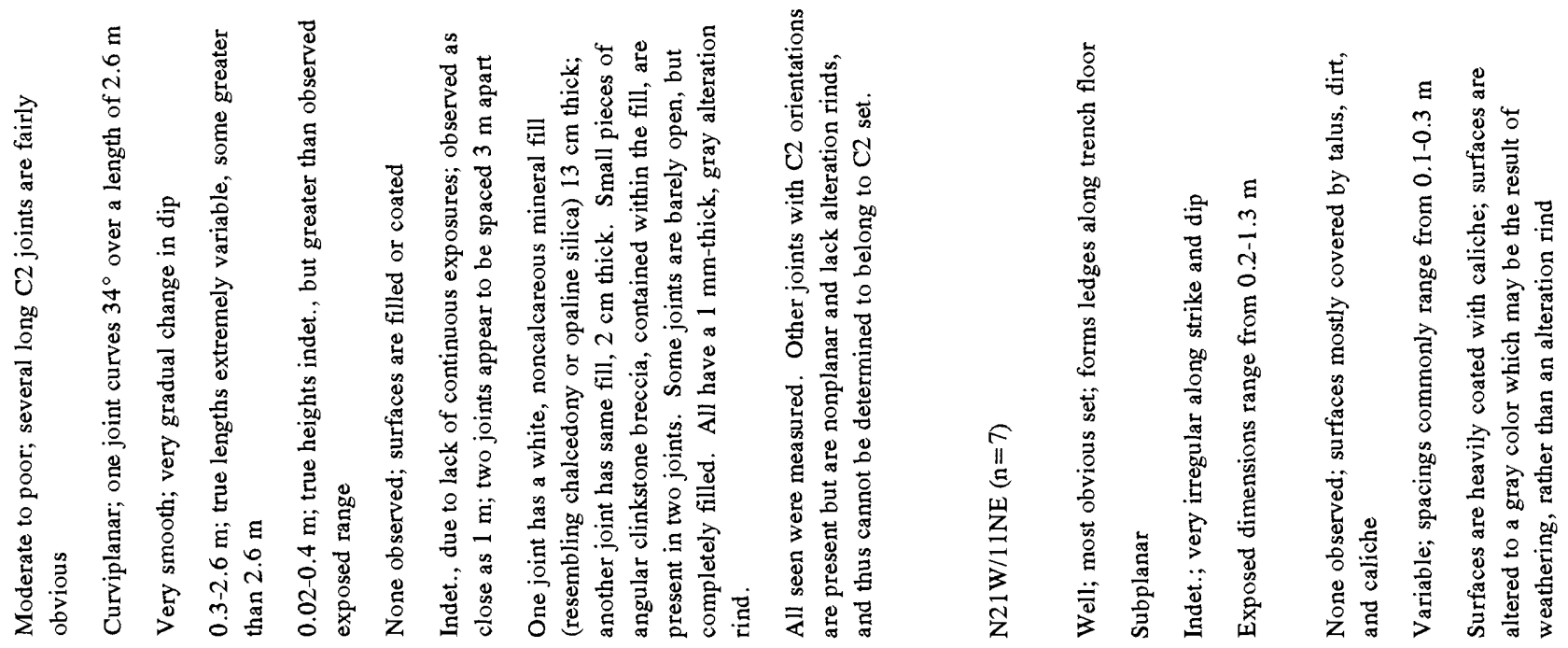

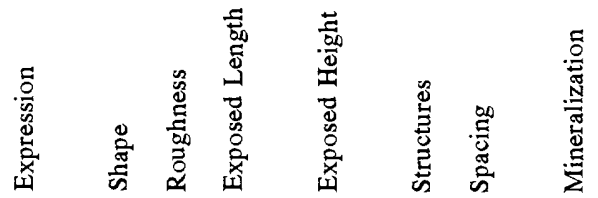

1 an! 1111

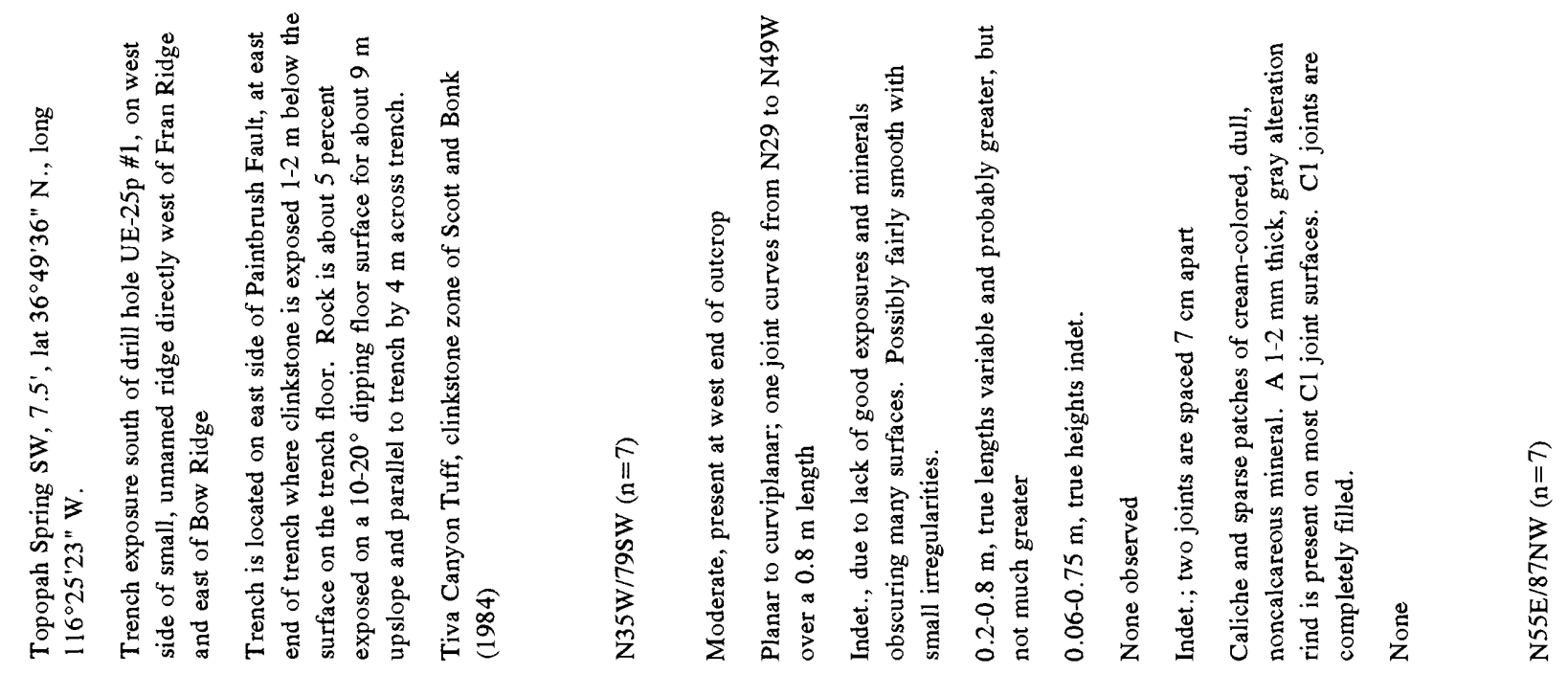

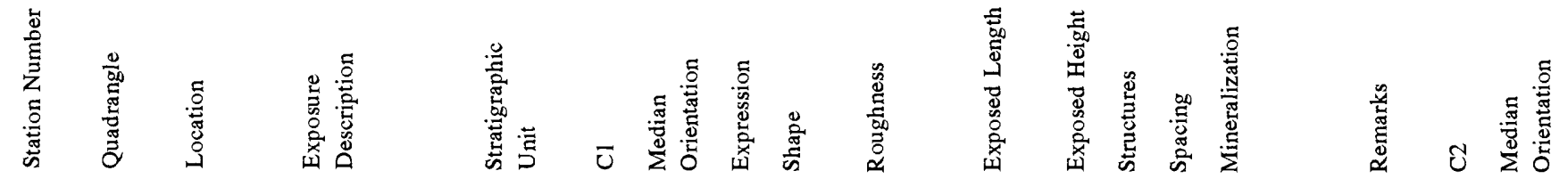




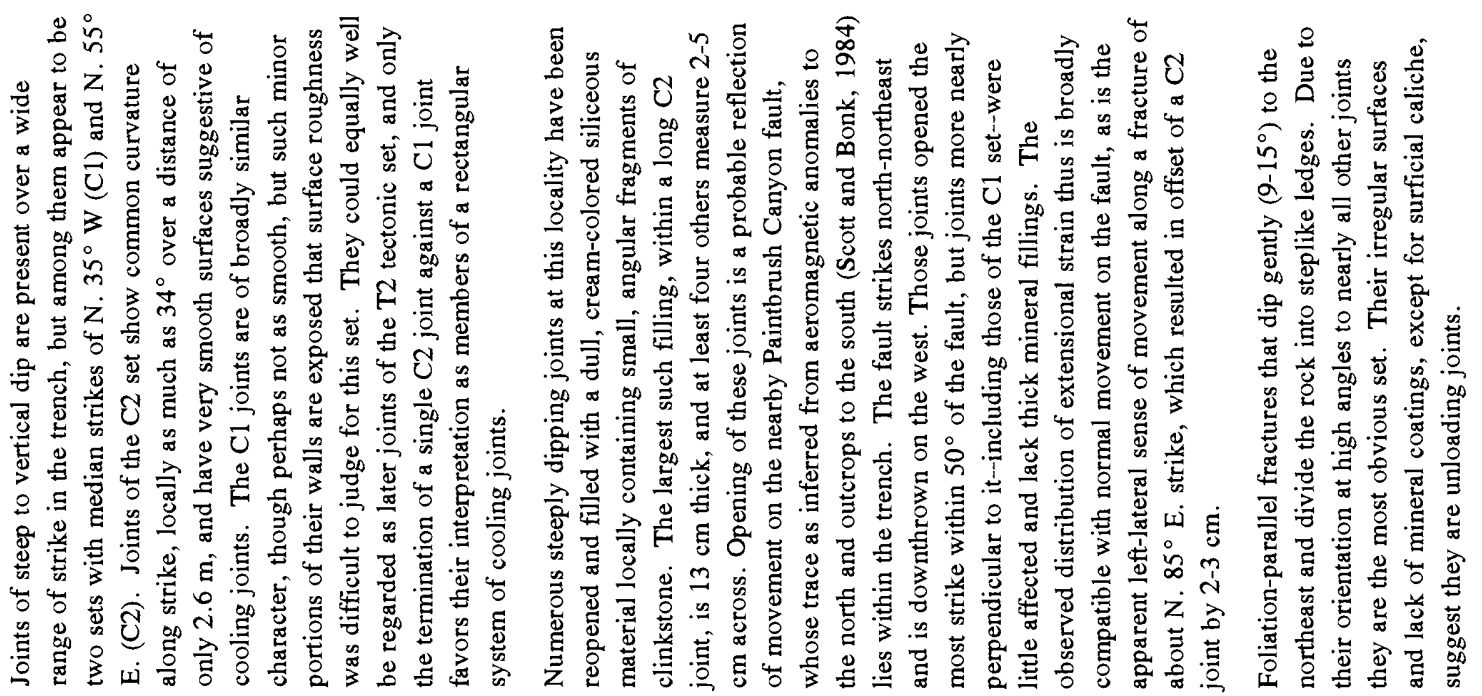

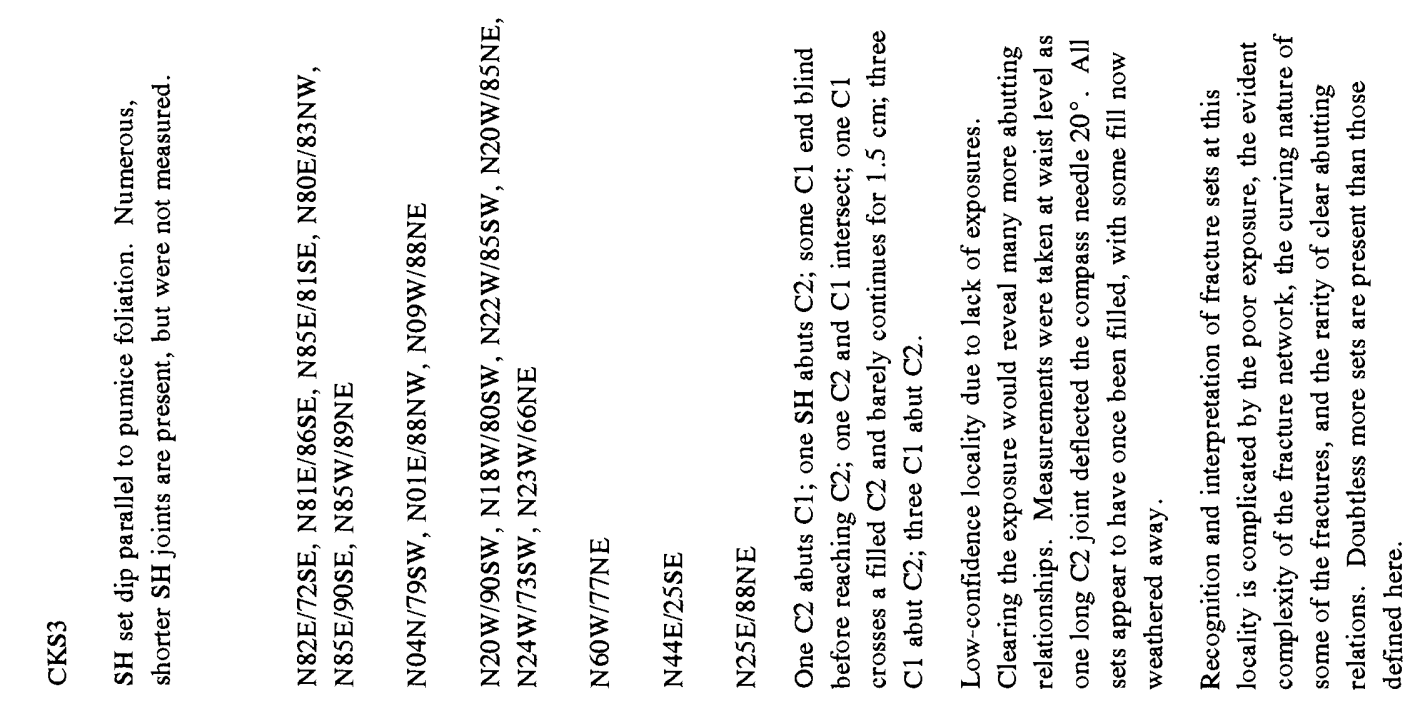

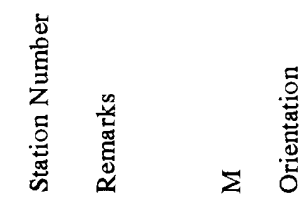

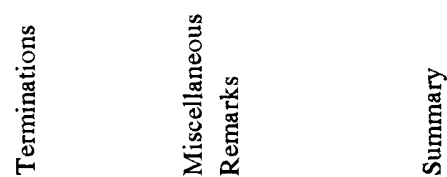



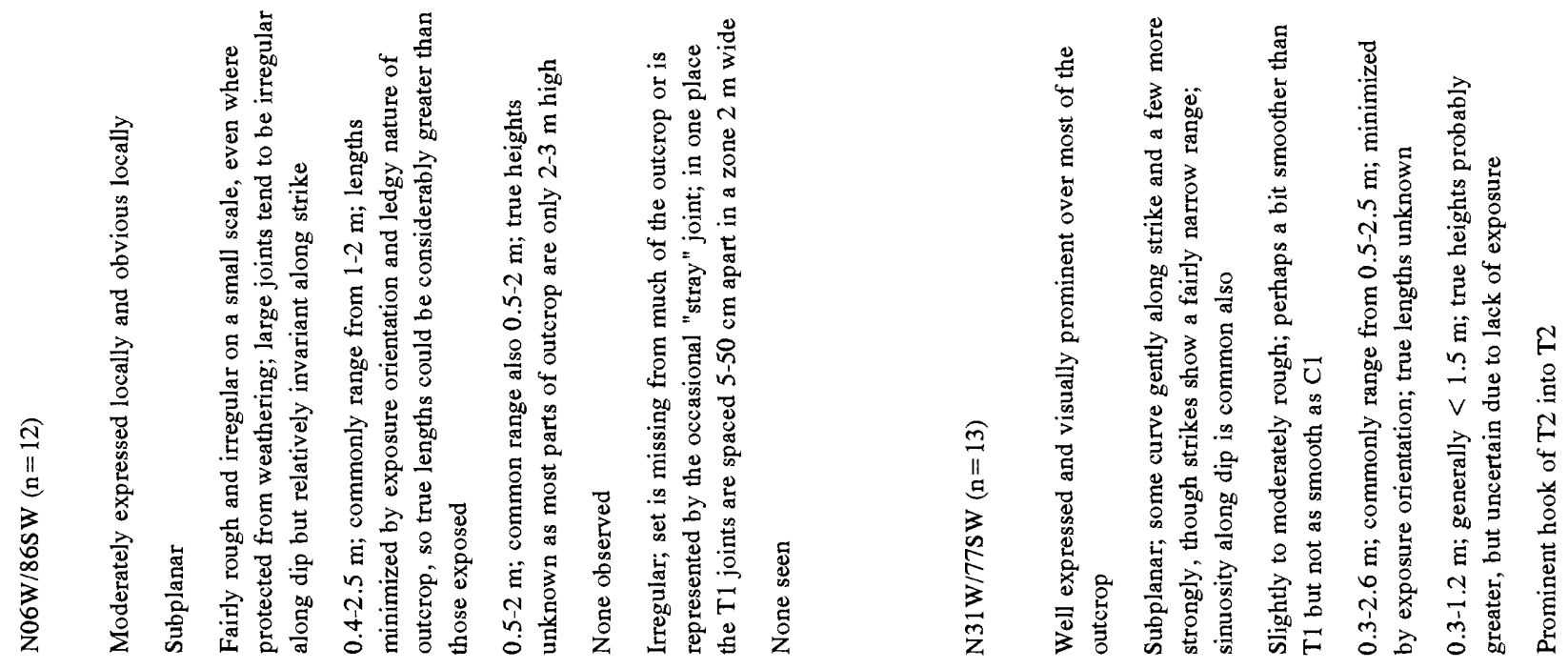

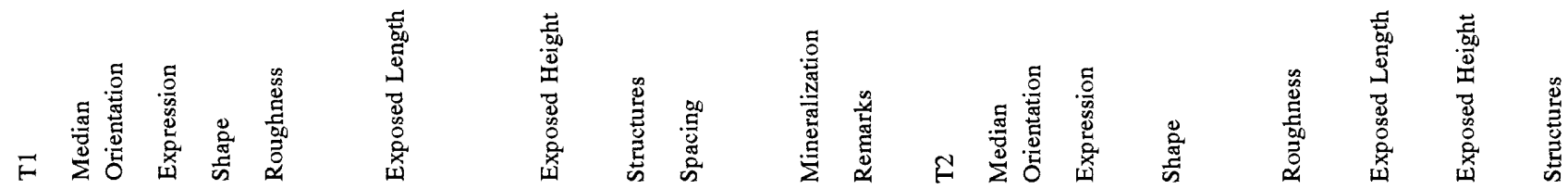

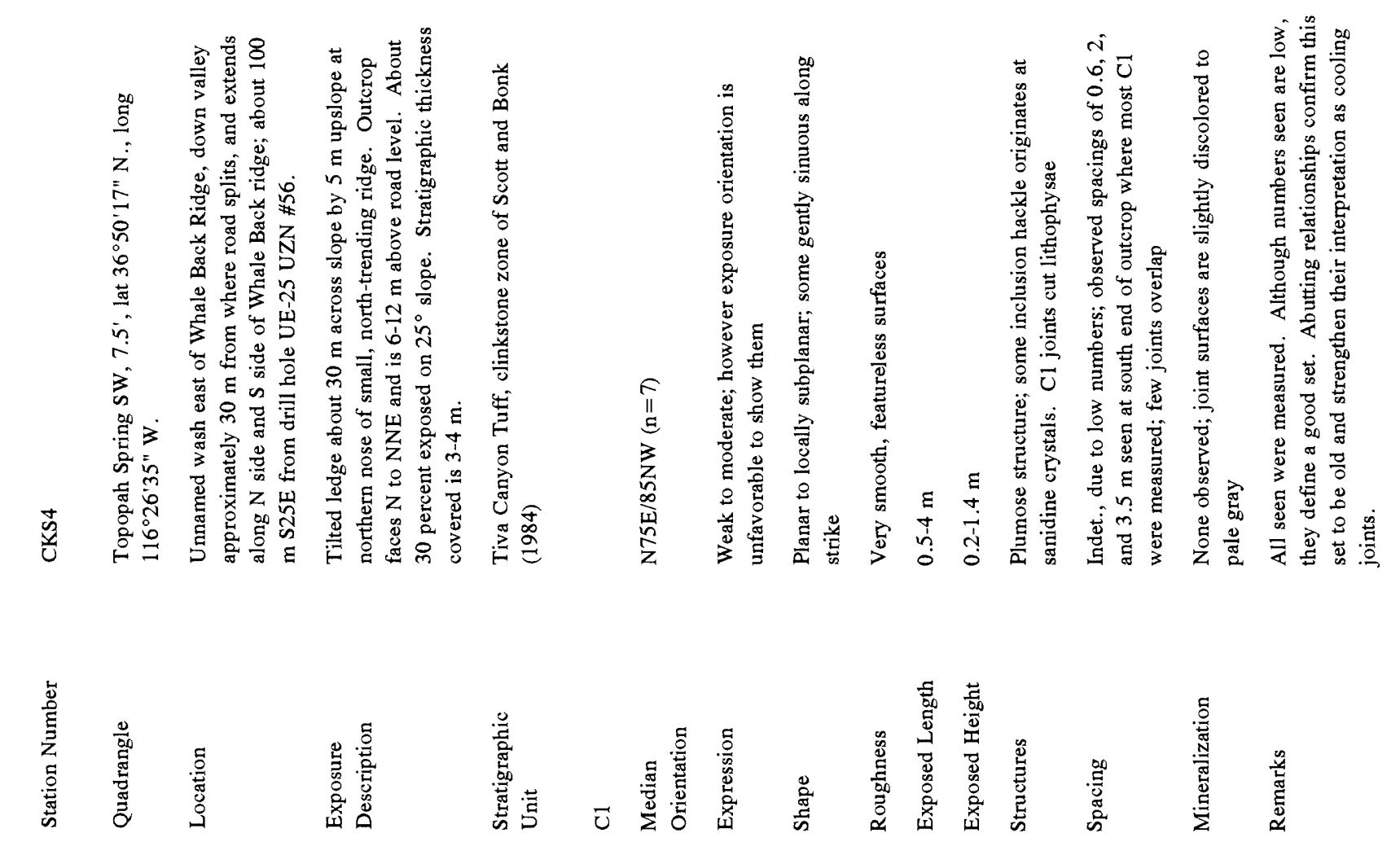




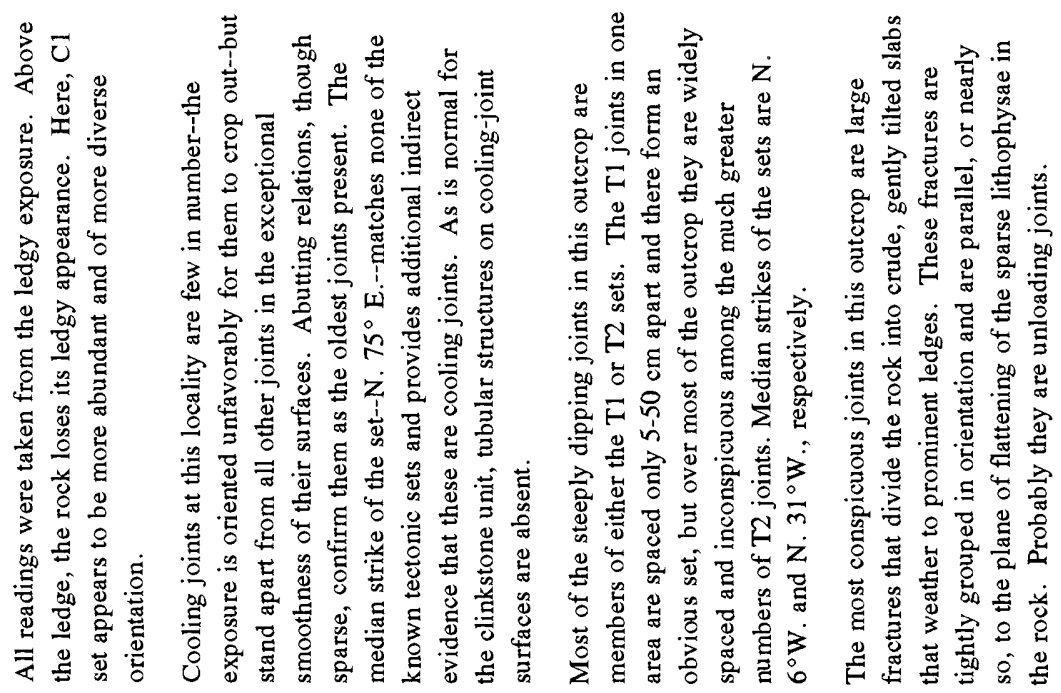

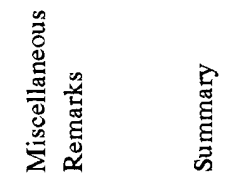

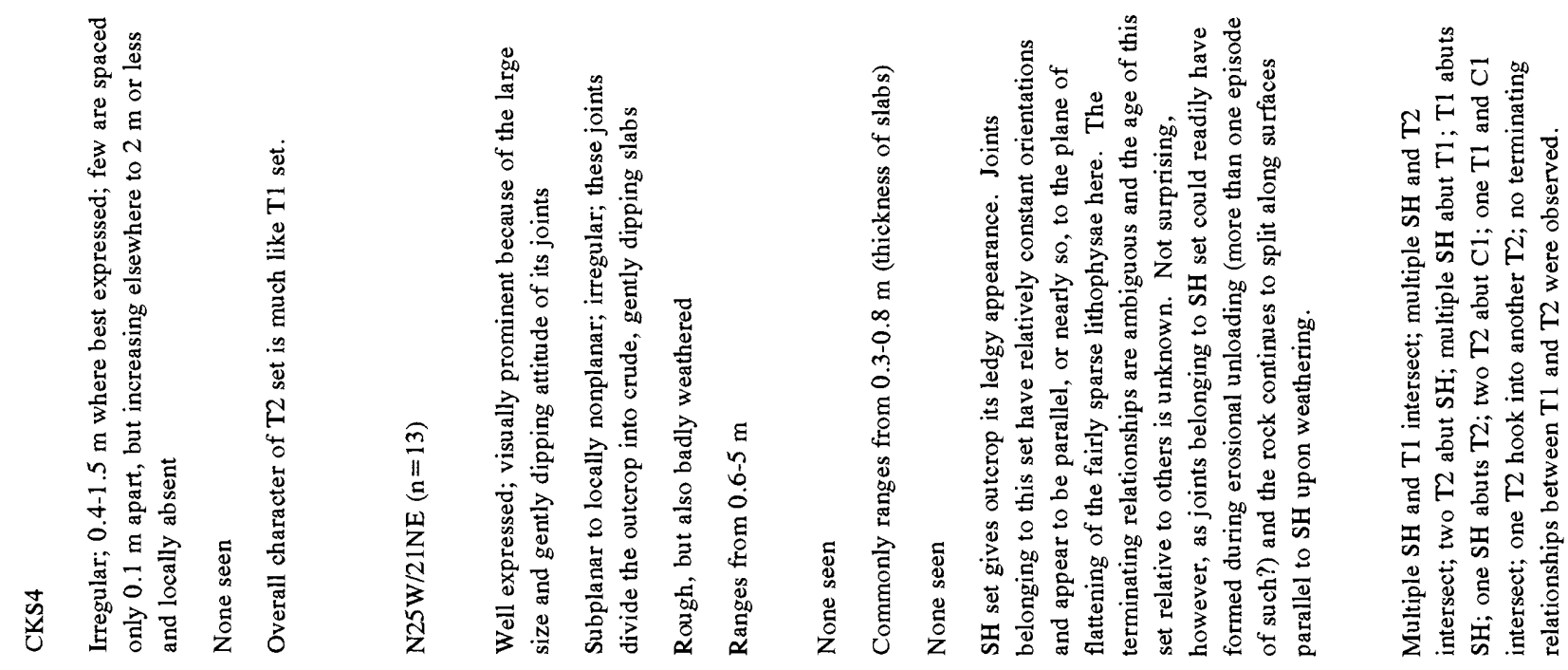

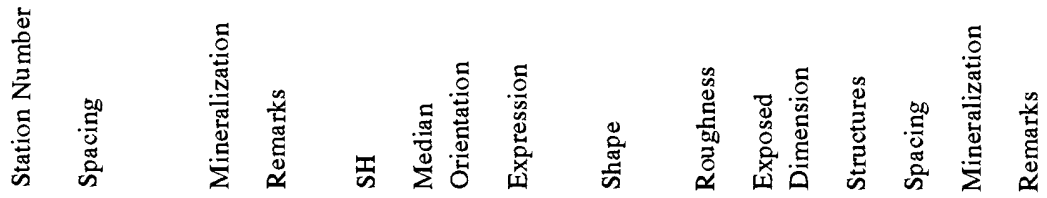

. 


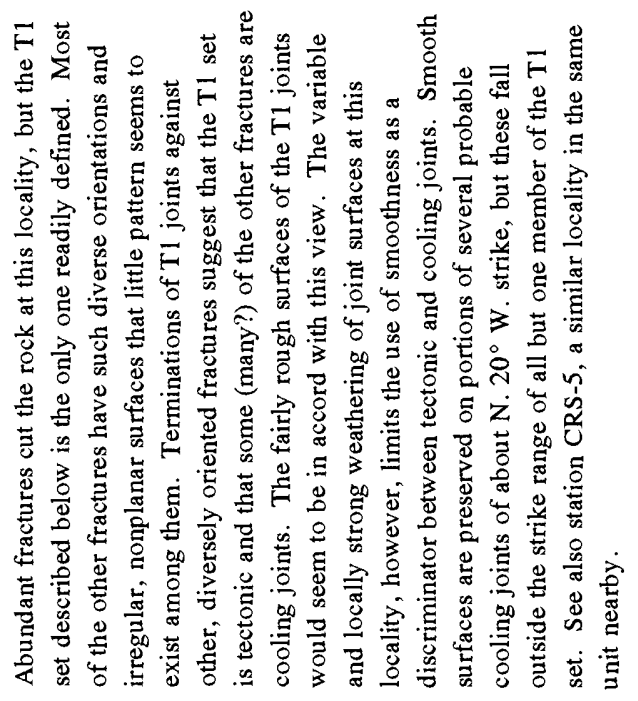

है

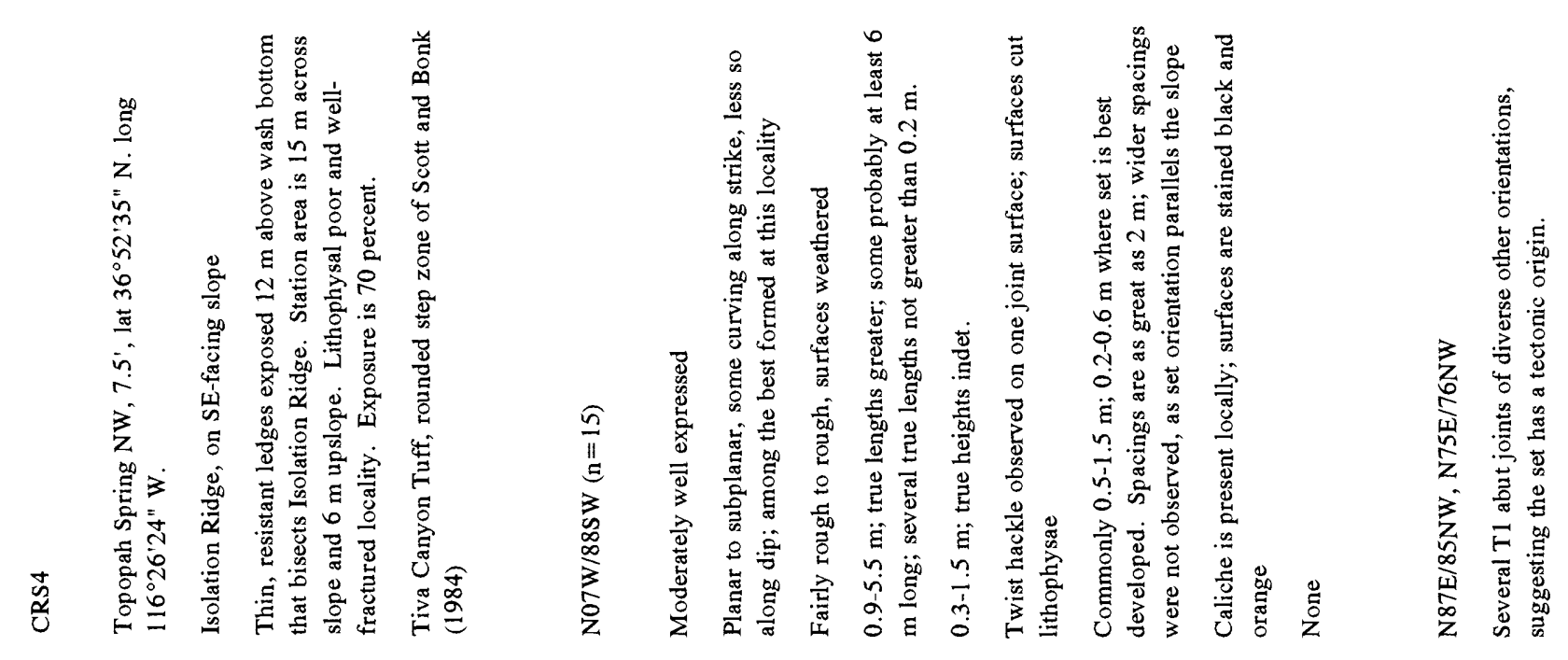

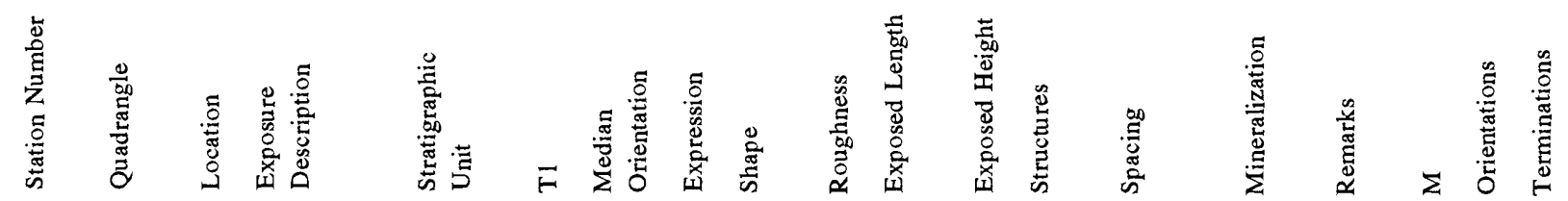




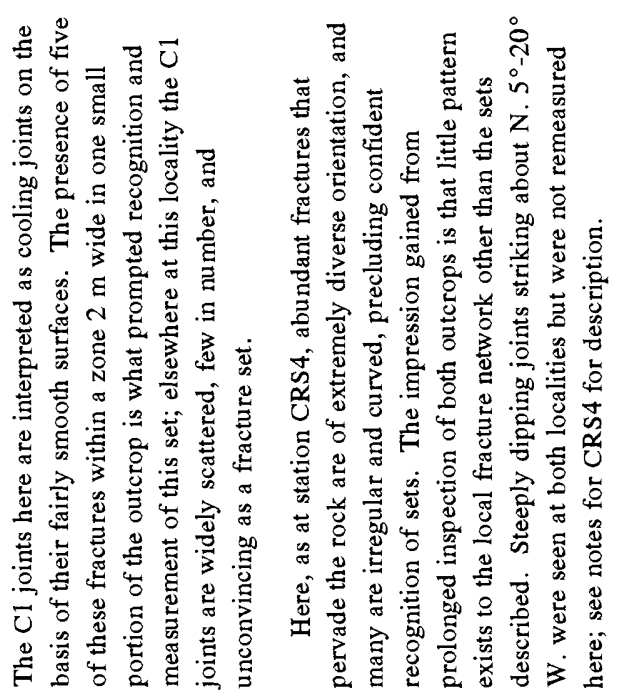

हू

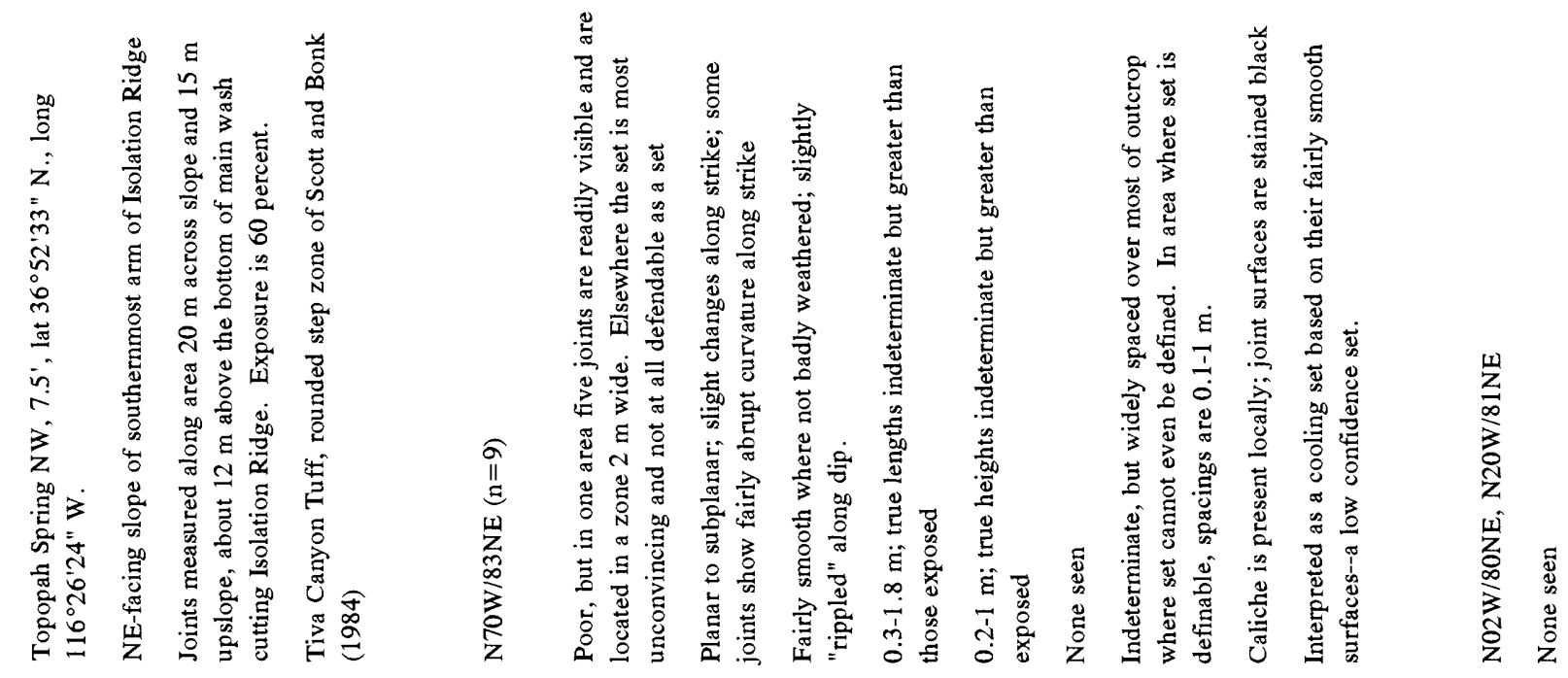

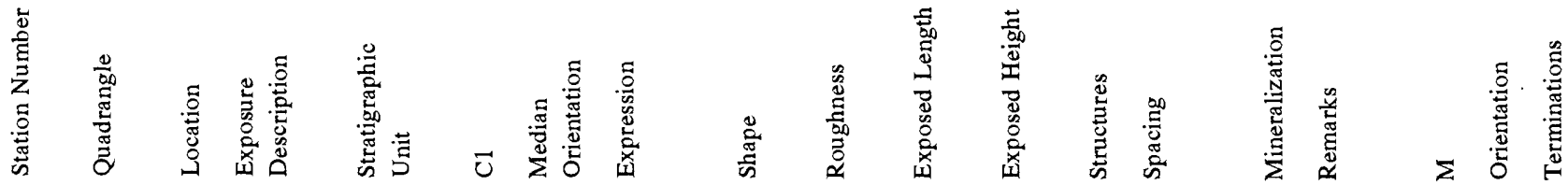



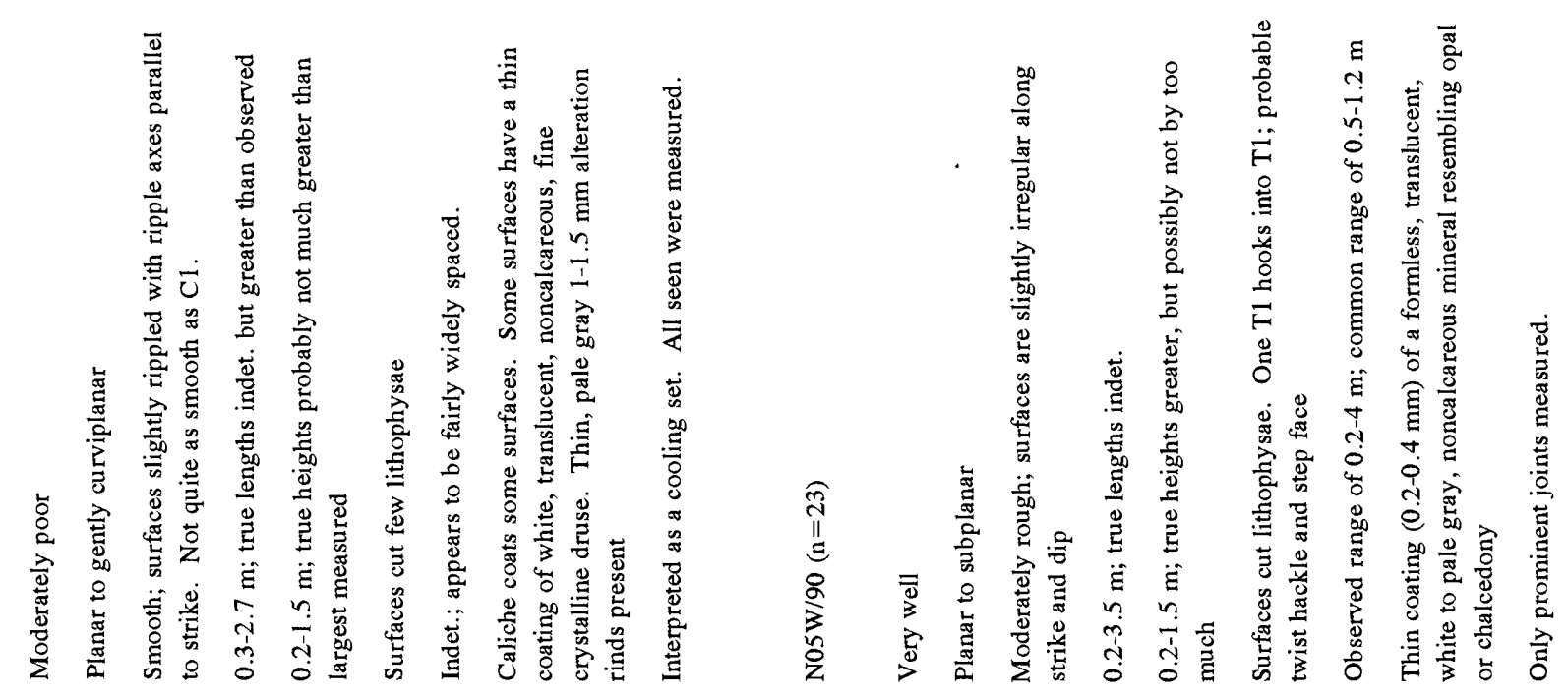

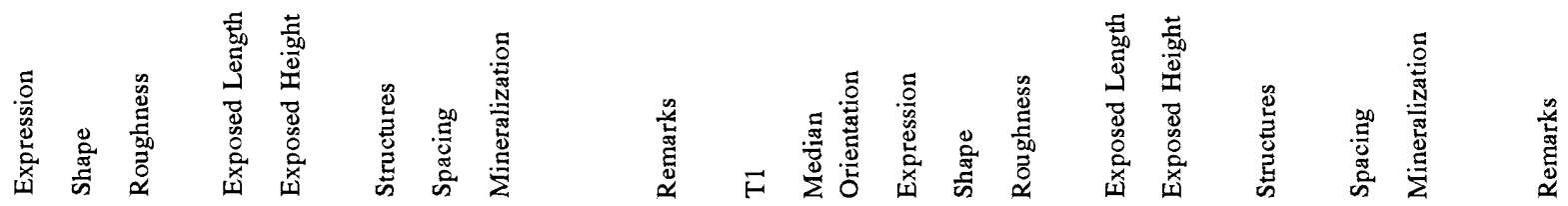

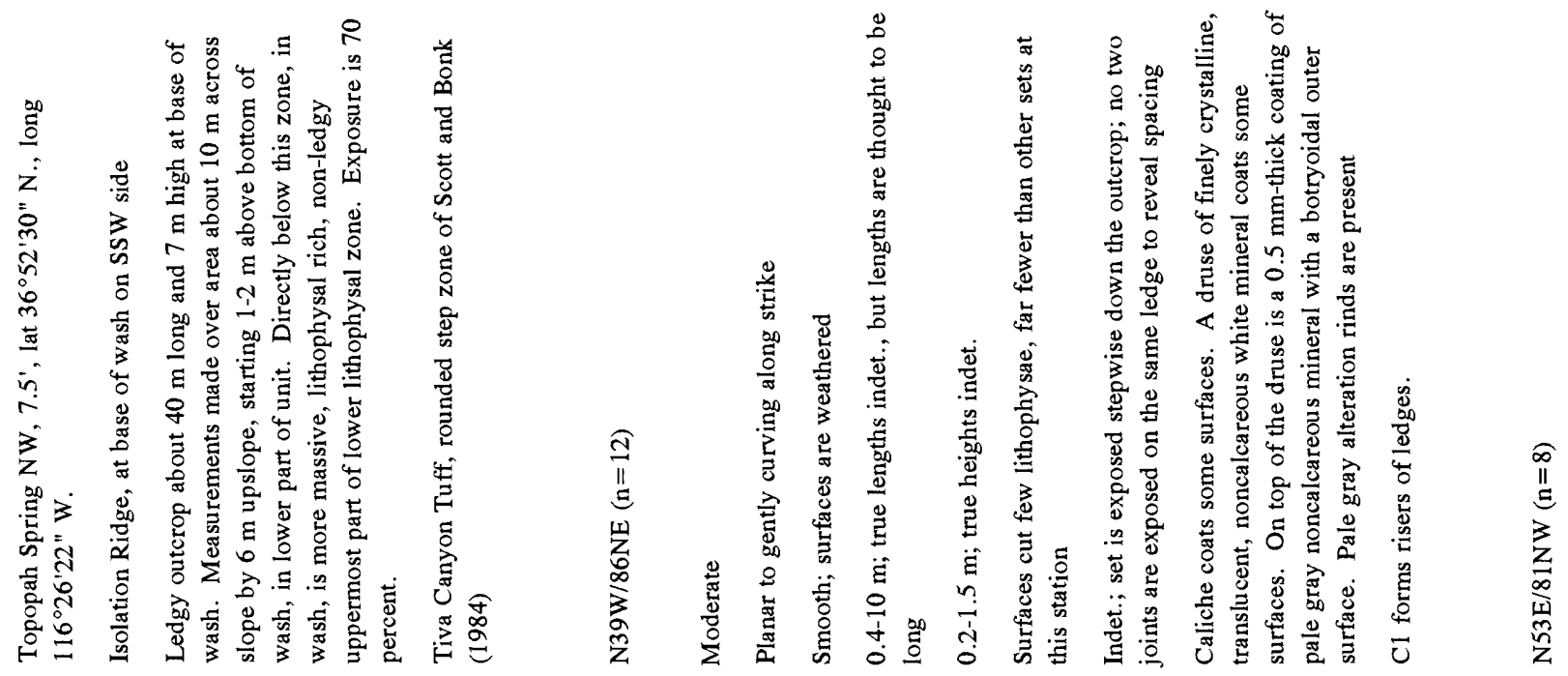

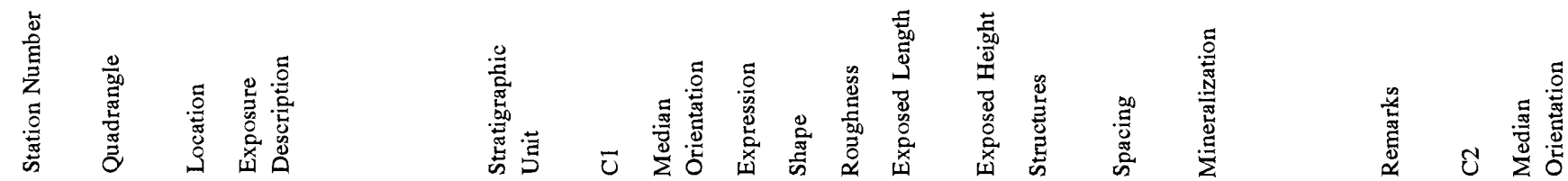




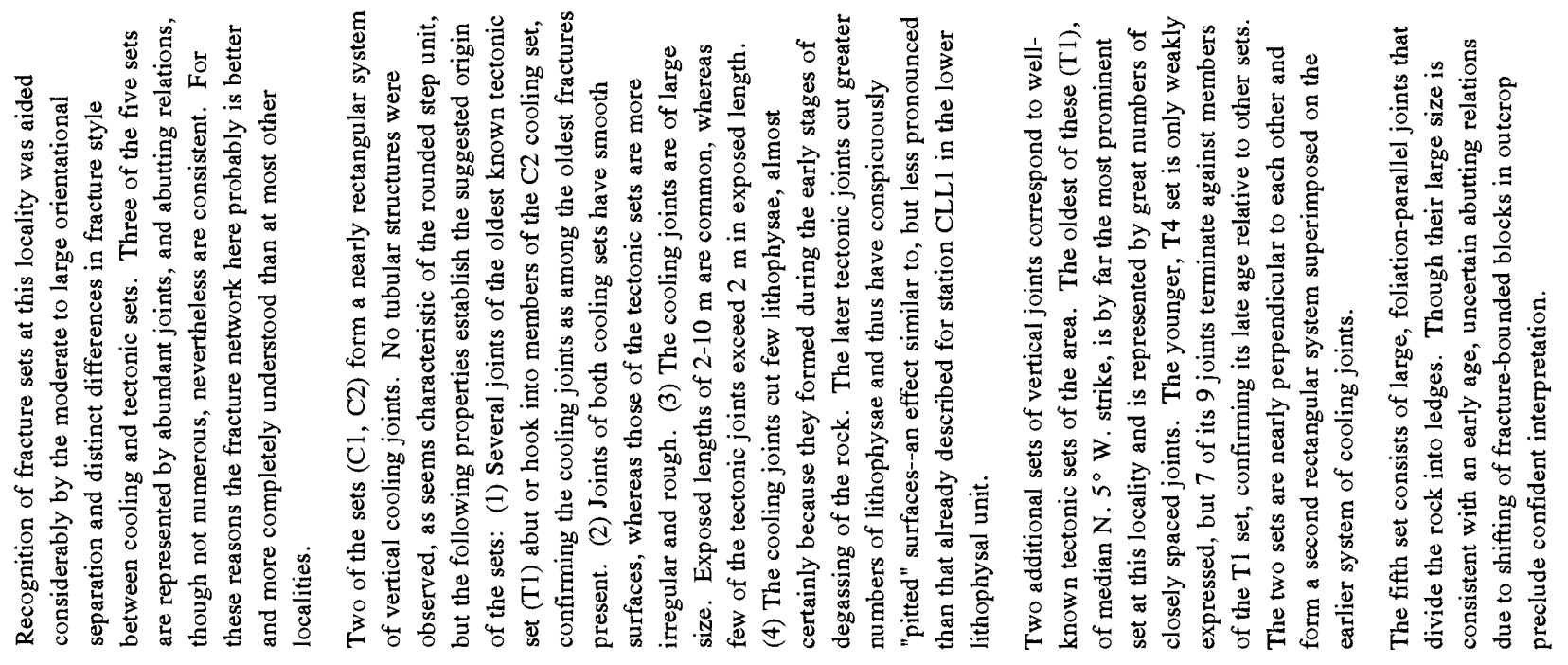

हूँ
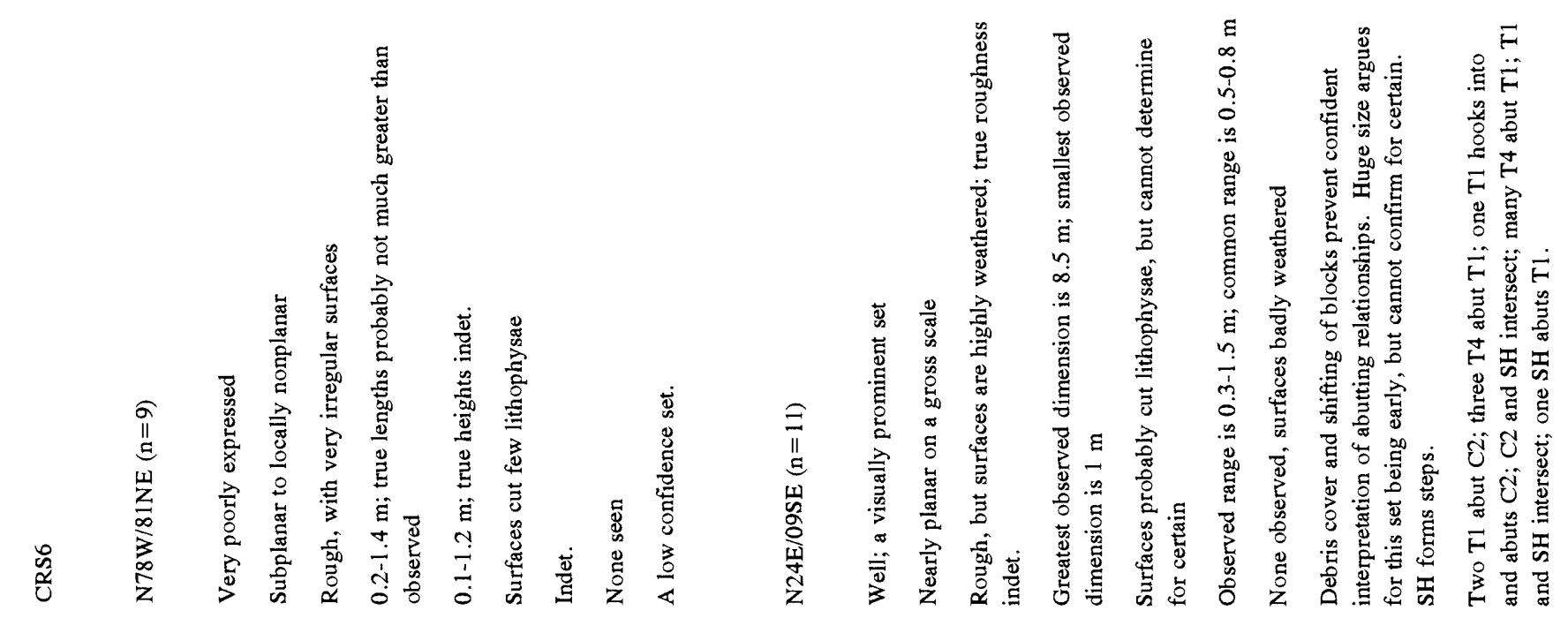

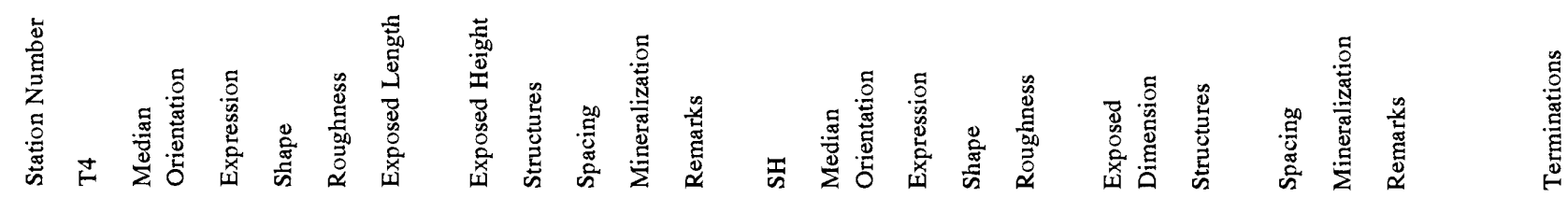




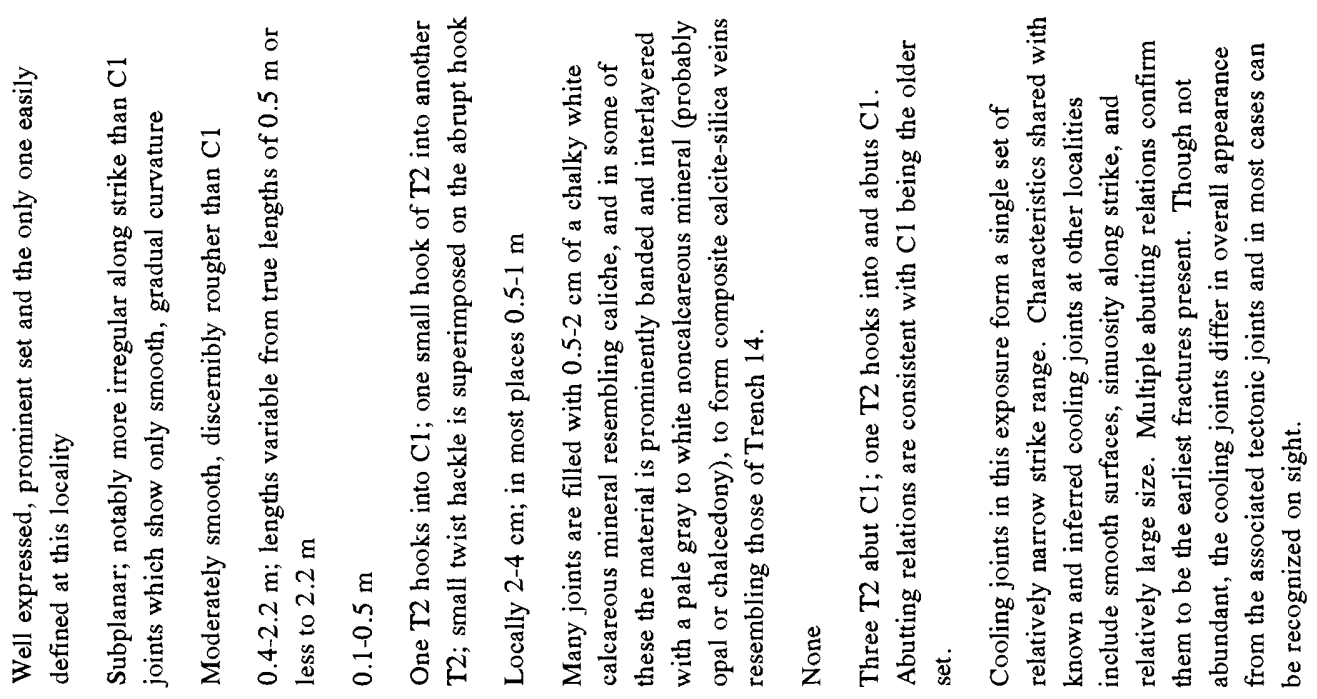

I

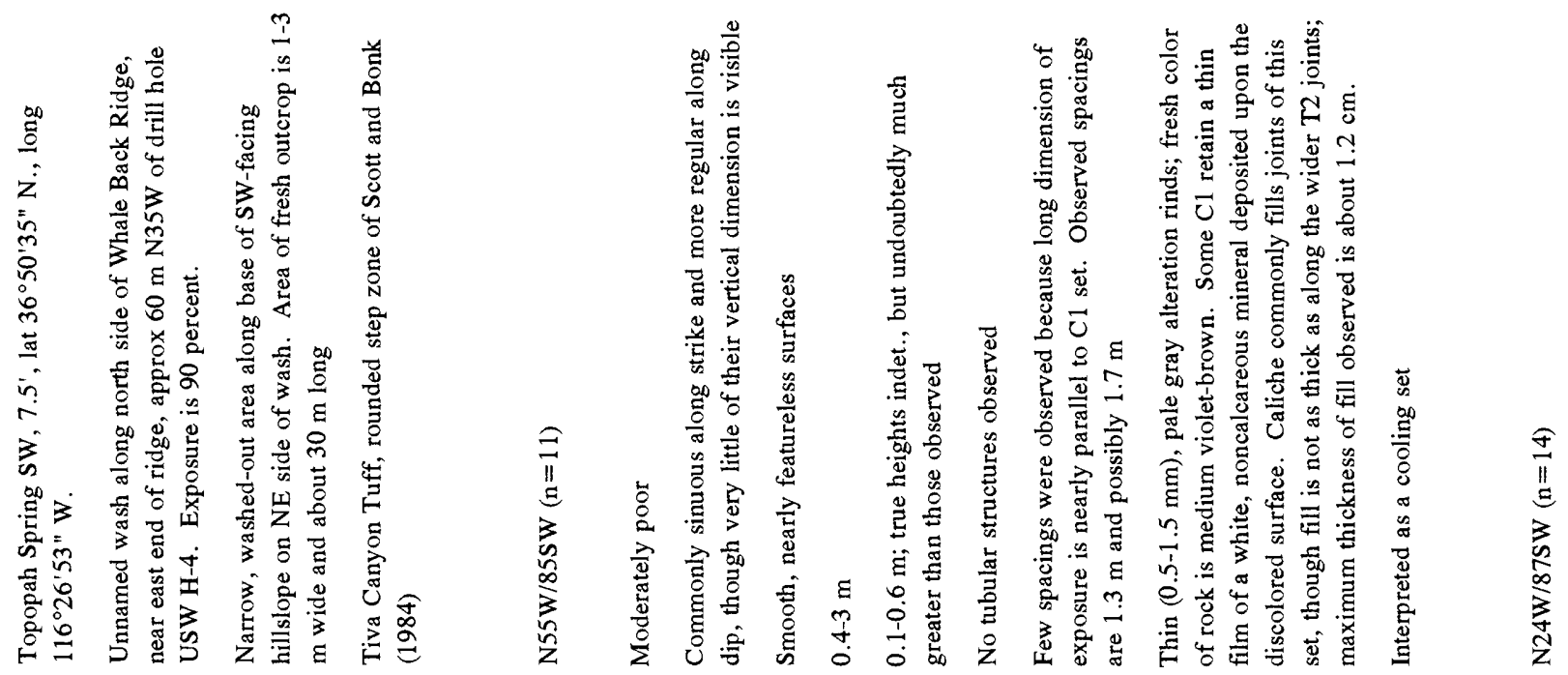

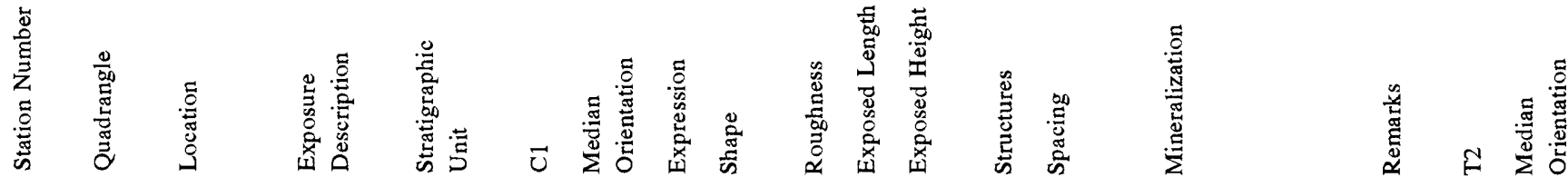


8

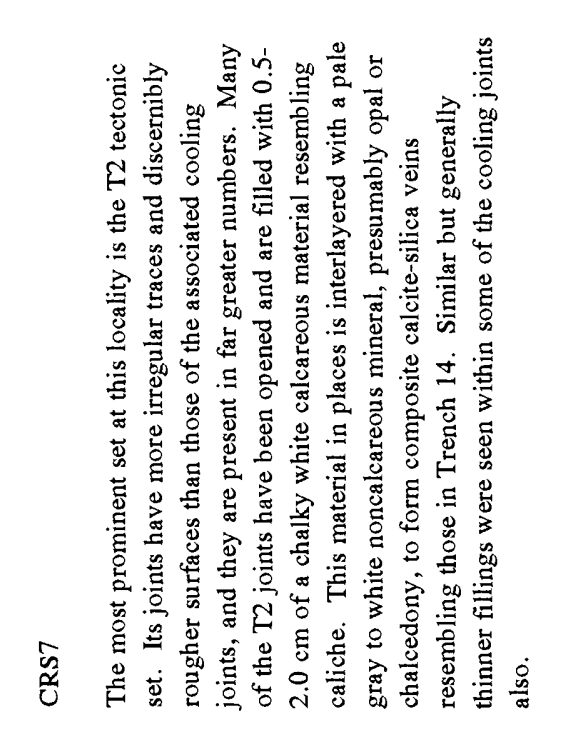

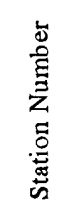




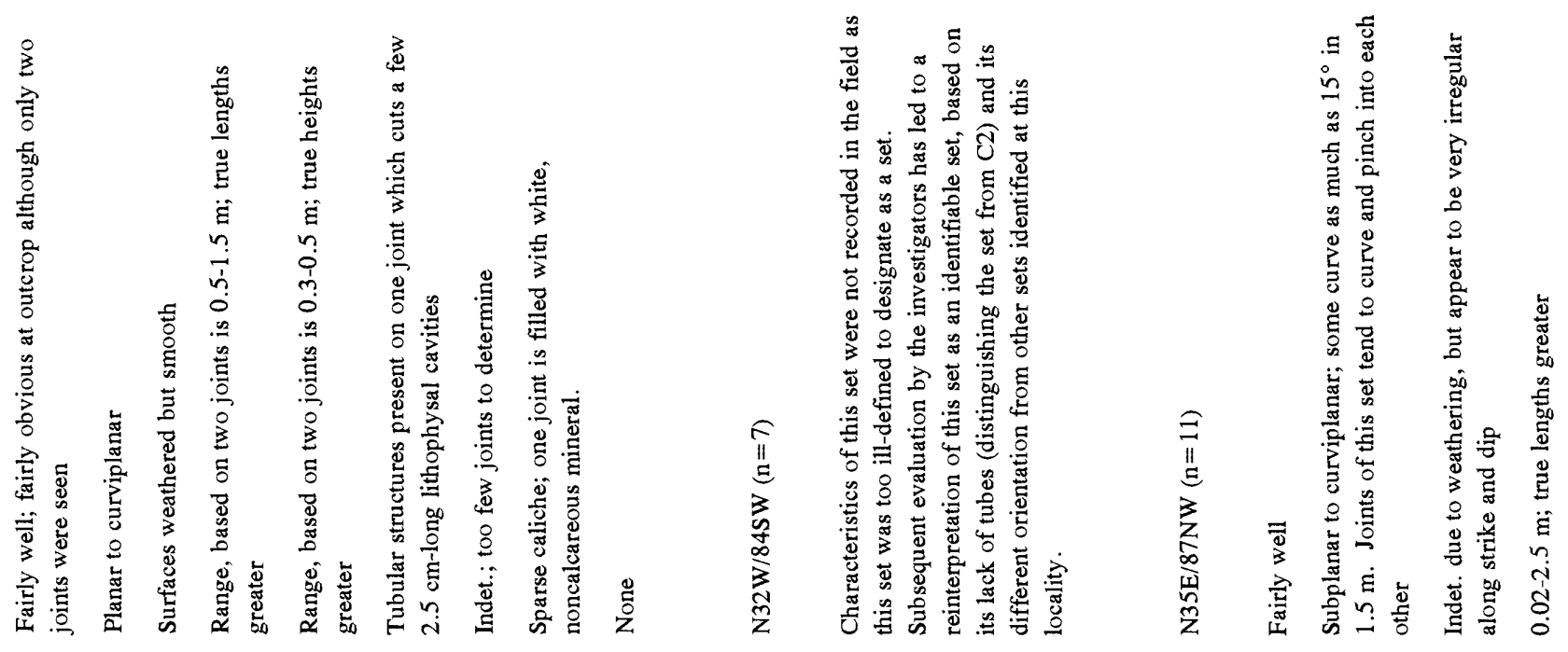

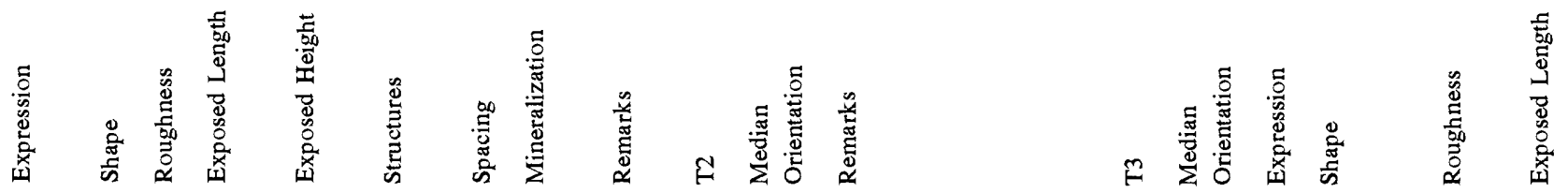

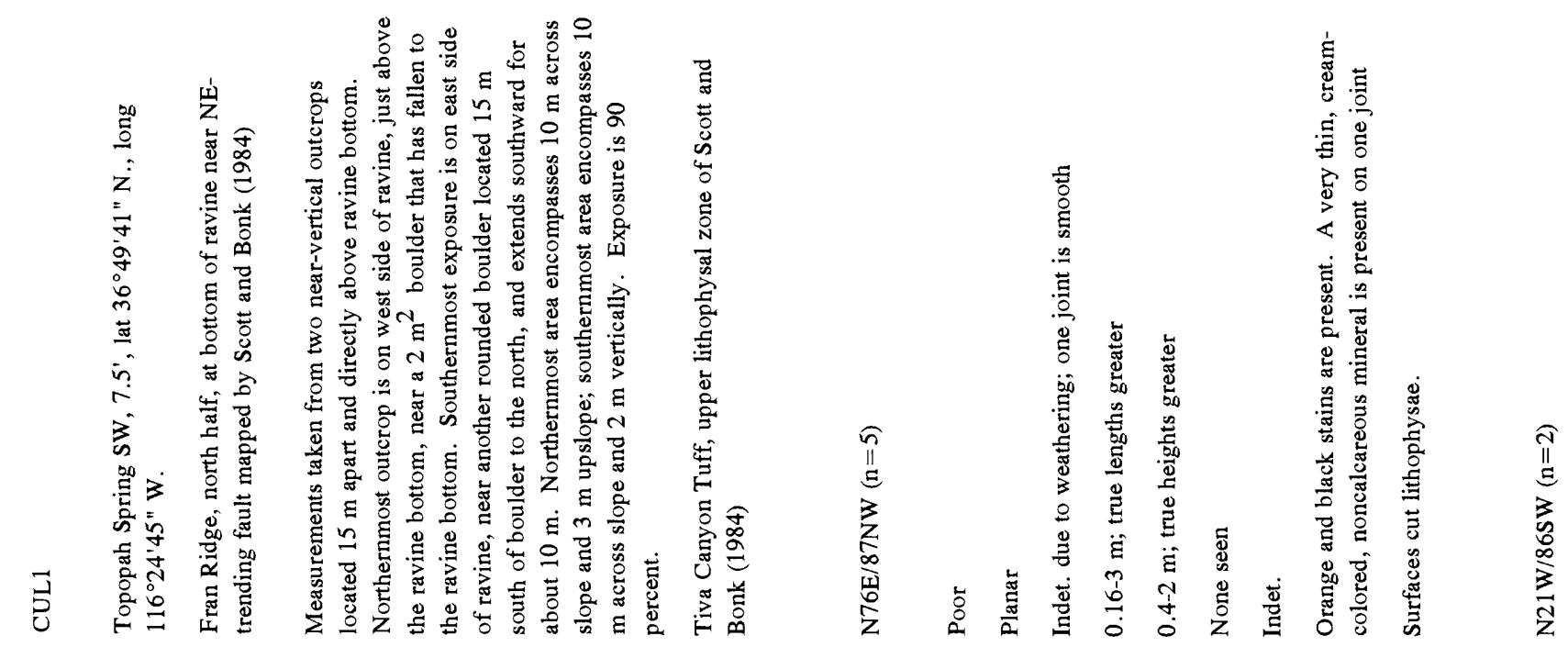

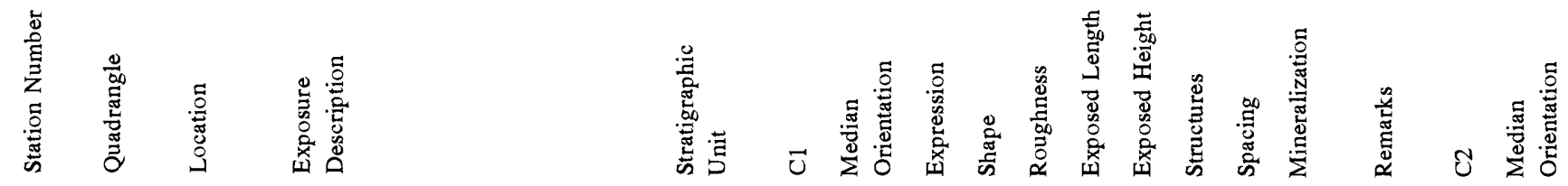




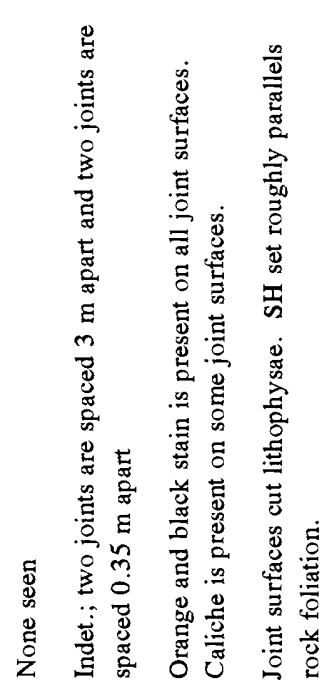

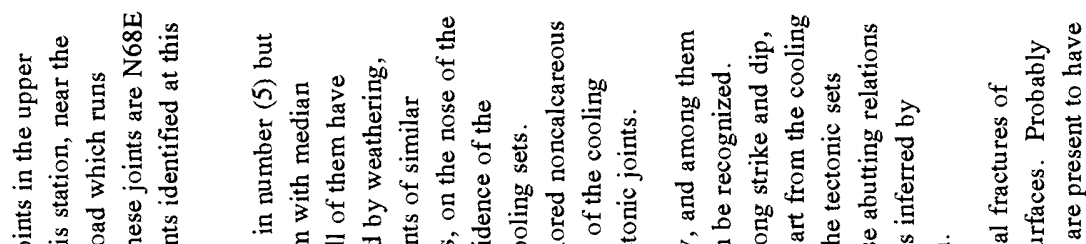

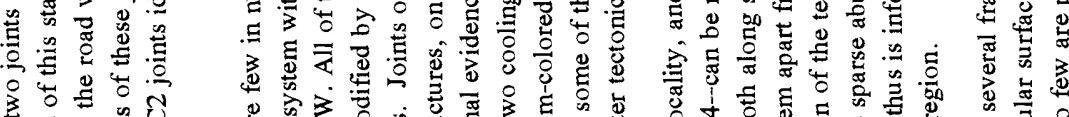

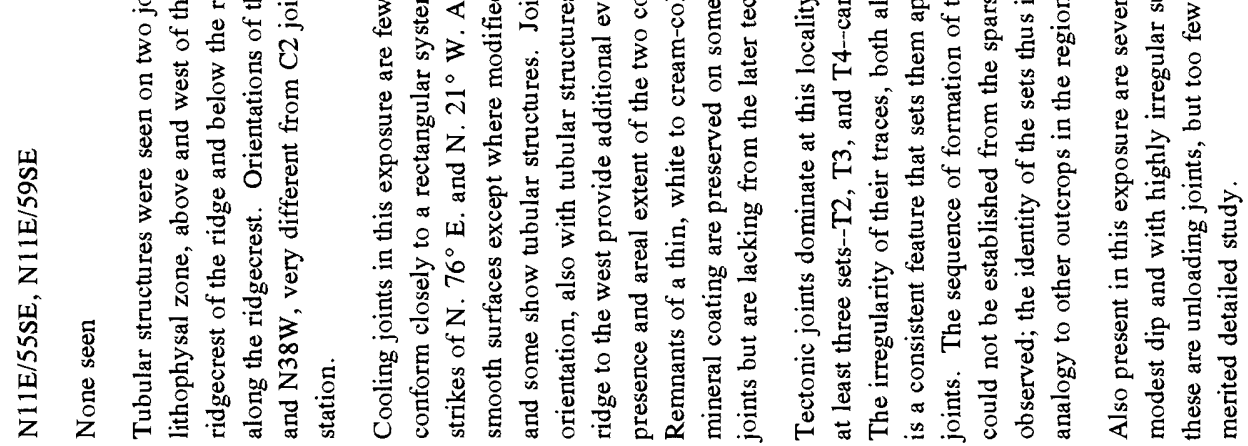

$\|1\|$,

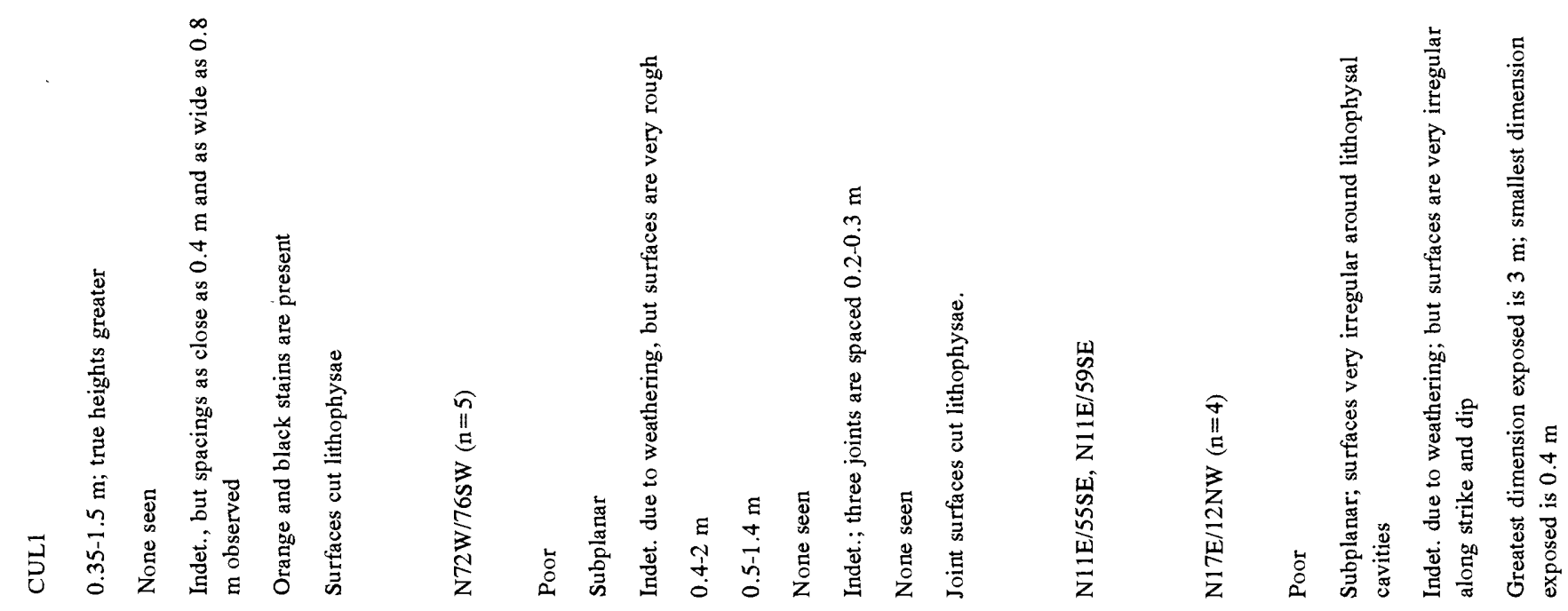

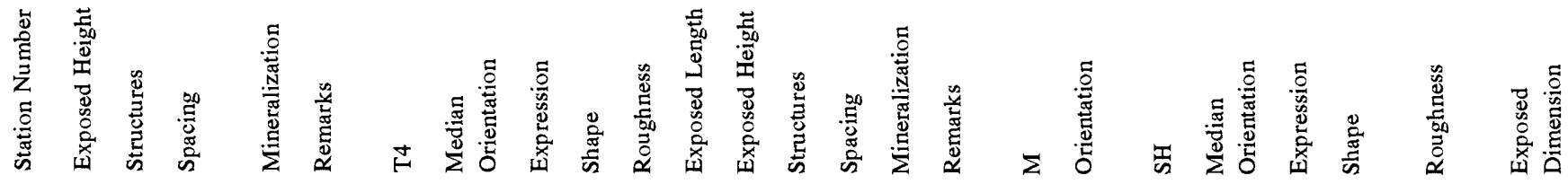




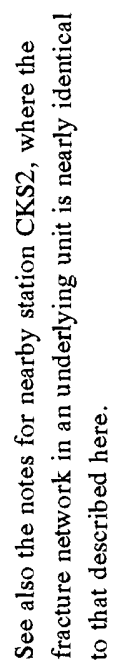

है 


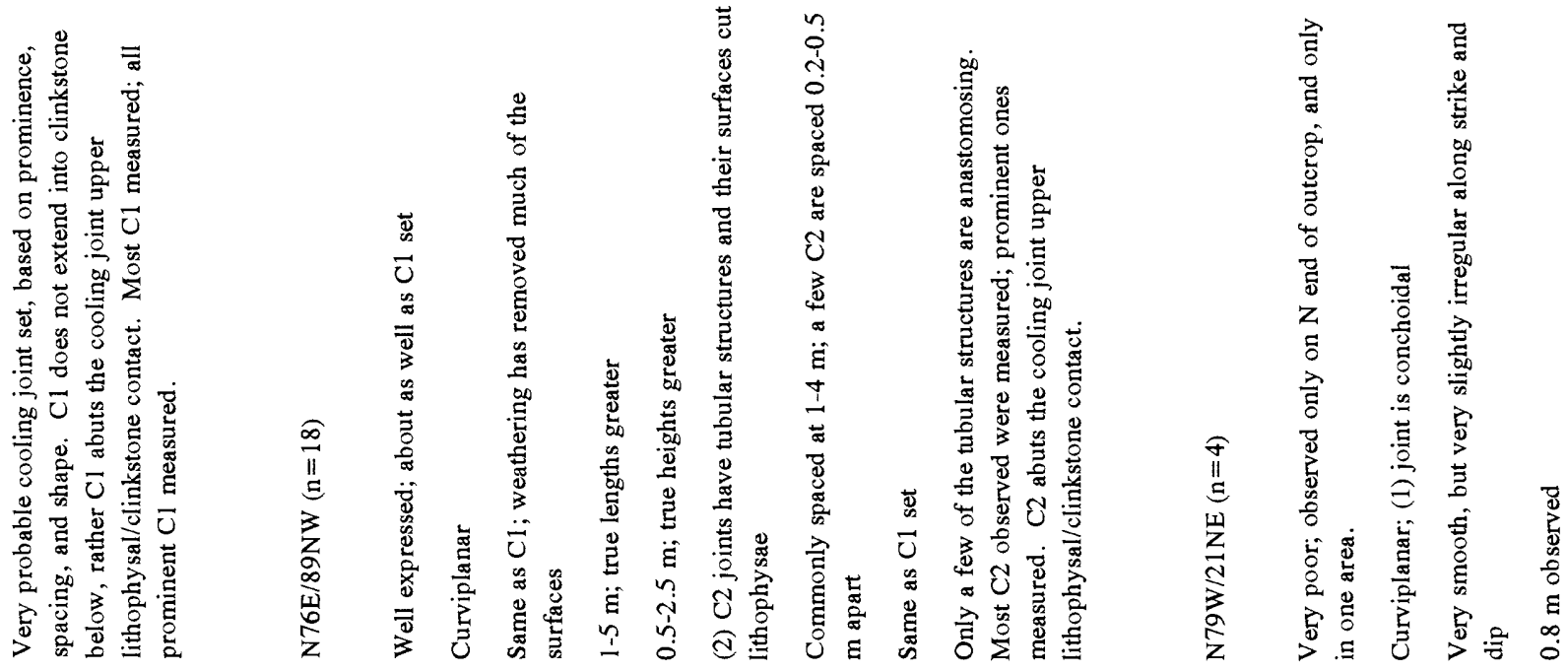

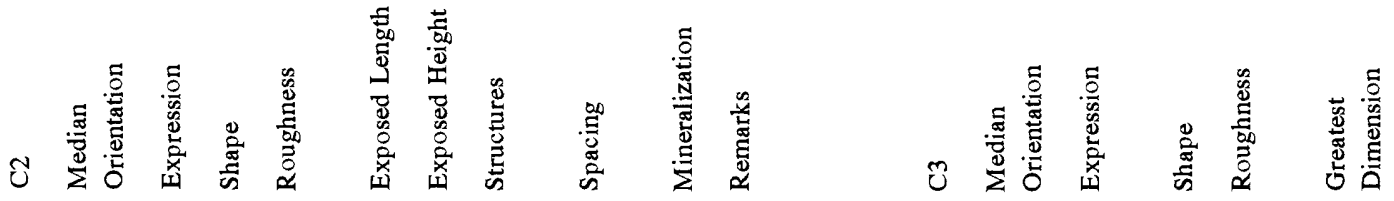

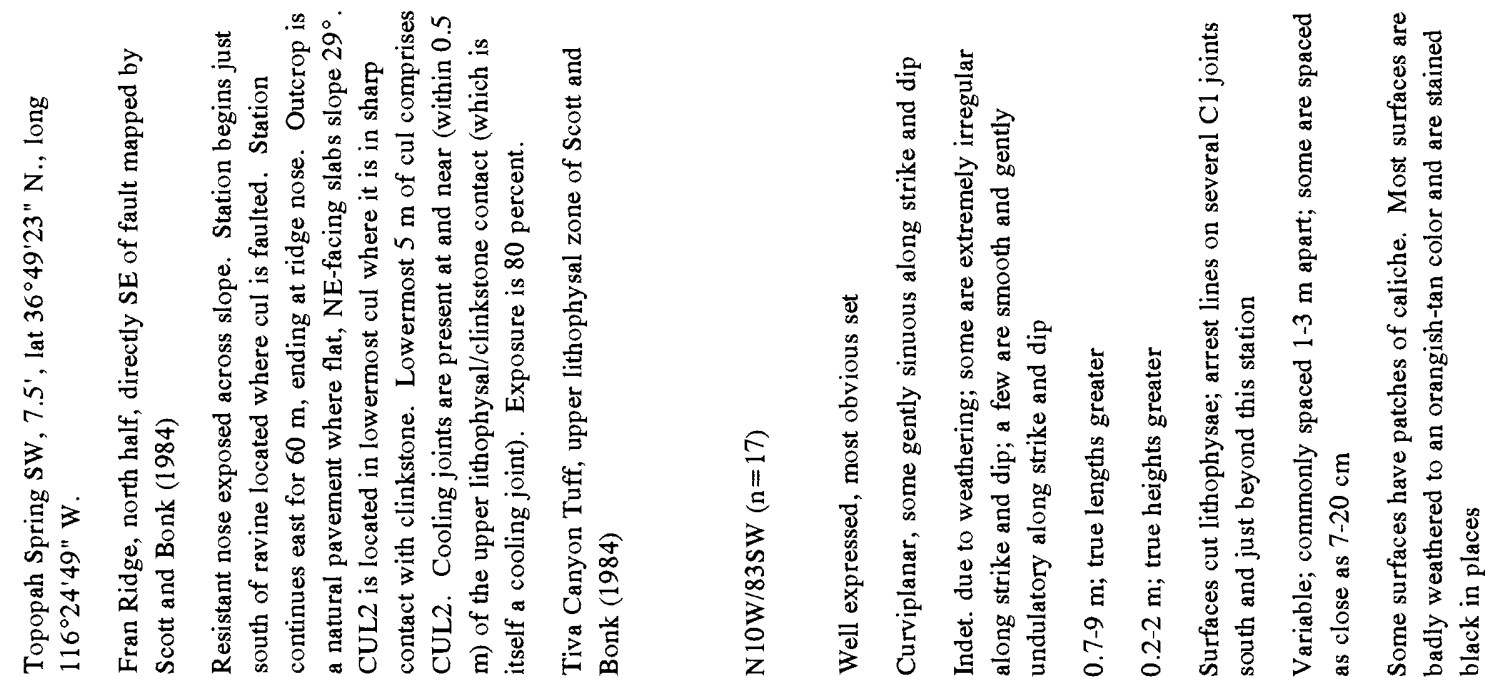

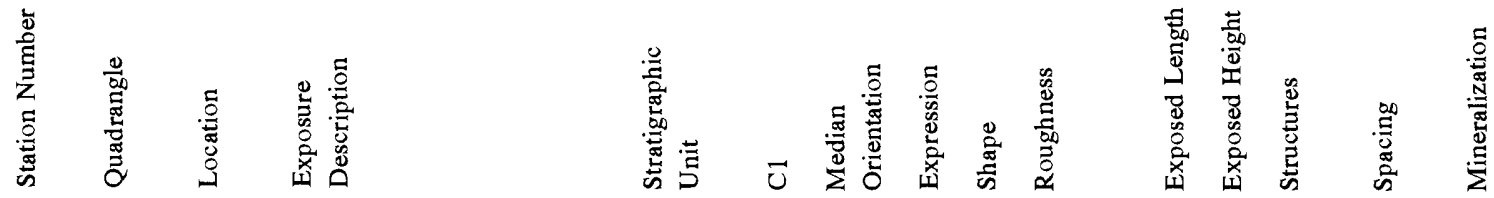


MUnWWInUm mentumm Mn WHX WIIDWM MEIUIUWUI

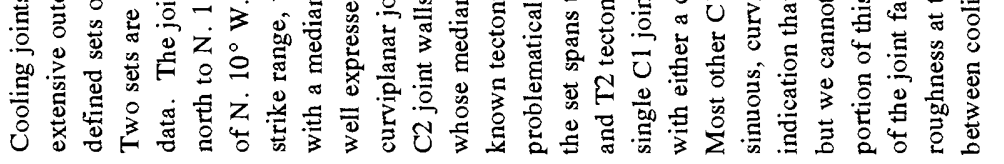

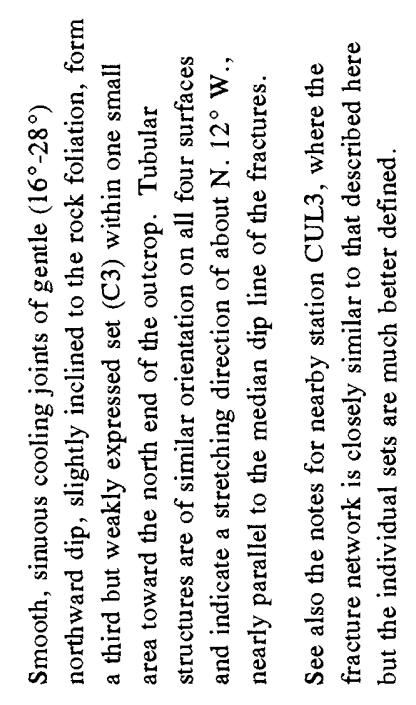

है

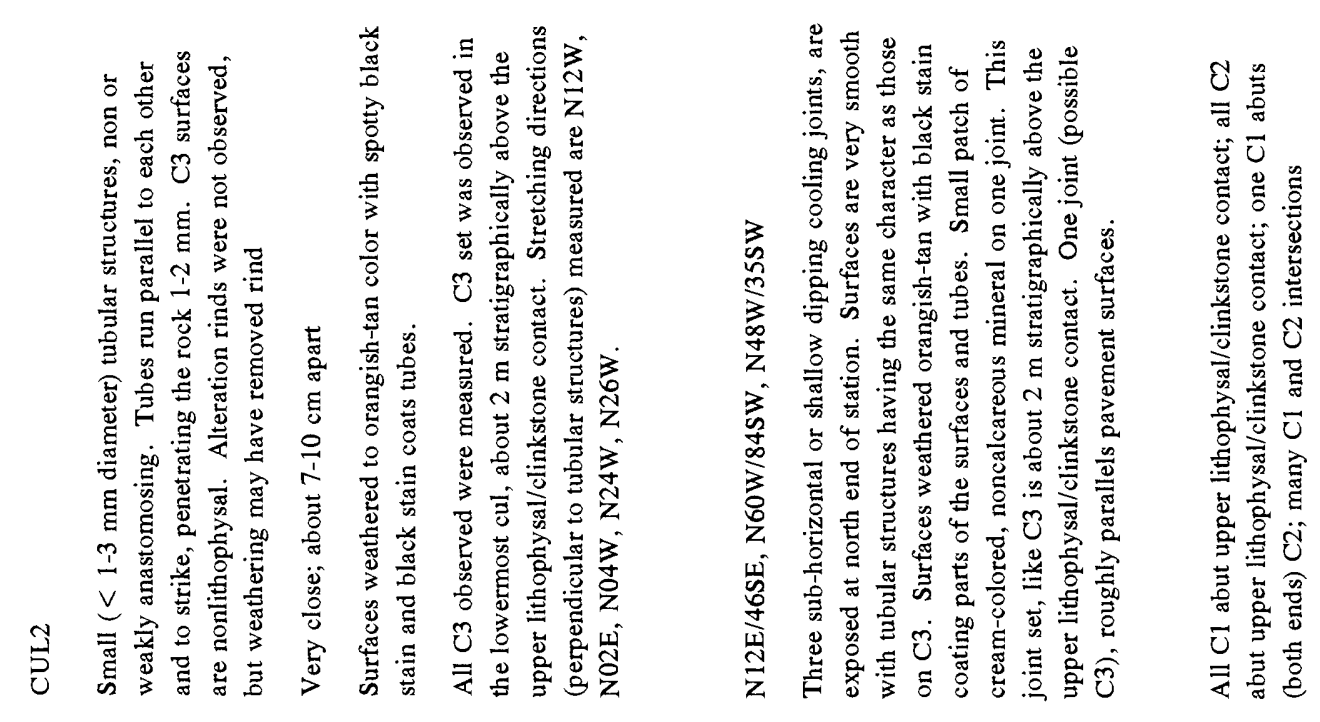

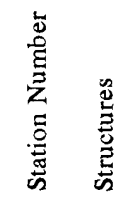

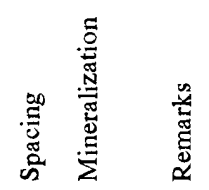

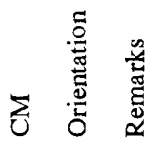

 


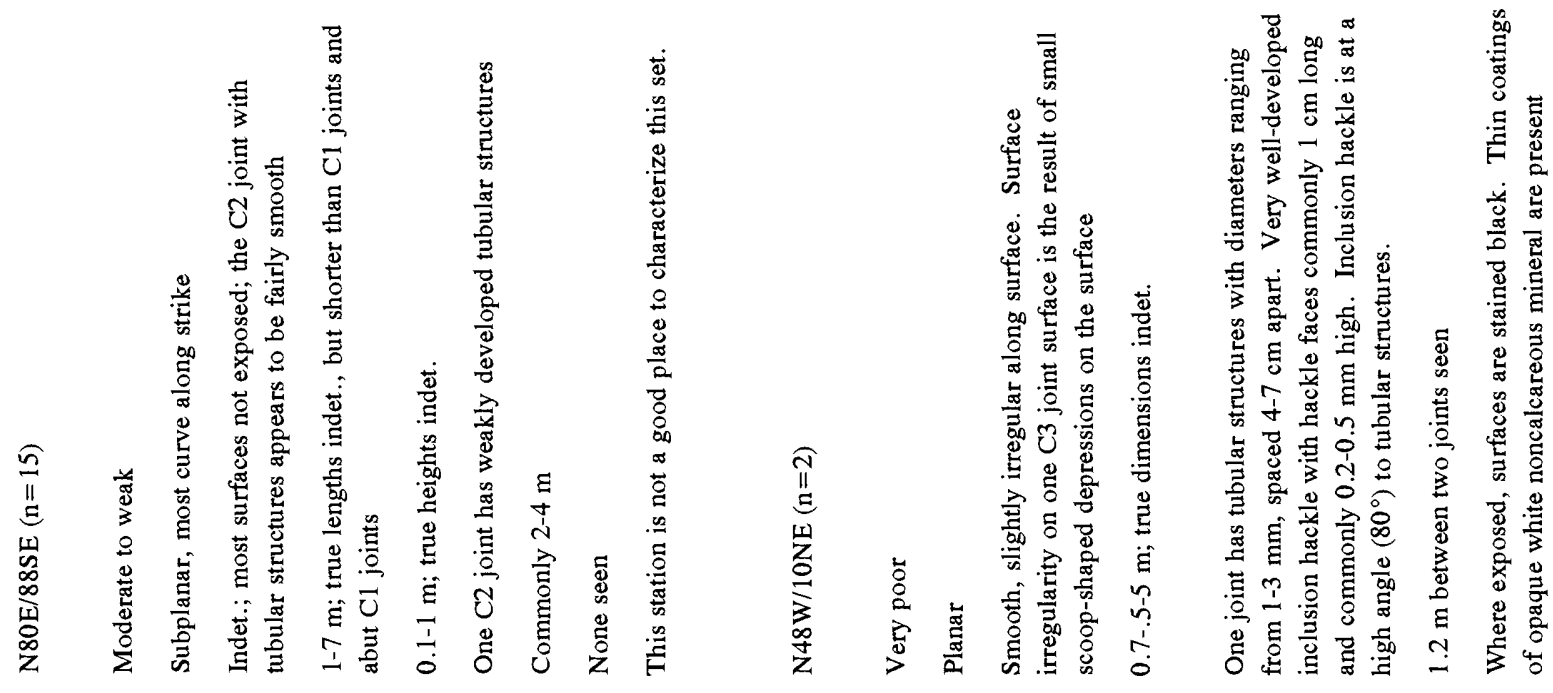

oแIn!

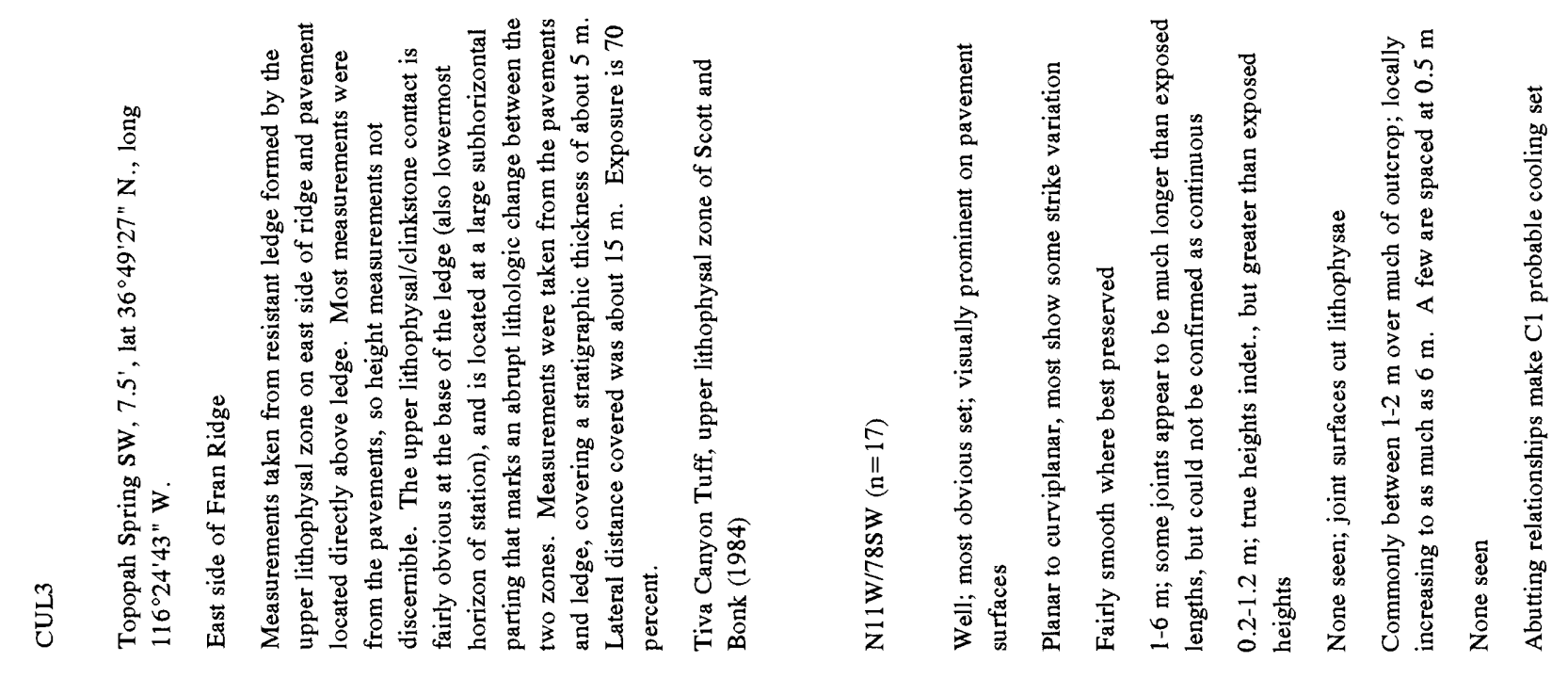

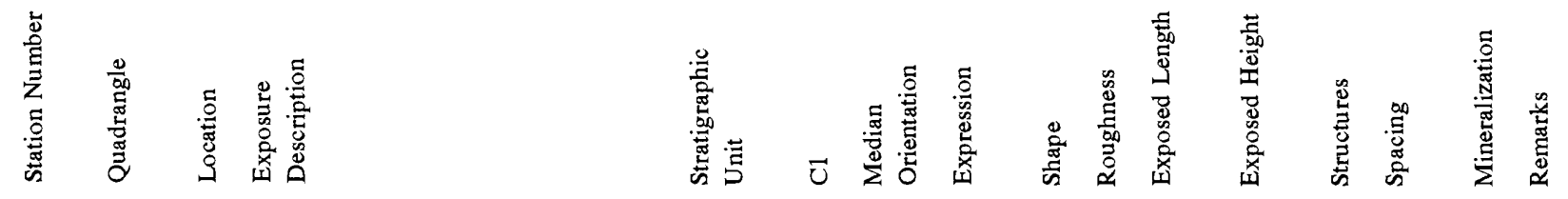



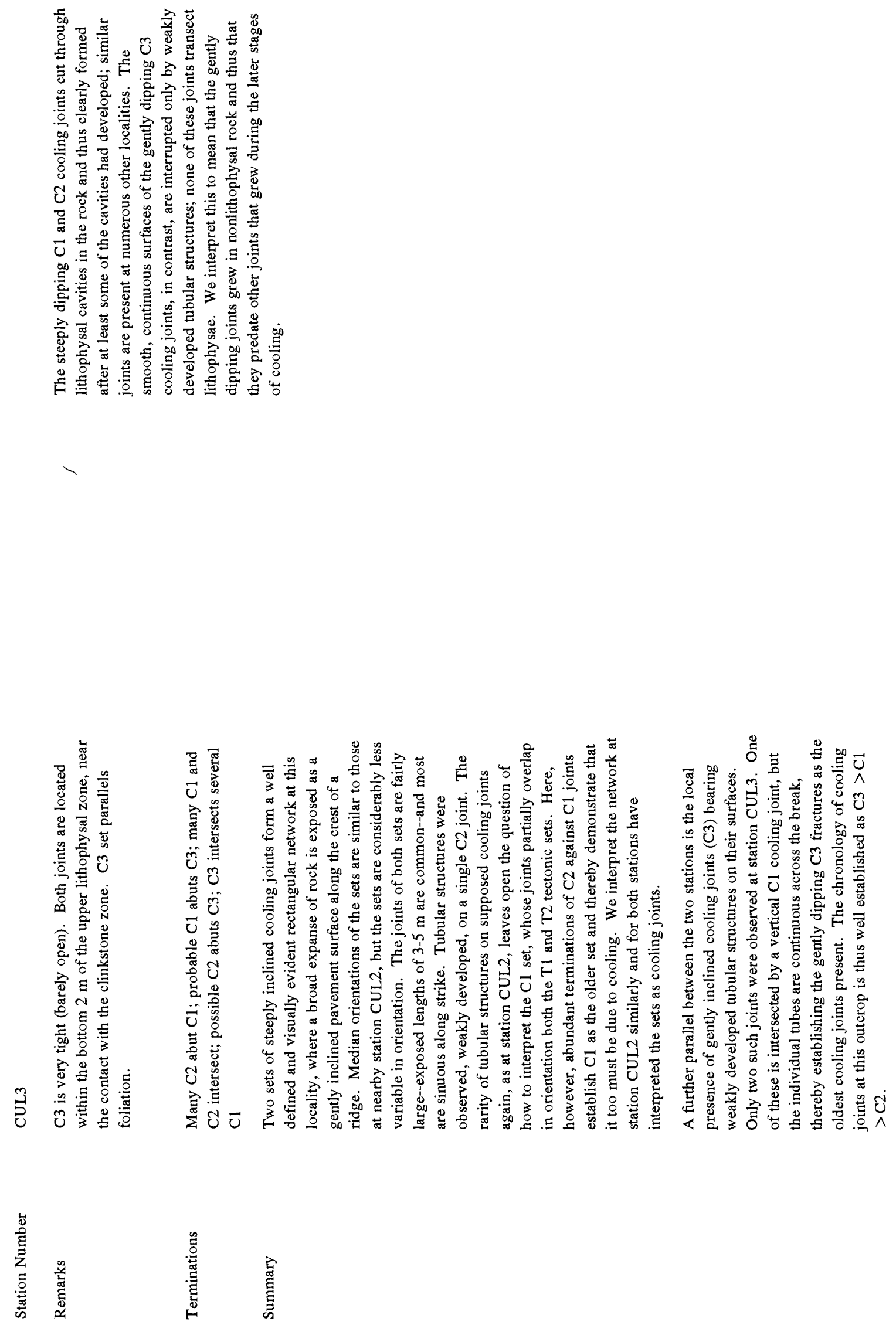


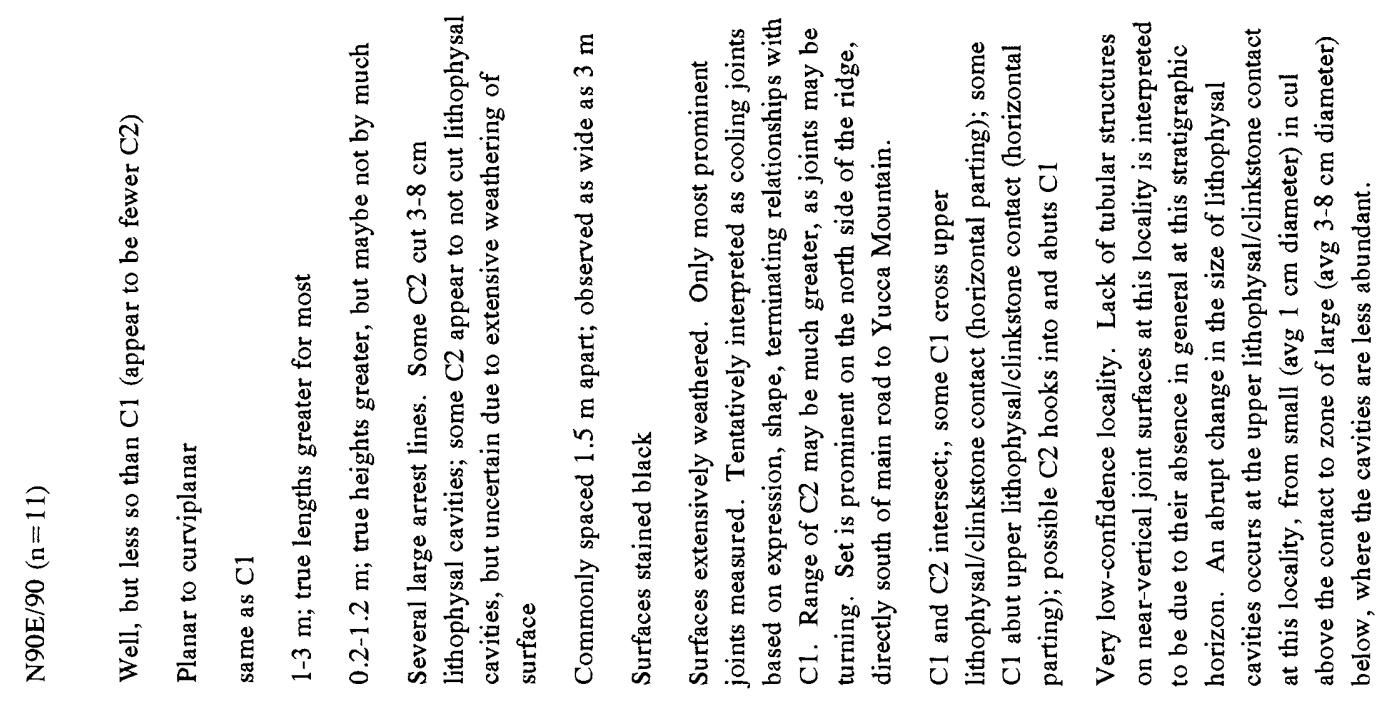

.11!I!

$\frac{8}{4}$

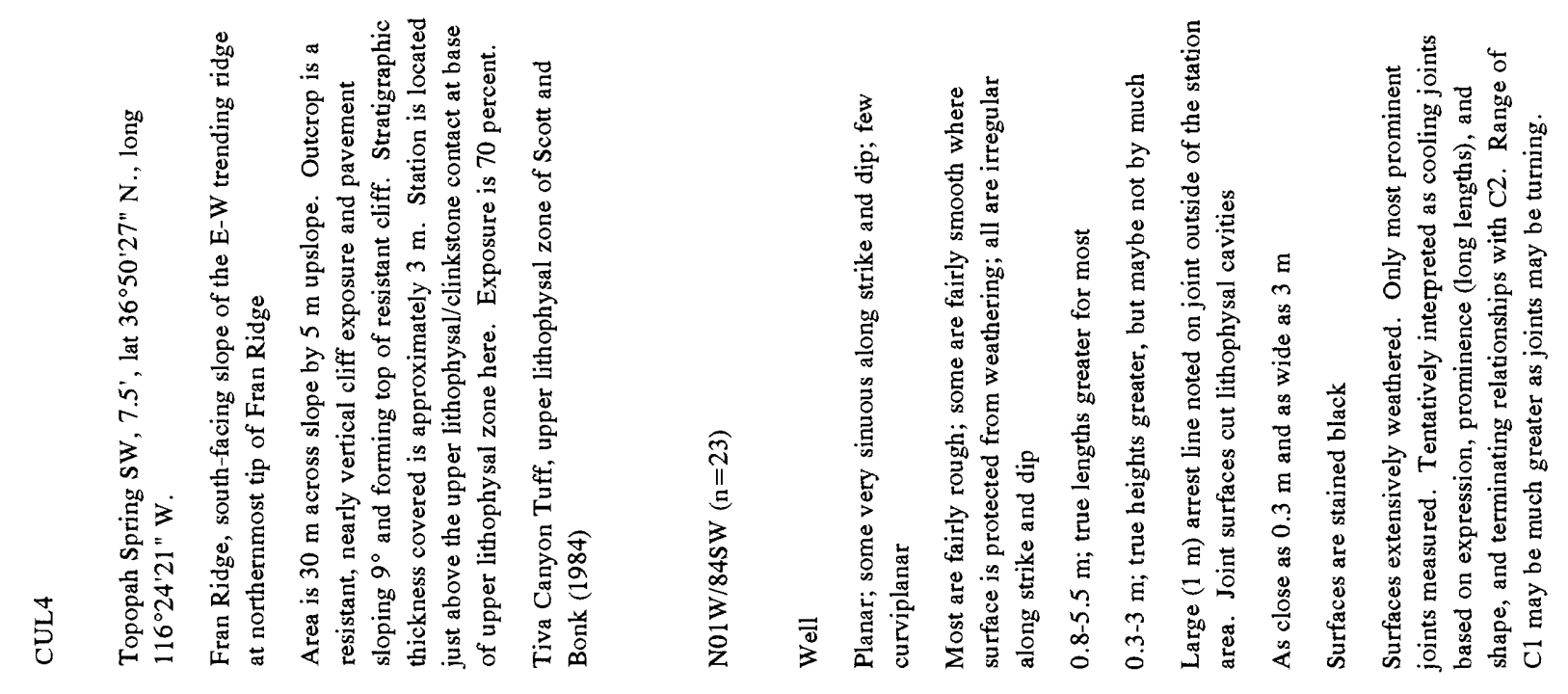

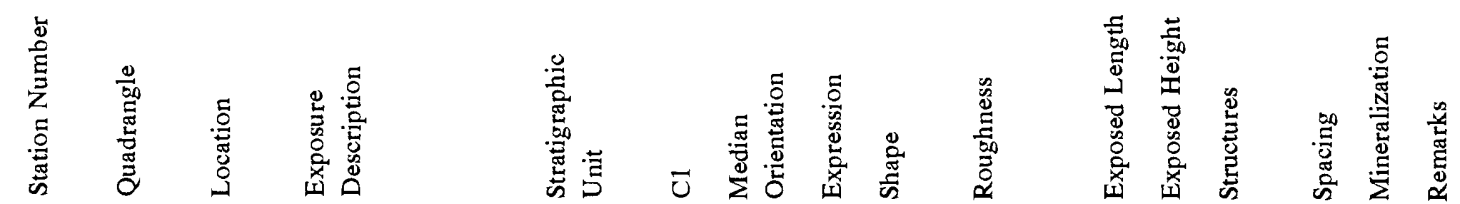




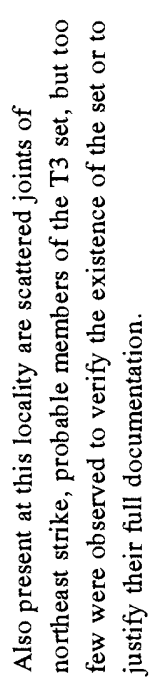

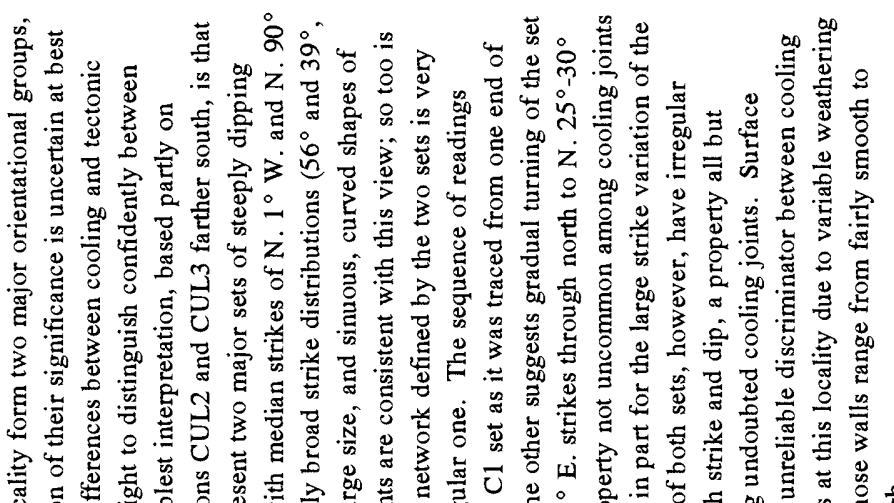

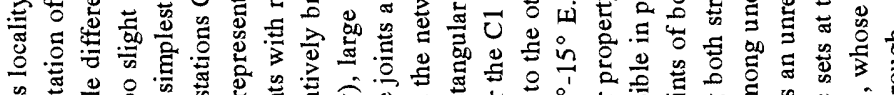

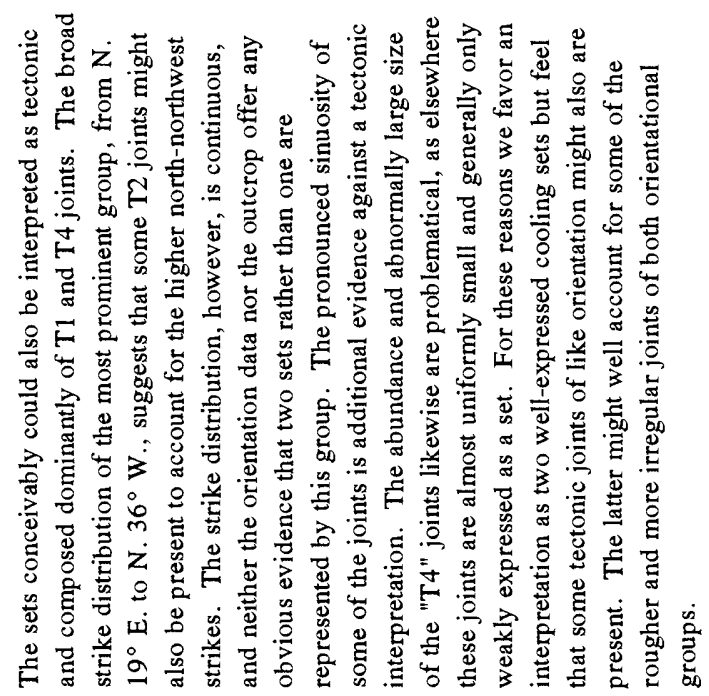




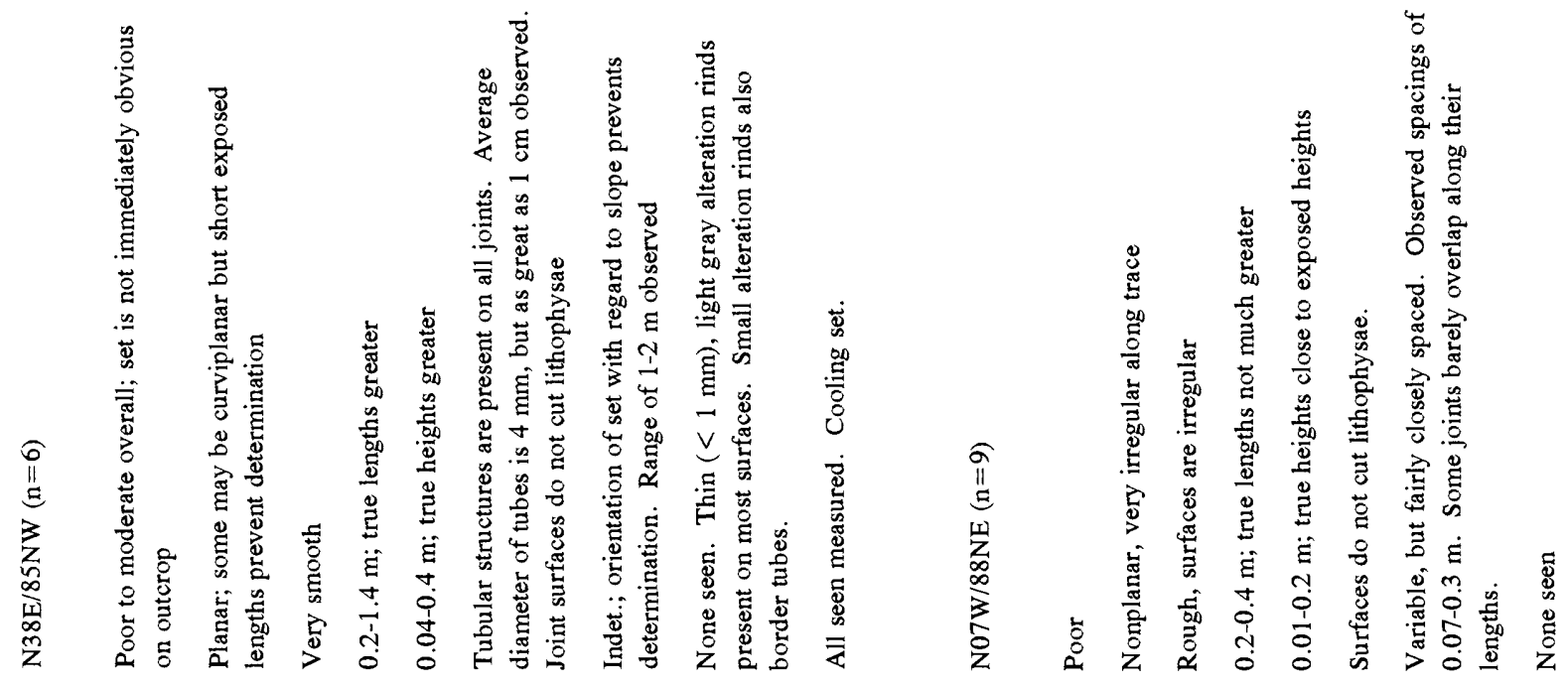

.11 $111 \mid$

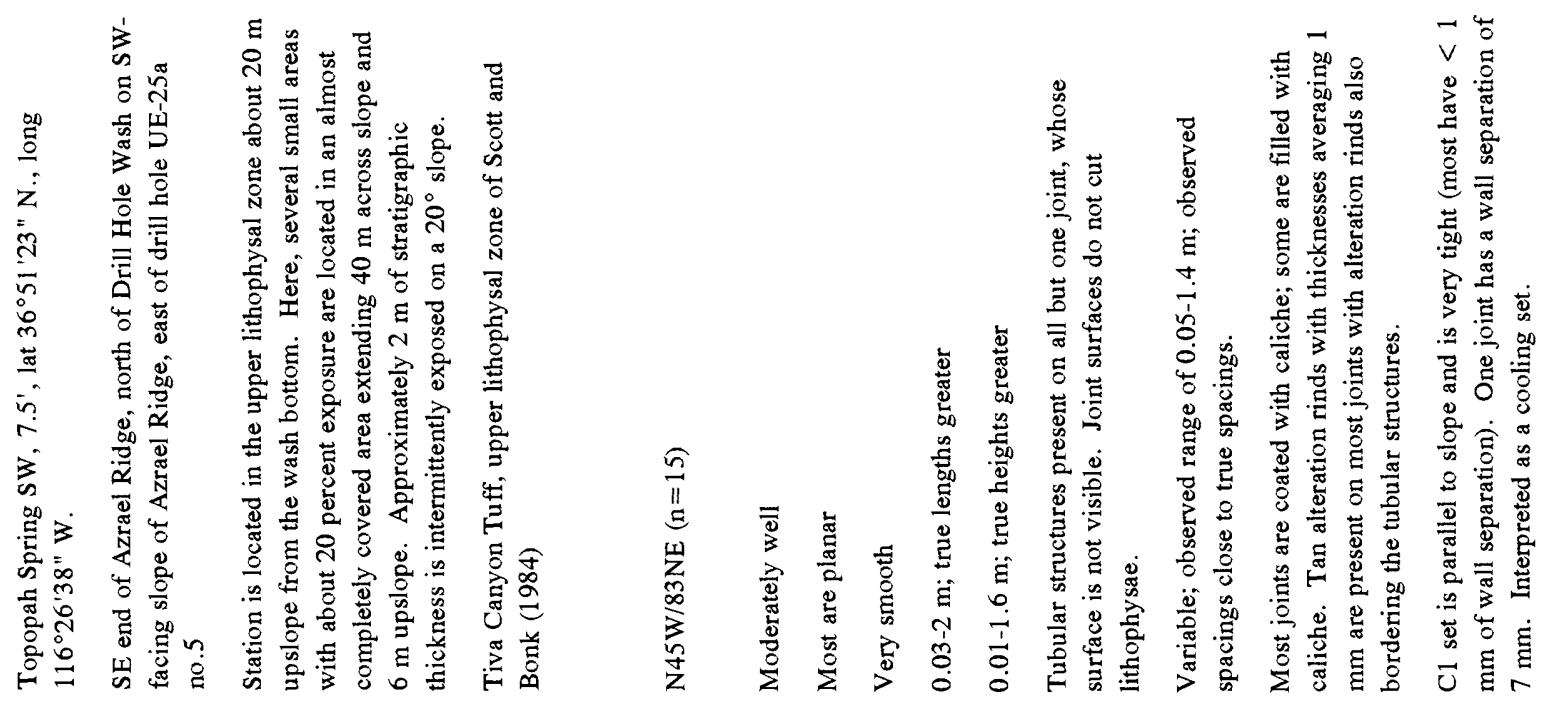

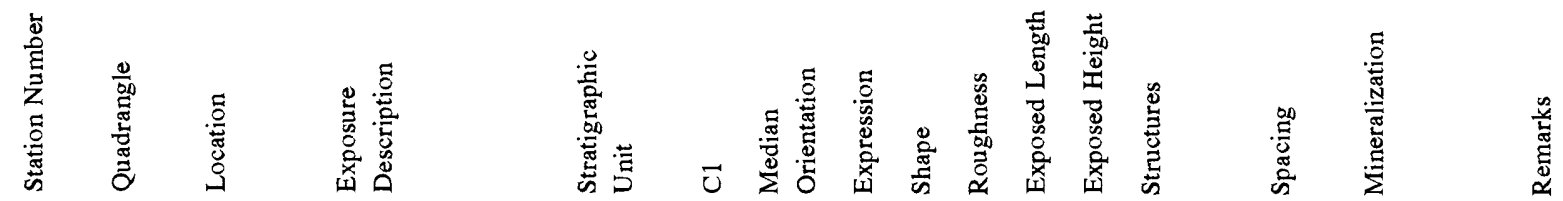




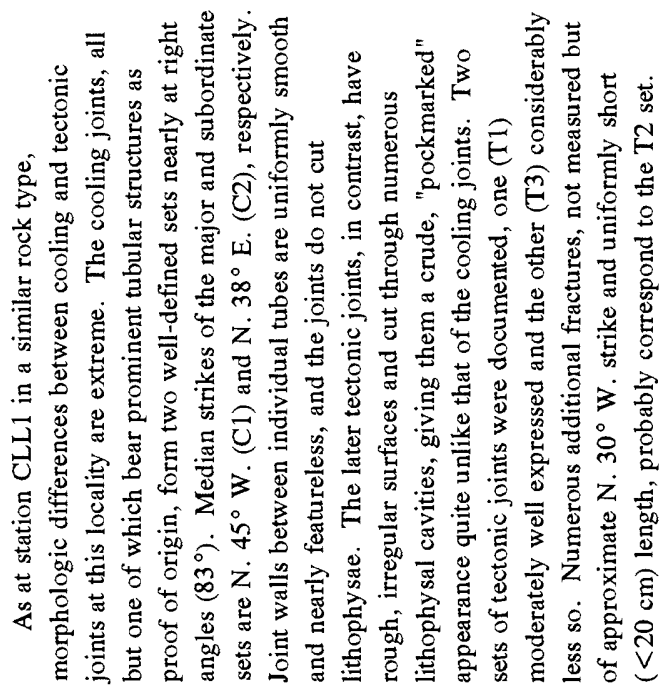

है

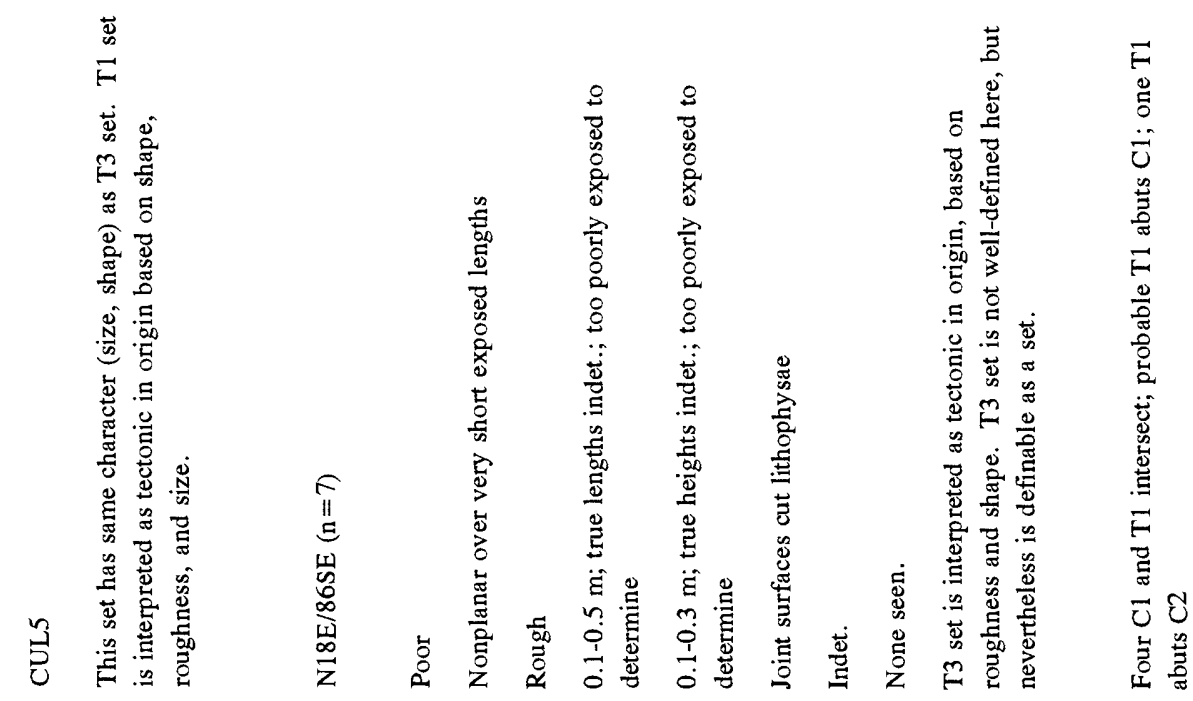

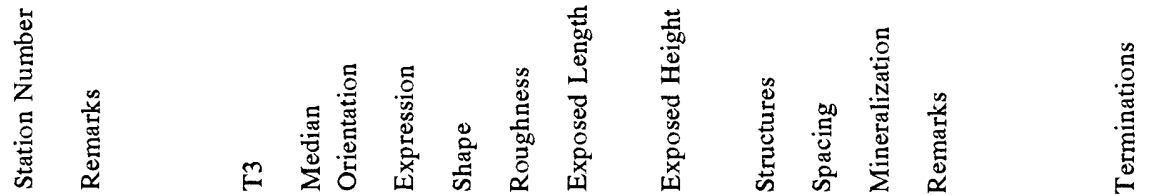




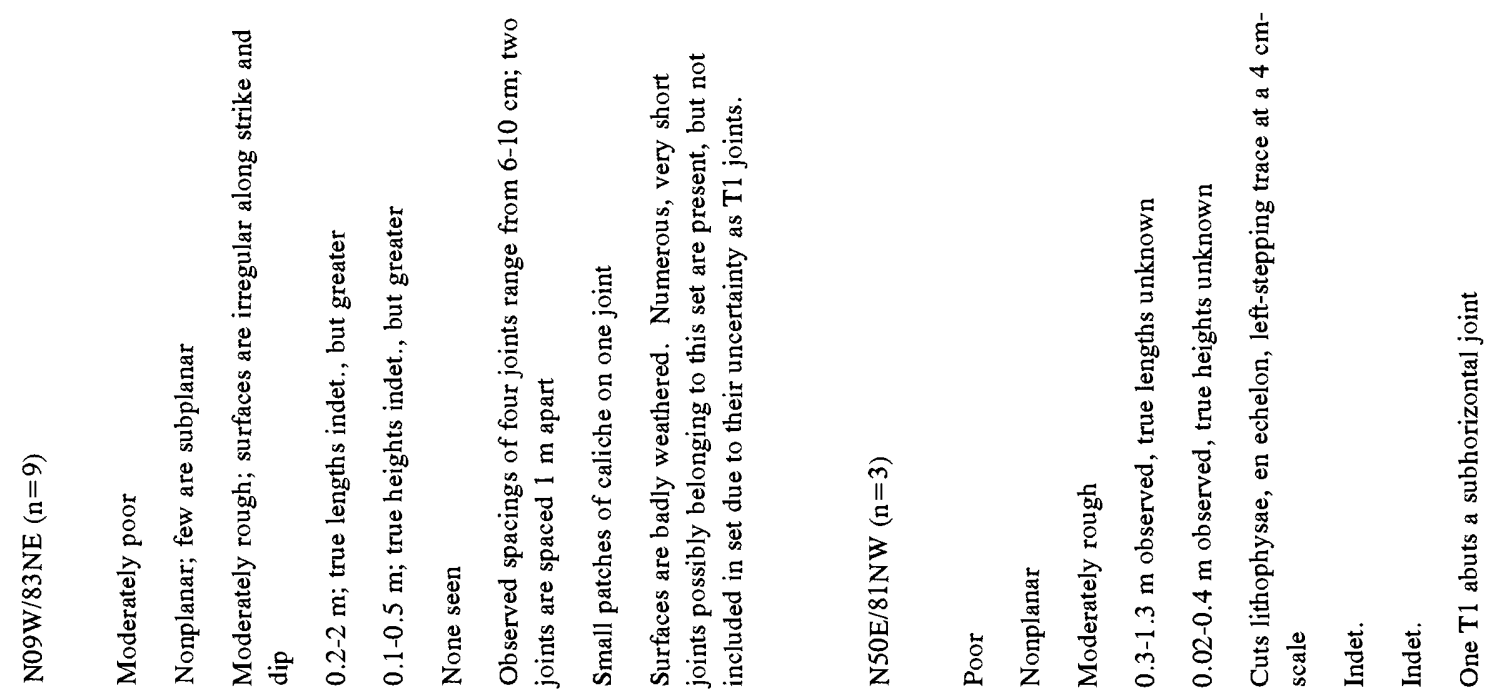

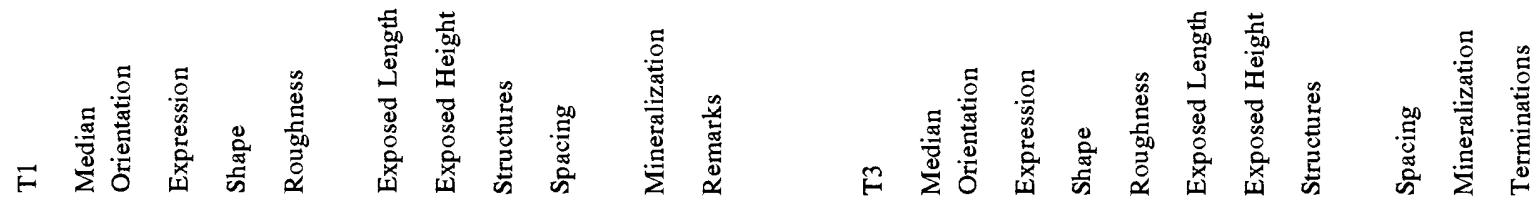

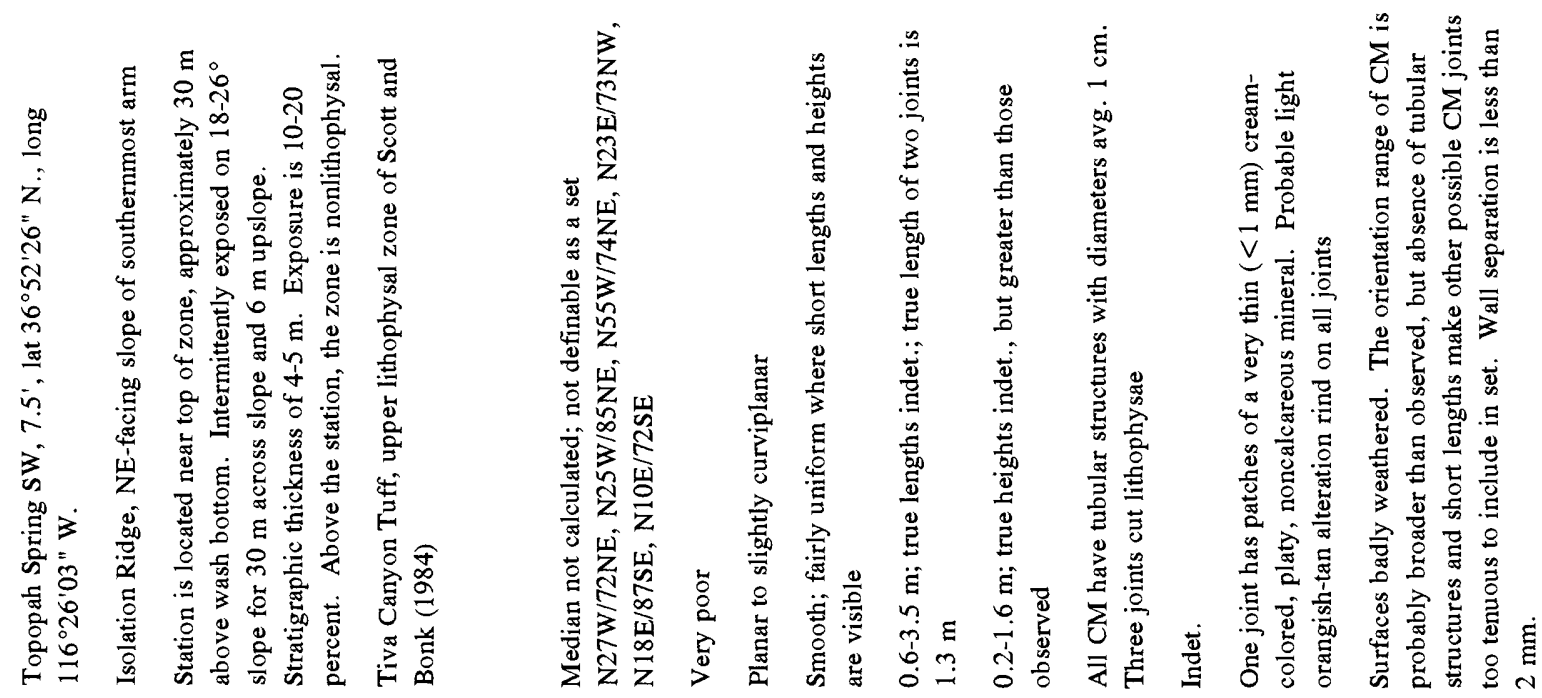

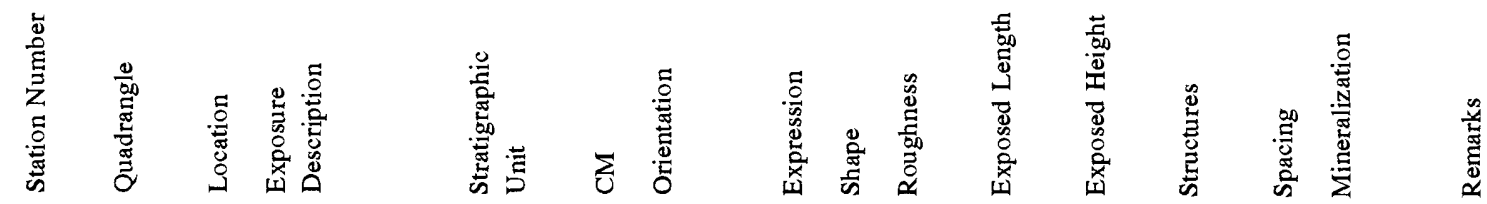



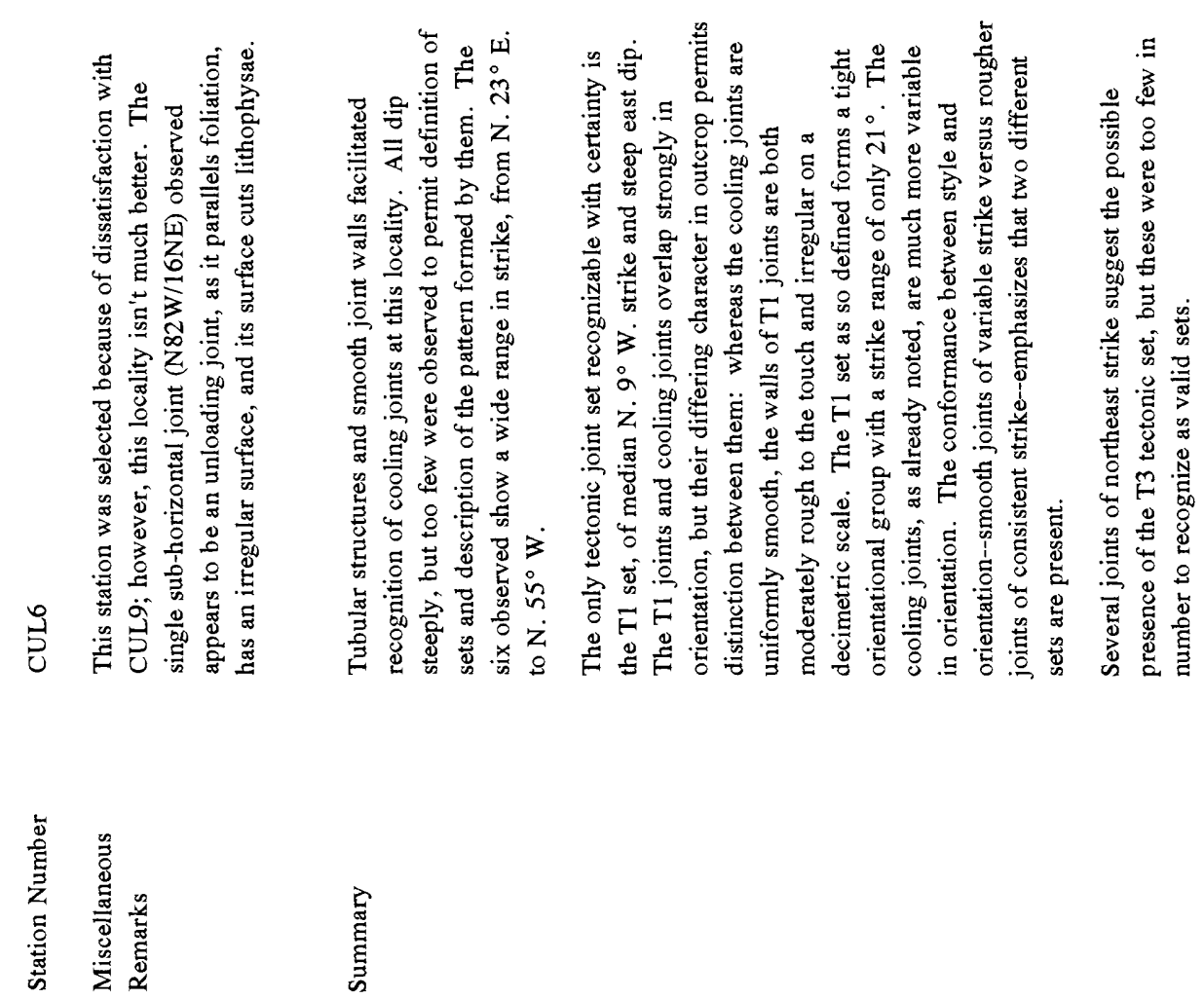


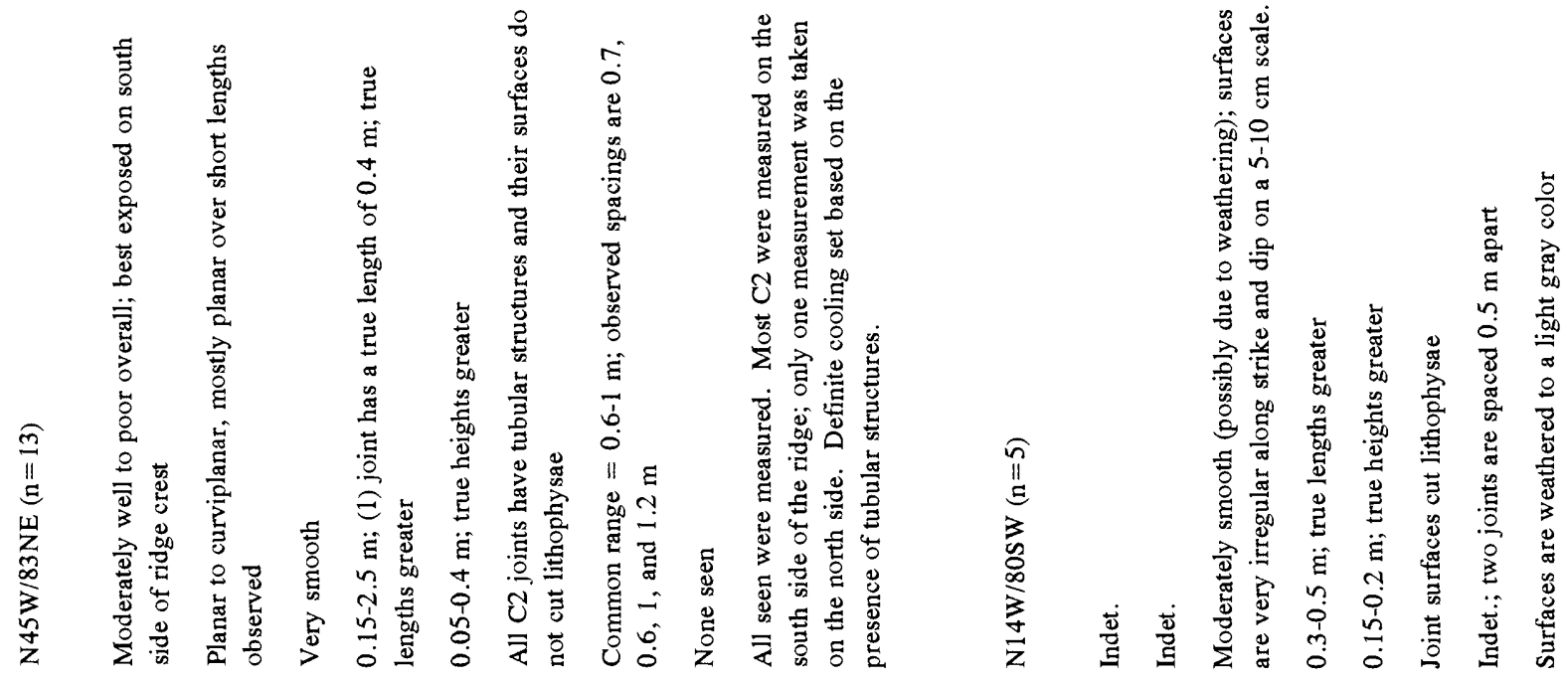

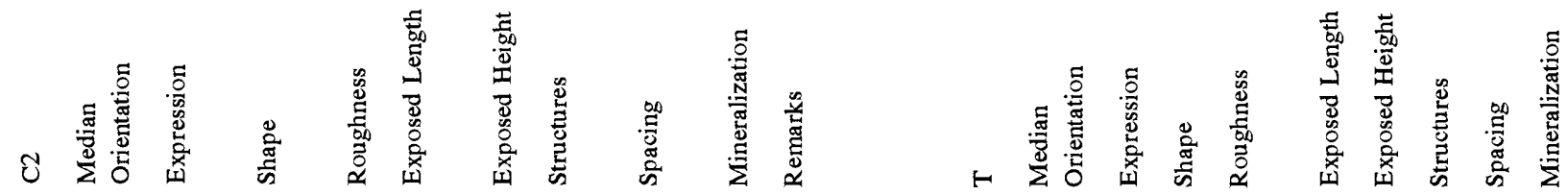
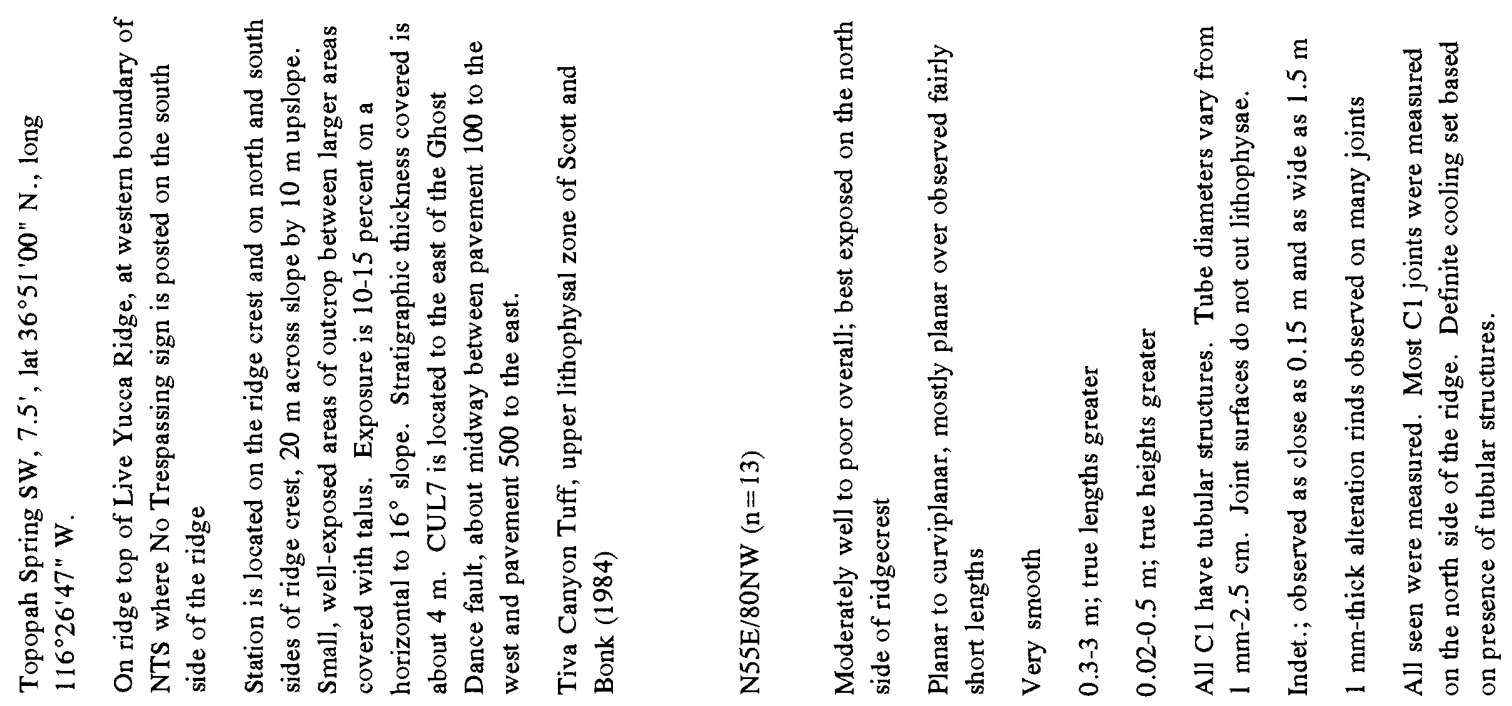

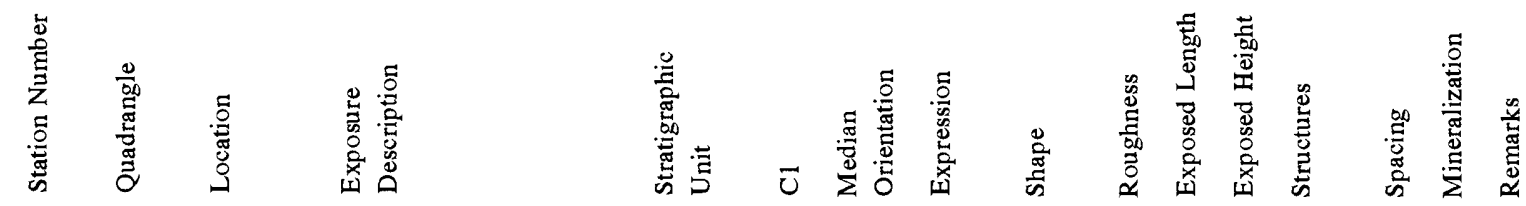



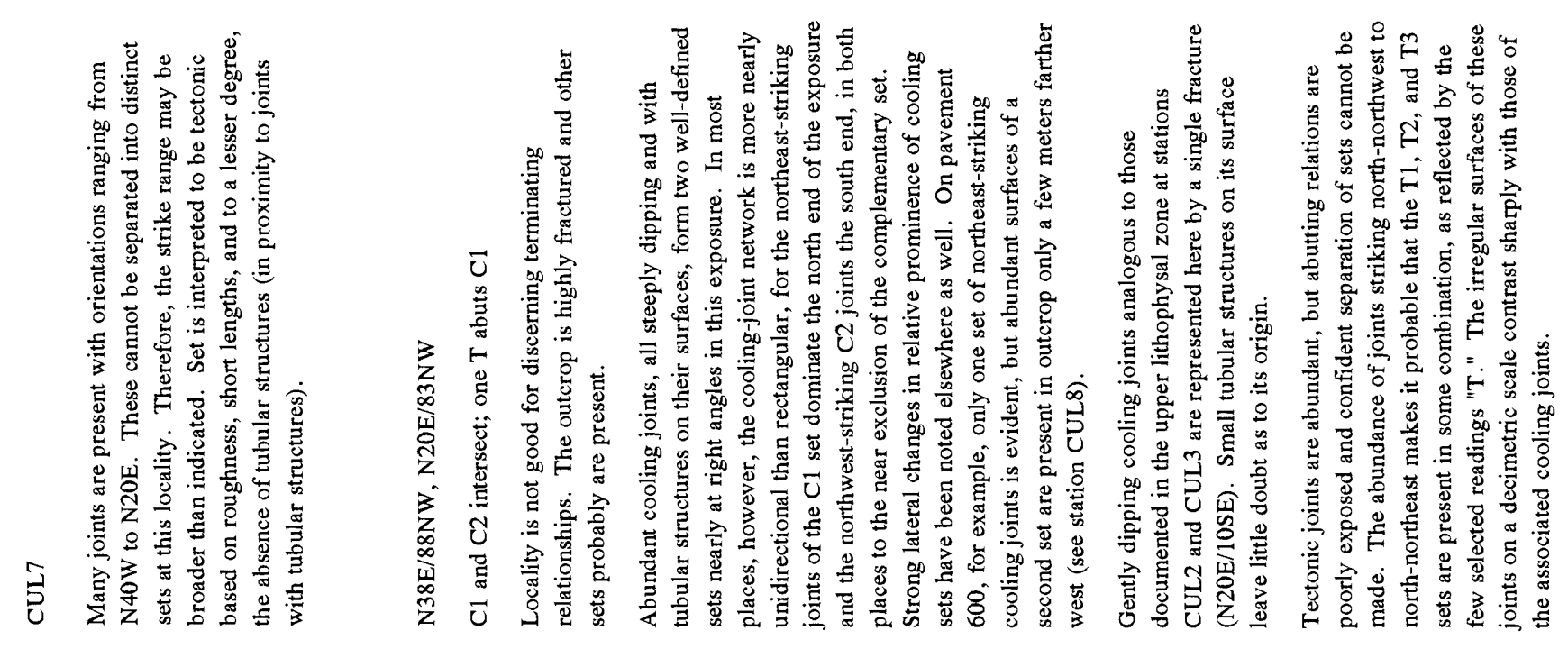

है

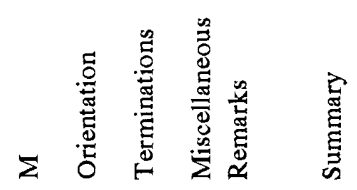




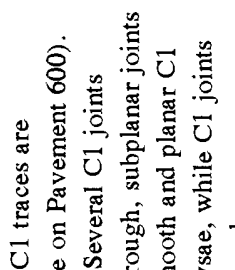

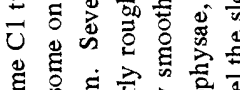

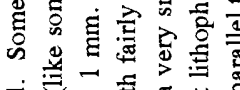

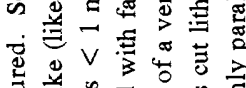

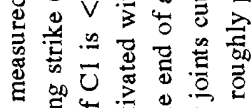

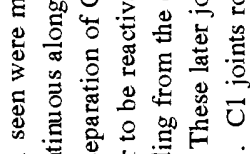

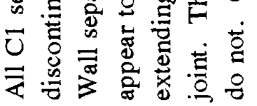
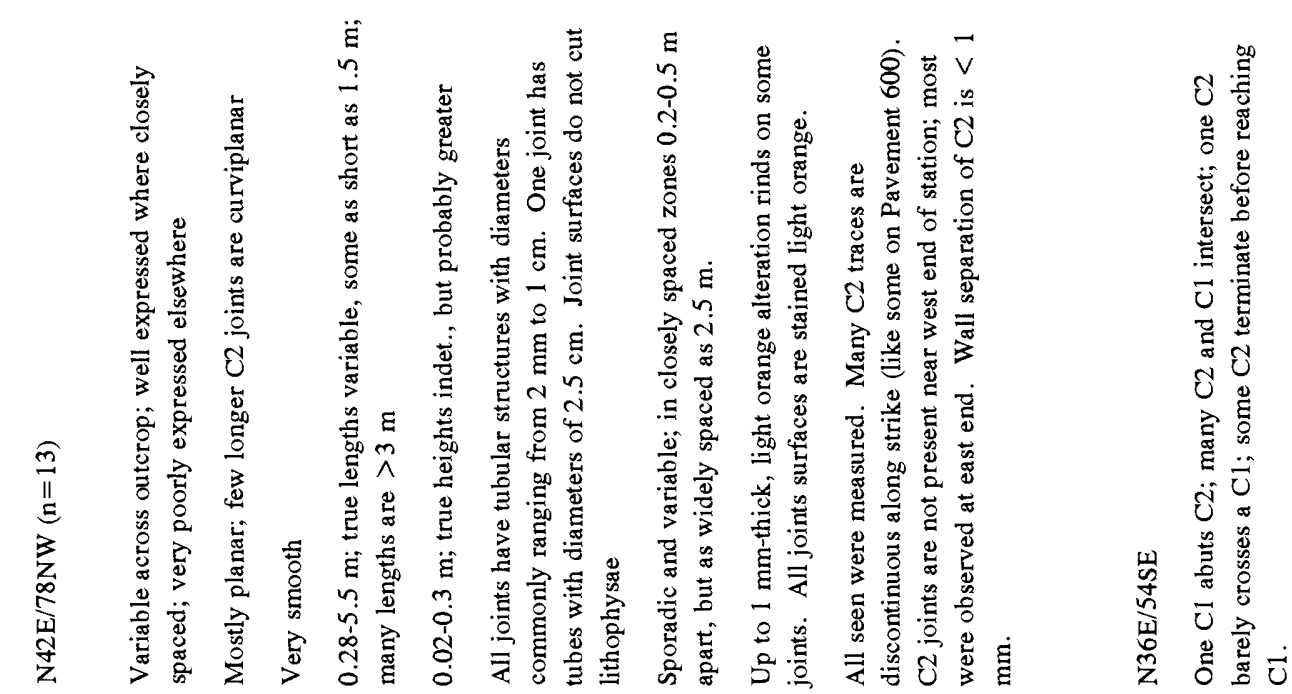

I
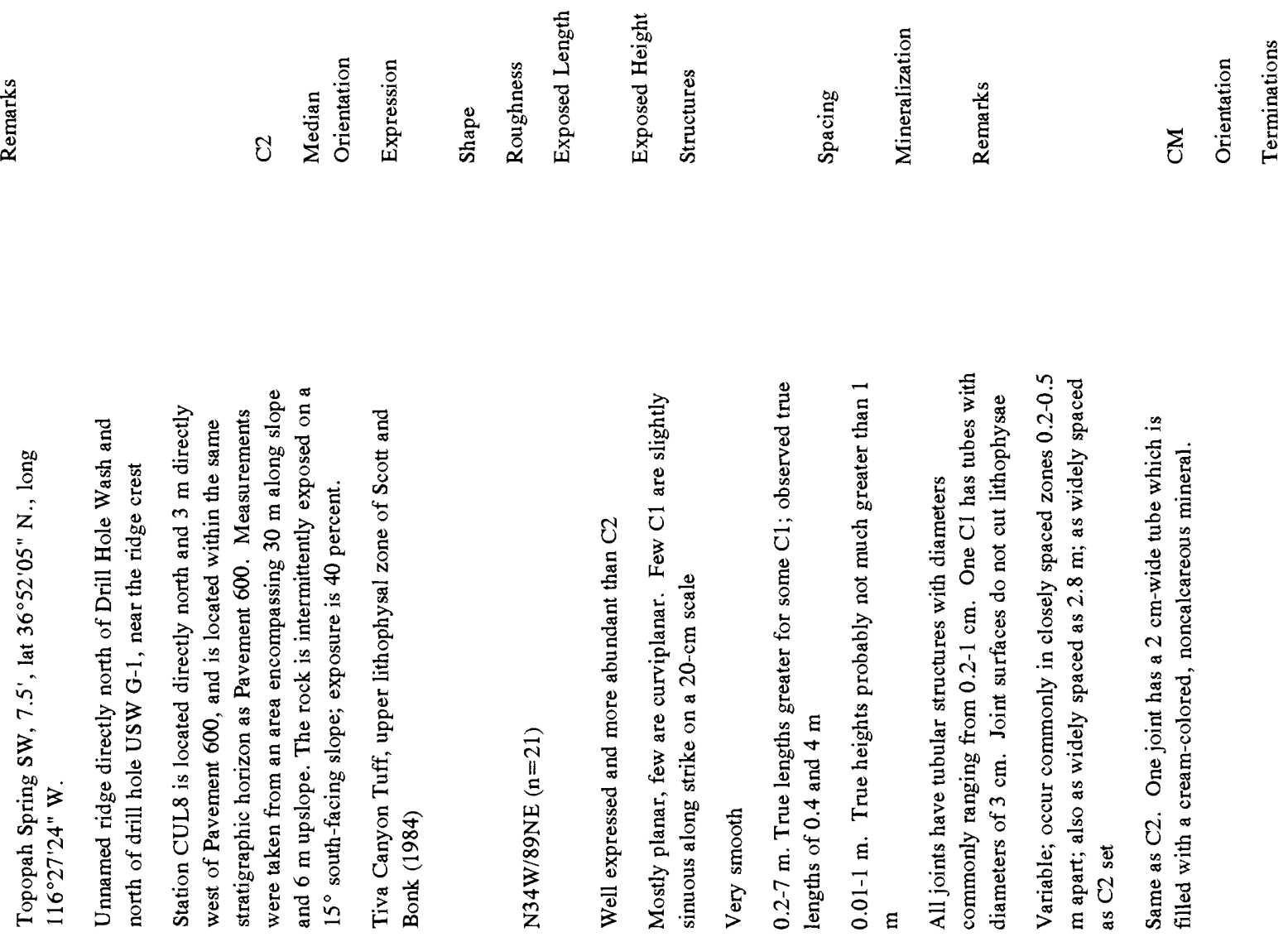

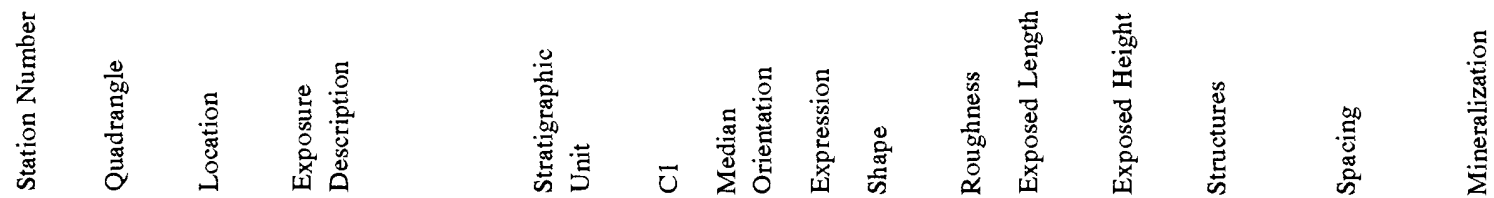



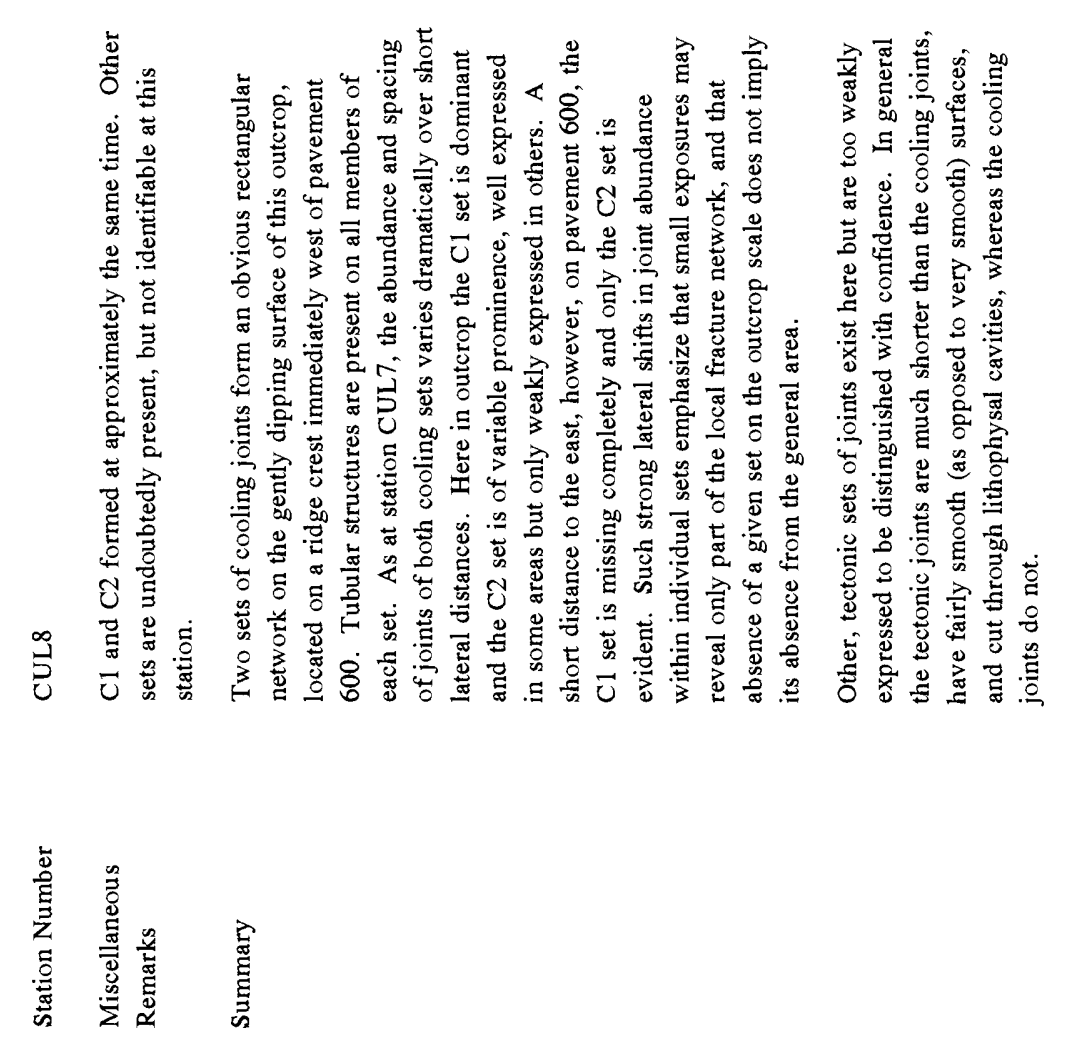

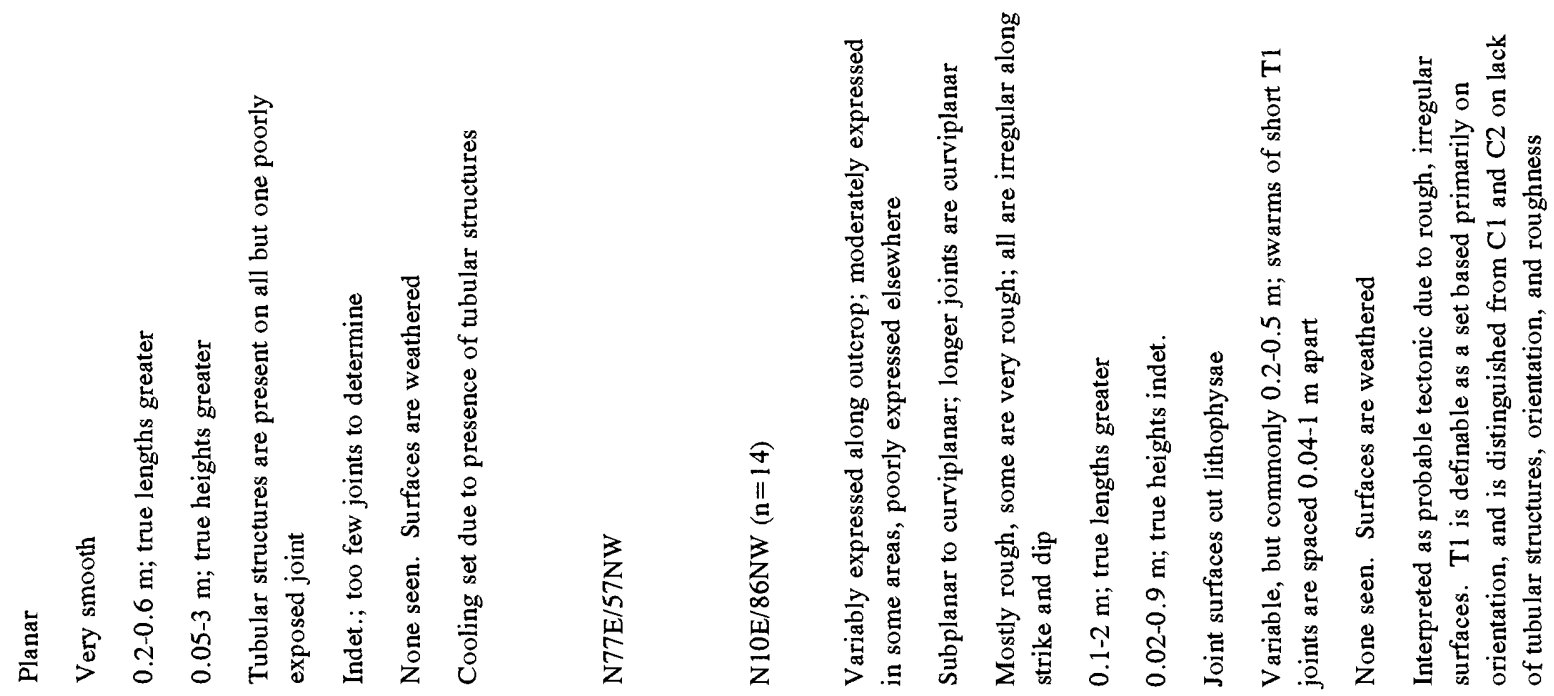

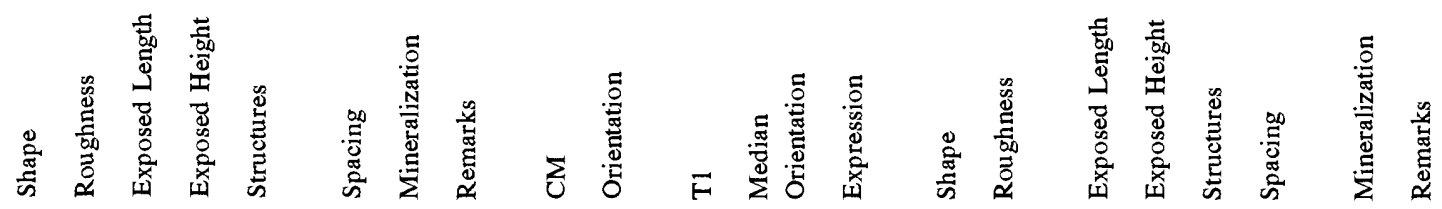

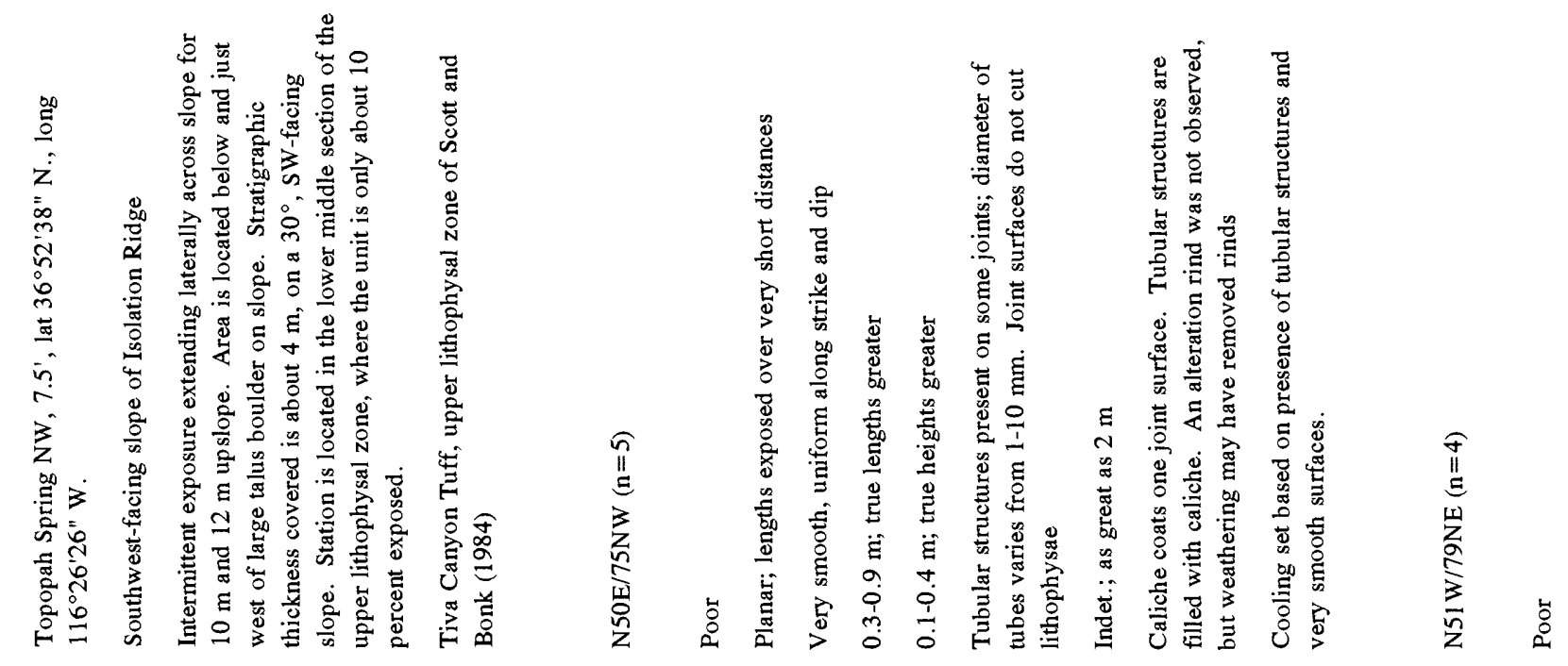

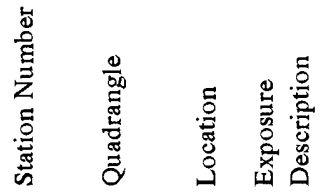

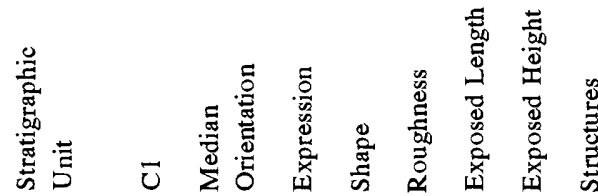

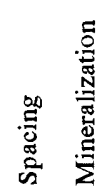

革

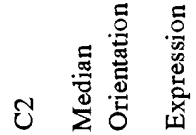



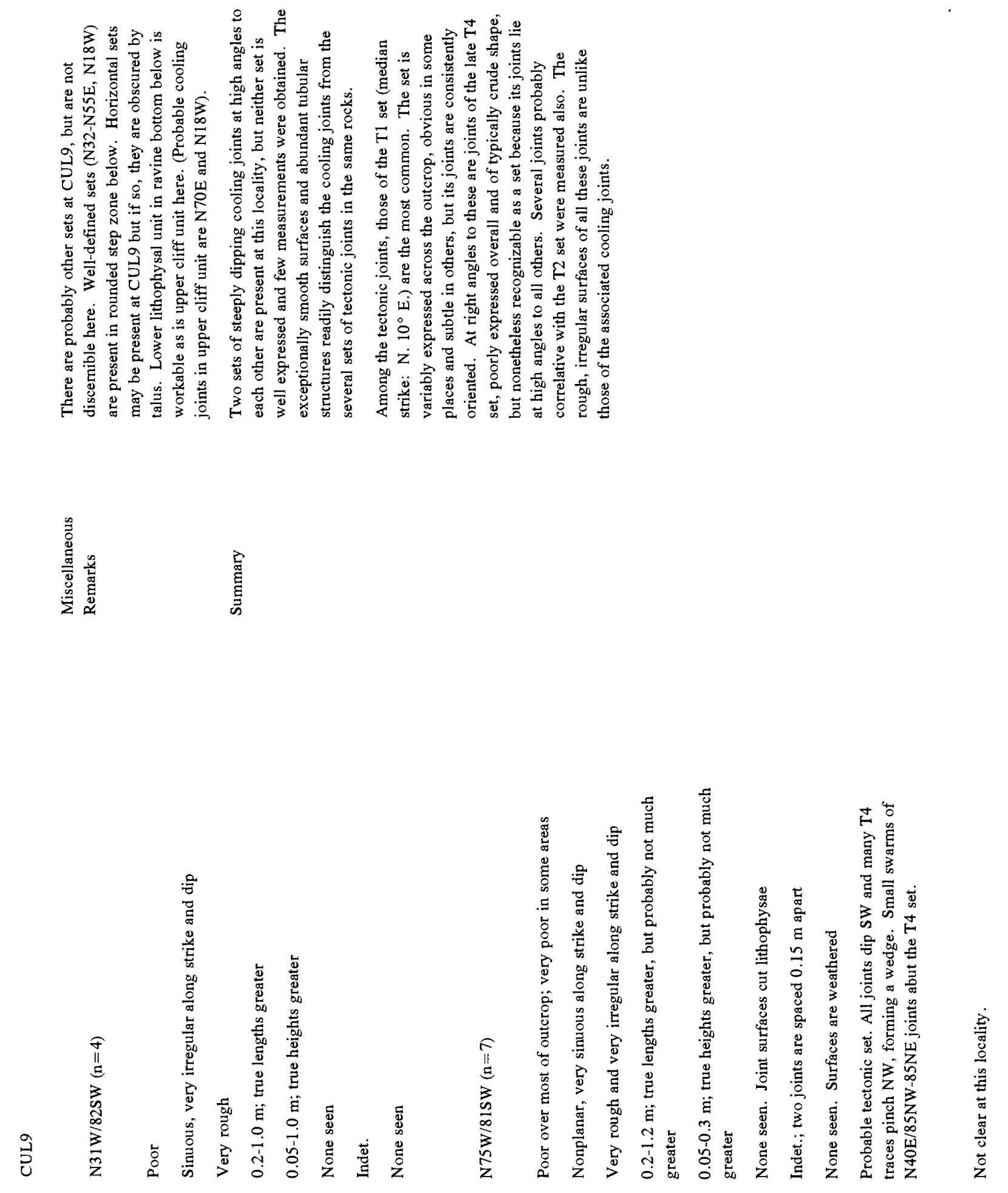

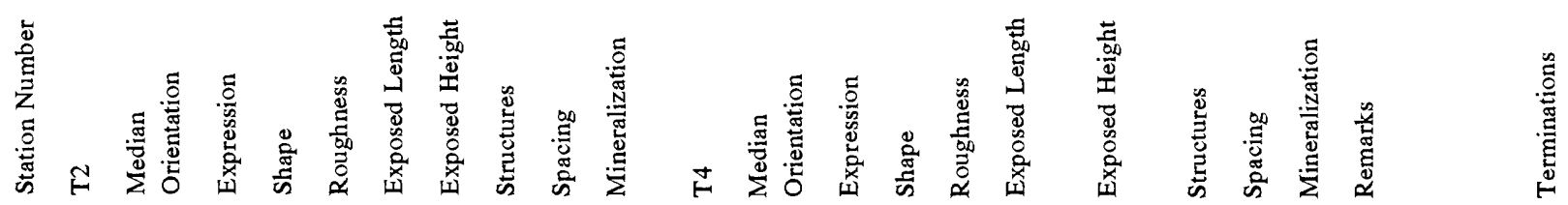




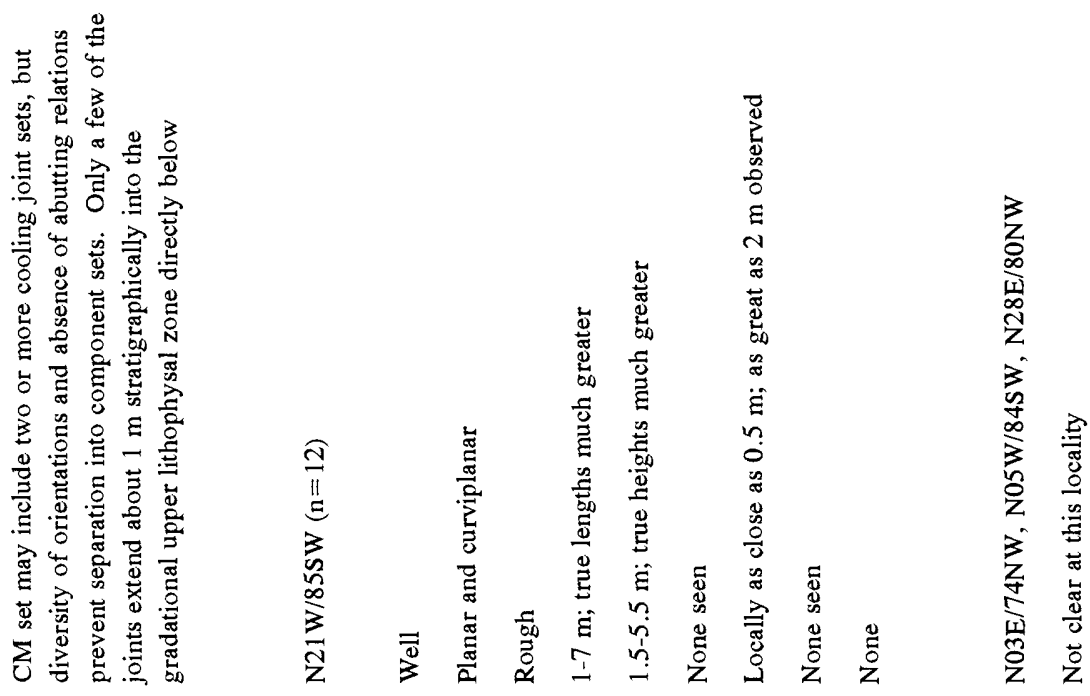

营

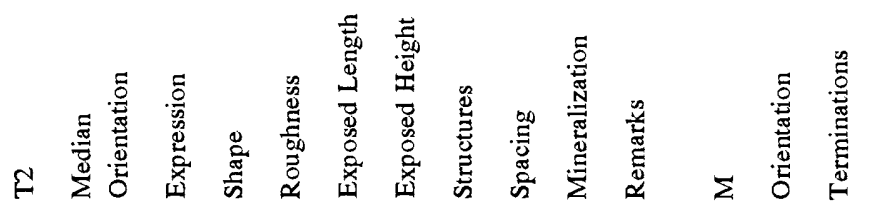

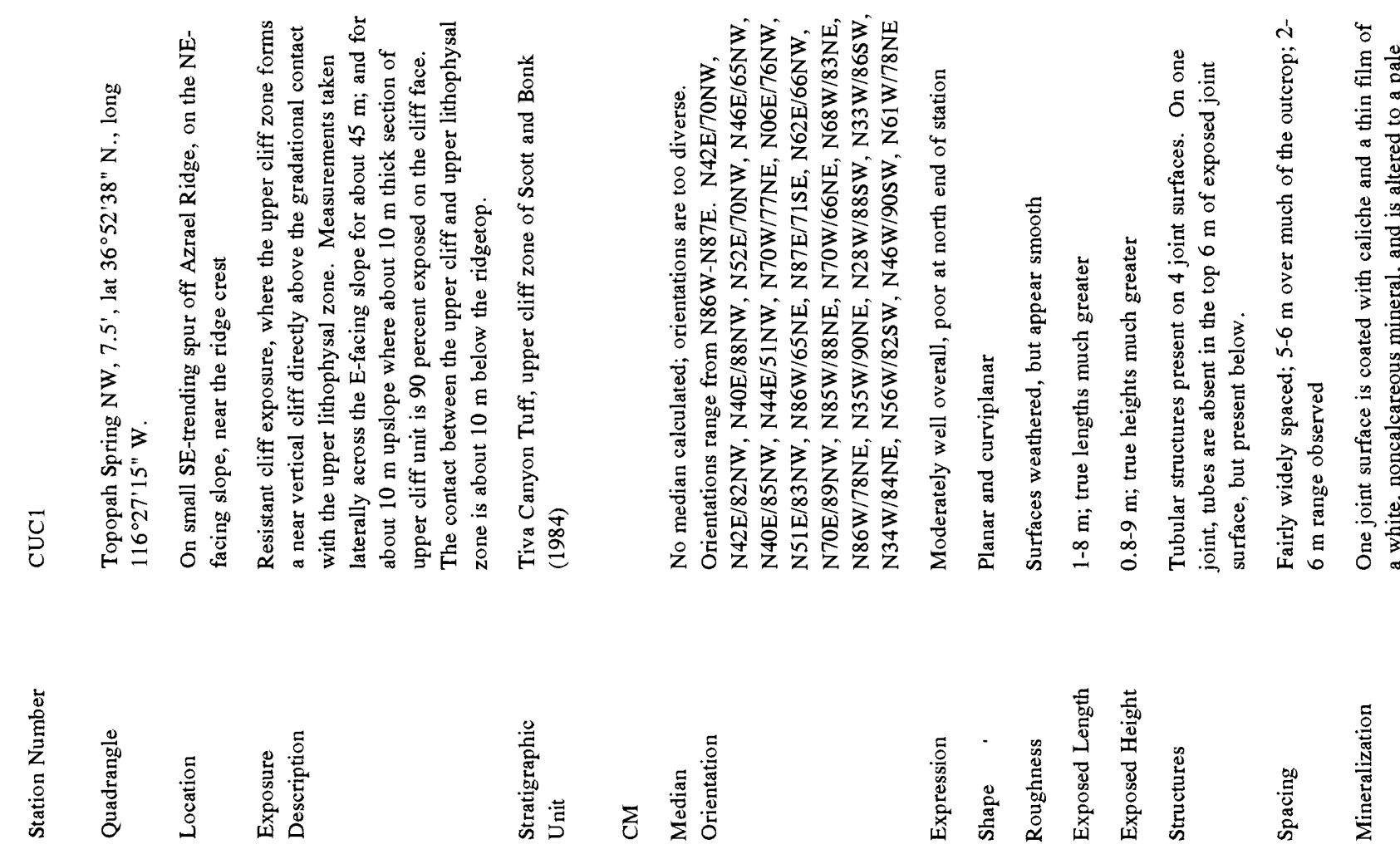



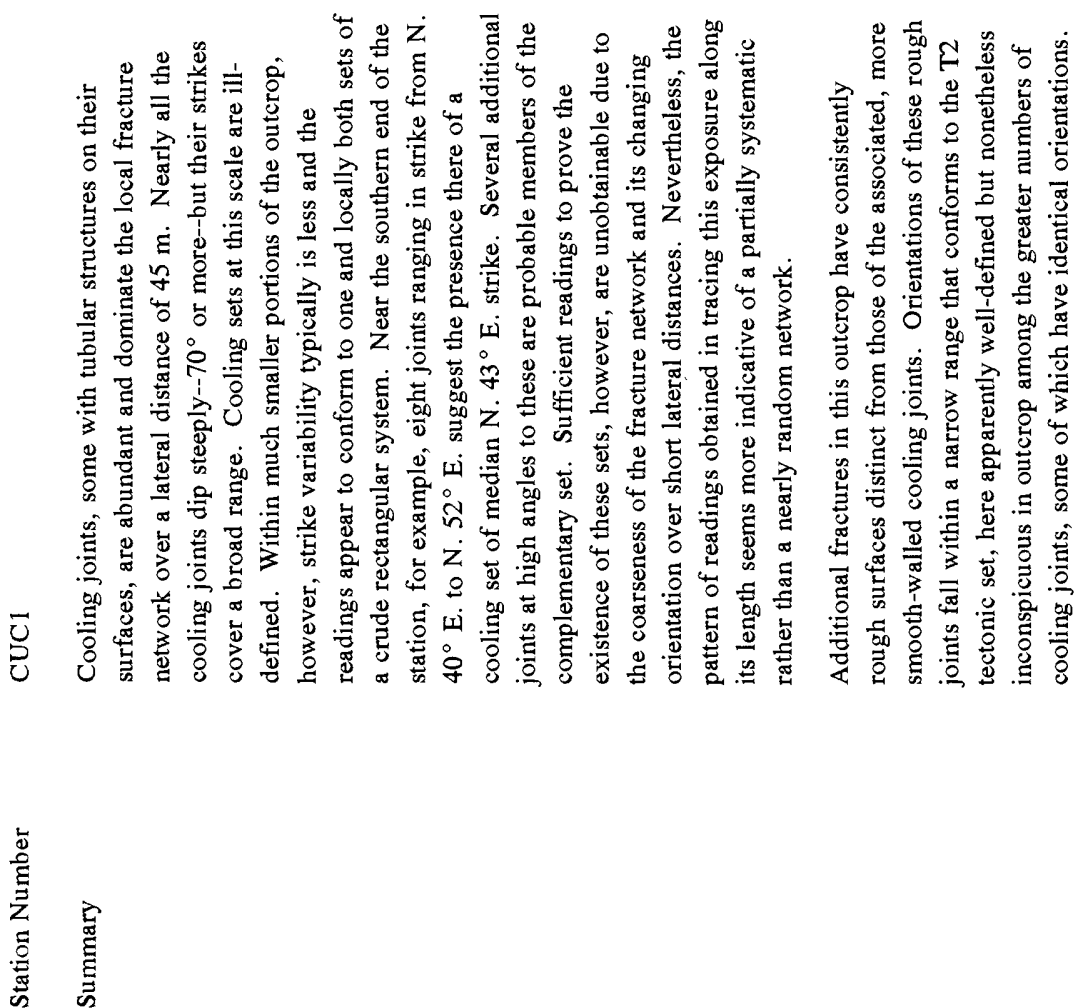


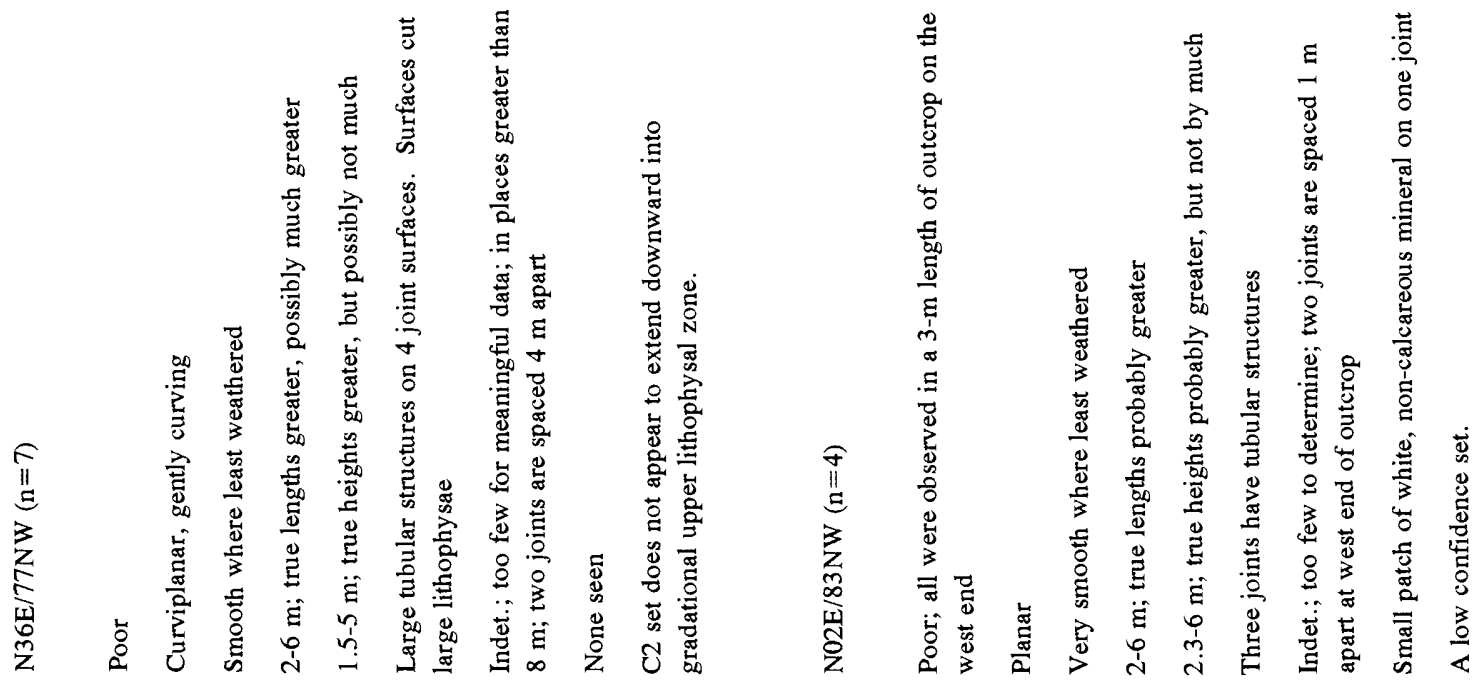

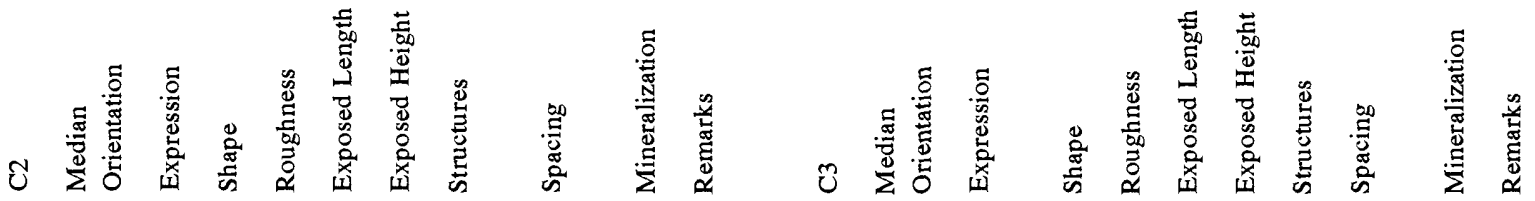

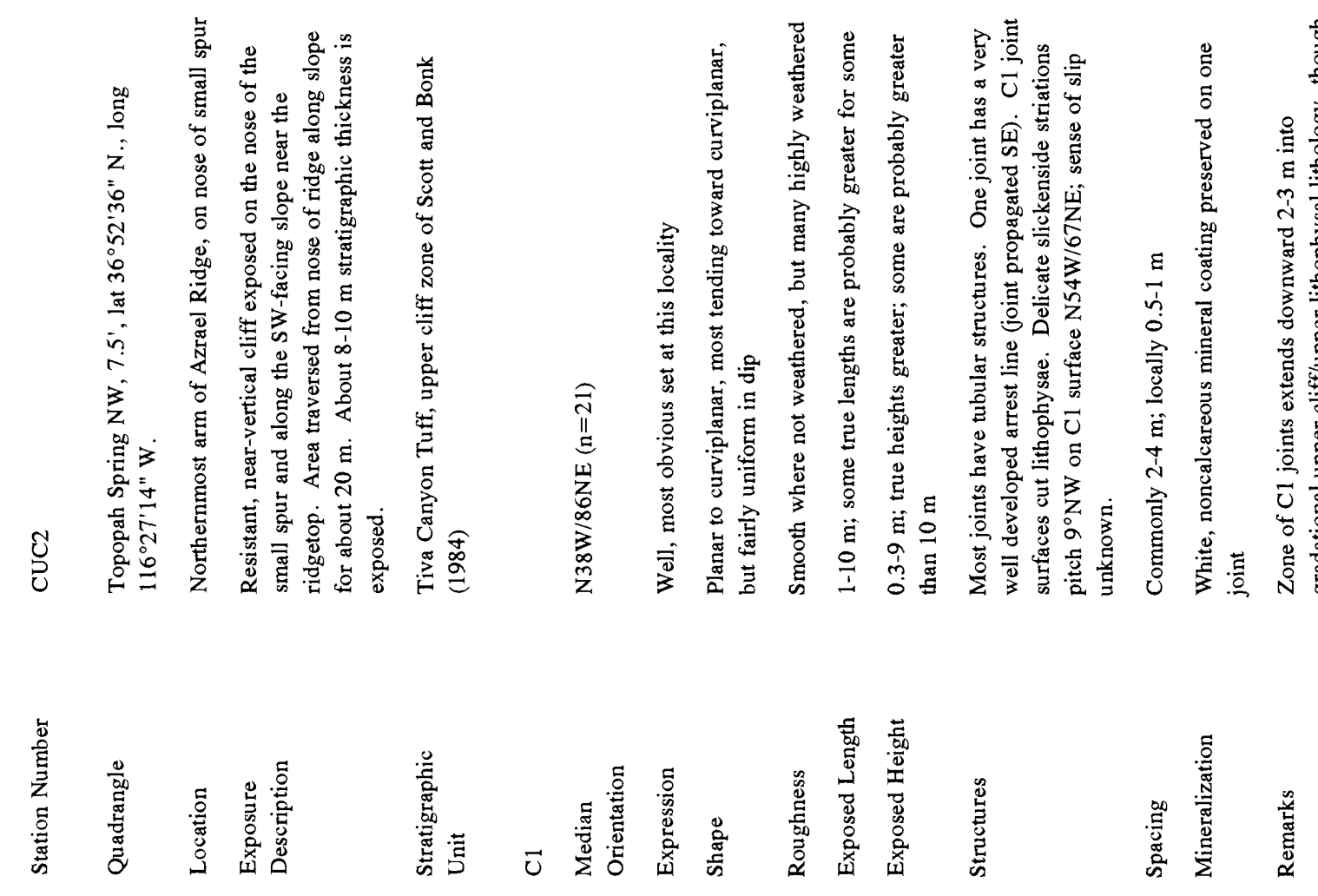



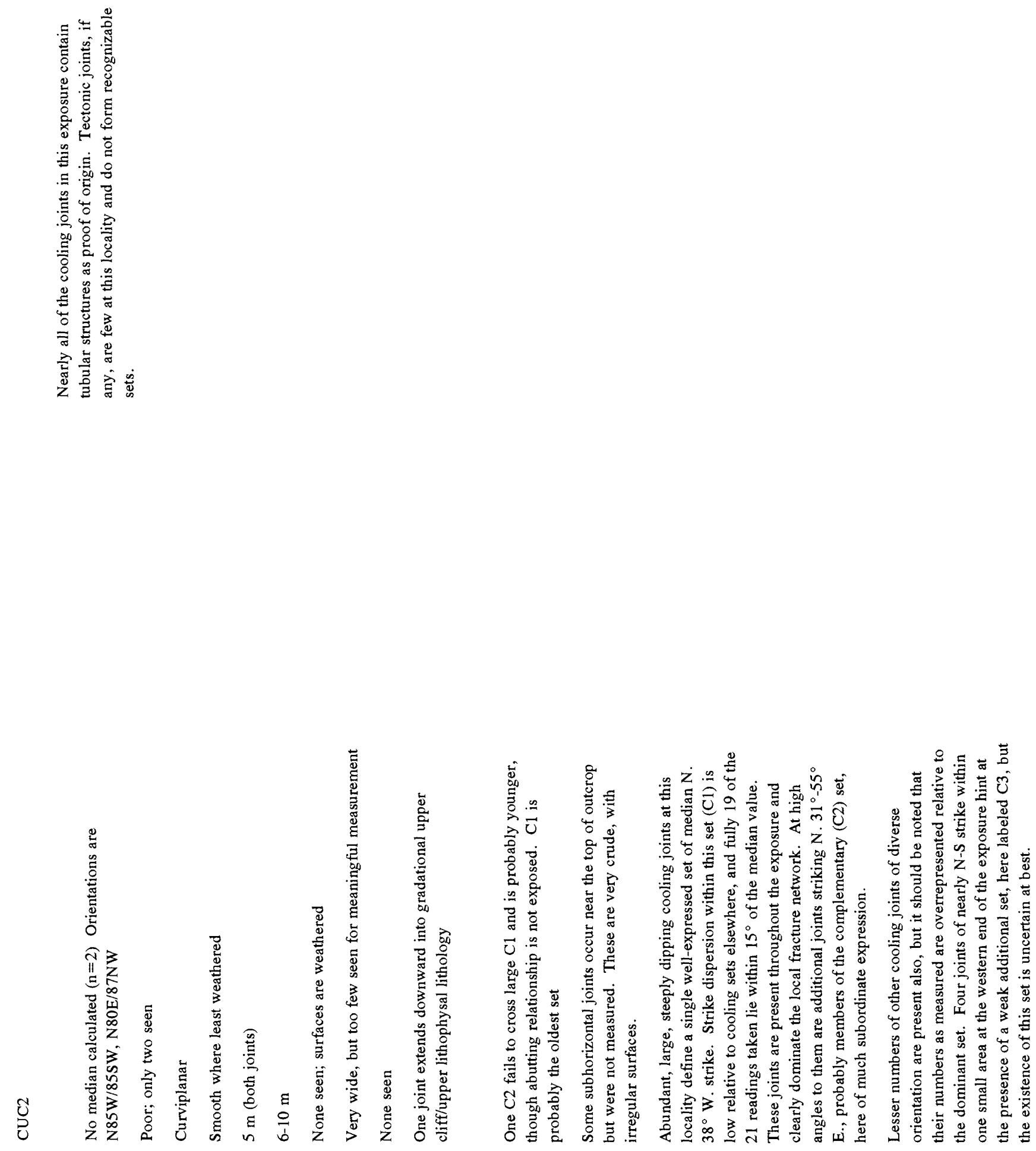

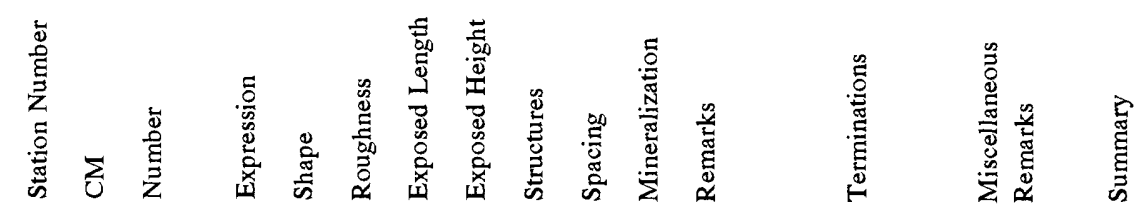


范

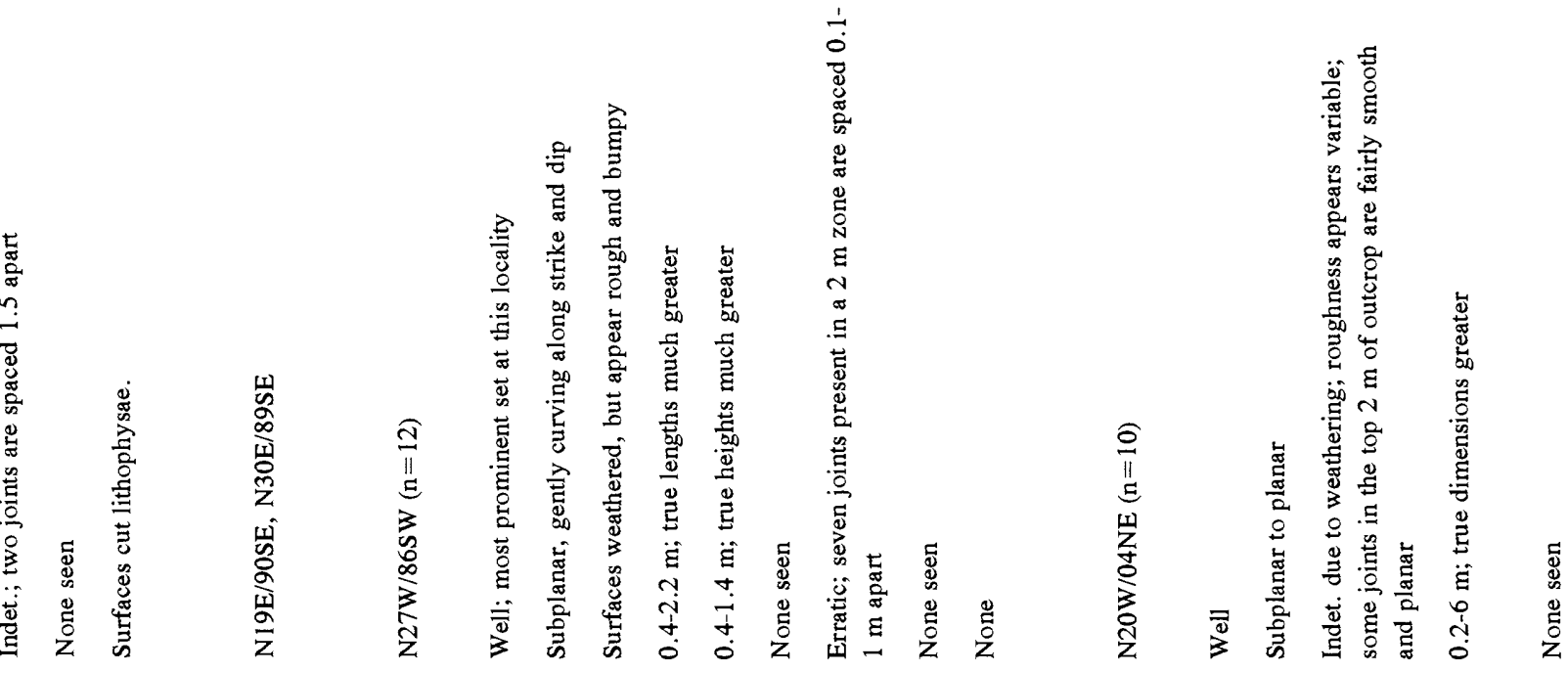

Mร:
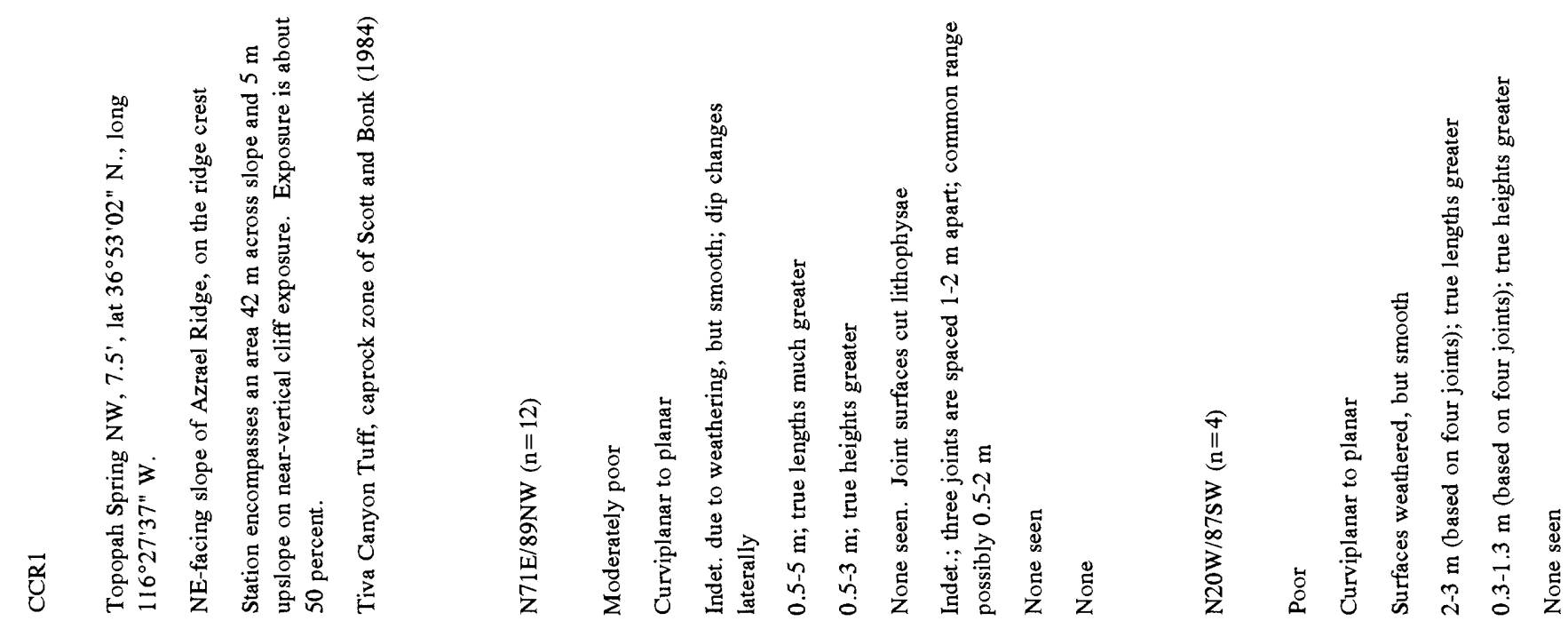

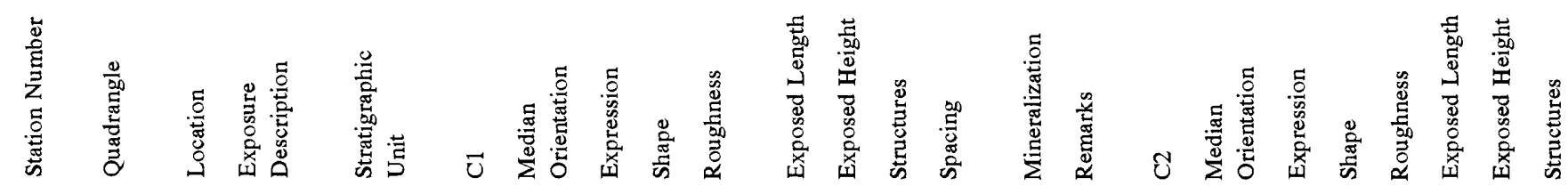




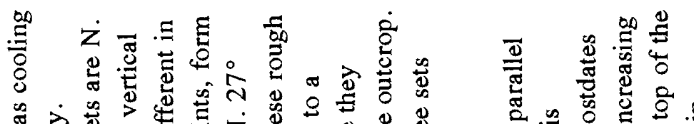

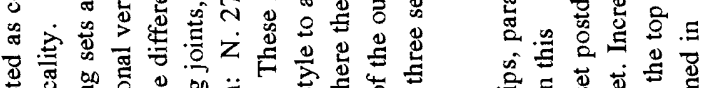

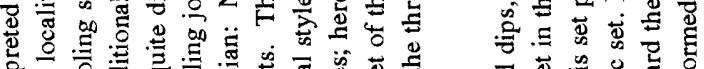

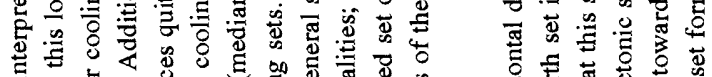

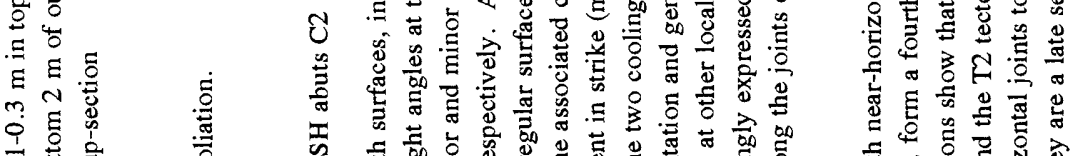

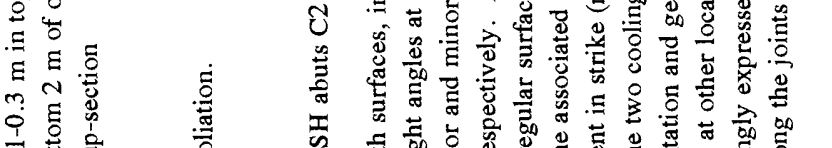

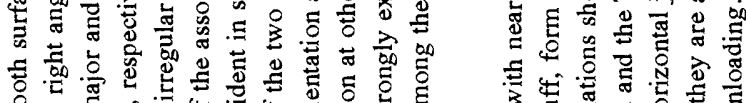




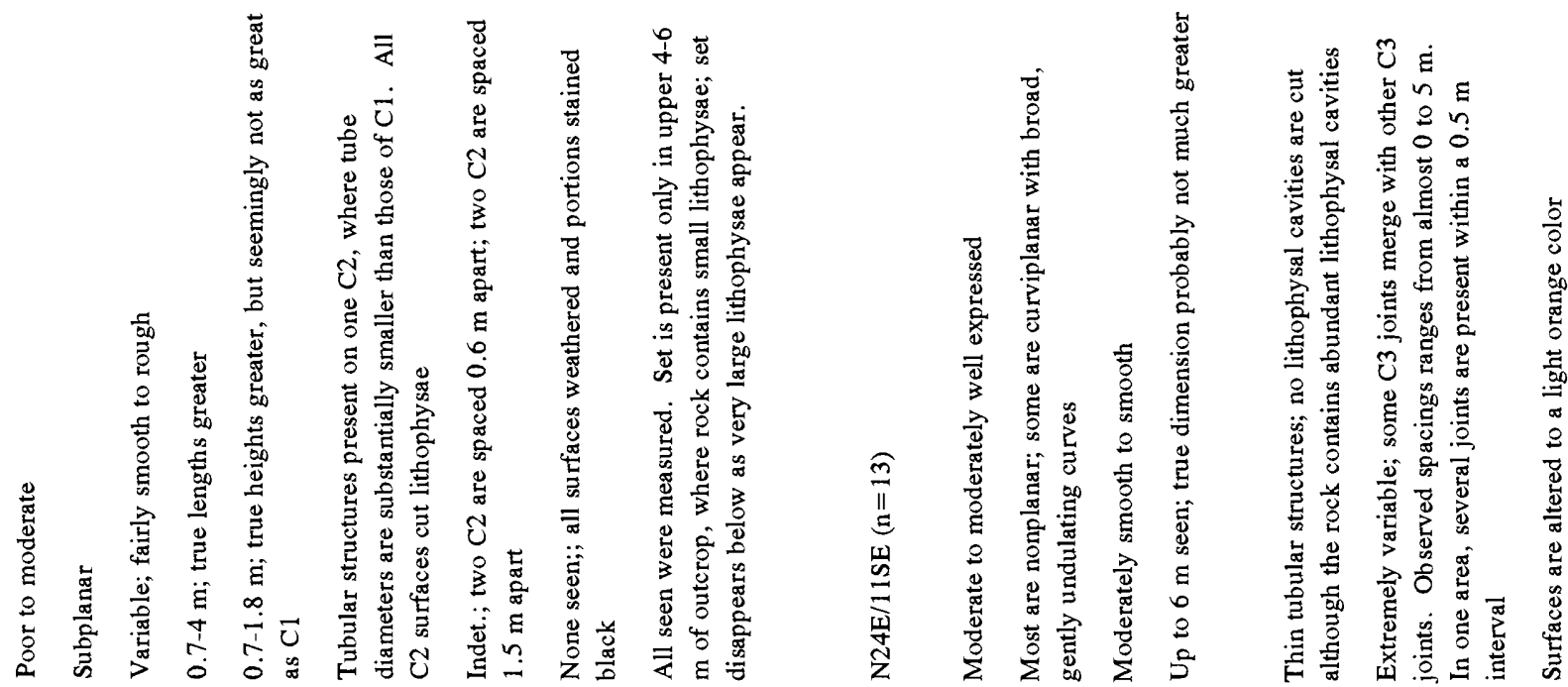

IIII
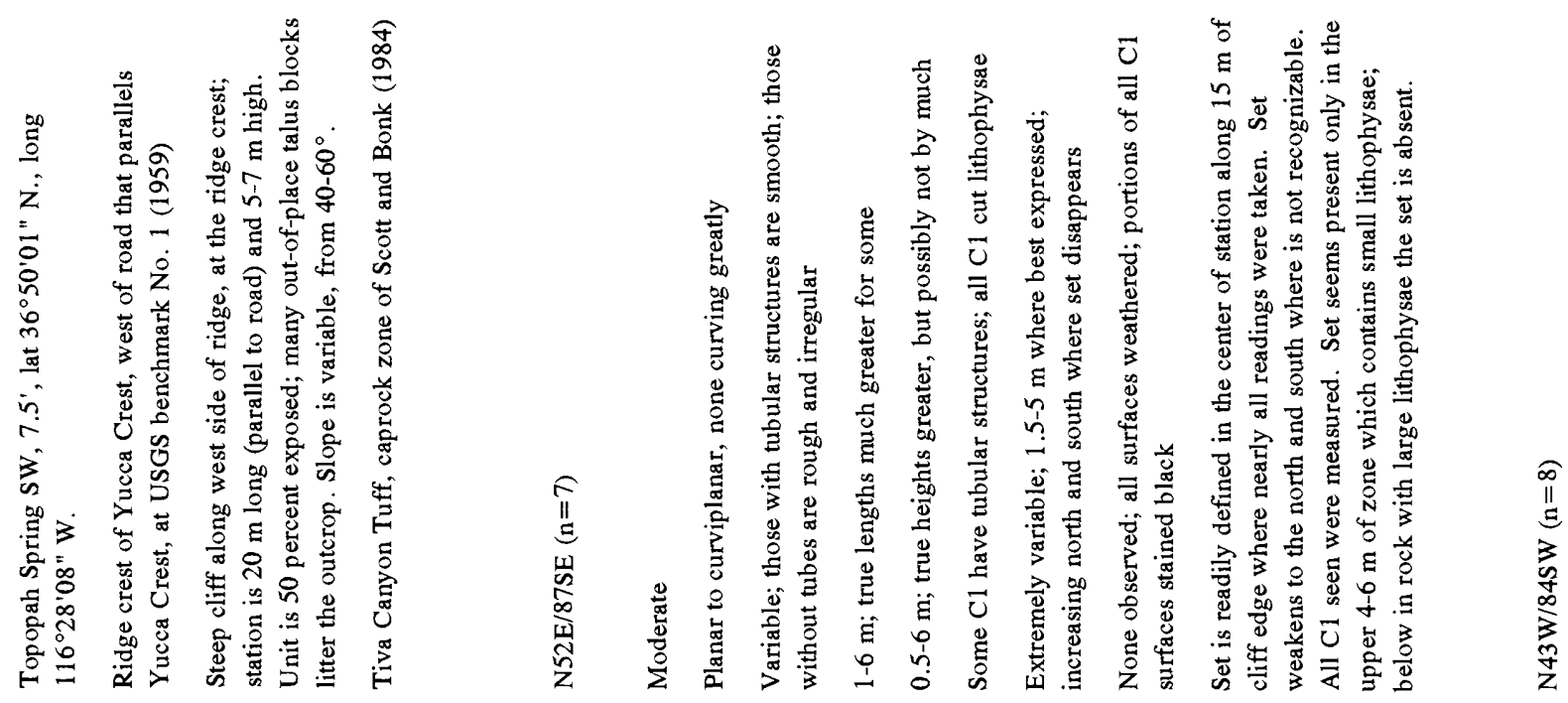

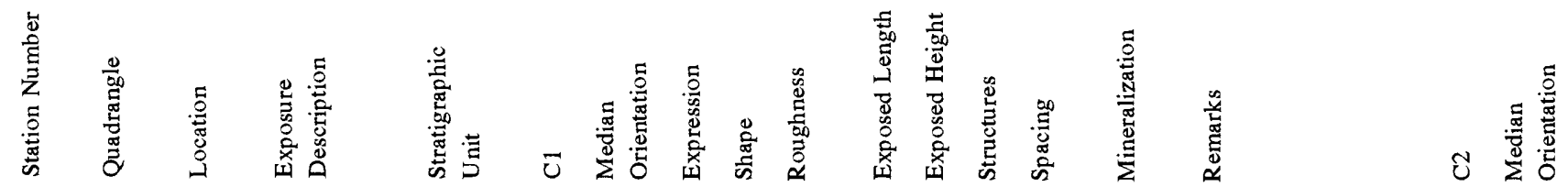



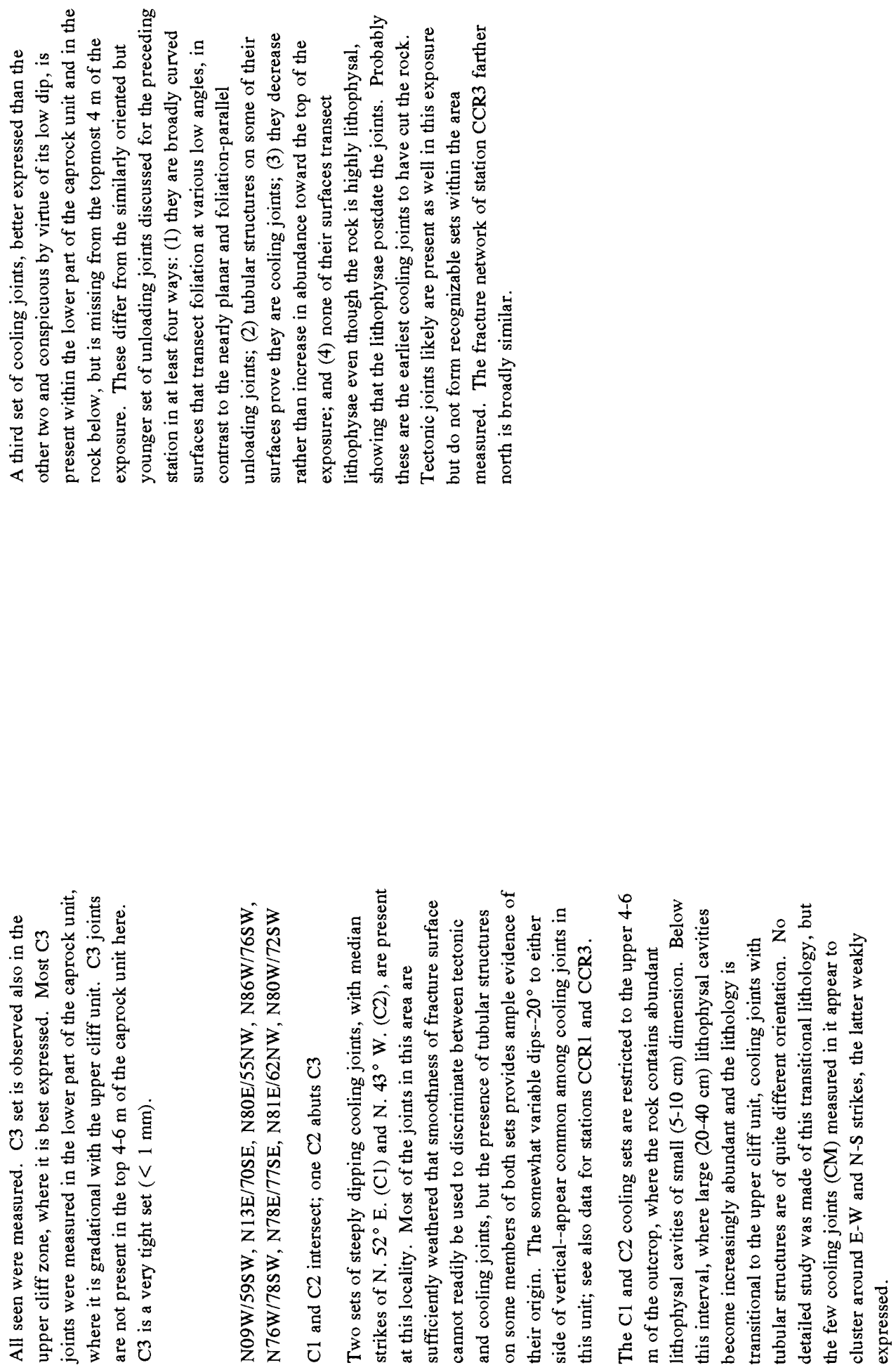

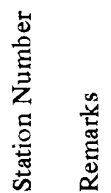

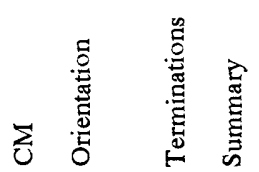




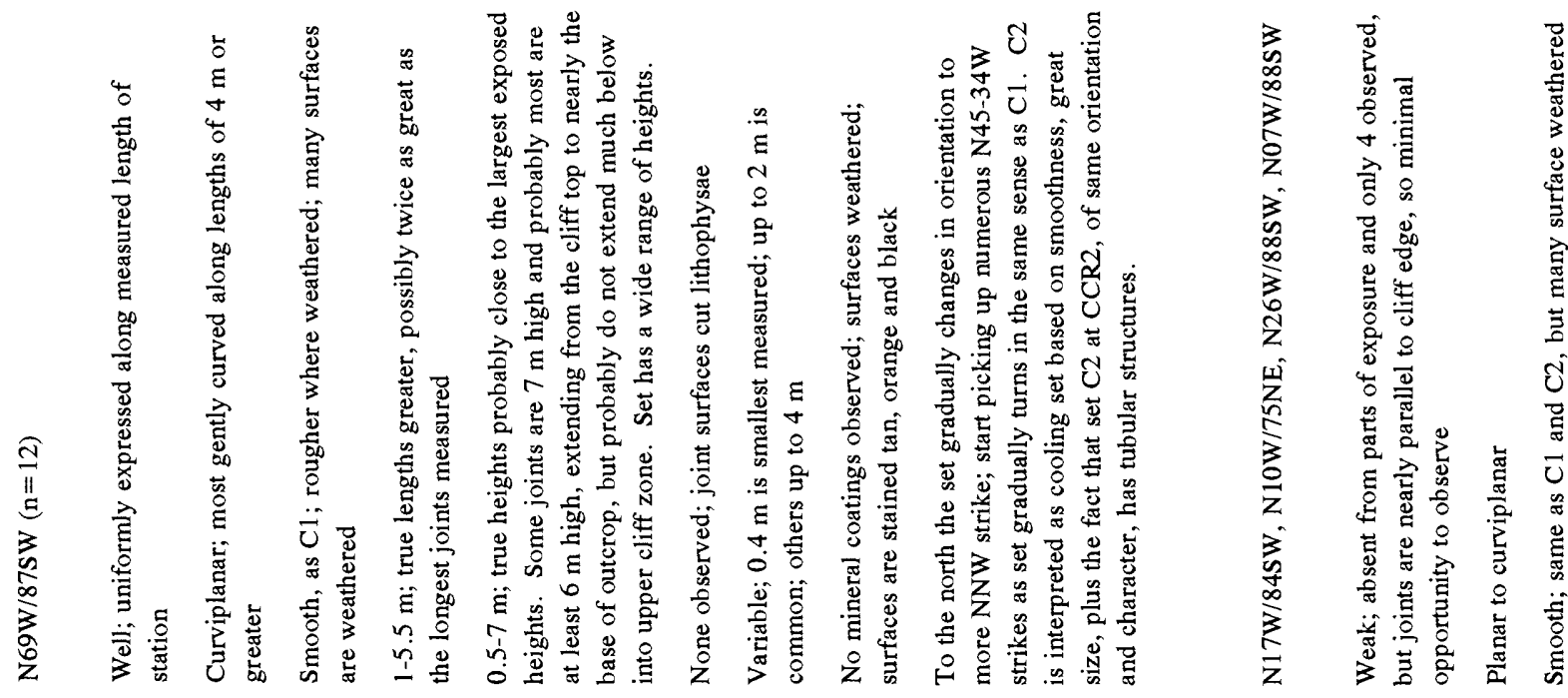

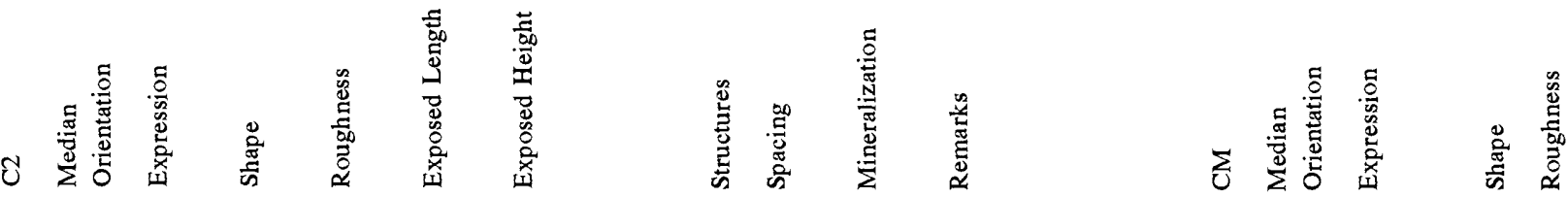

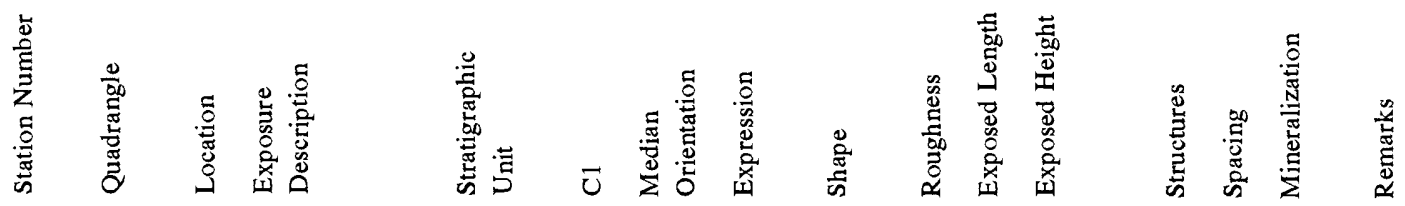



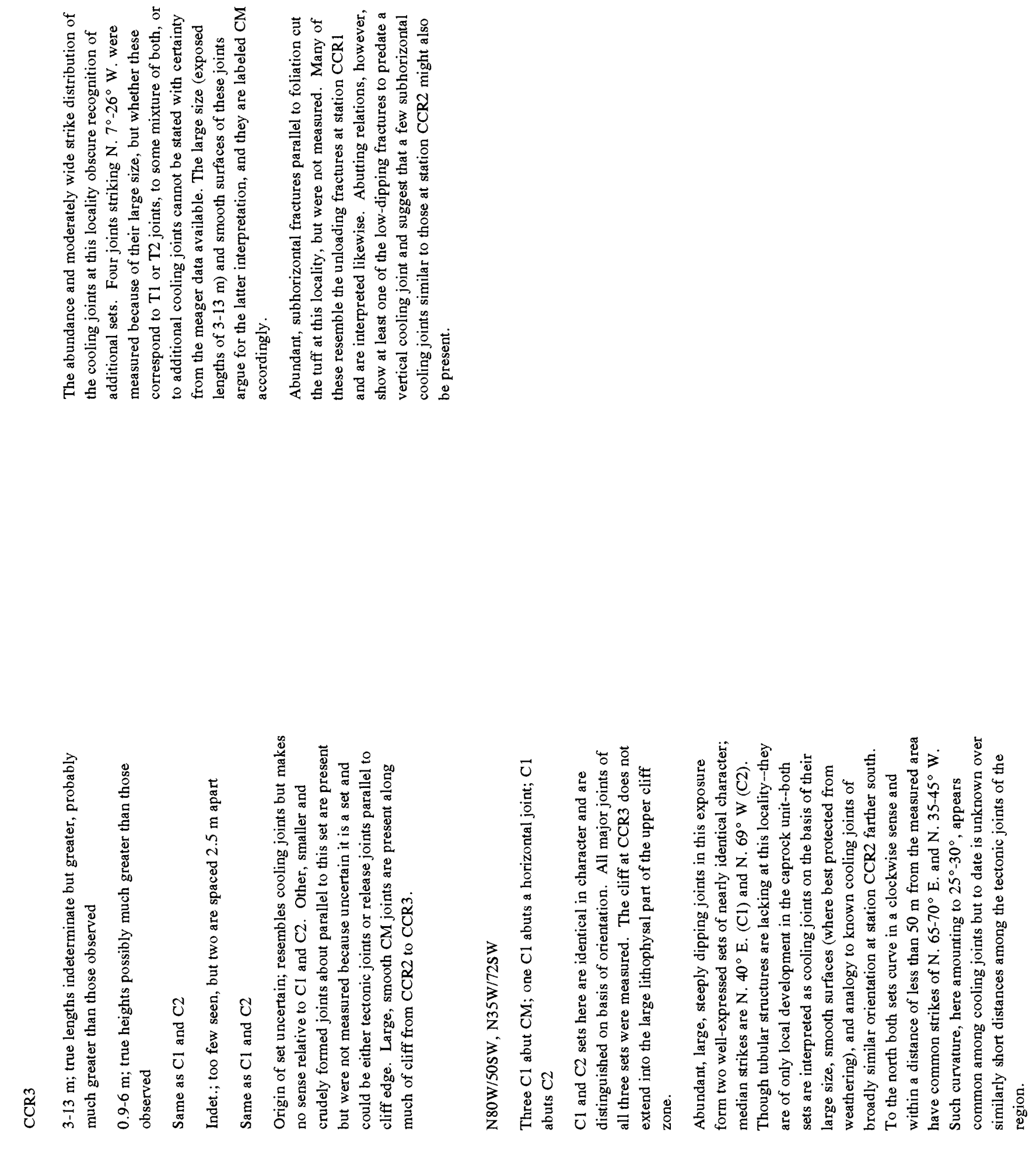

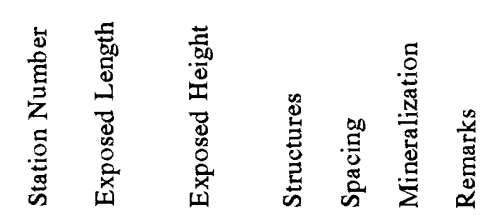

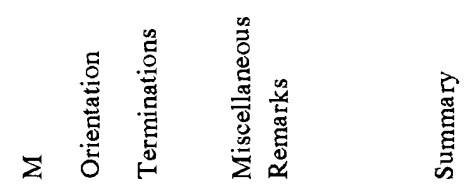




\section{APPENDIX B}

STATION TV1, COOLING JOINTS

$n=54$

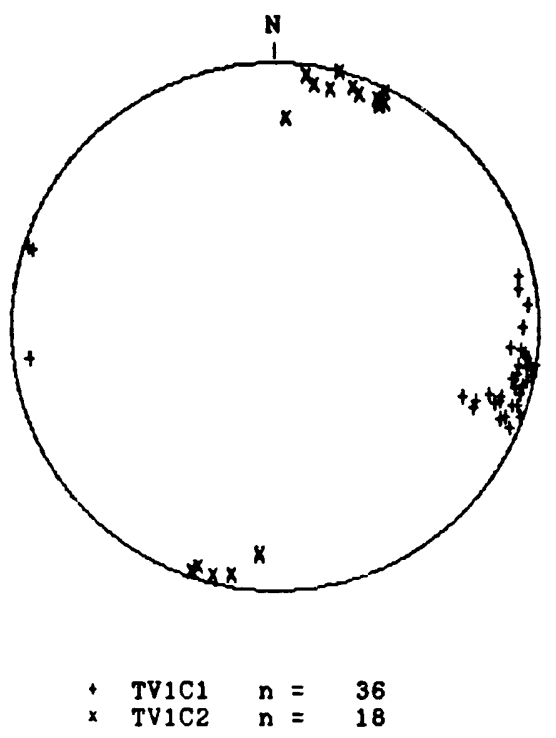

Schmidt net, lower hemisphere projection
STATION TV1, TRCTONIC JOINTS

$n=21$

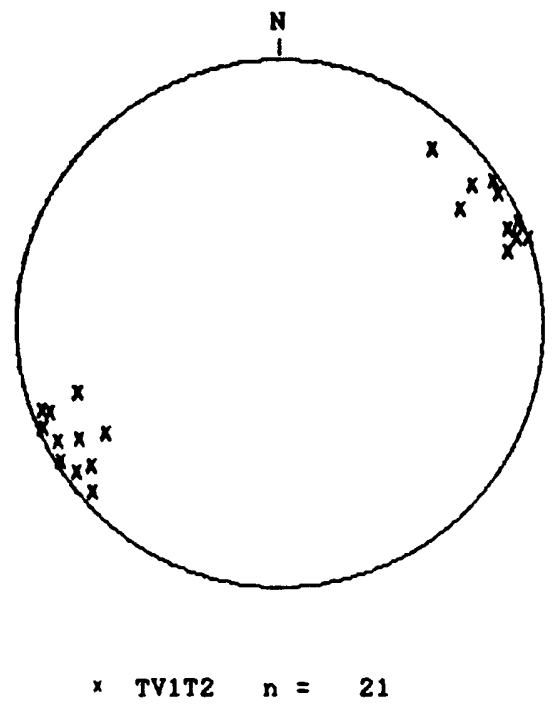

Schmidt net, lower hemisphere projection
TV1C1

N22E7ONW

N18E86NW

N17E79NW

N11E83NW

NOBE87NW

N1 $3 E 86 \mathrm{NW}$

N17E74NW

NO6E85NW

NO5E79NW

N07E86NW

NO5E83NW

N17E79NW

NO8E9ONW

N12E81NW

N05W86SW

N1 2W84SW

N19E77NW

N14E83NW

NO7W83NE

NO9E83NW
C1-cont. TV1C2

N20E65NW N86W75NE

N22E81NW N7OWB3SW

N15E86NW N72W85SW

N18E84NW N71W88NE

N11E89NW N83W85SW

N20E70NW N86W76NE

NOOE83NW N76W87NE

N20E89NW N65W88SW

N23E86NW N64W84SW

N21E83NW NB7W68SW

N18E79NW N72W85NE

N09E86NW N65W82SW

N12E87NW N81WB2SW

N18E86SE N76W90SW

N18E88SE N77W82SW

N09W83SW N66W84SW

N65W83SW

NBOW85NE
TV1T2

N31W86SW
N33W70SW
N1 $1680 S W$
N21W83NE
N20W86NE
N23W88SW
N24W88SE
N23W83SW
N20W85SW
N34W87SW
N32W88NE
N36W85NE
N49W77SW
N36W79SW
N37W79NE
N28W85NE
N19W7ONE
N32W67NE
N42W85NE
N30W77NE
N19W9OSW 
STATION TOB1, COOLING JOINTS

$n=31$

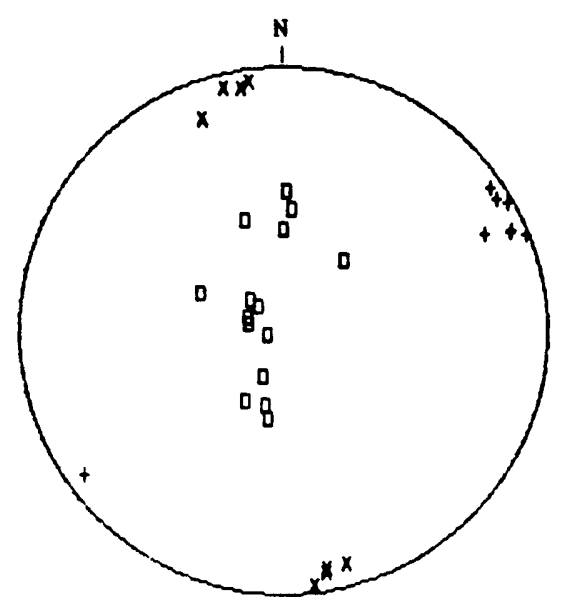

$\begin{array}{lll}\text { TOB1C1 } & n= & 8 \\ \text { TOB1C2 } & n= & 8 \\ \text { TOB1C3 } & n= & 15\end{array}$

Schmidt net, lower hemisphere projection
STATION TOB1, TECTONIC JOINTS

$n=35$

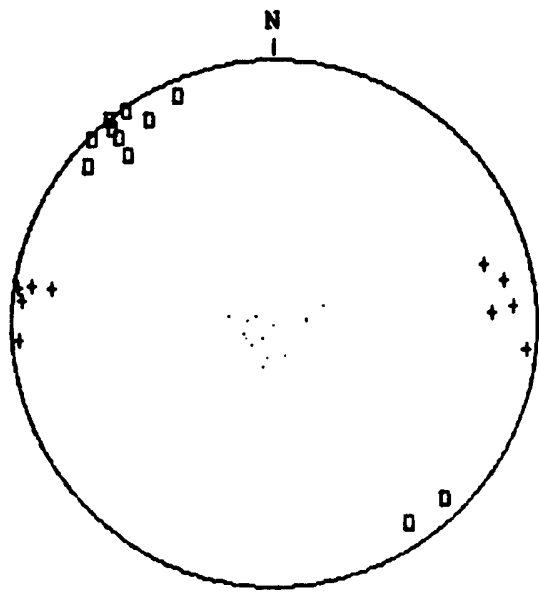

- TOB1T1 $n=10$

$\begin{array}{lll}\text { TOB1T3 } & n=11 \\ \text { TOB1SH } & n=14\end{array}$

Schmidt net, lower hemisphere projection

$\begin{array}{lll}\text { TOB1T1 } & \text { TOB1T3 } & \text { TOB1SH } \\ \text { NO5E86SE } & \text { N50E86SE } & \text { N52WO6NE } \\ \text { NO8E88SE } & \text { N58E80SE } & \text { NO3W1OSW } \\ \text { NO9E83SE } & \text { N46E82NW } & \text { NO3EO8SE } \\ \text { No3W72SW } & \text { N67E84SE } & \text { NO9E14SE } \\ \text { NO4W87NE } & \text { N55E88SE } & \text { NO8W1OSW } \\ \text { N16W72SW } & \text { N56E80NW } & \text { N45W1ONE } \\ \text { NO4W80SW } & \text { N49E74SE } & \text { N73E11NW } \\ \text { N06E86NW } & \text { N4OE82SE } & \text { N80W11NE } \\ \text { NO9E75SE } & \text { N51E90SE } & \text { N19W1ONE } \\ \text { N11H78SW } & \text { N50E82SE } & \text { N75W14NE } \\ & \text { N45E88SE } & \text { N3OW1ONE } \\ & & \text { N20W16SW } \\ & & \text { N17EO6SE } \\ & & \text { N61W01NE }\end{array}$


STATION TOB2, COOLING JOINTE

$\mathbf{n}=54$

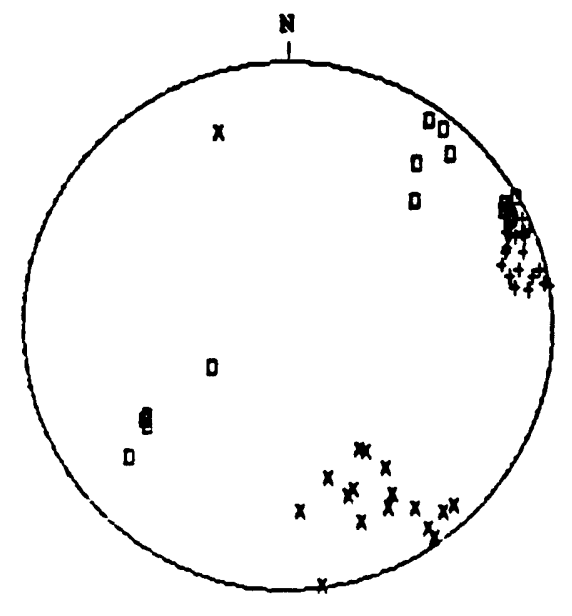

$\begin{array}{ll}\text { TOB2C1 } & n=21 \\ \text { TOB2C2 } & n=17 \\ \text { TOB2C3 } & n=16\end{array}$

Schridt net. lower hemisphere projection
STATION TOB2, TECTONIC JOINTS

$n=18$

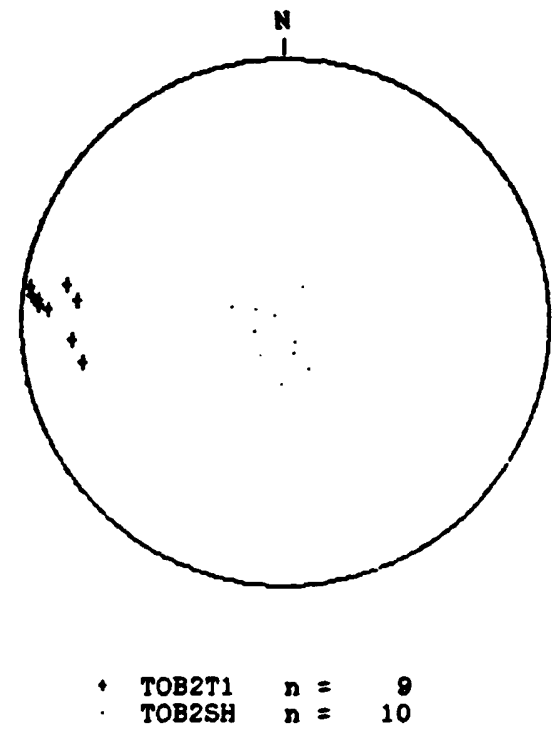

Schmidt net, lower howisphere projection

$\begin{array}{lllll}\text { TOB2C1 } & \text { TOB2C2 } & \text { TOB2C3 } & \text { TOB2T1 } & \text { TOB2SH } \\ \text { N21W85SW } & \text { N58E64NW } & \text { N36W55NE } & \text { NO6E86SE } & \text { N30E04SE } \\ \text { N22W85SW } & \text { N75E50NW } & \text { N34W55NE } & \text { N10E73SE } & \text { N53W13NE } \\ \text { N25W87SW } & \text { N68E57NW } & \text { N33W53NE } & \text { N04E83SE } & \text { N17E17SE } \\ \text { N29W84SW } & \text { N86E60NW } & \text { N29W27NE } & \text { NO3E79SE } & \text { N63W12SW } \\ \text { N23W80SW } & \text { N70E58NW } & \text { N40W67NE } & \text { N08E87SE } & \text { N17W110NE } \\ \text { N22W86SW } & \text { N58E47NW } & \text { N52W68SW } & \text { NO5W70NE } & \text { N86W19NE } \\ \text { N16W73SW } & \text { N55E55NW } & \text { N52W85SW } & \text { N11W67NE } & \text { N66E07NW } \\ \text { N18W83SW } & \text { N60E45NW } & \text { N56W84SW } & \text { N05E83SE } & \text { N75E10NW } \\ \text { N13W75SW } & \text { N69E68NW } & \text { N47W79SW } & \text { NO6E68SE } & \text { N64E16NW } \\ \text { N14W79SW } & \text { N61E68NW } & \text { N45W57SW } & & \text { N23E10SE } \\ \text { N13W76SW } & \text { N55E73NW } & \text { N26W82SW } & & \end{array}$


STATION TR1, COOLING JOINTS

$n=24$

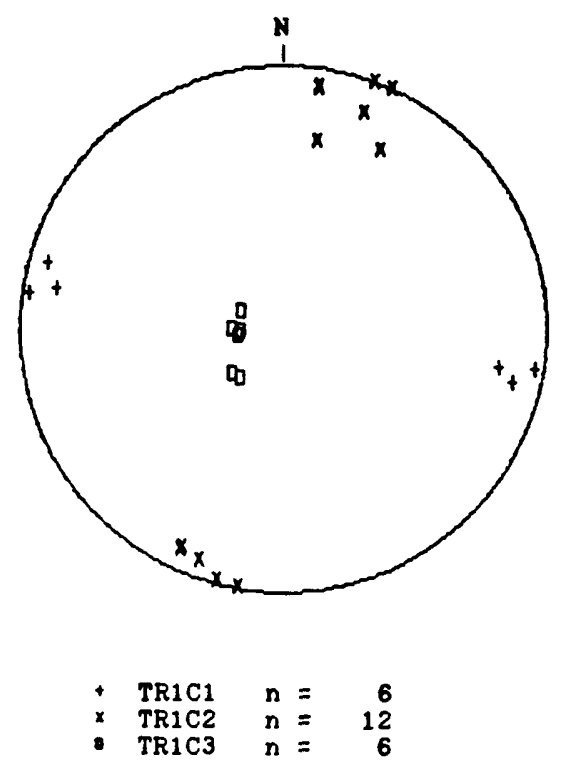

Schmidt not, lower hemisphere projection

$\begin{array}{lll}\text { TR1C1 } & \text { TR1C2 } & \text { TR1C3 } \\ \text { N13E78NW } & \text { N80W62SW } & \text { N22E14SE } \\ \text { N10E76SE } & \text { N70W77SW } & \text { N01E16SE } \\ \text { N16E82SE } & \text { N62W66SW } & \text { NOBW14NE } \\ \text { NO9E86NW } & \text { N65W8ONE } & \text { N48W2ONE } \\ \text { N10E72NW } & \text { N65W81NE } & \text { NO4W13NE } \\ \text { N08E87SE } & \text { N66W9OSW } & \text { N41W21NE } \\ & \text { N70WB2NE } & \\ & \text { N80W89NE } & \\ & \text { N7OW90SW } & \\ & \text { N75W88NE } & \\ & \text { N82WB3SW } & \\ & \text { N82W82SW } & \end{array}$

STATION TR1, TECTONIC JOINTS

$n=14$

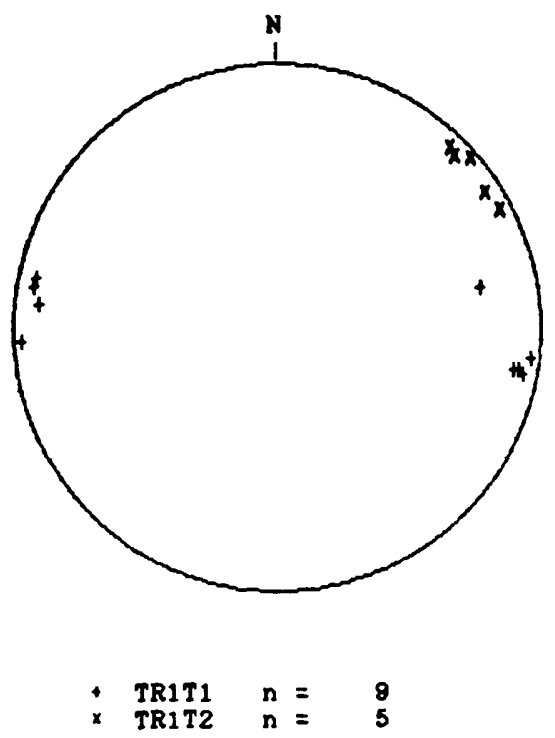

Schmidt net, lower hemisphere projection

TR1T 1

N1OEB3SE

N07E86NW

N11E84NW

N1OE 82NW

N12E83SE

NO6E BOSE

NO 3 WB $7 \mathrm{NE}$

N10E8ONW

N11W67SW
TR1T2

N33W83SW

N44WB 3SW

N46W84SW

N41WB7SW

N2BWB5SW 
STATION TC1, COOLING JOINTS

$n=28$

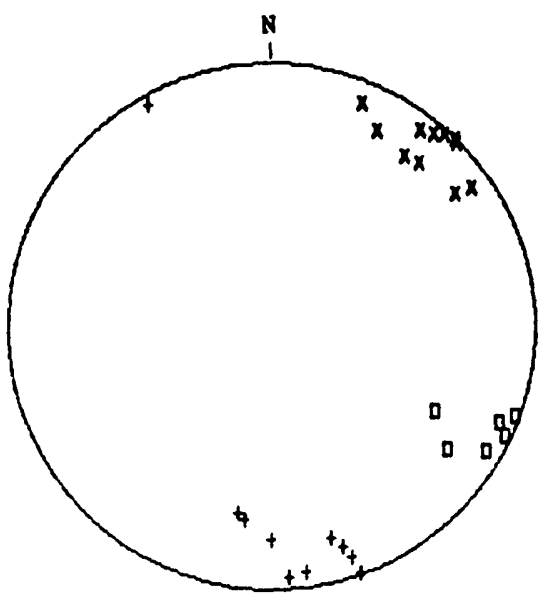

+ TC1C1 $n=10$

$\begin{array}{lll}x & \text { TC1C2 } & n=12 \\ 0 & \text { TC1C3 } & n=6\end{array}$

Schmidt net, lower hemisphere projection
STATION TC1, TECTONIC JOINTS

$n=25$

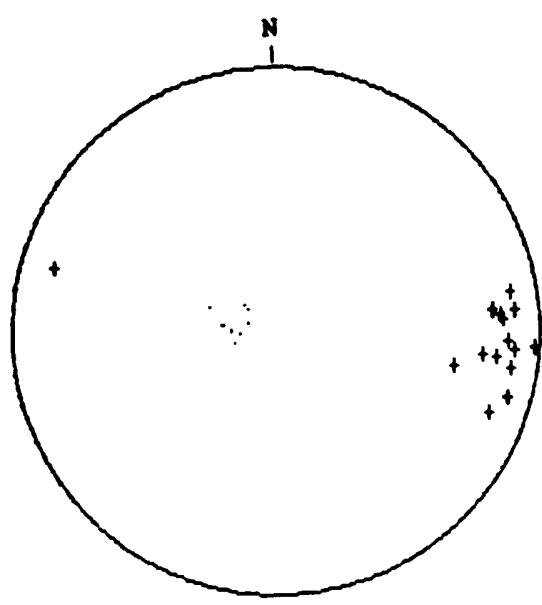

$\begin{array}{ll}\text { TC1T1 } & n=15 \\ \text { TC1SH } & n=10\end{array}$

Schmidt net, lower hemisphere projection

TC1T1 TC15H

N21E75NW NOBE17SE

NO5W71SW NOBE16SE

NO5WBOSW N39E11SE

N16E8ONW N41E13SE

N07E73NW N15W13NE

NO4E8BNW NO1W14NE

NO9E79NW N02W11NE

NO5EBONW N18E09SE

NO3W75SW N21E22SE

NO3E77NW NO3E14SE

NO9W79SW

NO7E68NW

N11E58NW

N04W74SW

N16R76SE 
STATION TC2, COOLING JOINTS

$n=61$

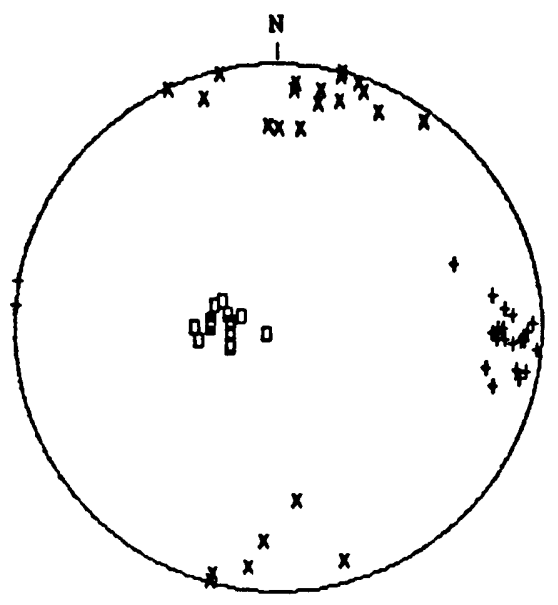

$\begin{array}{lll}+\operatorname{TC2C1} & n=24 \\ \times \operatorname{TC2C2} & n=23 \\ \text { TC2C3 } & n=14\end{array}$

Schmidt net, lower hemisphere projection
STATION TC2, TECTONIC JOINTS

$n=25$

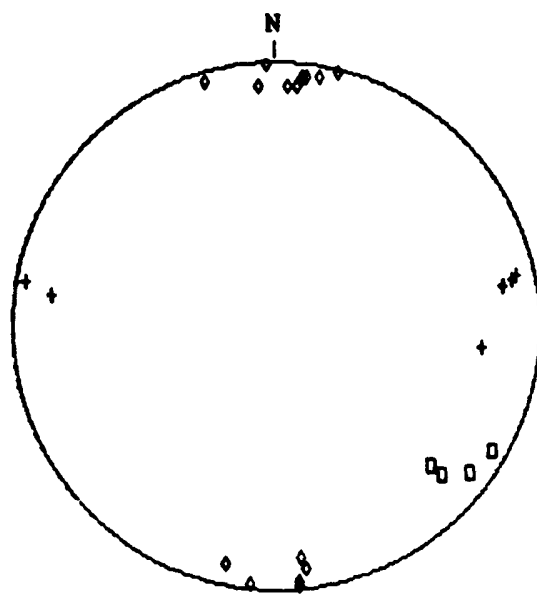

$\begin{array}{lll}\text { TC2T1 } & n= & 6 \\ \text { TC2T3 } & n= & 4 \\ \text { TC2T4 } & n= & 15\end{array}$

Schnidt net, lower hemisphere projection

\begin{tabular}{|c|c|c|}
\hline $\mathrm{TC} 2 \mathrm{C} 1$ & тс2C2 & TC2C3 \\
\hline 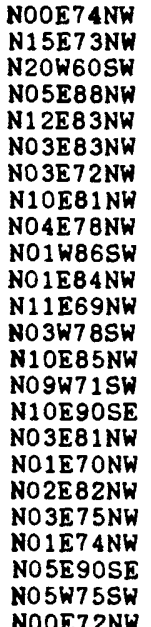 & $\begin{array}{l}\text { N90E65SE } \\
\text { N76W88SW } \\
\text { N80W81SW } \\
\text { N84W65SW } \\
\text { N75W78SW } \\
\text { N76W90SW } \\
\text { N65W79SW } \\
\text { N86W70NE } \\
\text { N83W81NE } \\
\text { N72W87SW } \\
\text { N77E88SE } \\
\text { N87E66SE } \\
\text { N74E81NW } \\
\text { N75W89NE } \\
\text { N72E80SE } \\
\text { N80W75SW } \\
\text { N70W84SW } \\
\text { N86W82SW } \\
\text { N86W79SW } \\
\text { N75W86NE } \\
\text { N65E89SW } \\
\text { N55W85SW } \\
\text { N84E56NW }\end{array}$ & $\begin{array}{l}\text { NOOE21SE } \\
\text { N21W16NE } \\
\text { N04E21SE } \\
\text { NO5E21SE } \\
\text { N15E16SE } \\
\text { N22W16NE } \\
\text { NO9W15NE } \\
\text { N26W04NE } \\
\text { NO6E15SE } \\
\text { N26E19SE } \\
\text { NO9W25NE } \\
\text { N15E12SE } \\
\text { N2OE21SE } \\
\text { NOOE26SE }\end{array}$ \\
\hline
\end{tabular}

$\begin{array}{lll}\text { TC2T1 } & \text { TC2T3 } & \text { TC2T4 } \\ \text { N12W82SW } & \text { N37E81NW } & \text { N87W80SW } \\ \text { N10W76SW } & \text { N3OE84NW } & \text { N88E89SE } \\ \text { No6E67NW } & \text { N42E68NW } & \text { N84E77NW } \\ \text { No8E75SE } & \text { N42E73NW } & \text { N85E89NW } \\ \text { N11W80SW } & & \text { N85W80SW } \\ \text { N10E86SE } & & \text { N83E82NW } \\ & & \text { N86E80SE } \\ & & \text { N8OW85SW } \\ & & \text { N78W81NL } \\ & \text { N76W89SW } \\ & \text { N74E86SE } \\ & \text { N84W88NE } \\ & \text { N84W84SW } \\ & \text { N85E87NW }\end{array}$


STATION TC3, COOLING JOINTS

$$
n=46
$$

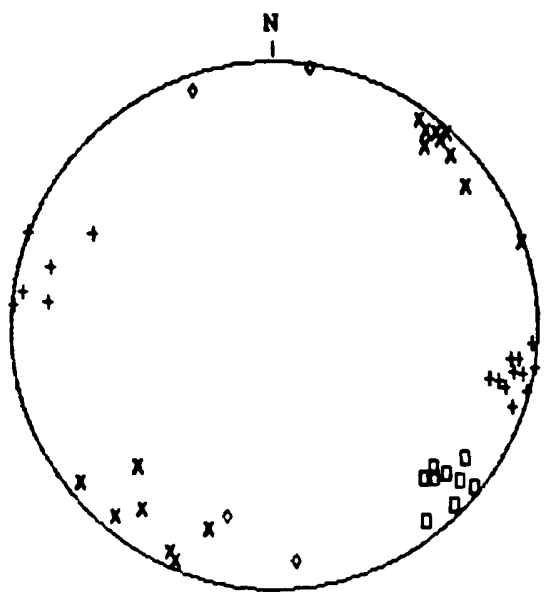

$$
\begin{array}{lll}
\text { TC3C1 } & n=17 \\
\text { TC3C2 } & n=1 \\
\text { TC3C3 } & n=1 \\
\text { TC3C4 } & n=4
\end{array}
$$

Schmidt net, lower hemisphere projection

TC3C1

NOBE BONW N14E73NW NORE83NW NO5E89SE NO9E9ONW N15E89NW N1 $1985 \mathrm{NW}$ NO 4 EBBNW N21E90SE N15E80NW N11E82NW N14E77NW N15E77SE N11E86NW NOBE $865 E$ NO6E75SE N27E66SE

TC3C2
N50W84NE
N39W84NE
N54W75NE
N46W64NE
N36W79SW
N55W85SW
N48W88SW
N52W83SW
N50W85SW
N50W78SW
N44W83SW
N1 $19689 S W$
N65W84NE
N72W70NE
N48W84SW
N67W87NE

TC3C3

N44E73NW N35E77NW N41875NW N39E87NW N45E86NW N46E70NW N42E97NW N40E81NW N52E83NW
STATION TC3, TECTONIC JOINTS

$n=31$

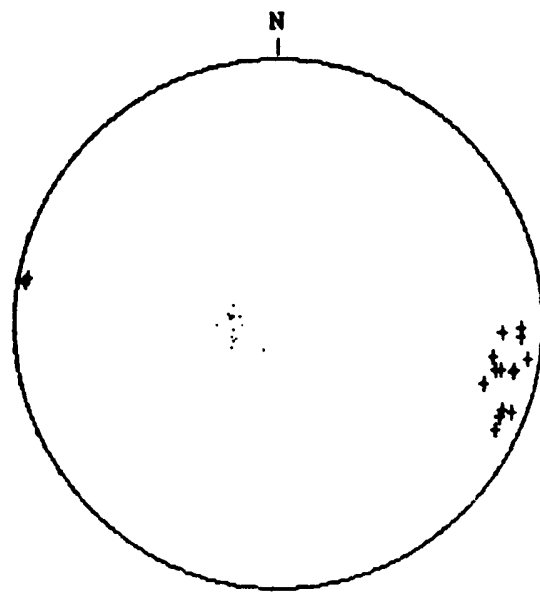

$$
\begin{array}{ll}
\text { TC3T1 } & n=16 \\
\text { TC3SH } & n=15
\end{array}
$$

Schmidt net, lower hemisphere projection
$\mathrm{TC3C}_{4}$

N76W64NE N82W88SW N85E7 8NW N7 12845
TC3T1

TC35H

N12E75NW

NO3E81NW

N23EBONW N26E81NW

N12E7 3NW

N16E70 NW

N21 EB4NW NO9E71NW

NO8EB5NW

N10E86SE

NO9E875E N12E80NW N02E74NW N21580NW NO1E81NW N1 1 R80NW
N27W16NE N20W15NE N20W1 4NE NOBE $145 E$

NO9E16SE

NO9W14NE

NO4E $155 E$

N05E08SE

N17W15NE

NOSW19NE

NO9E125E

NOSW $11 \mathrm{NE}$

N61W09NE

N21E15SE

NOBE15SE 
STATION TC4, COOLING JOINTS

$$
\mathbf{n}=11
$$

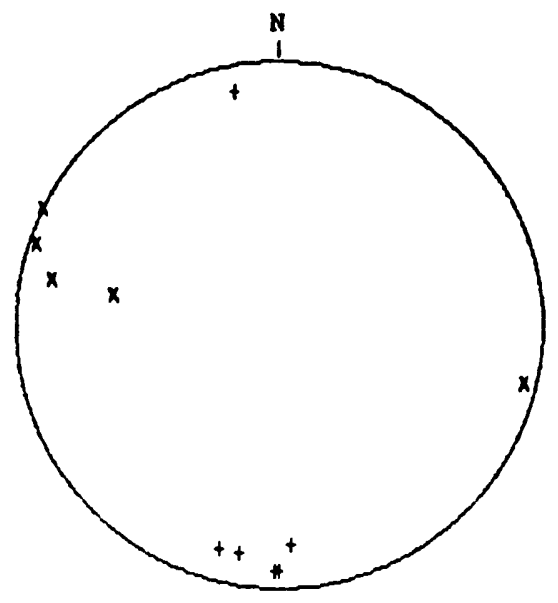

$$
\begin{array}{lll}
\text { TC4C1 } & n=6 \\
\times \quad \operatorname{TC} 4 C 2 & n=5
\end{array}
$$

Schmidt net, lower hemisphere projection
STATION TC4, TECTONIC JOINTS

$$
\mathbf{n}=53
$$

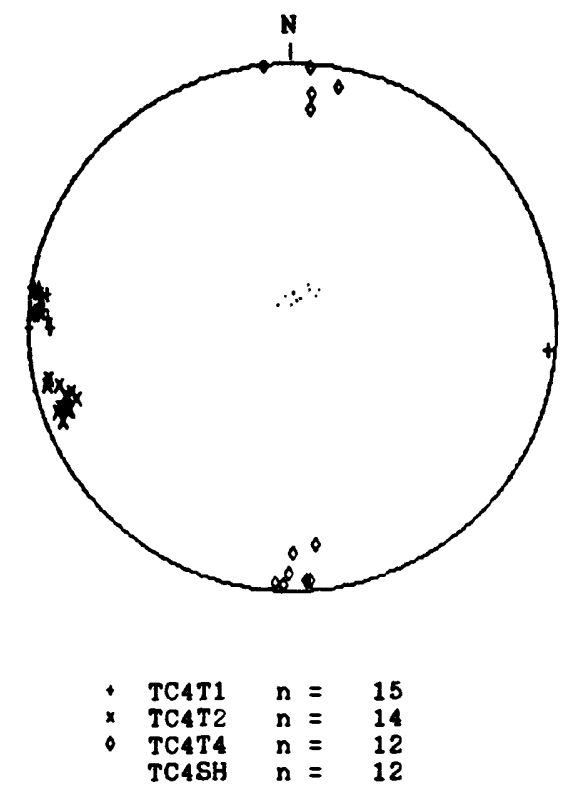

Schnidt net, lower hemisphere projection

\section{TC4T2}

N17W79NE N17W7BNE N1 BW75NE N16W76NE N2ONB4NE N12W84NE N19W81NE N19WB2NE N2OW79NE N12W84NE N2OWBONE N14W8ONE N22WB3NE N13W85NE
TC4T4

NB8W87NE N89W83NE N86E86NN NB7E86NW N84E72NW N84E9OSE N85W72SW N79W82S N79W82SW N86W89S N86WB7NE N9OE75NW
TC4SH

N85E07SE N57E08SE N7BE $\mathrm{OSE}$ N88W1OSW N87W11 S N74WO9SW N55W14SW N53W12SW N88W1 $1 S$ W N66W13Sw N7OW1 4SW N8OW0 8SW 
STATION CC1, TECTONIC JOINTS

$\mathbf{n}=70$

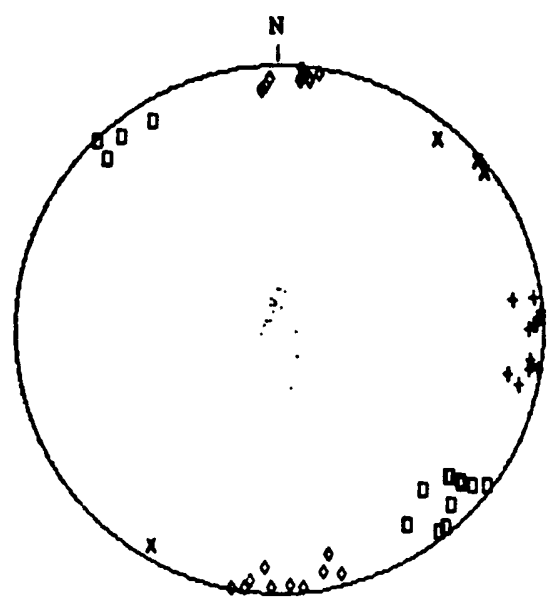

$\begin{array}{lllr}+\operatorname{cc} 1 T 1 & n= & 14 \\ x & \operatorname{cc} 1 T 2 & n= & 4 \\ \operatorname{cc} 1 T 3 & n= & 15 \\ \text { cc1T4 } & n= & 20 \\ \operatorname{cc1sH} & n= & 17\end{array}$

Schmidt net, lower hemisphere projection

CC1T1

NO9E85N

N11E77NW

NO1WB7SA

N13282N

NO9E85NW

N07N78Sh

NO1H86SW

NO7WB7SW

NO9E89NW

NOOEB4NW

NO8E86NW

NO4W89SH

N07585NW

NO3W89SW
CC1T2

N50\%835N

N37W875h

N4ONB8Sh

N59W85NE
CC1T3

N50E87NW

N45E81SE

N37288Nh

N57E77NH

N46E82NW

N41E73NW

N52EB7NW

N39EB 3NW

N40E78NK

N4BETONW

N41E74NW

N51E84SE

N46E89SE

N59EB2SE N4OE7 9 NW
cc1T4

N81W885W

N86W79NE

N87E82SE

N76E85NH

N85W90SW

N85W86SW

N7BE76NW

N88E85ST

N88W67NE

NB2WB8NE

N83W85NE

N79WB9NE

N84W87SW

N85W84SW

N83W85SW

NBOEB2NW

NB6E80SE

N83W84SW

N88E86NW

N85E8BNW ce1su

N86W075W

N82W135W

N58E1ONW

N36E05SE

N69E06SE

NATEO4SE

N76E1OSE

N82E08SE

N80E095E

N7OE0 8SE

N19E05SE

N8BW12SW

N78EOBSE

N11E05NW

N12W06NE

N88E12SE

NBOE 1BNW 
STATION CH1, COOLING JOINTS

$n=17$

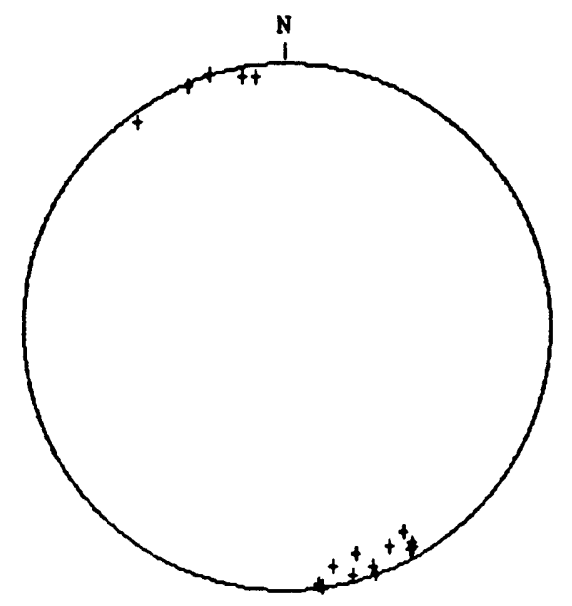

- CH1C1 $n=17$

Schmidt net, lower hemisphere projection
STATION CH1, TECTONIC JOINTS

$$
n=93
$$

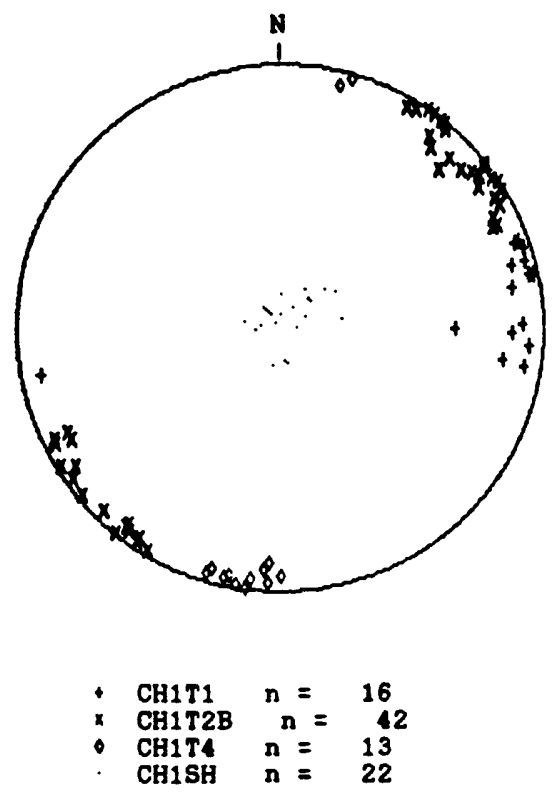

Schmidt net, lower hemisphere projection

$\begin{array}{ll}\text { CH1C1 } & \text { CH1T1 } \\ \text { N70E89NW } & \text { N20W86SW } \\ \text { N65E81NW } & \text { N12W86SW } \\ \text { N68E89SE } & \text { N15W8OSW } \\ \text { N75E87NW } & \text { N11W82NE } \\ \text { N82E89NW } & \text { N12W88SW } \\ \text { N70E86NW } & \text { NO1E77NW } \\ \text { N61E86NW } & \text { N15W86SW } \\ \text { N80E86SE } & \text { N18W87SW } \\ \text { N79E82NW } & \text { NO0E56NW } \\ \text { N73E79NW } & \text { N20W84SW } \\ \text { N83E85SE } & \text { N01W81SW } \\ \text { N60E84NW } & \text { NO8E74NW } \\ \text { N73E90SE } & \text { N12W88SW } \\ \text { N60E86NW } & \text { NO4E84NW } \\ \text { N54E86SE } & \text { N1OW78SW } \\ \text { N83E88NW } & \text { N09E83NW } \\ \text { N60578NW } & \end{array}$

CH1T2A
N45W80SW
N45W74SW
N53W85NE
N52W81SW
N41W8OSW
N52W89SW
N52W85NE
N54W9OSW
N56W85NE
N52W83NE
N59W8BNE
N56W87NE
N58W87SW
N60W86SW
N51W89NE
N46W86NE
N56W90SW
N50W78SW
N51W89SW
N50W87SW

CH1T2B

N25พ80SW N26W85NE

N38W88SW

N39WB 3SW

N25W78SW

N28W79NE

N39W89SW

N32W88NE

N27W80SW

N26W79NE

N39W89SW

N36W87NE

N32W89SW

N31W84SW

N34W9OSW

N40W88NE

N27W85NE

N29W85SW

N37W84SW

N35W8 8 SW

N35W81SW

N34W83NE
CH1T4

N82W89NE

N76W84SW

N83W85NE

N74W84NE

N9OE84NK

N80W88NE

N87W78NE

N86W81NE

N78W85NE

N77W86NE

N87W87NE

N73W86NE

N74WB8SW
CH1SH

NO8W1 9 NW

N06E06SE

N33E02SE

N06W08NE

N33W2OSW

N88W04SW

NO9E11SE

N41W12SW

N57W07S

N79E11NW

N56E05SE

N83E1ONW

N24W08SW

N48E08SE

N58W14SW

N51E06SE

NO3E05NW

N9OE1OSE

N49E07SE

N41W18S

N78W1 2NE

N46W12SW 
STATION CH2, TECTONIC JOINTS

$n=73$

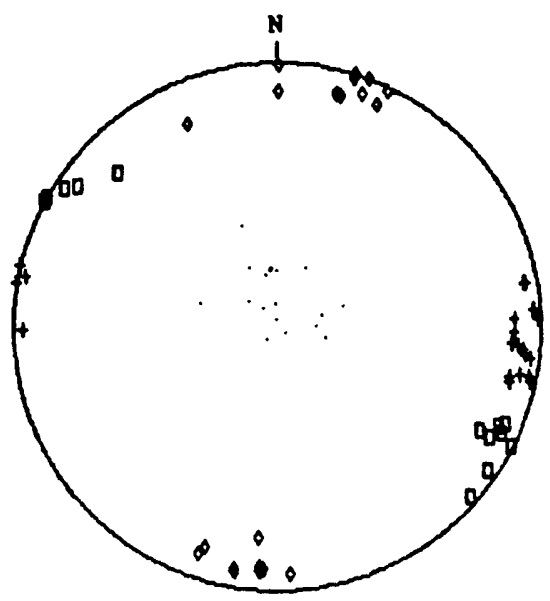

$\begin{array}{ll}\text { CH2T1 } & n=20 \\ \text { CH2T3 } & n=14 \\ \text { CH2T4 } & n=21 \\ \text { CH2SH } & n=18\end{array}$

schmidt net, lower hemisphere projection

CH2T1

NO4E81NW

N1OW84SW

N06E $84 N W$

NO1E79NW

N12E88NW

N02W79SW

N02W89SW

N04W875W

N01W86NE

N11E83NW

N1 3E90SE

N1OW85SW

N11E87NW

NO5E83NW

NO 9E9OSE

N12E79NW

NO 4 E78NW

N11E87SE

NO7E $86 \mathrm{NW}$
CH2T3

N27E89NW

N41E87NW

N24E81NW

N33E86SE

N27E79NW

N44E73SE

N23EB6NW

N23EB3NW

N29E $90 \mathrm{SE}$

N27E75NW

N34E86NW

N28E90SE

N35E $825 E$

N25E83NW
Ca2T4

N76WBOSW

N65W885W

N87E83NW

N85W69NE

N9OE89SE

N75WBOSW

N80WB 2NB

N87W81NE

N70w83S

N7 3W90S5

N63W88SW N86 WBONK

N9OE785E

N86W82NE

N70w90S

N66E735E

N73W88SW

N71WBONE

NBOWB $3 N E$

N66W81S

N72W77NE
CH2SH

N82E07SE

N64520SE

N75EO2SE

N16225SE

N89E17SE

N48E07SE

N51W05NB

N17W21SW

N4OE 1258

N7651655

N84E18SE

N12E15NW

N4OEO3NW

N65W205W

NOOE12NW

N81E175E

N70E335E

N15N14SN 
STATION CH3, TRCTONIC JOINTS

$D=61$

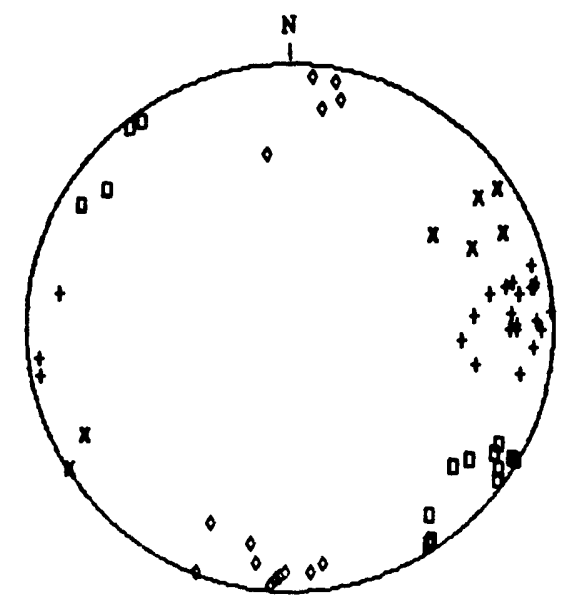

$\begin{array}{llr}\text { CH3T1 } & n= & 23 \\ \text { CH3T2 } & n= & 7 \\ \text { CH3T3 } & n= & 15 \\ \text { CH3T4 } & n= & 17\end{array}$

Schmidt net, lower hewisphere projection

\begin{tabular}{|c|c|c|c|}
\hline CH3T1 & ca3T2 & c43т 3 & c43T4 \\
\hline 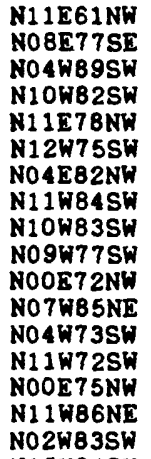 & $\begin{array}{l}\text { N33W89NE } \\
\text { N33W54SW } \\
\text { N28W77NE } \\
\text { N24W77SW } \\
\text { N34W84SW } \\
\text { N24W64SW } \\
\text { N35W76SW }\end{array}$ & $\begin{array}{l}\text { N56E86NN } \\
\text { N51E87SE } \\
\text { N29E8ONW } \\
\text { N40E7ONW } \\
\text { N31E80NW } \\
\text { N30E81SE } \\
\text { N53E77NW } \\
\text { N54E86SE } \\
\text { N34E85NW } \\
\text { N57E87NW } \\
\text { N36E87NW } \\
\text { N37E76SE } \\
\text { N36E73NW } \\
\text { N30E87NW } \\
\text { N30E89NW }\end{array}$ & $\begin{array}{l}\text { N85WB5SW } \\
\text { N82E56SE } \\
\text { N68W69NE } \\
\text { N82E79NW } \\
\text { N87W85NE } \\
\text { NB2W79NE } \\
\text { N85E82NW } \\
\text { N69W89NE } \\
\text { N82W73SW } \\
\text { N86W88NE } \\
\text { N85W85SW } \\
\text { N80W72NE } \\
\text { N89WB2NE } \\
\text { N80W84SW } \\
\text { N8BW84NE } \\
\text { N78W78SW } \\
\text { N65WB9NE }\end{array}$ \\
\hline
\end{tabular}


STATION CH4, TECTONIC JOINTS

$\mathrm{n}=62$

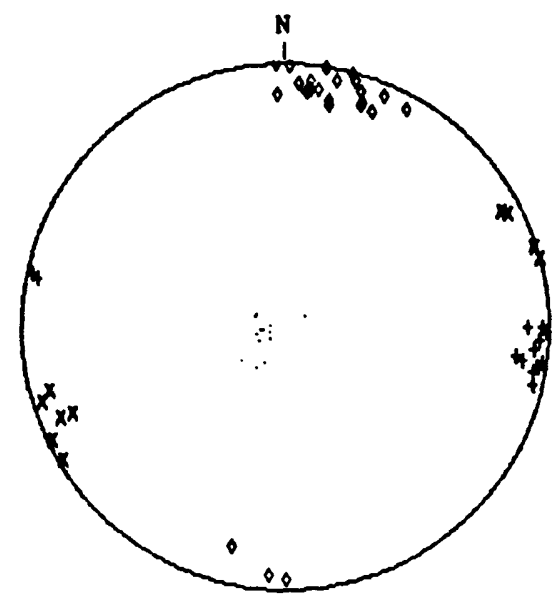

- CH4T1 $n=15$

$x$ CH4T2 $n=11$

$\begin{array}{ll}\text { CH4T4 } & n=23 \\ \text { CH4SH } & n=13\end{array}$

Schmidt net, lower hemisphere projection

CH4T1
NOOE81NW
NO9E87NW
NOOEB7NW
NO5E84NW
N11E85SE
NO1EB9NW
N10E85NW
N12E88SE
N13E86NW
NO9E86NW
NO7E77NW
N11EB5SE
NOBE80NW
NOBEB8NW
NO3E86NW

CH4T4

N88E77SE

N78W85SW

N9OE85NW

NB2WBOSW

N87W82SW

N84WB3SW

N76W75NE

N81W90SW

N79W76SW

N74WB7SW

N85W79SW

N86W84NE

N75W89SW

N71W79SW

N84WBOSW

N61W84SW

N72W83SW

N89W89SW

N67W85SW

N79W75SW

N68W775

N88E90SE

N71W78SW
CBASH

N35W06NE

N12W05NE

N11WO9NE

N06W08NE

NO4WO7NE

NO6E05SE

N32W07SW

N59W1 3NE

N53W15NE

N36W17NE

N21E1OSE

N25WO9NE

N26E1OSE 
STATION CH5, TECTONIC JOINTS

$n=24$

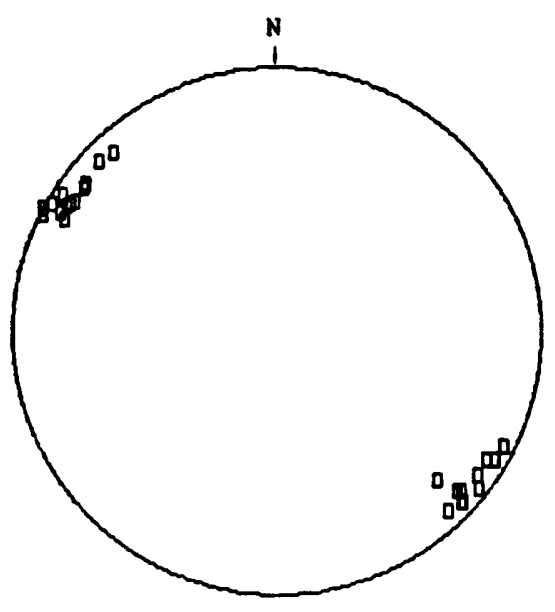

- CH5T3 $n=24$

Schnidt net, lower hemisphere projection

CH5T3

N28E80SE
N32EB2NW
N38E86NW
N28E90SE
N32E81SE
N31E85NW
N41E81NW
N37EB0SE
N31EB2SE
N3BE81SE
N36E82NW
N47E83NW
N27E89SE
N33E80SE
N43EB4NW
N42E80NW
N33E86SE
N30E8BSE
N27E85NW
N48E81SE
N29E83SE
N43E71NW
N43E85NW
N44E83SE 
STATION CH6, COOLING JOINTS

$\mathrm{n}=13$

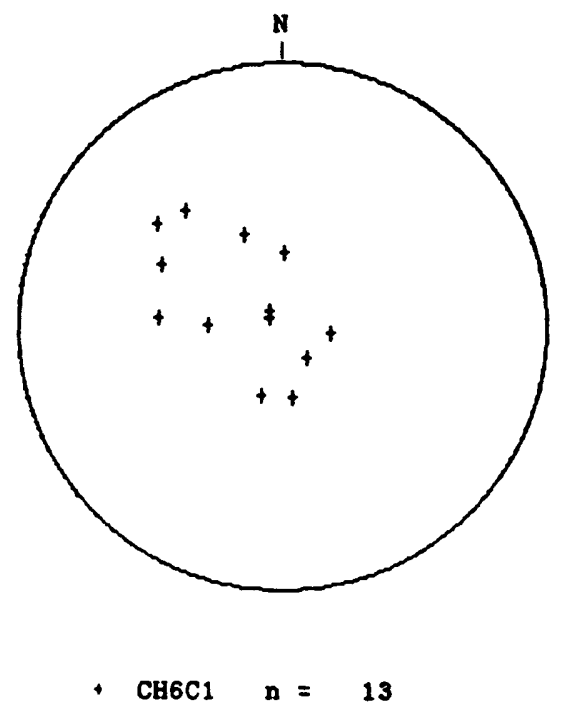

Schmidt net, lower hemisphere projection

$\mathrm{CH} 6 \mathrm{C} 1$

N49E06SE

N67E31SE

N33E05SE

N27E43SE

N39E51SE

N5OE48SE

N73W22NE

NOBE15NW

NO4E39SE

N89W23SW

NO1E23SE

NB3E22NW

N52E12NW

STATION CH6, TECTONIC JOINTS

$n=73$

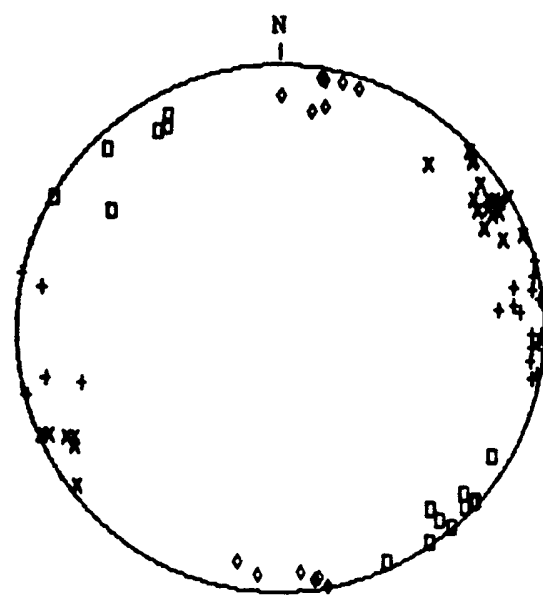

$\begin{array}{lll}\text { CH6T1 } & n=20 \\ \text { CH6T2 } & n=24 \\ \text { CH6T3 } & n=16 \\ \text { CH6T4 } & n=13\end{array}$

Schmidt net, lower hemisphere projection

CH6T1

N15W9OSW

N12W8ONE

NO4WBOSW

N12W8BSW

N1OE89NW

N15W67NE

NO $3 E B B N W$

NO1EB5NW

N1OE81SE

NO9WB6SW

NO4EB5NW

N10W79SW

NO6W78SW

NO7E85N

N15W89NE

NO7W89SW

N11E87NW

NOSW72SW

NO1EB9NW

N12E9OSE
C86T2

N26W75SW

N3OWB6S

N21WB8SW

N25W86NE

N31N76SW

N34W77 SW

N24W89NE

N3OW7 9NE

N38W87NE

N43WB 8SW

N28W77NF

N2BWBOSW

N36W83SW

N28WB3S

N41W86SW

N32WB2SW

N41W87SW

N3OW90SW

N48W73SW

N3OWBOSW

N22W80S

N31W83SW

N27WBONE

N31W84SW
С日6T3

N35E67SE

N62E61SE

N3OEB9SE

N42EB3N

N46E84SE

N49E89NW

N5OE78NW

N5OE84NW

N5BE77SE

N42E88N

N44E87NW

N65E87NW

N61E77SE

N41E88N

N31E83NW

N55E89NW
CH6T4

N90E77SE

N61W86SW

N76WB6SW

N82W72SW

NB2E86NW

N72W85SW

N81E85NW

NB5W83NE

N7 9E89NW

N79W75SW

NB5E82NW

NBOW85SW

NBOW7 9NE 
STATION CE7, TECTONIC JOINTS

$n=62$

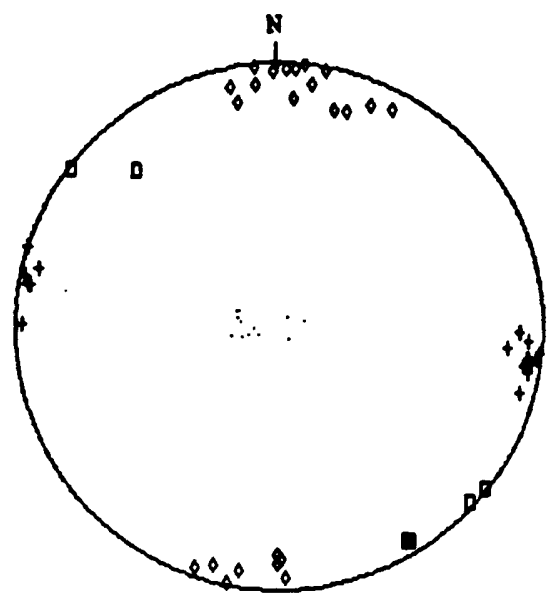

$\begin{array}{lll}\text { CH7T1 } & n= & 18 \\ \text { CH7T3 } & n= & 6 \\ \text { CH7T4 } & n= & 24 \\ \text { CH7SH } & n= & 12\end{array}$

Schmldt net, lower hemlsphere projection

CHTTI
NOBEB5NW
NO2EBONW
NO6E76NW
NO1EB7SE
NOBE88NW
NOBEBANW
N1 BE9OSE
N1OEB3NW
NO4EB4NW
N12EBBSE
N11EB5NW
N1OEB5SE
N1OEB3NW
N14EB3SE
NO9E8 NWW
NO9EB4NW
N1OEB6SE
N16EB4NW
NOTEB9NW

CH7T3
N48E69SE
N3BE89SE
N43E8BNW
N39E89NW
N59EB5NW
NGOEB4NW

CB7T4 CH7SH

N17W12NE

N11W15NE

N72W74SW N2OE14SE

N89E86SE N17W1ONE

N79W88SW N5OW04SW

N90E77NW N21E13SE

NB2W82SW NO7WO8NE

N74WB $3 N E$ N22WO7NE

NB9E65NW N11WOBSW

NB5E89SE N12E13SE

NB9W76NE N56E05NW

N67WBOSW

N80E75SE

N7OW86NE

N78W89NE

N62WB2SW

N85E81SE

NT9E82SE

N9OE9OSE

N8OW8 $3 \mathrm{NE}$

NB8W87SW

NB4W9OSW

N66W88SW

N75W73SW 
STATION CH8, TECTONIC JOINTS

$n=4$

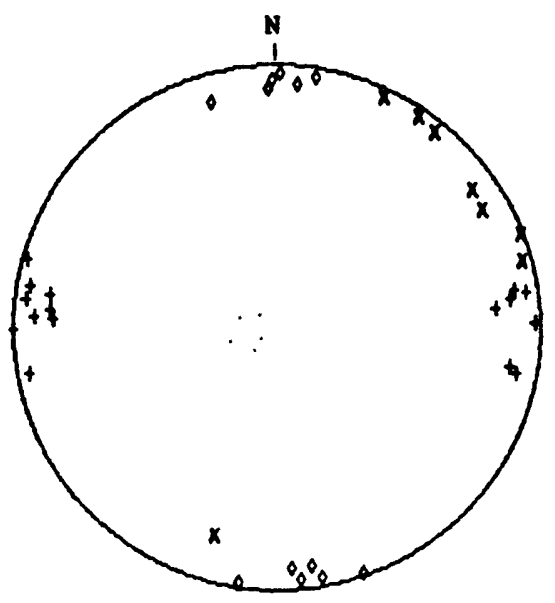

$\begin{array}{lll}\text { CH8T1 } & n=16 \\ \text { CH8T2 } & n=r \\ \text { CH8T4 } & n=12 \\ \text { CH8SH } & n= & 5\end{array}$

Schmidt net, lower hemisphere projection

$\begin{array}{llll}\text { CH8T1 } & \text { CH8T2 } & \text { CH8T4 } & \text { CH8SH } \\ \text { N16E88SE } & \text { N35W80SW } & \text { N74E78SE } & \text { N17E12SE } \\ \text { N03E81SE } & \text { N21W89SW } & \text { N89W86SW } & \text { N45W10NE } \\ \text { N10E78NW } & \text { N30W79SW } & \text { N87E81NW } & \text { N17W15NE } \\ \text { N10W85NE } & \text { N73W72NE } & \text { N85W82SW } & \text { N38WO6NE } \\ \text { N10E84SE } & \text { N51W85SW } & \text { N82E81NW } & \text { N38E07SE } \\ \text { N01W88SW } & \text { N56W86SW } & \text { N81W86SW } & \\ \text { NO3E74SE } & \text { N65W86SW } & \text { N88E80SE } & \\ \text { NO0E90SE } & \text { N15W86SW } & \text { N85E86NW } & \\ \text { NO9W8OSW } & & \text { N81W88NE } & \\ \text { N08W85SW } & & \text { N71E89NW } & \\ \text { N07E85SE } & & \text { N89E84SE } & \\ \text { N05W72SW } & & \text { N80E86NW } & \\ \text { N07W78SW } & & & \\ \text { N09E76SE } & & & \\ \text { N11E81NW } & & & \\ \text { N05E75SE } & & & \end{array}$


STATION CH9, COOLING JOINTS

$n=4$

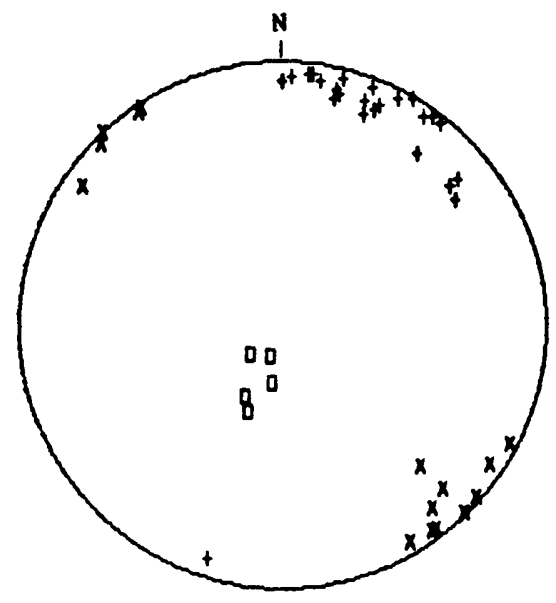

$\begin{array}{lll}\text { CH9C1 } & n=24 \\ \times \text { CH9C2 } & n=15 \\ \text { CH9C3 } & n=5\end{array}$

Schmidt net, lower hemisphere projection
STATION CH9, TECTONIC JOINTS

$$
n=29
$$

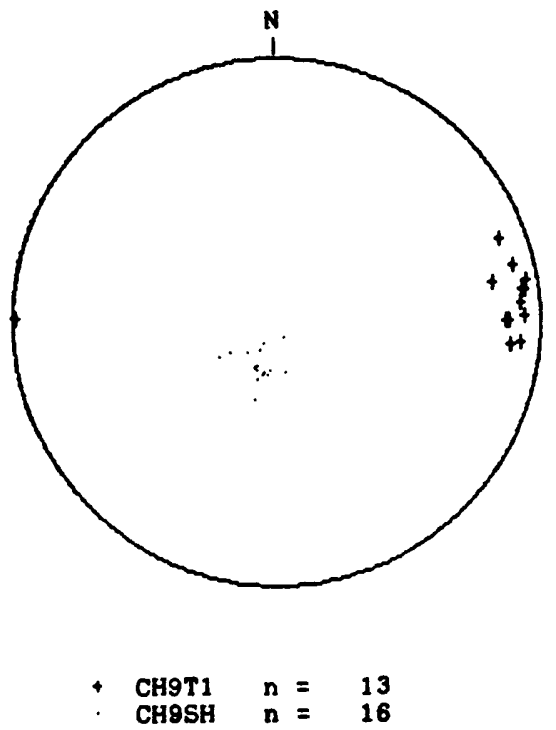

Schmidt net, lower hemisphere projection
CH9C1

N36W70SW N63W86SW

N90E82SE

N52W72SW

N56 W85SW

N4OW72SW

N67W78SW

N88W84SW

N72W82NE

N40W7 6SW

N52W87SW

N84W85SW

N70w80SW

N76W79SW

N83W85SW

N54W87SW

N77W77SW

N69W75SW

N76W86SW

N77W81SW

N81W83SW

N69W86SW

N60W89SW

N66WBOSW
CH9C3

N63W25NE

N42W13NE

N69W1ONE

N68W29NE

N79W18NE
CH9T1

CH9SH

N54

N46E76NW

N4 7E9OSE

N56E87SE

N46E64NW

N42E8BNW

N28EB7NW

N51E79NW

N46E89NW

N57E88SE

N6OE85NW

N35E82SE

N34E84NW
NOOE77NW

N05E82NW

N2OW79SW

No1W83SW

NO7W84SW

NO4W82SW

N07W83SW

N1 3W81SW

NO1E89SE

N10W72Sh

N06578NW

No9W85SW

NOOE76N
N64W16 16

N58W08NE

NBOW $17 \mathrm{NE}$

N67E05NW

N47W1 3NE

N33W17NE

N82W15NE

N74W25NE

N81E $16 \mathrm{~N}$

N68W16NE

N65W1 $5 \mathrm{NE}$

N74W17NE

N75W16NE

N32W21NE

N71W19NE

N59W1ONE 
STATION CLL1, COOLING JOINTS

$n=10$

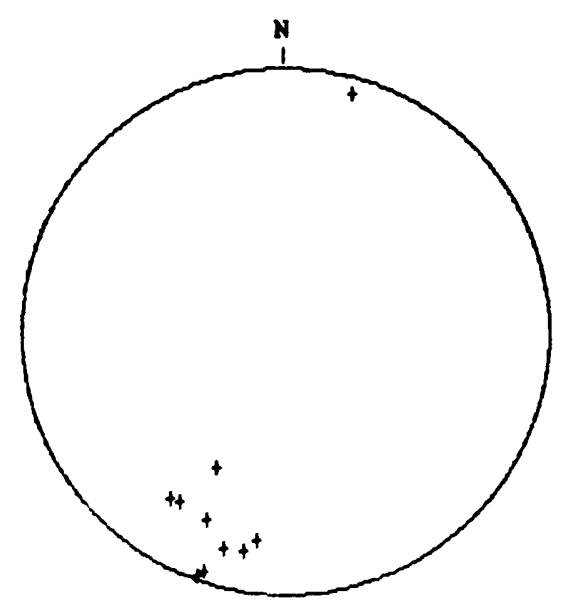

+ CLL1C1 $n=10$

Schmidt net, lower hemisphere projection

CLL1C1

N71W86NE

N82W69NE

N79W74 NE

N67W67NE

N58W65NE

N74W83SW

N63W48NE

N74W75NE

N55W66 NE

N70W88NE
STATION CLL1, TECTONIC JOINTS

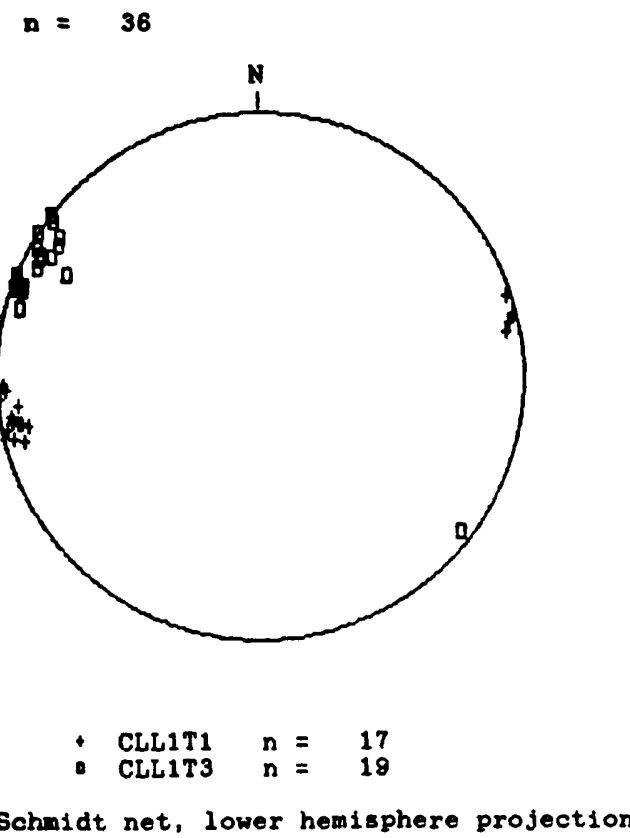

CLL1T1

CLL1T3

\begin{tabular}{|c|c|}
\hline $\begin{array}{l}\text { N1 } 1 \text { OWB5NE } \\
\text { N12W8BNE } \\
\text { N14W89SW } \\
\text { N09W85NE } \\
\text { N11W82NE } \\
\text { N15W82NE } \\
\text { N12WB6SW } \\
\text { N18W88SW } \\
\text { N11W83NE } \\
\text { N12W79NE } \\
\text { NO7W82NE } \\
\text { N14W86NE } \\
\text { NO2WB7NE } \\
\text { No3W86NE } \\
\text { N10W84SW } \\
\text { N05W89NE } \\
\text { N11W81NE }\end{array}$ & $\begin{array}{l}\text { N2OE89SE } \\
\text { N23E9OSE } \\
\text { N3OEB7SE } \\
\text { N38EB5NW } \\
\text { N37EB8SE } \\
\text { N35EB2SE } \\
\text { N29EB4SE } \\
\text { N28E84SE } \\
\text { N16EB4SE } \\
\text { N21E85SE } \\
\text { N21EB7SE } \\
\text { N3OEBOSE } \\
\text { N33EBOSE } \\
\text { N26E83SE } \\
\text { N3BE90SE } \\
\text { N21EB5SE } \\
\text { N33E90SE } \\
\text { N2BE72SE } \\
\text { N20EB5SE }\end{array}$ \\
\hline
\end{tabular}


STATION CKS1, TECTONIC JOINTS

$n=60$

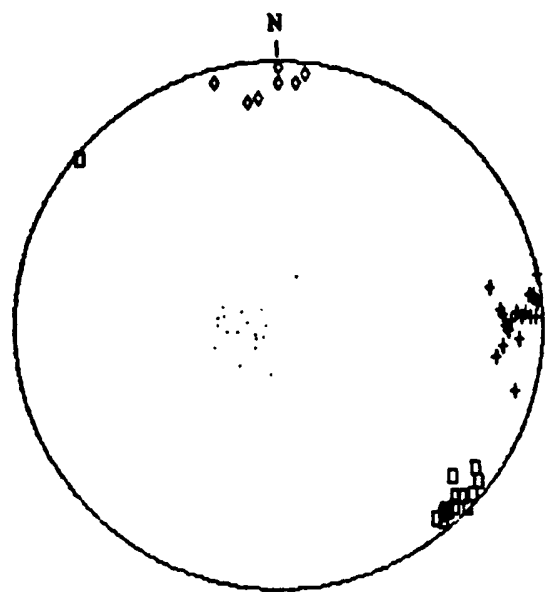

$\begin{array}{lll}\text { CKS1T1 } & n= & 18 \\ \text { CKS1T3 } & n= & 15 \\ \text { CKS1T4 } & n= \\ \text { CKS1SH } & n= & 18\end{array}$

Schnidt net, lower hemisphere projection

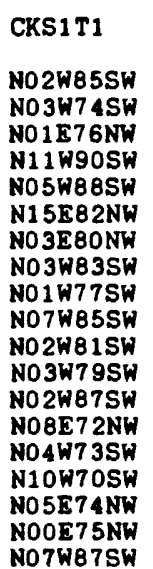

CKS1T3
N43E85NW
N48E85NW
N41E76NW
N41E87NW
N51E84NW
N44E82NW
N50E86NW
N48E83NW
N43E84NW
N44E89NW
N49E84NW
N36E81NW
N46E85NW
N40E88SE
N38E85NW

CKS1T4

CKS1SH

N85E75SE

N32W0 $6 \mathrm{NE}$

N84W85SW N32W08NE

NB2E74SE NO1W19NE

N86W81SW N70W16SW

N90E87SE N1OE17SE

N75E84SE NO1WO4NE

N90E81SE N2OW21NE

*NB6W NBOW15NE

N41W1ONE

NO3E1OSE

N07W1 $6 \mathrm{NE}$

N43W1 ONE

N2OE12SE

N41E07SE

N45W17NE

N08W1 3NE

NO6E 1 9SE

N17E1 BSE

N21W08NE

*dip not obtainable, orientation not plotted 
STATION CKS2, COOLING JOINTS

$n=26$

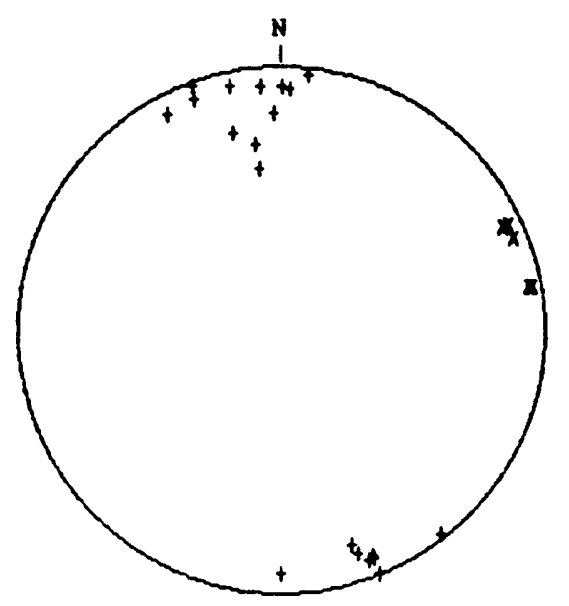

$\begin{array}{llr}\text { CKs2C1 } & n= & 21 \\ \times & \text { CKS2C2 } & n=\end{array}$

Schmidt net, lower hemisphere projection

CKS2C1

N82E52SE

N78E84SE

N62E82SE

N68E83NW

N68E82NW

N52E88NW

N72E75NW

N71E79NN

N82E61SE

N9OE82SE

N7OE88SE

N69E83SE

N85E82SE

N90E82NW

N82E61SE

N88W81SW

N84W87SW

N88E71SE

N68E9ONW

N7 6E66SE

N69E83NW station CKs2, TECTONIC JOINTS

$n=34$

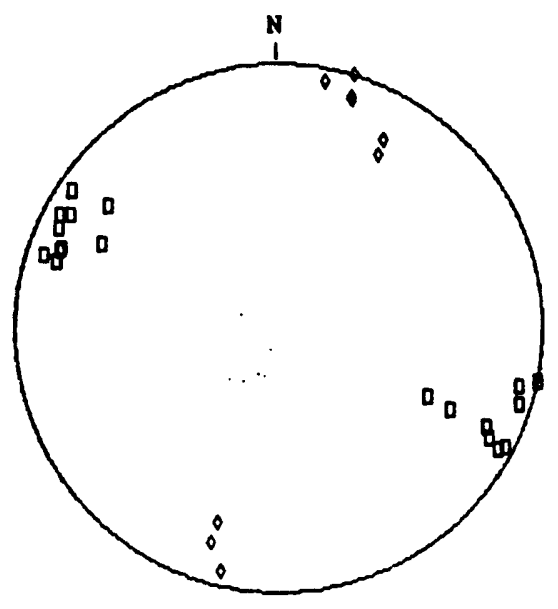

$\begin{array}{lllr}\text { CKS2T3 } & n= & 19 \\ \text { CKS2T4 } & n= & 8 \\ \text { CKS2SH } & n= & 6\end{array}$

Schmidt net, lower hemisphere projection
CKS2C2

N25W84SW

N22W84SW

N25W82SW

N10\%85SW

N10N86SW
CKS2T 3

N14E83NH

N1 BE83SE

N29E84NW

N20E775E

N36E69SE

N29E79SE

N25E81SE

N2BE86NW

N21E775E

N26E64SE

N34E84SE

N28E835E

N26E76NW

N18E85NW

N17E77SE

N26E79NW

N25E52NW

N12E9ONN

N26E61NW
CKS2T4

N60W65SW

N76W84NE

N61W71SW

N72W74NE

N72W66NE

N72W8OSW

N79W85SW

N72ผ81SW

N7 3N90Sh
CKs2sh

N7OW07NE

N73W16NE

N56W2ONE

N2OE $125 E$

N46W22NE

N66W16NE 
STATION CKS3, COOLING JOINTS

$\mathrm{n}=14$

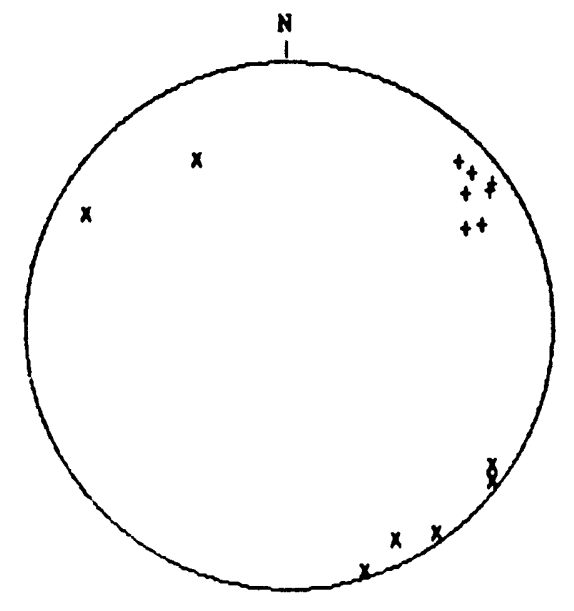

$\begin{array}{ll}\text { CKS3C1 } & n=7 \\ \text { CKS3C2 } & n=7\end{array}$

Schmidt net, lower hemisphere projection
STATION CKS3, TECTONIC JOINTS

$\mathbf{n}=\mathbf{7}$

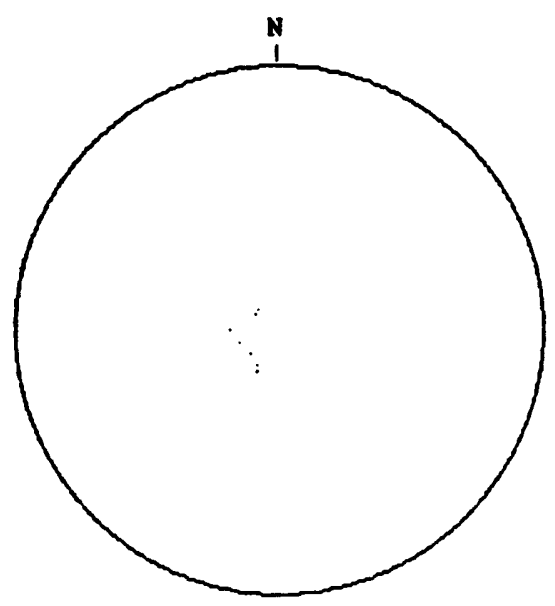

CKs3sh $n=7$

Schmidt net, lower hemisphere projection

$\begin{array}{ll}\text { CKS3C1 } & \text { CKS3C2 } \\ \text { N44W79SW } & \text { N38E87NW } \\ \text { N35W84SW } & \text { N73E87NW } \\ \text { N37W73SW } & \text { N55E86NW } \\ \text { N29W66SW } & \text { N35E83NW } \\ \text { N28W72SW } & \text { N29E77SE } \\ \text { N34W81SW } & \text { N64E8ONW } \\ \text { N40W80SW } & \text { N61E61SE }\end{array}$

CKs3SH

N62W15NE

N1 $8 W 13 \mathrm{NE}$

NOOE15SE

N40W12NE

N34 E09SE

N42EOSSE

N57W1 3NE 
STATION CKS4, COOLING JOINTS

$\mathrm{n}=\mathbf{7}$

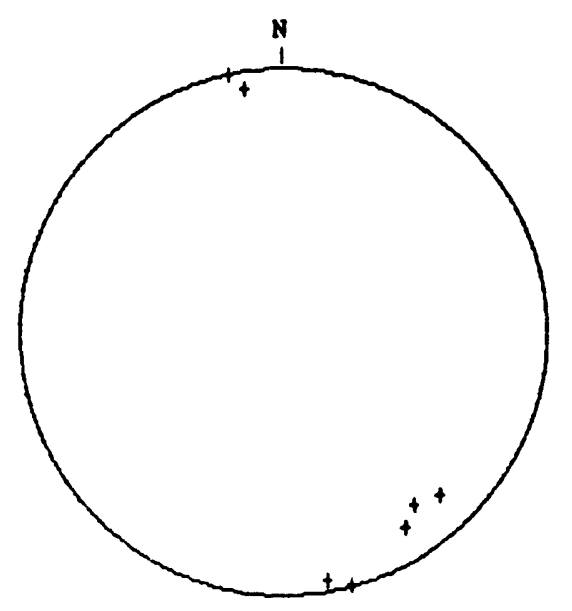

$$
\text { + CKS4C1 } n=7
$$

Schmidt net, lower hemisphere projection

CKS4C1

N78E90SE
N58E76NW
N53E71NW
N46E75NW
NB1E83SE
N80E85NW
N75E89NW
STATION CKS4, TECTONIC JOINTS

$\mathrm{n}=38$

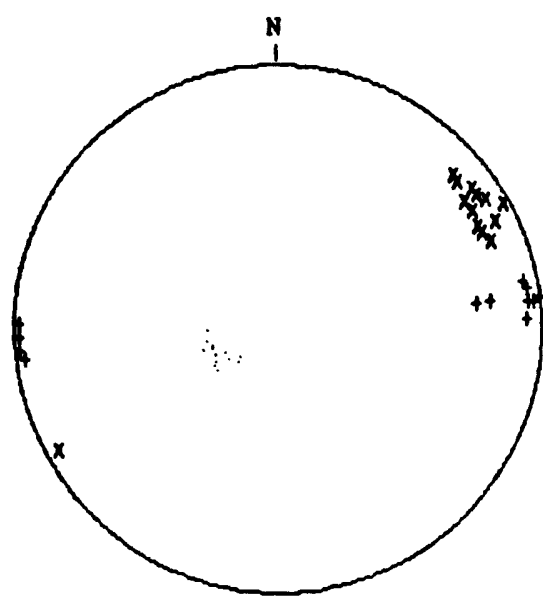

+ CKS4T1 $n=12$

$\begin{array}{ll}\text { CKS4T2 } & n=13 \\ \text { CKS4SH } & n=13\end{array}$

Schnidt net, lower hemisphere projection

$\begin{array}{lll}\text { CKS4T1 } & \text { CKS4T2 } & \text { CKS4SH } \\ \text { NO7W70SW } & \text { N36W80SW } & \text { N35W23NE } \\ \text { N11W84SW } & \text { N34W80SW } & \text { N16W21NE } \\ \text { N07W65SW } & \text { N26W81SW } & \text { N17W24NE } \\ \text { NO9W85SW } & \text { N31W75SW } & \text { N4OW16NE } \\ \text { N02W88NE } & \text { N34W74SW } & \text { N24W18NE } \\ \text { NO2W84SW } & \text { N32W82SW } & \text { N18W21NE } \\ \text { NO7W90SW } & \text { N29W87SW } & \text { N23W21NE } \\ \text { NO6W85SW } & \text { N39W77SW } & \text { NO2W22NE } \\ \text { N01288SE } & \text { N29W85NE } & \text { N28W22NE } \\ \text { N07W86NE } & \text { N27W74SW } & \text { N3OW23NE } \\ \text { NO6W87SW } & \text { N41W77SW } & \text { N1OW22NE } \\ \text { N05W88NE } & \text { N25W74SW } & \text { N37W15NE } \\ & \text { N22W76SW } & \text { N33W18NE }\end{array}$


STATION CRSA, TECTONIC JOINTS

$\mathrm{n}=15$

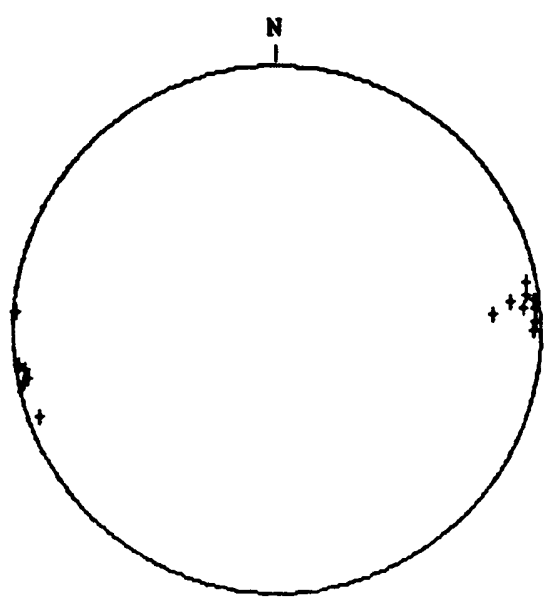

+ CRSAT1 n $=15$

Schmidt net, lower hemisphere projection

CRS4T1

N05W88SW
N04W71SW
N05W83SW
N02W88SW
No8W89NE
NO7W8BSW
N11W86SW
N20W85NE
N12W88NE
No8WBSSW
N11W86NE
N00E87NW
N04E89SE
N07W78SW
N09W86NE 
STATION CRSS, COOLING JOINTS

$\mathbf{n}=$

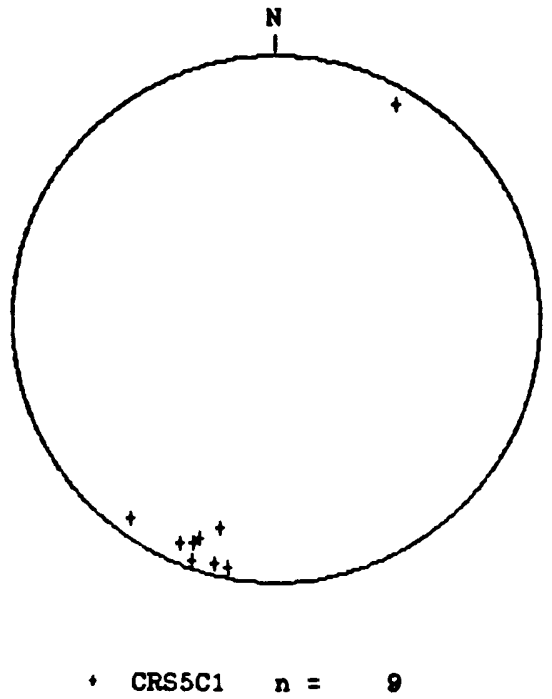

Schmidt net, lower hemisphere projection

CRS5C1

N7OWBONE

N71W77NE

N54W83NE

N79W86NE

N75W71NE

N71W87NE

N76W85NE

N6: WB3SW

N67WB2NE 
STATION CRS6, COOLING JOINTS

$\mathbf{n}=20$

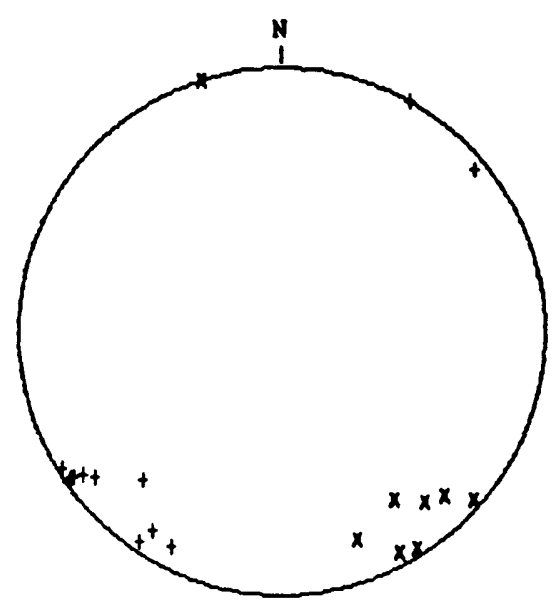

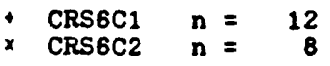

Schmidt net, lower hemisphere projection
STATION CRS6, TECTONIC JOINTS

$n=43$

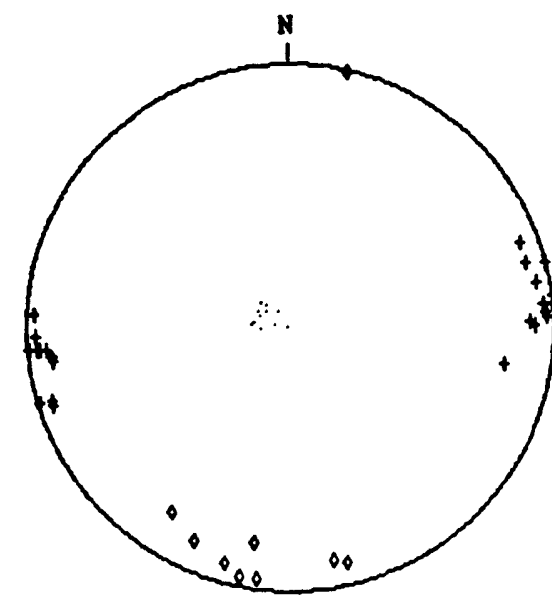

$\begin{array}{llr}\text { CRS6T1 } & \mathbf{n}= & 23 \\ \text { CRS6T4 } & n= & 9 \\ \text { CRS6SH } & n= & 11\end{array}$

Schmidt net, lower hemisphere projection

\begin{abstract}
CRS6C1
N35W87NE N63WB1NE N56W86NE N35W86NE N47W66NE N36W82NE N61H9OSW N57พ79NE N38W79NE

N35W88NE

N32W88NE N4OW65SW
\end{abstract}

CRS6C2
N70E73NW

N56E66NN

N5OE74NW

N45E77NW

N62565N

N58E87NN

N41E87NW

N72E90SE

\begin{abstract}
CRS6T1
No5W86SW

N14N82SW

N10W84SW

No2W87SW

No5N90SW

NO3W875W

HOBW80NE

NOIW8OSW

NO5N85NE

N18W64NE

N20\%82SN

NOTWBONE

N1OE71NW

NOOE82NW

No7W90SW

N05W86NE

NO2W86N

N05W82NE

N14W90SW

N17W89NE

N17W84NE

N05H89NE

NO3E87 SE
\end{abstract}

CRS6T4

CRS6SE 
STATION CRS7, COOLING JOINTS

$n=11$

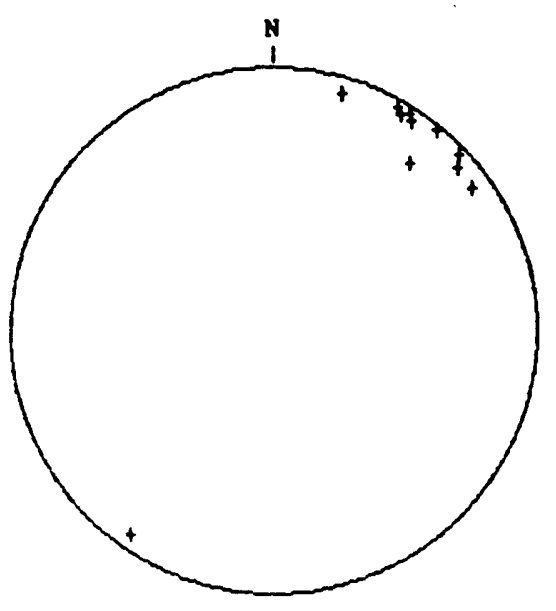

- CRSTC1 $n=11$

Schmidt net, lower hemisphere projection
STATION CRST, TECTONIC JOINTS

$n=14$

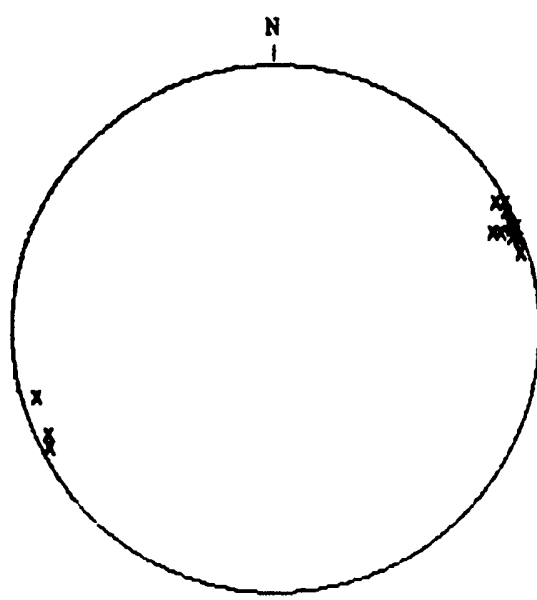

$x$ CRS7T2 $n=14$

Schnidt not, lower hemisphere projection
CRS7C1

N51W71SW

N36W82SW

N51W88SW

N74 WB 3SW

N55W84 NE

N57W85SW

N44W87SW

N42W83SW

N58W87SW

N60W85SW

N61W87SW
CR57 T2

N23W82SW
N16W84NE
N23W89SW
N24W87SW
N25W85NE
N17W87SW
N21W86SW
N23W87SW
N30W86SW
N28W87NE
N29W89SW
N24W79SW
N20W88SW
N27WB8SW


STATION CUL1, COOLING JOINTS

$n=7$

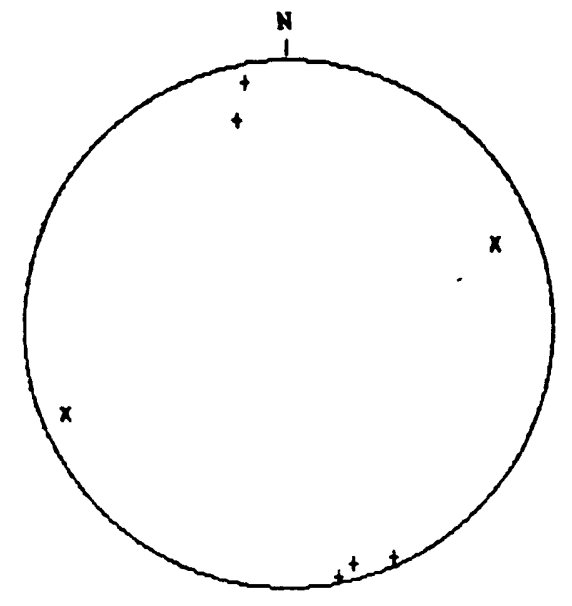

$\begin{array}{ll}\text { CUL1C1 } & n=1 \\ \text { CUL1C2 } & n=2\end{array}$

Schmidt net, lower hemisphere projection

$\begin{array}{ll}\text { CUL1C1 } & \text { CUL1C2 } \\ \text { N76E69SE } & \text { N22W80NE } \\ \text { N75E83NW } & \text { N21W73SW } \\ \text { N79E87NW } & \\ \text { N66E86NW } & \\ \text { N80E82SE } & \end{array}$

STATION CUL1, TECTONIC JOINTS

$\mathbf{n}=\mathbf{2 7}$

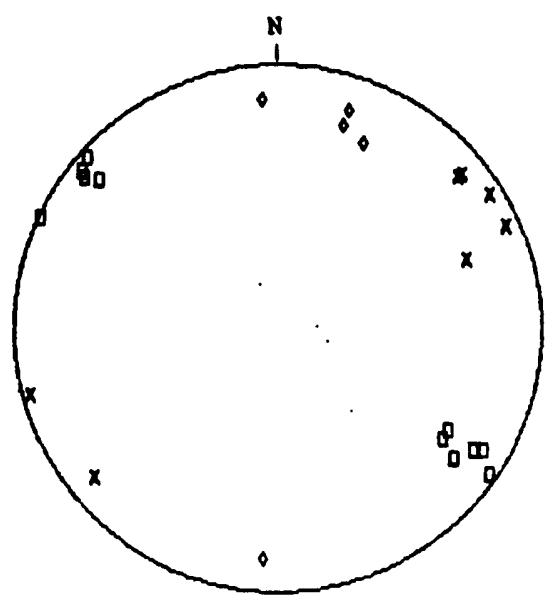

$\begin{array}{lllr}x \text { CUL1T2 } & n= & 7 \\ \text { CUL1T3 } & n= & 11 \\ \text { CUL1T4 } & n= & 5 \\ \text { CUL1SH } & n= & 4\end{array}$

Schmidt net, lower hemisphere projection

$\begin{array}{ll}\text { CUL1T2 } & \text { CUL1T3 } \\ \text { N4OW78SW } & \text { N25E89SE } \\ \text { N39W79NE } & \text { N31E79NW } \\ \text { N4OWBOSW } & \text { N38E82SE } \\ \text { N32W84SW } & \text { N40E77SE } \\ \text { N24W84SW } & \text { N42E87SE } \\ \text { N15W87NE } & \text { N39E85SE } \\ \text { N20W65SW } & \text { N34E64NW } \\ & \text { N31E64NW } \\ & \text { N32E76NW } \\ & \text { N37E72NW } \\ & \text { N35E87NW }\end{array}$

CULIT4

N86W77NE

N72W69SW

N65N66SW

N72N76SW

NB6E76SE
CUL1SH

N68E15SE

N04W12SW

N16E16NW

N48E34NW 
STATION CUL2, COOLING JOINTS

$\mathrm{n}=39$

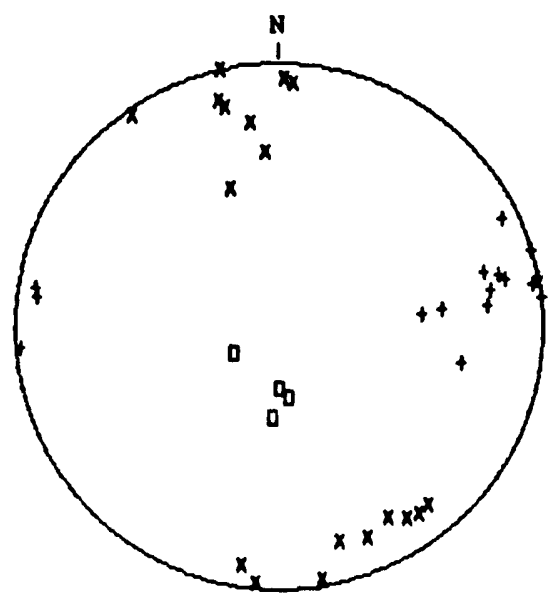

$\begin{array}{lll}\text { CUL2C1 } & n= & 17 \\ \text { CUL2C2 } & n= & 18 \\ \text { CUL2C3 } & n= & 4\end{array}$

Schmidt net, lower hemisphere projection

CUL2C1

N10พ87SW

N06W52SW

No5W45SW

N06W68SW

N15W69SW

N26W83SW

N11W89SW

N11W90SW

NO9E83SE

NO7E82SE

N12W76SW

N14W74SW

N17W9OSW

N05W88NE

N1OW7OSW

NO7W9OSW

N11E6ONW
CUL2C2

N67E76NW

N80E 87 NW

N82E67SE

N76E75SE

N75E78SE

N53E77NW

N56E76NW

N85W88NE

N81W81NE

N89W84SW

N74E74NW

N7OE46SE

N87W82SW

N77E90SE

N60E72NW

N50E77NW

N55E87SE

N85E56SE
CUL2C3

N82E22NW

N86W28NE

N3OW16NE

N9OE19NW 
STATION CUL3, COOLING JOINTS

$n=34$

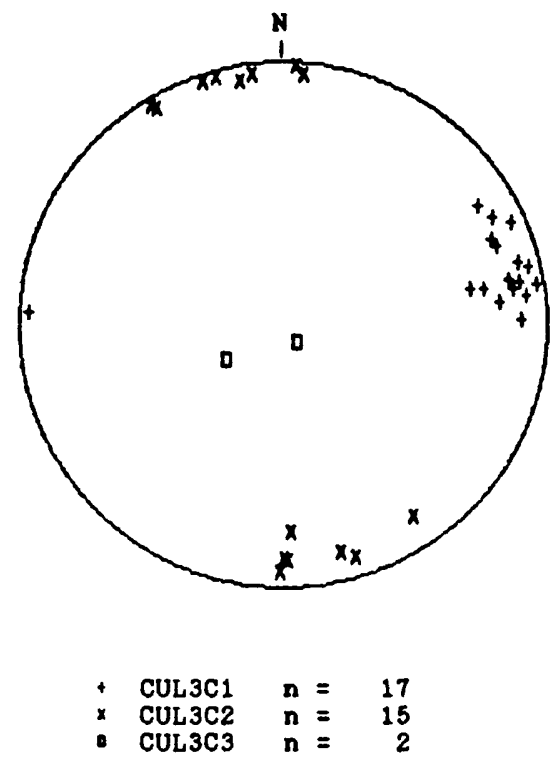

Schmidt net, lower hemisphere projection

$\begin{array}{lll}\text { CUL3C1 } & \text { COL3C2 } & \text { CUL3C3 } \\ \text { N31W75SW } & \text { N72E87SE } & \text { N32W21NE } \\ \text { N20W75SW } & \text { N88E68NW } & \text { N55E07NW } \\ \text { N24W84SW } & \text { N80E83SE } & \\ \text { N15W81SW } & \text { N76E78NW } & \\ \text { N06W71SW } & \text { N89E79NW } & \\ \text { N09W87SW } & \text { N73E82NW } \\ \text { N11W76SW } & \text { N56E77NW } \\ \text { N13W85SW } & \text { N83E85SE } \\ \text { N03E86SE } & \text { N75E87SE } \\ \text { N10W66SW } & \text { N59E87SE } \\ \text { N07W82SW } & \text { N87W8BSW } \\ \text { N01W79SW } & \text { N89W84NE } \\ \text { N22W74SW } & \text { N85W85S } \\ \text { NO9W77SW } & \text { N60E85SE } \\ \text { N11W61SW } & \text { N90E78NW } \\ \text { N27W78SW } & \\ \text { N10W80SW } & \end{array}$


STATION CULA, COOLING JOINTS

$n=34$

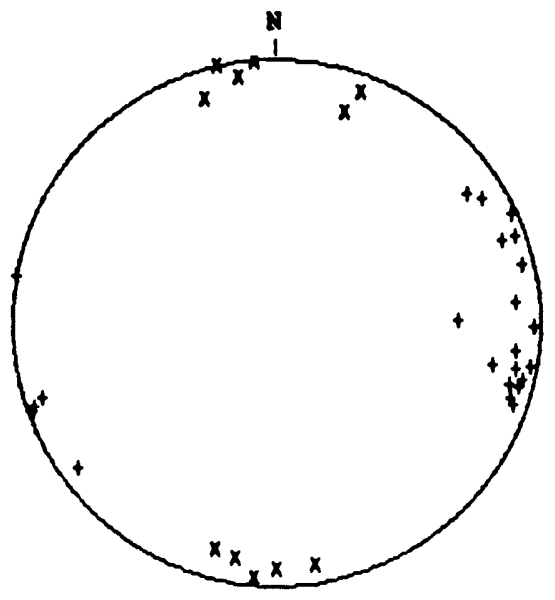

$\begin{array}{ll}\text { CUL4C1 } & n=23 \\ \text { CUL4C2 } & n=11\end{array}$

Schmidt net, lower hemisphere projection

$\begin{array}{ll}\text { CUL4C1 } & \text { CUL4C2 } \\ \text { N36W82NE } & \text { N90E83NW } \\ \text { N34H76SW } & \text { N81E82NW } \\ \text { N31W80SW } & \text { N80W80NE } \\ \text { N25W88SW } & \text { N77E90SE } \\ \text { N10E87NW } & \text { N75W78NE } \\ \text { N15E84NW } & \text { N85E90SE } \\ \text { N10E90SE } & \text { N85W87NE } \\ \text { NO1E87NW } & \text { N81E84SE } \\ \text { N13E85NW } & \text { N72E78SE } \\ \text { N11E81NW } & \text { N70W82SW } \\ \text { N19E84NW } & \text { N72W73SW } \\ \text { N15E80NW } & \\ \text { N18E82NW } & \\ \text { NO7E80NW } & \\ \text { N11E72NW } & \\ \text { N19W87NE } & \\ \text { N20W88NE } & \\ \text { N13W85SW } & \\ \text { NO1W58SW } & \\ \text { N05WBOSW } & \\ \text { N18W83NE } & \\ \text { N20W86SW } & \\ \text { N20W80SW } & \end{array}$


STATION CUL5, COOLING JOINTS

$n=21$

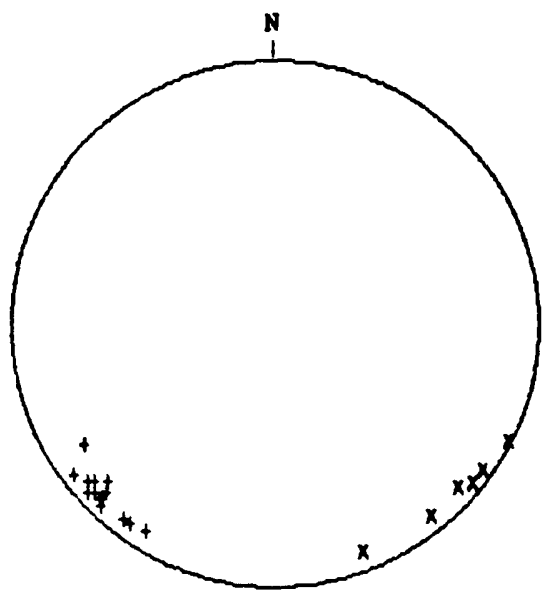

$$
\begin{array}{llr}
\text { CUL5C1 } & n= & 15 \\
\times \text { CUL5C2 } & n= & 6
\end{array}
$$

Schmidt net, lower hemisphere projection

$\begin{array}{ll}\text { CUL5C1 } & \text { CUL5C2 } \\ \text { N43W76NE } & \text { N69E82NW } \\ \text { N37W85NE } & \text { N51E83NW } \\ \text { N41W8ONE } & \text { N42E82NW } \\ \text { N43W83NE } & \text { N35E86NW } \\ \text { N45W84NE } & \text { N39E86NW } \\ \text { N45W83NE } & \text { N27E89NW } \\ \text { N52W83NE } & \\ \text { N58W82NE } & \\ \text { N54W83NE } & \\ \text { N32W74NE } & \\ \text { N40W82NE } & \\ \text { N42W85NE } & \\ \text { N46W85NE } & \\ \text { N45W82NE } & \\ \text { N45W8ONE } & \end{array}$

STATION CULS, TECTONIC JOINTS

$n=16$

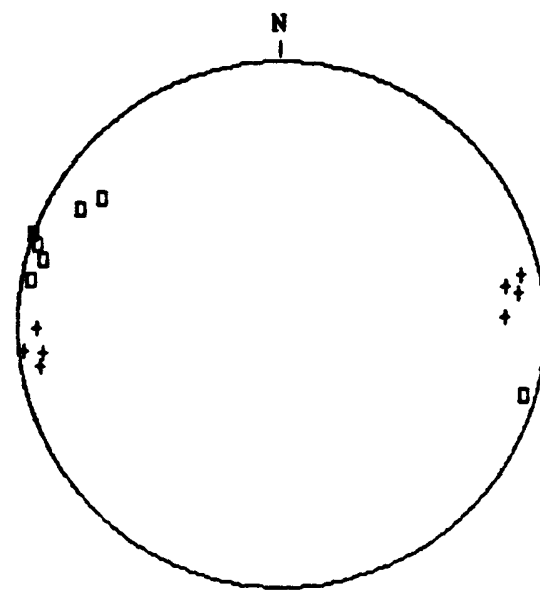

$\begin{array}{lll}\text { CUL5T1 } & n= & 9 \\ \text { cul5T3 } & n= & 7\end{array}$

Schmidt net, lower hemisphere projection

CUL5T1

N1OW82NE

NO1W82NE

NOIWB2NE

NOTWOONE

N10W75SW

N02W74SW

No8W8OSW

N12W82S

NO 6 W88NE
CUL5T3

N1 8E87SE

N3OE77 SE

N35E72SE

N16E85NW

N15E83SE

N1OE86SE

N20E90SE 
STATION CUL6, TECTONIC JOINTS

$n=12$

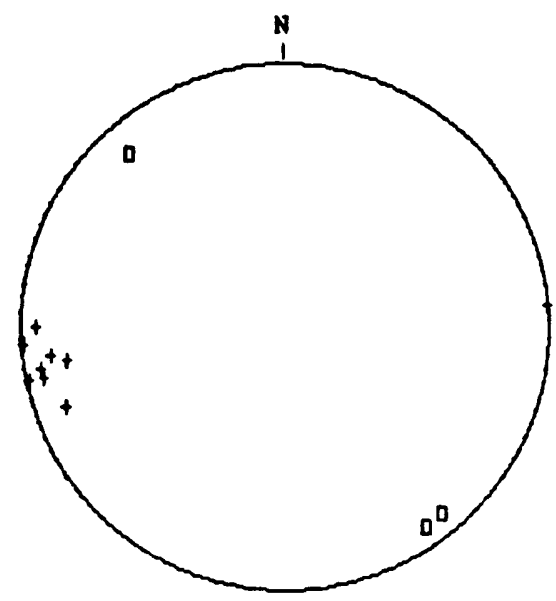

$\begin{array}{lll}\text { CUL6T1 } & n= & 9 \\ \text { CUL6T3 } & n= & 3\end{array}$

Schmidt net, lower hemisphere projection

$\begin{array}{ll}\text { CUL6T1 } & \text { CUL6T3 } \\ \text { NO5W9OSW } & \text { N50E81NW } \\ \text { NO7W78NE } & \text { N55E82NW } \\ \text { NO4WB9NE } & \text { N48E77SE } \\ \text { N12W83NE } & \\ \text { NO9W72NE } & \\ \text { N20W77NE } & \\ \text { N12W89NE } & \\ \text { N10W83NE } & \\ \text { NO0E84SE } & \end{array}$


STATION CUL7, COOLING JOINTS

$\mathrm{n}=27$

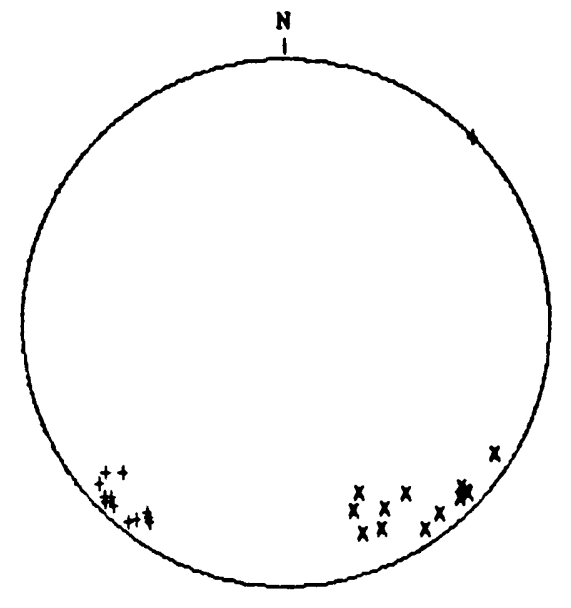

$\begin{array}{ll}\text { CUL7C1 } & n=13 \\ \times \text { CUL7C2 } & n=13\end{array}$

Schmidt net, lower hemisphere projection
STATION CUL7, TECTONIC JOINTS

$$
\mathbf{n}=\mathbf{8}
$$

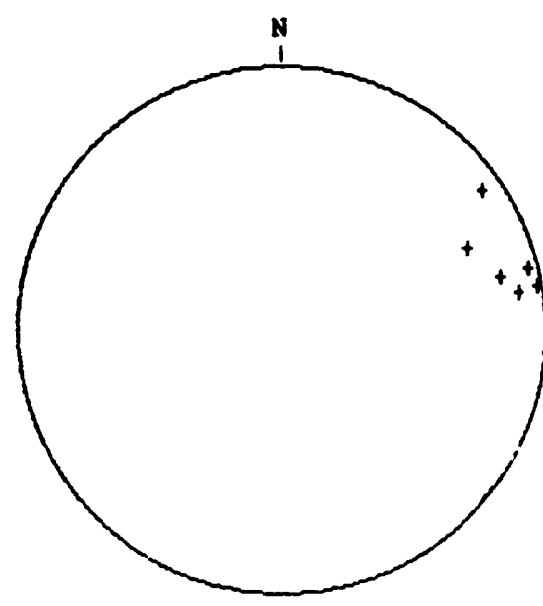

- CUL7T $n=6$

Schmidt net, lower hemisphere projection

$\begin{array}{ll}\text { CUL7C1 } & \text { CUL7C2 } \\ \text { N55W80NE } & \text { N45E83NW } \\ \text { N45W83NE } & \text { N43E83NW } \\ \text { N45W86NE } & \text { N56E84NW } \\ \text { N52W86NE } & \text { N65E75NW } \\ \text { N45W9OSW } & \text { N70E74NW } \\ \text { N54W78NE } & \text { N51E82NW } \\ \text { N41W83NE } & \text { N62E69NW } \\ \text { N47W85NE } & \text { N67E60NW } \\ \text { N56W81NE } & \text { N70E65NW } \\ \text { N40W78NE } & \text { N43E84NW } \\ \text { N53W83NE } & \text { N32E83NW } \\ \text { N44W85NE } & \text { N55E68NW } \\ \text { N43W73NE } & \text { N43E80NW }\end{array}$

CUL7T

N10W88SW

NO9W80SW

N14W86SW

N24W66SW

N14W74SW 
STATION CULB, COOLING JOINTS

$n=34$

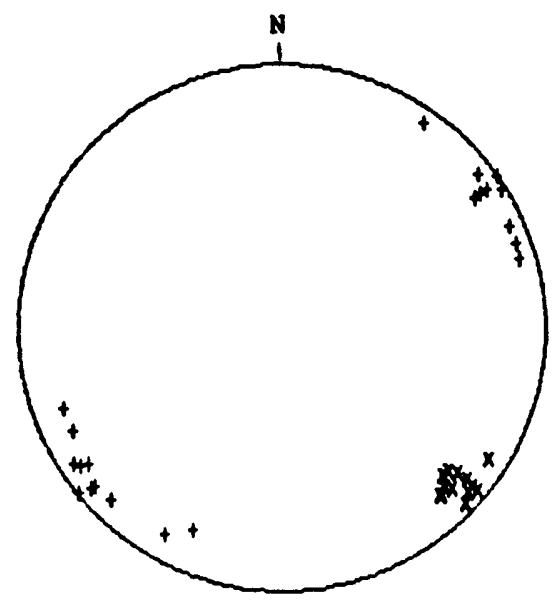

$\begin{array}{ll}\text { CUL8C1 } & n=21 \\ \times \text { CUL8C2 } & n=13\end{array}$

Schmidt net, lower henlsphere projection

CUL8C1 CUL8C2

N26W77NE N45E75NW

N32W88SW N40E83NN

N24W84SW N44E86NW

N38W84SW N42E84NW

N35W9OSW N4OE75NW

N39W89NE N33E82NN

N4OW82NE N43E72NW

N33W84NE N41E72NW

N45WB1NE N40E86NW

N66W73NE N44E78NW

N35W79NE N47E77NW

N34W82NE N47E76NW

N4ON84NE N4OE8ONW

N20W77NE

N34W80SW

N34W83SW

N34W77SW

N55W84SW

N20W84SW

N16W83SW

N6OW79NE 
STATION CULA, COOLING JOINTS

$n=9$

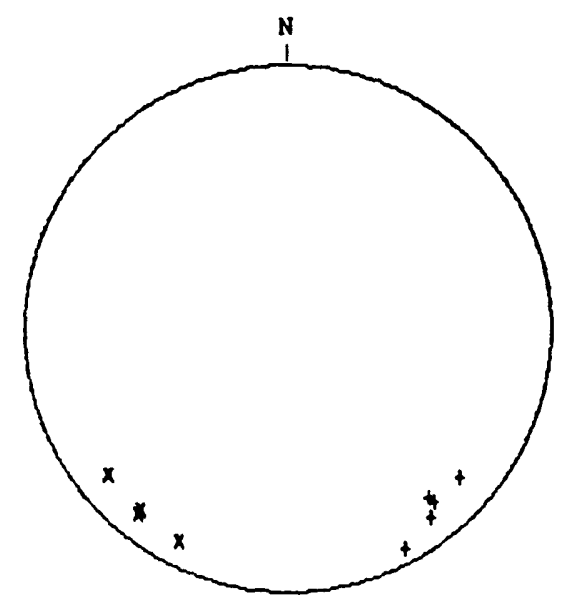

$\begin{array}{ll}\text { CUL9C1 } n= & 5 \\ \times \text { CUL8C2 } & n=4\end{array}$

Schmidt net, lower hemisphere projection

CUL9C1

CUL9C2

N62E84NW N50E72NW

N5OE75NW

N41E75NW

N63WBONE

N39W77NE

N51W8ONE

N51 1 พ78 NE

STATION CULA, TECTONIC JOINTS

$n=25$

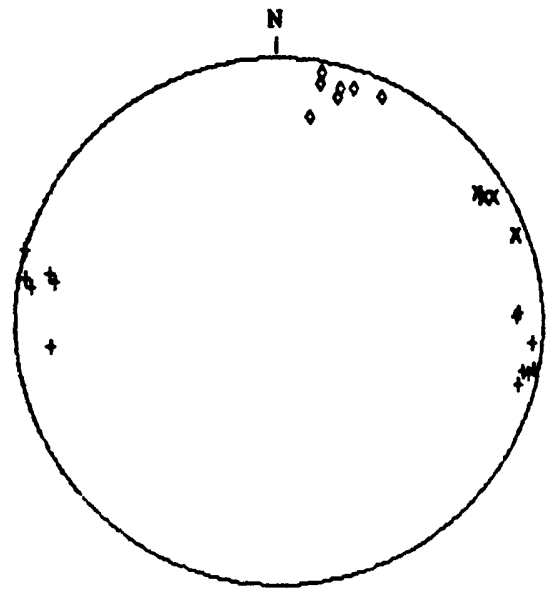

$\begin{array}{lllr}\text { CUL9T1 } & n= & 14 \\ \times \text { CUL9T2 } & n= & 4 \\ \text { CUL9T } & n= & 7\end{array}$

Schmidt net, lower henlsphere projection

CUL8T 1

N12E86NW

NO5E86NW

N10E75SE

No2W80SW

N11588NW

N15E83NW

NO1N78SW

N06W76NE

N12E78SE

N10E87SE

N12E84NW

N16E90SE

NOBE84SE

N12E84NW
CUL9T2 CUL9T4

N33W79SW N75W77SW

N3OWB 3SW NBOWB1SW

N2OWB5SW N75WB1SW

N31W8OSW NBOW85SW

N81พ67SW

N65WB3SW

N72W82SW 
STATION CUC1, TECTONIC JOINTS

$n=12$

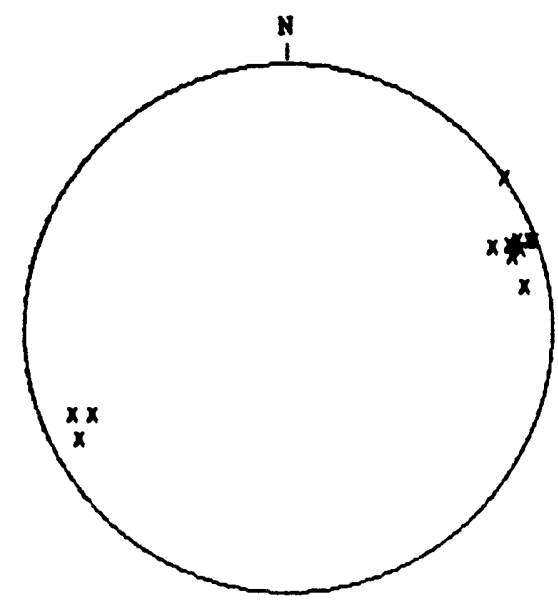

$\times$ CUC1T2 $n=12$

Schmidt net, lower hemisphere projection

CUC1T2

N21W82SW

N20W87SW

N19W82SW

N21W79SW

N28W7 ONE

N24W7ONE

N35W90SW

N20W89SW

N1OWBOSW

N18W78SW

N22W72SW

N22W77NE 
STATION CUC2, COOLING JOINTS

$\mathbf{n}=$ 28

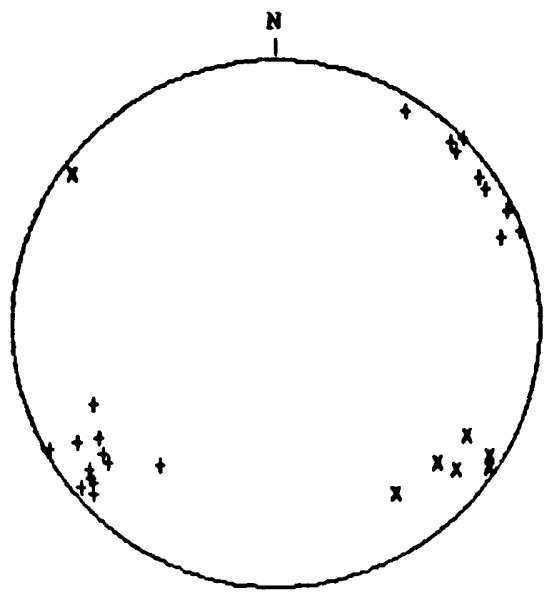

$\begin{array}{ll}\text { Cuc2c1 } & n=21 \\ \text { Cuc2C2 } & n=7\end{array}$

Schmidt net, lower hemisphere projection

$\begin{array}{lll}\text { CUC2C1 } & \text { CUC2C2 } & \text { CUC2C3 } \\ \text { N33W84SW } & \text { N31E73NW } & \text { N13E83NW } \\ \text { N40W81NE } & \text { N34E87NW } & \text { N09W84SW } \\ \text { N29W88NE } & \text { N32E85NW } & \text { N02E83NW } \\ \text { N26W87SW } & \text { N39E77NW } & \text { N03E82NW } \\ \text { N21W89SW } & \text { N41E70NW } & \\ \text { N21W80SW } & \text { N36E85SE } & \\ \text { N40W86NE } & \text { N55E68NW } & \\ \text { N33W69NE } & \\ \text { N38W79NE } & \\ \text { N36W84SW } & \\ \text { N45W90SW } & \\ \text { N24W65NE } & \\ \text { N46W85SW } & \\ \text { N31W77NE } & \\ \text { N37W71NE } & \\ \text { N51W59NE } & \\ \text { N40W72NE } & \\ \text { N59684SW } & \\ \text { N43W84NE } & \\ \text { N41W81NE } & \\ \text { N44W84SW } & \end{array}$


STATION CCR1, COOLING JOINTS

$n=16$

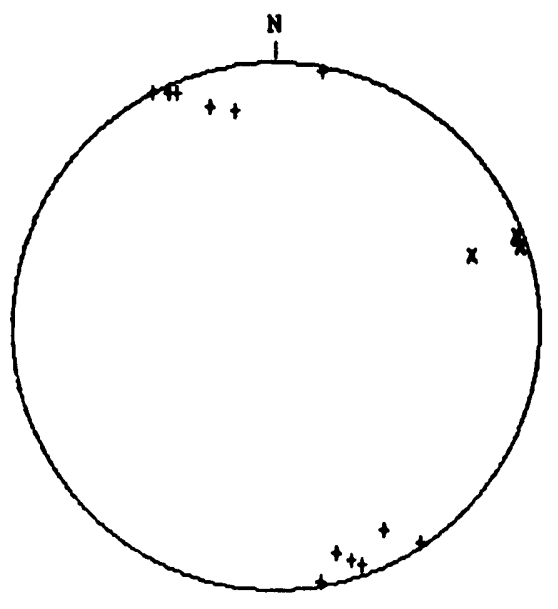

$\begin{array}{ll}\text { CCR1C1 } & n=12 \\ \text { CCR1C2 } & n=4\end{array}$

Schmidt net, lower hemisphere projection
STATION CCR1, TECTONIC JOINTS

$n=22$

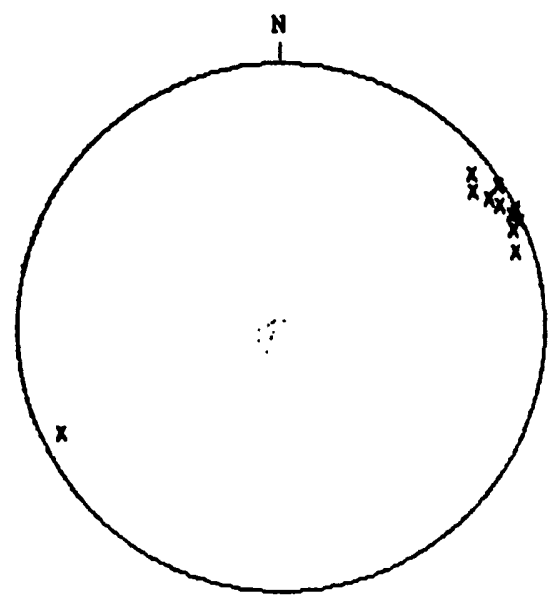

$\begin{array}{lll}\text { CCR1T2 } & n=12 \\ \text { CCR1SH } & n=10\end{array}$

Schnidt net, lower hemisphere projection

\begin{abstract}
CCR1C1
N73E76SE

N65E87SE

N79E72SE

N80W88SW

N67E86SE

N56E88NW

N72E82NW

N62E76NN

N62E9OSE

N7OE85NW

N75E78NW

NBOEB8NW
\end{abstract}

CCR1C2
N18W87SW

N2OWB75W
CCR1T2

N39W82SW
N29w84SW
N33W88SW
N27W90SW
N26W82NE
N32W82SW
N35W78SW
N24W89SW
N18W83SW
N23W85SW
N26W87SW
N26W89SW

CCR1SH

N45W04NE

N5OEO3SE

NOBWO7NE

N29W08N!

NO6EO4SI

N47W05NE

N21 E03ST

N31 HO3NE

N71 W02S

N60W09NE 
STATION CCR2, COOLING JOINTS

$n=28$

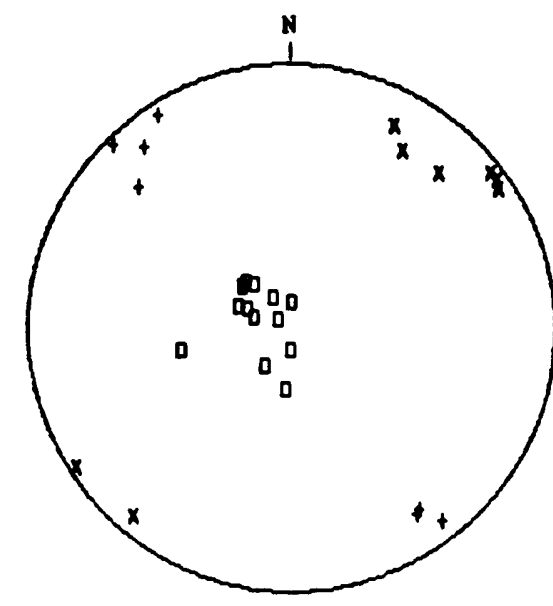

$\begin{array}{lll}\operatorname{CCR2C1} & n= & 7 \\ \mathbf{C C R 2 C 2} & n= & 8 \\ 0 \mathrm{CCR2C3} & \mathrm{n}= & 13\end{array}$

Schmidt net, lower hemisphere projection

$\begin{array}{lll}\text { CCR2C1 } & \text { CCR2C2 } & \text { CCR2C3 } \\ \text { N55E73NW } & \text { N47W70SW } & \text { N11W35NE } \\ \text { N51E78SE } & \text { N34W84SW } & \text { N87W07NE } \\ \text { N46E87SE } & \text { N36W86SW } & \text { N90EOBSE } \\ \text { N52E82NW } & \text { N50W83NE } & \text { N23E18SE } \\ \text { N56E74NW } & \text { N33W87NE } & \text { N37E05SE } \\ \text { N58E85SE } & \text { N58W68SW } & \text { N18E13SE } \\ \text { N43E68SE } & \text { N63W75SW } & \text { N40E20SE } \\ & \text { N38W85SW } & \text { N84W19NE } \\ & & \text { N55W14NE } \\ & & \text { N46E20SE } \\ & & \text { N59E11SE } \\ & & \text { N50E18SE } \\ & & \text { N25E15SE }\end{array}$


STATION CCR3, COOLING JOINTS

$n=28$

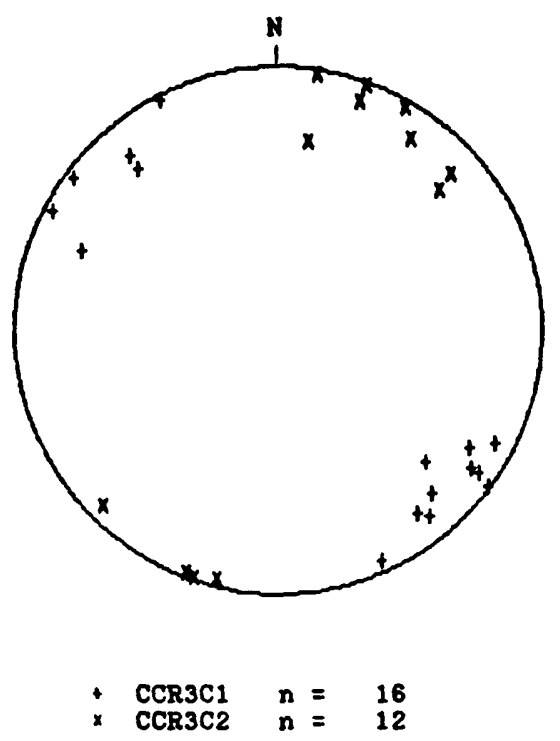

Schmldt net, lower hemisphere projection

$\begin{array}{ll}\text { CCR3C1 } & \text { CCR3C2 } \\ \text { N50E76SE } & \text { N7OW81SW } \\ \text { N49E70SE } & \text { N81W62SW } \\ \text { N37E89NW } & \text { N70W88SW } \\ \text { N53E76NW } & \text { N60W87SW } \\ \text { N47E74NW } & \text { N45W84NE } \\ \text { N28E86SE } & \text { N71W89NE } \\ \text { N36E83NW } & \text { N76W87NE } \\ \text { N22E69SE } & \text { N69W88NE } \\ \text { N28E82NW } & \text { N81W88SW } \\ \text { N37E86SE } & \text { N55W77SW } \\ \text { N42E64NW } & \text { N41W70SW } \\ \text { N36E79NW } & \text { N42W77SW } \\ \text { N63E88SE } & \\ \text { N32E74NW } & \\ \text { N51E80NW } & \\ \text { N66E85NW } & \\ \end{array}$

